\title{
COBRA-SFS Modifications and Cask Model Optimization
}

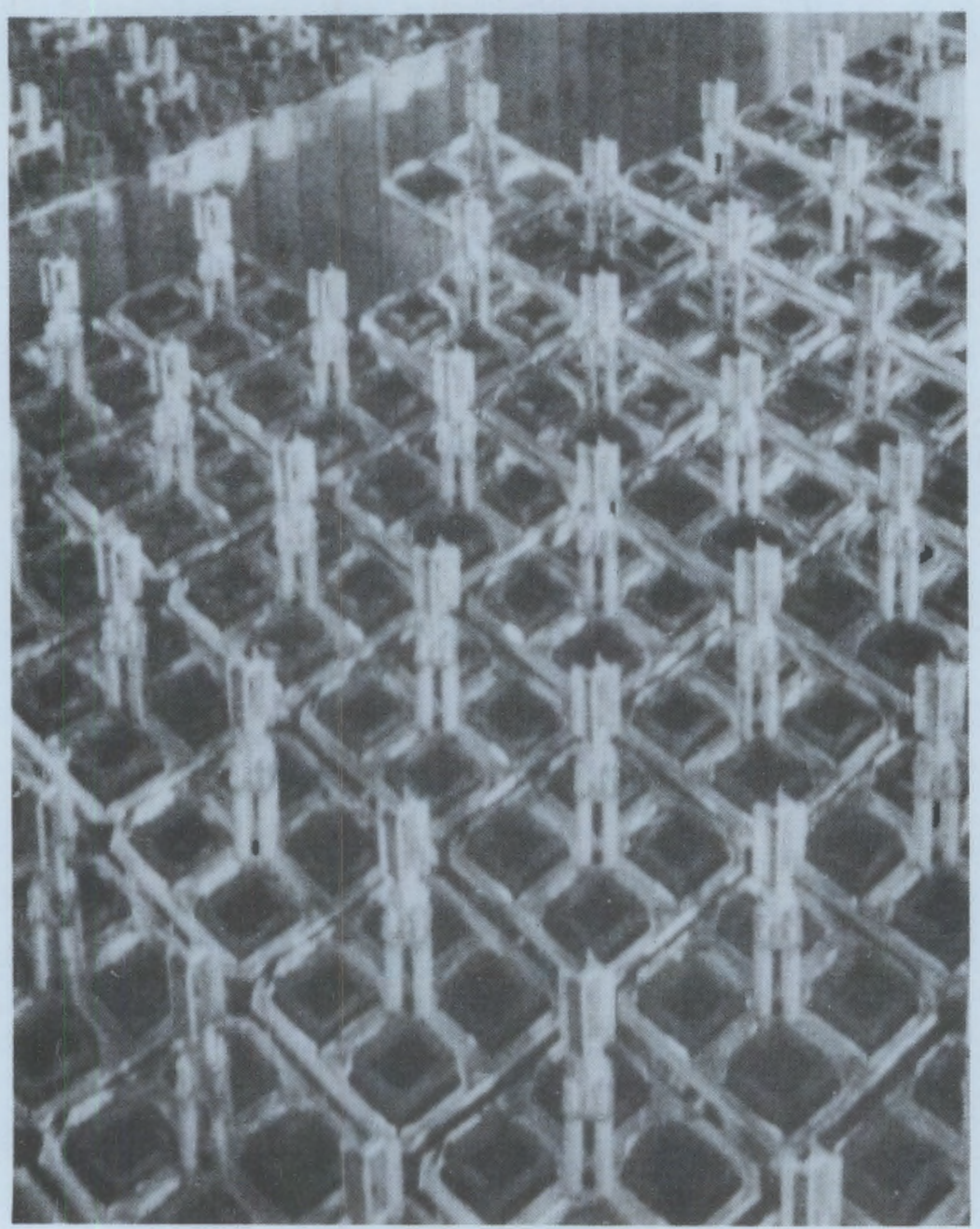

January 1989

Prepared for the U.S. Department of Energy under Contract DE-AC06-76RLO 1830

Pacific Northwest Laboratory Operated for the U.S. Department of Energy by Battelle Memorial Institute 


\title{
DISCLAIMER
}

This report was prepared as an account of work sponsored by an agency of the United States Government. Neither the United States Government nor any agency thereof, nor Battelle Memorial Institute, nor any or their employees, makes any warranty, expressed or implied, or assumes any legal liability or responsibility for the accuracy, completeness, or usefulness of any information, apparatus, product, or process disclosed, or represents that its use would not infringe privately owned rights. Reference herein to any specific commercial product, process, or service by trade name, trademark, manufacturer, or otherwise does not necessarily constitute or imply its endorsement, recommendation, or favoring by the United States Government or any agency thereof, or Battelle Memorial Institute. The views and opinions of authors expressed herein do not necessarily state or reflect those of the United States Government or any agency thereof.

\section{PACIFIC NORTHWEST LABORATORY \\ operated by \\ BATTELLE MEMORIAL INSTITUTE \\ for the \\ UNITED STATES DEPARTMENT OF ENERGY \\ under Contract DE-AC06-76RLO 1830}

\author{
Printed in the United States of America \\ Available from \\ National Technical Information Service \\ United States Department of Commerce \\ 5285 Port Royal Road \\ Springfield, Virginia 22161 \\ NTIS Price Codes \\ Microfiche A01 \\ Printed Copy
}

$\begin{array}{cc}\begin{array}{c}\text { Pages } \\ 001-025\end{array} & \begin{array}{c}\text { Price } \\ \text { Codes } \\ 026-050\end{array} \\ \text { A051-075 } & \text { A03 } \\ 076-100 & \text { A04 } \\ 101-125 & \text { A05 } \\ 126-150 & \text { A06 } \\ 151-175 & \text { A07 } \\ 176-200 & \text { A08 } \\ 201-225 & \text { A09 } \\ 226-250 & \text { A10 } \\ 251-275 & \text { A11 } \\ 276-300 & \text { A12 } \\ & \text { A13 }\end{array}$


D. R. Rector

T. E. Michener

January 1989

Prepared for

the U.S. Department of Energy

under Contract DE-ACD6-76RLO 1830

Pacific Northwest Laboratory

Richland, Washington 99352 



\section{ABSTRACT}

Spent-fuel storage systems are complex systems and developing a computational model for one can be a difficult task. The COBRA-SFS computer code provides many capabilities for modeling the details of these systems, but these capabilities can also allow users to specify a more complex model than necessary. This report provides important guidance to users that dramatically reduces the size of the model while maintaining the accuracy of the calculation. A series of model optimization studies was performed, based on the TN-24P spent-fuel storage cask, to determine the optimal model geometry. Expanded modeling capabilities of the code are also described. These include adding fluid shear stress terms and a detailed plenum model. The mathematical models for each code modification are described, along with the associated verification results. 


\section{ACKNOWLEDGMENTS}

The authors would like to thank the U.S. Department of Energy for sponsoring this work. Thanks are also extended to J. M. Creer of the Pacific - Northwest Laboratory Commercial Spent Fuel Management (CSFM) Program. Appreciation is extended to M. A. Mckinnon for his support. Finally, thanks to N. C. Waugh, word processor, and T. L. Gilbride, editor, for their assistance in preparing this document. 
3 , 


\section{NOMENCLATURE}

\section{SYMBOLS AND NOTATIONS}

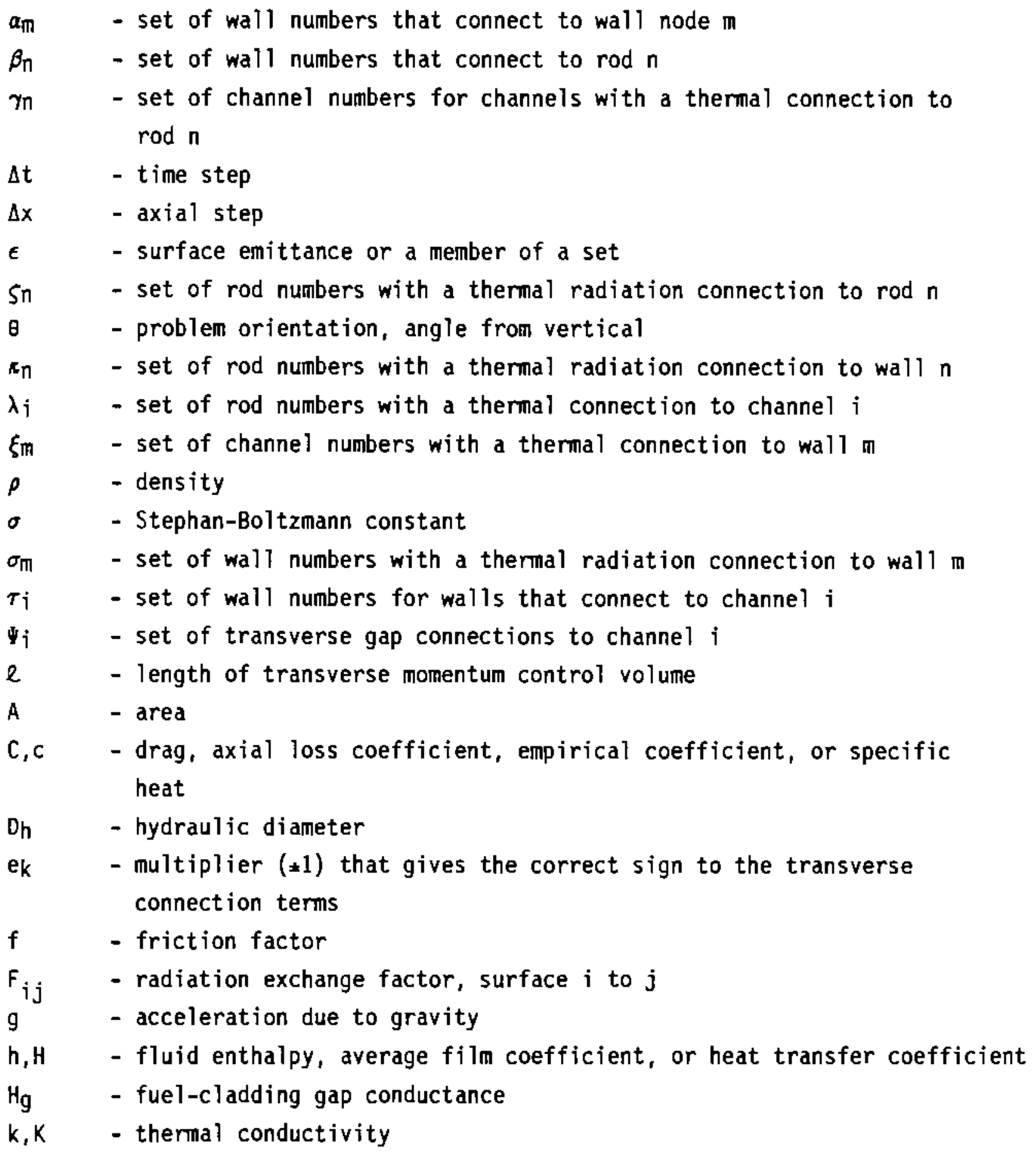




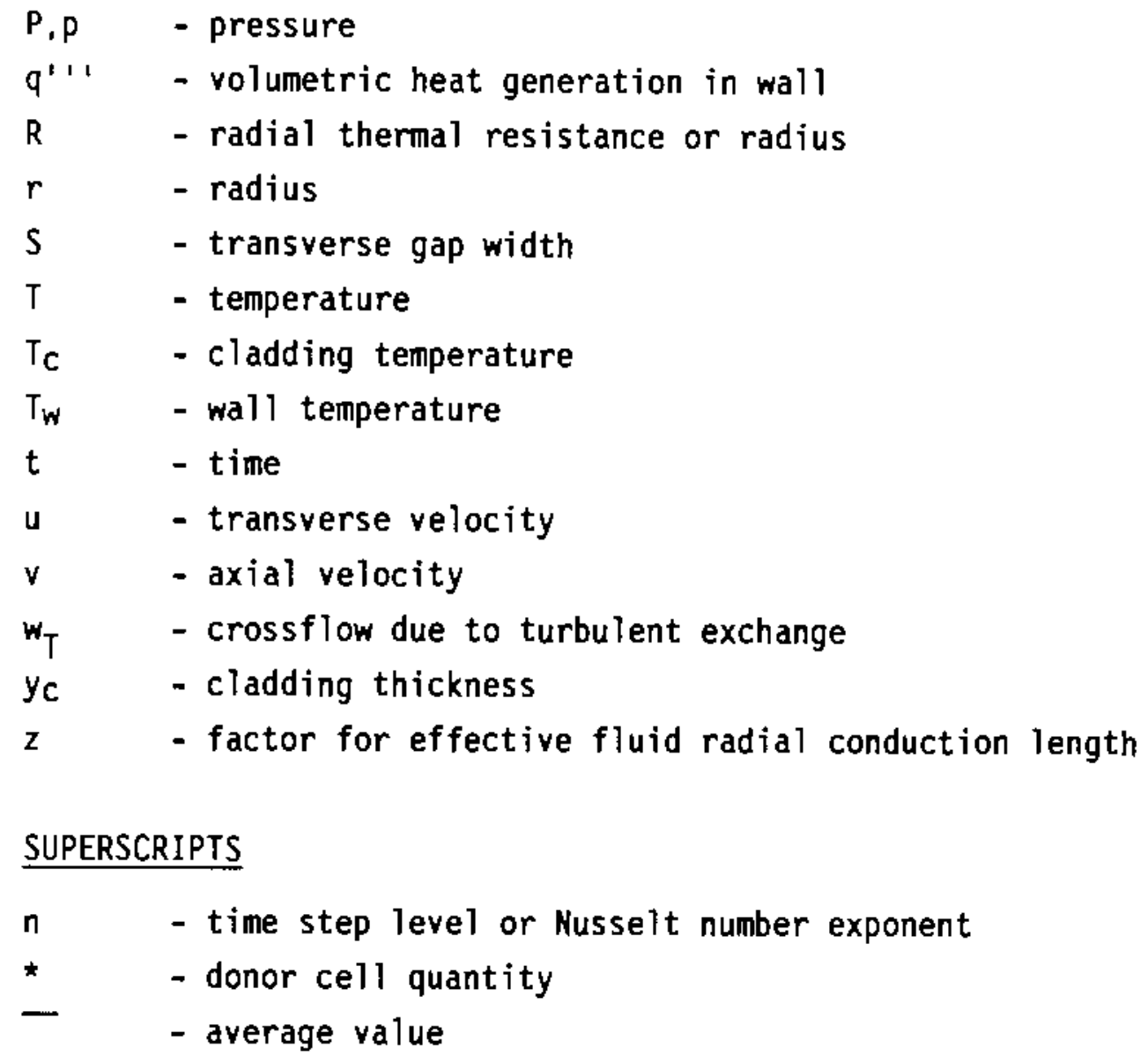

\section{SUBSCRIPTS}

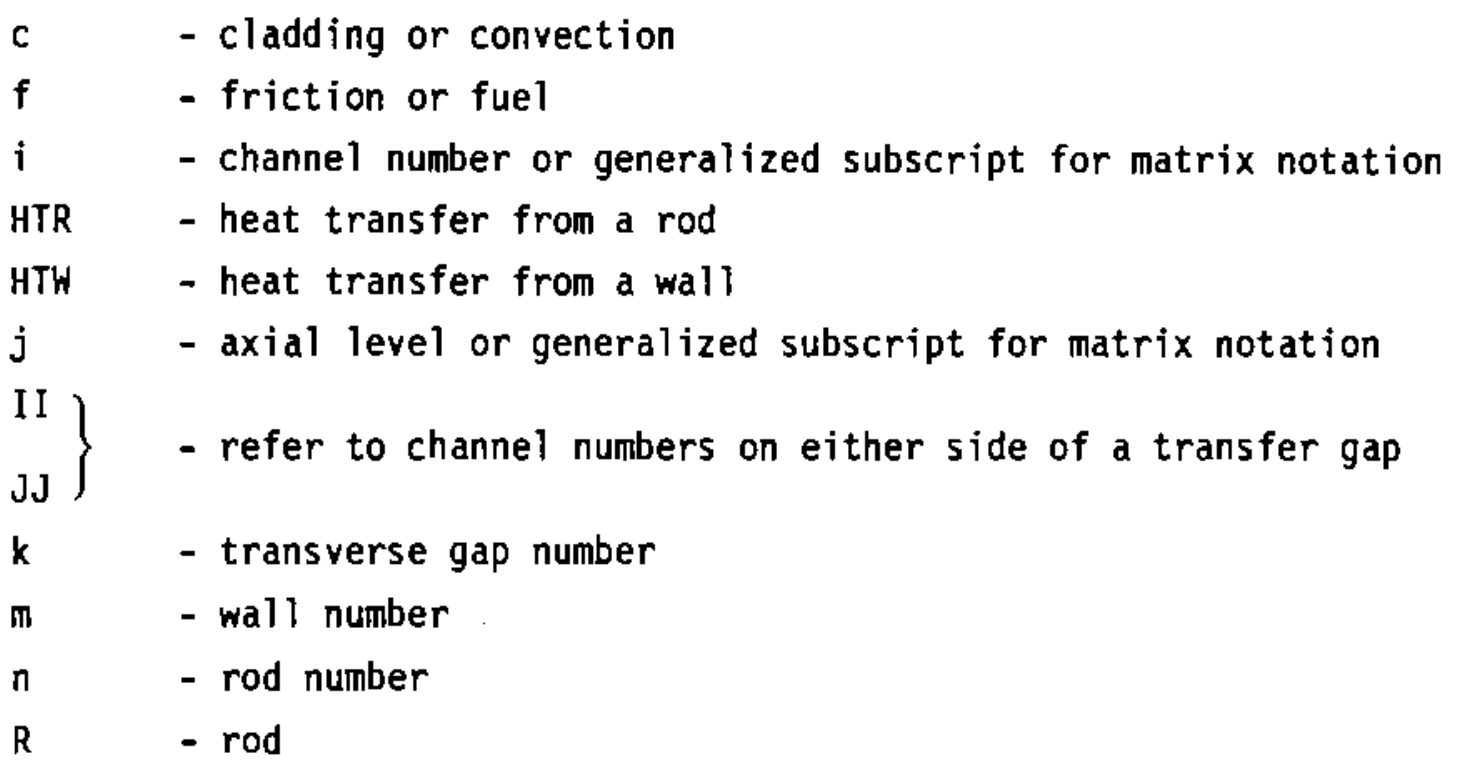




$$
\begin{array}{ll}
\mathrm{T} & \text { - transverse } \\
\mathrm{W} & \text { - wall }
\end{array}
$$



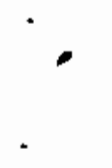


\section{CONTENTS}

ABSTRACT ................................

ACKNOWLEDGMENTS. . . . . . . . . . . . . . . . . . . v v

NOMENCLATURE . . . . . . . . . . . . . . . . . . . . . vii

1.0 INTRODUCTION . . . . . . . . . . . . . . . . . . . 1.1

2.0 CONCLUSIONS AND RECOMMENDATIONS . . . . . . . . . . . . . 2.1

2.1 CONCLUSIONS . . . . . . . . . . . . . . . 2.1

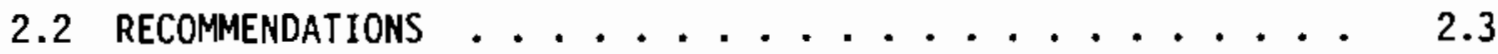

3.0 COBRA-SFS DESCRIPTION . . . . . . . . . . . . . . . . 3.1

3.1 MODELING CAPABILITIES . . . . . . . . . . 3.2

3.2 CONSERVATION EQUATIONS . . . . . . . . . . . 3.2

4.0 CASK MODEL OPTIMIZATION . . . . . . . . . . . . . . . . 4.1

4.1 MODEL DEVELOPMENT . . . . . . . . . . . . . . . 4.1

4.1.1 Cask Symmetry ................... 4.1

4.1.2 Model Requirements . . . . . . . . . . . 4.3

4.1.3 Effect of Temperature Distribution . . . . . . 4.3

4.2 BASE MODEL DESCRIPTION . . . . . . . . . . . . 4.3

4.2.1 TN-24P Cask Description . . . . . . . . . . 4.4

4.2.2 TN-24P Base Model Description . . . . . . . . . 4.4

4.3 ASSEMBLY NODALIZATION . . . . . . . . . . . . . . 4.6

4.3.1 Assembly Model Set $1(120 / 105$ Rod Nodes, $136 / 57$
Channel Nodes) . . . . . . . . . . . . . 4.7

4.3 .2 Assembly Model Set $\$ 2(1 / 1$ Rod Nodes, $1 / 1$ Channe1
Nodes) . . . . . . . . . . . . . . 4.8

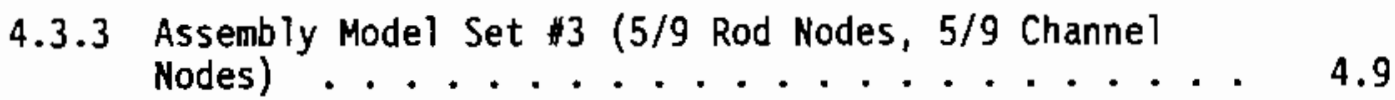


4.3.4 Assembly Model Set \#4 (28/49 Rod Nodes, 28/49 Channel Nodes) . . . . . . . . . . . . . . .

4.3.5 Assembly Model Set \#5 (120/225 Rod Nodes, 136/256 Channel Nodes) .............. 4.9

4.3.6 Assembly Model Set \#6 (120/1 Rod Nodes, 136/1 Channel Nodes) . . . . . . . . . . . . . .

4.3.7 Assembly Model Set $\# 7$ (120/5/9 Rod Nodes, 136/5/9 Channel Nodes) . . . . . . . . . . .

4.3.8 Assembly Model Set \#8 (120/49/28 Rod Nodes, 136/49/28 Channel Nodes)

4.4 SOLID STRUCTURE MODELING . . . . . . . . . . 4.11

4.5 AXIAL NODING STUDY . . . . . . . . . . . 4.13

4.5.1 Axial Level Model 1 (24 Uniform Levels) . . . . 4 4.13

4.5.2 Axial Level Mode1 \#2 (18 Uniform Levels) . . . . 4.13

4.5.3 Axial Level Model \#3 (12 Uniform Levels) . . . . 4 4.13

4.5.4 Axial Level Model \#4 (8 Uniform Levels) . . . . . 4.14

4.5.5 Axial Level Model \#5a (12 Nonuniform Levels) . . . 4.14

4.5.6 Axial Level Model \#5b (12 Nonuniform Levels) . . . 4.15

4.6 PARAMETER OPTIMIZATION . . . . . . . . . . . . . 4.15

4.6.1 Solid Structure Equation Acceleration Factor . . . . 4.16

4.6.2 Rod Equation Damping Factor . . . . . . . . . 4.17

4.6.3 Axial Rebalancing Factor .......... 4. 4. . . .

5.0 FLOW SOLUTION IMPROVEMENTS $\ldots \ldots \ldots . \ldots . \ldots . \ldots . \ldots$

5.1 DESCRIPIION OF MODIFICATIONS . . . . . . . . . 5.1

5.2 INPUT CHANGES ...................... 5.6

5.3 VERIFICATION ASSESSMENT . . . . . . . . . . 5.8

5.3.1 Flow in Plane Channel ........... 5.9

5.3.2 Flow in Cylindrical Pipe .......... 5.9 
5.3.3 Flow in a Square Duct............ 5.10

5.3.4 Thermal-Entry-Length Pipe Heat Transfer . . . . . 5.10

5.3.5 Thermal-Entry-Length for Square Duct . . . . . 5.11

6.0 PLENUM MOdEL IMPROVEMENTS . . . . . . . . . . . 6.1

6.1 DESCRIPIION OF MODIFICATIONS . . . . . . . . . 6.1

6.1 .1 Flow Solution Modifications ......... 6.2

6.1 .2 Plenum Heat Transfer Modifications . . . . . . 6.4

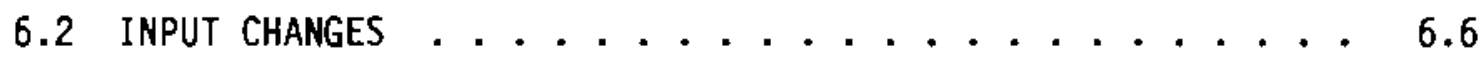

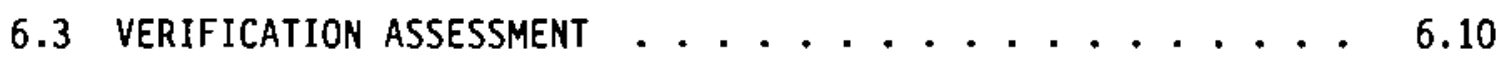

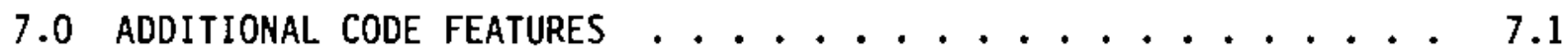

7.1 TEMPERATURE-DEPENDENT SOLID THERMAL CONDUCTIVITIES . . . . 7.1

7.2 SOLID HEAT Generation tRanSIENT TABLES . . . . . . 7.3

7.3 AXIALLY VARYING MATERIAL TYPES ........... 7.3

7.4 SOLID-TO-FLUID CONNECTIONS . . . . . . . . . . 7.6

8.0 REFERENCES ........................... 8.1

APPENDIX A - DEVELOPING FLOW IN A PLANAR ChanNel OUTPUT . . . . . A.1

APPENDIX B - DEVELOPING FLOW IN A CYLINDRICAL PIPE OUTPUT . . . . B B.1

APPENDIX C - DEVELOPING FLOW IN A SQUARE DUCT OUTPUT . . . . . . . c. c.

APPENDIX D - NATURAL CIRCULATION IN A SQUARE CAVITY OUTPUT $\ldots \ldots . . . .1$ 
-

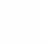




\section{FIGURES}

3.1 Channel Definition . . . . . . . . . . . . 3.8

3.2 Transverse Momentum Control Volume . . . . . . . . . 3.8

4.1 TN-24P One-Half Section Cask Model . . . . . . . . . 4.19

4.2 TN-24P One-Eighth Section Cask Model . . . . . . . . . 4.20

4.3 TN-24P Cask Cross Section ................. 4.21

4.4 COBRA-SFS TN-24P Axial Computational Cask Model . . . . . 4.22

4.5 One-Half Fuel Assembly Rod and Channel Computational Model . . 4.23

4.6 Full Fuel Assembly Lumped Rod and Lumped Channel Computational Mode1 .....................

4.7 Axial Temperature Profiles of Experimental Data and COBRA-SFS Predictions for Assembly Model Set \#1 for the TN-24P SpentFuel Cask, Helium Backfill Case . . . . . . . . . . . 4.24

4.8 Axial Temperature Profiles of Experimental Data and COBRA-SFS Predictions for Assembly Model Set $\# 1$ for the TN-24P SpentFuel Cask, Nitrogen Backfill Case . . . . . . . . . .

4.9 Axial Temperature Profiles of Experimental Data and COBRA-SFS Predictions for Assembly Model Set $\# 1$ for the TN-24P SpentFuel Cask, Vacuum Backfill Case ..............

4.10 Radial Temperature Profiles of Experimental Data and COBRA-SFS Predictions for Assembly Model Set \#1 for the TN-24P Spent-Fuel Cask, Helium Backfill Case ................

4.11 Radial Temperature Profiles of Experimental Data and COBRA-SFS Predictions for Assembly Model Set \#1 for the TN-24P Spent-Fuel Cask, Nitrogen Backfill Case . . . . . . . . . . . . .

4.12 Radial Temperature Profiles of Experimental Data and COBRA-SFS Predictions for Assembly Model Set $\# 1$ for the TN-24P Spent-Fuel Cask, Vacuum Backfill Case ................

4.13 Axial Temperature Profiles of COBRA-SFS Predictions for Assembly Model Sets \#2 and \#1 (Detailed Models) for the TN-24P Spent-Fuel Cask, Helium Backfill Case . . . . . . . . . . . . . . 
4.14 Axial Temperature Profiles of COBRA-SFS Predictions for Assembly Mode] Sets \#2 and \#1 for the TN-24P Spent-Fuel Cask, Nitrogen Backfjll Case ....................

4.15 Axial Temperature Profiles of COBRA-SFS Predictions for Assembly Model Sets \#2 and \#1 for the TN-24P Spent-Fuel Cask, Vacuum Backfill Case ...................

4.16 Radial Temperature Profiles of COBRA-SFS Predictions for Assembly Model Sets \#2 and \#1 for the TN-24P Spent-Fuel Cask, Helium

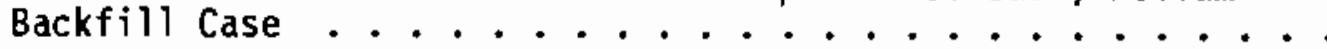

4.17 Radial Temperature Profiles of COBRA-SFS Predictions for Assembly Model Sets \#2 and \#1 for the TN-24P Spent-Fuel Cask, Nitrogen Backfill Case ...................

4.18 Radial Temperature Profiles of COBRA-SFS Predictions for Assembly Model Sets \#2 and \#1 for the TN-24P Spent-Fuel Cask, Vacuum Backfill Case ....................

4.19 COBRA-SFS TN-24P Half Assembly Model Set \#3 (5 rod and 5 channel nodes per assembly)

4.20 COBRA-SFS TN-24P Full Assembly Model Set \$3 (9 rod and 9 channel nodes per assembly) ................

4.21 Axial Temperature Profiles of COBRA-SFS Predictions for Assembly Model Sets \#3, \#2, and 11 for the TN-24P Spent-Fuel Cask, Helium Backfill Case .....................

4.22 Axial Temperature Profiles of COBRA-SFS Predictions for Assembly Model Sets \#3, \#2, and \#1 for the TN-24P Spent-Fuel Cask, Nitrogen Backfill Case .....................

4.23 Axial Temperature Profiles of COBRA-SFS Predictions for Assembly Model Sets \#3, \#2, and \#1 for the TK-24P Spent-Fuel Cask, Vacuum Backfill Case ........................

4.24 Radial Temperature Profiles of COBRA-SFS Predictions for Assembly Model Sets \#3, \#2, and \#1 for the TN-24P Spent-Fuel Cask, Helium Backfill Case ..................

4.25 Radial Temperature Profiles of COBRA-SFS Predictions for Assembly Model Sets \#3, \#2, and 1 for the TN-24P Spent-Fuel Cask, Nitrogen Backfill Case .................

4.26 Radial Temperature Profiles of COBRA-SFS Predictions for Assembly Model Sets \#3, \#2, and \#1 for the TN-24P Spent-Fuel Cask, Vacuum Backfill Case....................... 
4.27 COBRA-SFS TN-24P Half Assembly Model Set $\# 4$ (28 rod and 28 channel nodes per assembly) . . . . . . . . . . . .

4.28 COBRA-SFS TN-24P Full Assembly Model Set $\# 4$ (49 rod and 49 channel nodes per assembly) ...............

4.29 Axial Temperature Profiles of COBRA-SFS Predictions for Assembly Model Sets \#4, $3, \# 2$, and $\# 1$ for the TN-24P Spent-Fuel Cask, Helium Backfill Case . . . . . . . . . . . . . .

4.30 Axial Temperature Profiles of COBRA-SFS Predictions for Assembly Model Sets $\# 4, \# 3, \# 2$, and $\# 1$ for the TN-24P Spent-Fuel Cask, Nitrogen Backfill Case ...................

4.31 Axial Temperature Profiles of COBRA-SFS Predictions for Assembiy Model Sets $\# 4, \# 3, \# 2$, and \#1 for the TN-24P Spent-Fuel Cask, Vacuum Backfill Case ... . . . . . . . . . . . . .

4.32 Radial Temperature Profiles of COBRA-SFS Predictions for Assembly Model Sets $\$ 4, \# 3, \# 2$, and $\# 1$ for the TN-24P SpentFuel Cask, Helium Backfill Case ..............

4.33 Radial Temperature Profiles of COBRA-SFS Predictions for Assembly Model Sets $\$ 4, \# 3, \# 2$, and $\# 1$ for the TN-24P Spent Fuel Cask, Nitrogen Backfill Case ................

4.34 Radial Temperature Profiles of COBRA-SFS Predictions for Assembly Model Sets \#4, \#3, \#2, and 1 for the TN-24P Spent-Fuel Cask, Vacuum Backfill Case ...............

4.35 COBRA-SFS TN-24P Full Assembly Model for Set $\$ 5$. . . . . .

4.36 Axial Temperature Profiles of COBRA-SFS Predictions for Assembly Model Sets $\# 5$ and $\# 1$ for the TN-24P Spent-Fuel Cask, Helium

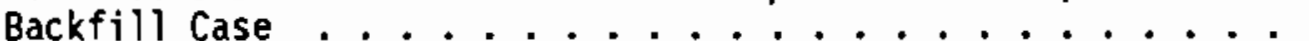

4.37 Axial Temperature Profiles of COBRA-SFS Predictions for Assembly Model Sets $\$ 5$ and $\# 1$ for the TN-24P Spent-Fuel Cask, Nitrogen Backfill Case .....................

4.38 Axial Temperature Profiles of COBRA-SFS Predictions for Assembly Model Sets $\$ 5$ and $\# 1$ for the TN-24P Spent-Fuel Cask, Vacuum

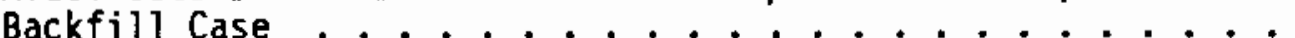

4.39 Radial Temperature Profiles of COBRA-SFS Predictions for Assembly Model Sets $\$ 5$ and $\# 1$ for the TN-24P Spent-Fuel Cask, Helium Backfill Case ................... 
4.40 Radial Temperature Profiles of COBRA-SFS Predictions for Assembly Mode1 Sets $\# 5$ and $\# 1$ for the TN-24P Spent-Fuel Cask, Nitrogen Backfill Case ...............

4.41 Radial Temperature Profiles of COBRA-SFS Predictions for Assembly Model Sets $\# 5$ and $\# 1$ for the TN-24P Spent-Fuel Cask,

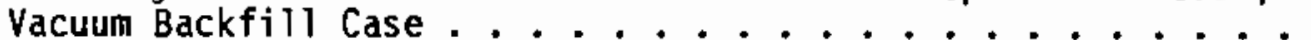

4.42 Axial Temperature Profiles of COBRA-SFS Predictions for AssembTy Model Sets \#6 and \#5 for the TN-24P Spent-Fuel Cask, Helium

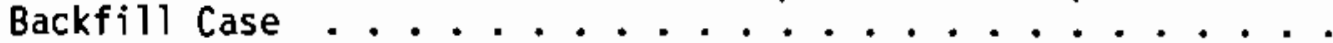

4.43 Axial Temperature Profiles of COBRA-SFS Predictions for Assembly Model Sets \#6 and \#5 for the TN-24P Spent-Fuel Cask, Nitrogen

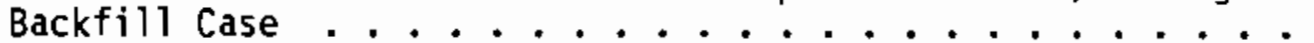

4.44 Axial Temperature Profiles of COBRA-SFS Predictions for Assembly Model Sets \#6 and \#5 for the TN-24P Spent-Fuel Cask, Vacuum

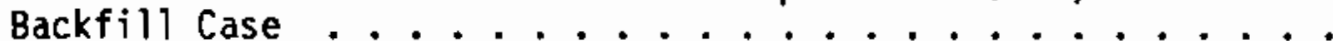

4.45 Radial Temperature Profiles of COBRA-SFS Predictions for Assembly Model Sets \#6 and \#5 for the TN-24P Spent-Fuel Cask, Helium Backfill Case .................

4.46 Radial Temperature Profiles of COBRA-SFS Predictions for Assembly Model Sets $\# 6$ and $\# 5$ for the TN-24P Spent-Fuel Cask, Nitrogen Backfill Case ................

4.47 Radial Temperature Profiles of COBRA-SFS Predictions for Assembly Model Sets $\# 6$ and \#5 for the TN-24P Spent-Fuel Cask, Vacuum Backfill Case ................

4.48 Axial Temperature Profiles of COBRA-SFS Predictions for Assembly Model Sets $\# 7$, \#6, and \#5 for the TN-24P Spent-Fuel Cask, Helium Backfill Case .................

4.49 Axial Temperature Profiles of COBRA-SFS Predictions for Assembly Model Sets \#7, \#6, and \#5 for the TN-24P Spent-Fuel Cask, Nitrogen Backfill Case ...............

4.50 Axial Temperature Profiles of COBRA-SFS Predictions for Assembly Model Sets \#7, \#6, and \#5 for the TN-24P Spent-Fue 1 Cask, Vacuum

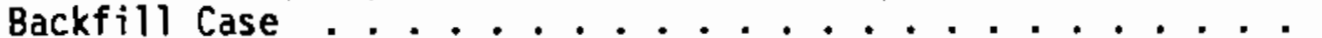

4.51 Radial Temperature Profiles of COBRA-SFS Predictions for Assembly Mode T Sets \#7, \#6, and \#5 for the TN-24P Spent-Fue] Cask, Helium Backfill Case ............. 
4.52 Radial Temperature Profiles of COBRA-SFS Predictions for Assembly Model Sets $\# 7, \# 6$, and $\# 5$ for the TN-24P Spent-Fue 1 Cask, Nitrogen Backfili Case .............

4.53 Radial Temperature Profiles of COBRA-SFS Predictions for Assembly Model Sets $\# 7, \# 6$, and \#5 for the TN-24P Spent-Fuel Cask, Vacuum Backfill Case ..............

4.54 Axial Temperature Profiles of COBRA-SFS Predictions for Assembly Model Sets $\# B$ and $\# 5$ for the TN-24P Spent-Fuel Cask, Helium

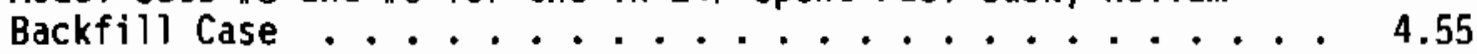

4.55 Axial Temperature Profiles of COBRA-SFS Predictions for Assembly Model Sets $\# 8$ and \#5 for the TN-24P Spent-Fuel Cask, Nitrogen

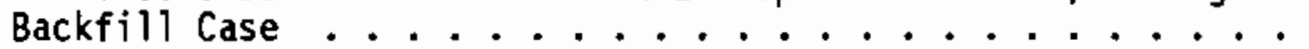

4.56 Axial Temperature Profiles of COBRA-SFS Predictions for Assembly Model Sets \#8 and \#5 for the TN-24P Spent-Fuel Cask, Vacuum

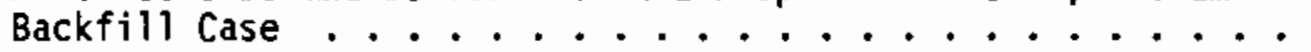

4.57 Radial Temperature Profiles of COBRA-SFS Predictions for Assembly Model Sets \#8 and \#5 for the TN-24P Spent-Fuel Cask, Helium Backfill Case ................

4.58 Radial Temperature Profiles of COBRA-SFS Predictions for Assembly Model Sets \#8 and \#5 for the TN-24P Spent-Fuel Cask, Nitrogen Backfill Case . . . . . . . . . . . .

4.59 Radial Temperature Profiles of COBRA-SFS Predictions for Assembly Model Sets \#8 and \#5 for the TN-24P Spent-Fuel Cask, Vacuum Backfill case ................ 4..58

4.60 TN-24P Solid Structure Noding . . . . . . . . . . 4.59

4.61 TN-24P Model with Reduced Shell Noding . . . . . . . . 4.59

4.62 Solid Structure Basket Noding . . . . . . . . . 4.60

4.63 Axial Temperature Profiles of Experimental Data and COBRA-SFS Predictions Using Axial Model Set \#1 (24 levels) for the TN-24P Spent-Fuel Cask, Helium Backfill Case . . . . . . . . . .

4.64 Axial Temperature Profiles of Experimental Data and COBRA-SFS Predictions Using Axial Model Set \#1 (24 levels) for the TN-24P Spent-Fuel Cask, Nitrogen Backfill Case ..........

4.65 Axial Temperature Profiles of Experimental Data and COBRA-SFS Predictions Using Axial Model Set \#1 (24 levels) for the TN-24P Spent-Fuel Cask, Vacuum Backfill Case .......... 
4.79 COBRA-SFS Axial Model \#5b, 12 Levels with Nonuniform Noding . . . . . . . . . . . . 4.70

4.80 Axial Temperature Profiles of COBRA-SFS Predictions for Axial Model Sets \#5b (12 nonuniform levels) and \#1 (24 levels) for the TN-24P Spent-Fuel Cask, Helium Backfill Case . . . . . .

4.81 Axial Temperature Profiles of COBRA-SFS Predictions for Axial Model Sets \#5b (12 nonuniform levels) and \#1 (24 levels) for the TN-24P Spent-Fuel Cask, Nitrogen Backfill Case . . . . . 4.71

4.82 Axial Temperature Profiles of COBRA-SFS Predictions for Axial Model Sets \#5b (12 nonuniform levels) and \#1 (24 levels) for the TN-24P Spent-Fuel Cask, Vacuum Backfill Case . . . . . 4.72

5.1 Subchannel Control volume .............. 5.13

5.2 Axial Momentum Balance on a Subchannel Control Volume ..... 5.13

5.3 Transverse Momentum Balance on a Control Volume . . . . . . 5.14

5.4 Transverse Control Volume for Open Flow Region . . . . . . . 5.14

5.5 Control Volume for Wall Shear Stress ............ 5.14

5.6 Axial Transfer of Transverse Momentum . . . . . . . 5.15

5.7 Lateral Transfer of Transverse Momentum . . . . . . . . 5.15

5.8 Plane Channel Model Geometry . . . . . . . . . . . . 5.16

5.9 Velocity Profiles for a Two-Dimensional Planar Channel with Uniform Inlet Velocity and Constant Cell Spacing, $\mathrm{Re}=50$ case ....................... 5.16

5.10 Velocity Profiles for a Two-Dimensional Planar Channel with Uniform Inlet Velocity and Constant Cell Spacing, $\mathrm{Re}=200$ Case .................. 5.17

5.11 Cylindrical Pipe Model Geometry ............. 5.18

5.12 Velocity Profiles for a Two-Dimensional, Cylindrical-Channel Flow with Uniform Inlet Velocity and Constant Cell Spacing, $R e=100$ Case ..................... 5.19

5.13 Square Duct Model Geometry . . . . . . . . . . . . . 5.20

5.14 Velocity Profiles for a Three-Dimensional Cartesian Square Channel with Uniform Inlet Velocity, Re $=200$ Case . . . . . 
4.66 Axial Temperature Profiles of COBRA-SFS Predictions for Axial Model Sets $\# 2$ (18 levels) and \#1 (24 levels) for the TN-24P Spent-Fuel Cask, Helium Backfill Case . . . . . . . . 4.62

4.67 Axial Temperature Profiles of COBRA-SFS Predictions for Axial Model Sets $\# 2$ (18 levels) and $\# 1$ (24 levels) for the TN-24P Spent-Fuel Cask, Nitrogen Backfill Case . . . . . . . . .

4.68 Axial Temperature Profiles of COBRA-SFS Predictions for Axial Model Sets \#2 (18 levels) and \#1 (24 levels) for the TN-24P Spent-Fuel Cask, Vacuum Backfill Case ............

4.69 Axial Temperature Profiles of COBRA-SFS Predictions for Axial Model Sets \#3 (12 levels) and \#1 (24 levels) for the TN-24P Spent-Fuel Cask, Helium Backfill Case ............

4.70 Axial Temperature Profiles of COBRA-SFS Predictions for Axial Model Sets \#3 (12 levels) and \#1 (24 levels) for the TN-24P Spent-Fuel Cask, Nitrogen Backfill Case ...........

4.71 Axial Temperature Profiles of COBRA-SFS Predictions for Axial Model Sets $\$ 3$ (12 levels) and $\# 1$ (24 levels) for the TN-24P Spent-Fuel Cask, Vacuum Backfill Case . . . . . . . . .

4.72 Axial Temperature Profiles of COBRA-SFS Predictions for Axial Model Sets \#4 (8 levels) and \#1 (24 levels) for the TN-24P Spent-Fuel Cask, Helium Backfill Case . . . . . . . . . .

4.73 Axial Temperature Profiles of COBRA-SFS Predictions for Axial Model Sets $\# 4$ ( 8 levels) and 1 (24 levels) for the TN-24P Spent-Fuel Cask, Nitrogen Backfill Case ...........

4.74 Axial Temperature Profiles of COBRA-SFS Predictions for Axial Model Sets \#4 (8 levels) and \#1 (24 levels) for the TN-24P Spent-Fuel Cask, Vacuum Backfill Case ............

4.75 COBRA-SFS Axial Model $¥ 5 a, 12$ Levels with Nonuniform Noding . . . . . . . . . . . . . . . . . . . . .

4.76 Axial Temperature Profiles of COBRA-SFS Predictions for Axial Model Sets \#5a (12 nonuniform levels) and \#1 (24 levels) for the TN-24P Spent-Fuel Cask, Helium Backfill Case . . . . . .

4.77 Axial Temperature Profiles of COBRA-SFS Predictions for Axial Model Sets \#5a (12 nonuniform levels) and \#1 (24 levels) for the TN-24P Spent-Fuel Cask, Nitrogen Backfill Case . . . . .

4.78 Axial Temperature Profiles of COBRA-SFS Predictions for Axial Model Sets \#5a (12 nonuniform levels) and \#1 (24 levels) for the TN-24P Spent-Fuel Cask, Vacuum Backfill Case . . . . . . . 
5.15 Centerline Velosity Profile for a Square Channel with Uniform Inlet Velocity, $\operatorname{Re}=200$ Case . . . . . . . . . . 5.22

6.1 Cut-Away Sketch of a Typical Spent Fuel Cask . . . . . . . . . 6.11

6.2 Typical COBRA-SFS Cask Mode1 . . . . . . . . . . 6.12

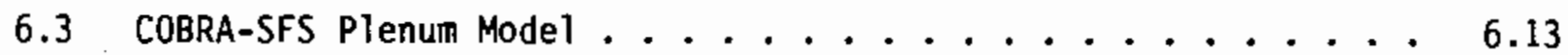

6.4 Detailed Plenum Model . . . . . . . . . . . . 6.13

6.5 Detailed Plenum Heat Transfer Model . . . . . . . . . . 6.14

6.6 Geometry of a Square Cavity . . . . . . . . . . . 6.14

6.7 Natural Convection in a Two-Dimensional Cavity . . . . . . . 6.15

7.1 Temperature Profiles for Heat-Generating Plate with Linearly

Varying Thermal Conductivity ............. 7.8

\section{$\underline{\text { TABLES }}$}

3.1 COBRA-SFS Capabilities and Limitations . . . . . . . . . . 3.9

4.1 Material Properties . . . . . . . . . . . . . . . 4.73

4.2 Parameter ACCELW Results . . . . . . . . . . . . . 4.73

4.3 Parameter ACCROD Results . . . . . . . . . . . . 4.74

4.4 Parameter ACCAX Results . . . . . . . . . . . . . . 4 4.74

5.1 Nusselt Numbers and Mean Temperatures for Constant Surface Temperature Pipe ................ 5.23

5.2 Nusselt Numbers for Square Duct with Constant Surface Temperature ....................... 


\section{COBRA-SFS MODIFICATIONS AND CASK MODEL OPTIMIZATION}

\subsection{INTRODUCTION}

The COBRA-SFS (Spent Fuel Storage) code is designed to perform thermalhydraulic analysis of multiassembly spent-fuel storage systems. The objective of the COBRA-SFS user is to develop a COBRA-SFS model that is both accurate and efficient. This study examines methods and factors that will assist the user in optimizing the nodalization of a storage cask model. This report also describes new code modeling capabilities that have been added to allow a more detailed representation of a system. This study was conducted by the Pacific Northwest Laboratory (PNL) (a) for the U.S. Department of Energy (DOE).

The accuracy of a storage system analys is is highly dependent on node distribution and the quantity and location of temperature points on a given cask. Although COBRA-SFS can handle very large problems (consisting of hundreds of channel and rod nodes), there is a practical upper limit, generally dictated by computer memory requirements. Also, the larger the problem, the more expensive it is to run; thus, cost considerations provide a significant incentive to limit problem size. The level of detail provided by rod-andchannel modeling is not always required for flow and heat transfer problems in fuel assemblies. Experience with COBRA codes has shown that reasonable results can often be obtained with much coarser representations of the assembly geometry (Rector, Cuta, and Lombardo 1986).

One objective of this work is to provide the COBRA-SFS user with a guide to developing the optimal model for a particular spent-fuel cask. Model aspects that were explored include geometry considerations, such as assembly, slab, and axial nodalization, and optimization of the numerical solution parameters.

Certain aspects of the original COBRA-SFS code (cycle 0 ) limited the scope and accuracy of the thermal-hydraulic calculations. One limitation of the code

\footnotetext{
(a) Operated for the U.S. Department of Energy by Battelle Memorial Institute under Contract DE-ACO6-76RLO 1830.
} 
was the absence of fluid shear stress terms in the momentum equations. As a result, open flow regions could only be modeled using large channel nodes that may not represent the velocity distribution within the region with the desired accuracy. Fluid shear stress terms have been added to allow finer nodalization and more detailed information in these regions.

Another limiting aspect of the code was the plenum models that were used to represent the upper and lower portions of storage casks. In using these models, it was assumed that all fluid entering a plenum region was uniformly mixed and that no temperature variation existed in the region. In addition, heat transfer from each region to ambient conditions was modeled using two one-dimensional heat transfer paths. The limitations of these plenum models have been identified in several previous cask analysis studies. A detailed plenum model was added to allow the calculation of temperature and flow distributions in the plenum regions.

The conclusions and recommendations based on this study are presented in Section 2.0. A brief description of the COBRA-SFS code is presented in Section 3.0. In Section 4.0, the results of the model optimization studies based on the TN-24P spent-fuel cask are presented, and general guidelines for model optimization are discussed. Modifications to the COBRA-SFS code are describe 1 in Sections 5.0,6.0, and 7.0. Section 5.0 describes the addition of fluid shear stress terms to the momentum equations. Section 6.0 describes the add $i$ tion of a detailed plenum model. Section 7.0 describes a series of additional code improvements including temperature-dependent solid thermal conductivity and axially varying solid material types. 


\subsection{CONCLUSIONS AND RECOMMENDATIONS}

COBRA-SFS optimization is somewhat cask-specific; however, the conclusions and recommendations presented here, based on the TN-24P spent-fuel cask described in Section 4.0, apply in general to all COBRA-SFS cask models. It is recommended that all COBRA-SFS users investigate the benefits of optimization for their specific model based on the procedures detailed in this document.

\subsection{CONCLUSIONS}

The conclusions for this study are divided into two areas: 1) those related to the optimization of cask nodalization and 2) those related to the addition of new code modeling capabilities. The following conclusions were drawn from the cask model optimization study.

- Spent-fuel assemblies can be represented by coarse assembly models using composite channels and rods. The temperature predictions for the simulations using different combinations of coarse and detailed assembly models compared well with the completely detailed assembly model predictions. Therefore, combinations of coarse and detailed assembly models can be used in a multiassembly cask model to reduce the problem size by half of a fully detailed model, with less than $5 \%$ change in peak temperature prediction compared to the fully detailed analysis. This was true for all three backfills: helium, nitrogen, and low-pressure nitrogen (vacuum).

- In many cases, the number of slab nodes used in a cask model can be reduced. Circumferential temperature gradients in many spent-fuel cask shells can be neglected so that only radial nodes are required. Radial nodes of similar materials may be combined, except in casks where an interfacial gap is involved. When the basket is constructed of a highconductivity material, the model can be more coarsely noded than for a low-conductivity material. The $\mathrm{TN}-24 \mathrm{P}$ cask basket temperature predictions varied by less than $2 \%$, when the basket nodes were reduced by $66 \%$. 
- There is a limit to the minimum number of axial levels that will provide accurate temperature profiles. In this study, the 24-, 18-, and 12-axial level models all predicted temperature profiles within $5 \%$ of each other. However, when the 8-level model was applied, the temperature predictions differed by as much as $13 \%$ from the other axial model predictions. This effect was most apparent in the nitrogen backfill case, where convection is a major contributor to the overall heat transfer. It is important to know the sensitivity of a specified cask-to-axial noding to ensure that the predictions are accurate.

- By optimizing the parameters controlling the numerical solution, the computational time required for a cask simulation can be significantly reduced without affecting the accuracy of the solution. The optimum values for parameters ACCELW and ACCROD vary as a function of backfill media. The optimum value for ACCELW was determined to be 1.6 for the helium backfill case and 1.5 for the nitrogen case. The optimum value for ACCROD was found to be 0.6 for the helium and nitrogen cases, and 0.4 for the vacuum case. For all backfills the optimum value of ACCAX was determined to be 1.0 .

The following conclusions were drawn from the addition of new code modeling capabilities:

- The fluid shear stress terms have been successfully added to the COBRA-SFS momentum equations. These terms allow the modeling of open flow regions with several channels. Verification runs have been performed for developing flows in a planar channel, cylindrical pipe, and square duct. The heat transfer terms were verified by comparing code results with analytically determined Nusselt numbers. In all cases, results show excellent agreement.

- An improved plenum model has been added that allows detailed modeling of fluid velocities and enthalpies in the plenum region. The model was verified by comparing the code results with data for natural circulation in a square cavity. The comparison shows very good agreement. 
- Several other improvements have been made to the COBRA-SFS code, including temperature-dependent solid thermal conductivities, axially varying solid material types, solid heat generation transient tables, and dimensionless solid-to-fluid connections. The temperature-dependent conductivities were verified by comparing code results with the analytical solution for heat generation in a slab with linearly-varying thermal conductivity.

\subsection{RECOMMENDATIONS}

The following recommendations are offered:

- The results presented in this study were based on the TN-24P spent-fue1 cask but apply in general to all COBRA-SFS cask models. For each code application, a limited optimization study should be performed based on the methods detailed in this report to determine the most efficient model. The study should include axial and assembly noding sensitivity investigations.

- One major feature of the COBRA-SFS code that has not yet been verified is its transient capability. It is recommended that a series of runs be performed and documented to verify this capability and extend its applicability to transient heat transfer systems. 


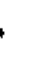




\subsection{COBRA-SFS DESCRIPIION}

The COBRA-SFS code is a steady-state, lumped-parameter, finite-difference computer code that predicts flow and temperature distributions in spent-fue 1 storage systems and fuel assemblies under mixed and/or natural convection conditions. Derived from the COBRA family of codes (Rowe 1973; Stewart et al. 1977; George et al. 1980; Khan et al. 1981), which have been extensively evaluated against in-pile and out-of-pile data, COBRA-SFS retains all the important features of the COBRA codes and extends the range of application to problems with two-dimensional radiation and conduction heat transfer. This capability permits analyses of single- and multiassembly spent-fuel storage systems with unconsolidated or consolidated fuel, with a variety of fill media (Cuta, Rector, and Creer 1984; Lombardo et al. 1986a; Cuta and Creer 1986; Wiles et a1. 1986; Rector, Cuta, and Lombardo 1986; Rector et al. 1986a; McKinnon et al. 1986; Wheeler et al. 1986).

COBRA-SFS provides finite-difference solutions to the equations governing mass, momentum, and energy conservation for incompressible flows. Analyses are conducted using a channel approach in which the flow areas of assemblies or storage systems are divided axially into discrete control volumes for which the conservation equations of mass, momentum, and energy are written. These equations are then solved using an iterative implicit method. The energy equations for the coolant, rod cladding, fuel, and structural members (slabs) are solved implicitly by iteration, but simultaneously in a plane. Axial conduction in the structural members is modeled. A nonparticipating gray body radiation heat transfer model also allows two-dimensional radiant heat exchange among all solid surfaces in an enclosure and is iteratively coupled to the rod and wall energy equations.

The flow field may be either user-prescribed or internally calculated as a function of the gravitational and dynamic pressure losses. Specifications of heat losses from the boundary may vary circumferentially and axially, and can include both radiation and convection heat transfer. Axial heat transfer from the channel model to plenum regions (regions above and below the fuel assemblies) also can be modeled. 
In the following sections, the COBRA-SFS modeling capabilities are outlined, and a brief description of the conservation equations is given.

\subsection{MODELING CAPABILITIES}

COBRA-SFS allows simulations of a wide range of dry storage systems. In addition to the multiassembly cask analys is described in this report, applications have included analyses of single-assembly spent-fuel storage systems under multiple orientations and fill media (Lombardo et al. 1986a), multiassembly systems with unconsolidated spent-fuel (Wiles et al. 1986; Rector et a1. 1986a; Mckinnon et a1. 1986), and analyses of both single- and multiassembly consolidated fuel storage systems (Cuta, Rector, and Creer 1984; Cuta and Creer 1986; and Rector et al. 1986b). The code contains thermalhydraulic models for pressure drop, turbulent mixing, diversion crossflow, buoyancy-induced flow recirculation, and conduction and radiation heat transfer. A versatile fuel rod model allows simulation of consolidated fuel assemblies. The code's capabilities and limitations are outlined in Table 3.1.

\subsection{CONSERVATION EQUATIONS}

The COBRA-SFS code solves the conservation equations of mass, momentum, and energy in a fuel assembly or fuel storage system using finite-difference equations derived by performing suitable balances on finite control volumes. Empirical relationships are used where needed to close the set of equations. The conservation equations presented below are derived in more detail in Rectar, Wheeler, and Lombardo (1986).

The fluid control volume for continuity, axial momentum, and energy is characterized by a flow cross-sectional area, $A_{;}$an axial length, $\Delta x ;$ and a gap width, S, for the connection between itself and adjacent control volumes. Figure 3.1 shows the relationship of a channel control volume to a fuel storaje system; a typical channel control volume is also displayed. Any series of control volumes connected axially is considered a channel. In the following equations, the finite-difference terms are presented with the corresponding word definitions given immediately below each equation. The list of symbols 
in the Nomenclature section of this document should be referred to for explanation of the notation.

Continuity Equation (for channel i)

$$
\begin{aligned}
& \bar{A} \frac{\left(\rho-\rho^{n}\right)}{\Delta t} j=\frac{v_{j-1} A_{j-1} \rho_{j-1}^{*}}{\Delta x_{j}}-\frac{v_{j} A_{j} \rho_{j}^{*}}{\Delta x_{j}}+\sum_{k \in \Psi_{i}} e_{k}\left(u_{k} S_{k} \rho_{k}^{\star}\right)_{j} \\
& {\left[\begin{array}{l}
\text { mass } \\
\text { storage }
\end{array}\right]=\left[\begin{array}{l}
\text { mass transported } \\
\text { axially }
\end{array}\right]+\left[\begin{array}{l}
\text { mass transported } \\
\text { laterally }
\end{array}\right]}
\end{aligned}
$$

The asterisk denotes donor cell values convected by the velocities $u$ and $v$.

Fluid Energy Equation (for channel i)

$$
\begin{aligned}
& \bar{A} \frac{\left[\rho h-(\rho h)^{n}\right]}{\Delta t} j=\frac{v_{j-1} A_{j-1} \rho_{j-1}^{*} h_{j-1}^{*}}{\Delta x_{j}}-\frac{v_{j} A_{j} \rho_{j}^{*} h_{j}^{*}}{\Delta x_{j}}+\sum_{k \in \mathbb{I}_{i}} e_{k}\left(u_{k} S_{k} \rho_{k}^{*} h_{k}^{*}\right)_{j} \\
& {\left[\begin{array}{l}
\text { energy } \\
\text { storage }
\end{array}\right]=\left[\begin{array}{l}
\text { energy transported } \\
\text { axially }
\end{array}\right]+\left[\begin{array}{l}
\text { energy transported } \\
\text { laterally }
\end{array}\right]} \\
& +\underset{n \epsilon \lambda_{i}}{\sum} \frac{A_{H T R} H_{R}}{\Delta x_{j}}\left(T_{c}-T_{n}\right)+\underset{m \epsilon \gamma_{j}}{\Sigma} \frac{A_{H T W} H_{W}}{\Delta x_{j}}\left(T_{w}-T_{m}\right) \\
& +[\text { rod heat flux }]+[\text { wall heat flux }] \\
& +\underset{k \in \Phi_{i}}{\sum} e_{k} S_{k} k_{k} \frac{T_{I I}-T_{J J}}{l_{k} z_{k}}+\underset{k \in \Psi_{i}}{\sum} \frac{e_{k} W_{T}}{\Delta x_{j}}\left(h_{I I}-h_{J J}\right)
\end{aligned}
$$




$$
+\left[\begin{array}{l}
\text { conductive heat } \\
\text { transfer laterally }
\end{array}\right]+[\text { turbulent energy exchange }]
$$

A11 other forms of energy transport that are not explicitly represented in Equation (3.2) (e.g., potential and kinetic energy) have been neglected.

Axial Momentum Equation (for channel i)

$$
\begin{aligned}
& \bar{A} \frac{\left[\rho v-(\rho v)^{n_{1}}\right]}{\Delta t} j=\frac{A_{j-1} v_{j-1} v_{j-1}^{*} \rho_{j-1}^{*}}{\Delta x_{j}}-\frac{A_{j} v_{j} v_{j}^{*} \rho_{j}^{*}}{\Delta x_{j}}+\sum_{k \in \mathbb{\Psi}_{i}} e_{k}\left(u_{k} S_{k} v_{k}^{*} \rho_{k}^{*}\right)_{j} \\
& {\left[\begin{array}{l}
\text { axial } \\
\text { momentum } \\
\text { storage }
\end{array}\right]=\left[\begin{array}{l}
\text { axial momentum } \\
\text { transported } \\
\text { axially }
\end{array}\right]+\left[\begin{array}{l}
\text { axial momentum } \\
\text { transported } \\
\text { laterally }
\end{array}\right]} \\
& +\bar{A}_{j} \frac{P_{j-1}-P_{j}}{\Delta x_{j}}+\underset{k \in v_{j}}{\sum} \frac{e_{k} w_{T}}{\Delta x_{j}}\left(v_{I I}-v_{J J}\right) \\
& {\left[\begin{array}{l}
\text { pressure } \\
\text { gradient }
\end{array}\right]+\left[\begin{array}{l}
\text { turbulent momentum } \\
\text { exchange }
\end{array}\right]} \\
& -\frac{1}{2}\left(\frac{f}{D_{h}}+\frac{C}{\Delta x_{j}}\right) \rho_{j} v_{j}\left|v_{j}\right| A_{j}-A \rho g \cos \theta \\
& \text { - } \left.\left[\begin{array}{l}
\text { irreversible friction } \\
\text { and form losses }
\end{array}\right] \text { - [gravitational head }\right]
\end{aligned}
$$

In the derivation of the axial momentum equation, it is assumed that all irreversible losses can be obtained by use of suitable friction factors and 
loss coefficients applied to the bulk velocity. Also, it is assumed that pressure changes linearly along the control volume and the shear stress terms due to flow in the adjacent channels can be neglected.

Transverse Momentum Equation

$$
\begin{aligned}
& S \Delta x_{j} \frac{\left[\rho^{*} u-\left(\rho^{*} u\right)^{n}\right]}{\Delta t} k=S_{k} v_{j-1}\left(\rho^{*} u\right)_{k, j-1}^{*}-S_{k} v_{j}\left(\rho^{*} u\right)_{k, j}^{*} \\
& {\left[\begin{array}{l}
\text { lateral } \\
\text { momentum } \\
\text { storage }
\end{array}\right]=\left[\begin{array}{l}
\text { transverse momentum } \\
\text { transported axia11y }
\end{array}\right]} \\
& +\left(P_{1 I}-P_{J j}\right)_{j-1} \frac{S_{k}^{\Delta x_{j}}}{\ell_{k}}-C_{T} u_{k}\left|u_{k}\right| \frac{\rho S \Delta x_{j}}{2 \ell_{k}} \\
& +\left[\text { pressure gradient] }-\left[\begin{array}{l}
\text { irreversible form and } \\
\text { friction loss }
\end{array}\right]\right.
\end{aligned}
$$

The momentum control volume length, $l$, and gap width, $S$, define a transverse momentum control volume as shown in Figure 3.2. Inside this control volume, the transverse velocity is normal to the gap; the flow is assumed to have no transverse component outside the transverse momentum control volume. A further assumption in the transverse momentum equation is that there are no applied body forces in the transverse direction. Therefore, natural convection in the transverse direction cannot be modeled.

Fuel Rod and Cladding Energy Equations

$$
y_{c} \rho_{c} c_{c} \frac{T_{c}-T_{c}^{n}}{\Delta t}=H_{R}\left(T_{c}-T\right) \quad+H_{g} \frac{R_{f}}{R_{c}}\left(T_{f s}-T_{c}\right)
$$




$$
\begin{aligned}
{\left[\begin{array}{l}
\text { energy } \\
\text { storage }
\end{array}\right] } & =\left[\begin{array}{l}
\text { convective } \\
\text { transfer to } \\
\text { the fluid }
\end{array}\right]+\left[\begin{array}{l}
\text { heat transfer } \\
\text { from fuel }
\end{array}\right] \\
& +\sigma \underset{n \in S_{n}}{F_{i n}}\left(T_{c}^{4}-T_{C_{n}}{ }^{4}\right)+\sigma \sum_{m \in k_{m}} F_{i m}\left(T_{c}^{4}-T_{W_{n}}^{4}\right) \\
& +\left[\begin{array}{l}
\text { radiation heat } \\
\text { transfer from } \\
\text { rods }
\end{array}\right]+\left[\begin{array}{l}
\text { radiation heat } \\
\text { transfer from } \\
\text { walls }
\end{array}\right]
\end{aligned}
$$

By assuming that 1) there is no heat transfer axially, 2) the heat is generated uniformly throughout the fuel at a given axial location, and 3 ) the fuel properties do not vary with the radial variation in temperature, the . cladding temperature is obtained by performing a lumped energy balance on the cladding material at each axial level. The film coefficient, $H_{R^{\prime}}$ is given by user-specified correlations, and the gap conductance between fuel pellet and cladding, $\mathrm{H}_{g}$, is assumed constant. $F_{i n}$ and $F_{i m}$ are gray body radiation exchange factors that account for multiple reflections within an enclosure. $F_{\text {in }}$ is a coefficient for rod-to-rod heat transfer, while $F_{i m}$ is a coefficient for rodto-slab heat transfer. Both are derived by assuming constant surface emissivity. The gray body exchange factors can be user-prescribed or calculated internally by specifying black body view factors and surface emissivity values.

\section{Slab Energy Equations}

$$
\rho_{w} c_{w} t_{w} \frac{T_{w}-T_{w}^{n}}{\Delta t}=\sum_{\Delta \in \psi_{i}} U\left(T-T_{w}\right) \quad+\sigma \underset{m \in \sigma_{m}}{N W} F_{i m}\left(T_{w}-T_{m}^{4}\right)
$$




$$
\begin{aligned}
& \text { [energy storage] }=\left[\begin{array}{l}
\text { heat transfer from } \\
\text { adjacent channels }
\end{array}\right]+\left[\begin{array}{l}
\text { radiation heat transfer } \\
\text { from walls }
\end{array}\right] \\
& +\sigma \sum_{n \in \beta_{n}}^{N R} F_{i n}\left(T_{w}^{4}-T_{c_{n}}^{4}\right)+q^{\prime \prime \prime} \\
& +\left[\begin{array}{l}
\text { radiation heat transfer } \\
\text { from rods }
\end{array}\right]+\left[\begin{array}{l}
\text { heat } \\
\text { generation }
\end{array}\right] \\
& +U_{j-1}\left(T_{w}-T_{w_{j-1}}\right)+U_{j+1}\left(T_{w}-T_{w_{j+1}}\right)+\sum_{m \in a_{m}} U\left(T_{w}-T_{w_{m}}\right) \\
& +[\text { axial conduction heat transfer }]+\left[\begin{array}{l}
\text { heat transfer } \\
\text { from adjacent } \\
\text { walls }
\end{array}\right]
\end{aligned}
$$

As before, $F_{i m}$ and $F_{i n}$ are the gray body exchange factors from wall node $i$ to wall node $m$ and rod node $n$, respectively. Axial heat transfer from the walls to a plenum region can be included at the top and bottom axial levels. 
Storage System

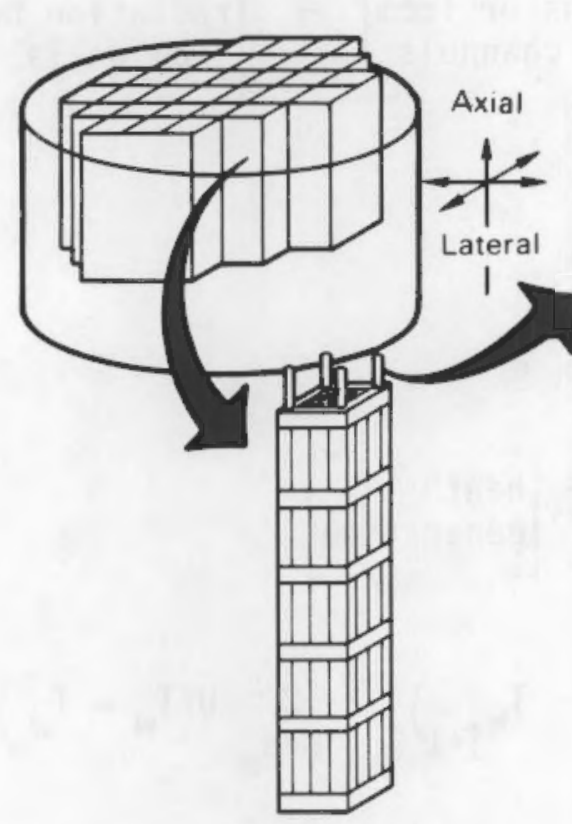

Fuel Assembly

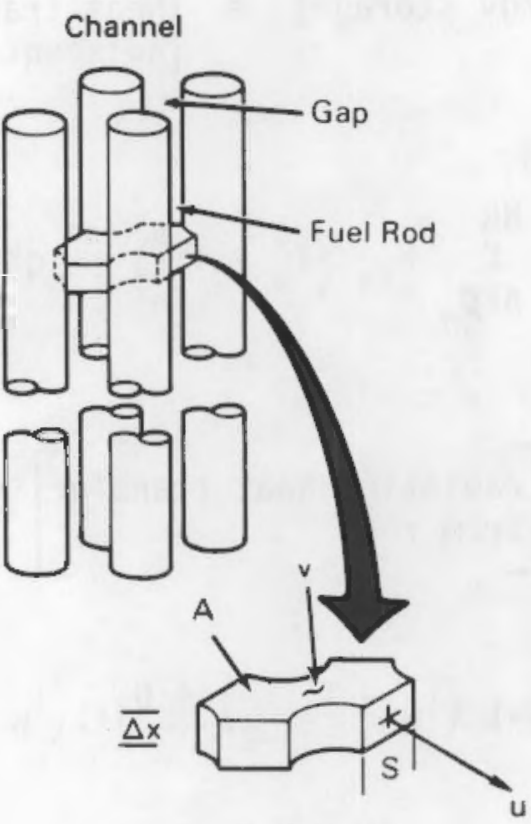

Control Volume

FIGURE 3.1. Channel Definition

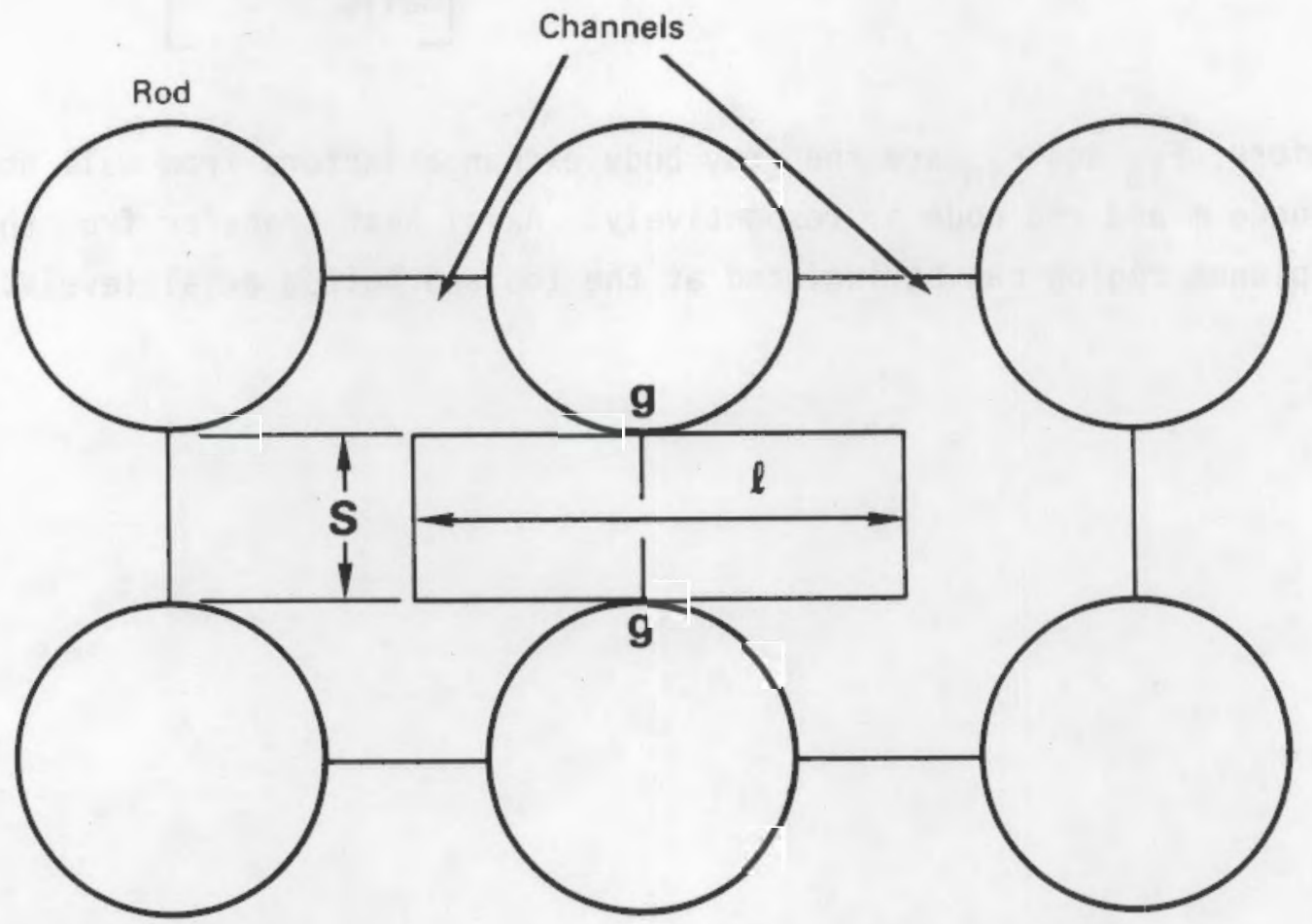

FIGURE 3.2. Transverse Momentum Control Volume 
TABLE 3.1. COBRA-SFS Capabilities and Limitations Modeling Capabilities

Steady state

Triangular, square, or consolidated rod arrays

Recirculating flows

Zero net flow solution option

Interassembly and intra-assembly heat transfer

Nonparticipating radiation ( $p l a n a r)$

Variable axial grid spacing

Multiple flow regions

Fluid conduction and turbulent mixing

Pressure drop model (network and channel)

Variable material property rod mode]

Prescribed heat flux

Use of specified or prescribed flow regions

Variable fluid properties

Program and I/0 Control

Constant prescribed flow

Zero net flow option

Restart and post-processing dump

Decoupled hydrodynamics (no buoyancy)

Fully coupled hydrodynamics

Result execution and time monitoring

Variable/constant fluid properties

Pressure drop initialization scheme

Data "roll" option to reduce memory for large problems

Limitations and Assumptions

Incompressible flow

One-dimensional boundary heat transfer 
. 


\subsection{CASK MODEL OPTIMIZATION}

The accuracy of a cask thermal-hydraulic analysis is dependent upon how the cask is noded; i.e., how the cask geometry is divided into nodes. In addition, the analysis cost and memory requirements are directly related to the number of nodes used in the model. Therefore, the objective of model development is to achieve the maximum level of accuracy with the minimum number of nodes.

\subsection{MODEL DEVELOPMENT}

A COBRA-SFS cask model is constructed by dividing the cask into a set of finite volumes or nodes. Three types of nodes are used in a typical cask model--channels, rods, and slabs. The channel nodes are used to represent the fluid regions of the cask, the rod nodes are used to represent the spent fuel rods, and the slab nodes are used to represent the solid structures of the

- cask such as the basket and cask shell.

In a COBRA-SFS cask mode1, the geometry in the channel region of the cask is assumed to be uniform in the axial direction. The first step in developing a COBRA-SFS model is to prepare a two-dimensional nodalization map of the cask cross section. To aid in preparing a nodalization map, the following points should be considered:

- Use symmetry to determine what portion of the cask must be modeled.

- Decide what information is required from the model.

- From what is known about the temperature distribution in the cask, arrange the nodes for maximum accuracy.

Each of these points is discussed in more detail below.

\subsubsection{Cask Symmetry}

In most cases, the entire cask cross section does not have to be modeled. Where symmetry exists, the cask may be modeled using a portion of the cross section with appropriately averaged operating and boundary conditions. Symmetry assumes that the cask may be divided into uniform sections, so that 
negligible heat crosses the boundaries between the modeled section and other sections. Before symmetry can be assumed, the following conditions must be satisfied:

- The geometry is symmetric.

- The decay heat generation is symmetric.

- The boundary conditions are symmetric.

A symmetric geometry may be obtained by folding the cross section along symmetry lines that run through the center of the cask. For a cask with a square basket, this procedure may result in a one-half, one-fourth, or oneeighth section of the cask. Noding maps for the TN-24P cask are presented in Figure 4.1 for a one-half section and Figure 4.2 for a one-eighth section. Note that the one-eighth symmetry allows greater detail using fewer nodes.

The geometric symmetry may change as a function of cask orientation. When a cask is placed in a horizontal position, the assembly basket, if separate from the cask shell, may shift, changing the gap widths between the basket and shell. In addition, the fuel assemblies may shift their position within the basket and make contact on one side. If these changes are significant, a one-half symmetry must be used to represent the cask.

If the decay heat generation is not perfectly symnetric, two possible approaches are suggested. One is to average the heat generation for assemblies with the same relative position to the center of the cask for all sections. This approach has the advantage of maintaining the correct total power for the problem. If a conservative analys is is desired, the peak heat generation for each assembly location can be used.

For most cask problems it can be assumed that the boundary conditions are uniform around the cask. The resistance to thermal conduction around the circumference of the cask is generally quite low as compared to the thermal resistance to ambient temperature. One major exception to this is a cask in a horizontal position with a significant thermal contact to the supporting surface. 


\subsubsection{Model Requirements}

The development of a cask model is influenced by the type of information desired from the analysis. If specific values such as the peak cladding temperature are desired, the cask may be modeled to give greater detail in the areas of interest and less detail in other areas of the cask. This is especially true of spent-fuel casks with baskets of high thermal conductivity. In such a case, the radial temperature profile of one assembly does not greatly affect that of an adjacent assembly. The assemblies where the peak temperature is not expected to occur may be noded with less detail. The primary concern for these assemblies would be to provide the correct average flow and temperature to the plenums and to provide the proper radial resistance to heat flow. Examples of this type of noding simplification will be presented in Section 4.3 .

\subsubsection{Effect of Temperature Distribution}

The COBRA-SFS code, like most finite-difference codes, models heat transfer from one node to another by assuming a constant heat flux between node points. For nodes with the same thermal conductivity, this is characterized by a lineartemperature gradient between node centers. If the heat flux or temperature gradient through a series of node connections is constant, they can be replaced by a single node connection without loss in accuracy. Therefore, nodes may be minimized in areas of constant temperature gradient or heat flux. However, when the temperature gradient is significantly nonuniform, a single linear node connection will do a poor job of representing the heat transfer through that region. Instead, the region should be modeled using a series of finer node connections and nodes should be concentrated in areas where the temperature gradient or heat flux is most nonuniform.

Examples of this type of noding simplification will be presented in Sections 4.3 and 4.4 .

\subsection{BASE MODEL DESCRIPTION}

Several sensitivity studies have been performed to demonstrate the effect of model nodalization on the solution accuracy and computational size. The Transnuclear TN-24P spent-fuel cask was selected as the basis for these studies. 
A brief description of the cask is presented in Section 4.2.1. The cask model used in these studies is described in Section 4.2.2. More detailed informaticn about both the cask and model may be found in (McKinnon et al. 1986).

\subsubsection{TN-24P Cask Description}

The TN-24P spent-fuel storage cask consists of a forged steel body for structural integrity and ganma shielding, surrounded by a resin layer for neutron shielding. The resin layer is enclosed in a smooth steel outer shell. The cask cross section is shown in Figure 4.3. The cask is $5.0 \mathrm{~m}(16 \mathrm{ft})$ long and $2.3 \mathrm{~m}(7.5 \mathrm{ft})$ in diameter and weighs approximately 100 tons when loaded with unconsolidated PWR spent fuel. The fuel basket within the cask is configured to hold 24 PWR spent-fuel assemblies and is composed of stacked, interlocking plates constructed of aluminum and boron. The cask is closed with a lid having two concentric metallic 0 -ring seals plus a protective cover sealed with one rubber 0 -ring gasket to seal the cask cavity from the environment.

\subsubsection{IN-24P Base Model Description}

A one-eighth section model of 18 uniform axial levels as depicted in Figure 4.4 was developed to analyze the TN-24P spent fuel cask. Each axial level comprised 51 wall nodes, 386 channels, and 450 rod nodes (Figure 4.2).

The wall nodes included 27 basket nodes, 12 cask body nodes, 4 neutron shield nodes, and 8 cask shell nodes. The four outermost shell nodes are zero-thickness nodes that represent the cask surface temperature for the purpose of accurately calculating the contribution of radiation and convection heat transfer to the environment.

One of the lines of symmetry used to define the one-eighth section model runs through two of the basket fuel tubes. Fuel assemblies in these locations were modeled with one rod surface node per rod, for a total of 120 rod surface nodes. This representation, along with the layout of the 136 fluid channels used to describe the flow, is shown in Figure 4.5. In the noding of the full fuel assemblies, the flexibility of the COBRA-SFS channel approact was used to selectively lump rods together and channels together to decrease the size of the computational model, as displayed in Figure 4.6. The 225 
rods were represented by 105 lumped rods. The flow area within the assemblies was modeled by 57 channels.

Decay heat from the fuel assemblies is removed by conduction, convection, and radiation heat transfer. The following is a discussion of COBRA-SFS modeling of each of these modes for the TN-24P cask.

Fluid-fluid conduction between neighboring channels was modeled using a transverse control volume defined by a gap width, a centroid-to-centroid length, and an axial length. Axial fluid-fluid conduction was neglected.

Conduction heat transfer in the walls was modeled in the radial, circumferential, and axial directions via an input specification of thermal resistances between neighboring nodes. Each thermal resistance can reflect any combination of parallel and/or series resistance paths. An example of such a composite resistance in the TN-24P analyses is the polyethylene resin and copper fins, which formed the side neutron shield. In this region a resistance was calculated that represented the two parallel paths through the shield.

The contribution of convection heat transfer within the cask is dependent on the predicted flow field. For the TN-24P simulations, the flow field was obtained iteratively by adjusting the total pressure drop until 1) the pressure drop across all channels was equal and 2) the total net flow rate was zero. Therefore, the basket and the fuel assembly flow resistances were important convection parameters. The surface friction for all of the channels was approximated using a friction factor of $f=100 /$ Re, which was derived for a square rod array with pitch-to-diameter ratios typical of PWRs (Sparrow and Loeffler 1959).

Convective heat transfer from the rod and wall surfaces to the fluid was prescribed using a $\mathrm{film}$ coefficient having the form $\mathrm{Nu}=3.66$ (Kays and Crawford 1980). This correlation is the analytical solution of the energy equation for a constant temperature wall and fully developed temperature and velocity profiles in a circular tube. Previous work (Wiles et al. 1986) that investigated the effect of various values of Nusselt number on COBRA-SFS temperature 
predictions determined that a value of 3.66 gave the best overall results for the nitrogen and helium fill media.

Radiation heat transfer was treated on an assembly-by-assembly basis. In each basket fuel tube containing a pressurized water reactor (PWR) fuel assembly, rod-rod, rod-wall, and wall-wall radiative heat transfer were modeled by specification of gray body exchange factors. The exchange factors for the fuel rods and walls were calculated using one-quarter pin surface segments to define the radiation generation view factors and the cross-string correlation method of Hottel (Cox 1977). This is a more exact approach than the assumption of uniform radiosity around a rod surface. Radiation exchange in the empty basket enclosures, which consisted of either basket walls, or basket walls and the inner cask wall, was determined using wall-wall view factors input by the user. The COBRA-SFS code used these factors along with appropricte emissivities to calculate the gray body exchange factors.

The material properties used for the TN-24P model are presented in Table 4.1. All surface emissivities and the greater portion of the solid thermal conductivities were provided by Transnuclear, Inc. The thermal properties of the solids were assumed constant, and properties of the fill gas were specified as a function of temperature.

The effects of deviations from the base COBRA-SFS model are described in the following three sections. Section 4.3 focuses on assembly model nodalization. The slab nodalization concerns are addressed in Section 4.4 and, lastly, the axial nodalization sensitivity is described in Section 4.5.

\subsection{ASSEMBLY NODALIZATION}

The noding of the individual assemblies is discussed in this section. It is especially important to minimize the number of assembly nodes in the case of a multiassembly cask. If one node per fuel rod is used, the information can end up being more detailed than required, the cost prohibitive, and in some cases the problem will not fit on currently available computers. However, the analyst may require more detailed information from certain areas of the cask, or large temperature gradients may require a more detailed nodinç 
scheme. The goal of the modeler is to balance cost and size versus accuracy and detail requirements.

The effect of seven different assembly node model sets on temperature distribution in the TN-24P spent-fuel storage cask is addressed. Axial and radial temperature profiles are provided for each model. The bottom data point of the axial temperature profiles represents the bulk temperature of the lower plenum and the top data point represents the bulk temperature of the upper plenum. Comparisons discussed in this section and Section 4.5 pertain only to the fuel assembly region of the COBRA-SFS models. Each assembly model is discussed separately, and then a brief discussion of all of the temperature predictions is provided.

Each assembly model set includes a pattern description within its section title. Two different pattern descriptors are used. For the first six model sets, the following is used:

\section{(A/B Rod Nodes, D/E Channel Nodes)}

where $A=$ number of rod nodes in each of the two half assemblies

$B=$ number of rod nodes in each full assembly

$D=$ number channel nodes in the half assemblies

$E$ = number of channel nodes in each full assembly.

For the last two assembly models, the format is as follows:

$$
\text { (A/B/C Rod Nodes, D/E/F Channel Nodes) }
$$

where

$A=$ number of rod assemblies in the center half assembly

$B=$ number of rod nodes in the outer half assembly

$C=$ number of rod nodes in each of the full assemblies

$D, E, F=$ number of channel nodes in the corresponding assemblies.

\subsubsection{Assembly Model Set $\# 1$ (120/105 Rod Nodes, 136/57 Channel Nodes)}

A description of this assembly model set was given in Section 4.2. The design goal for this assembly model set was to provide detailed temperature 
information for the hottest assembly. The TN-24P cask was modeled by a oneeighth section model (Figure 4.2). This required two assembly models, one for the two assemblies split in half, and another for the two whole assemblies. Using past experience and a knowledge of the spent-fuel loading pattern, it was determined that the center assembly would be the hottest. The center one-half assembly model was therefore developed with the detailed noding shown in Figure 4.5. This model was also applied to the remaining one-half assembly model for the sake of simplicity.

The full assembly model was not noded in as much detail in an effort to keep the computational model as small as possible. An initial test run was made with a detailed one node-one rod model to find out what temperature distribution in the full assembly would result. Based on the isotherms resulting from the test run, the noding pattern displayed in Figure 4.6 was selected. This scheme required only 105 rod nodes and 57 channel nodes, insterad of the 225 rod nodes and 256 channel nodes a full assembly detailed model requires.

The comparisons of assembly model set \#1 predicted axial temperatures with experimental data for three backfill cases of helium, nitrogen, and vacuum (low-pressure nitrogen) are presented in Figures 4.7 through 4.9 . The axial temperature profiles correspond to the hottest instrumented rod location in the center assembly. The radial temperature profiles displayed in Figures 4.10 through 4.12 , and in all other radial temperature profiles presented in this report, represent selected locations through the cask at the peak measured temperature axial level. For the helium and vacuum cases (Figures 4.7 and 4.9), the predicted temperatures are in very close agreement with the measured values. For the nitrogen case (Figure 4.8 ), the prediction is somewhat conservative, probably because of underprediction of the actual amount of natural convection heat transfer in the cask. In the following sections the effect of varying the assembly noding structure is described.

\subsubsection{Assembly Mode1 Set \#2 (1/1 Rod Nodes, 1/1 Channel Nodes)}

The simplest COBRA-SFS spent fuel assembly model would consist of 1 rod node representing all rods and 1 channel node representing the channel area. 
Although this results in a much faster and smaller model, accuracy may be drastically reduced. Axial and radial temperature profiles for each of the backfill cases are displayed along with the post-test model results in Figures 4.13 through 4.18 .

The loss of accuracy is clear for the coarsest assembly model. For most applications this model would be insufficient.

\subsubsection{Assembly Model Set $\# 3$ (5/9 Rod Nodes, 5/9 Channel Nodes)}

The effect of increasing the assembly model sizes from the minimum sizes is shown in the third model set. The half assemblies were modeled with 5 rod nodes and 5 channel nodes and the full assemblies were modeled with 9 rod nodes and 9 channel nodes as depicted in Figures 4.19 and 4.20 . The effect of an increase in nodes per assembly is shown in the comparison of the axial and radial temperature profiles with the two previous models sets (Figures 4.21 through 4.26). However, this model still provides only a rough approximation.

\subsubsection{Assembly Model Set \#4 (28/49 Rod Nodes, 28/49 Channel Nodes) -}

The fourth set consisted of 28 rod and channel nodes in the half assemblies and 49 in the full assemblies (Figures 4.27 and 4.28). As expected, the comparison of model sets 2,3 , and 4 with the post-test set shows improved temperature predictions as the number of nodes increases, with the greatest improvement shown in the going from $5 / 9$ nodes per assembly to $28 / 49$ nodes per assembly (Figures 4.29 through 4.34 ).

\subsubsection{Assembly Model Set $\$ 5$ (120/225 Rod Nodes, $136 / 256$ Channel Nodes)}

This model set represents the fully detailed assembly model. In both the half assembly model and the full assembly model, each rod and each channel are modeled with one node (Figure 4.5 and Figure 4.35). A comparison of the axial and radial temperature profiles for model set No. 1 and the fully detailed model is provided in Figures 4.36 through 4.41 . The change in temperature predictions is small (less than $5^{\circ} \mathrm{C}$ in the center assembly, and less than $10^{\circ} \mathrm{C}$ in the outer assembly), indicating that model set No. 1 was not under noded in the assembly regions. It is possible that a model smaller than model set No. 1 may have been acceptable, or a different assembly modeling approach 
could have been applied. Some such approaches are addressed in the following assembly model descriptions.

\subsubsection{Assembly Model Set \#6 (120/1 Rod Nodes, 136/1 Channel Nodes)}

This set combines the accuracy of a detailed assembly model for the center assembly, the minimizing of storage requirements in the full assemblies, and a decrease in required CPU time. This approach is designed to give detailed information in the center (hottest) assembly and provide an accurate prediction for the peak cladding temperature. For the sake of simplicity, both haif assemblies were modeled in a detailed fashion. Comparisons of axial and radial temperature profiles with the detailed model set (assembly model set \#5) for the three backfills are presented in Figures 4.42 through 4.47 . For all three backfills, the agreement in the center assembly is fair. Peak temperature predictions were within $10^{\circ} \mathrm{C}$ for the nitrogen and vacuum case; however, the helium peak temperature underpredicted the assembly model set \#5 temperatures by $22^{\circ} \mathrm{C}$. If more detailed temperature information is required in the full assemblies, this model set would not be appropriate.

\subsubsection{Assembly Model Set \#7 (120/5/9 Rod Nodes, 136/5/9 Channel Nodes)}

Assembly model set $\# 7$ consisted of three assembly models. The center half assembly was modeled with 120 rod nodes and 136 channel nodes, the other half assembly was modeled with 5 rod nodes and 5 channel nodes (Figure 4.19), and the full assemblies were modeled with 9 rod and 9 channel nodes. This decrease in computational size, as compared with assembly model set \#6, is brought about by a major decrease in the number of nodes in the outer half assembly in conjunction with only a minor increase in the number of nodes in the two full assemblies. The predictions from this model set are displayed along with the detailed model set and assembly model set \#6 predictions for the three backfills in Figures 4.48 through 4.53. This model set results in an overall improvement over the previous model set while at the same time requiring less CPU time. Peak temperature predictions were within $5^{\circ} \mathrm{C}$ of the detailed model predictions for all three backfill cases. The radial temperature profiles reflect the inability of this model to match the detailed temperature 
predictions in the outer assemblies, underpredicting the temperatures by as much as $36^{\circ} \mathrm{C}$.

\subsubsection{Assembly Model Set \#8 (120/49/28 Rod Nodes, 136/49/28 Channel Nodes).}

This final model set was also a three-assembly model set. The center assembly was modeled in the detailed fashion described previously, while the other assemblies were modeled using the noding logic described for assembly model set \#4 (Figures 4.27 and 4.28 ). In the center assembly the temperature predictions were with in $5^{\circ} \mathrm{C}$ of the predictions from the detailed model for the three backfill cases (Figures 4.54 through 4.59 ). The outer assembly temperature predictions were within $15^{\circ} \mathrm{C}$ of the detailed model predictions. In many cases this model would suffice, but if detailed information in the outer assemblies is required this model may not be sufficient.

As expected, the accuracy of the temperature predictions is highly dependent on the quantity of assembly nodes. The more nodes, the more detailed the predictions. However, selective assembly noding strategies have been proven effective in producing peak temperatures in the hot assembly with in $5^{\circ} \mathrm{C}$ of the detailed model. This allows the COBRA-SFS user to decrease the size and associated running time of the problem without sacrificing detail in selected regions. Other important considerations are the slab noding and axial noding models. The following section addresses the sensitivity of the temperature prediction to slab noding.

\subsection{SOLID STRUCTURE MODELING}

Solid structures in a cask, such as the assembly basket and cask shell, are modeled using finite volume nodes known as slabs. Each slab may be thermally connected to adjacent slabs, fluid channels, and contacting rods. Solid structure nodes are described in Section 3.0. The themal connection between two adjacent slabs may be characterized by using either of two methods. The total solid conduction resistance can be specified directly as input. Alternatively, the user can define the geometry of the thermal connection by entering conduction geometry factors for the two adjacent slabs. The code 
then calculates the solid resistance from the geometry factors and thermal conductivities of the slabs.

Methods of optimizing the slab nodalization for a cask are demonstrated using the TN-24P cask model. The solid structure noding for the TN-24P cask is shown in Figure 4.60. The assembly basket is represented by 27 slabs and the cask she 11 is represented by 20 slabs.

The cask shell is divided in both the radial and circumferential directions. In most cases the temperature gradient in the circumferential direction is negligibly small and the heat transfer can be characterized as onedimensional in the radial direction. This was done for the TN-24P cask model, representing the cask shell with five radial nodes as shown in Figure 4.61 . The peak clad temperature for this case was $281.6^{\circ} \mathrm{C}$ as compared to $282.0^{\circ} \mathrm{C}$ for the detailed cask shell case, a difference of $0.4^{\circ} \mathrm{C}$.

For steady-state calculations, the number of radial nodes may also be reduced without loss in accuracy. For example, using three radial nodes to represent the steel body is no more accurate than one node. The only regions where the temperatures must be calculated are surfaces where radiation heat transfer occurs. This includes the inner and outer shell surfaces and interior gaps that are evacuated or gas filled.

Special care must be taken in modeling interior gaps. These gaps generally occur at material interfaces within the shell. The temperature drop across gaps can be extremely high and can affect the accuracy of the entire analyses. The parameters used to describe the gap, i.e., gap width and surface emissivities, must be known as accurately as possible to properly describe the heat transfer through the gap.

The number of $s$ lab nodes required to describe the assembly basket is dependent on basket material and how the basket is constructed. When a high conductivity material such as copper or aluminum is used, the temperature drop through the basket is small, and fewer nodes can be used without significantly affecting accuracy. When a relatively low conductivity material such as stainless steel is used, a larger variation in temperature gradient occurs and a more detailed noding may be required. An example of how the basket can 
be modeled with different levels of detail is shown in Figure 4.62. The basket shown in Figure $4.62 \mathrm{a}$ is noded with a relatively high level of detail. When a coarser noding is desired, the nodes may be combined to form cruciforms as shown in Figure $4.62 \mathrm{~b}$. This results in five times fewer nodes than used in representing the basket.

\subsection{AXIAL NODING STUDY}

This section addresses the effect of axial node size on the temperature predictions. It is important to minimize the number of axial levels specified because the COBRA-SFS computer memory requirement is approximately proportional to the number of axial levels. Six axial modeling strategies were developed for the basic post-test COBRA-SFS TN-24P model. A description of each axial model and a temperature comparison with the 24 axial level model is provided for all cases.

\subsubsection{Axial Level Model \#1 (24 Uniform Levels)}

Axial level model \#1 was the most detailed model investigated. The spentfuel region of the cask was modeled with 24 uniform levels of $16.9 \mathrm{~cm}$. Three backfill cases--helium, nitrogen, and vacuum--were run using assembly model set \#1 from the COBRA-SFS TN-24P post-test analysis. Axial temperature profiles for experimental data and COBRA-SFS predictions are presented in Figures 4.63 through 4.65 .

\subsubsection{Axial Level Model \#2 (18 Uniform Levels)}

An 18-level model was developed for the post-test COBRA-SFS TN-24P analysis. Each axial level comprised $22.5 \mathrm{~cm}$ of the spent-fuel region of the cask. Comparisons of the axial temperature profiles for this model and the detailed 24-axial-level model are provided in Figure 4.66 through 4.68 . All three backfill cases relate only minor differences, less than $5^{\circ} \mathrm{C}$, between the two models temperature predictions over the entire temperature profile.

\subsubsection{Axial Level Model \$3 (12 Uniform Levels)}

The third model consisted of 12 uniform axial levels, each $33.8 \mathrm{~cm}$ in height. Temperature profiles for this model and the 24-level model are dis- 
played in Figures 4.69 through 4.71 . The comparisons of the temperature profiles are good in the lower and middle portion of the cask for the helium and vacuum backfills, with some differences $\left(<20^{\circ} \mathrm{C}\right)$ in the upper portion of the temperature profiles. The nitrogen backfill case shows an overall fair agreement between the two models, with a maximum difference of $15^{\circ} \mathrm{C}$ in the upper portion of the profile.

\subsubsection{Axial Level Model \#4 (8 Uniform Levels)}

Axial level model \#4 consisted of 8 axial levels, each $50.6 \mathrm{~cm}$ in height. The axial temperature profiles for this model are displayed for the three backfills along with the detailed model predictions in Figures 4.72 through 4.74. The results reflect a failure of the model to accurately match the 24axial-level model temperature distributions for a nitrogen backfill. The helium and vacuum backfill temperature predictions were within $5^{\circ} \mathrm{C}$ over the entire profile, however the nitrogen temperature predictions differed by as much as $15^{\circ} \mathrm{C}$ in the upper and lower portions of the cask.

\subsubsection{Axial Level Model \#5a (12 Nonuniform Levels)}

The COBRA-SFS computer code has the capability of modeling casks using nonuniform axial node sizes. This feature was employed in an effort to match the detailed axial model temperature predictions by concentrating the axial nodes in areas where the temperature gradient was the steepest. In this model large axial nodes $(67.6 \mathrm{~cm})$ were used in the center of the model, where the temperature gradient is generally the flattest, and small nodes $(16.9 \mathrm{~cm})$ were applied in the upper and lower portions of the model, where the temperature gradient is the steepest. The axial noding pattern for this model is displayed in Figure 4.75. Comparisons of axial temperature profiles for this model and the detailed (24 levels, model \#1) uniform axial node model are presented in Figure 4.76 through 4.79. This model affected an overall improvement in the predictions; however, some differences still existed in the upper portion of the temperature profiles. Temperature predictions were within $5^{\circ} \mathrm{C}$ of the 24axial-level model for the helium and vacuum cases, while the nitrogen predictions differed by less than $10^{\circ} \mathrm{C}$. 


\subsubsection{Axial Level Model \#5b (12 Nonuniform Levels)}

A variation of axial level model \#5a was developed in an effort to decrease the discrepancy between temperature predictions in the upper portion of the profile. In this model, the nodes' sizes ranged from a high of $50.7 \mathrm{~cm}$ in the center to a low of $16.9 \mathrm{~cm}$ in the upper and lower locations of the model, with transition nodes $33.8 \mathrm{~cm}$ between. The axial model is displayed in Figure 4.79. Axial temperature profiles for the detailed axial model and this model are provided in Figures 4.80 through 4.82 . In general the temperature predictions from this model matched the detailed model predictions more closely than model \#5a. For the helium and vacuum cases, the predictions were within $3^{\circ} \mathrm{C}$, and the nitrogen case predictions were within $8^{\circ} \mathrm{C}$ of the 24 -axial-level model.

In summary, the application of axial model \#3 (12 uniform levels) resulted in temperature predictions nearly identical to axial model \#1 (24 uniform levels), while requiring nearly half the computational size and time. However, there is a definite point where a reduction in axial nodes reduces the temperature prediction accuracy significantly, as was seen in the results from axial model \#4 (8 uniform levels). Lastly, variable axial noding is a successful method of further improving COBRA-SFS temperature predictions, as shown by the results from axial models $5 a$ and $5 b$.

\subsection{PARAMETER OPTIMIZATION}

The numerical solution of a particular cask simulation is controlled by various calculational parameters specified in input group CALC. The computational time required for the simulation may be reduced if the values specified for these parameters are optimized. This is especially true for parameters associated with the energy solution. A typical COBRA-SFS cask simulation uses more than $80 \%$ of the total computational time for the energy solution.

Three parameters are associated with the control of the numerical solution of the energy equations. These are the acceleration factor for the solid structure energy equation (ACCELW), the damping factor for the rod energy solution (ACCROD), and the acceleration factor for the axial energy rebalancing (ACCAX). The factors are applied as 


$$
x^{n}=a x^{n}+(1-a) x^{n-1}
$$

where $X=$ calculational variable

$a=$ damping or acceleration factor

$\mathrm{n}=$ current iteration number.

A series of TN-24P runs was performed using the detailed cask model to determine the sensitivity of the run time to each of the three parameters. The results are presented below for each parameter.

\subsubsection{Solid Structure Equation Acceleration Factor}

The fluid and solid structure energy equations are solved simultaneously at each axial level. The acceleration factor for the fluid equations (ACCELH) is set to a permanent value of 1.2 in the current version of the COBRA-SFS code. The acceleration factor for the solid structure equations (ACCELW) is an input parameter on card CALC.2 with a default value of 1.2.

The values assigned to these parameters typically fall in the range of 1.0 to 2.0. Values at the low end of the range do not adequately accelerate the solution and require more computational time than necessary. However, values at the high end of the range tend to cause instabilities in the soluticn. Therefore, a series of runs were performed with ACCELW values ranging from 1.2 to 1.6 to obtain the run times associated with each. Cases were run for both nitrogen and helium backfills. The results are presented in Table 4.2. The runs were performed on a CRAY X/MP using the CTSS operating system.

For both the nitrogen and helium cases, the optimum value for ACCELW exceeds the default value of 1.2. The optimum value for nitrogen is 1.5 and the optimum value for helium is at least 1.6. The improvement in total computational time is over $6 \%$ in the nitrogen case and over $22 \%$ in the helium case. One reason that this improvement is not greater is the use of energy rebalancing for both the fluid and solid structure equations every fifth iteration in the axial level energy solution. Rebalancing optimizes the enercy solution for large-scale enthalpy and temperature changes, and the optimization of ACCELH optimizes the detailed changes in the solution. 
The optimum value for ACCELW is highly problem specific. However, experience shows that 1.4 appears to be an appropriate value for ACCELW for a wide range of cask models.

\subsubsection{Rod Equation Damping Factor}

The rod energy equations are solved simultaneously at each axial level while assuming a fixed fluid enthalpy and slab temperature distribution. The damping factor for the rod solution (ACCROD) is an input parameter on card CALC.2 with a default value of 0.5 .

Rods may be thermally coupled either by rod-to-rod contact (as in the case of consolidated fuel) or by thermal radiation. If the rods are not coupled, only one iteration is required for the solution. If the rods are coupled by rod-to-rod contact, the solution may need to be accelerated by specifying a value for ACCROD of greater than one. The optimum value will be highly dependent on the rod-to-rod contact coefficient.

If the rods are coupled by thermal radiation, the solution may require damping due to the highly nonlinear nature of the problem. The amount of damping that is required is dependent on how tightly connected the rods are to the fluid enthalpy distribution. These connections, in turn, are dependent on the Nusselt number expression and the thermal conductivity of the fluid.

To determine the optimum values for ACCROD, a series of runs were performed using the detailed TN-24P cask model. Cases were run for nitrogen, helium, and vacuum backfill. A Nusselt number of 3.66 was specified for the helium and nitrogen cases and a value of 1.0 was specified for the vacuum case. The results are presented in Table 4.3.

As expected, the optimum value for ACCROD is dependent on the backfill medium considered. The optimum value for nitrogen is 0.6 ; for helium it is at least 0.8 ; and for vacuum it is 0.4 . However, the change in total computational time is not large, less than $5 \%$ in all cases. Note also that the optimum value for ACCROD is not far from values which cause instability in the solution procedure. Therefore, it is recommended that a conservatively low value for ACCROD be used, especially for the nitrogen and vacuum cases. 


\subsubsection{Axial Rebalancing Factor}

The energy solution for the cask is performed by solving for enthalpies and temperatures at each axial level while holding values on adjacent levels fixed. Using this method, the solution may develop slowly due to thermal connections in the axial direction. To accelerate the solution, an axial energy rebalancing solution was added that calculates the temperature increment required to reduce the total energy error for each axial level to zero. The axial rebalancing is applied on the axial upsweep of every third iteration.

The axial rebalancing factor (ACCAX) is a multiplier on the temperature increments that are to be added to the different axial levels. The factor ACCAX is an input parameter that is read on card CALC. 2 and has a default value of 1.0. In some cases, such as those where no side boundary connection exists, axial energy rebalancing may not be desired. In that case, ACCAX should be set to a very small value. For most cask problems, however, ACCAX should have a value of at least 1.0 .

To determine the optimum value for ACCAX, a series of runs were performed with parameter values of $0.9,1.0$, and 1.1. A backfill medium of nitrogen was used in all cases. The results are presented in Table 4.4. Since the primary goal in energy rebalancing is to reduce the total energy error, the fraction of error remaining after 20 iterations is used as the basis for comparison. The optimum value for ACCAX is 1.0 . 


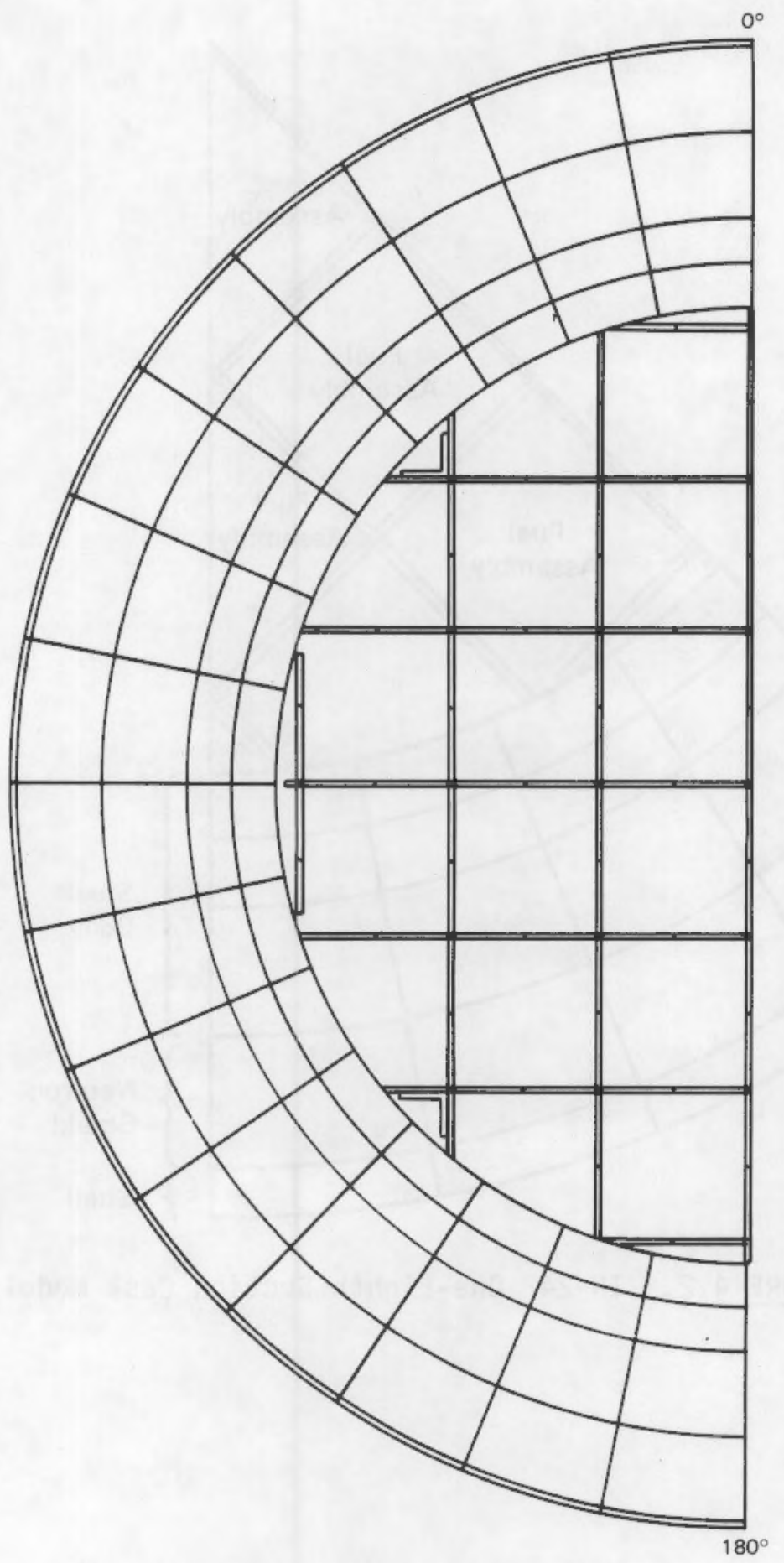

FIGURE 4.1. TN-24P One-Half Section Cask Model 


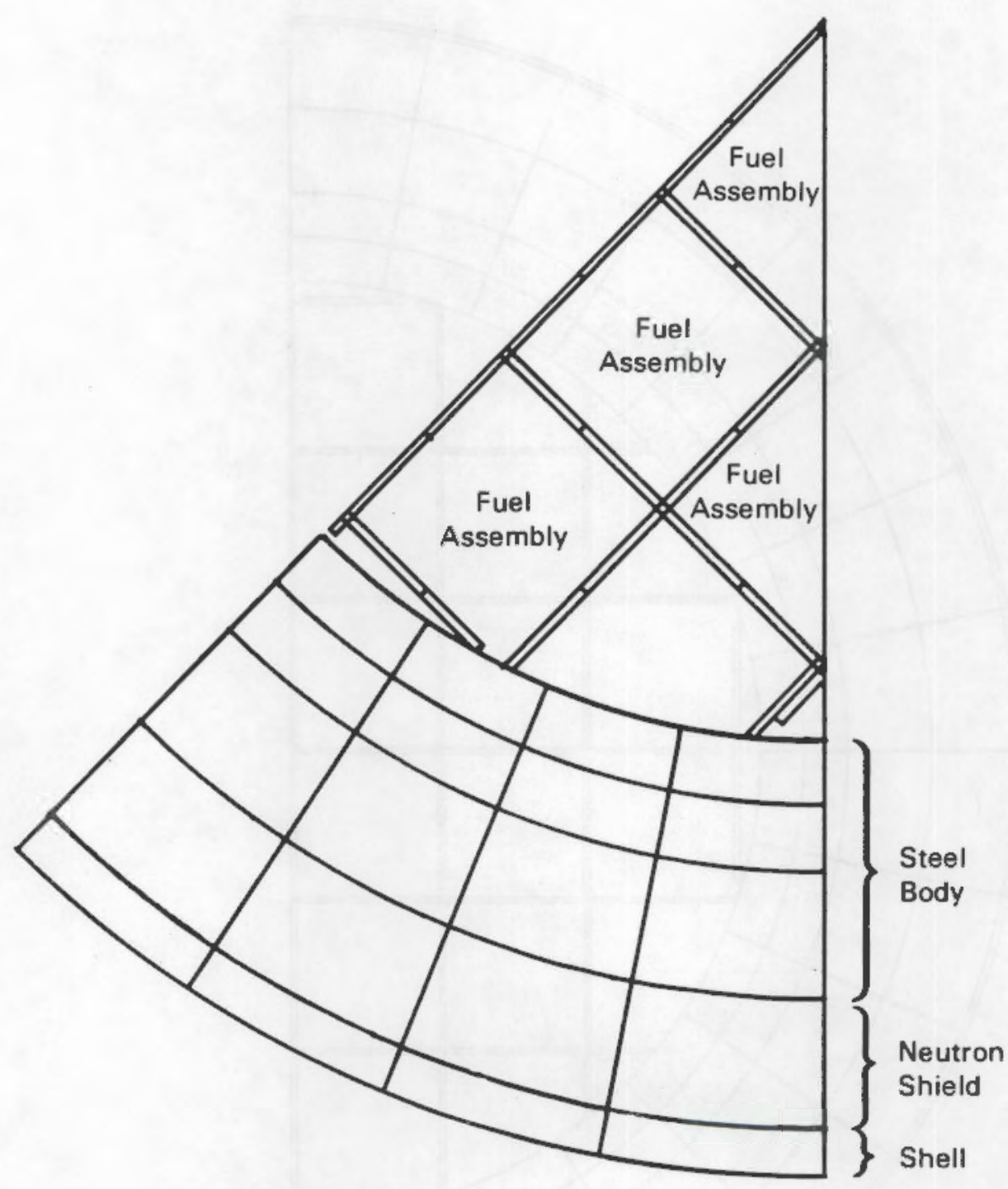

FIGURE 4.2. TN-24P One-Eighth Section Cask Model 


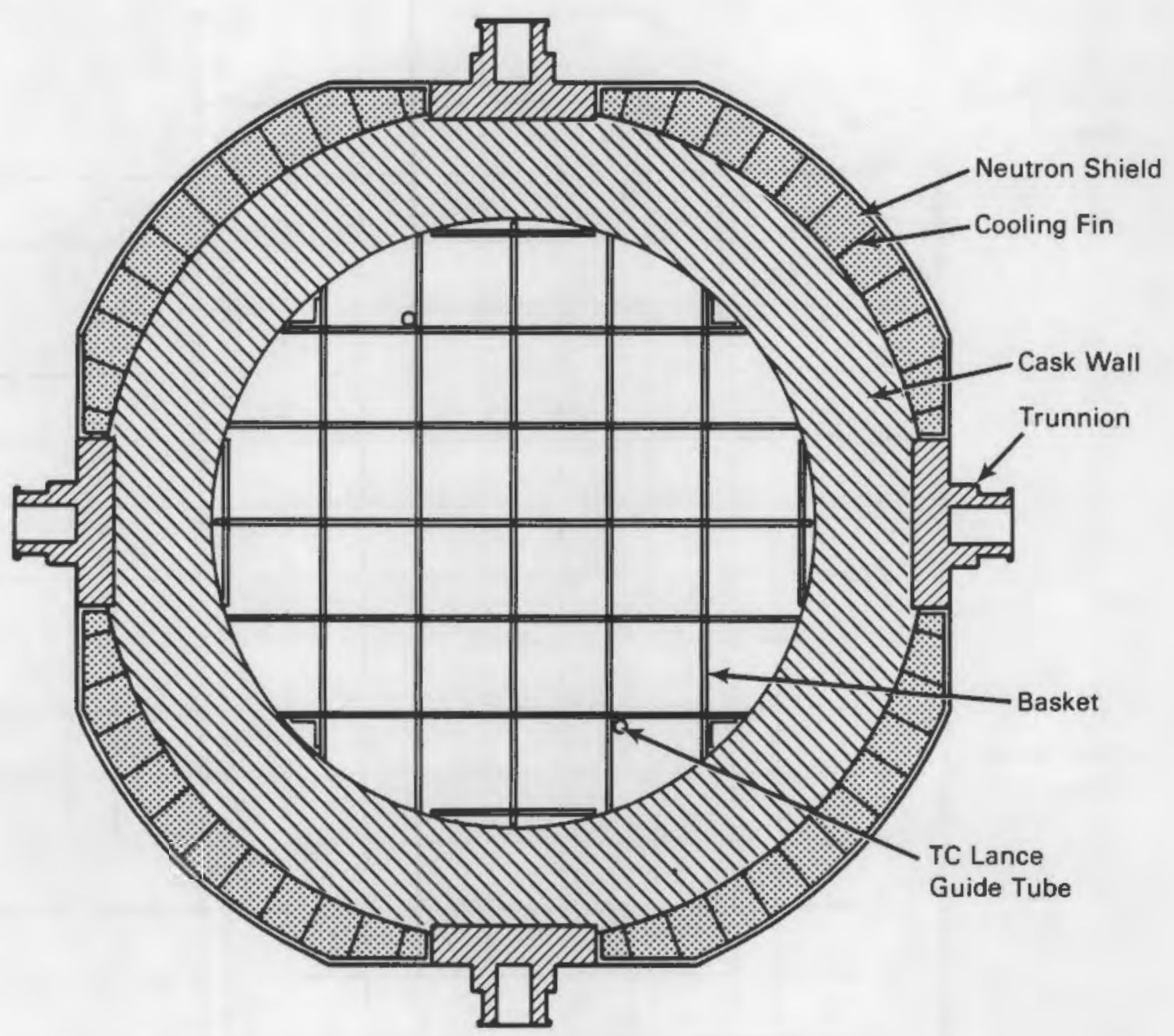

FIGURE 4.3. TN-24P Cask Cross Section 


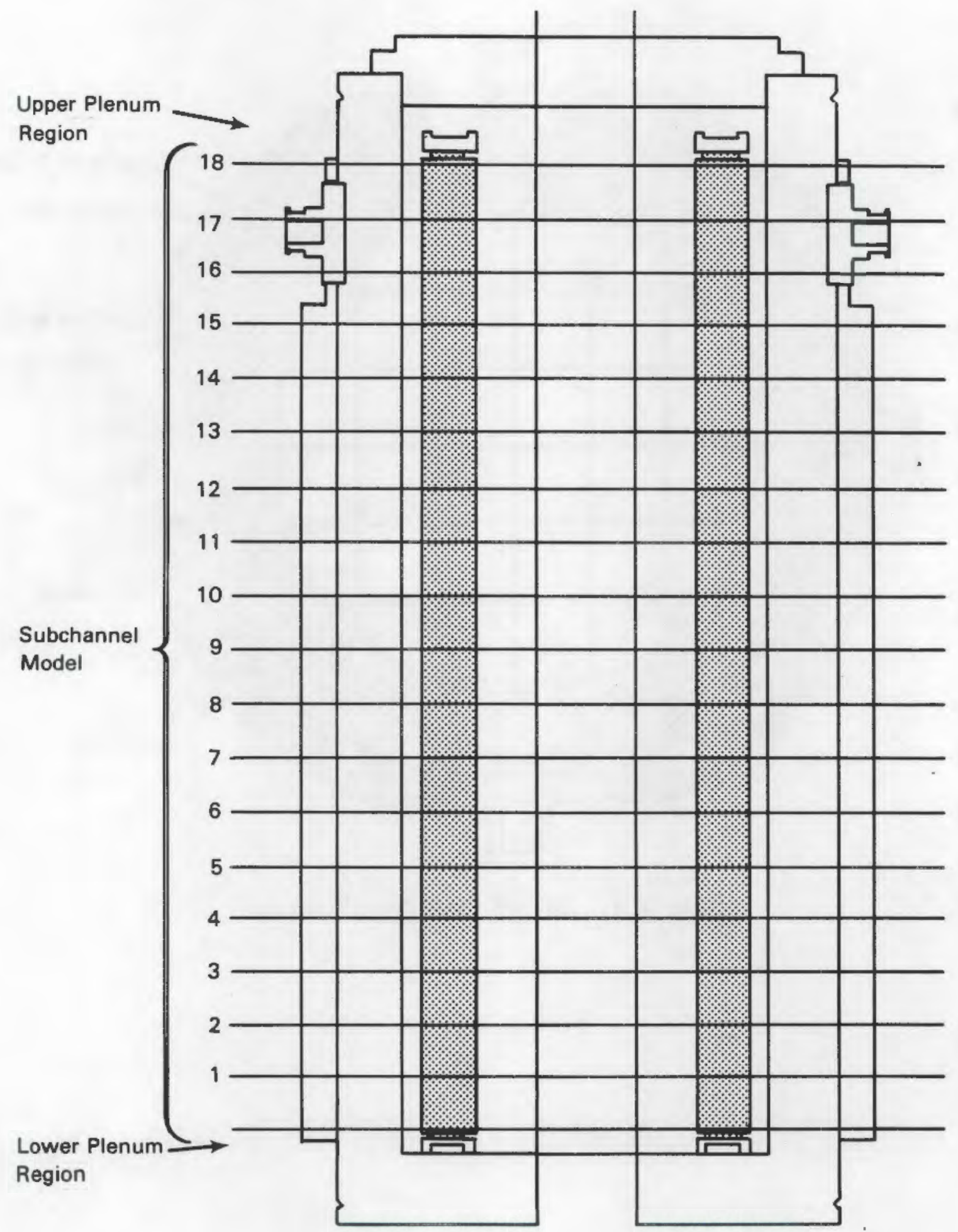

FIGURE 4.4. COBRA-SFS TN-24P Axial Computational Cask Model 


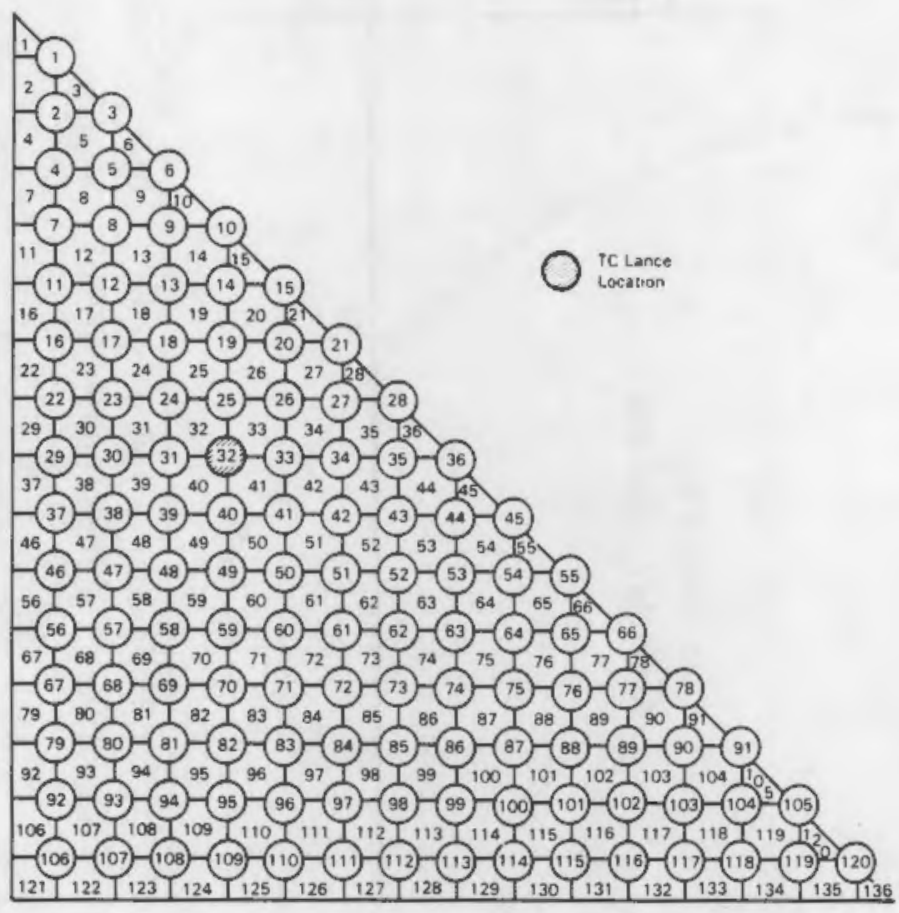

FIGURE 4.5. One-Half Fuel Assembly Rod \& Channel Computational Model

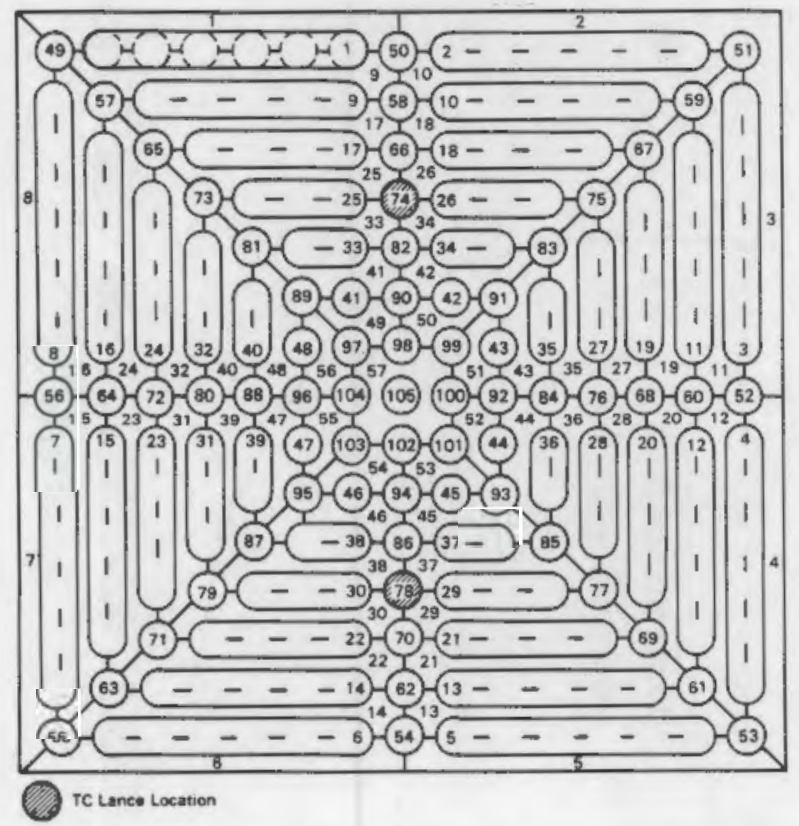

FIGURE 4.6. Full Fuel Assembly Lumped Rod and Lumped Channel Computational Model 


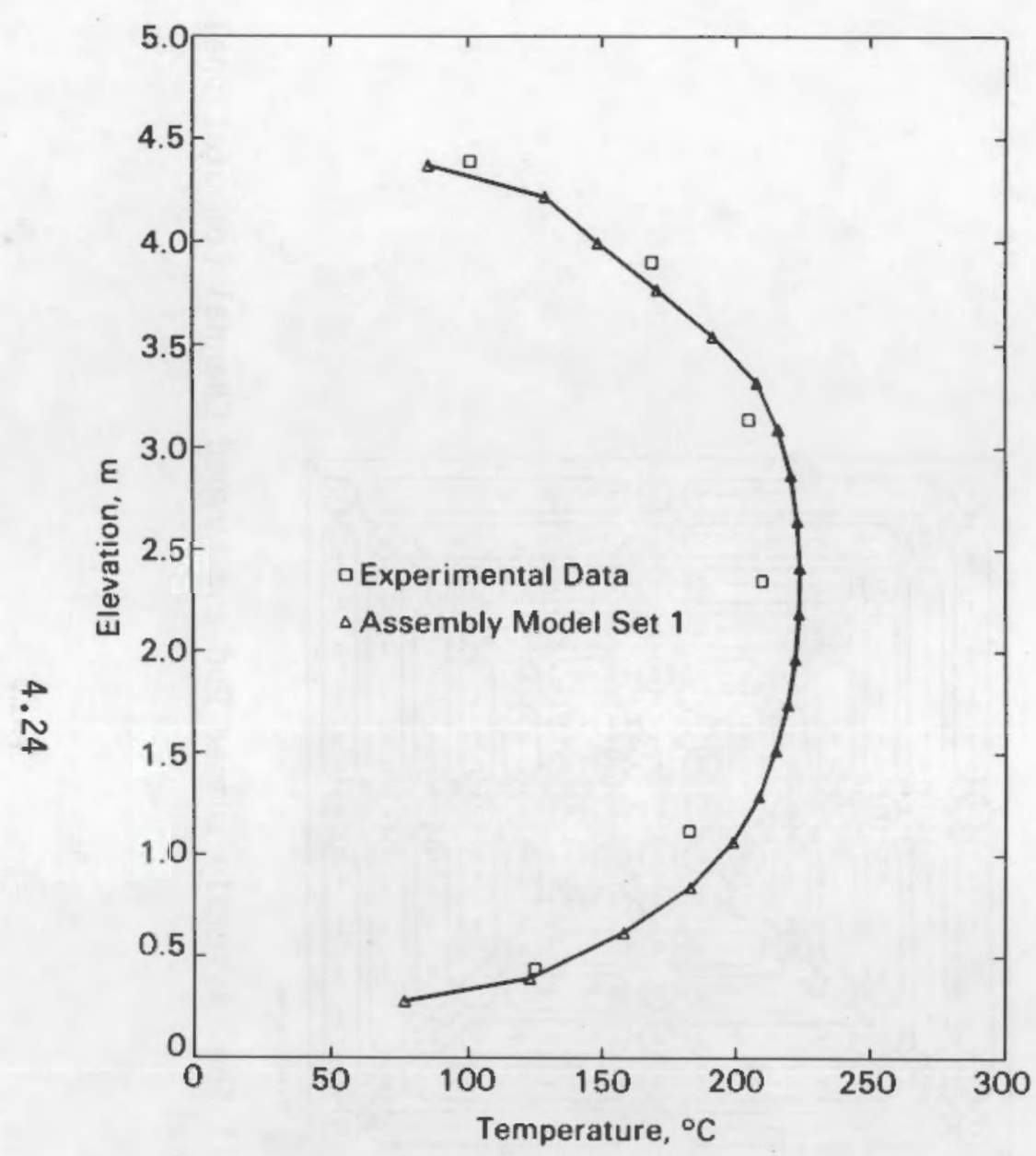

FIGURE 4.7. Axial Temperature Profiles of Experimental Data and COBRA-SFS Predictions for Assembly Model Set \#1 for the TN-24P Spent-Fuel Cask, Helium Backfill Case

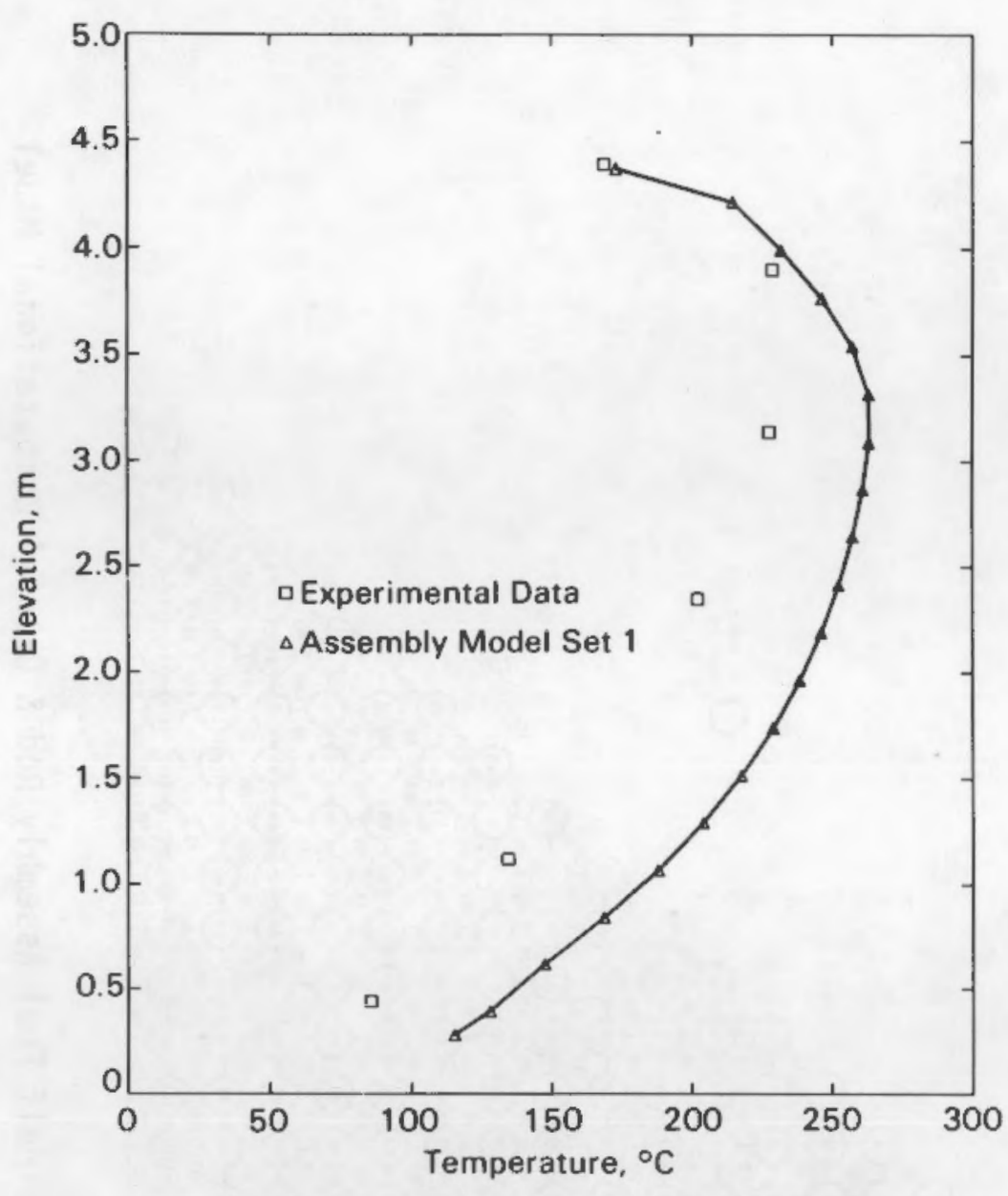

FIGURE 4.8. Axial Temperature Profiles of Experimental Data and COBRA-SFS Predictions for Assembly Model Set 1 for the TN-24P Spent-Fuel Cask, Nitrogen Backfill Case 


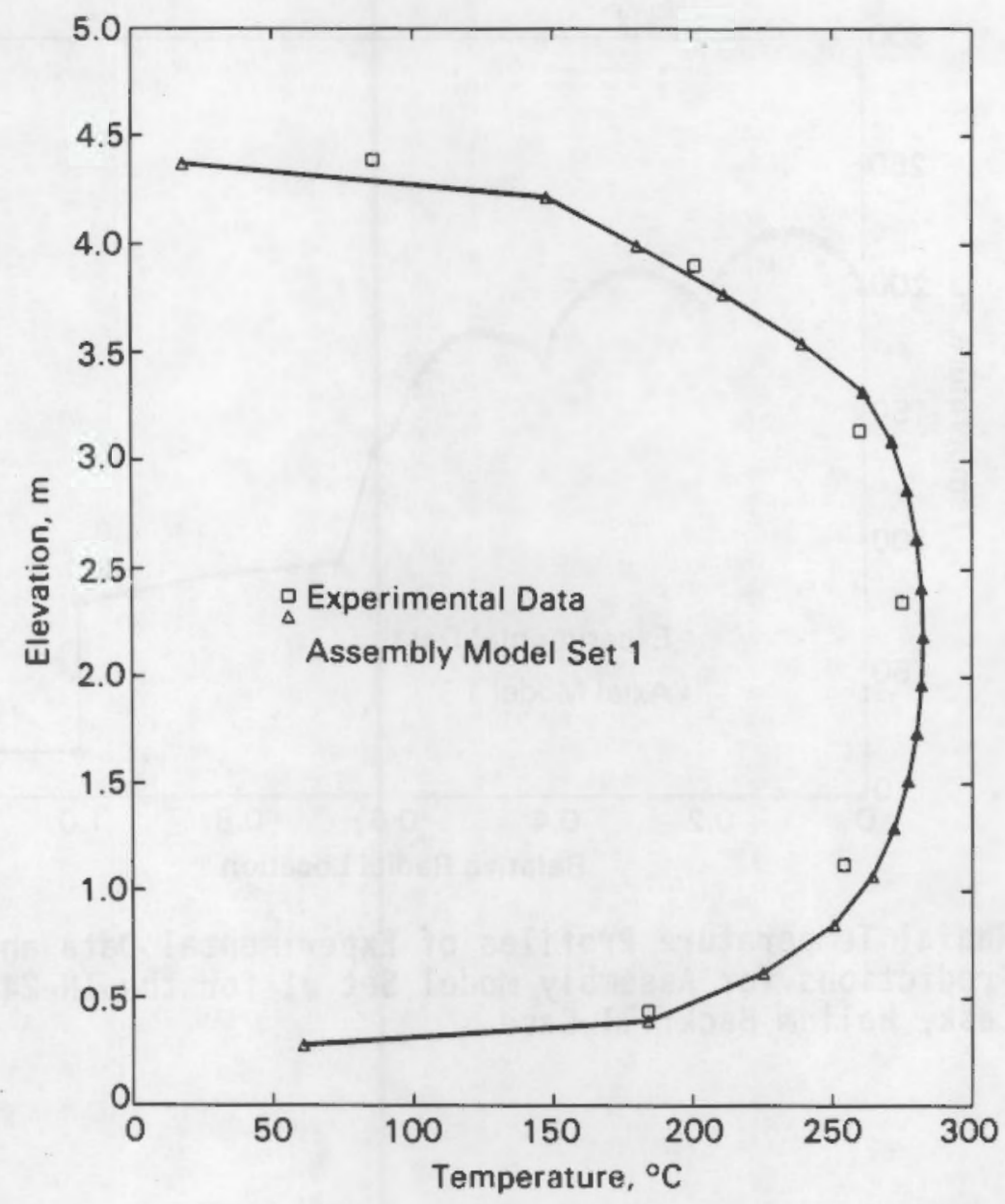

FIGURE 4.9. Axial Temperature Profiles of Experimental Data and COBRA-SFS Predictions for Assembly Model Set \#1 for the TN-24P SpentFuel Cask, Vacuum Backfill Case 


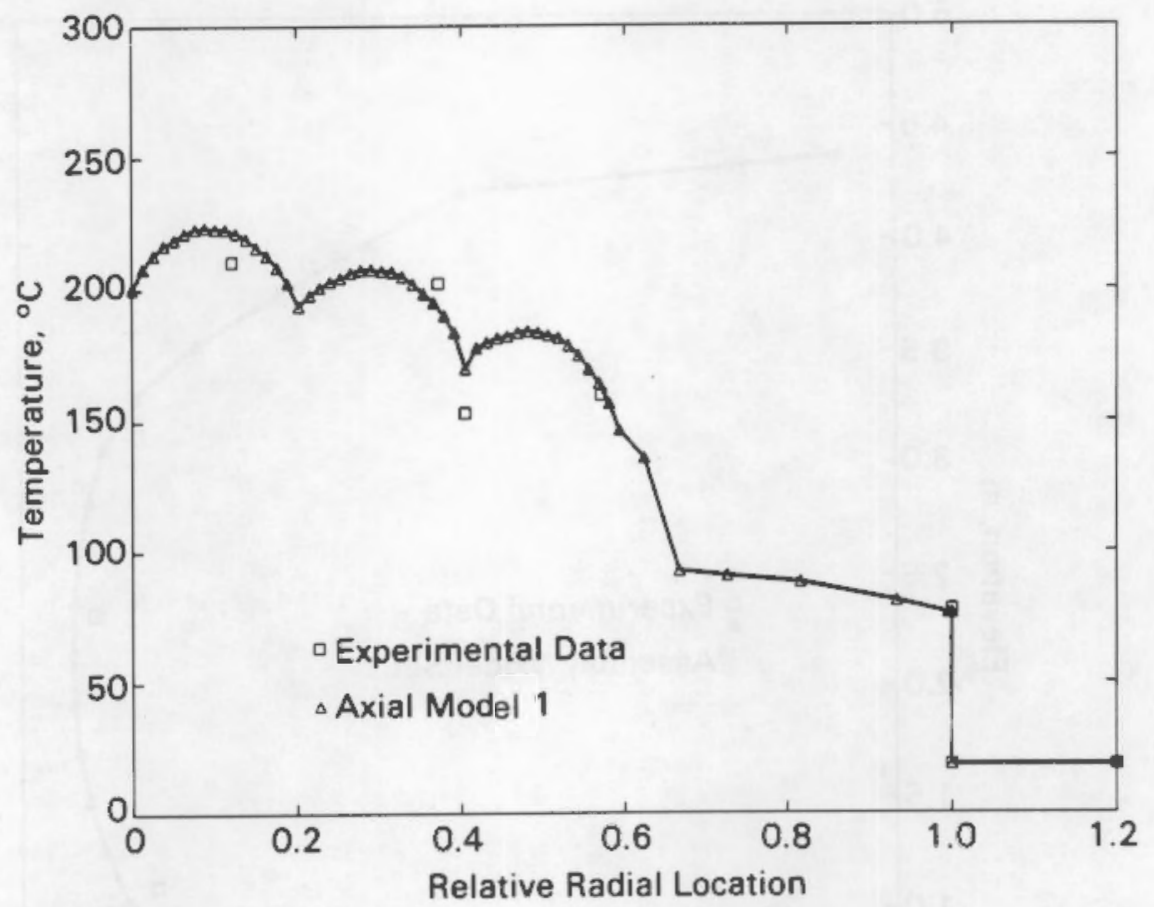

FIGURE 4.10. Radial Temperature Profiles of Experimental Data and COBRA-SFS Predictions for Assembly Model Set \#1 for the TN-24P Spent-Fuel Cask, Helium Backfill Case 


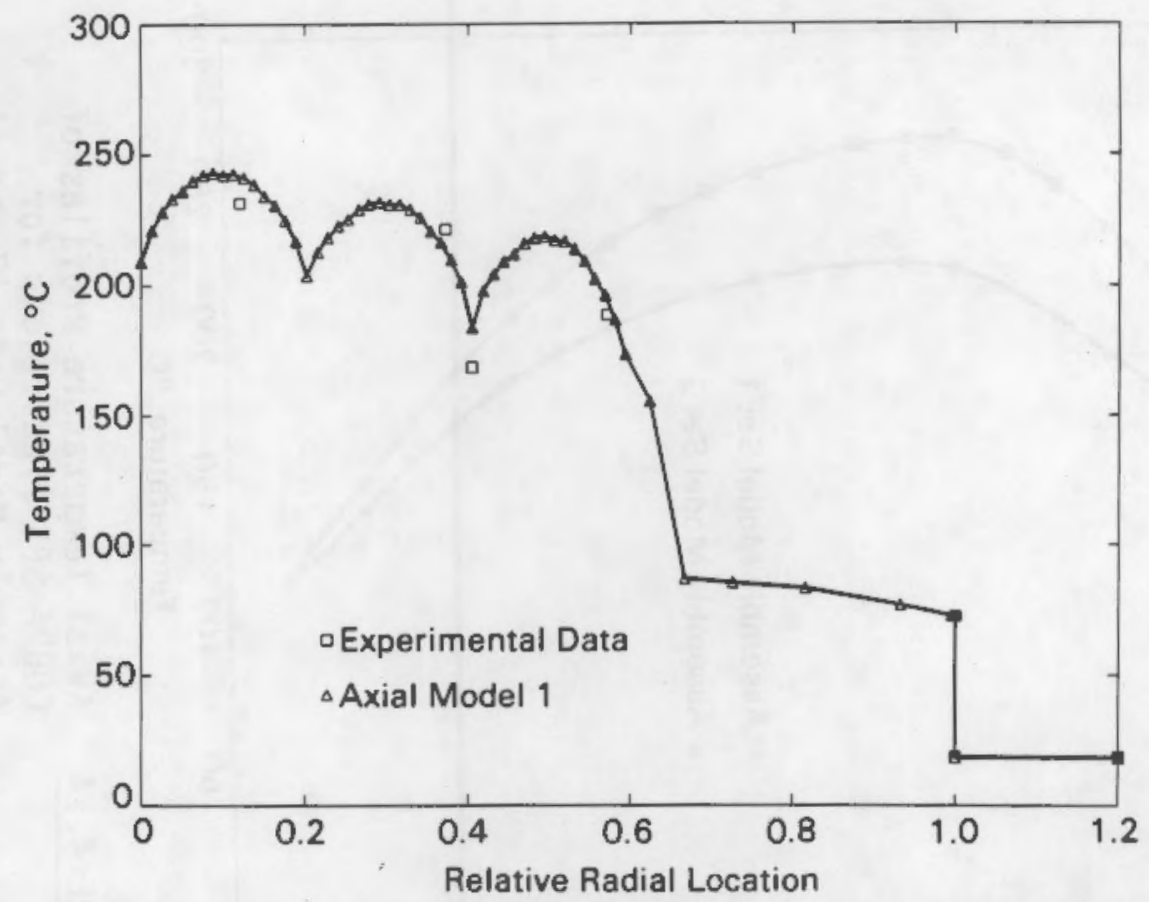

FIGURE 4.11. Radial Temperature Profiles of Experimental Data and COBRA-SFS Predictions for Assembly Model Set \#1 for the TN-24P Spent-Fuel Cask, Nitrogen Backfill Case

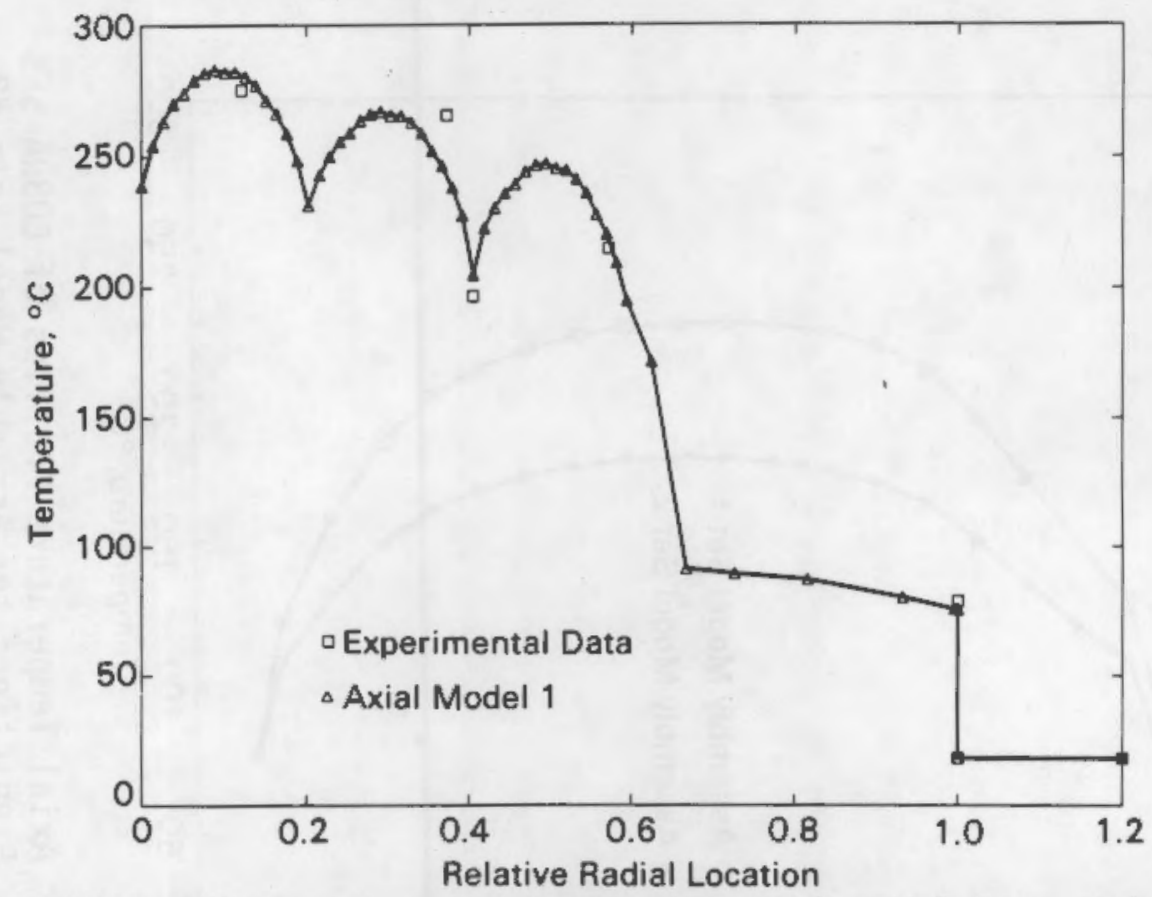

FIGURE 4.12. Radial Temperature Profiles of Experimental Data and COBRA-SFS

Predictions for Assembly Model Set $\# 1$ for the TN-24P Spent-Fuel Cask, Vacuum Backfill Case 


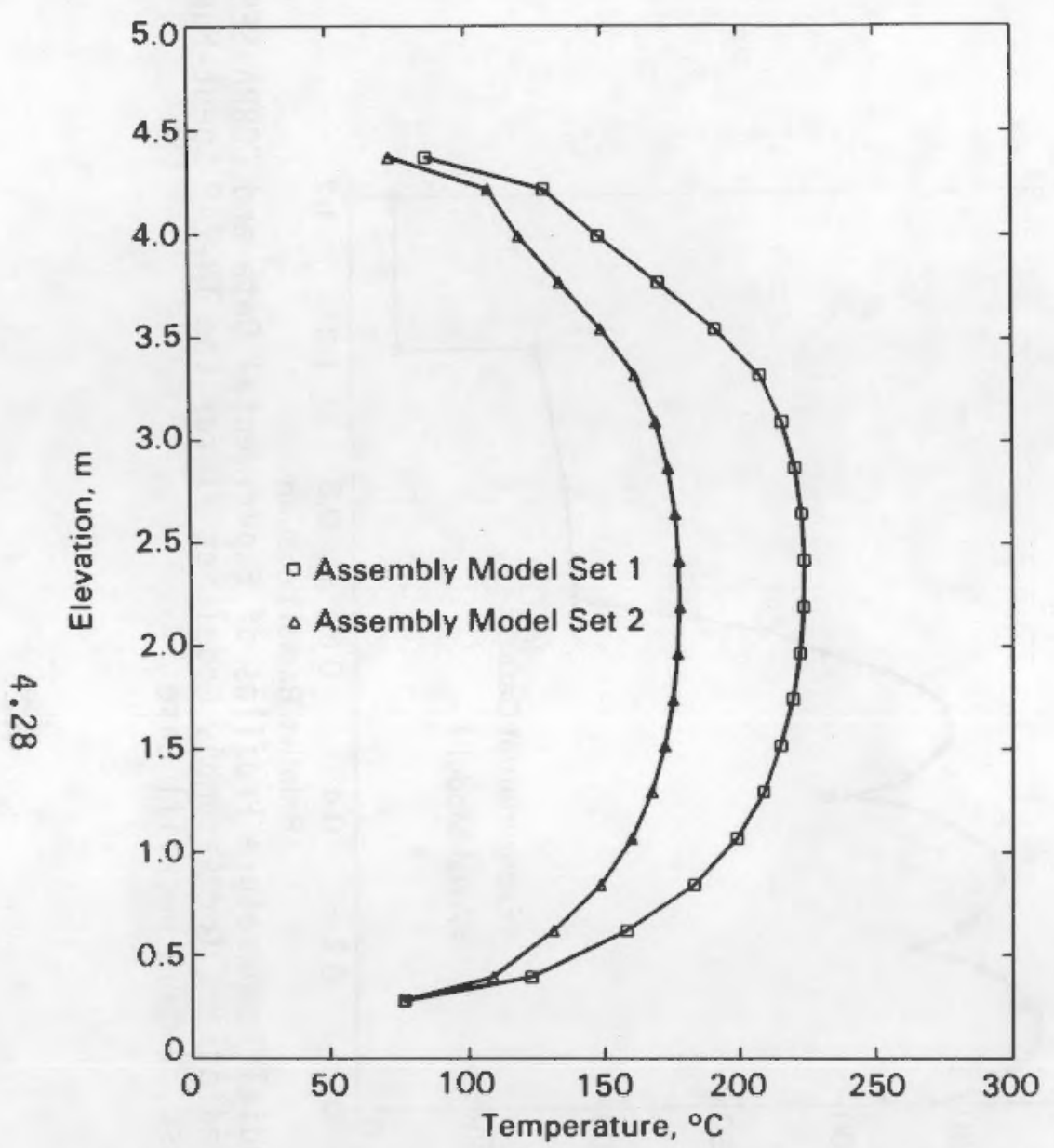

FIGURE 4.13. Axial Temperature Profiles of COBRA-SFS Predictions for Assembly Model Sets \#2 and \#1 (Detailed Models) for the TN-24P Spent-Fuel Cask, Helium Backfill Case

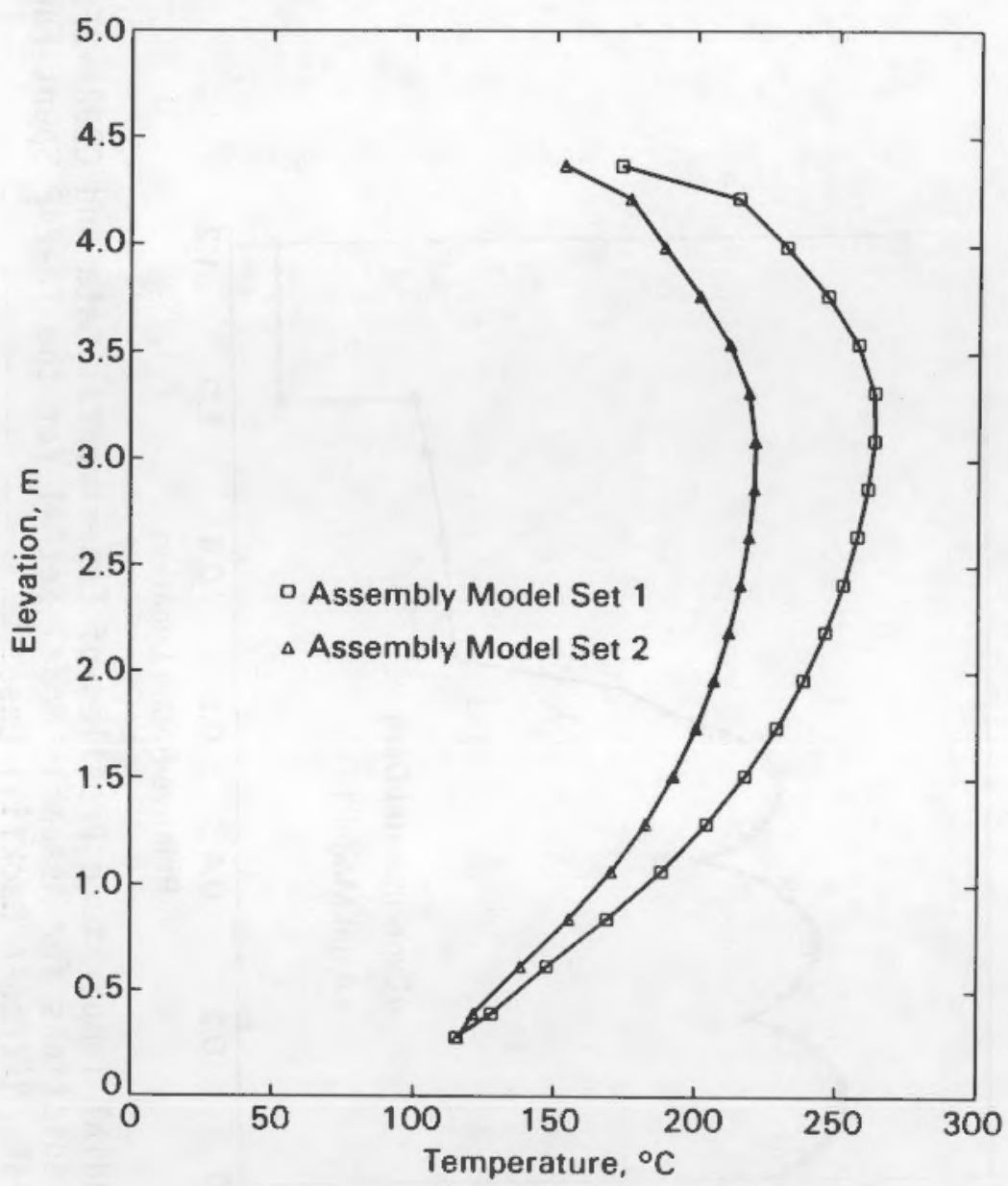

FIGURE 4.14. Axial Temperature Profiles of COBRA-SFS Predictions for Assembly Model Sets \#2 and \#1 for the TN-24P Spent-Fuel Cask Nitrogen Backfill Case 


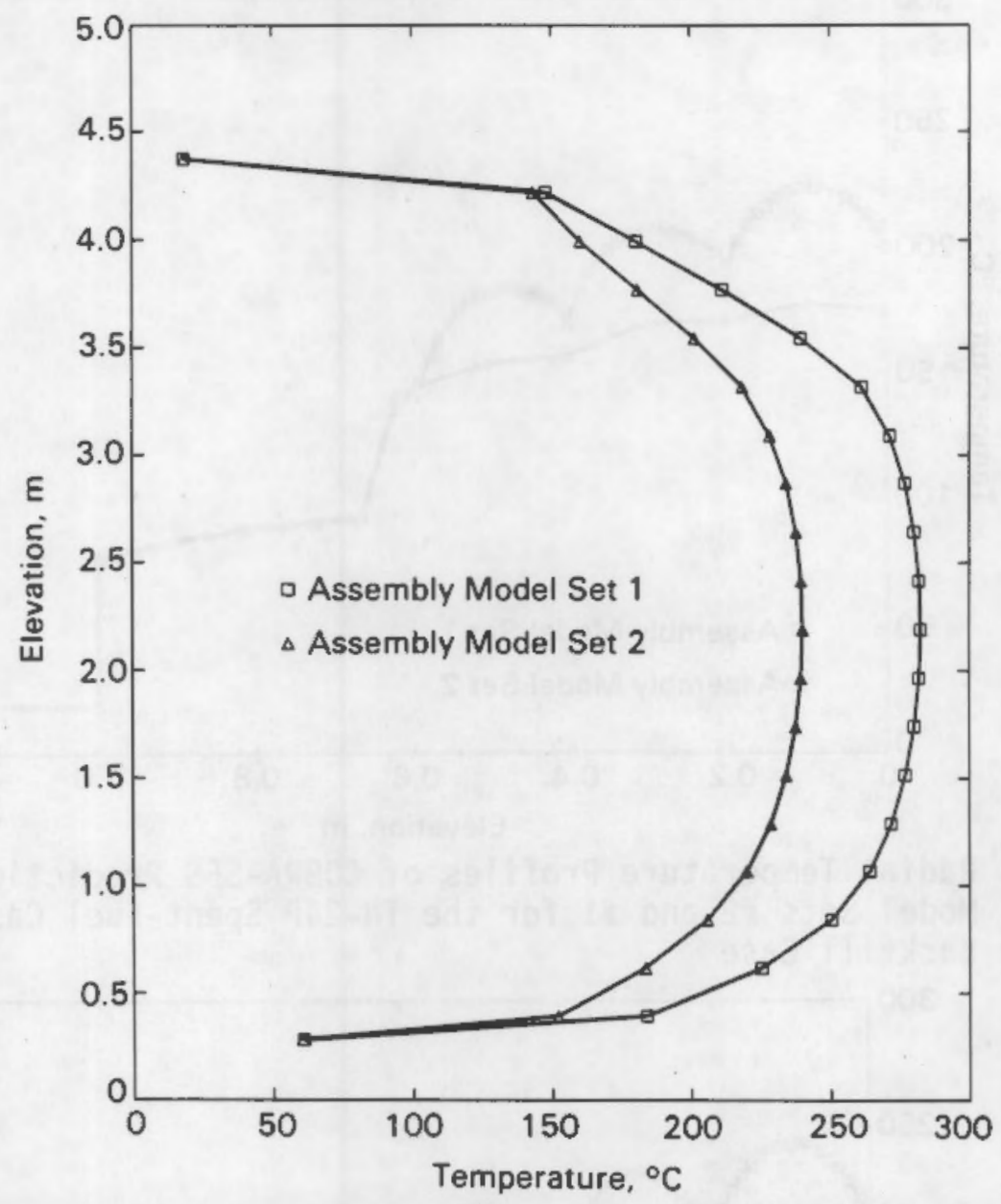

FIGURE 4.15. Axial Temperature Profiles of COBRA-SFS Predictions for Assembly Model Sets \#2 and \#1 for the TN-24P Spent-Fuel Cask, Vacuum Backfill Case 


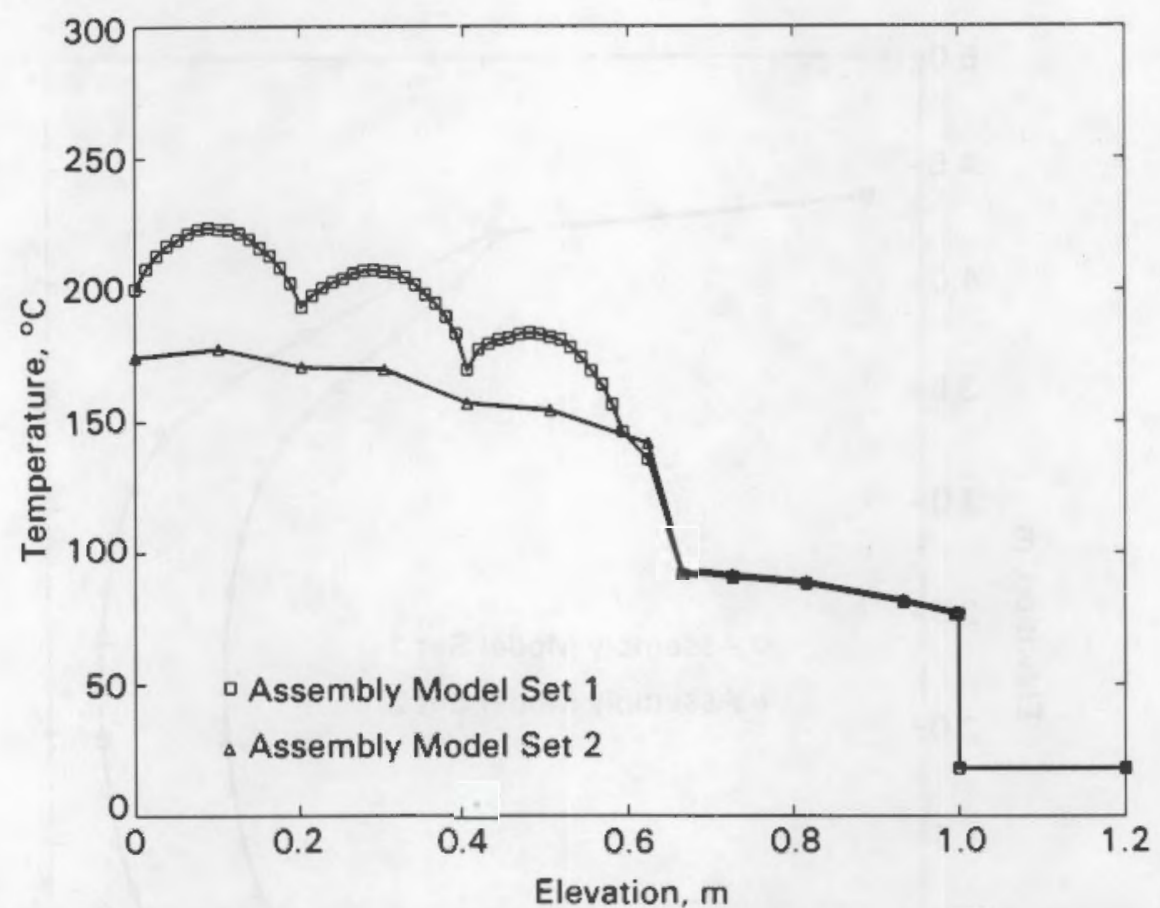

FIGURE 4.16. Radial Temperature Profiles of COBRA-SFS Predictions for Assembly Model Sets \#2 and \#1 for the TN-24P Spent-Fuel Cask, Helium Backfill Case

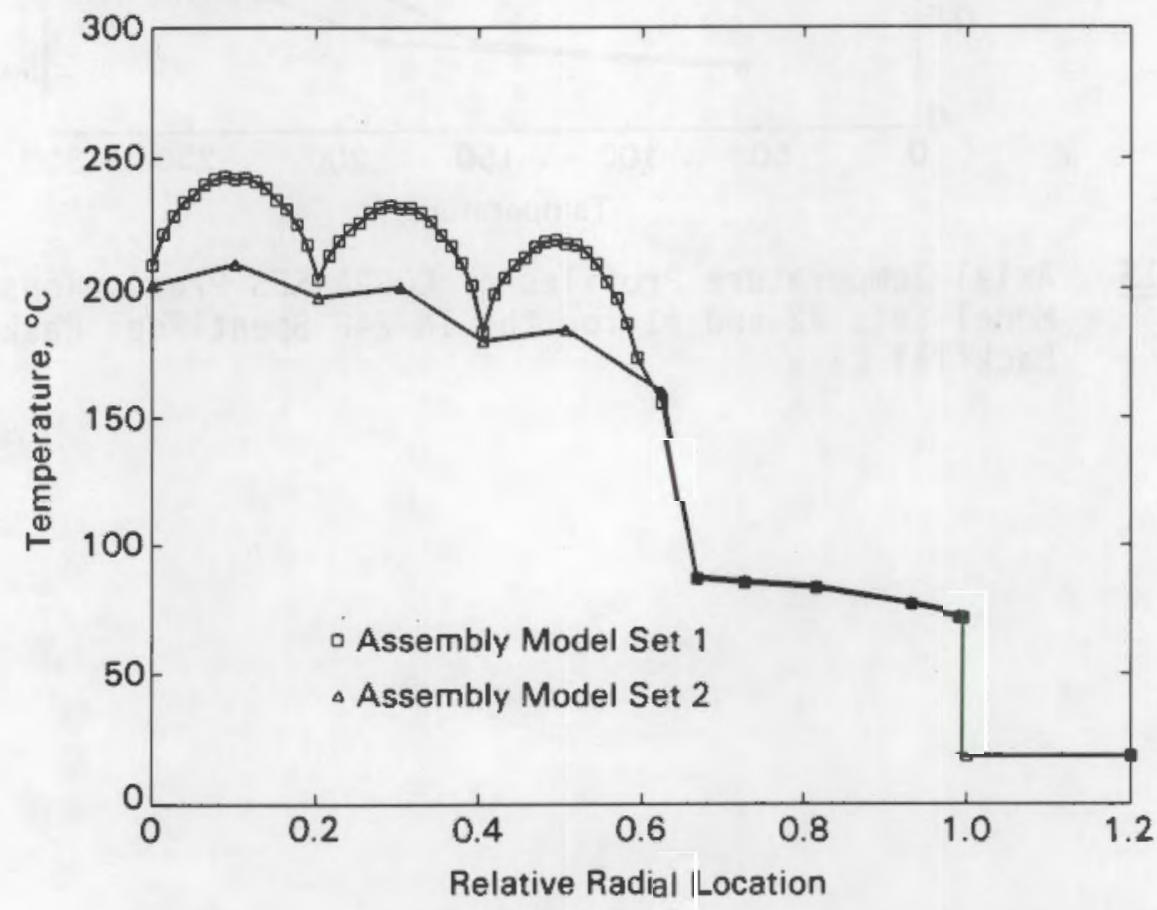

FIGURE 4.17. Radial Temperature Profiles of COBRA-SFS Predictions for Assembly Model Sets \#2 and \#1 for the TN-24P Spent-Fuel Cask, Nitrogen Backfill Case 


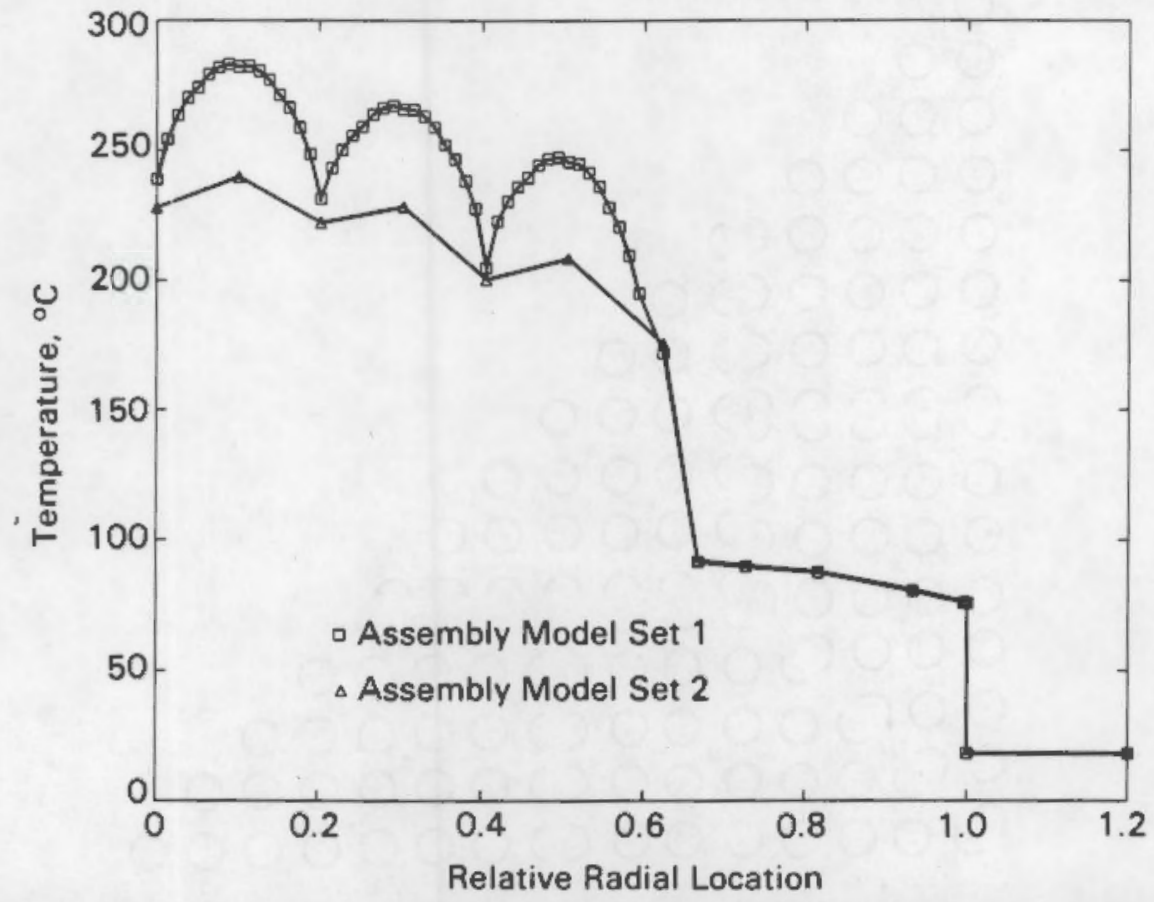

FIGURE 4.18. Radial Temperature Profiles of COBRA-SFS Predictions for Assembly Model Sets \#2 and \#1 for the TN-24P Spent-Fuel Cask, Vacuum Backfill Case 


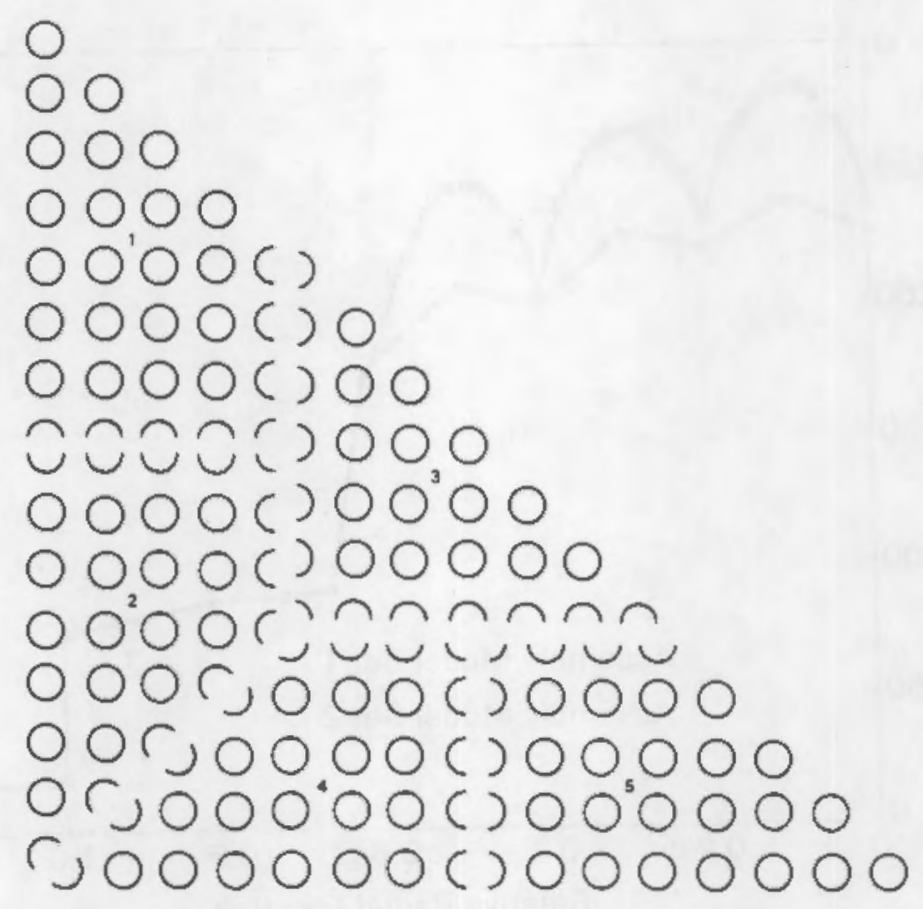

FIGURE 4.19. COBRA-SFS TN-24P Half Assembly Model Set \#3 (5 rod and 5 channel nodes per assembly)

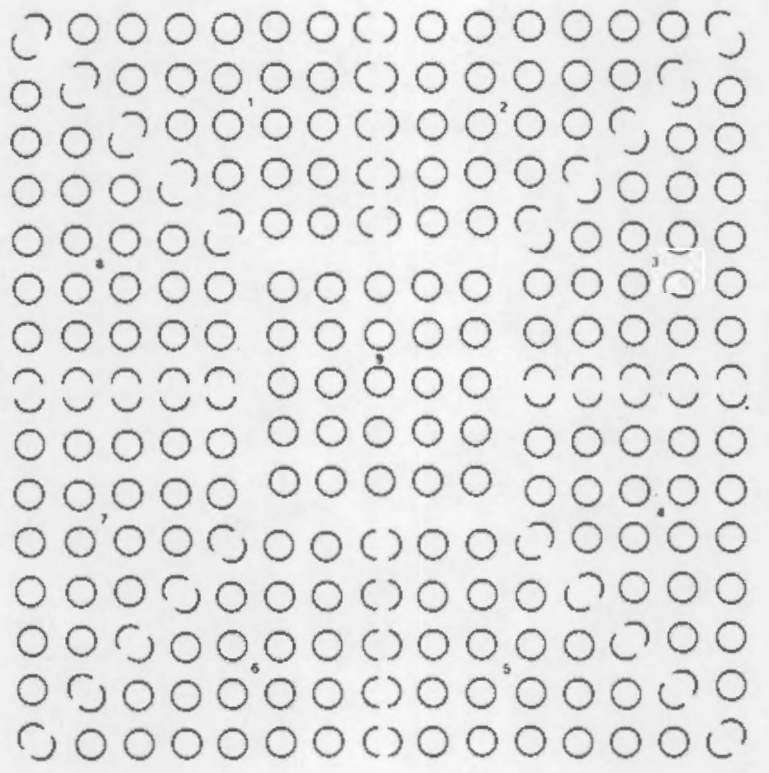

FIGURE 4.20. COBRA-SFS TN-24P Full Assembly Model Set \#3 (9 rod and 9 channel nodes per assembly) 


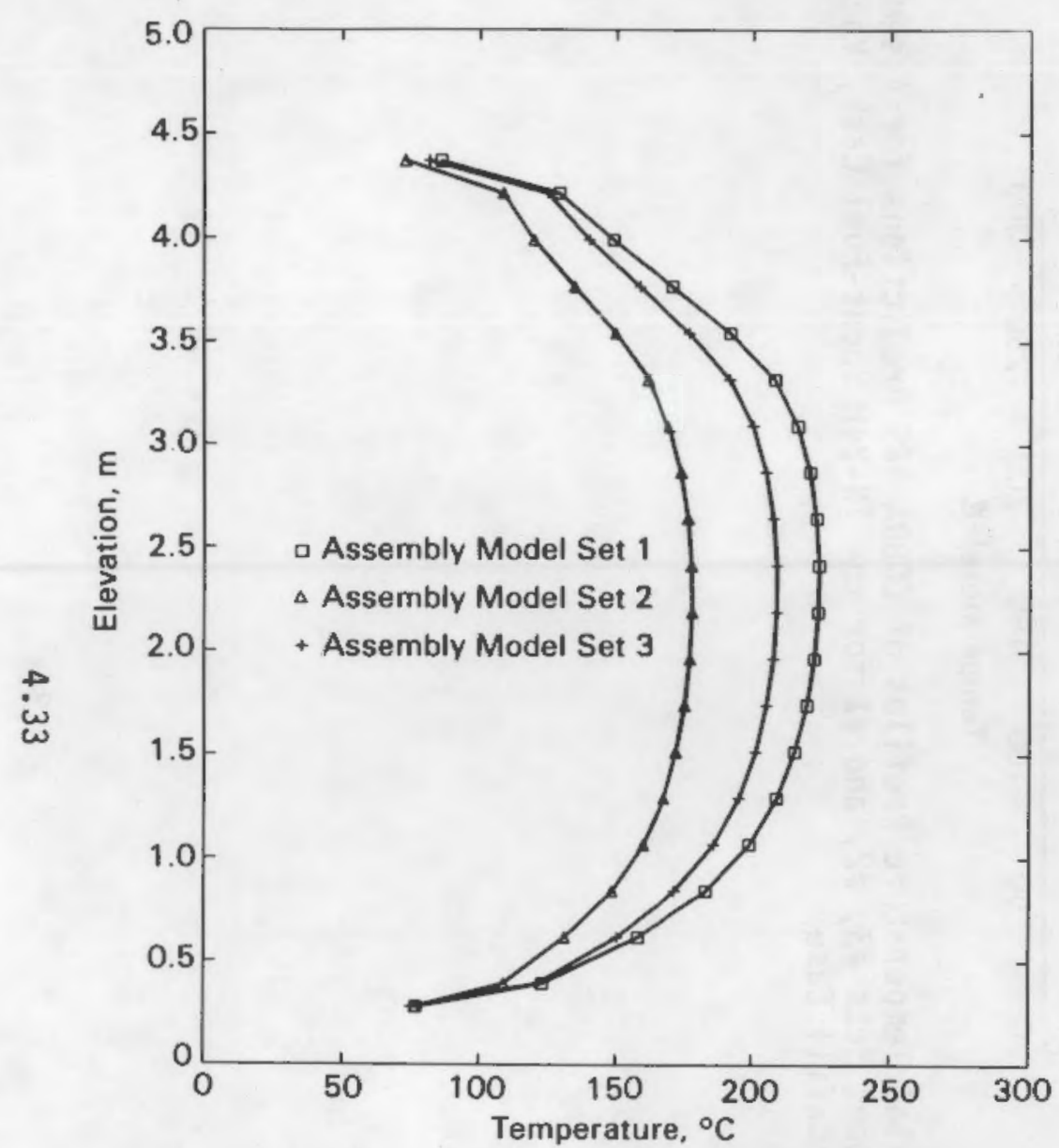

FIGURE 4.21. Axial Temperature Profiles of COBRA-SFS Predictions for Assembly Model Sets \#3, $\# 2$, and $\# 1$ for the TN-24P Spent-Fuel Cask, Helium Backfill Case

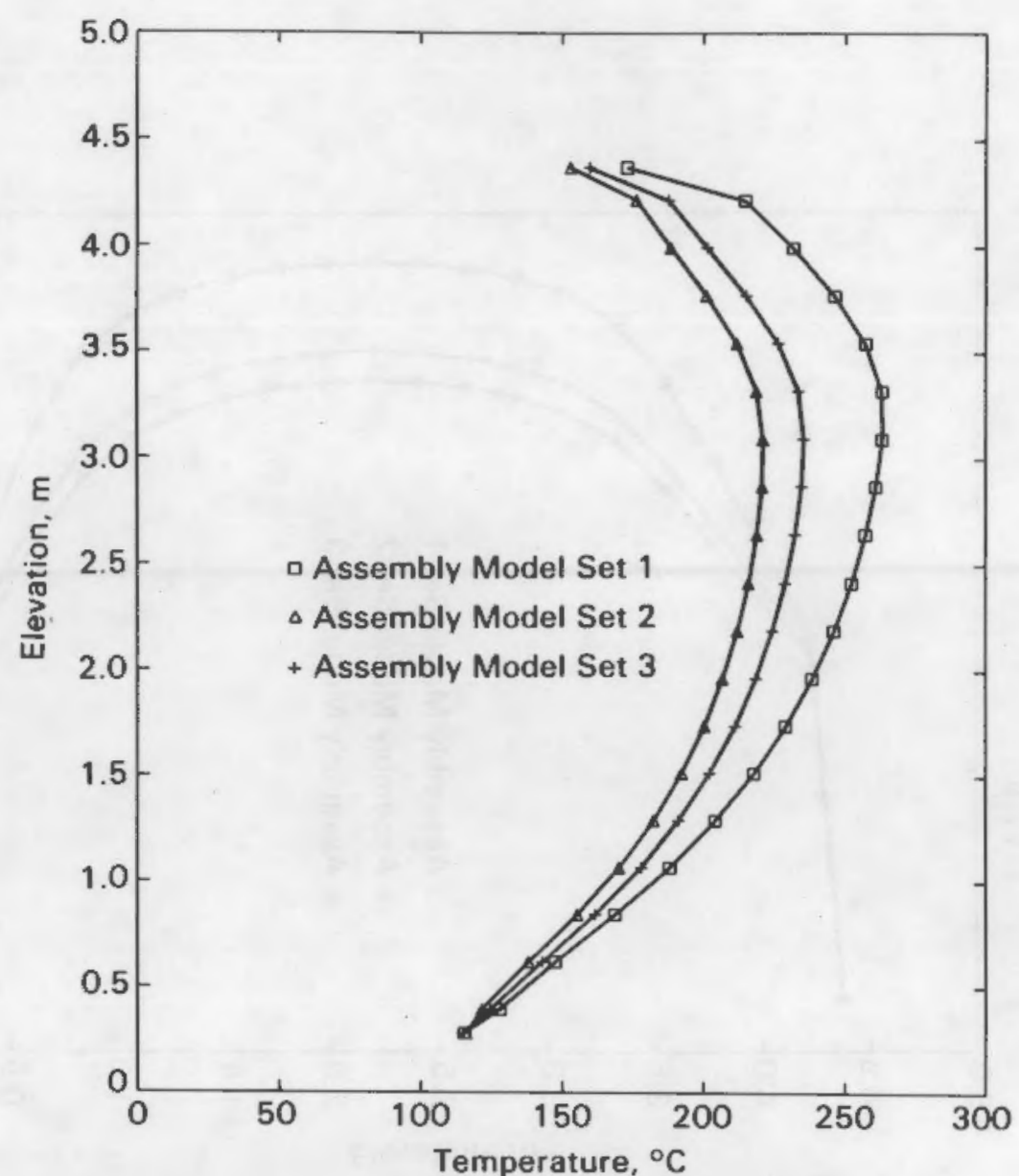

FIGURE 4.22. Axial Temperature Profiles of COBRA-SFS Predictions for Assembly Model Sets \#3, \#2, and \#1 for the TN-24P Spent-Fuel Cask, Nitrogen Backfill Case 


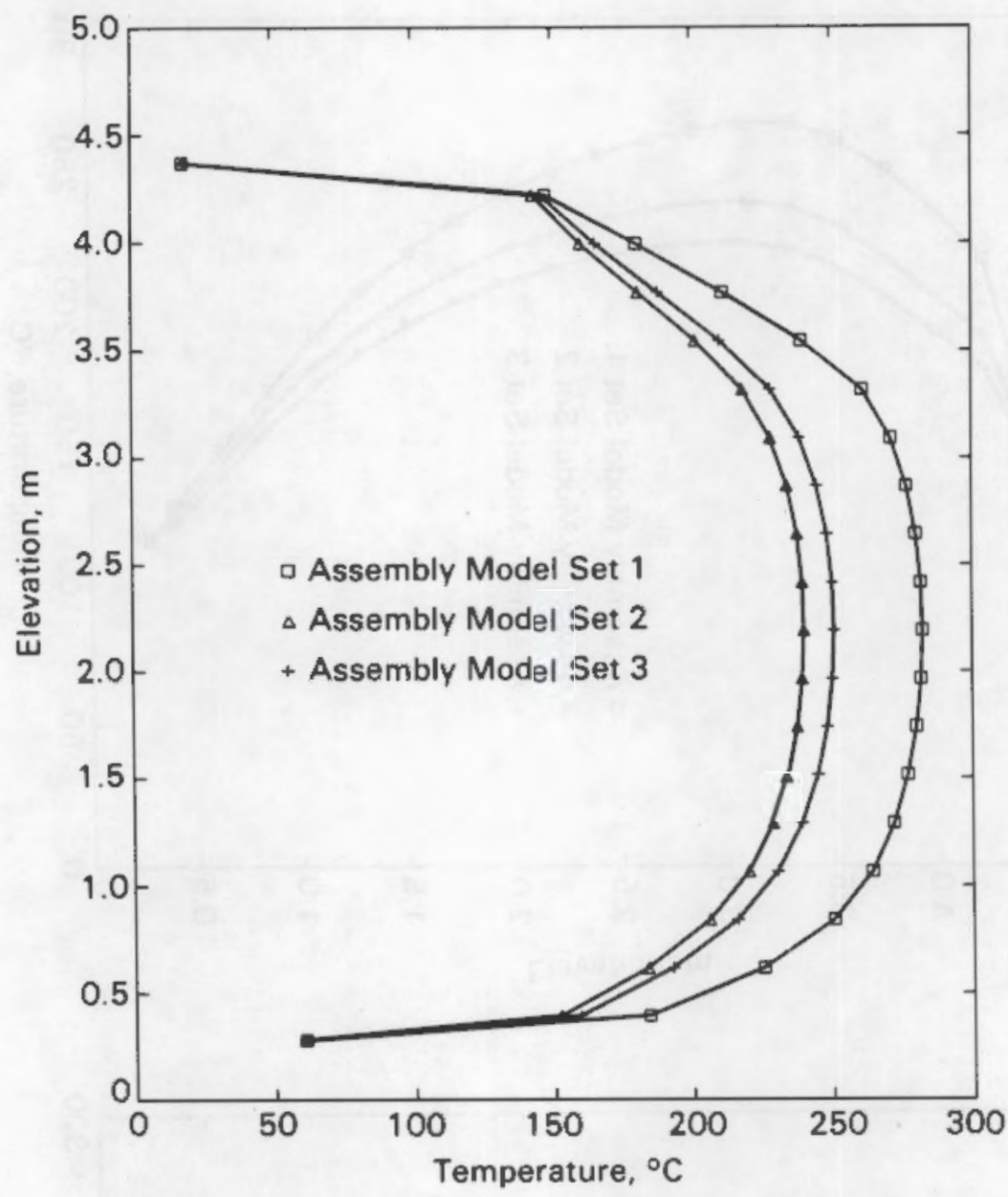

FIGURE 4.23. Axial Temperature Profiles of COBRA-SFS Predictions for Assembly Model Sets \#3, \#2, and \#1 for the TN-24P Spent-Fuel Cask, Vacuum Backfill Case 


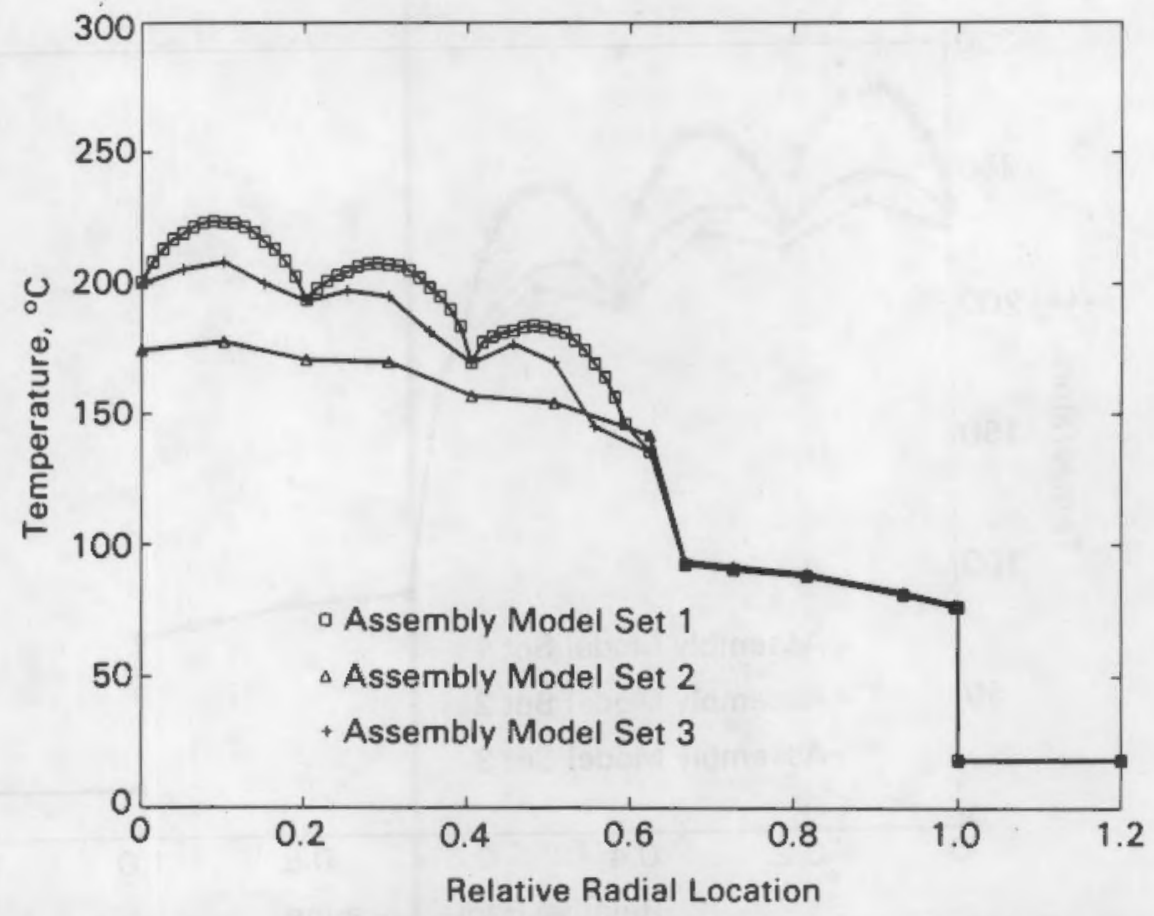

FIGURE 4.24. Radial Temperature Profiles of COBRA-SFS Predictions for Assembly Model Sets \#3, \#2, and \#1 for the TN-24P Spent-Fuel Cask, Helium Backfill Case

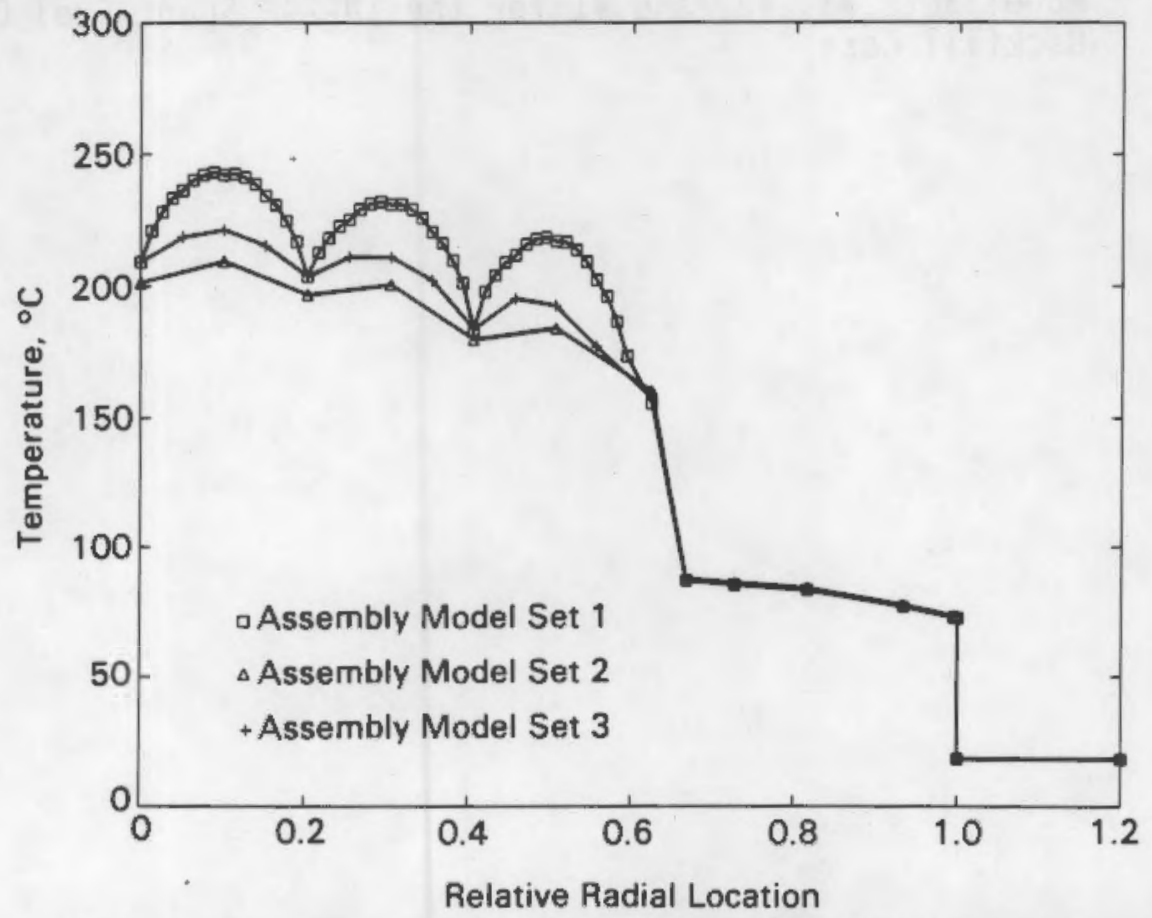

FIGURE 4.25. Radial Temperature Profiles of COBRA-SFS Predictions for Assembly Model Sets \#3, \#2, and \#1 for the TN-24P Spent-Fuel Cask, Nitrogen Backfill Case 


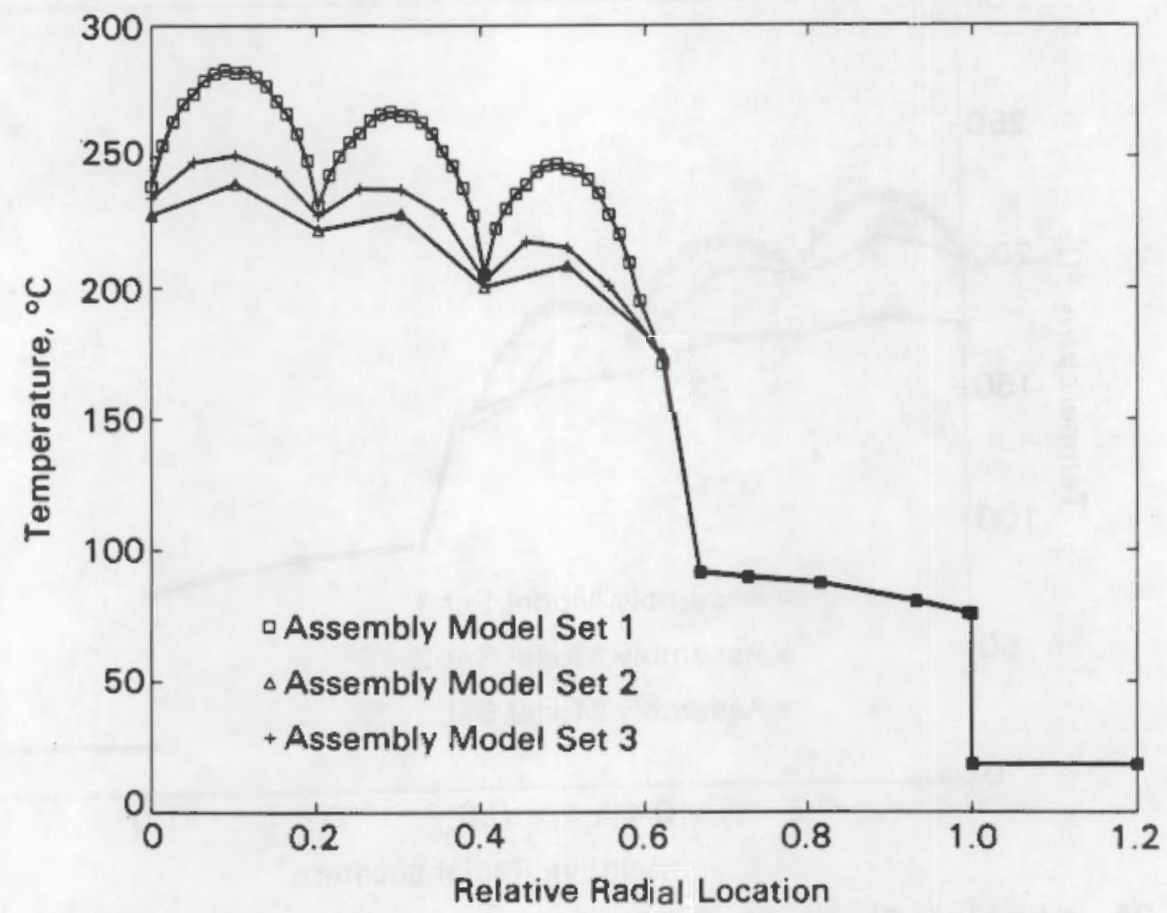

FIGURE 4.26. Radial Temperature Profiles of COBRA-SFS Predictions for Assembly Model Sets \#3, \#2, and \#1 for the TN-24P Spent-Fuel Cask, Vacuum Backfill Case 


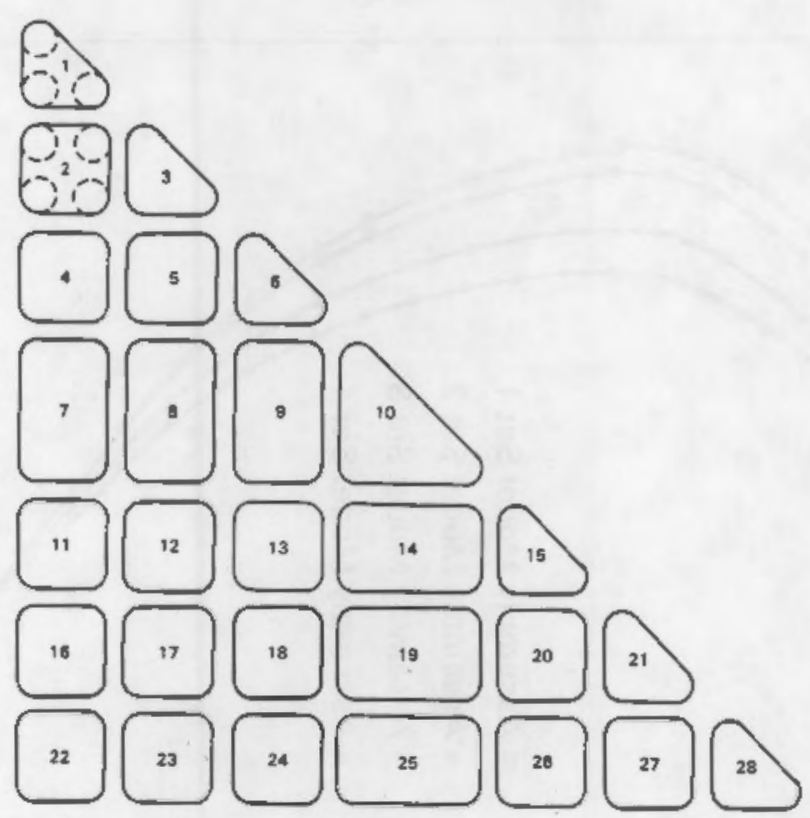

FIGURE 4.27. COBRA-SFS TN-24P Half Assembly Model Set \#4 (28 rod and 28 channel nodes per assembly)

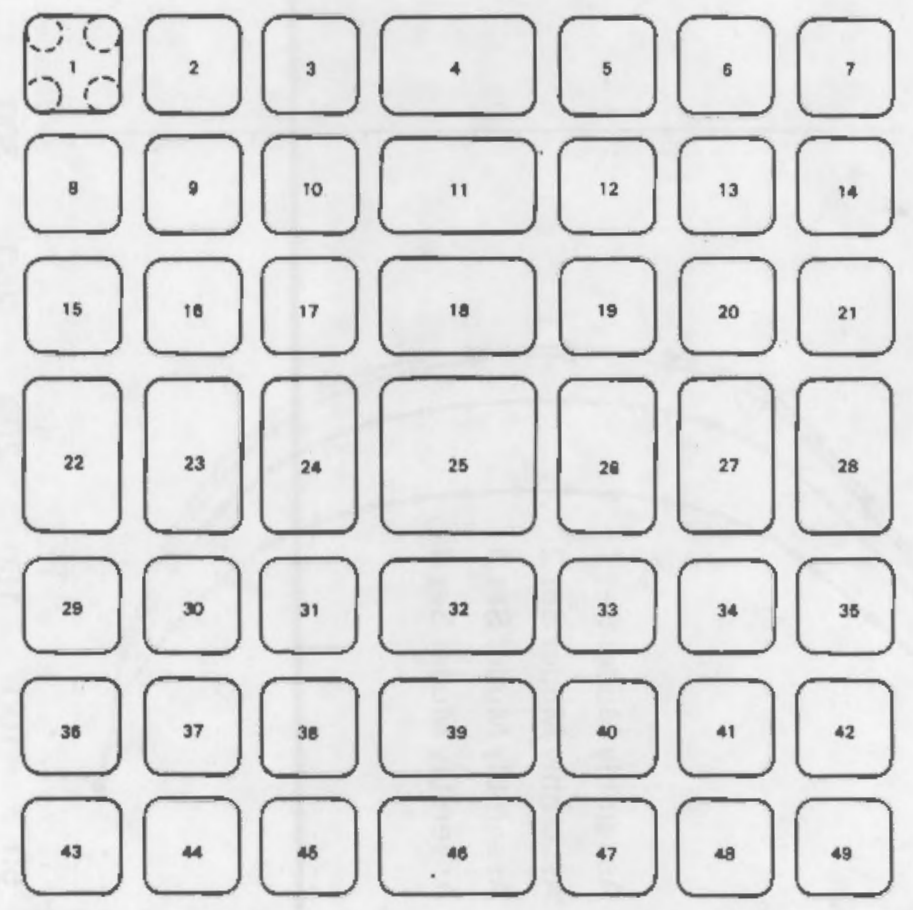

FIGURE 4.28. COBRA-SFS TN-24P Full Assembly Model Set \#4 (49 rod and 49 channel nodes per assembly) 


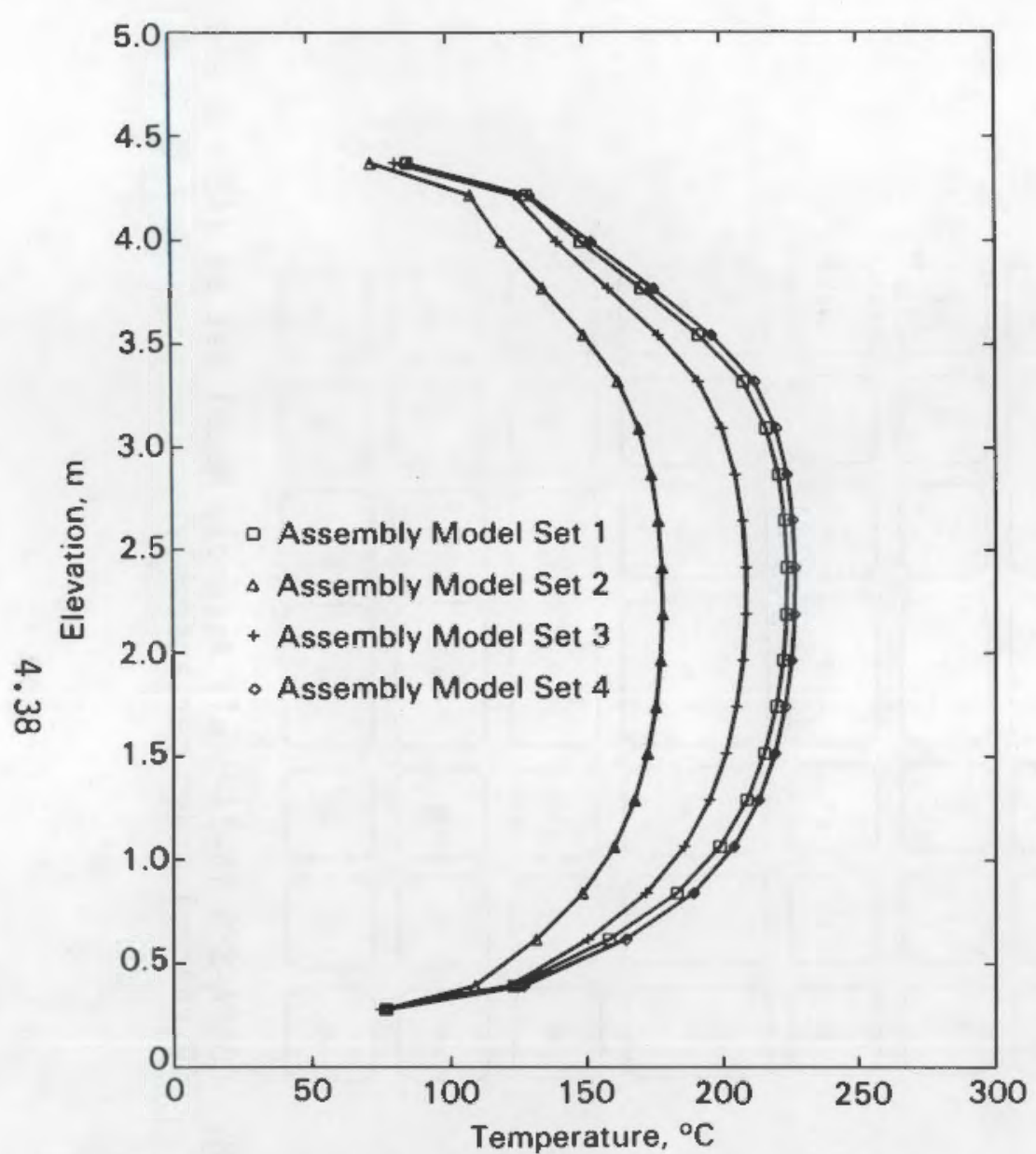

FIGURE 4.29. Axial Temperature Profiles of COBRA-SFS Predictions for Assembly Model Sets \#4, \#3, 2, and \#1 for the TN-24P SpentFuel Cask, Helium Backfill Case

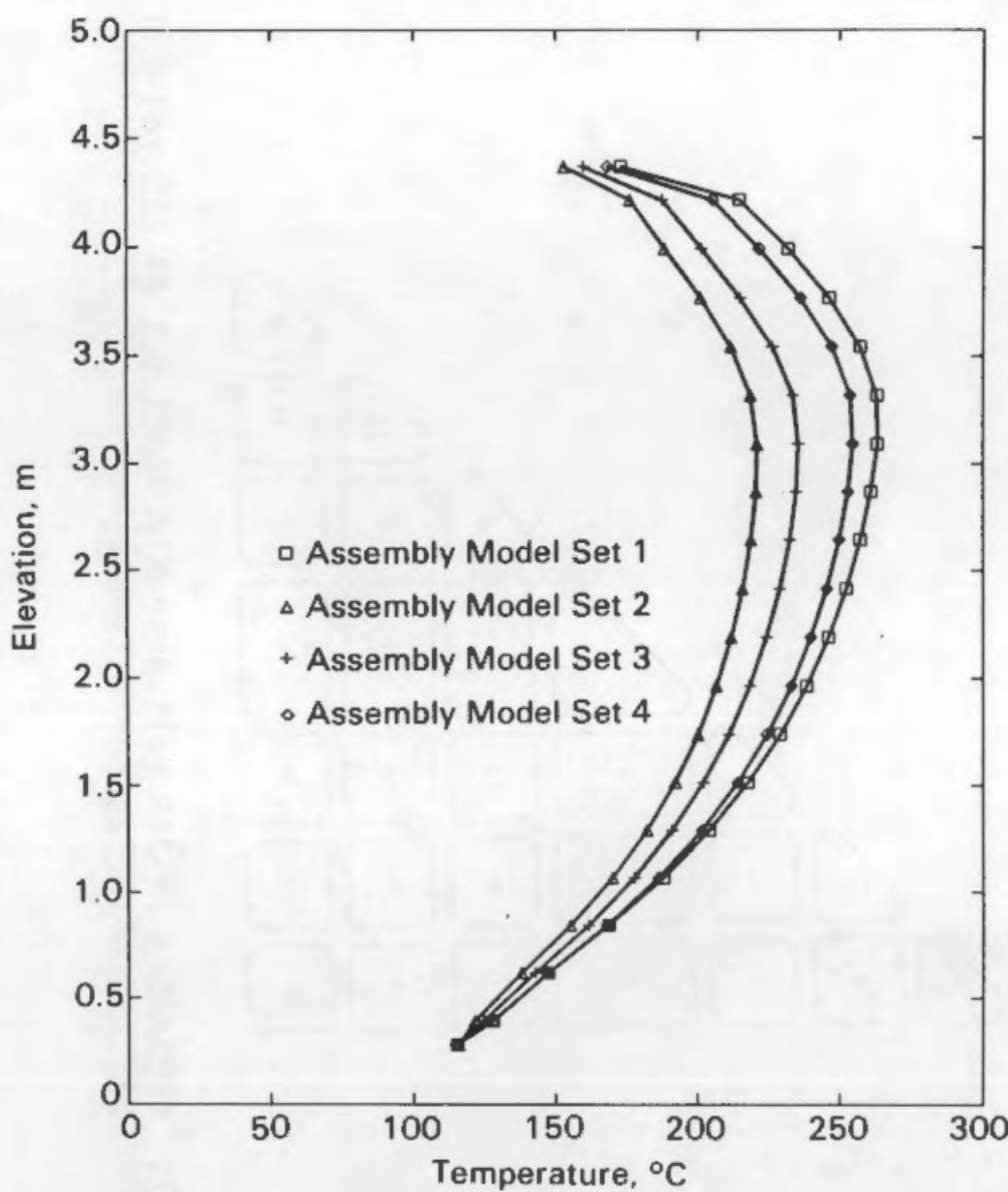

FIGURE 4.30. Axial Temperature Profiles of COBRA-SFS Predictions for Assembly Model Sets \#4, \#3, \#2, and \#1 for the TN-24P Spent-Fuel Cask, Nitrogen Backfill Case 


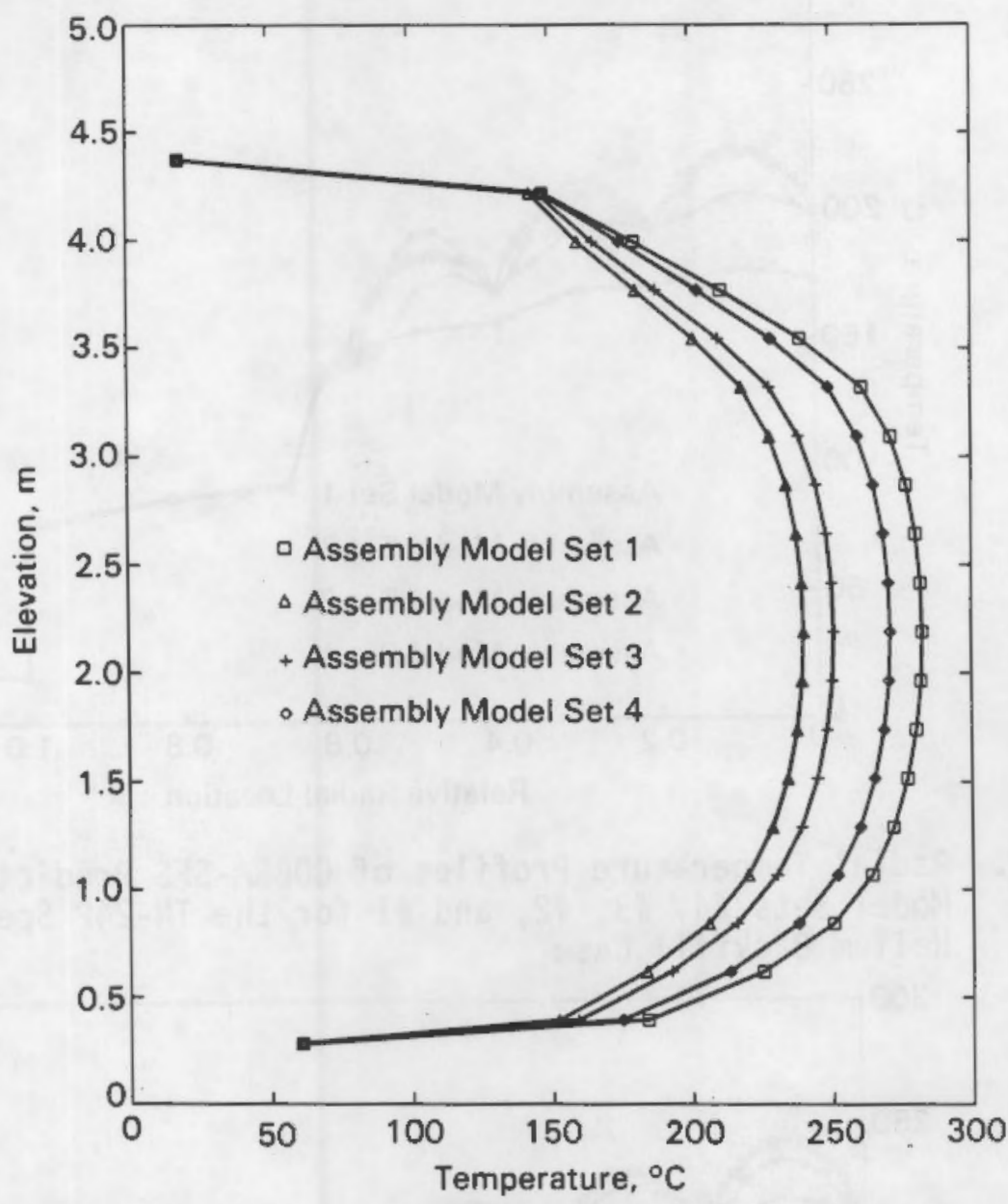

FIGURE 4.31. Axial Temperature Profiles of COBRA-SFS Predictions for Assembly Model Sets \#4, \#3, \#2, and \#1 for the TN-24P Spent-Fuel Cask, Vacuum Backfill Case 


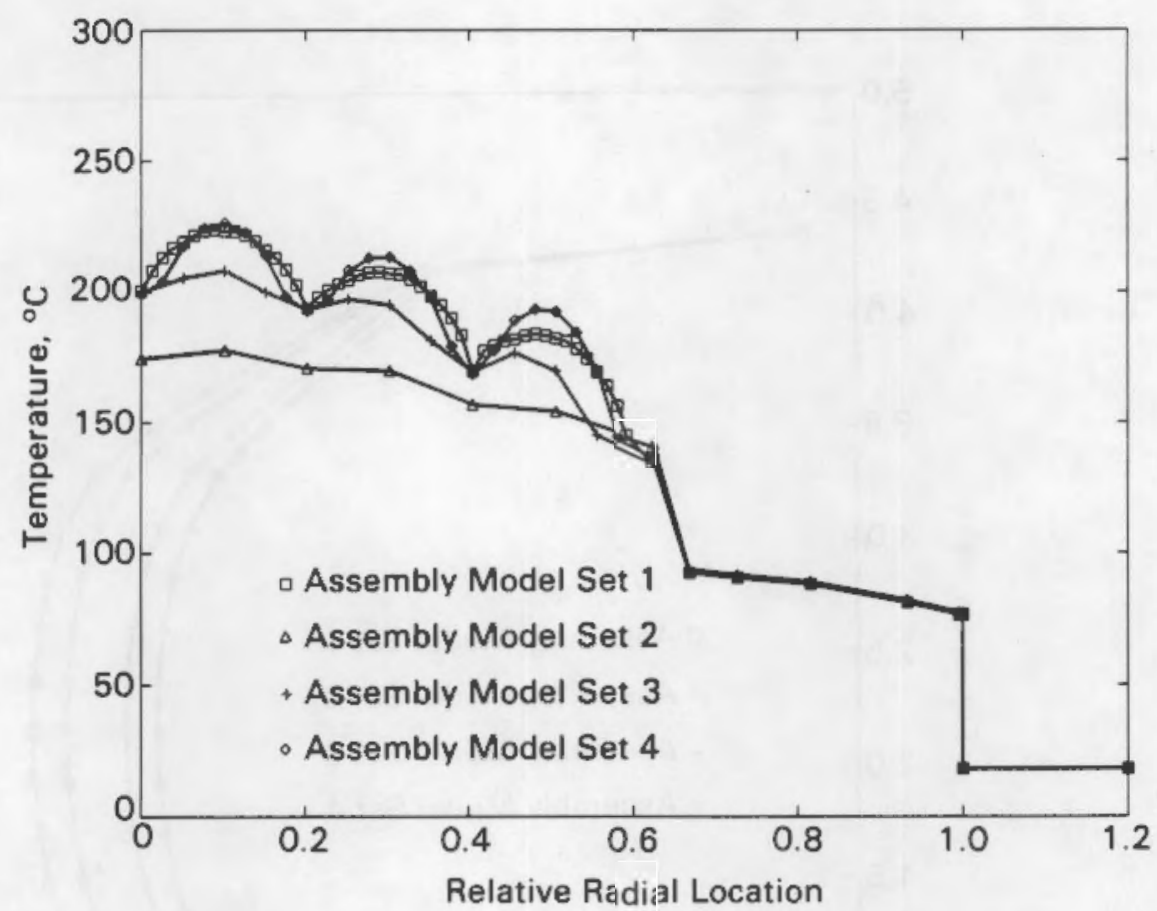

FIGURE 4.32. Radial Temperature Profiles of COBRA-SFS Predictions for Assembly Model Sets \#4, \#3, \#2, and \#1 for the TN-24P Spent-Fuel Cask, Helium Backfill Case

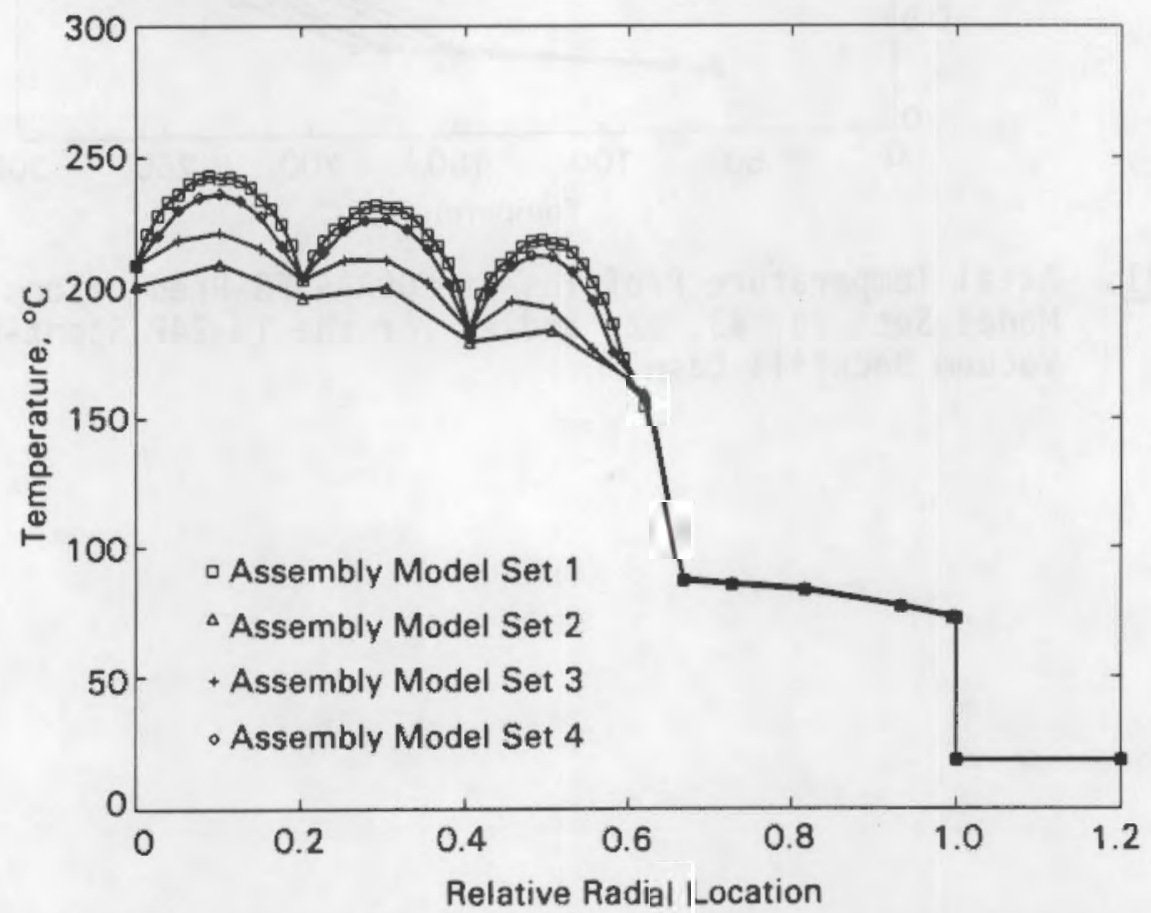

FIGURE 4.33. Radial Temperature Profiles of COBRA-SFS Predictions for Assembly Model Sets \#4,\#3, \#2, and \#1 for the TN-24P Spent Fuel Cask, Nitrogen Backfill Case 


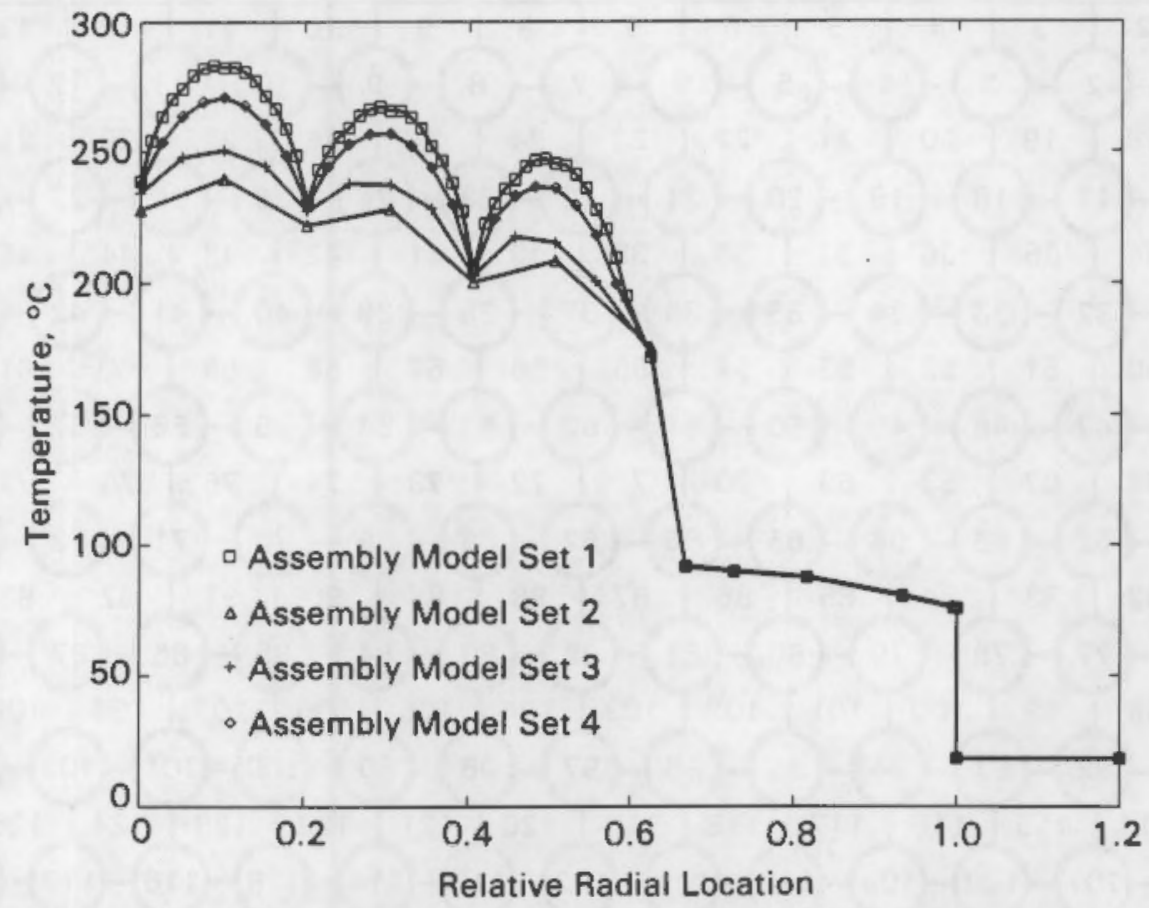

FIGURE 4.34. Radial Temperature Profiles of COBRA-SFS Predictions for Assembly Model Sets \#4, \#3, \#2, and \#1 for the TN-24P Spent-Fuel Cask, Vacuum Backfill Case 


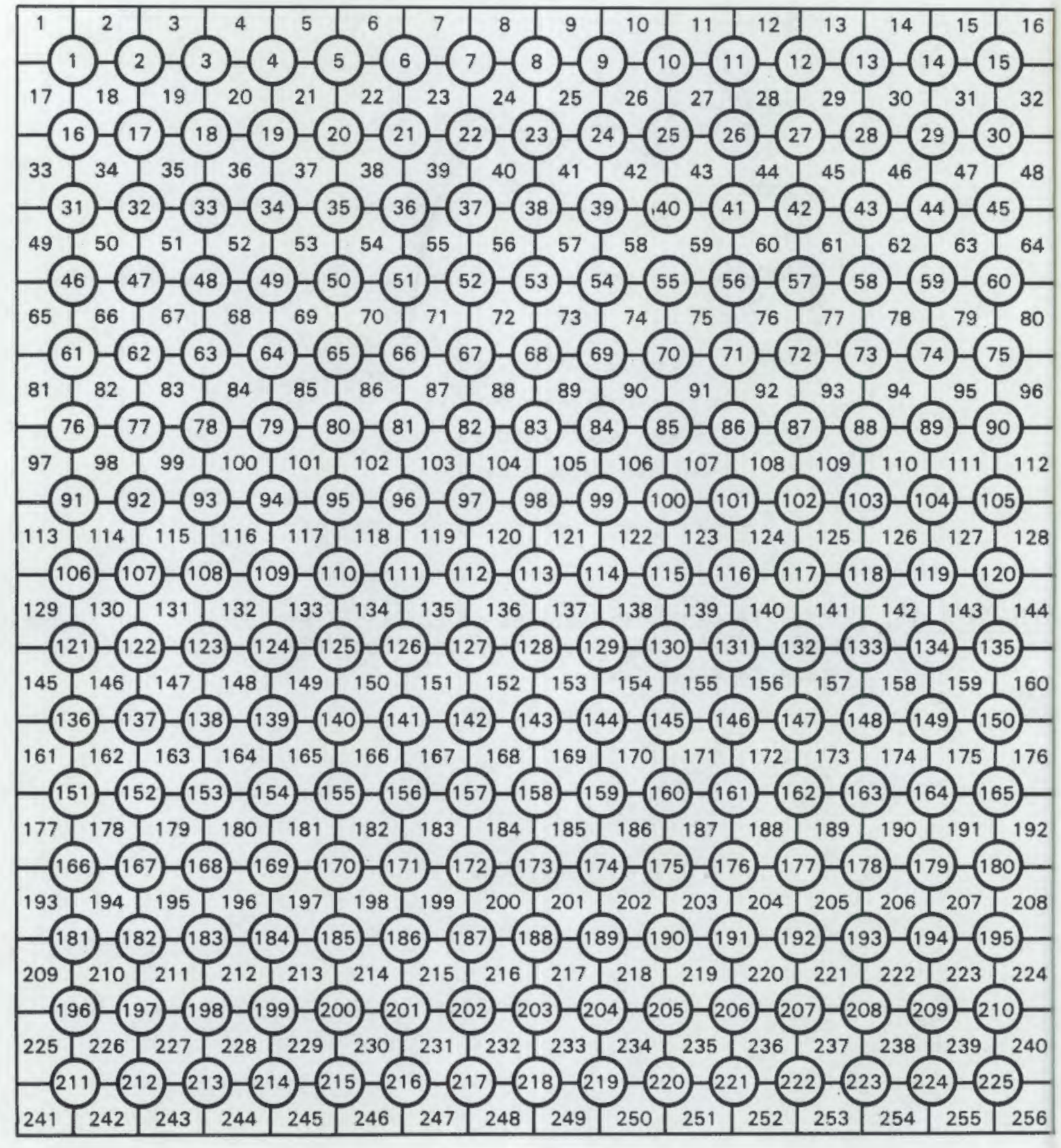

FIGURE 4.35. COBRA-SFS TN-24P Full Assembly Model for Set \#5 


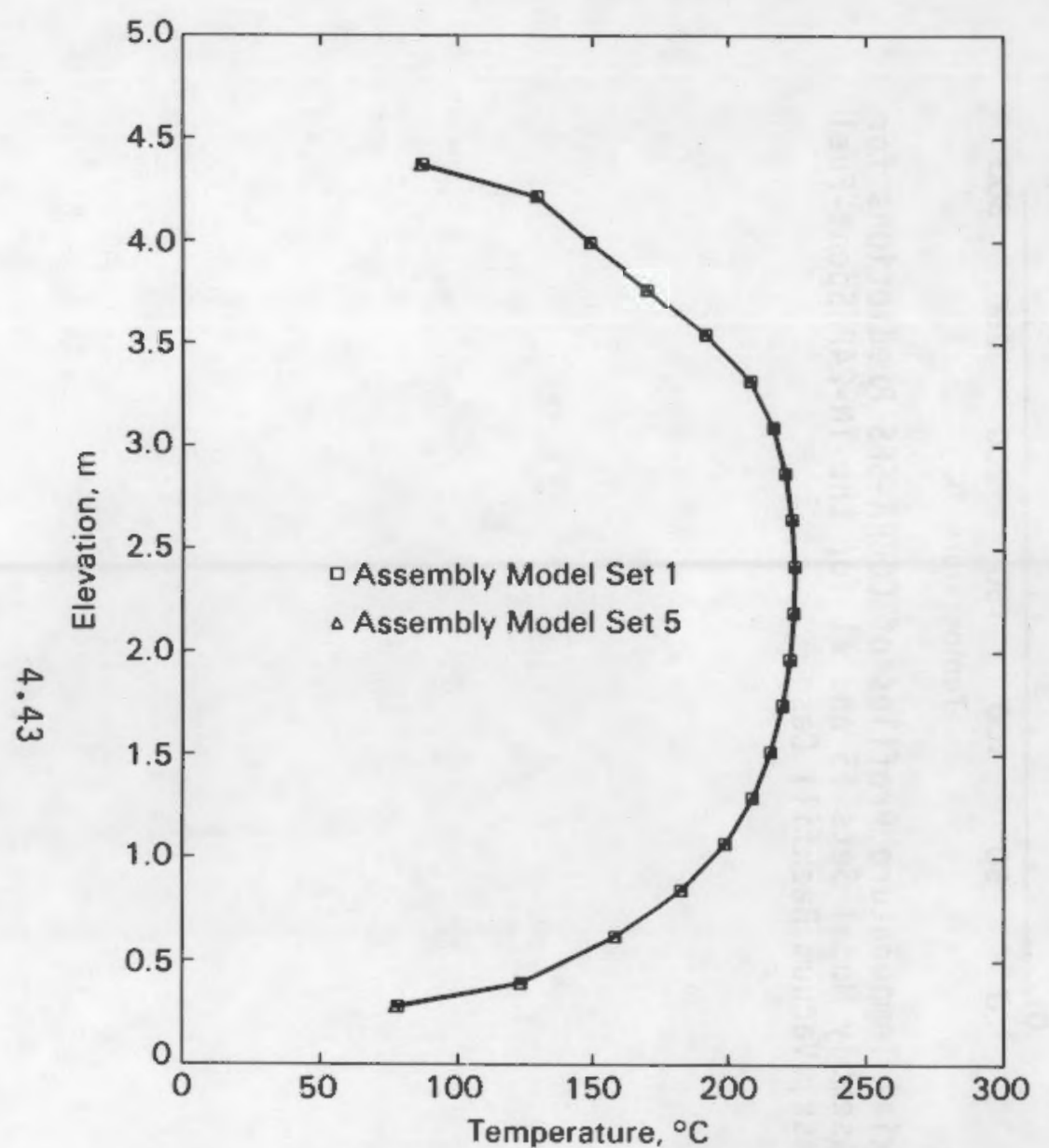

FIGURE 4.36. Axial Temperature Profiles of COBRA-SFS Predictions for Assembly Model Sets \#5 and \#1 for the TN-24P Spent-Fuel Cask, Helium Backfill Case

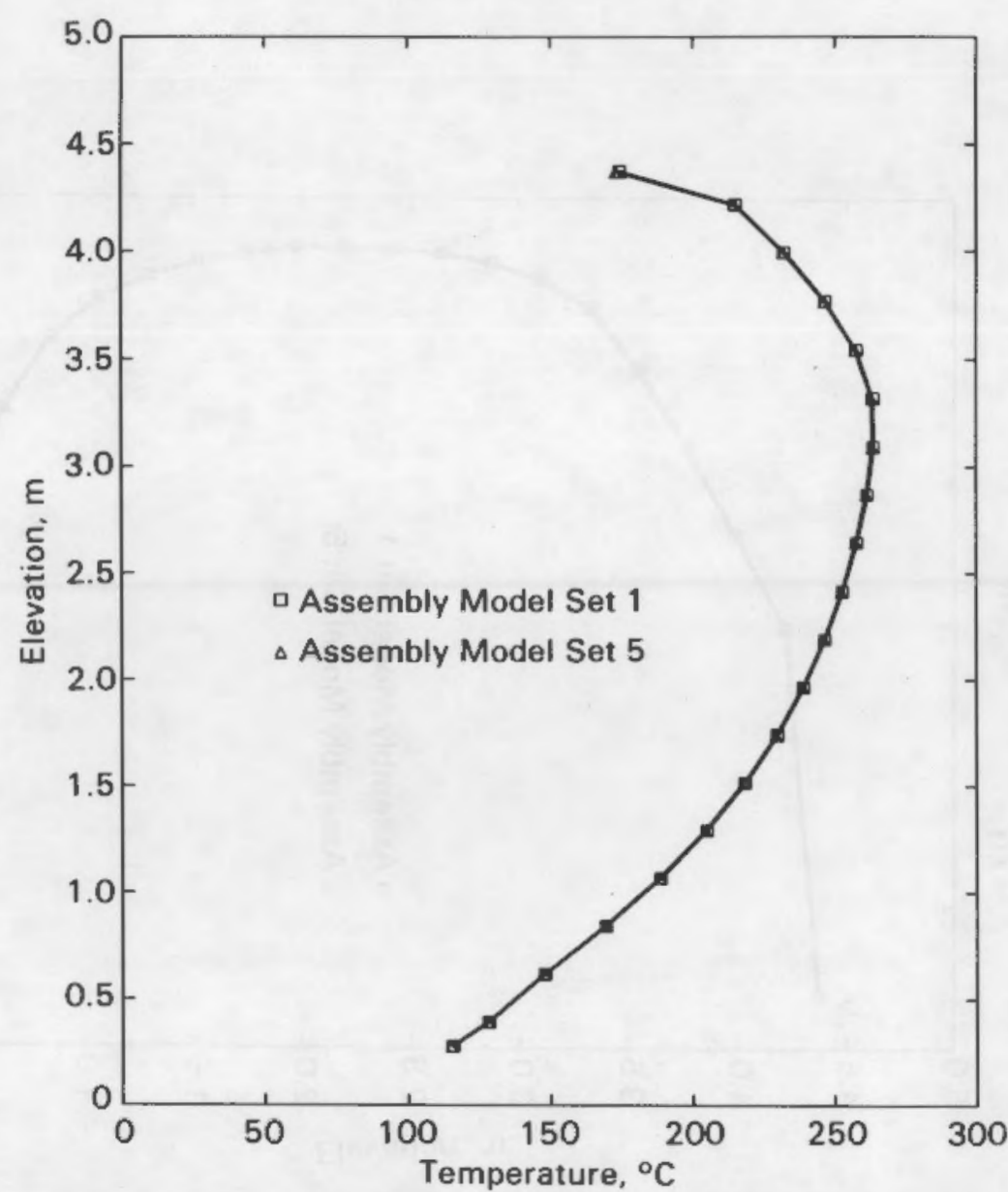

FIGURE 4.37. Axial Temperature Profiles of COBRA-SFS Predictions for Assembly Model Sets \#5 and \#1 for the TN-24P Spent-Fuel Cask, Nitrogen Backfill Case 


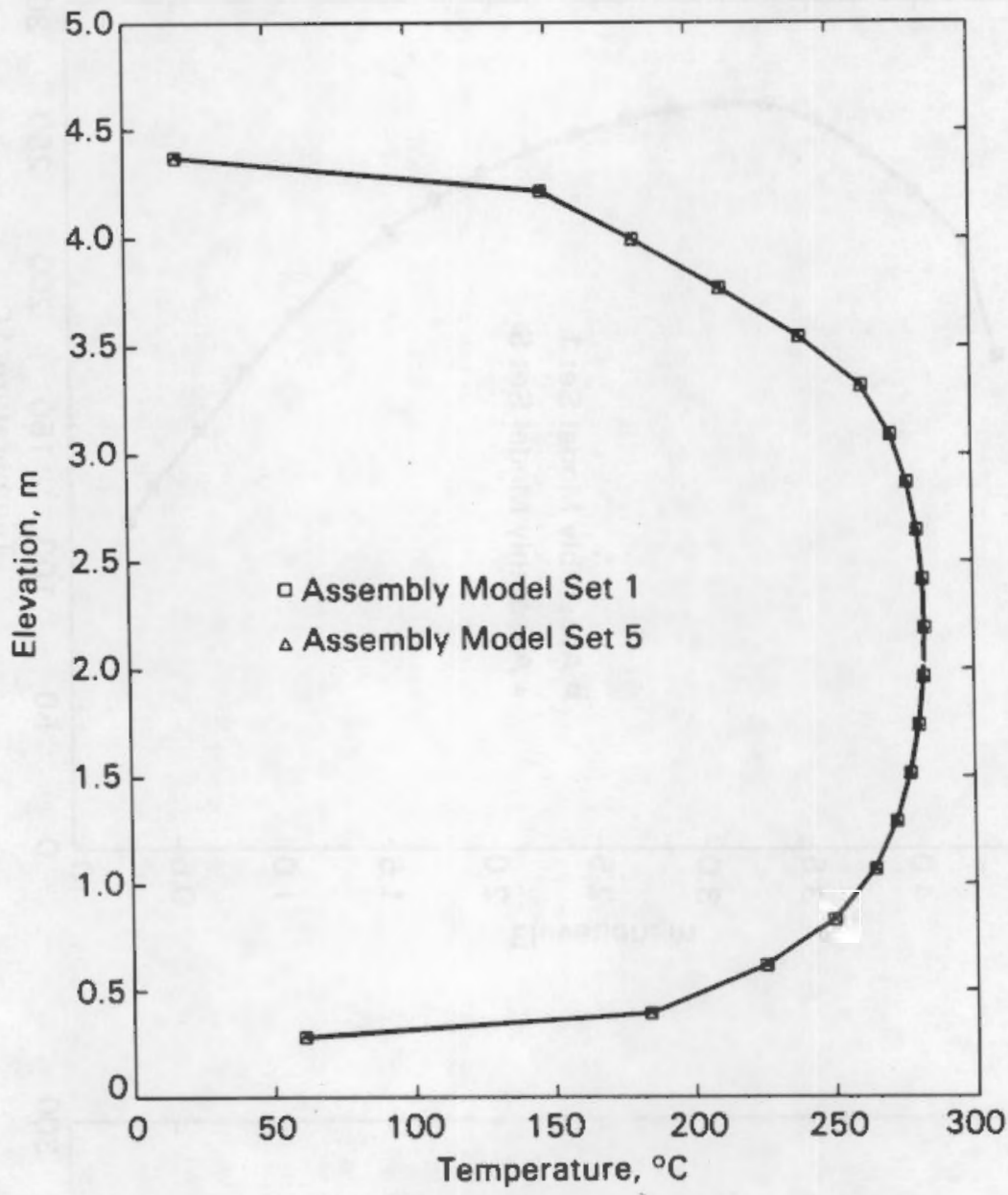

FIGURE 4.38. Axial Temperature Profiles of COBRA-SFS Predictions for Assembly Model Sets \#5 and \#1 for the TN-24P Spent-Fuel Cask, Vacuum Backfill Case 


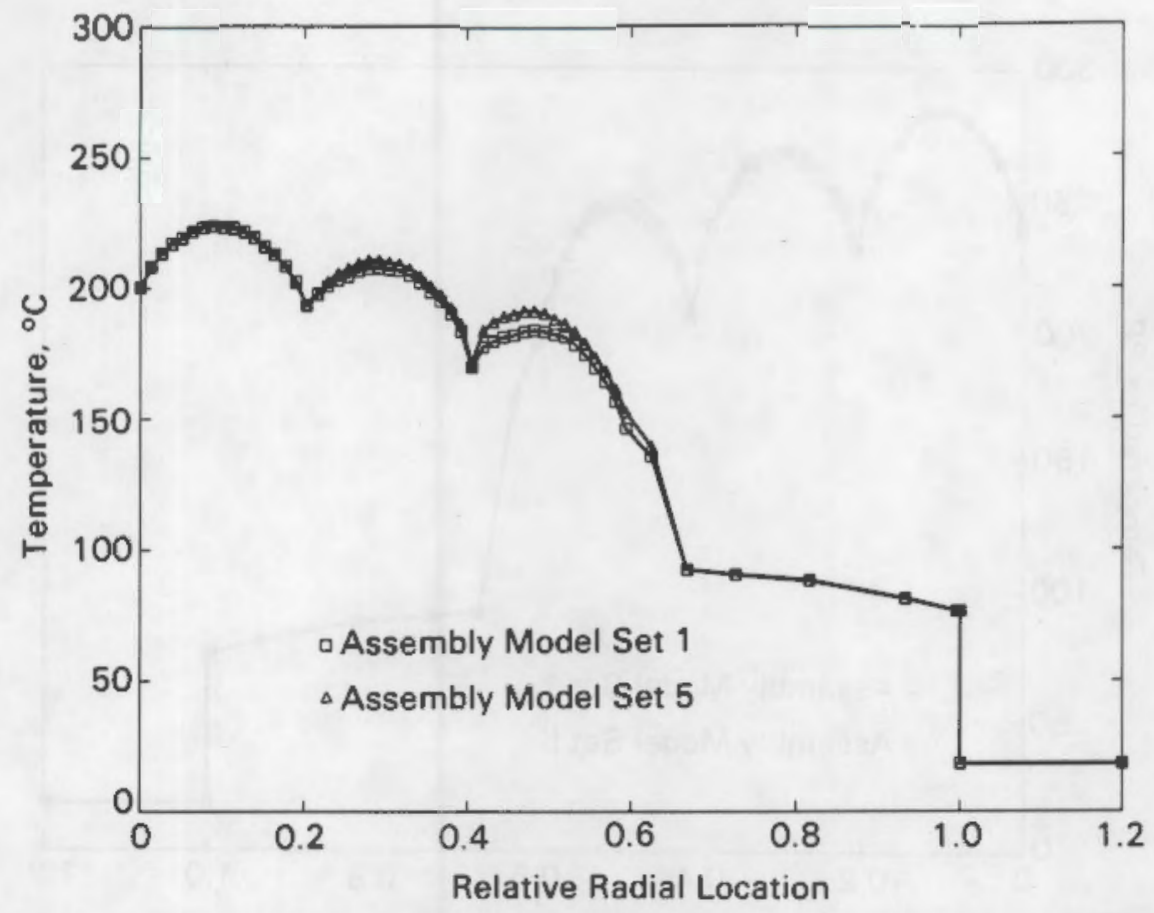

FIGURE 4.39. Radial Temperature Profiles of COBRA-SFS Predictions for Assembly Model Sets \#5 and \#1 for the TN-24P Spent-Fuel Cask, Helium Backfill Case

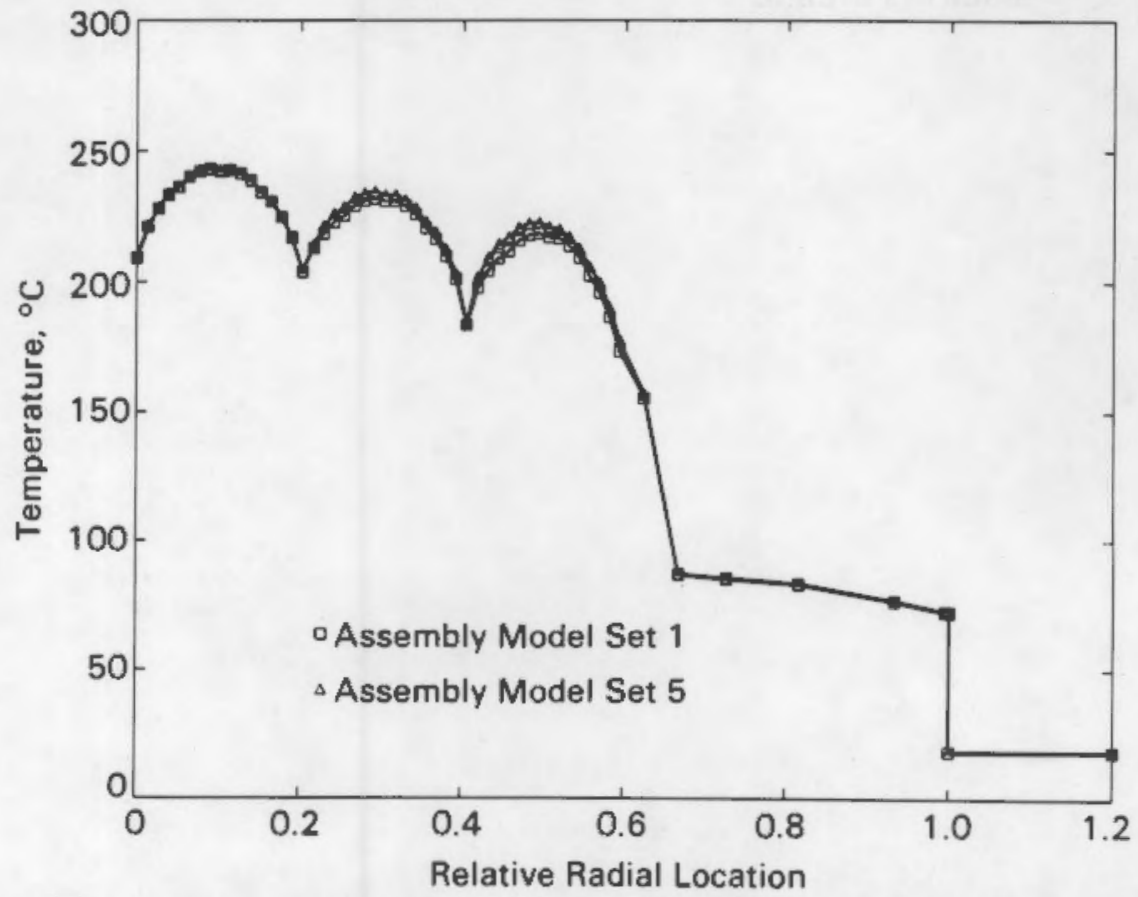

FIGURE 4.40. Radial Temperature Profiles of COBRA-SFS Predictions for Assembly Model Sets \#5 and \#1 for the TN-24P Spent-Fuel Cask, Nitrogen Backfill Case 


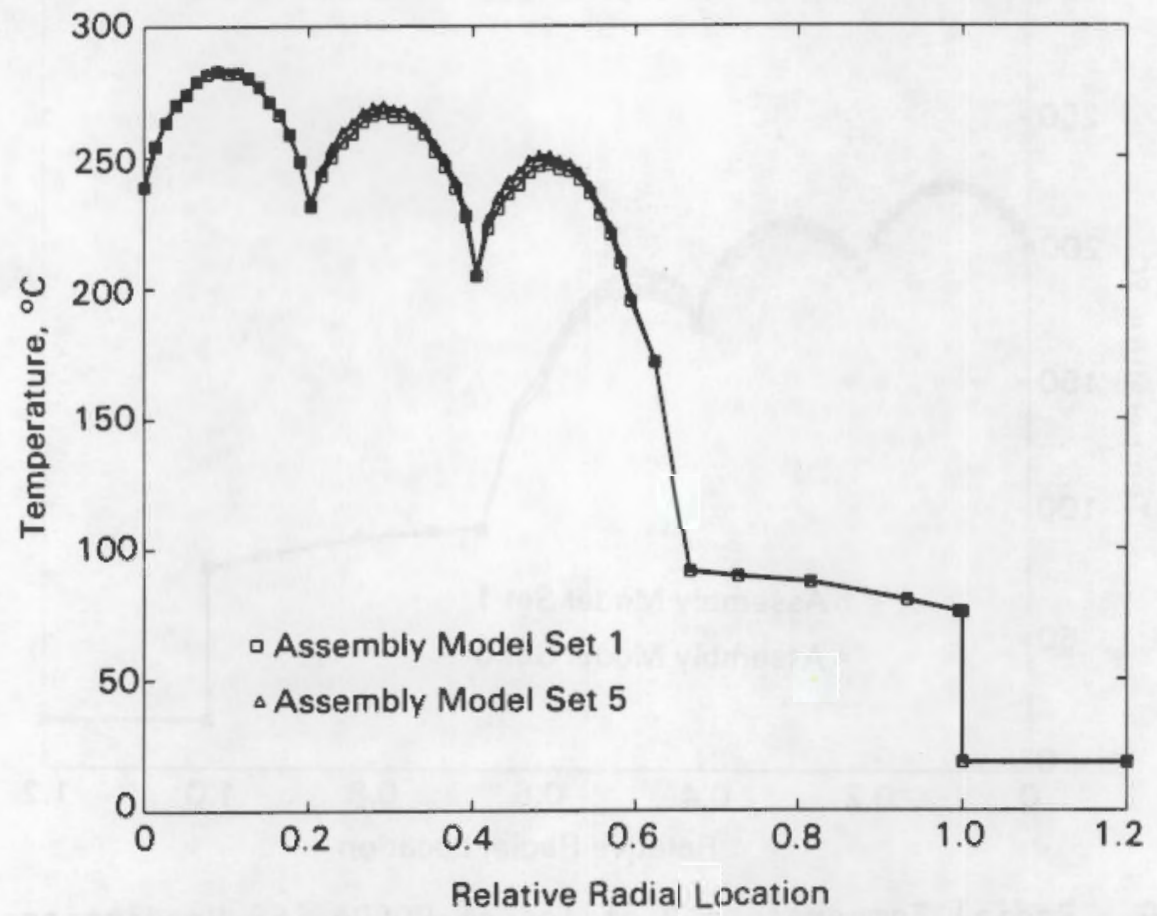

FIGURE 4.41. Radial Temperature Profiles of COBRA-SFS Predictions for Assembly Model Sets \#5 and \#1 for the TN-24P Spent-Fuel Cask, Vacuum Backfill Case 


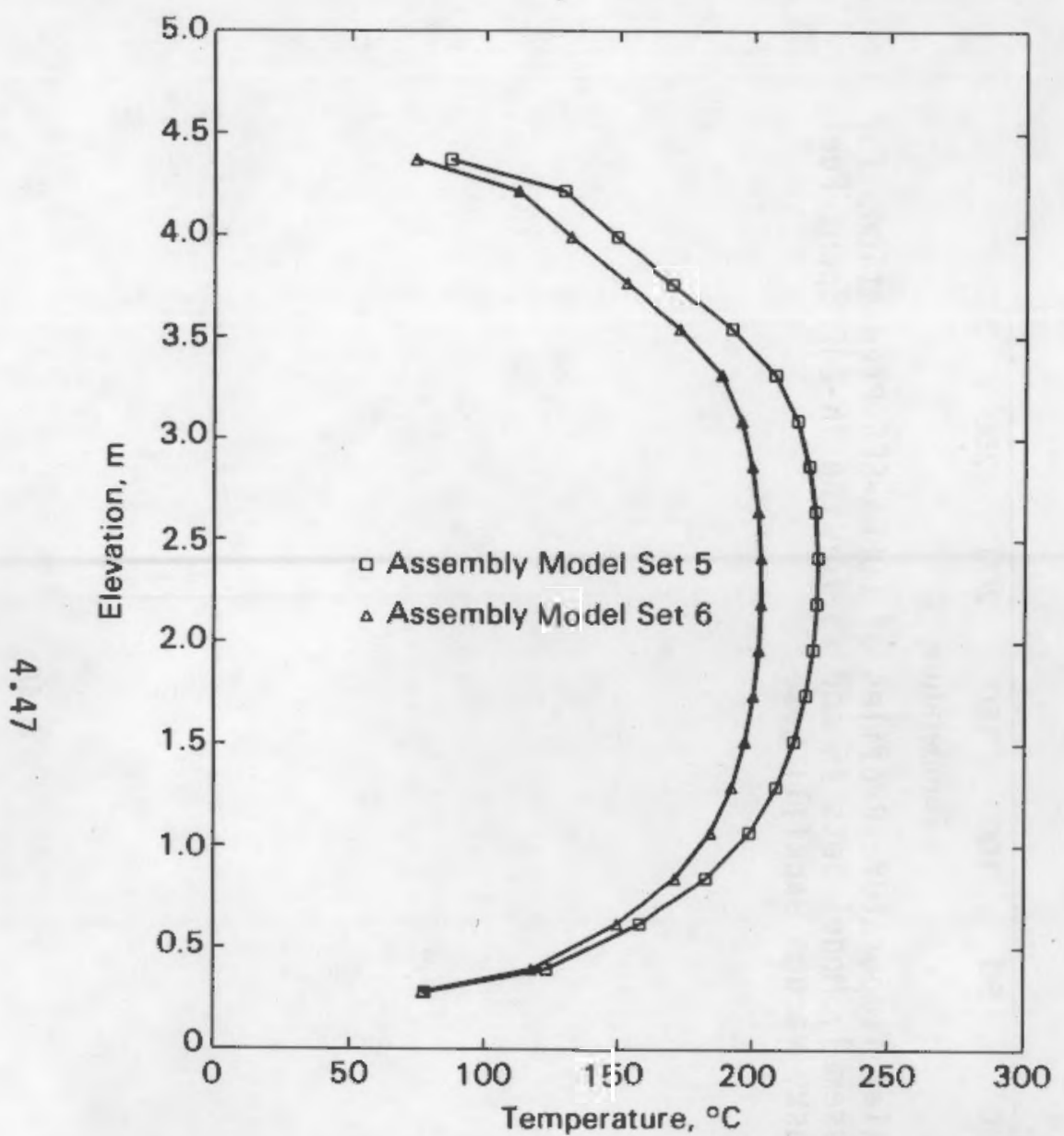

FIGURE 4.42. Axial Temperature Profiles of COBRA-SFS Predictions for Assembly Model Sets \#6 and \#5 for the TN-24P Spent-Fuel Cask, Helium Backfill Case

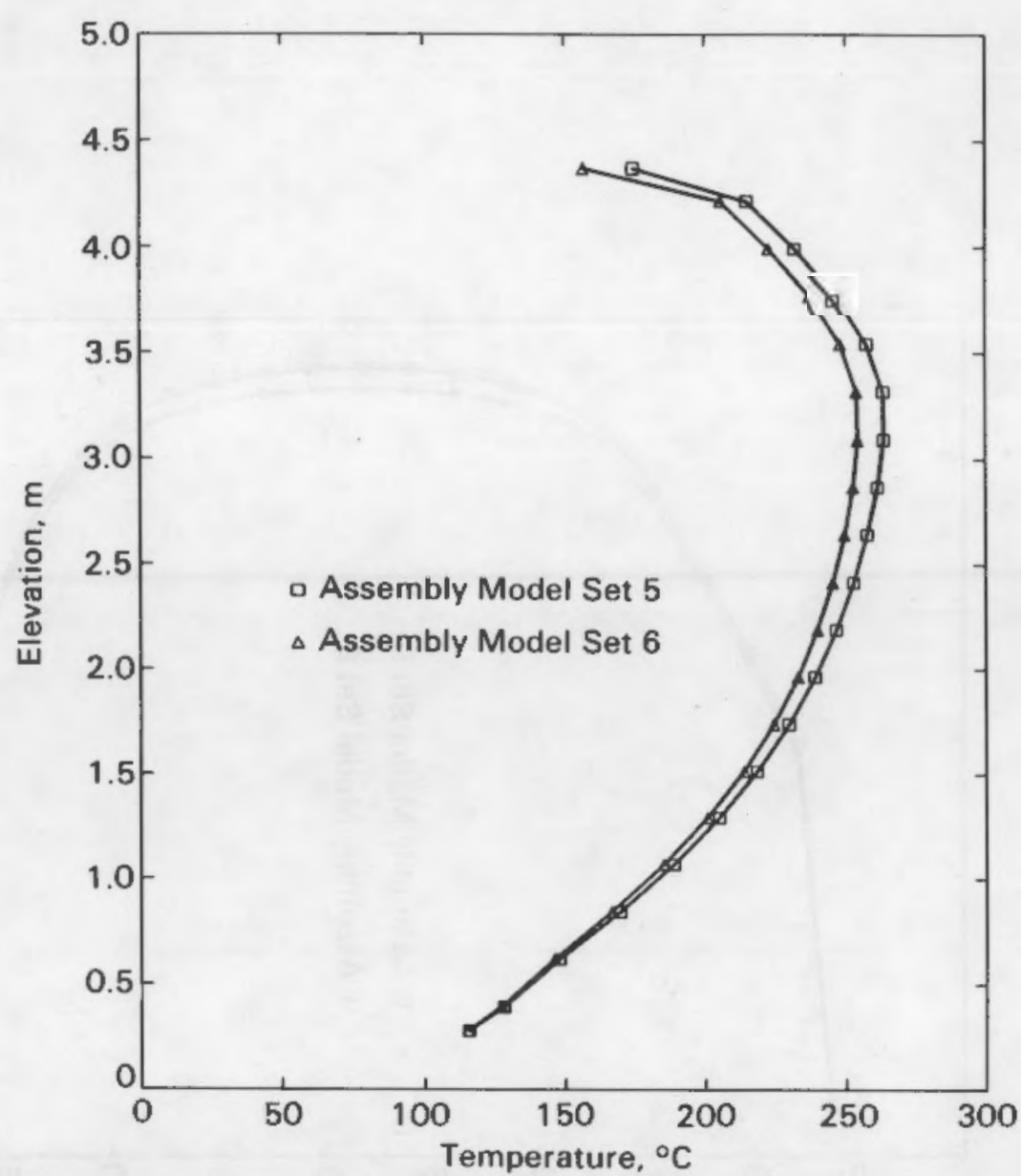

FIGURE 4.43. Axial Temperature Profiles of COBRA-SFS Predictions for Assembly Model Sets \#6 and \#5 for the TN-24P Spent-Fuel Cask, Nitrogen Backfill Case 


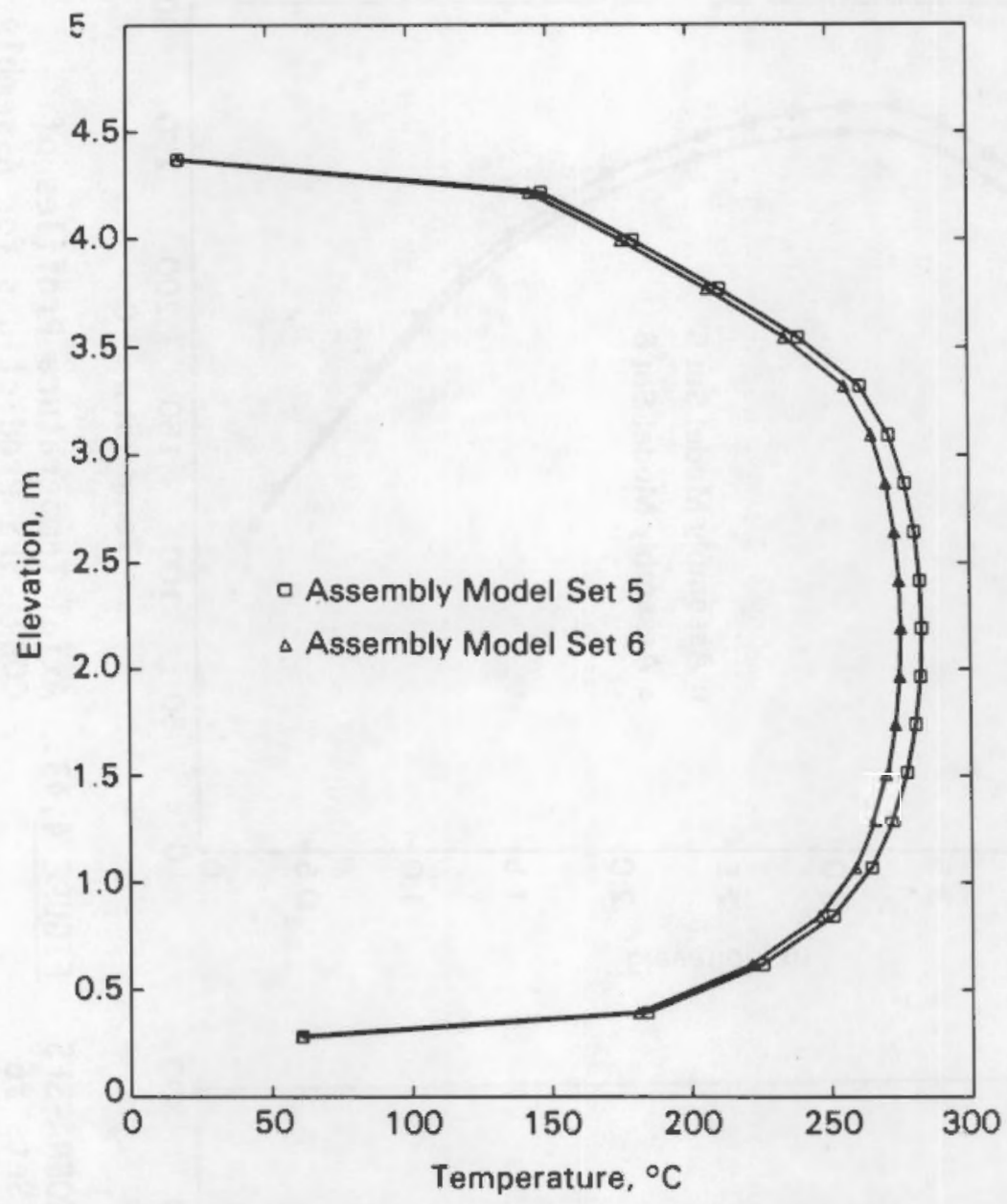

FIGURE 4.44. Axial Temperature Profiles of COBRA-SFS Predictions for Assembly Model Sets \#6 and \#5 for the TN-24P Spent-Fuel Cask, Vacuum Backfill Case 


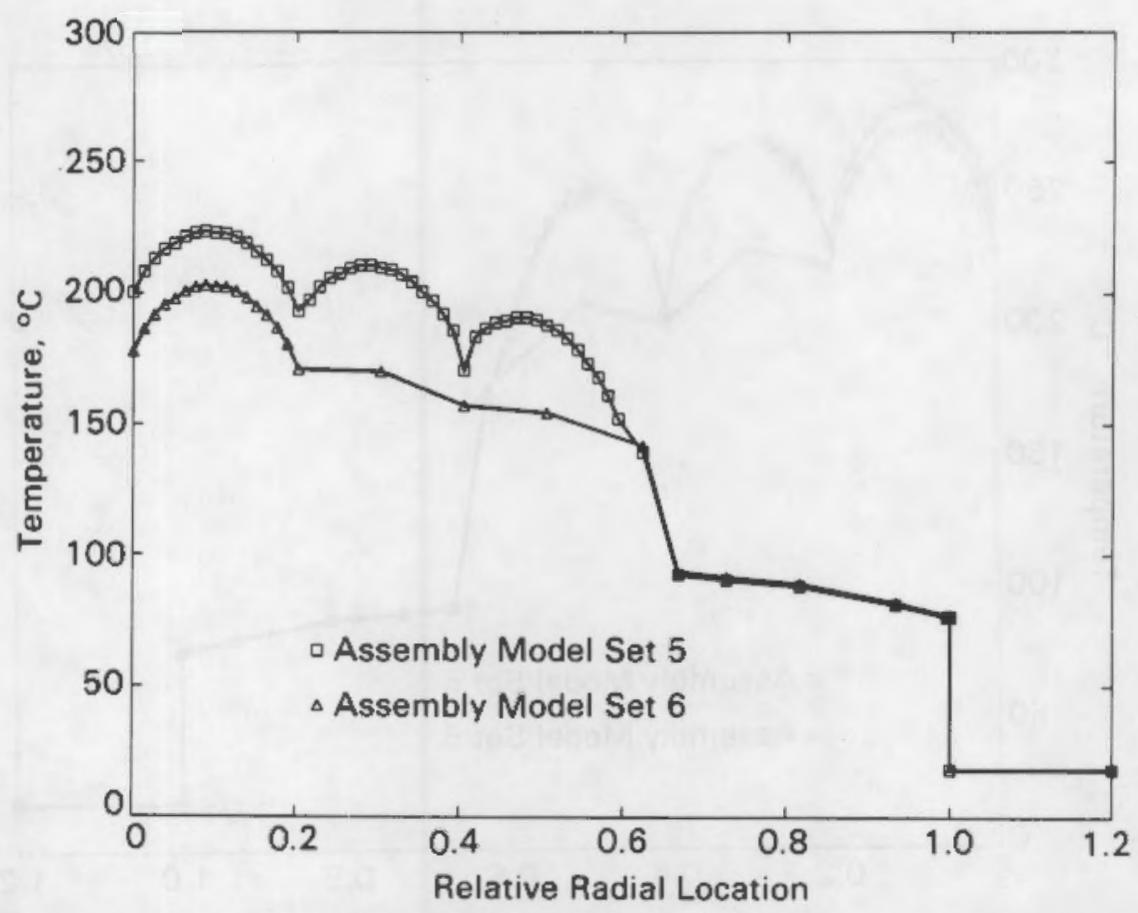

FIGURE 4.45. Radial Temperature Profiles of COBRA-SFS Predictions for Assembly Model Sets \#6 and \#5 for the TN-24P Spent-Fuel Cask, Helium Backfill Case

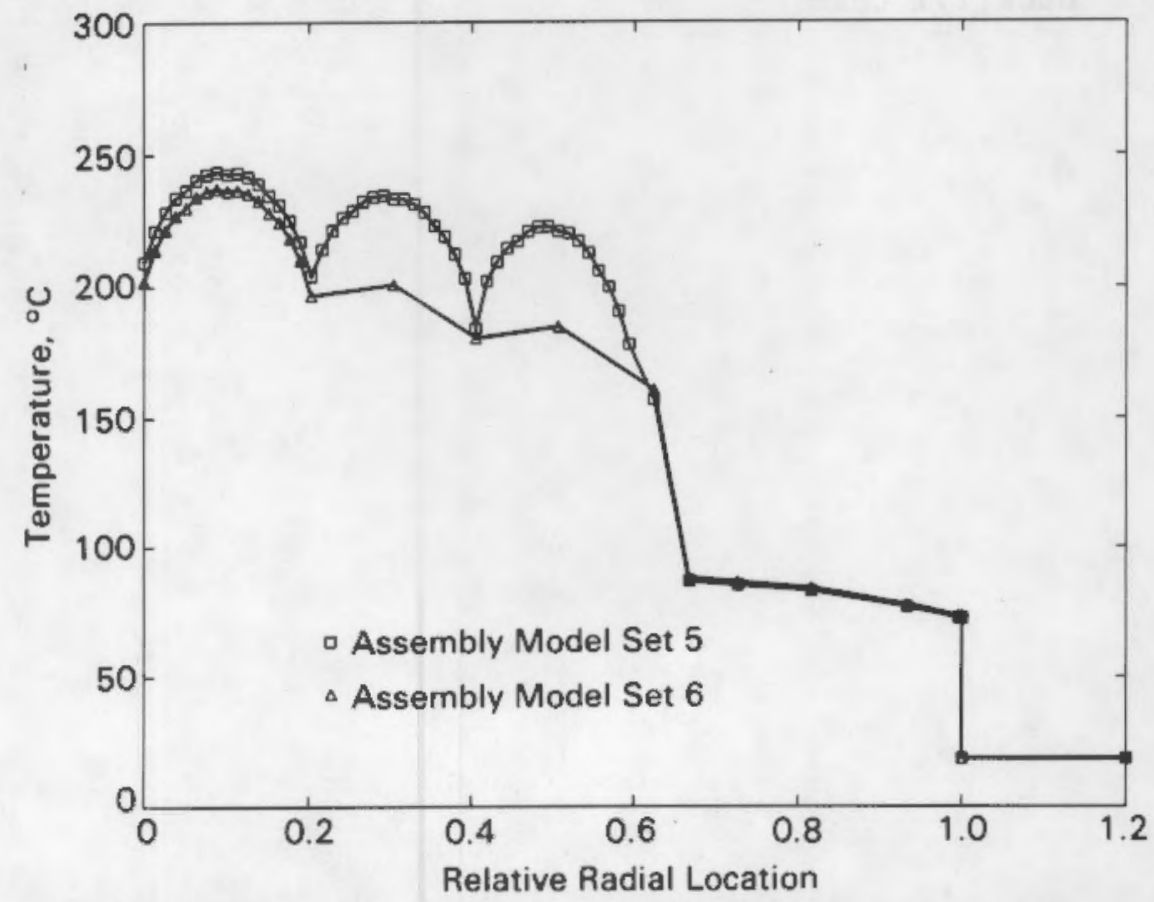

FIGURE 4.46. Radial Temperature Profiles of COBRA-SFS Predictions for Assembly Model Sets \#6 and \#5 for the TN-24P Spent-Fuel Cask, Nitrogen Backfill Case 


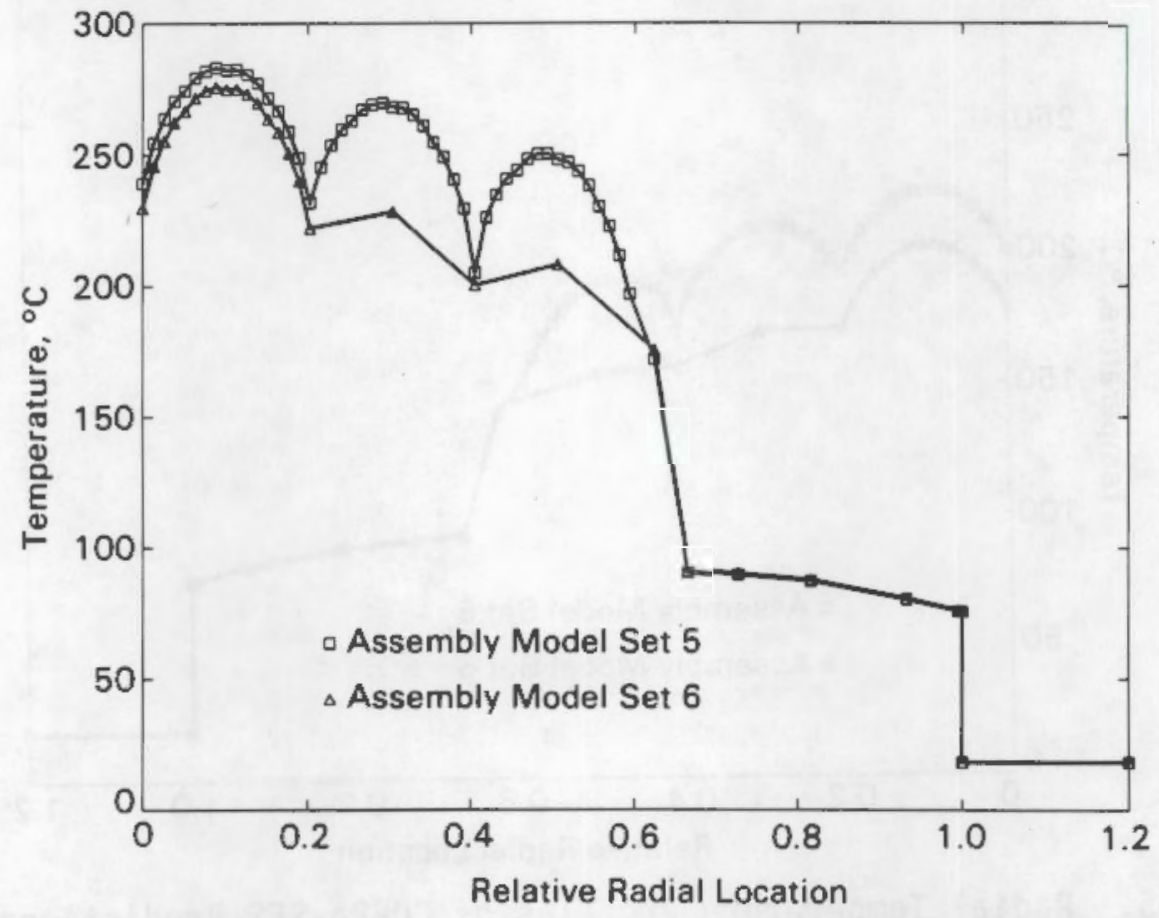

FIGURE 4.47. Radial Temperature Profiles of COBRA-SFS Predictions for Assembly Model Sets \#6 and \#5 for the TN-24P Spent-Fuel Cask, Vacuum Backfill Case 


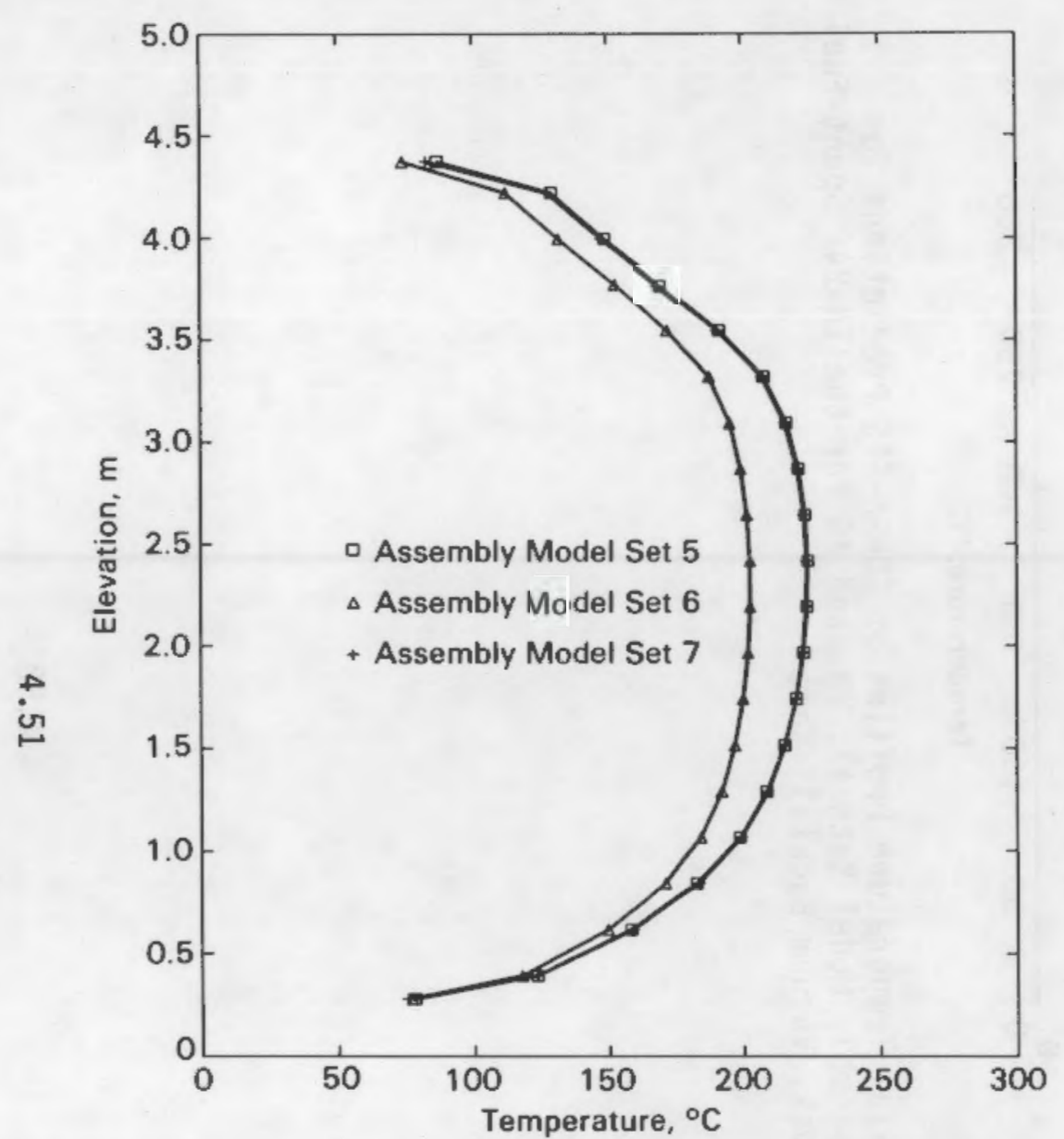

FIGURE 4.48. Axial Temperature Profiles of COBRA-SFS Predictions for Assembly Model Sets \#7, $\# 6$, and \#5 for the TN-24P Spent-Fuel Cask, Helium Backfill Case

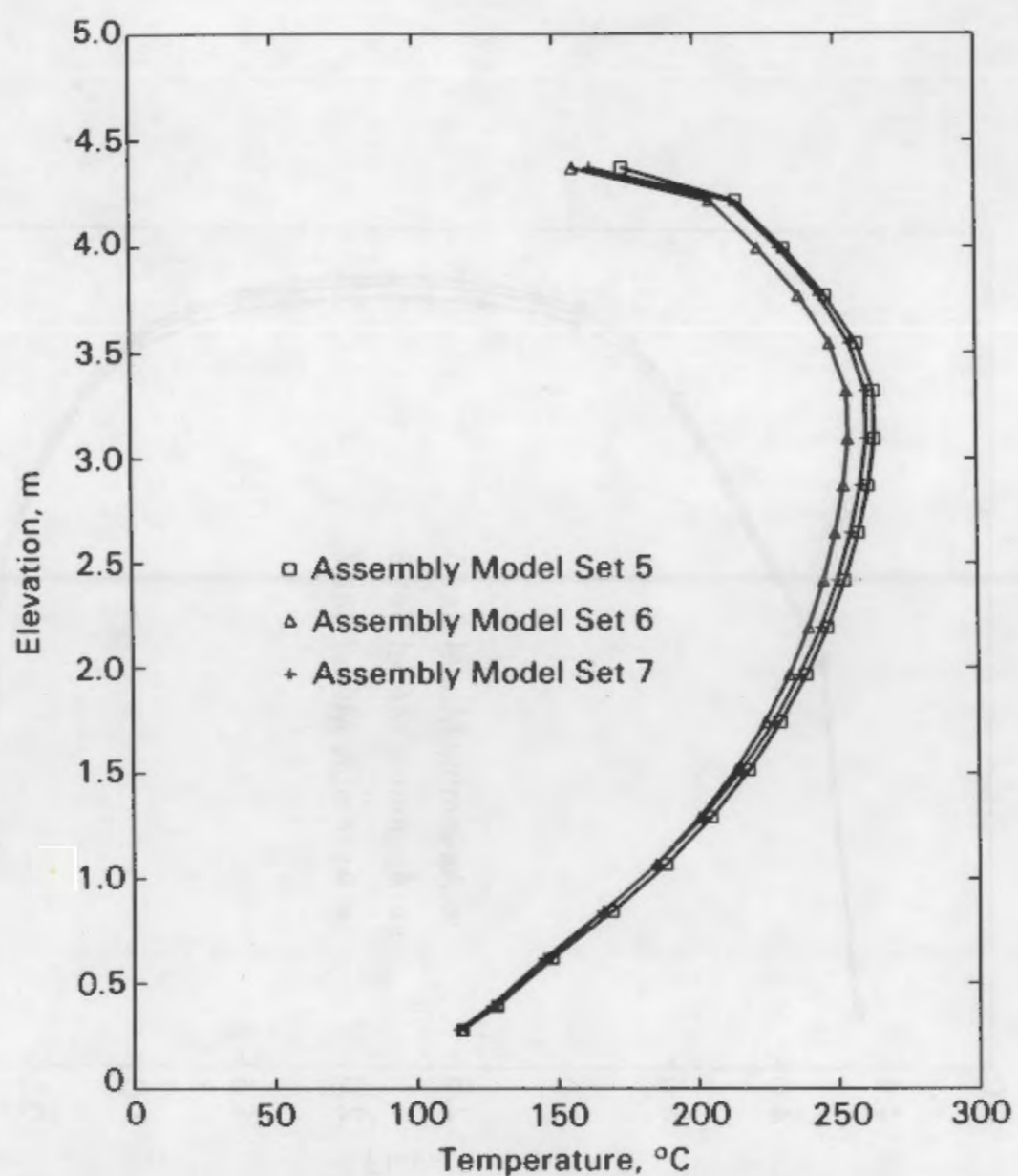

FIGURE 4.49. Axial Temperature Profiles of COBRA-SFS Predictions for Assembly Model Sets $\# 7, \# 6$, and $\# 5$ for the TN-24P Spent-Fuel Cask, Nitrogen Backfill Case 


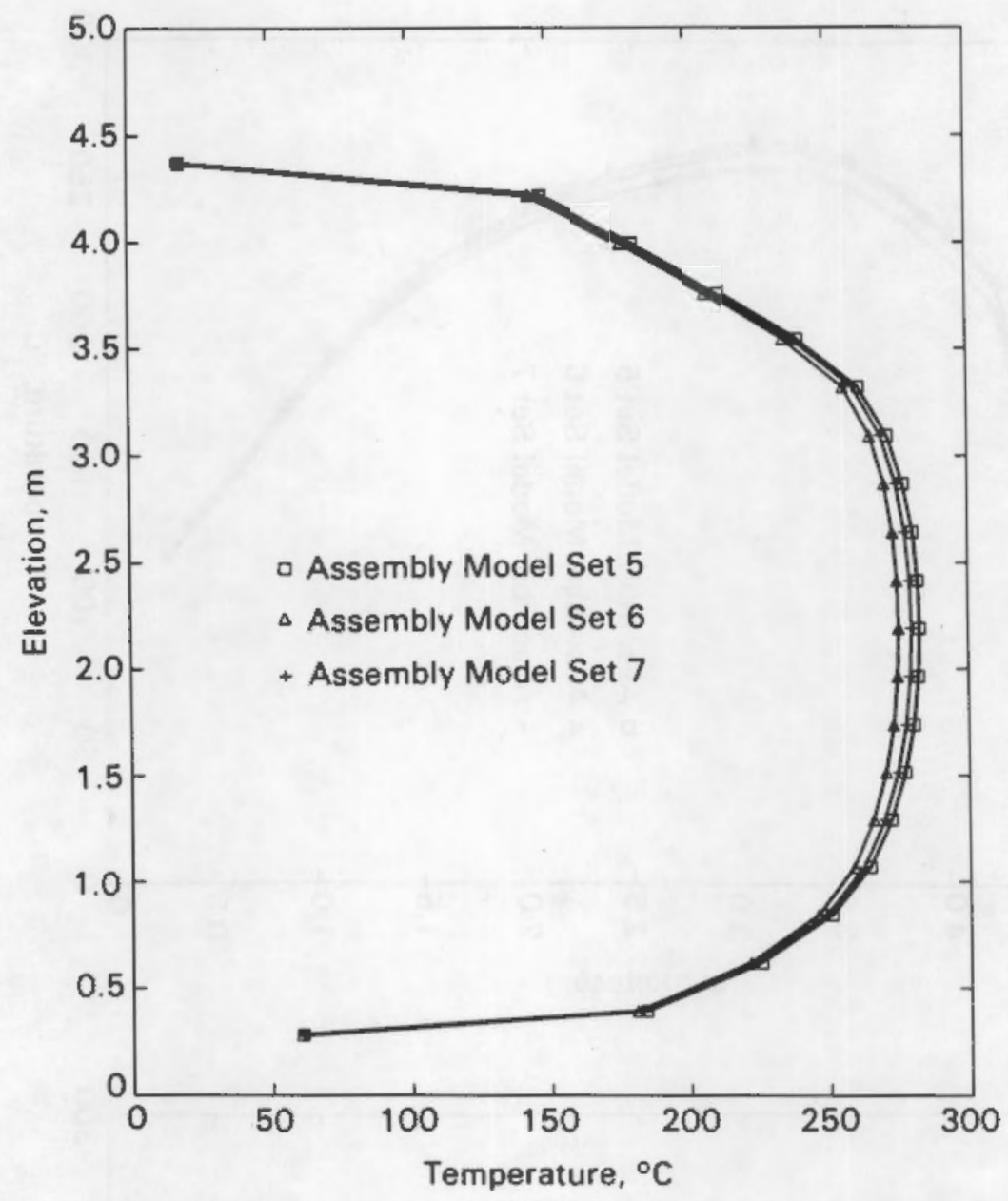

FIGURE 4.50. Axial Temperature Profiles of COBRA-SFS Predictions for Assembly Model Sets \#7, \#6, and \#5 for the TN-24P Spent-Fuel Cask, Vacuum Backfill Case 


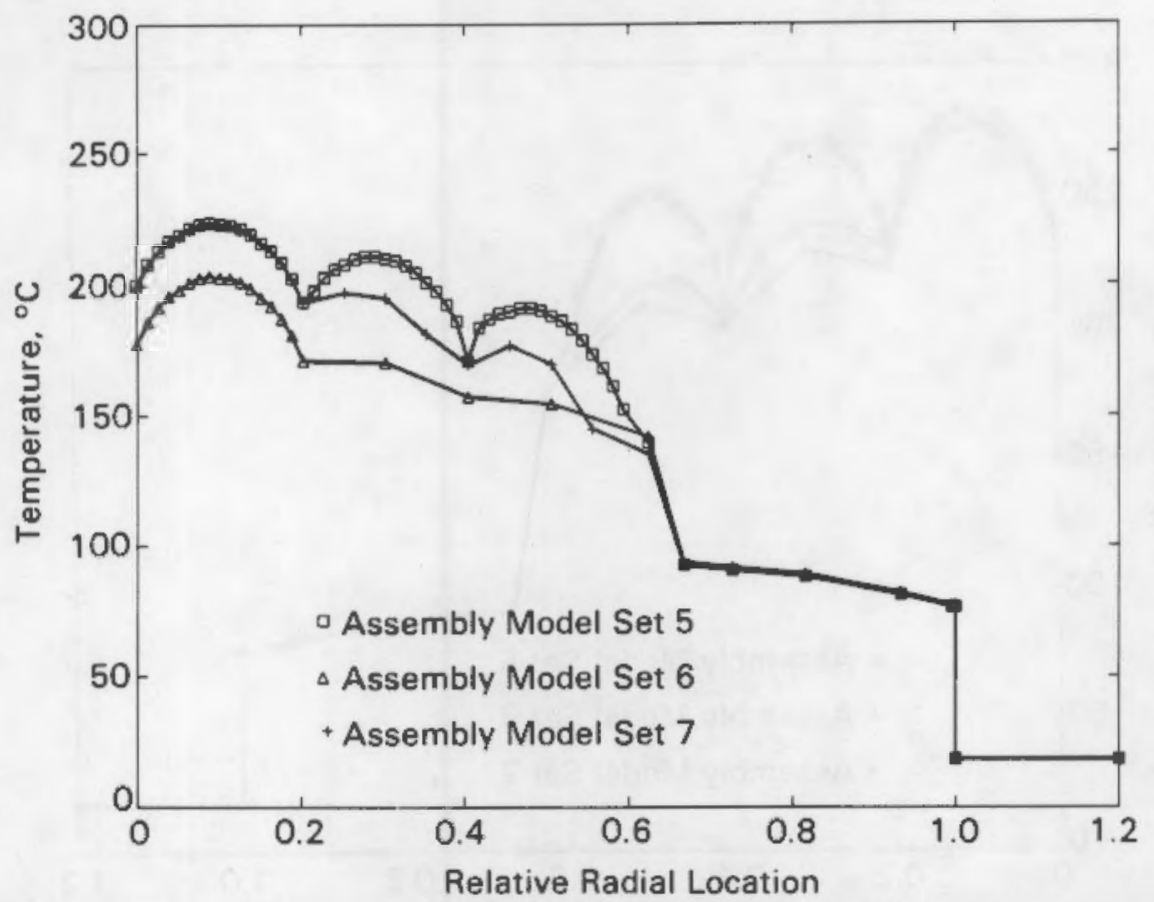

FIGURE 4.51. Radial Temperature Profiles of COBRA-SFS Predictions for Assembly Model Sets \#7, \#6, and \#5 for the TN-24P Spent-Fuel Cask, Helium Backfill Case

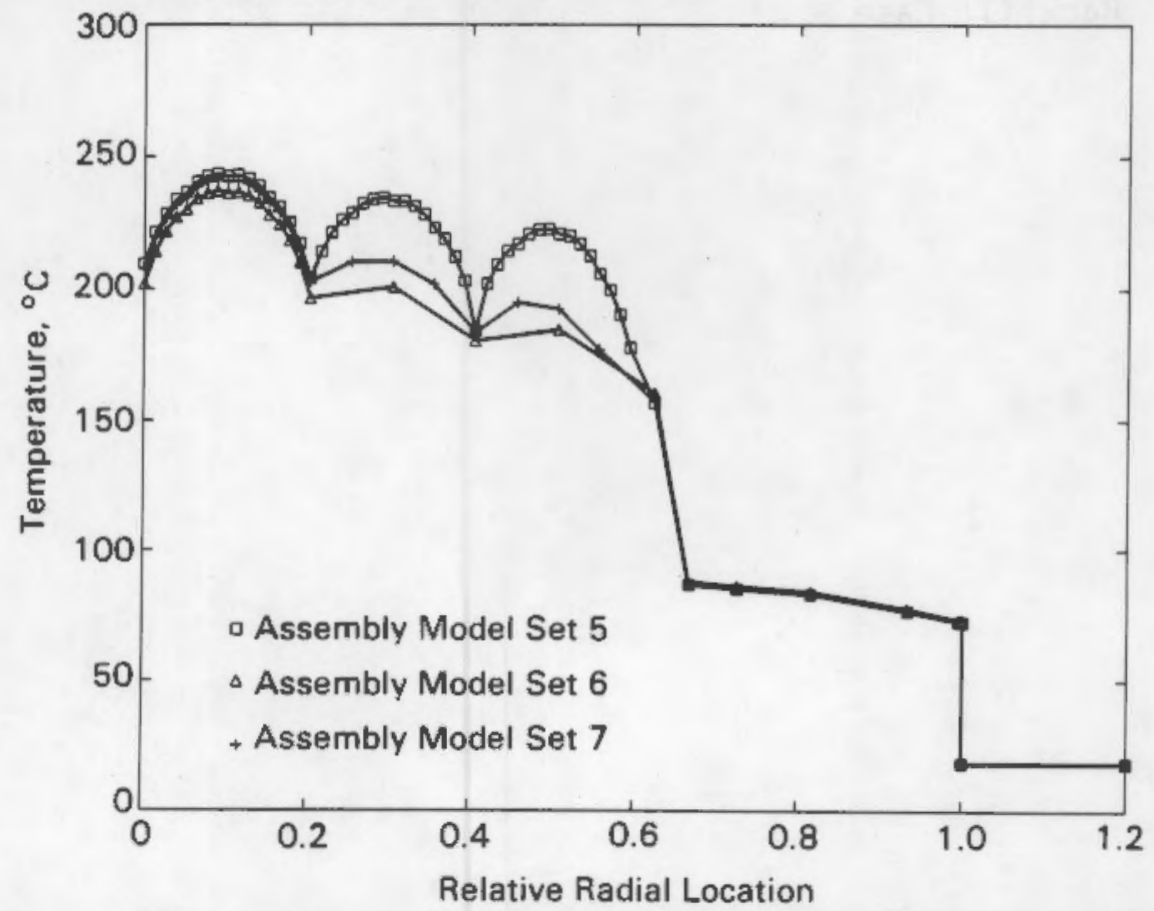

FIGURE 4.52. Radial Temperature Profiles of COBRA-SFS Predictions for Assembly Model Sets \#7, \#6, and \#5 for the TN-24P Spent-Fuel Cask, Nitrogen Backfill Case 


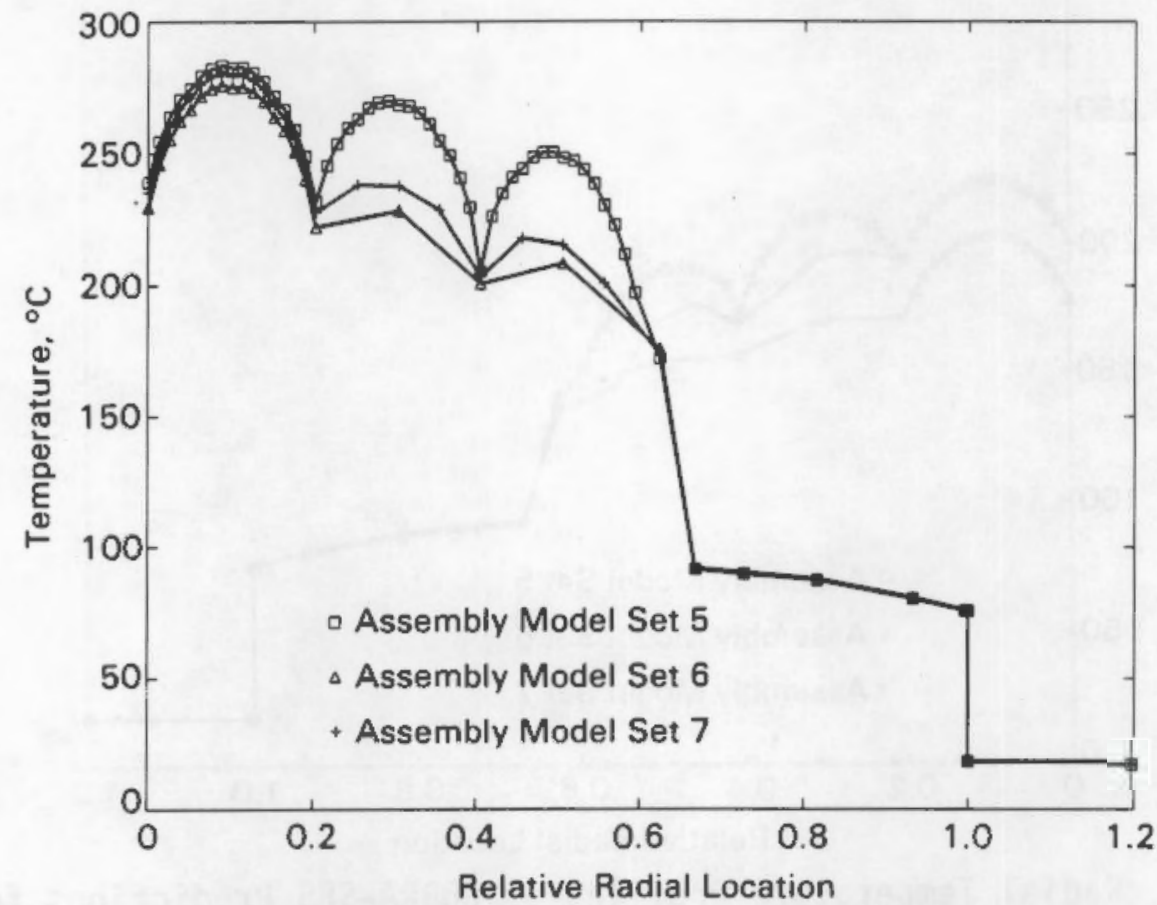

FIGURE 4.53. Radial Temperature Profiles of COBRA-SFS Predictions for Assembly Model Sets \#7, \#6, and \#5 for the TN-24P Spent-Fuel Cask, Vacuum Backfill Case 


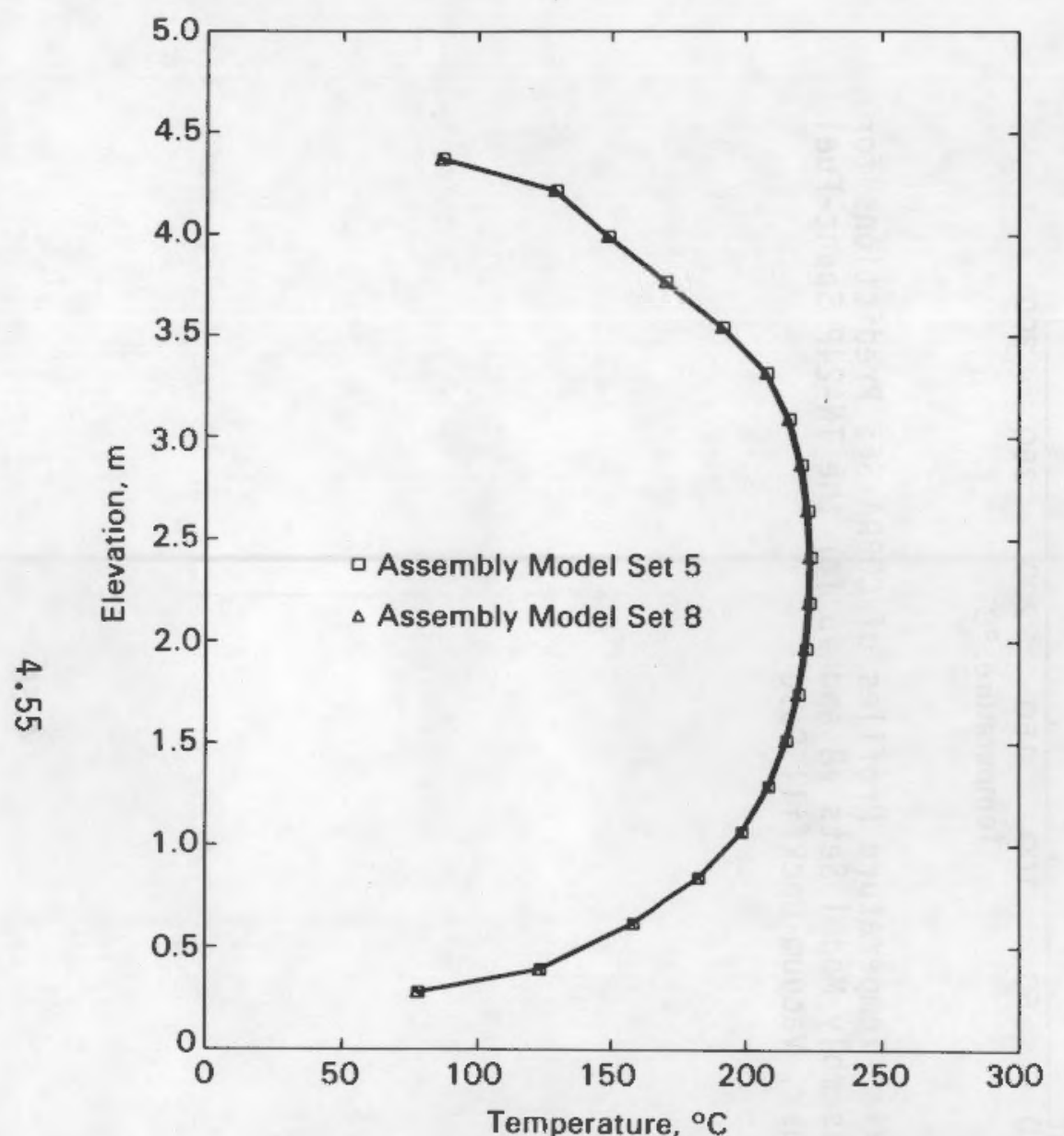

FIGURE 4.54. Axial Temperature Profiles of COBRA-SFS Predictions for Assembly Model Sets \#8 and \#5 for the TN-24P Spent-Fuel Cask, Helium Backfill Case

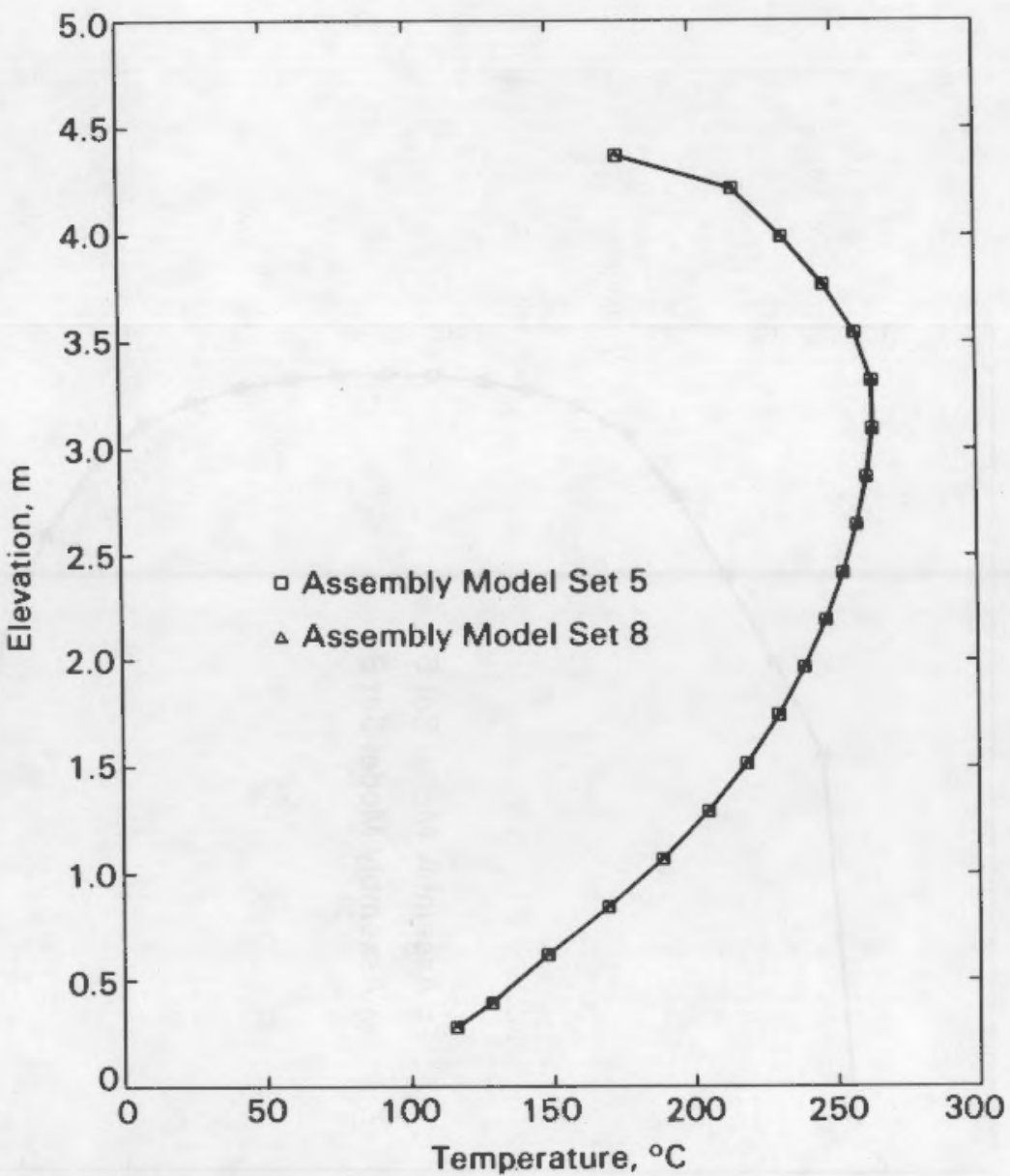

FIGURE 4.55. Axial Temperature Profiles of COBRA-SFS Predictions for Assembly Model Sets $\# 8$ and $\# 5$ for the TN-24P Spent-Fuel Cask, Nitrogen Backfill Case 


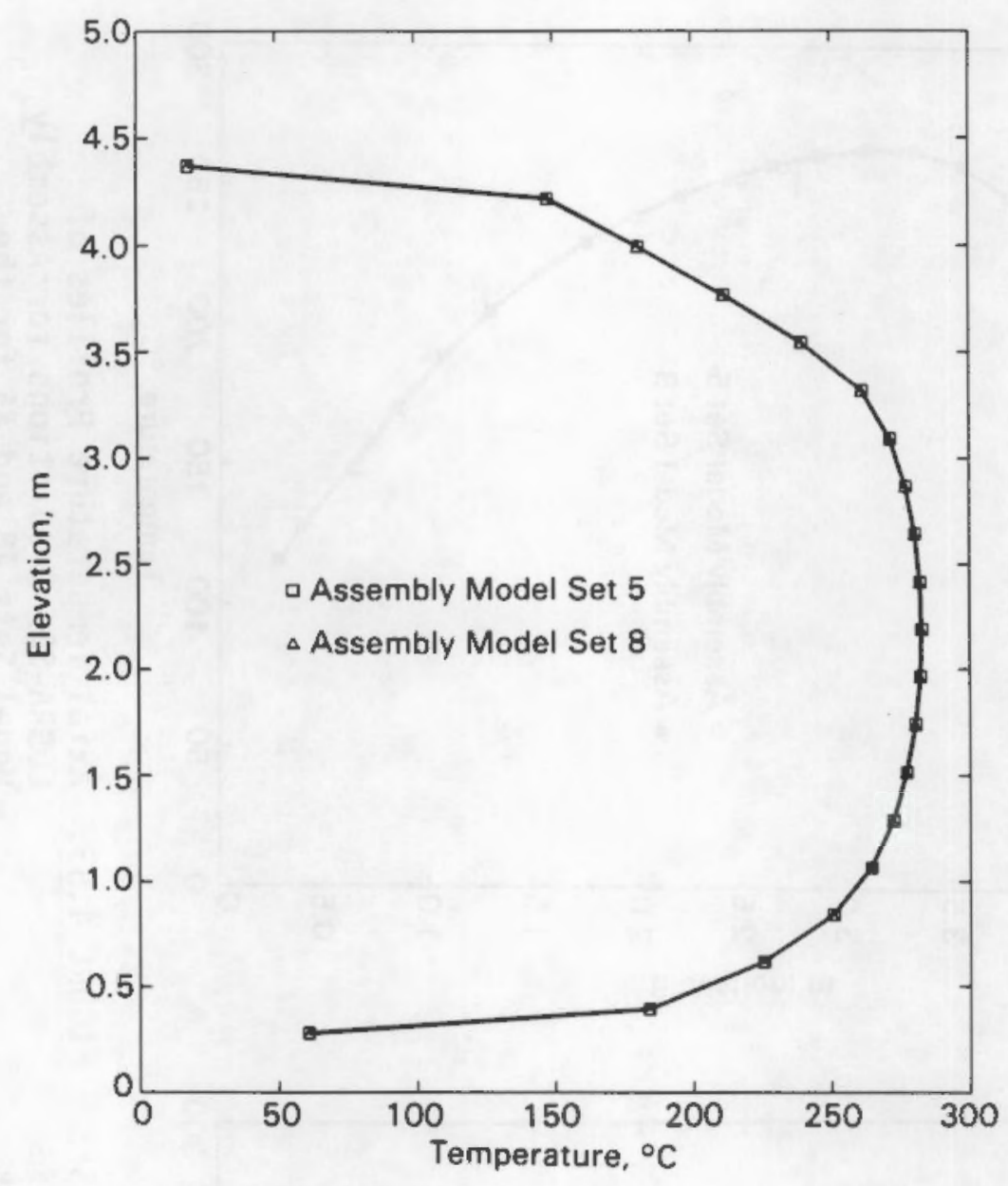

FIGURE 4.56. Axial Temperature Profiles of COBRA-SFS Predictions for Assembly Model Sets \#8 and \#5 for the TN-24P Spent-Fuel Cask, Vacuum Backfill Case 


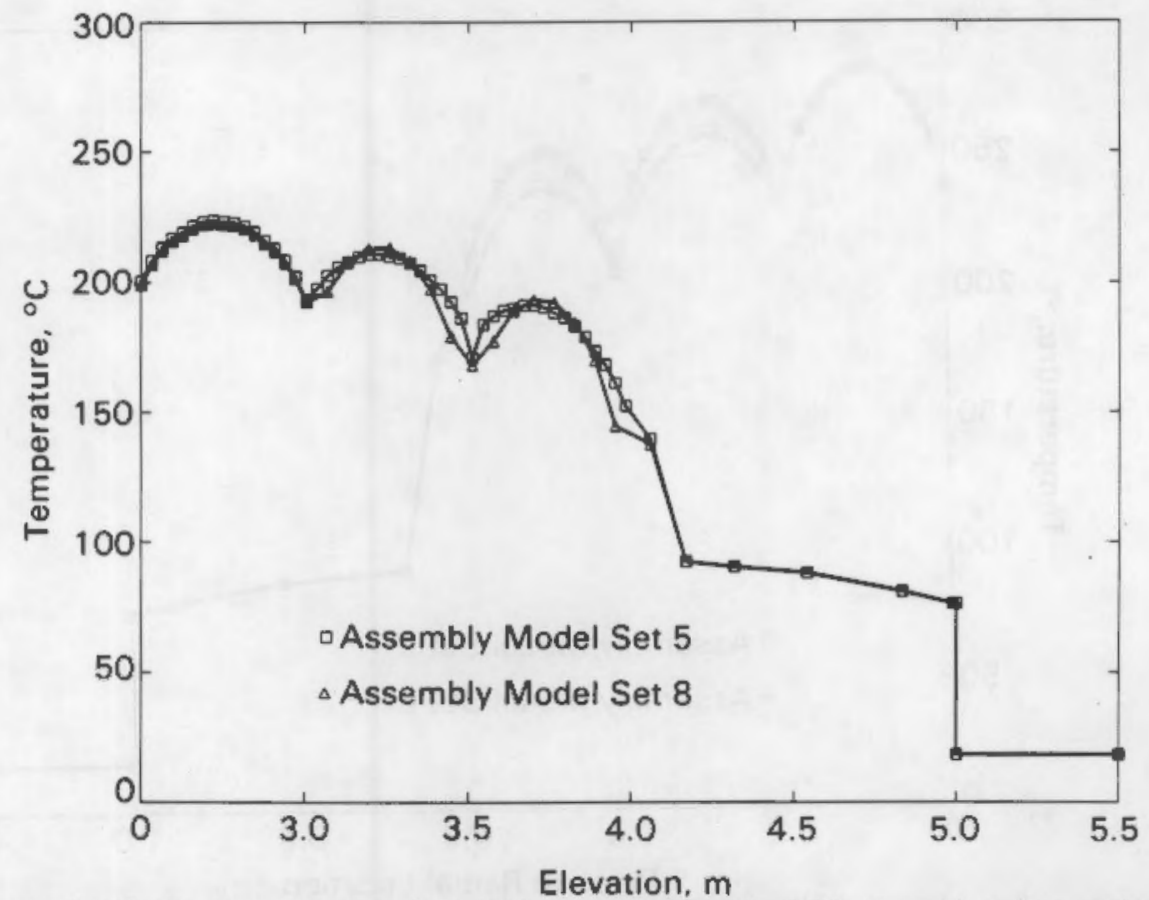

FIGURE 4.57. Radial Temperature Profiles of COBRA-SFS Predictions for Assembly Model Sets \#8 and \#5 for the TN-24P Spent-Fuel Cask, Helium Backfill Case

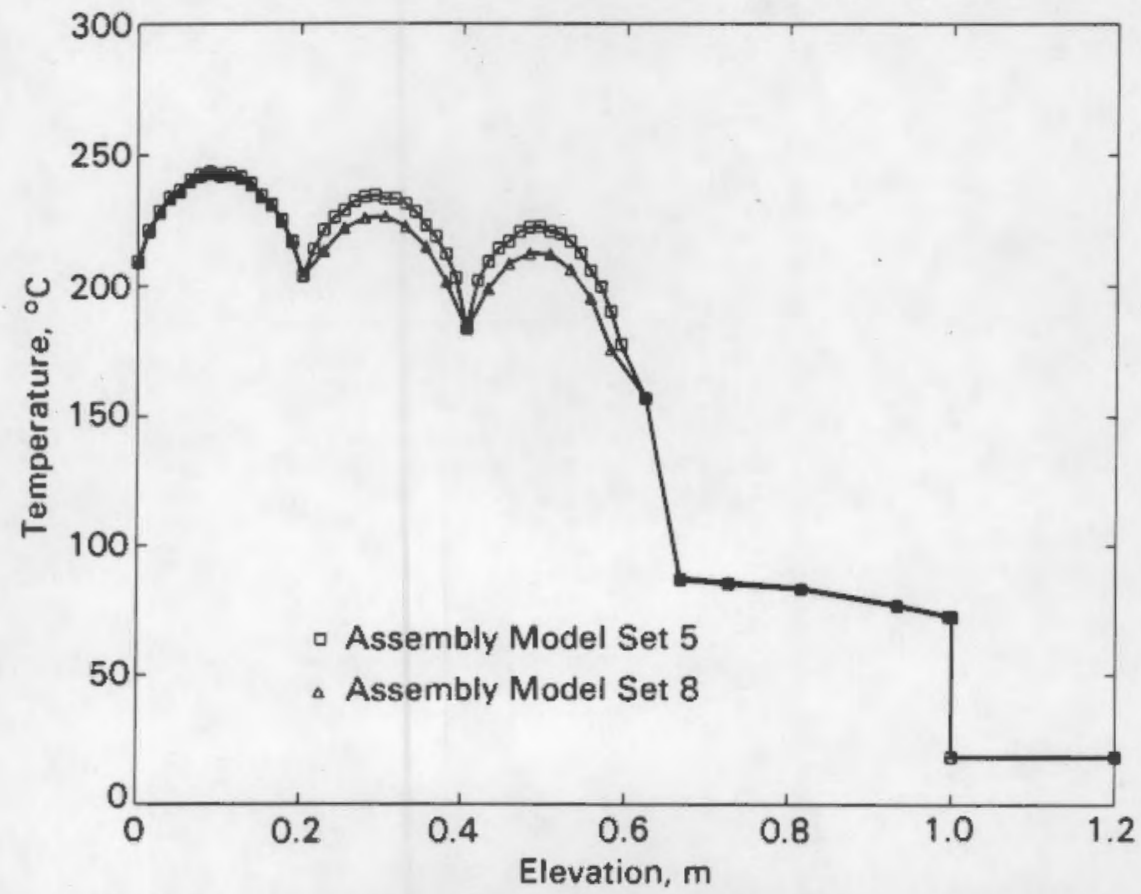

FIGURE 4.58. Radial Temperature Profiles of COBRA-SFS Predictions for Assembly Model Sets \#8 and \#5 for the TN-24P Spent-Fuel Cask, Nitrogen Backfill Case 


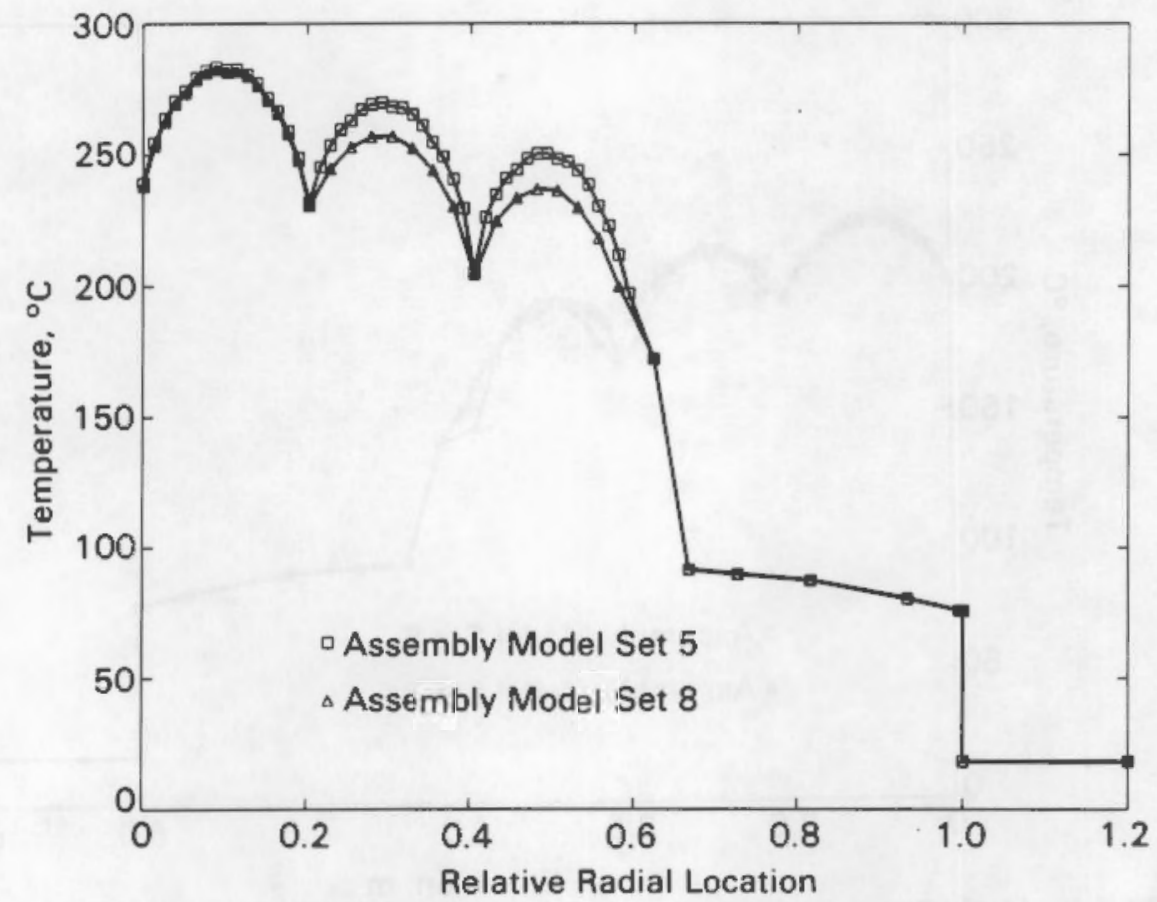

FIGURE 4.59. Radial Temperature Profiles of COBRA-SFS Predictions for Assembly Model Sets \#8 and \#5 for the TN-24P Spent-Fuel Cask, Vacuum Backfill Case 


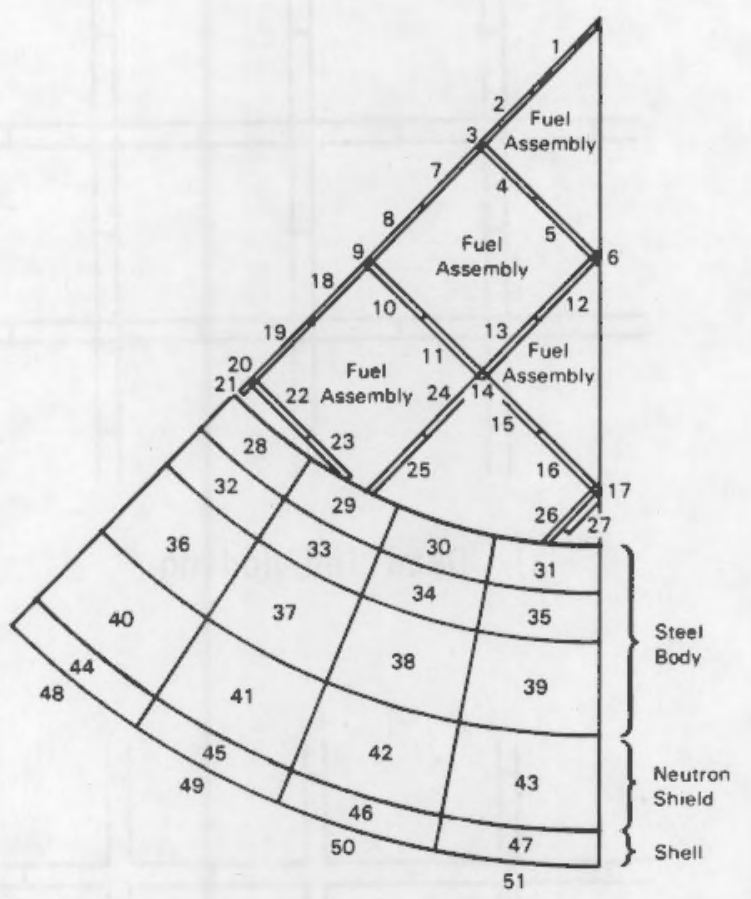

FIGURE 4.60. TN-24P Solid Structure Noding

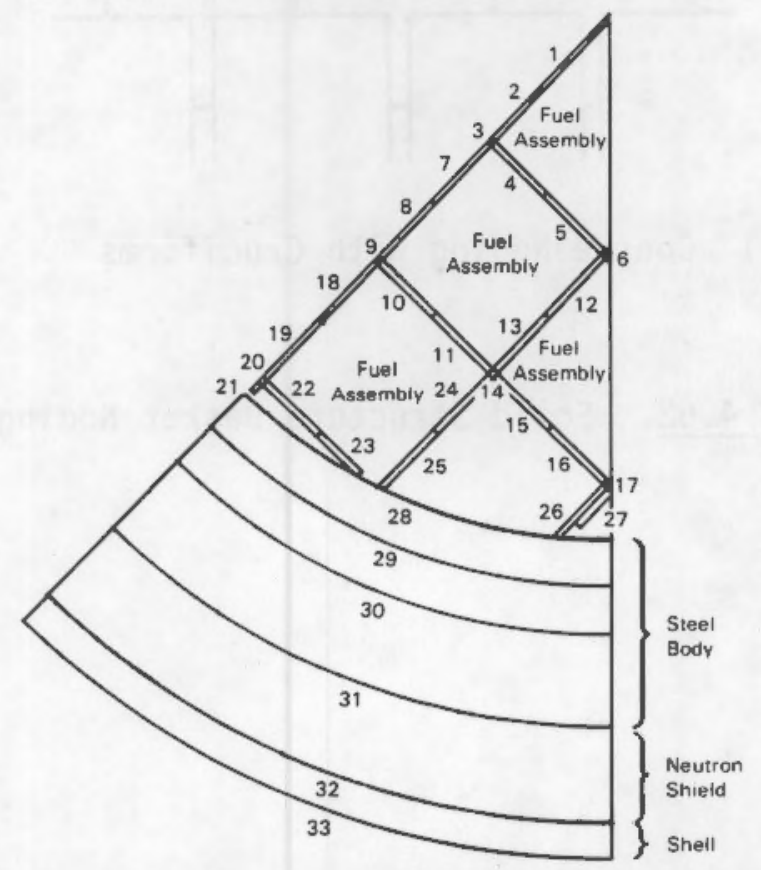

FIGURE 4.61. TN-24P Model with Reduced Shell Noding 


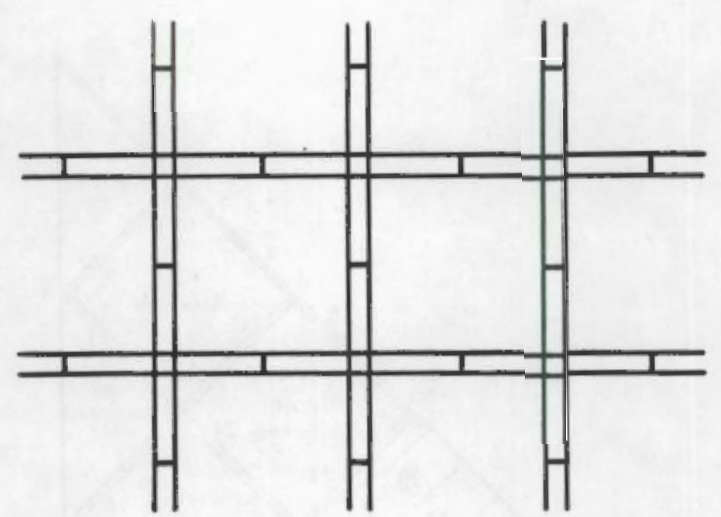

a) Detailed Noding

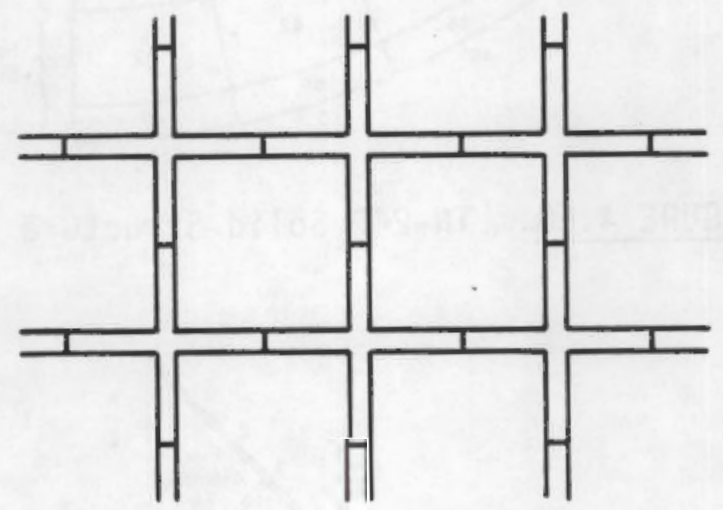

b) Coarse Noding with Cruciforms

FIGURE 4.62. Solid Structure Basket Noding 


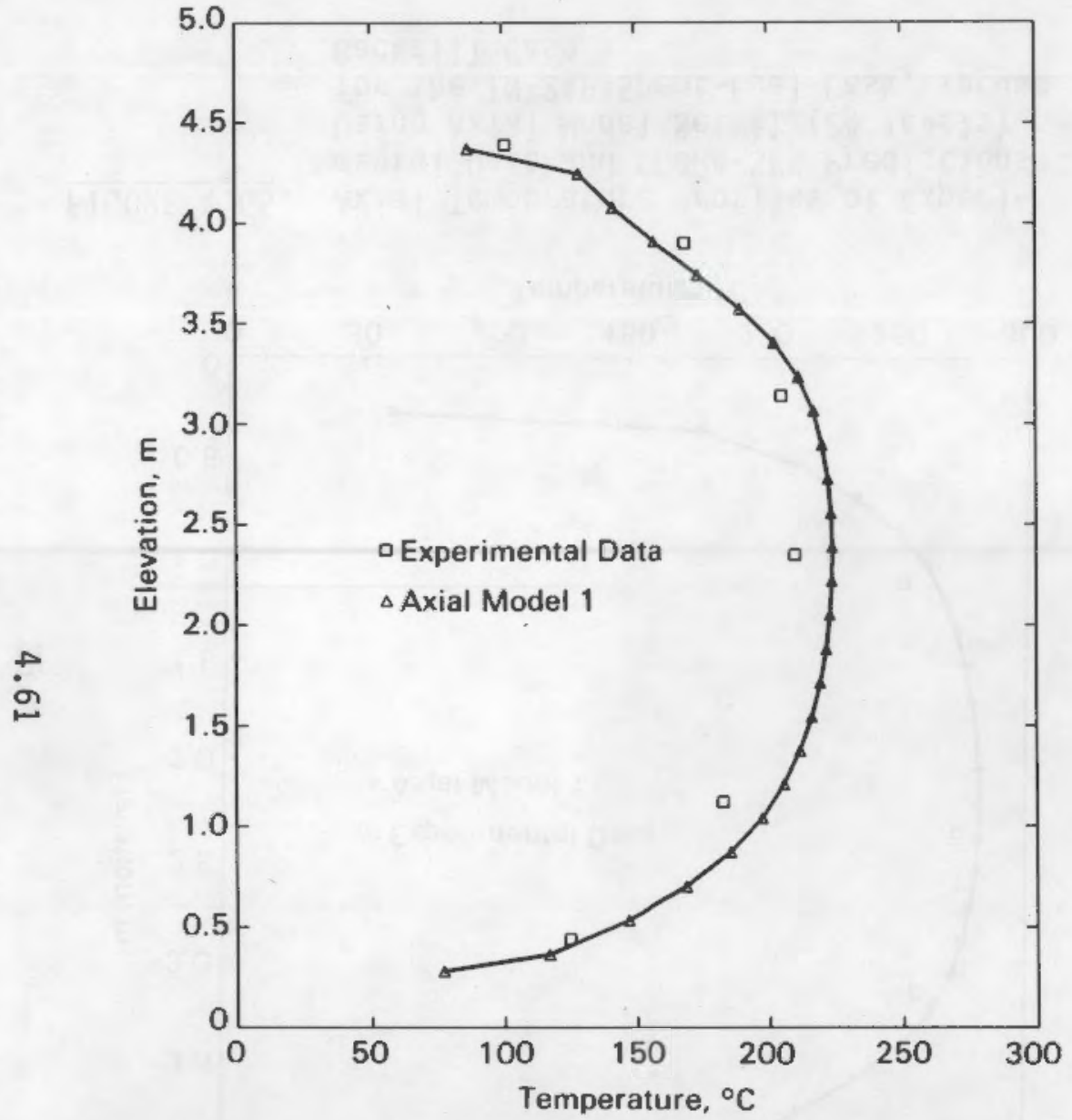

FIGURE 4.63. Axial Temperature Profiles of Experimental Data and COBRA-SFS Predictions Using Axial Model Set \#1 (24 levels) for the TN-24P Spent-Fuel Cask, Helium Backfill Case

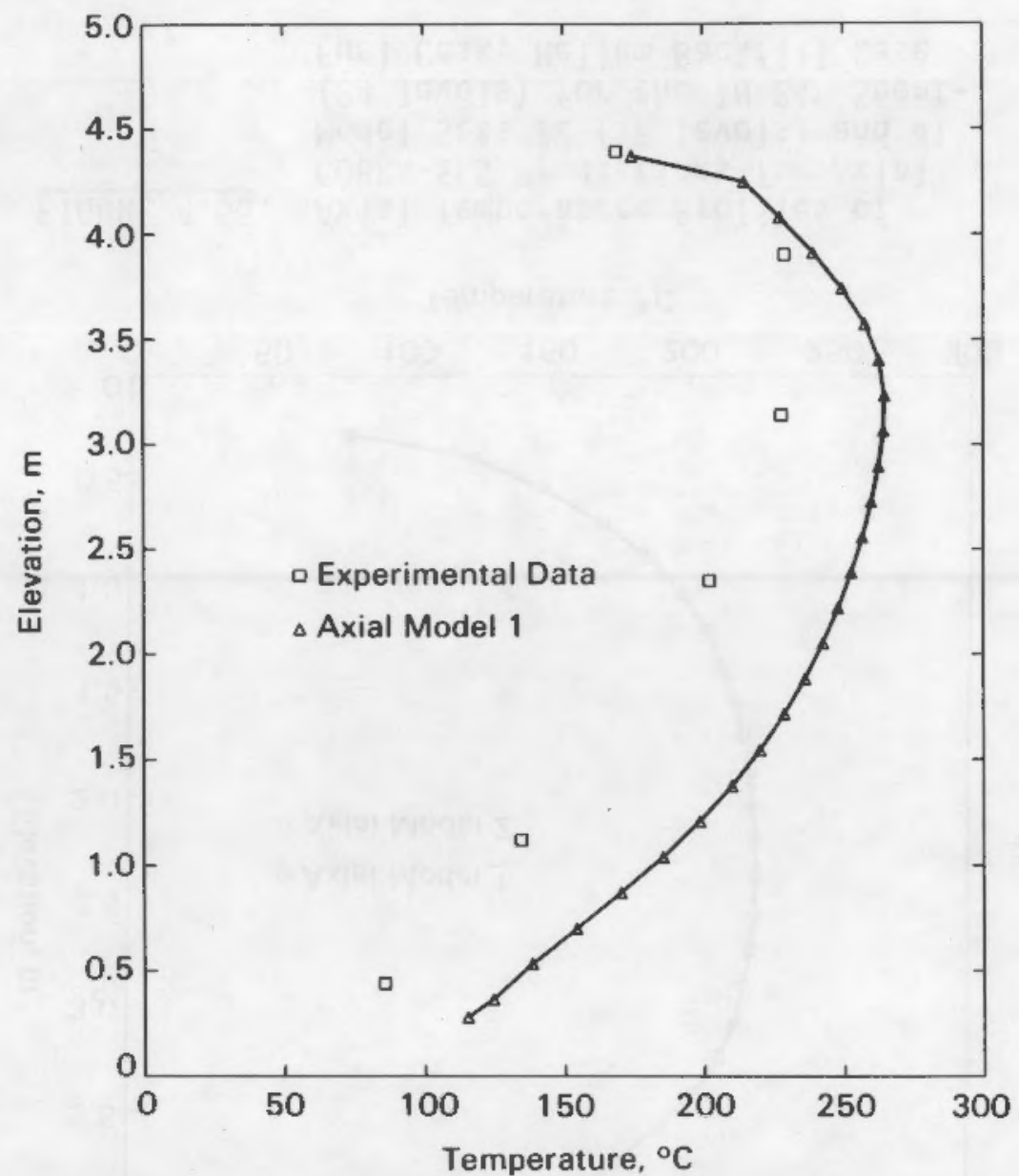

FIGURE 4.64. Axial Temperature Profiles of Experimental Data and COBRA-SFS Predictions Using Axial Model Set \#1 (24 levels) for the TN-24P Spent-Fuel Cask, Nitrogen Backfill Case 


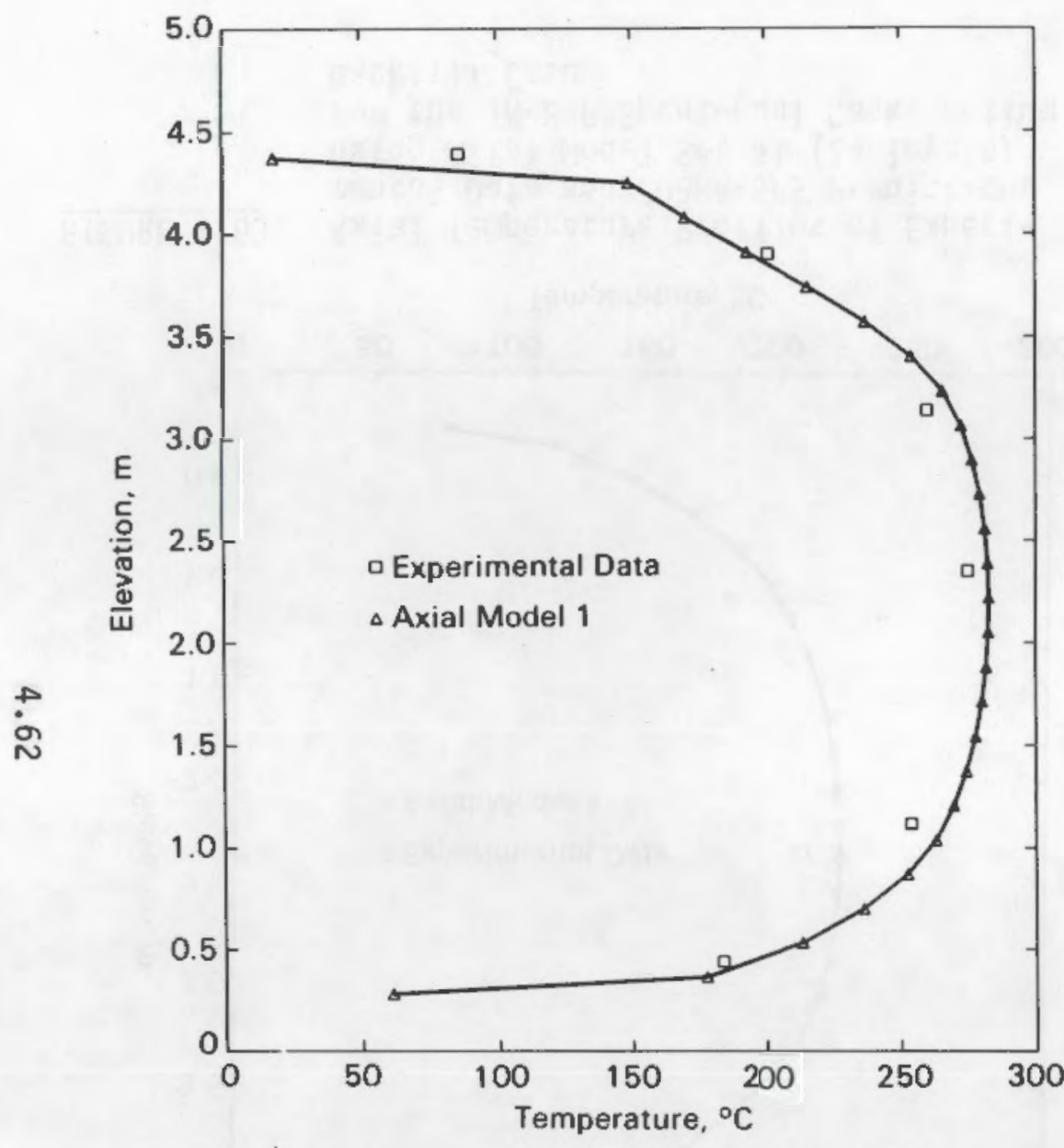

FIGURE 4.65. Axial Temperature Profiles of Experimental Data and COBRA-SFS Predictions Using Axial Model Set \#1 (24 levels) for the TN-24P Spent-Fuel Cask, Vacuum Backfill Case

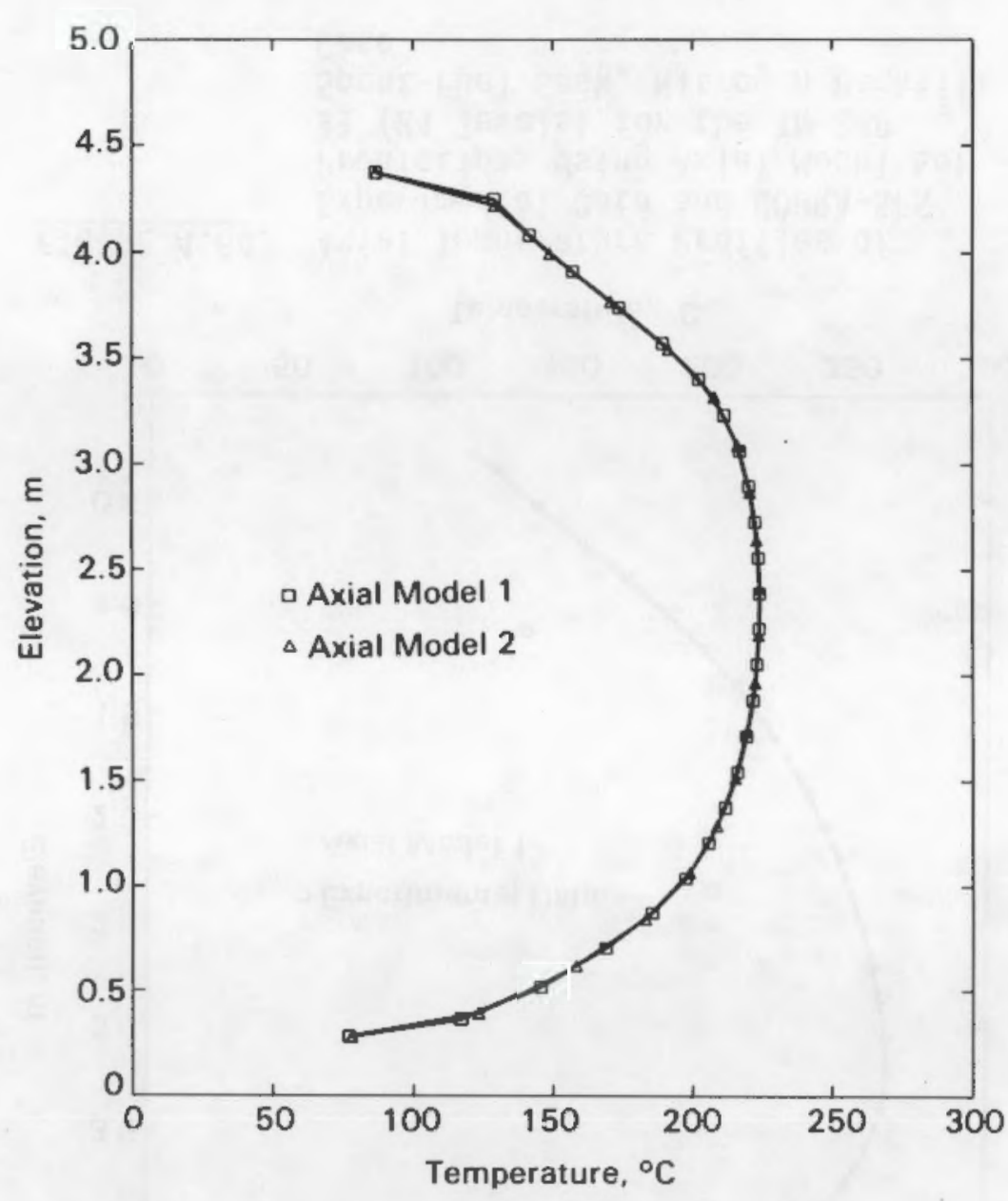

FIGURE 4.66. Axial Temperature Profiles of COBRA-SFS Predictions for Axial Model Sets $\# 2$ (18 levels) and \#1 (24 levels) for the TN-24P SpentFuel Cask, Helium Backfill Case 


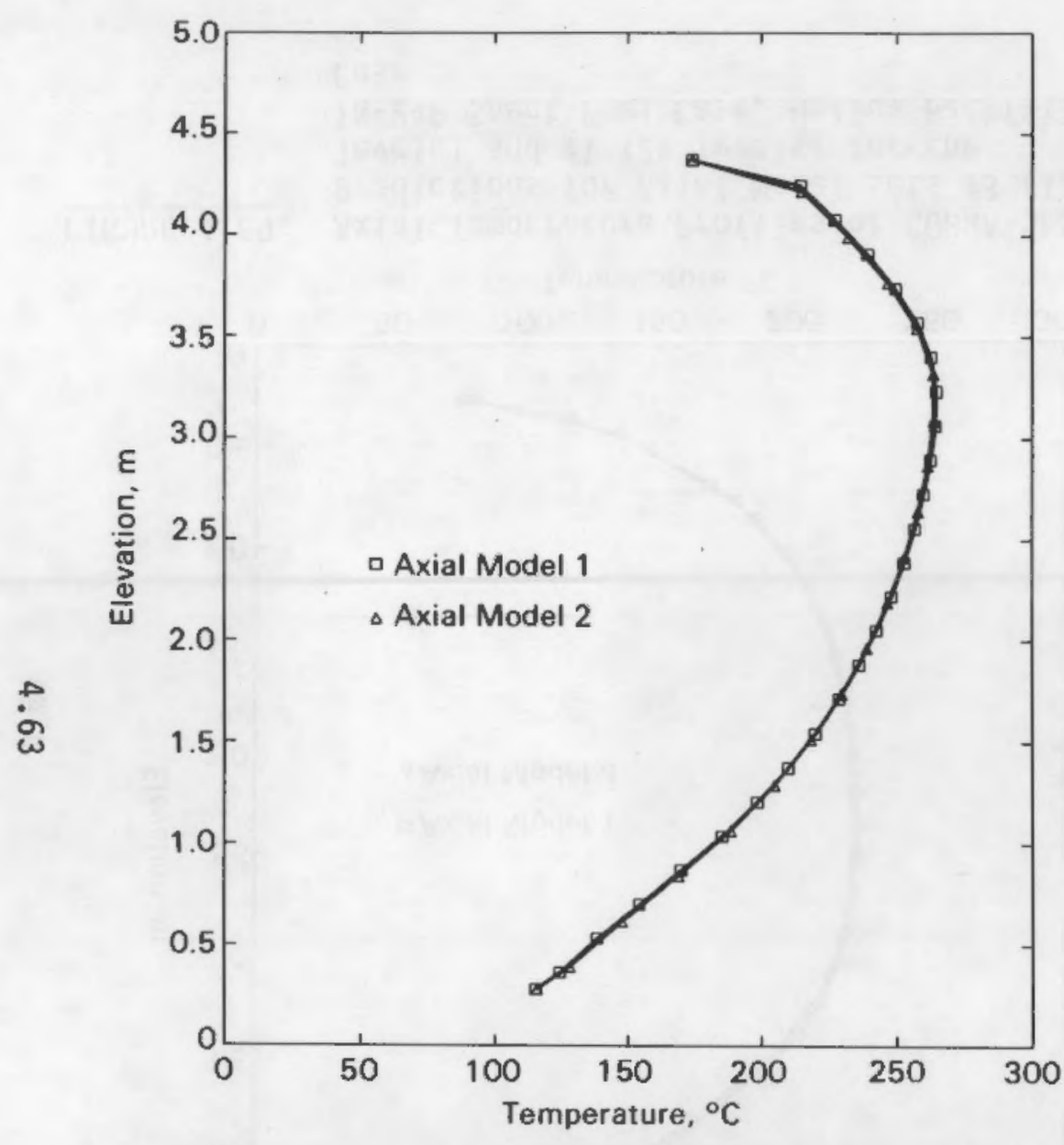

FIGURE 4.67. Axial Temperature Profiles of COBRA-SFS Predictions for Axial Model Sets \#2 (18 levels) and \#1 (24 levels) for the TN-24P TN-24P Spent-Fuel Cask, Nitrogen Backfill Case

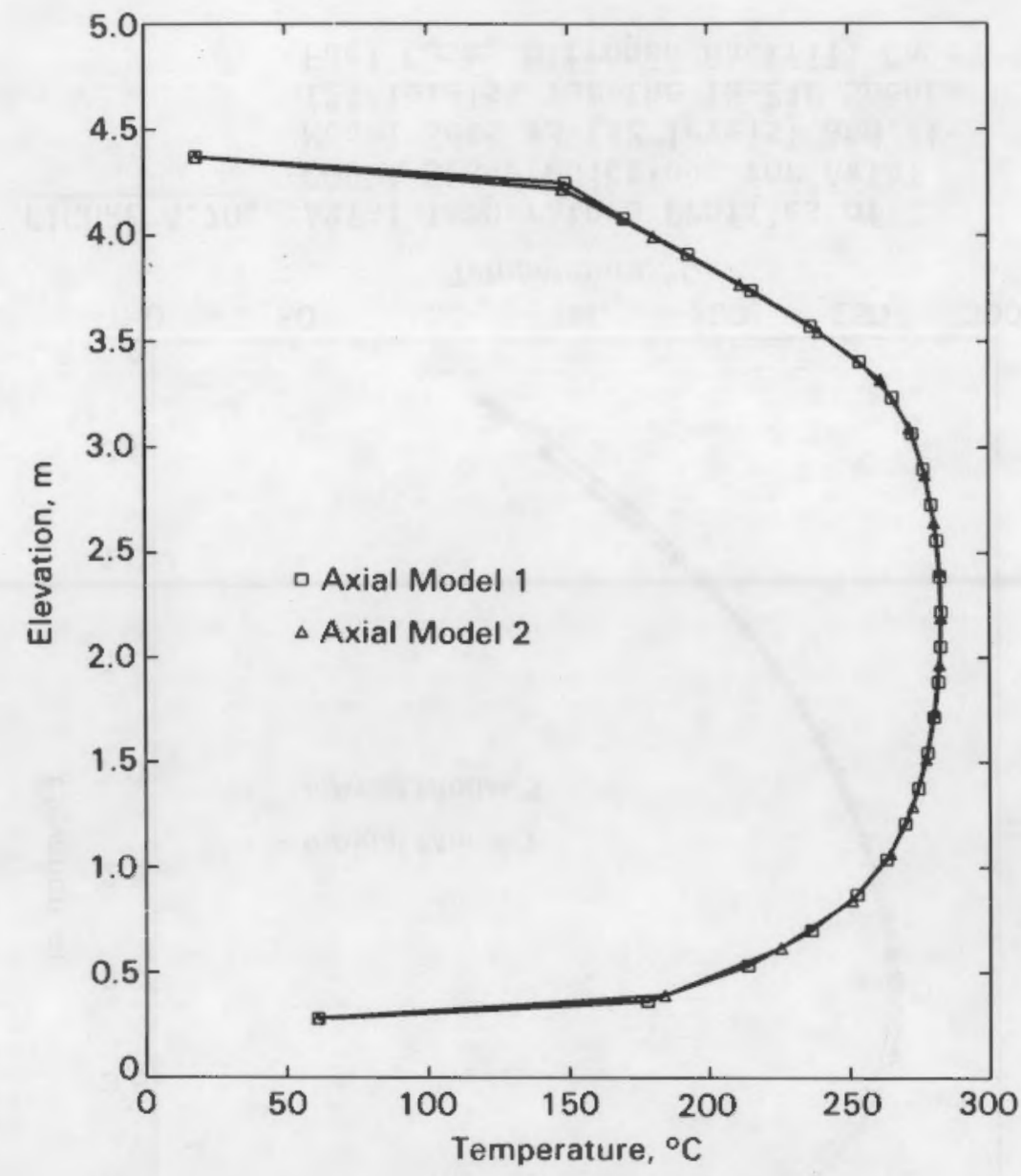

FIGURE 4.68. Axial Temperature Profiles of COBRA-SFS Predictions for Axial Model Sets \#2 (18 levels) and \#1 (24 levels) for the TN-24P SpentFuel Cask, Vacuum Backfill Case 


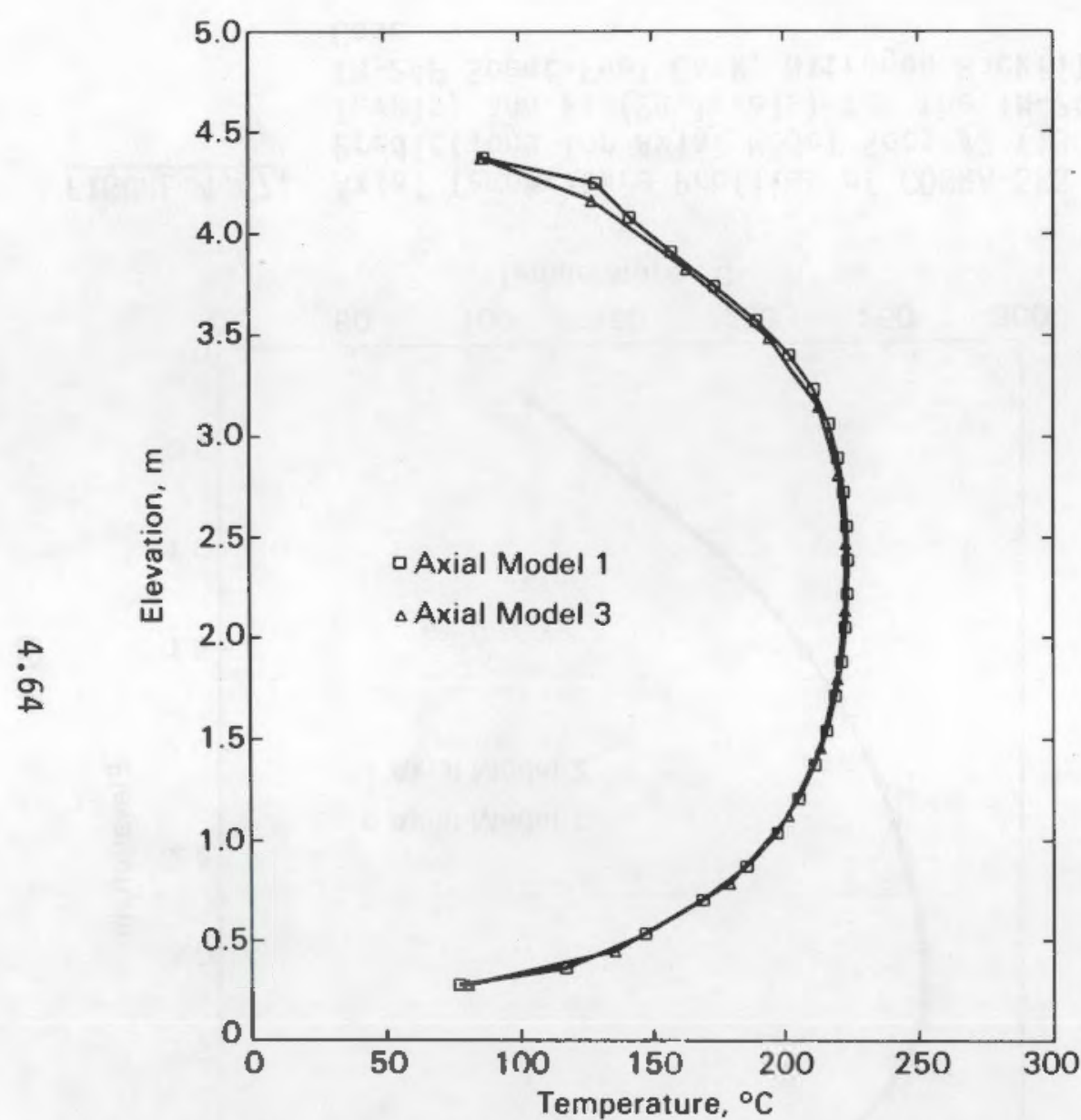

FIGURE 4.69. Axial Temperature Profiles of COBRA-SFS Predictions for Axial Model Sets \#3 (12 levels) and \#1 (24 levels) for the

TN-24P Spent-Fuel Cask, Helium Backfill Case

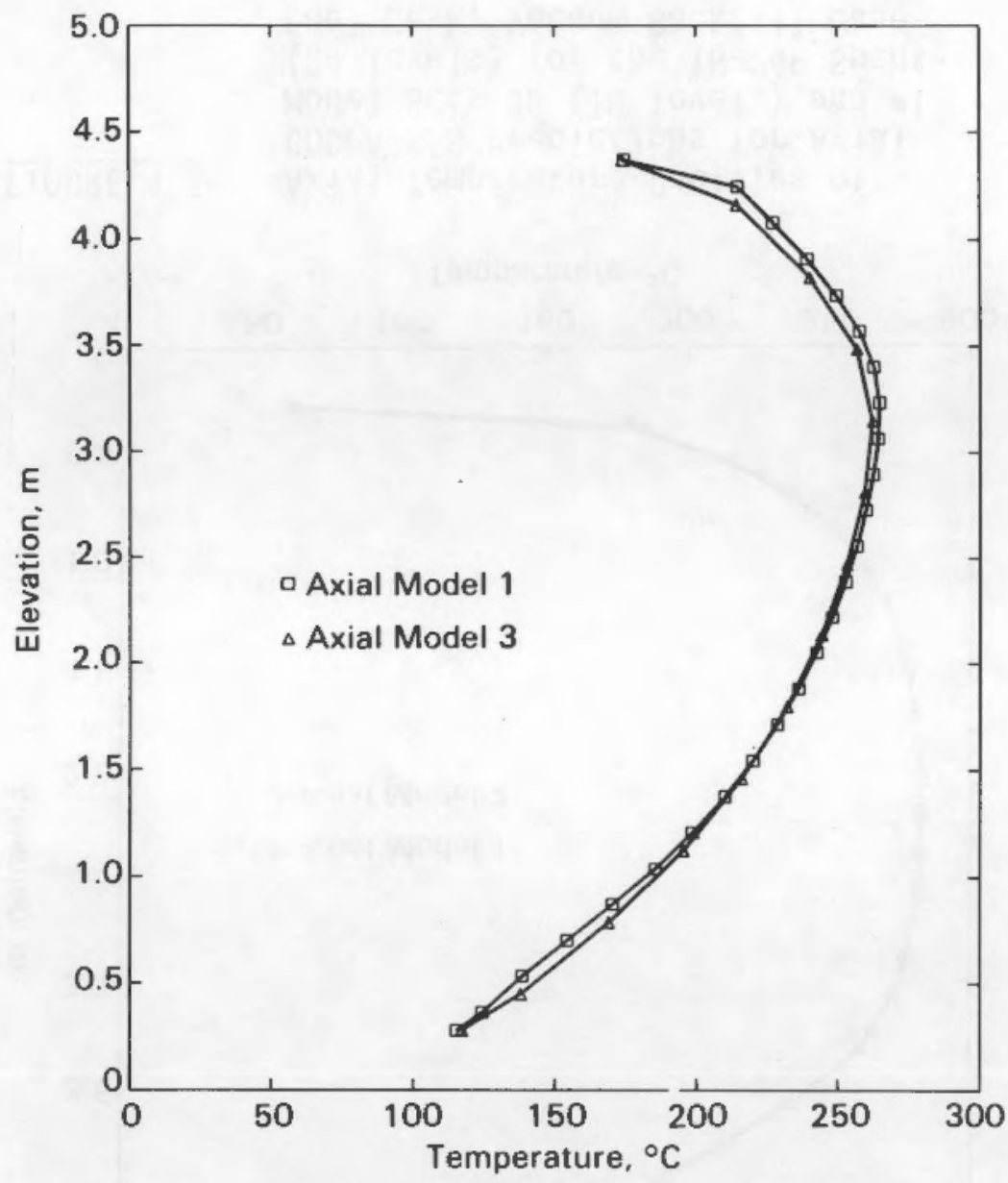

FIGURE 4.70. Axial Temperature Profiles of COBRA-SFS Predictions for Axial Model Sets \#3 (12 levels) and \#1 (24 levels) for the TN-24P SpentFuel Cask, Nitrogen Backfill Case 


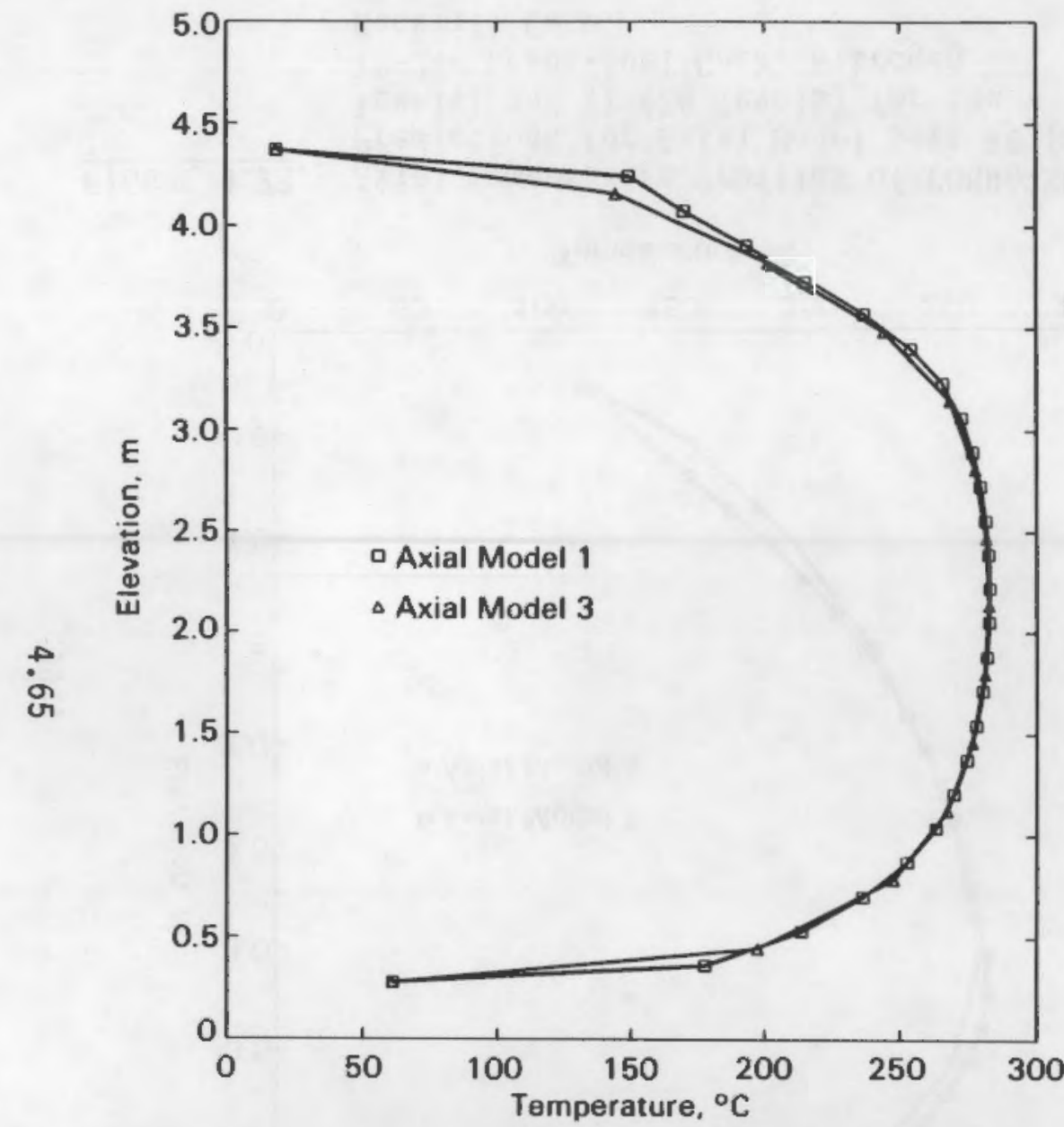

FIGURE 4.71. Axial Temperature Profiles of COBRA-SFS Predictions for Axial Model Sets $\$ 3$ (12 levels) and 11 (24 levels) for the TN-24P Spent-Fuel Cask, Vacuum Backfill Case

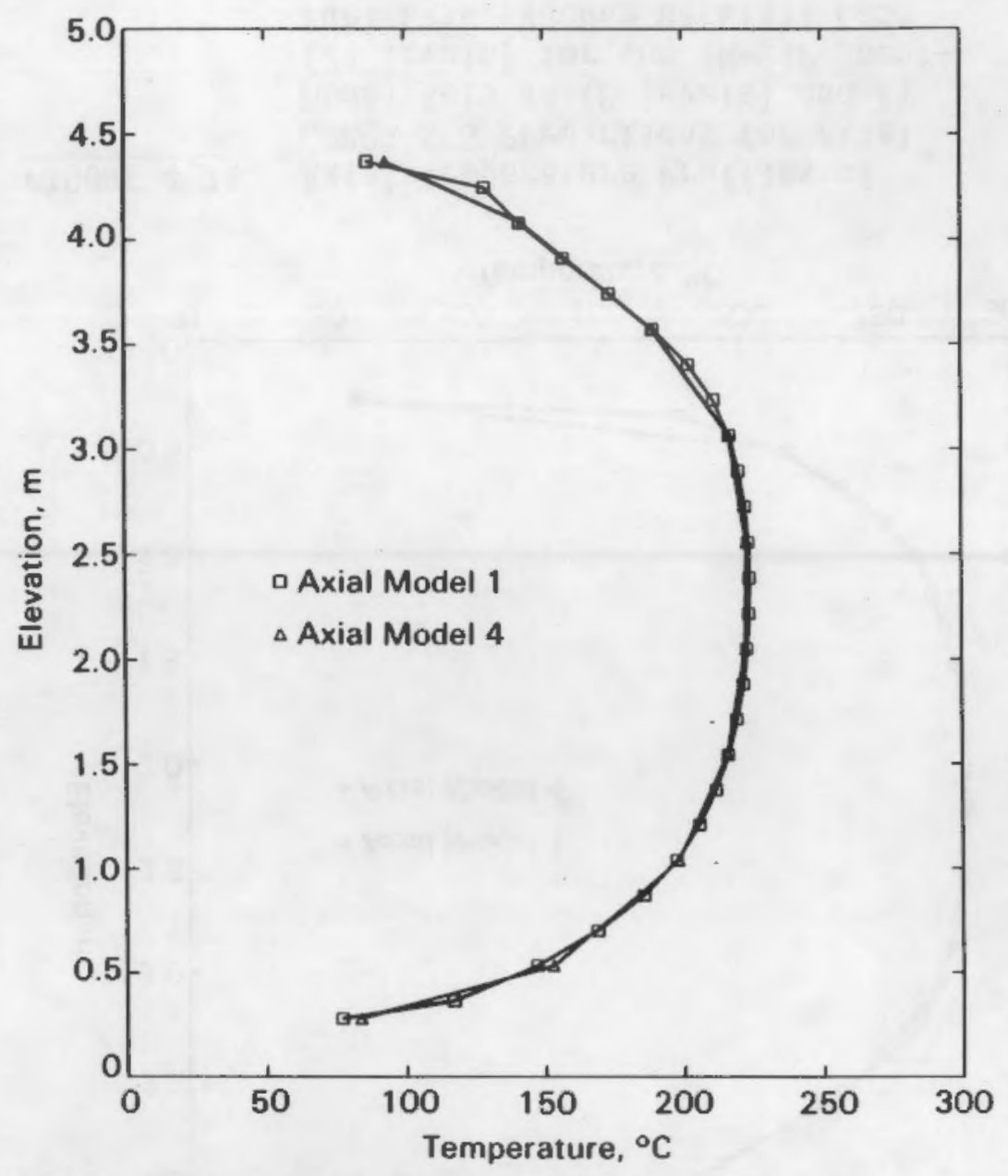

FIGURE 4.72. Axial Temperature Profiles of COBRA-SFS Predictions for Axial Model Sets 14 (8 levels) and $\# 1$ (24 levels) for the TN-24P SpentFuel Cask, Helium Backfill Case 


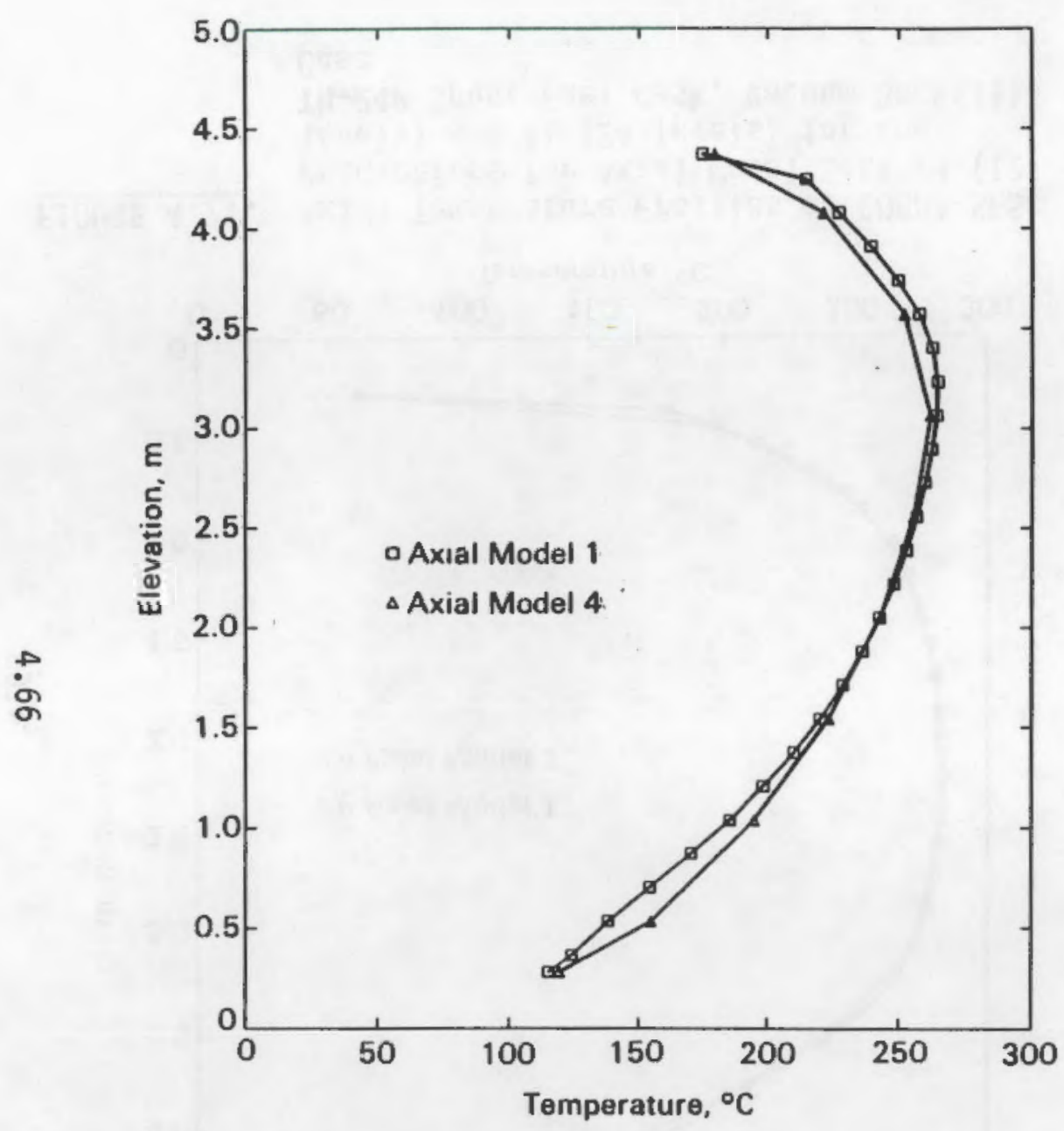

FIGURE 4.73. Axial Temperature Profiles of COBRA-SFS Predictions for Axial Model Sets \#4 (8 levels) and \#1 (24 levels) for the TN-24P Spent-Fuel Cask, Nitrogen Backfill Case

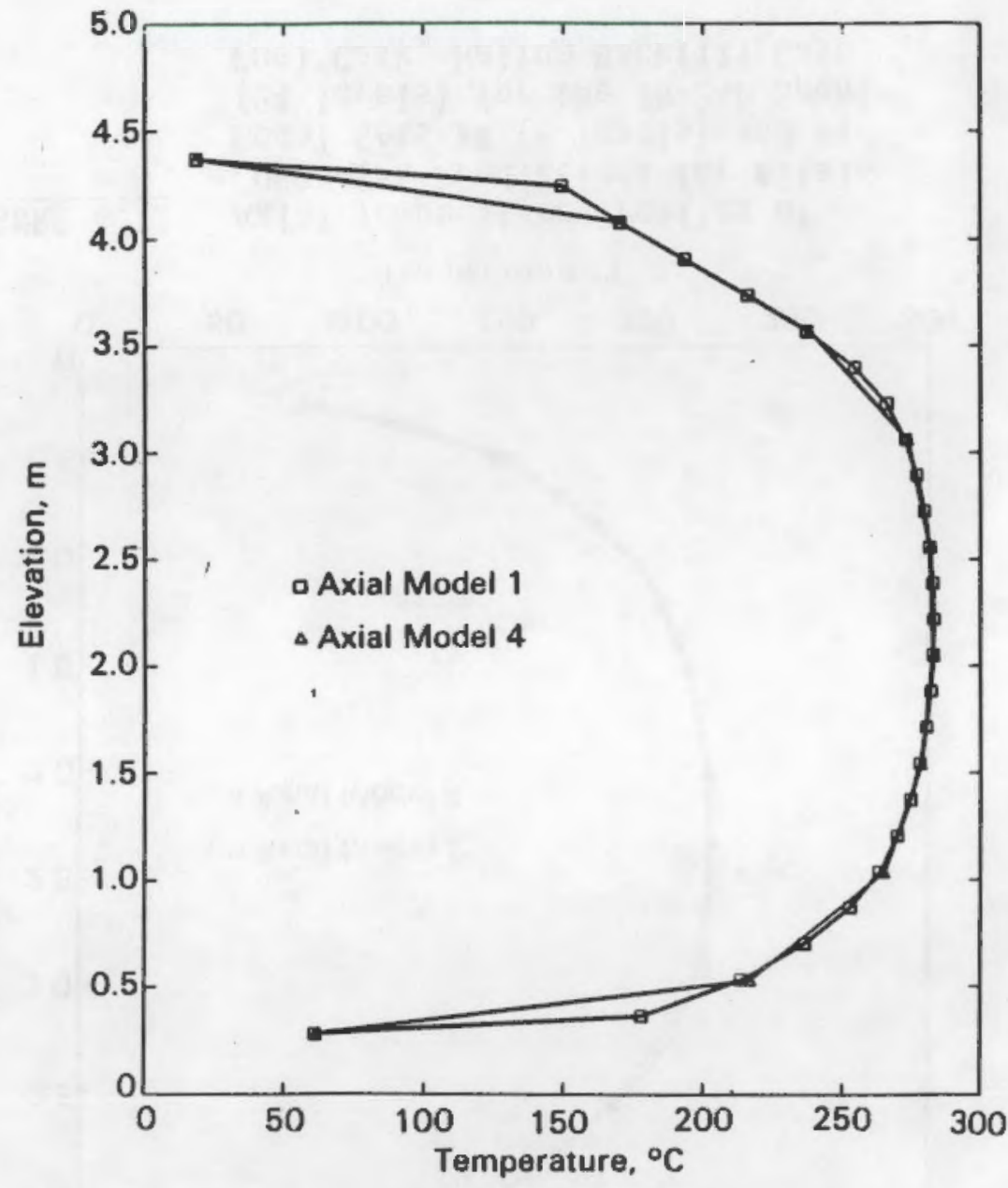

FIGURE 4.74. Axial Temperature Profiles of COBRA-SFS Predictions for Axial Model Sets \#4 (8 levels) and \#1 (24 levels) for the TN-24P SpentFuel Cask, Vacuum Backfill Case 


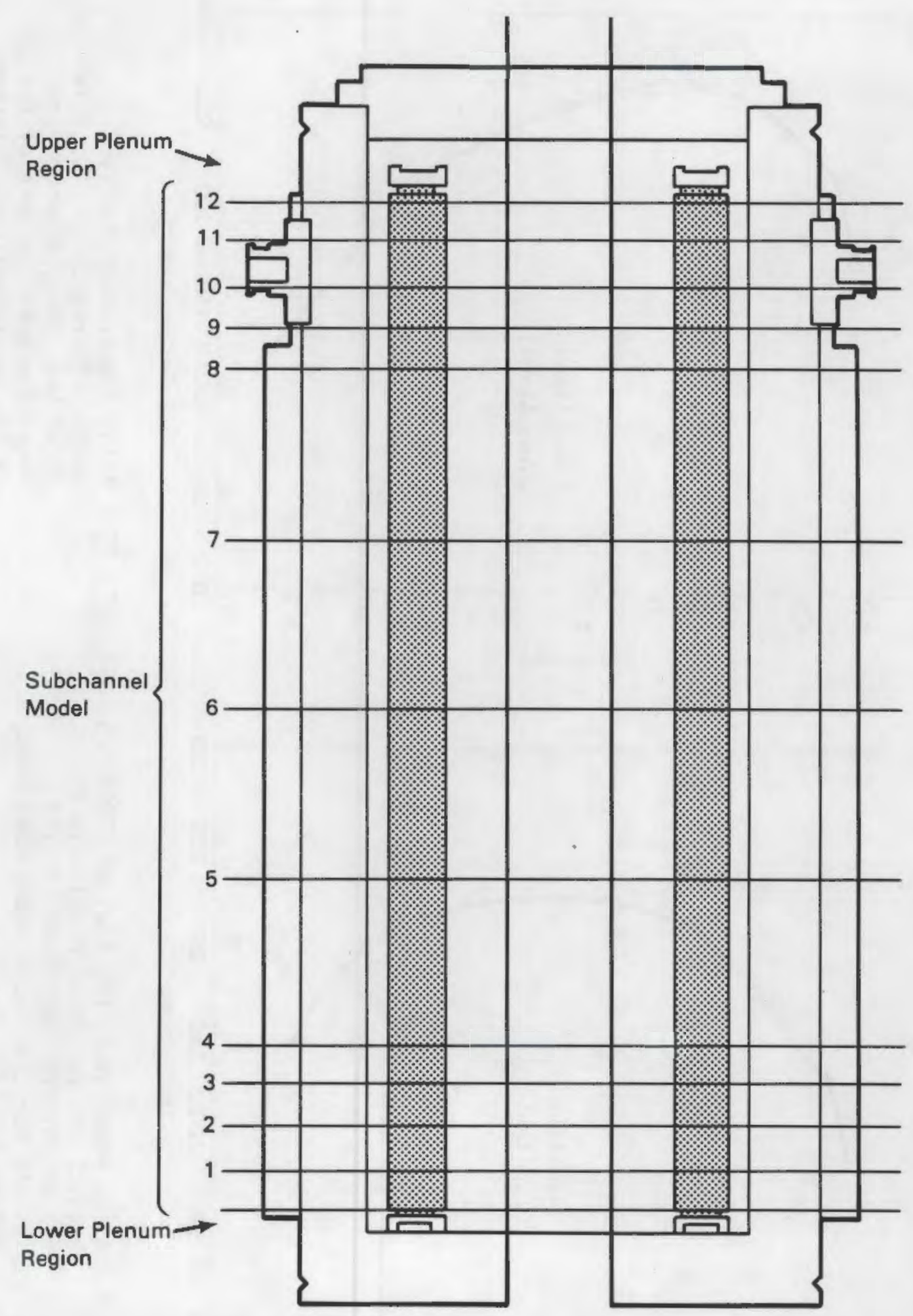

FIGURE 4.75. COBRA-SFS Axial Model \#5a, 12 Levels with Nonuniform Noding 


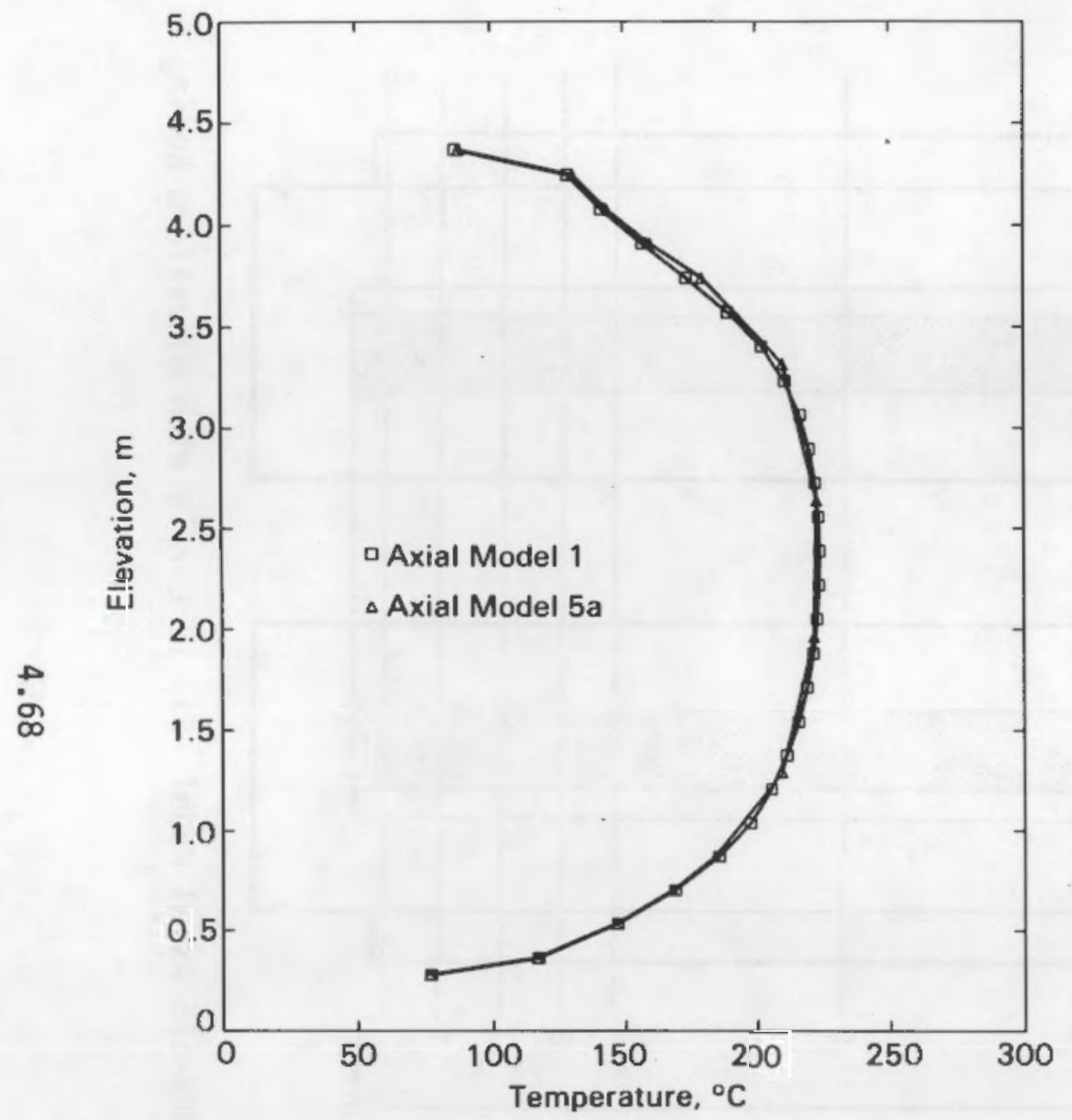

FIGURE 4.76. Axial Temperature Profiles of COBRA-SFS Predictions for Axial Model Sets $\# 5$ a (12 nonuniform levels) and \#1 (24 levels) for the TN-24P Spent-Fuel Cask, Helium Backfill Case

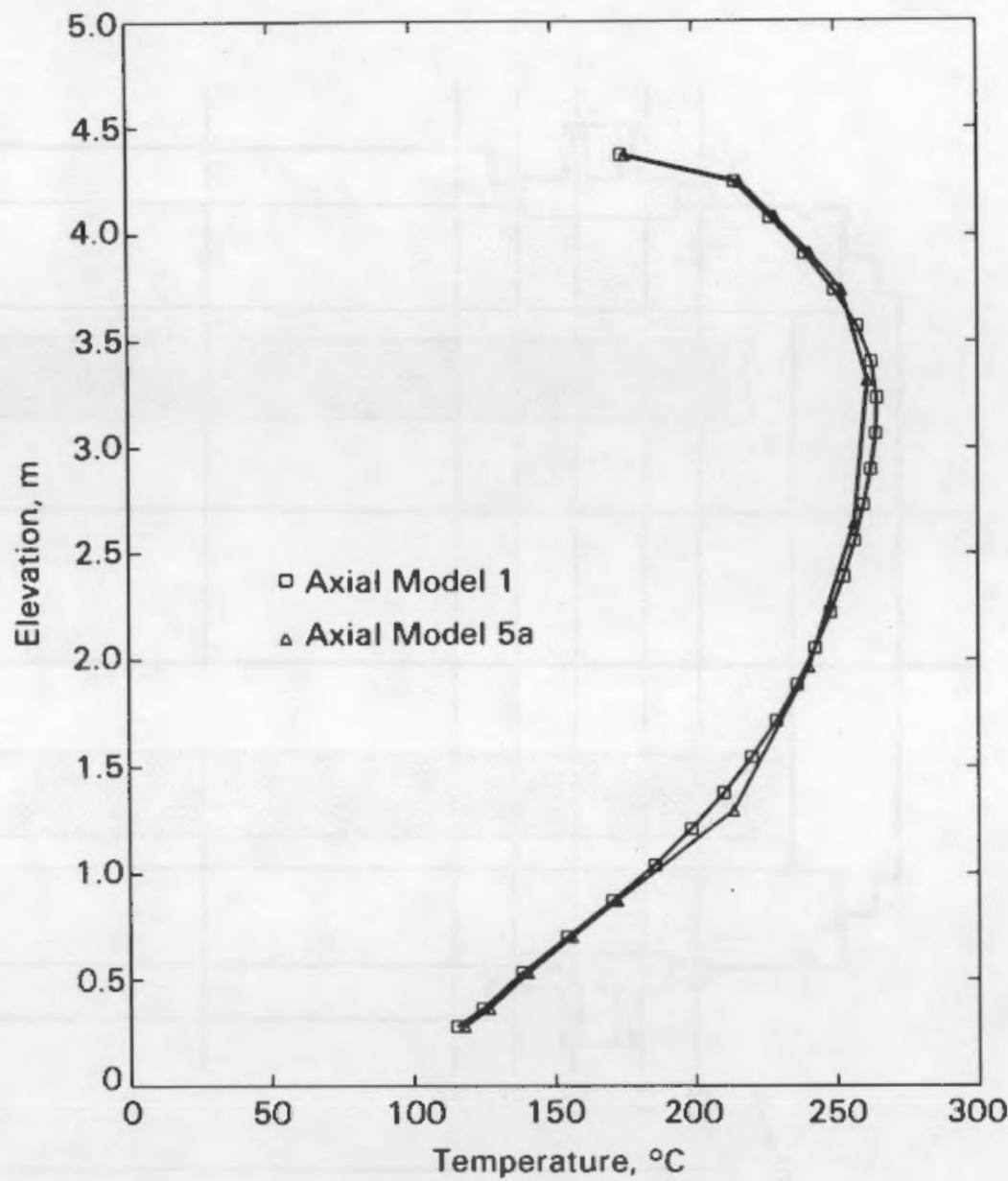

FIGURE 4.77. Axial Temperature Profiles of COBRA-SFS Predictions for Axial Model Sets $\# 5$ a (12 nonuniform levels) and \#1 (24 levels) for the TN-24P Spent-Fuel Cask, Nitrogen Backfill Case 


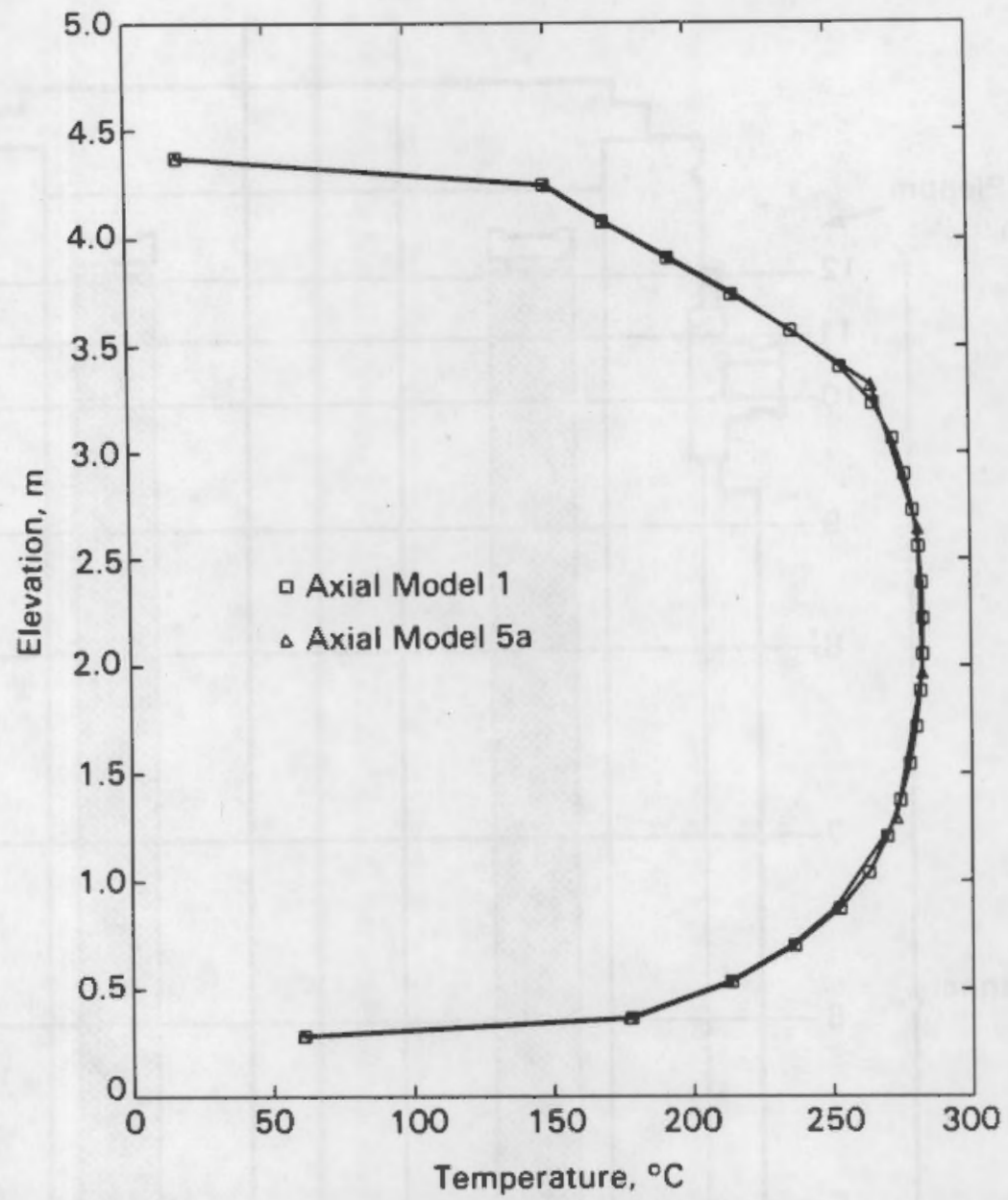

FIGURE 4.78. Axial Temperature Profiles of COBRA-SFS Predictions for Axial Model Sets \#5a (12 nonuniform levels) and \#1 (24 levels) for the TN-24P Spent-Fuel Cask, Vacuum Backfill Case 


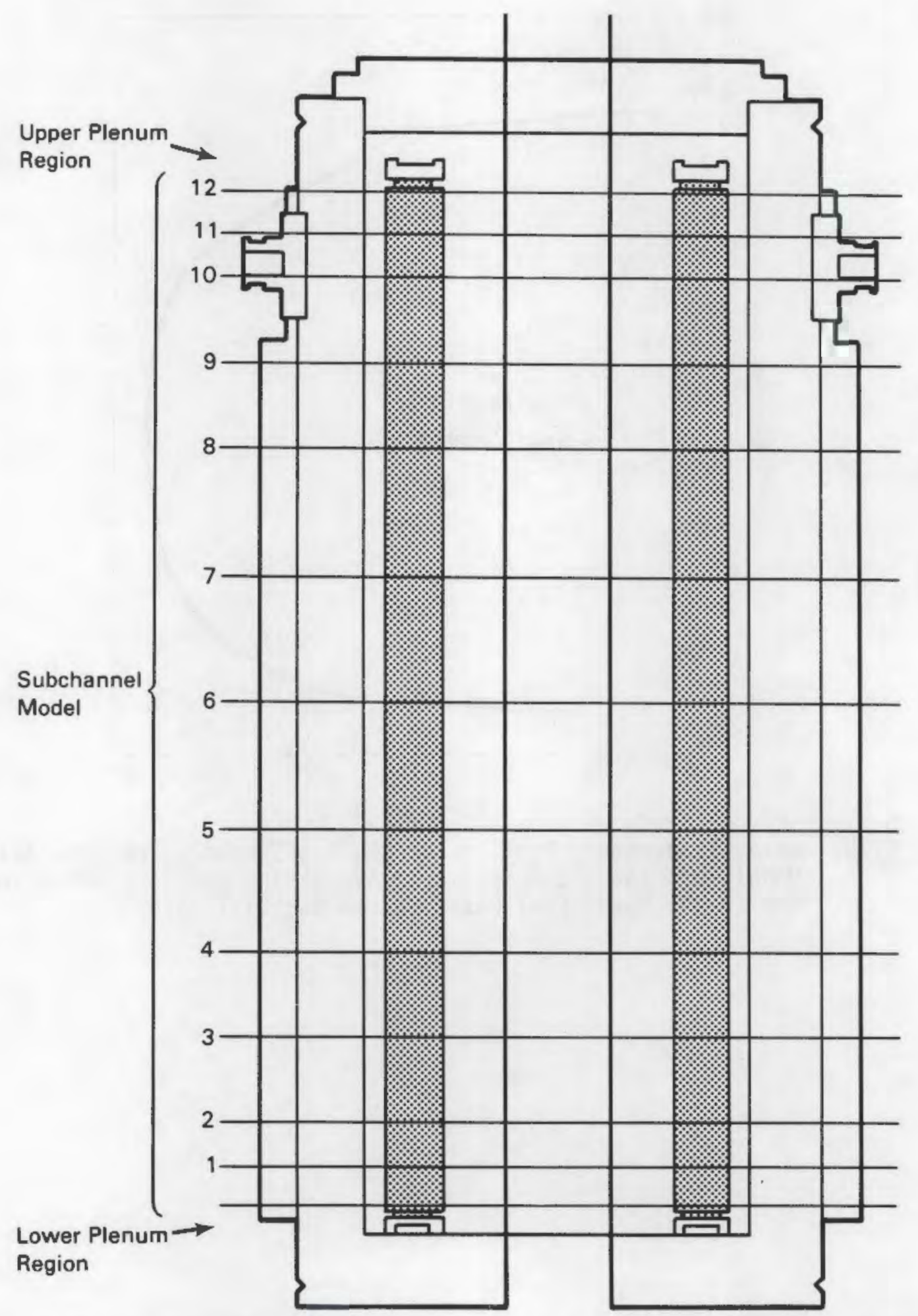

FIGURE 4.79. COBRA-SFS Axial Model \#5b, 12 Levels with Nonuniform Noding 


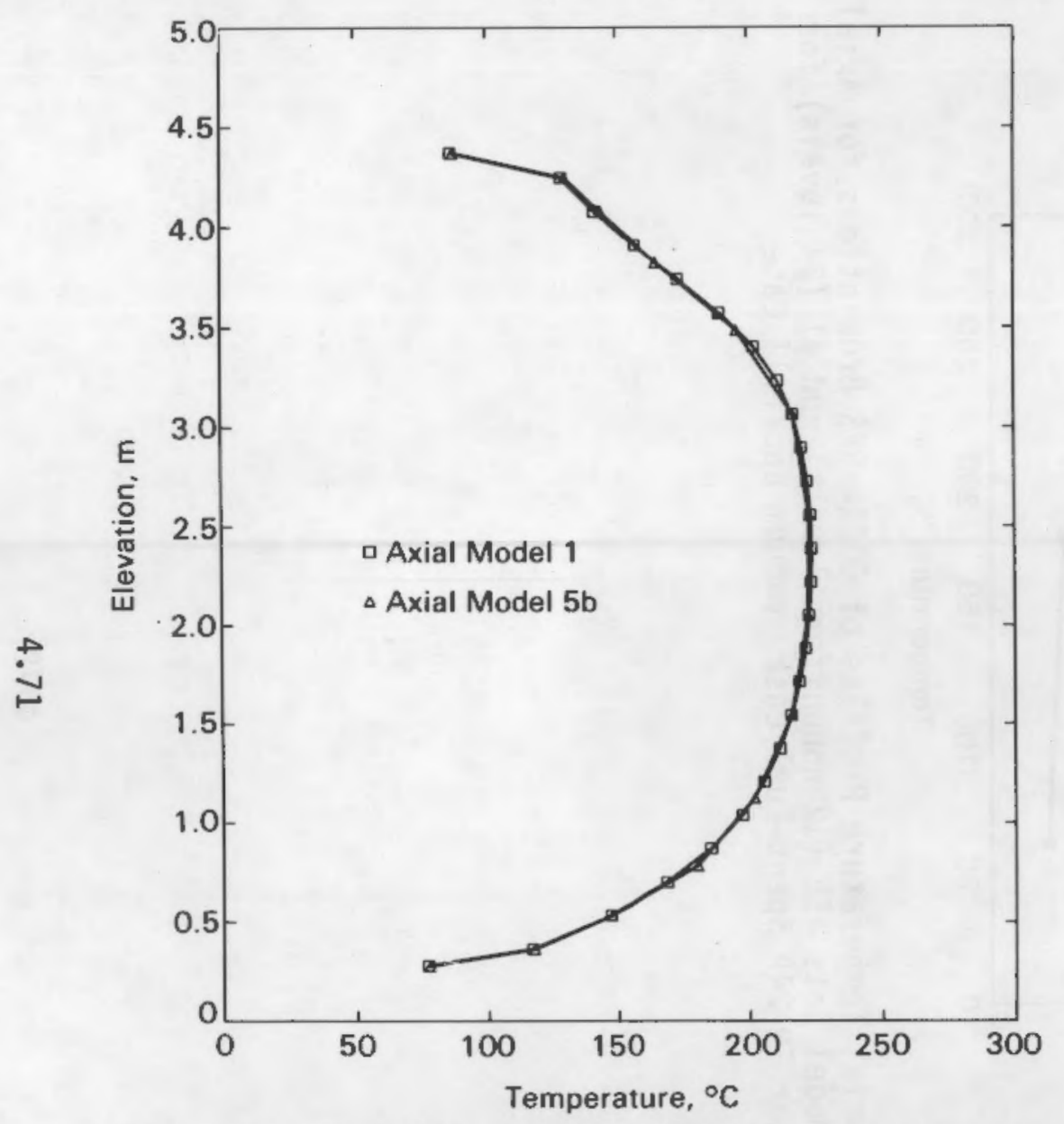

FIGURE 4.80. Axial Temperature Profiles of COBRA-SFS Predictions for Axial Model Sets $\# 5 b$ (12 nonuniform levels) and 1 (24 levels) for the TN-24P Spent-Fuel Cask, Helium Backfill Case

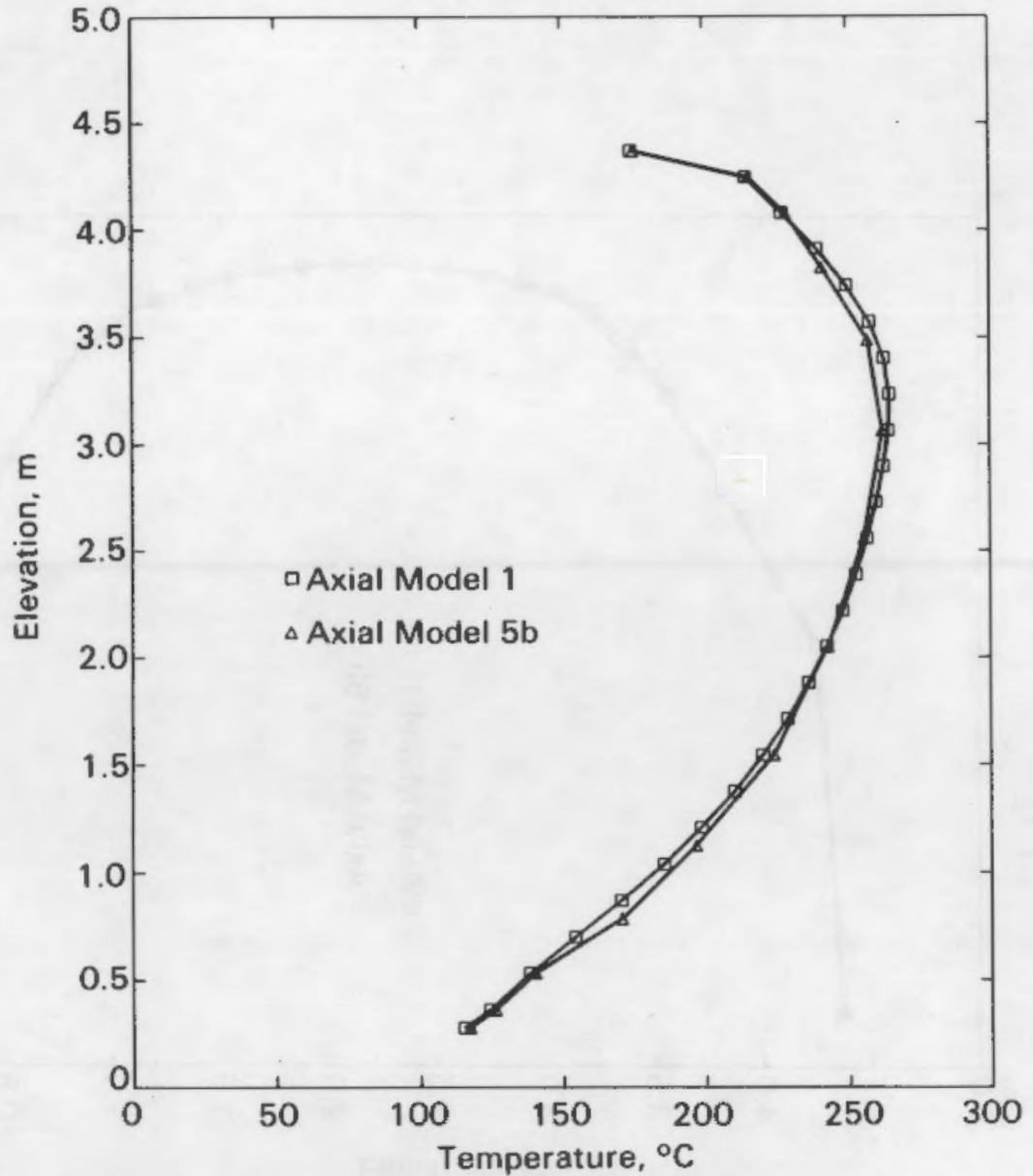

FIGURE 4.81. Axial Temperature Profiles of COBRA-SFS Predictions for Axial Model Sets \#5b (12 nonuniform levels) and \#1 (24 levels) for the TN-24P Spent-Fuel Cask, Nitrogen Backfill Case 


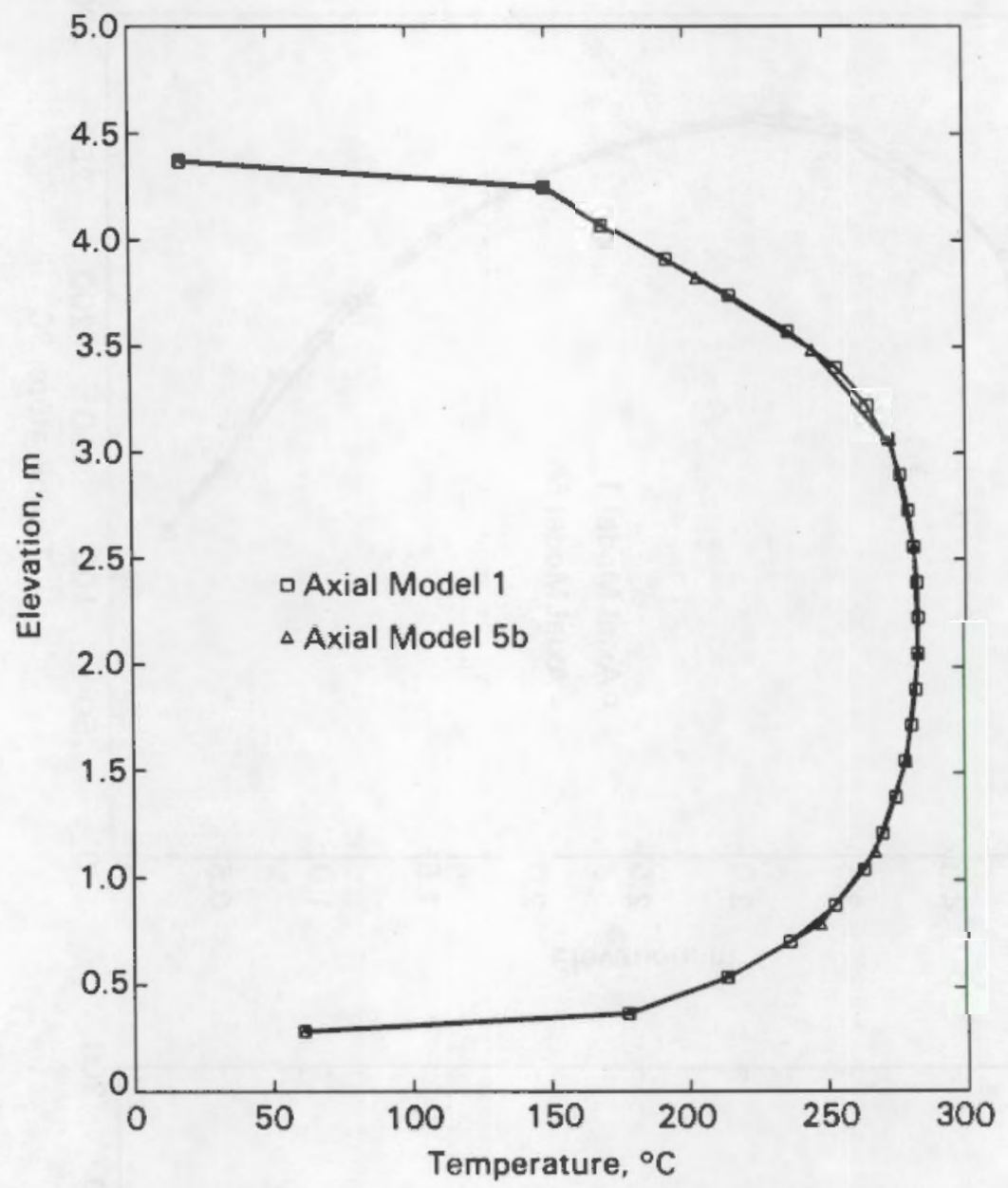

FIGURE 4.82. Axial Temperature Profiles of COBRA-SFS Predictions for Axial Model Sets \#5b (12 nonuniform levels) and \#1 (24 levels) for the TN-24P Spent-Fuel Cask, Vacuum Backfill Case 
IABLE 4.1. Material Properties

\begin{tabular}{|c|c|c|c|}
\hline Thermal Conductivit & ties (Btı & Surface Emissi & ivities \\
\hline Steel cask body & $=24.0$ & Fuel rods & $=0.8$ \\
\hline Polyethylene resin & $=0.1$ & Fuel basket & $=0.8$ \\
\hline Aluminum basket & $=119.0$ & Plated cask surfaces & $=0.9$ \\
\hline Copper fins & $=218.0$ & Painted cask surfaces & $=0.9$ \\
\hline Steel shell & $=24.0$ & Copper fin surface & $=0.5$ \\
\hline Polypropylene & $=0.1$ & & \\
\hline
\end{tabular}

TABLE 4.2. Parameter ACCELW Results

\begin{tabular}{|c|c|c|}
\hline ACCELW & Computational Time, sec. & Number of Iterations \\
\hline 1.2 & 1290.27 & 40 \\
\hline 1.3 & 1245.62 & 40 \\
\hline 1.4 & 1230.71 & 40 \\
\hline 1.5 & 1208.17 & 40 \\
\hline 1.6 & 1240.79 & 40 \\
\hline \multicolumn{3}{|c|}{ Helium Cases: } \\
\hline ACCELW & Computational rime, sec. & Number of Iterations \\
\hline 1.2 & 1164.34 & 33 \\
\hline 1.3 & 1127.06 & 33 \\
\hline 1.4 & 1024.70 & 30 \\
\hline 1.5 & 1002.46 & 30 \\
\hline 1.6 & 904.33 & 27 \\
\hline
\end{tabular}


TABLE 4.3. Parameter ACCROD Results

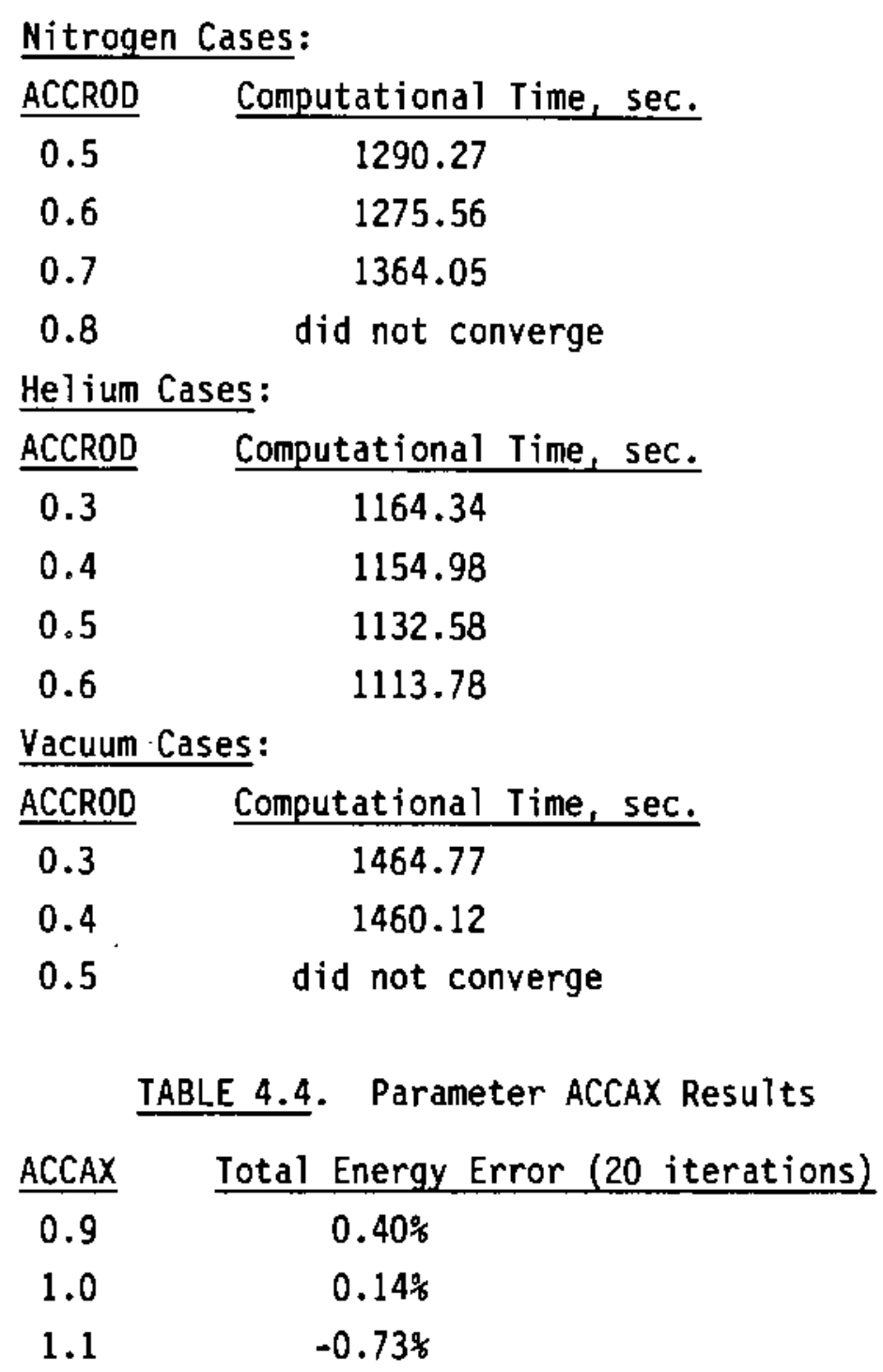




\subsection{FLOW SOLUTION IMPROVEMENTS}

The COBRA-SFS thermal-hydraulic analysis of a spent fuel system is separated into two parts--a flow field solution and an energy solution. The flow field is determined by solving a set of finite-volume equations governing conservation of mass and momentum.

In the original release of the COBRA-SFS code, shear stress on the fluid resulted solely from adjacent solid surfaces, such as slabs or rods, and shear stress from adjacent fluid channels was neglected. This is appropriate for flow in rod bundles, where each channel is surrounded by solid surfaces. However, in many applications, the geometry includes large open flow areas that must be modeled. Using the original COBRA-SFS code with no fluid shear stress terms, such an area is modeled using a single channel.

To improve the modeling of open flow regions, fluid shear stress terms have been added to the momentum equations used in the COBRA-SFS code. The addition of these terms will allow more detailed modeling of large open flow regions with several channels. The modifications are described in Section 5.1. The input changes resulting from these modifications are described in Section 5.2. In Section 5.3, the results from a series of verification runs are compared with the analytical solutions.

\subsection{DESCRIPTION OF MODIFICATIONS}

The flow field of a spent fuel storage system is determined by solving a set of finite-volume equations governing conservation of mass and momentum. The conservation equations described below are taken from Rector, wheeler, and Lombardo (1986). To determine the conservation equations, suitable balances are performed on the typical control volume shown in Figure 5.1. The axial length of the control volume is denoted by $\Delta x$. The axial flow area at the upper and lower surfaces is denoted by $A$ and the axial velocity by $U$.

Lateral flow between adjacent subchannel control volumes passes through a region between separated solid surfaces. The width of the gap between surfaces is $S$ and the lateral velocity is $V$. Each channel can have an arbitrary 
number of lateral flow connections (three in the case of Figure 5.1) to adjacent channels, and the gap width (S) may vary from connection to connection.

In deriving the axial momentum equation, the shear stress on the fluid from adjacent channels was neglected. Applying conservation of momentum to the control volume shown in Figure 5.2 gives the following finite-volume form of the axial momentum equation

$$
\begin{aligned}
& \Delta \times A\left(\frac{\rho U-(\rho U)^{n}}{\Delta t}\right)_{j}+\left(\rho^{\star} U_{j}\right){ }^{*} A_{j} 0_{j}-\left(\rho^{*} U_{j-1}\right)^{\star} A_{j} D_{j-1}+ \\
& {\left[\begin{array}{l}
\text { axial momentum } \\
\text { storage }
\end{array}\right]+\left[\begin{array}{l}
\text { axial momentum } \\
\text { transported axially }
\end{array}\right]+} \\
& \sum_{k \in \varphi_{i}} e_{i k}\left(\rho^{\star} U\right) \nabla_{k} S_{k} S_{k} \Delta x+F_{T} \\
& {\left[\begin{array}{l}
\text { axial momentum } \\
\text { transported laterally }
\end{array}\right]+\left[\begin{array}{l}
\text { turbulent momentum } \\
\text { exchange }
\end{array}\right]} \\
& P_{j-1} A_{j-1}-P_{j} A_{j}-P\left(A_{j-1}-A_{j}\right)+F_{s}-F_{g} \\
& \text { [pressure forces] - [wall drag forces] - [body forces] }
\end{aligned}
$$

In the originat version of COBRA-SFS, the shear forces are limited to wall interfaces and are expressed in terms of empirical wall friction factor correlations and local form loss coefficients. This term is expressed as

$$
F_{s}=\frac{1}{2}\left(\frac{f \Delta x}{D_{h}}+k\right) \rho U|U| A
$$

where $D_{h}$ is the hydraulic diameter, $f$ is the Darcy-Keisbach friction factor, and $K$ is the form loss coefficient to account for local obstructions such as grid spacers. 
When fluid shear is considered, axial momentum is transferred between each channel and every adjacent channel through gap connections. This term is expressed as

$$
F_{f}=\sum_{k \in \Psi_{i}} e_{i k}\left(U_{i j}-U_{j j}\right) \frac{S}{l} \mu_{k} \Delta x
$$

where $k$ is the gap connection, $e_{i k}$ is a switch function indicating the direction of momentum transfer, and $i j$ and $j j$ are channel numbers on either side of gap $k$. The gap viscosity, $\mu_{k}$, is assumed to be the average viscosity of the two adjacent channels.

The values for gap width, $S$, and transverse control volume, $l$, depend on the flow geometry being modeled. For rod bundles, the transverse control volume is defined as a rectangle with the width equal to the gap distance between rods and the length equal to the distance between channel centroids. A typical rod bundle transverse control volume is shown in Figure 5.3. When a large flow area is divided into channels, as shown in Figure 5.4, the dimensions of the transverse control volume depend on the geometry of the model. If the model fits a Cartesian coordinate system, the gap width $S$ corresponds to the interface between the two channels and the length $l$ is the channel centroid-to-centroid distance.

When a large flow region is divided into a large number of channels, the wall shear forces exerted on the outer channels should be expressed as a linear function of channel velocity, not friction factor or form loss coefficients as in Equation (5.2). For example, a rectangular channel adjacent to a wall is shown in Figure 5.5. The length from the wall to the channel centroid is assumed to be

$$
\ell=A / 2 P
$$

where the channel area is $A$ and the sum of slab perimeters contacting the channel is $P$. The wall shear forces can then be expressed as 


$$
F_{S}=\mu \frac{P}{l} U_{j} \Delta x=2 \mu \frac{p^{2}}{A} U_{j} \Delta x
$$

In deriving the transverse momentum equation, the shear stress on the fluid from adjacent axial levels and adjacent transverse flow connections was assumed to be negligible. Applying conservation of momentum to the control volume shown in Figure 5.3 gives the following finite-volume form of the transverse momentum equation

$$
\begin{aligned}
& \Delta x S_{k}\left(\frac{\rho v-(\rho V)^{n}}{\Delta t}\right)+\rho^{*} v_{j}^{*} s_{k} \bar{u}_{j}-\rho^{*} v_{j-1} S_{k} \bar{u}_{j-1} \\
& {\left[\begin{array}{l}
\text { transverse monentum } \\
\text { storage }
\end{array}\right]+\left[\begin{array}{l}
\text { transverse momentum } \\
\text { transported axialiy }
\end{array}\right]} \\
& =\frac{\Delta x S_{k}}{l_{k}} g_{c}\left(P_{i j}-P_{j j}\right)_{j-1}-F_{s} \\
& =\text { [pressure forces] - [wall shear forces] }
\end{aligned}
$$

In the original version of COBRA-SFS, the shear forces were exerted only by the walls and fuel rods and were expressed in terms of empirical local form loss coefficients. The shear force per unit length, $F_{S}$, was expressed as

$$
F_{S}=-1 / 2 K_{G}|V| v \frac{\Delta x S p}{l}
$$

where $K$ is the form loss coefficient.

When fluid shear is considered, transverse momentum is transferred in the axial direction and laterally between adjacent crossflows. In the axial direction, momentum is transferred to the transverse control volumes above and below the current axial level, as shown in Figure 5.6. This term is expressed as 


$$
F_{a x}=S e\left[\frac{2 \mu_{j-\frac{1}{2}}\left(v_{j}-v_{j-1}\right)}{\Delta x_{j}+\Delta x_{j+1}}+\frac{2 \mu_{j+\frac{1}{2}}\left(v_{j}-v_{j+1}\right)}{\Delta x_{j}+\Delta x_{j+1}}\right]
$$

where the viscosities $\mu_{j-\frac{1}{2}}$ and $\mu_{j+\frac{1}{2}}$ are defined as

$$
\begin{aligned}
& \mu_{j-\frac{1}{i}}=\left(\mu_{i j, j}+\mu_{j j, j}+\mu_{i j, j-1}+\mu_{j j, j-1}\right) / 4 \\
& \mu_{j+\frac{1}{2}}=\left(\mu_{i j, j}+\mu_{j j, j}+\mu_{i i, j+1}+\mu_{j j, j+1}\right) / 4
\end{aligned}
$$

and $i \mathrm{i}$ and $\mathrm{j} j$ are the indices of the channels connected by the transverse control volume.

The location and orientation of transverse connections between channels was not specified in the original COBRA-SFS input. To properly calculate momentum transferred laterally between adjacent transverse control volumes,

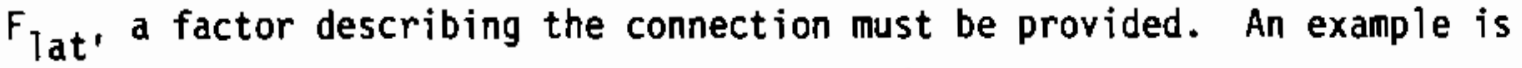
shown in Figure 5.7. This term is expressed as

$$
F_{\text {lat }}=\sum \ell \Delta x \bar{\mu}\left[\frac{2\left(v_{k}-v_{n}\right)}{S_{k}+S_{n}}\right]
$$

where $n$ is the index of a transverse control volume connected to control volume $k$ and $\bar{\mu}$ is defined as

$$
\bar{\mu}=\left(\mu_{i j, k}+\mu_{j j, k}+\mu_{i i, n}+\mu_{j j, n}\right) / 4
$$

A maximum of two other crossflows may be coupled to each crossflow in this manner. 


\subsection{INPUT CHANGES}

Modifications to the flow solution described in Section 5.1 required changes in the COBRA-SFS input structure. These changes are described below on a line-by-line basis. The input description format used here is similar to that used in the COBRA-SFS users' manual (Rector et al. 1986b).

CHAN.1 AGROUP, NASSEM, NDX, NAZONE, ISHEAR, NSHEAR $\operatorname{FORMAT}(A 4,1 X, 5$ I5)

\begin{tabular}{|c|c|c|}
\hline Columns & Variable & Description \\
\hline $1-4$ & AGROUP & Enter CHAN. \\
\hline $6-10$ & NASSEM & Number of assemblies. \\
\hline $11-15$ & NDX & Number of axial nodes. \\
\hline $16-20$ & NAZONE & $\begin{array}{l}\text { Flag for variable axial node sizes: } \\
=0 \text {; uniform axial nodes. } \\
>0 \text {; number of regions in variable axial } \\
\text { node size table (read on CHAN. } 3 \text { ). }\end{array}$ \\
\hline $21-25$ & ISHEAR & $\begin{array}{l}\text { Flag for fluid shear stress: } \\
=0 ; \text { fluid shear stress not considered } \\
=1 ; \text { fluid shear stress included. }\end{array}$ \\
\hline $26-30$ & NSHEAR & $\begin{array}{l}\text { Number of crossflow pairs connected by } \\
\text { fluid shear in the lateral direct ion (read } \\
\text { on CHAN.8). (This is meaningful only if } \\
\text { ISHEAR = 1.) }\end{array}$ \\
\hline
\end{tabular}

The flag for fluid shear stress (ISHEAR[CHAN.1]) determines whether the fluid shear terms are calculated and included in the flow solution. For situations involving rod bundles or separated channels, fluid shear may not be an important consideration. For situations with open flow areas that are divided into channeis, the fluid shear terms must be included in the flow solution.

When ISHEAR[CHAN.1] is set equal to one, certain fluid shear terms are automatically calculated. These include the transfer of axial momentum through 
the transverse control volume and the transfer of transverse momentum to adjacent axjal levels. The third type of fluid shear terms, the transfer of transverse momentum laterally between adjacent crossflows, requires additional information. The number of crossflow pairs that are connected by fluid shear is specified in MSHEAR [CHAN.1]. The individual pairs are read on CHAN.8, which is described later in this section.

CHAN.4 NASS, ITYPA, NCHANA, INTAPE, IFREE FORMAT (5I5)

\begin{tabular}{|c|c|c|}
\hline Columns & Variable & Description \\
\hline $1-5$ & NASS & Assembly number. \\
\hline $6-10$ & ITYPA & $\begin{array}{l}\text { Assembly type number (corresponding to a } \\
\text { channel geometry description entered on } \\
\text { CHAN.6). }\end{array}$ \\
\hline $11-15$ & NCHANA & Number of channels in assembly NASS. \\
\hline $16-20$ & INTAPE & $\begin{array}{l}\text { Flag for } I / 0 \text { unit source of the channel } \\
\text { input (CHAN.6) for assembly NASS: } \\
=0 ; \text { read from the input file } \\
=N \text {; read from the } I / 0 \text { unit } N \text {. }\end{array}$ \\
\hline $21-25$ & IFREE & $\begin{array}{l}\text { Flag for specifying wall shear boundary } \\
\text { condition for assembly NASS } \\
=0 \text {; wall shear specified by friction factor } \\
\text { correlation }\end{array}$ \\
\hline & & 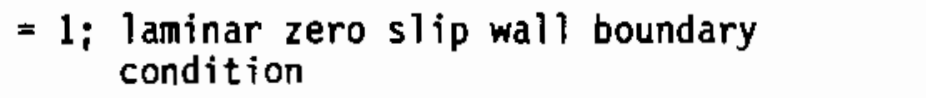 \\
\hline
\end{tabular}

Two methods are available for specifying the shear forces exerted by solid structures such as slabs and rods on fluid flowing in channels. These methods are specified using the flag IFREE CHAN.4 for each assembly. One method (IFREE[CHAN.4] = 0) is to specify the shear forces in terms of empirica] wall friction factor correlations and local form loss coefficients. In this case, the friction term is based on the hydraulic diameter of the channel, which is calculated using the wetted perimeter (PW[CHAN.6]) and the channel 
area. This method is appropriate for assemblies where each channel contacts solid surfaces, as in a rod bundle.

The other method (IFREE[CHAN.4] = 1) is to specify a laminar zero slip wall boundary condition. The fluid at the wall is assumed to have zero velocity. The shear stress is calculated assuming a linear velocity profile between the wall and the center of the adjacent channel. The wetted perimeter of each channel is the sum of slab perimeters (WID[SLAB.4]) contacting that channel. This method is appropriate for assemblies that consist of a large open flow area where only the outside channels contact a solid surface.

CHAN.8

(III (L) ,JJJ (L), L = 1 , NSHEAR[CHAN.1]) Read only if NSHEAR $>0$ FORMAT (12I5)

Columns

$1-5,11-15$

etc.

6-10,16-20 JJJ(L)
Variable

III (L)

$(L)$

etc.

Description

Identification numbers of transverse connections that are connected by fluid shear in the lateral direction.

When NSHEAR[CHAN.1] is set equal to a value greater than zero, pairs of crossflows that are connected by fluid shear are specified in card CHAN.8. Six pairs may be specified in each line. The crossflow connections are read from card CHAN.6 for each channel. The connections are numbered sequentially as they are read. The distance between crossflow centroids and width of the connection are automatically calculated from the crossflow information provided in CHAN.6.

\subsection{VERIFICATION ASSESSMENT}

A series of verification cases was performed to assess the fluid shear stress terms added to the COBRA-SFS code. The first few cases represent simple flow problems that demonstrate the effect of fluid-fluid and wall-fluid shear stresses. A comparison of code results and analytical solution is presented 
for each case. In addition, the solid-to-fluid heat transfer tems added to the code were verified by comparing analytically determined Nusselt numbers with code results.

\subsubsection{Flow in Plane Channel}

A series of simulations of developing forced-convection laminar flow in a plane channel was performed for Reynolds numbers of 50 and 200 . The plane channel model used is shown in Figure 5.8. Symmetry was assumed and half of the channel was modeled using ten channels. The axial length was divided into 30 levels with constant spacing. The output for the $R e=50$ case is presented in Appendix A.

The predicted cross channel profiles and centerline velocity as a function of distance from the entrance are shown in Figures 5.9 and 5.10 for Reynolds numbers of 50 and 200, respectively. The analytical solution for fully developed flow in a plane channel is a parabolic velocity profile with a centerline velocity of 1.5 times the bulk velocity. Both predictions show this analytical value being approached asymtotically.

\subsubsection{Flow in Cylindrical Pipe}

A simulation of two-dimensional, forced-convection laminar flow in a cylindrical pipe was performed for a Reynolds number of 100 . The cylindrical pipe model used is shown in Figure 5.11. The pipe cross section was divided into 10 channels. The length was represented by 30 axial levels. A uniform inlet flow was assumed. The output for this case is presented in Appendix B.

The cross-section velocity development and centerline velocity are shown in Figure 5.12. The fully developed, analytical velocity profile for this geometry is a parabolic profile given by

$$
\frac{U}{0}=2\left[1-(r / R)^{2}\right]
$$

where $r$ is the distance from the center of the pipe, $R$ is the inner radius of the pipe, and 0 is the bulk velocity. The prediction shows the analytical centerline value of $\mathrm{U} / 0=2$ being asymptotically approached. 


\subsubsection{Flow in a Square Duct}

Entry flow development in a square duct was chosen for analys is because a reliable data base for centerline velocity is available. The test case was a 1/4-symmetry model using a $5 \times 5$ channel grid with flow at $\operatorname{Re}=200$. The square duct model used is shown in Figure 5.13. The duct length was modeled using 30 axial levels. Constant cell spacing was used. The output for this case is presented in Appendix $C$. Cross-stream velocity profile results are shown in Figure 5.14, and the centerline flow development profile is compared to the experimental data of Kreid (1967) and Goldstein and Kreid (1967) in Figure 5.15 .

Because the code computes velocity at the channel centroid, it is impossible to obtain velocity at the duct center using symmetry modeling. Thus both Figures 5.14 and 5.15 show velocity extrapolated to the centerline as the flow attains a near-parabolic cross-stream profile upon full development. Figure 5.15 shows that the computed results underpredict the centerline velocity by a maximum of $5 \%$ to $7 \%$ during the early stages of development and $1 \%$ to $3 \%$ at full development. This underprediction may be caused by the assumed uniform velocity entrance condition.

\subsubsection{Thermal-Entry-Length Pipe Heat Transfer}

To evaluate the free field heat transfer terms added to COBRA-SFS, two simulations were performed for a developing thermal profile in a pipe with a uniform surface temperature. The simulations used models with 10 and 20 channels, respectively. The code results are compared with analytical values presented in (Kays and Crawford 1980). Since the analytical values are based on a fully developed velocity profile at the inlet, an entry length is used to develop the velocity profile before the surface temperature is changed. A total of 30 axial levels were used, 15 for the developing flow region and 15 for the developing thermal region.

The comparison of results with analytical values from Kays and Crawford (1980) are presented in Table 5.1. The location is expressed in terms of $x^{+}$, which is defined as 


$$
x^{+}=\frac{x / r_{0}}{\operatorname{Re} P_{r}}
$$

The dimensionless temperature is defined as

$$
\theta_{m}\left(x^{+}\right)=\frac{t_{0}-t_{m}}{t_{0}-t_{e}}
$$

where $t_{0}$ is the surface temperature, $t_{e}$ is the entry temperature, and $t_{m}$ is the mixed mean temperature at $x^{+}$. The heat transfer in the entry length can be expressed in terms of a mean Nusselt number, $\mathrm{Nu}_{\mathrm{m}}$. The relationship between the mean Nusselt number and the dimensionless temperature can be expressed as

$$
N u_{m}=1 / 2 x^{+} \ln 1 / \theta_{m}
$$

The results show very good comparison with analytical results, especially for higher values of $\mathrm{x}^{+}$. When the 20 -channel model is used, the error in the mean Nusselt number is less than $3 \%$ for values of $x^{+}$above 0.01 . The discrepancy at $x^{+}=0.01$ may be due to the use of only one axial level to represent the development in that region.

\subsubsection{Thermal-Entry-Length for Square Duct}

A simulation was performed for a developing thermal profile in a square duct with a uniform surface temperature. The case used a 1/4-symmetry mode] using a $5 \times 5$ channel grid with $R e=200$. The code results are compared with an analytical expression for the Nusselt number presented in Kays and Crawford (1980). Since the analytical expression is based on a fully developed velocity profile at the inlet, an entry length is used to develop the velocity profile before the surface temperature is changed. A total of 30 axial levels were used, 15 for the developing flow region and 15 for the developing thermal region. 
The comparison of COBRA-SFS results with values from the analytical expression in Kays and Crawford (1980) is presented in Table 5.2. The expression for mean Nusselt number for a square duct in given as

$$
N u_{m}=2.98+0.11 / x^{+}
$$

The Nusselt number determined from the COBRA-SFS solution is calculated using the expression

$$
N u_{m}=1 / 2 x^{+} \ln 1 / \theta_{m}
$$

The results show very good comparison with analytical results, especially for higher values of $x^{+}$. The error for values at $x^{+}=0.10$ and greater is less than $1 \%$. 


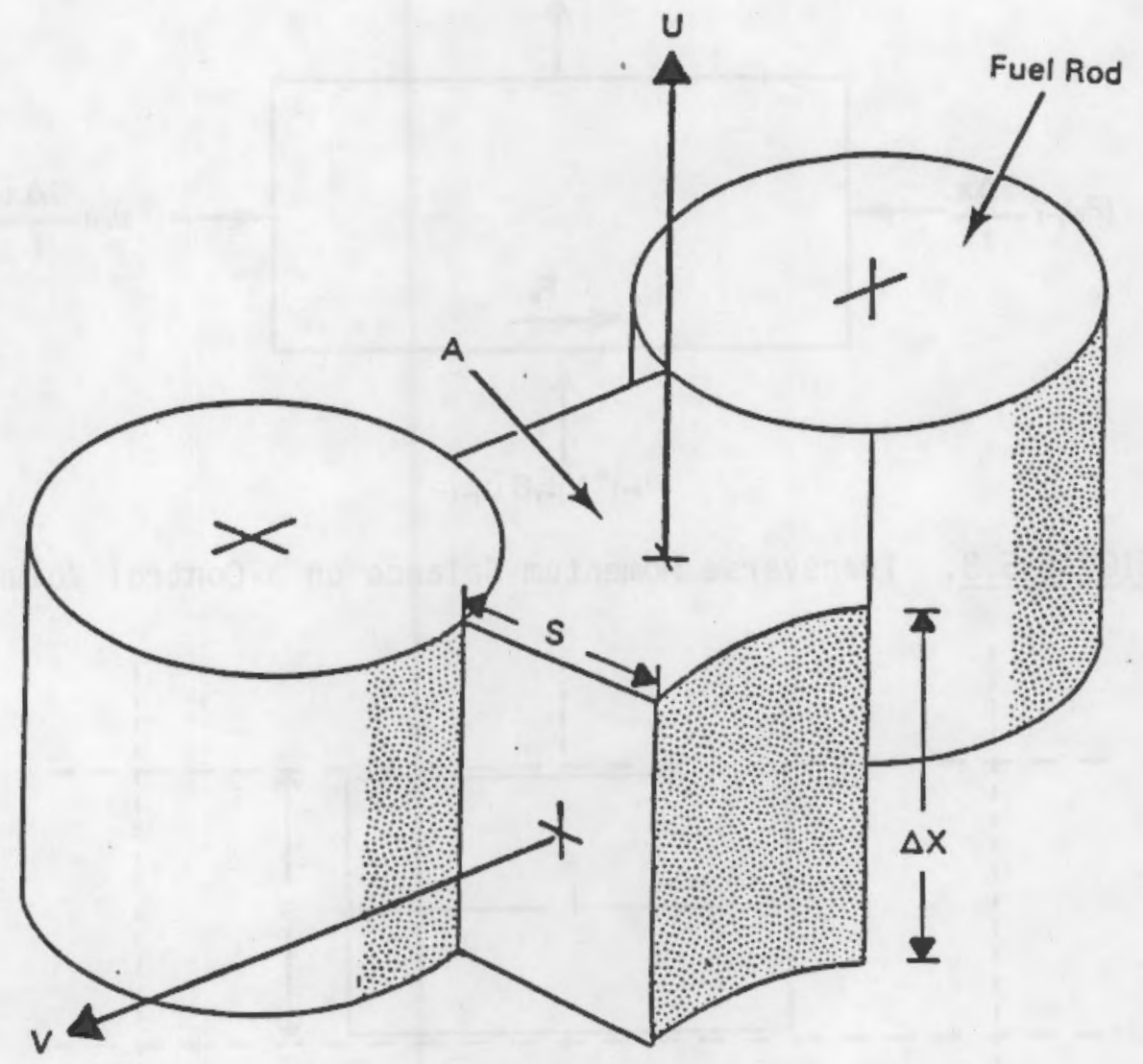

FIGURE 5.1. Subchannel Control Volume

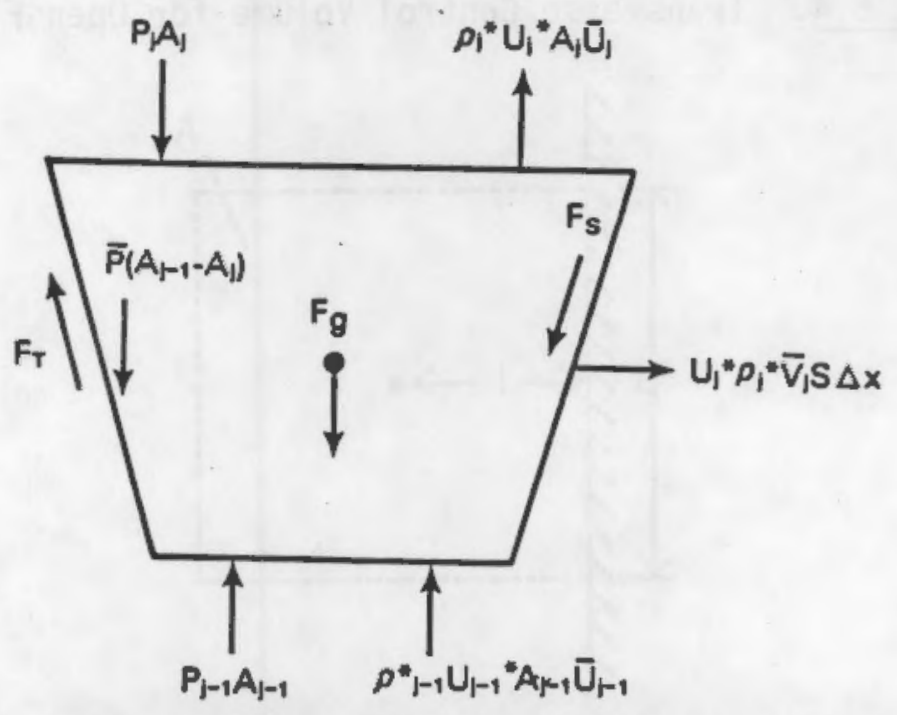

FIGURE 5.2. Axial Momentum Balance on a Subchannel Control Volume 


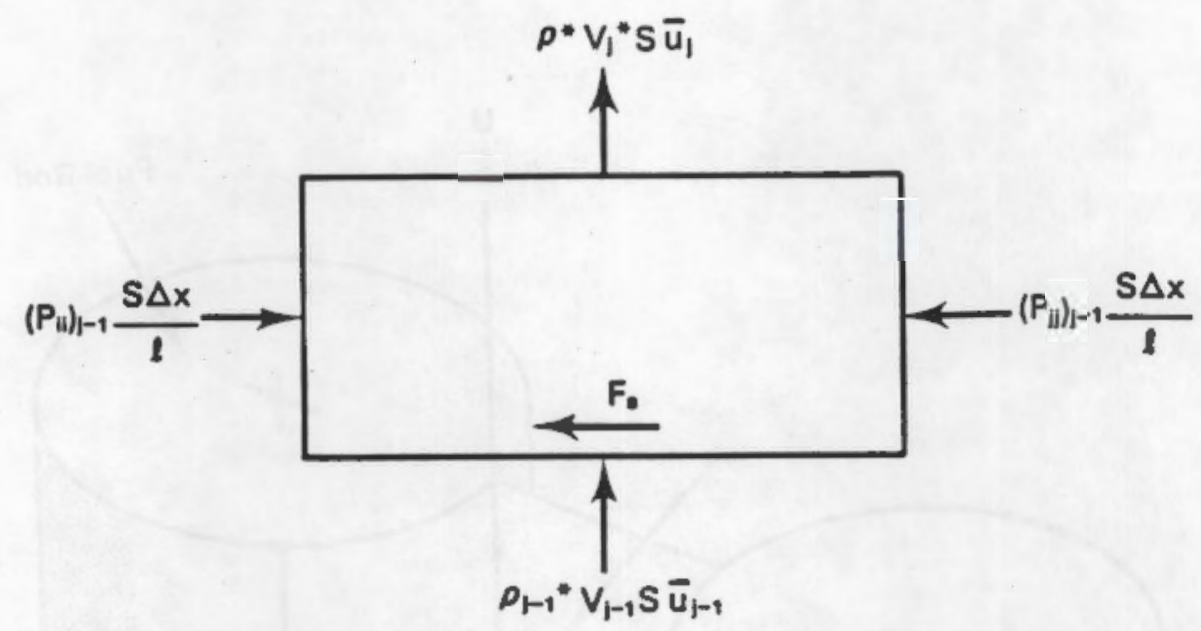

FIGURE 5.3. Transverse Momentum Balance on a Control Volume

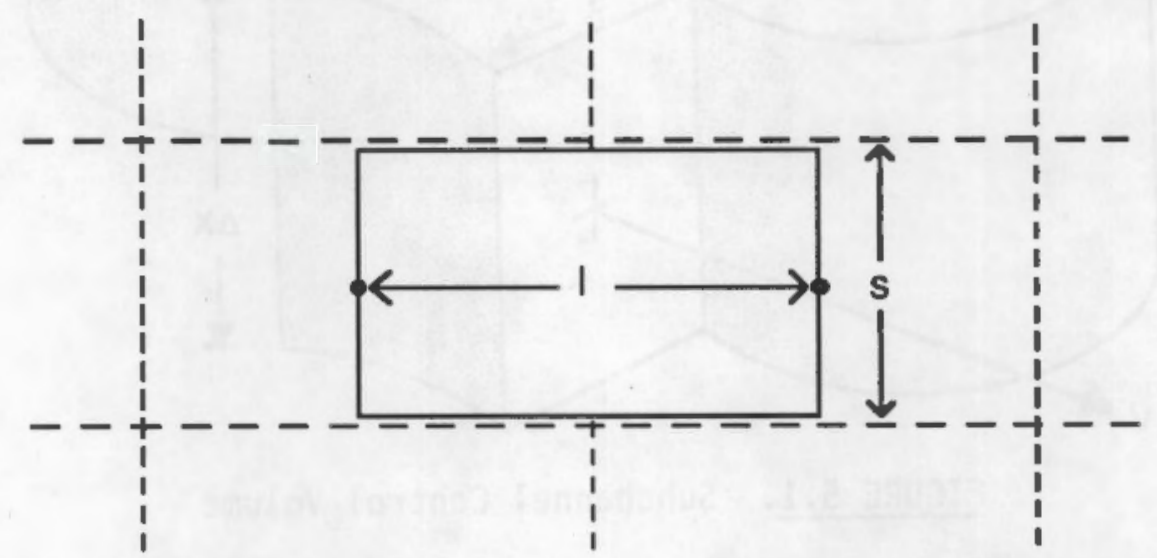

FIGURE 5.4. Transverse Control Volume for Open Flow Region

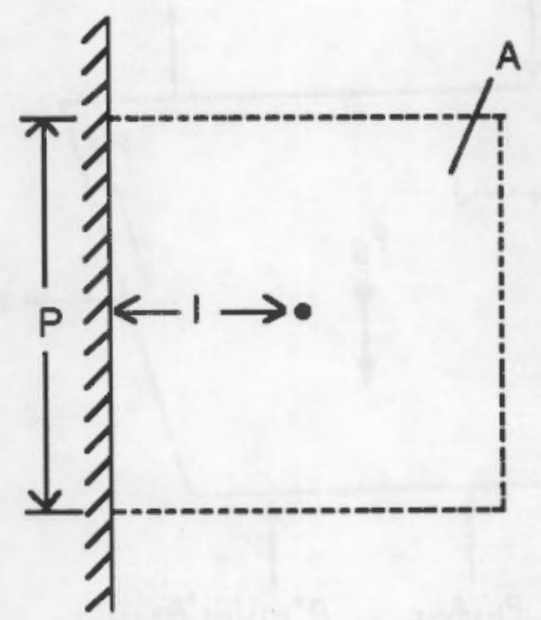

FIGURE 5.5. Control Volume for Wall Shear Stress 


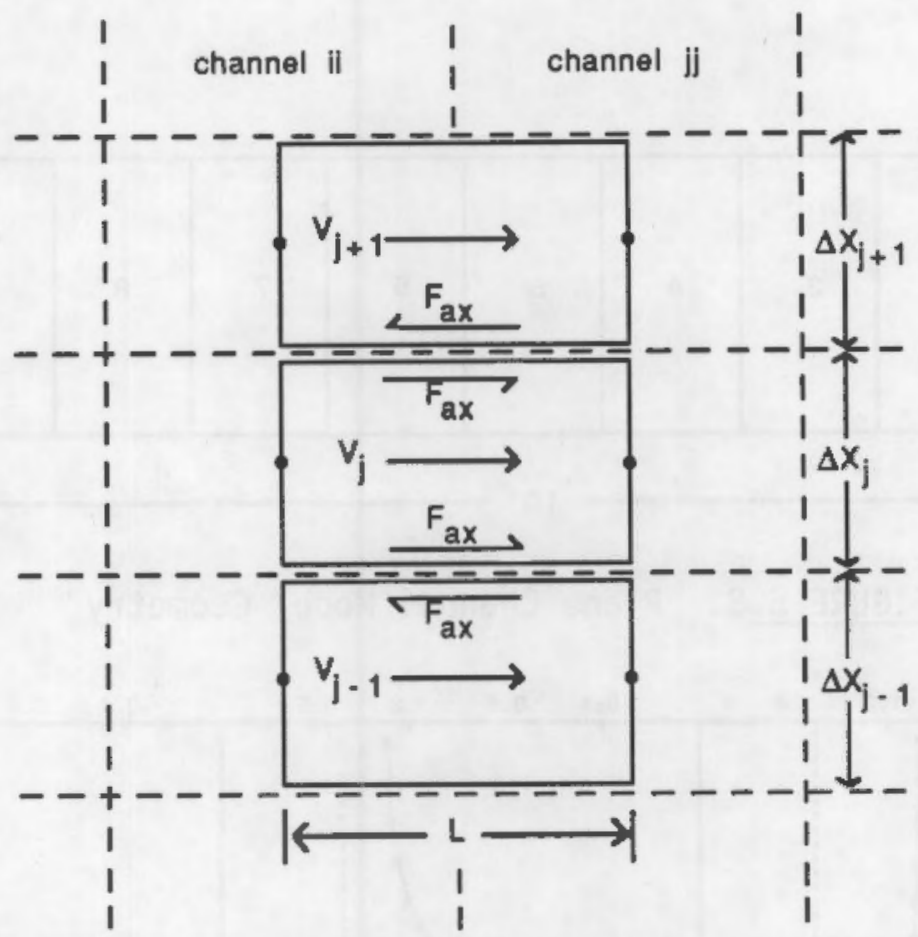

FIGURE 5.6. Axial Transfer of Transverse Momentum

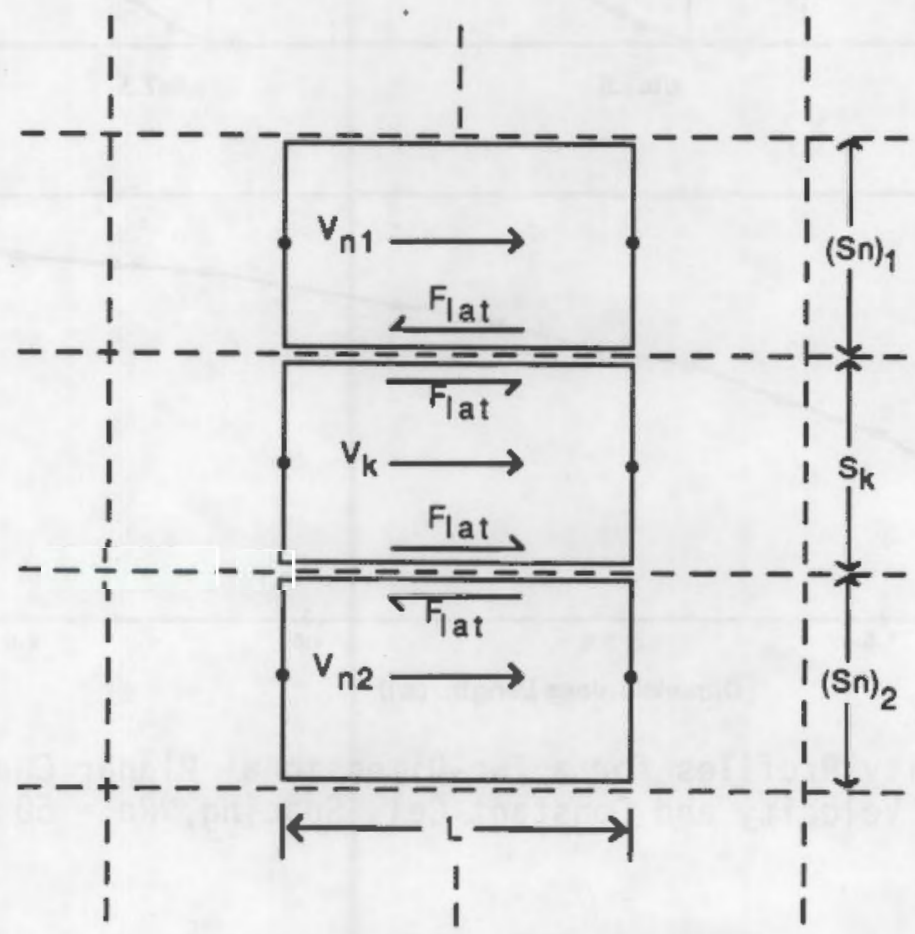

FIGURE 5.7. Lateral Transfer of Transverse Momentum 


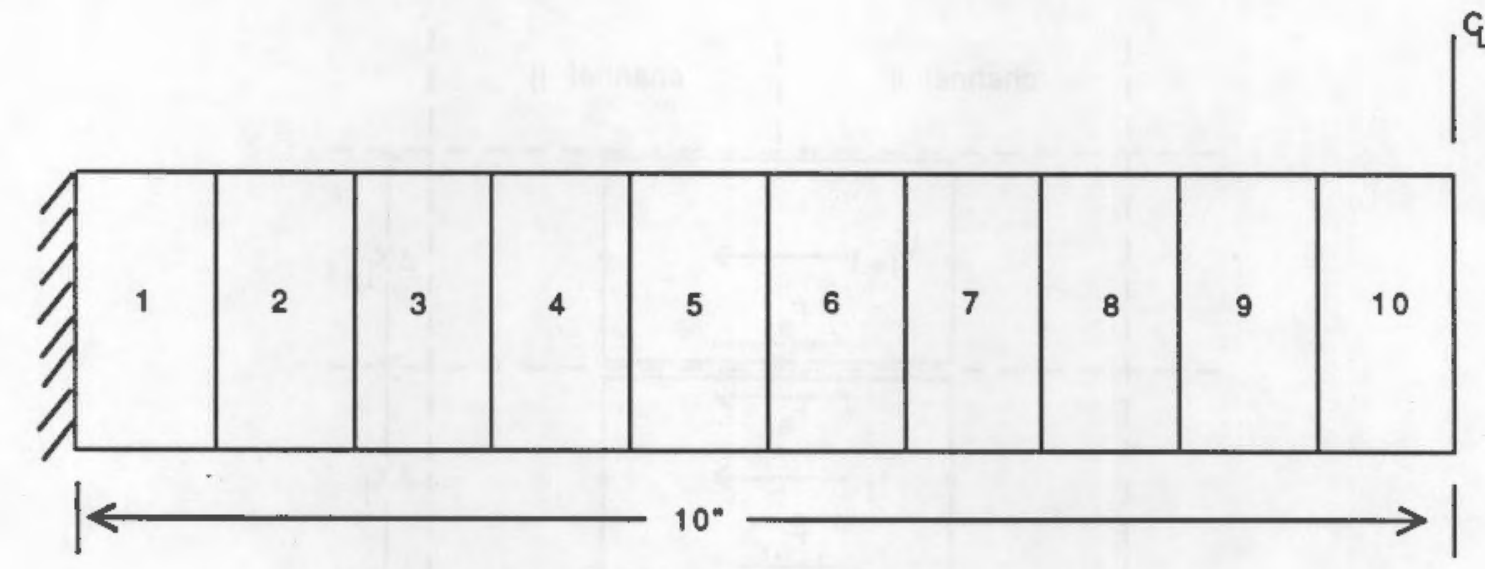

FIGURE 5.8. Plane Channel Model Geometry
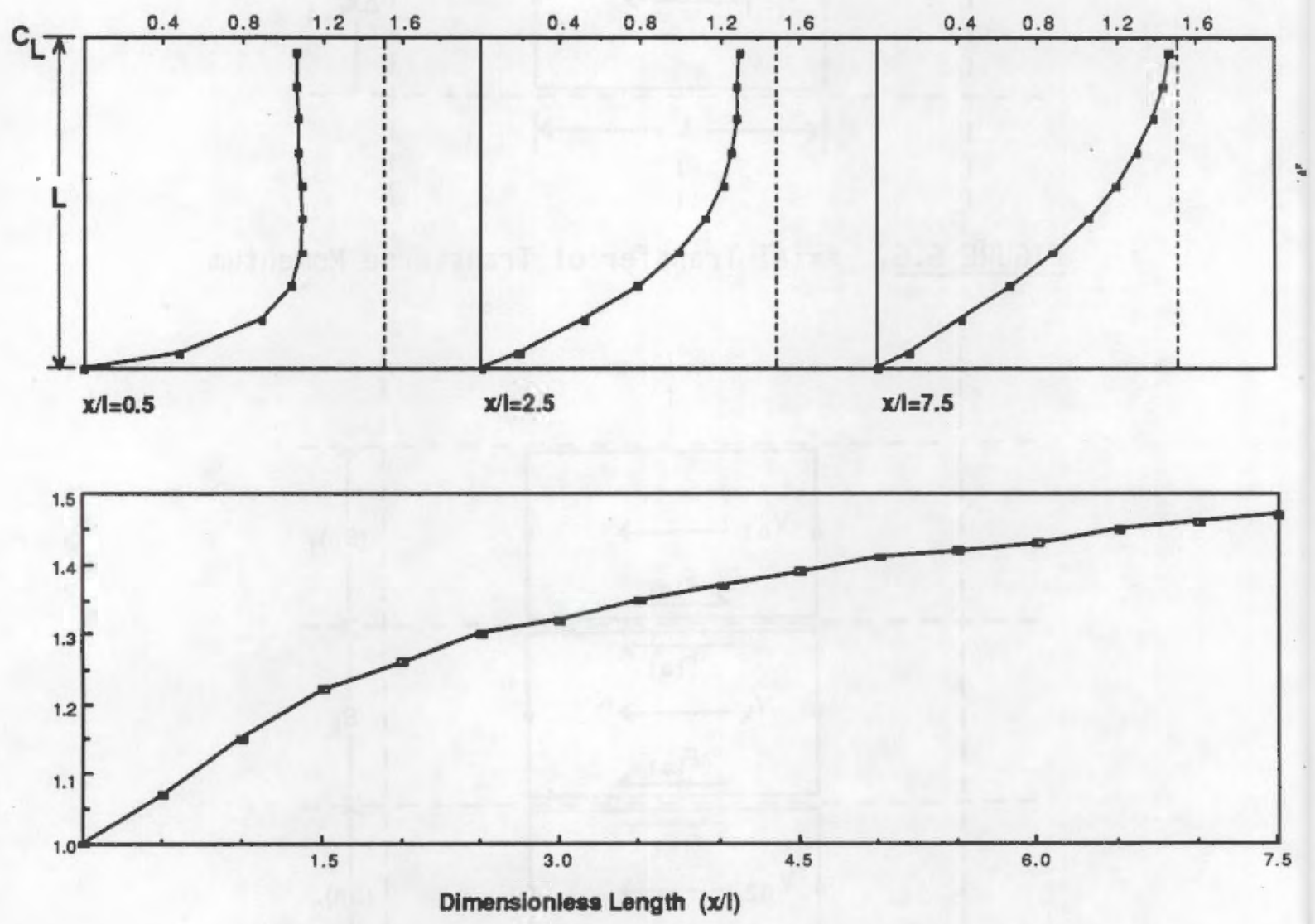

FIGURE 5.9. Velocity Profiles for a Two-Dimensional Planar Channel with Uniform Inlet Velocity and Constant Cell Spacing, Re $=50$ Case 

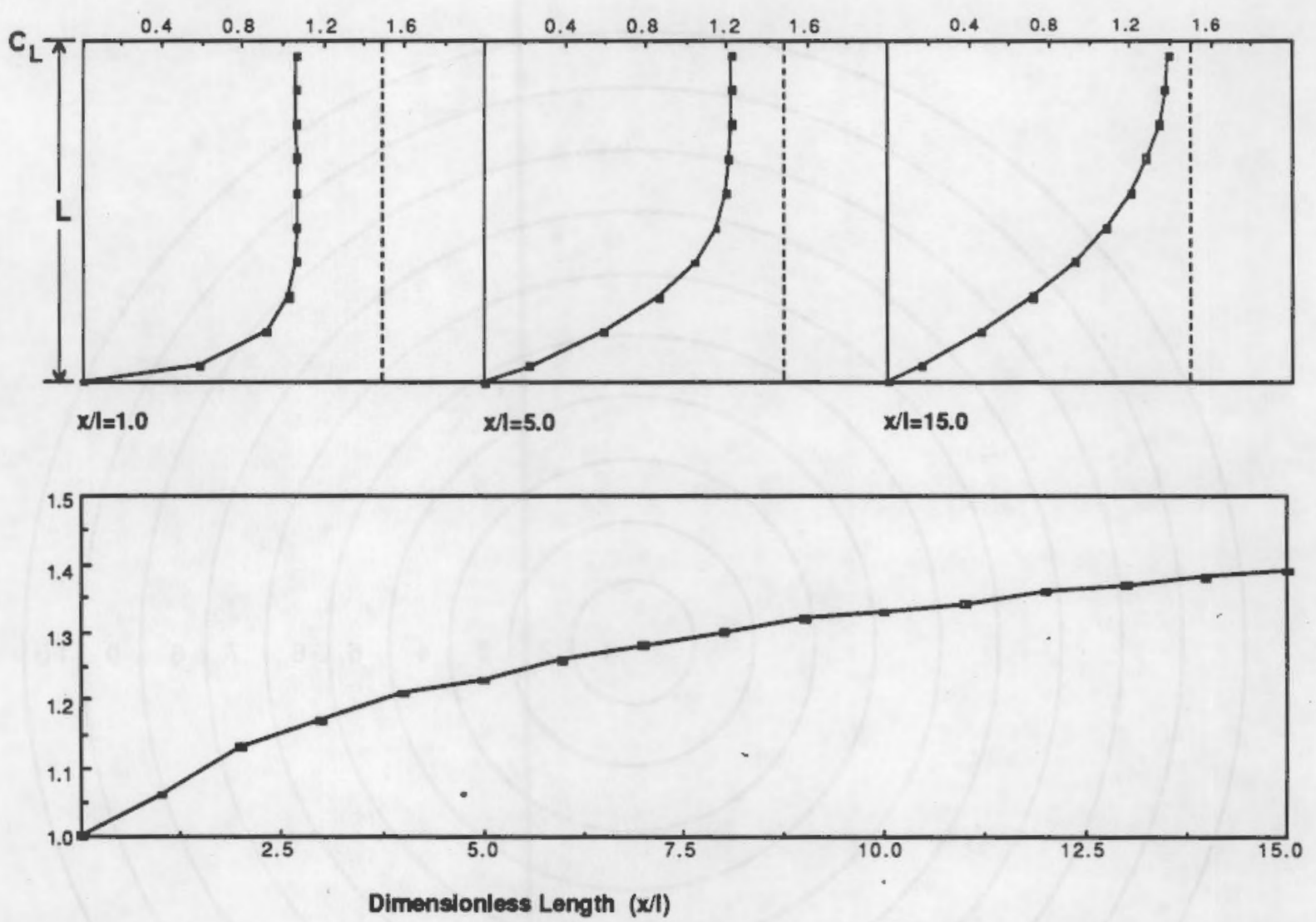

FIGURE 5.10. Velocity Profiles for a Two-Dimensional Planar Channel with Uniform Inlet Velocity and Constant Cell Spacing, Re $=200$ Case 


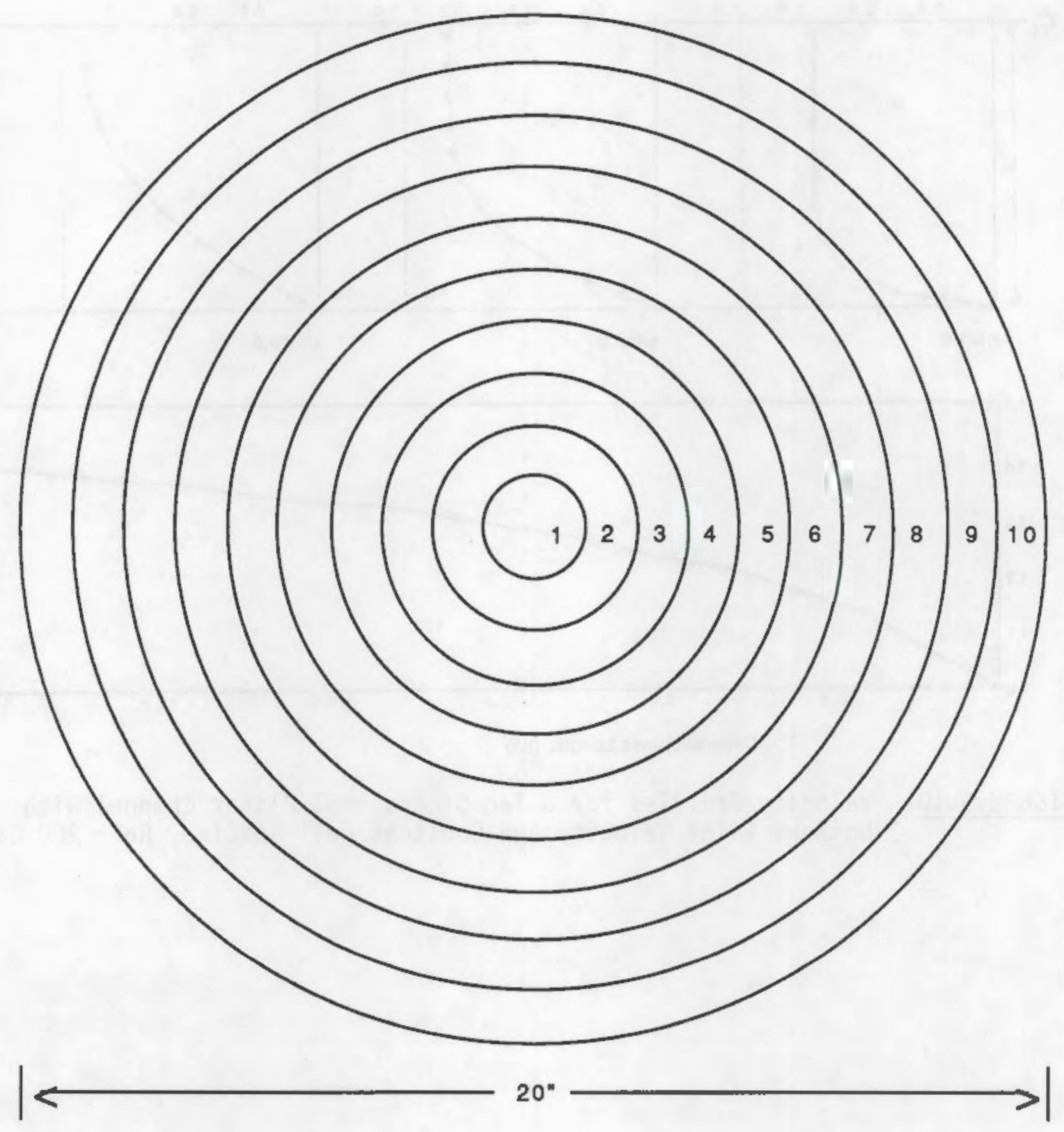

FIGURE 5.11. Cylindrical Pipe Model Geometry 

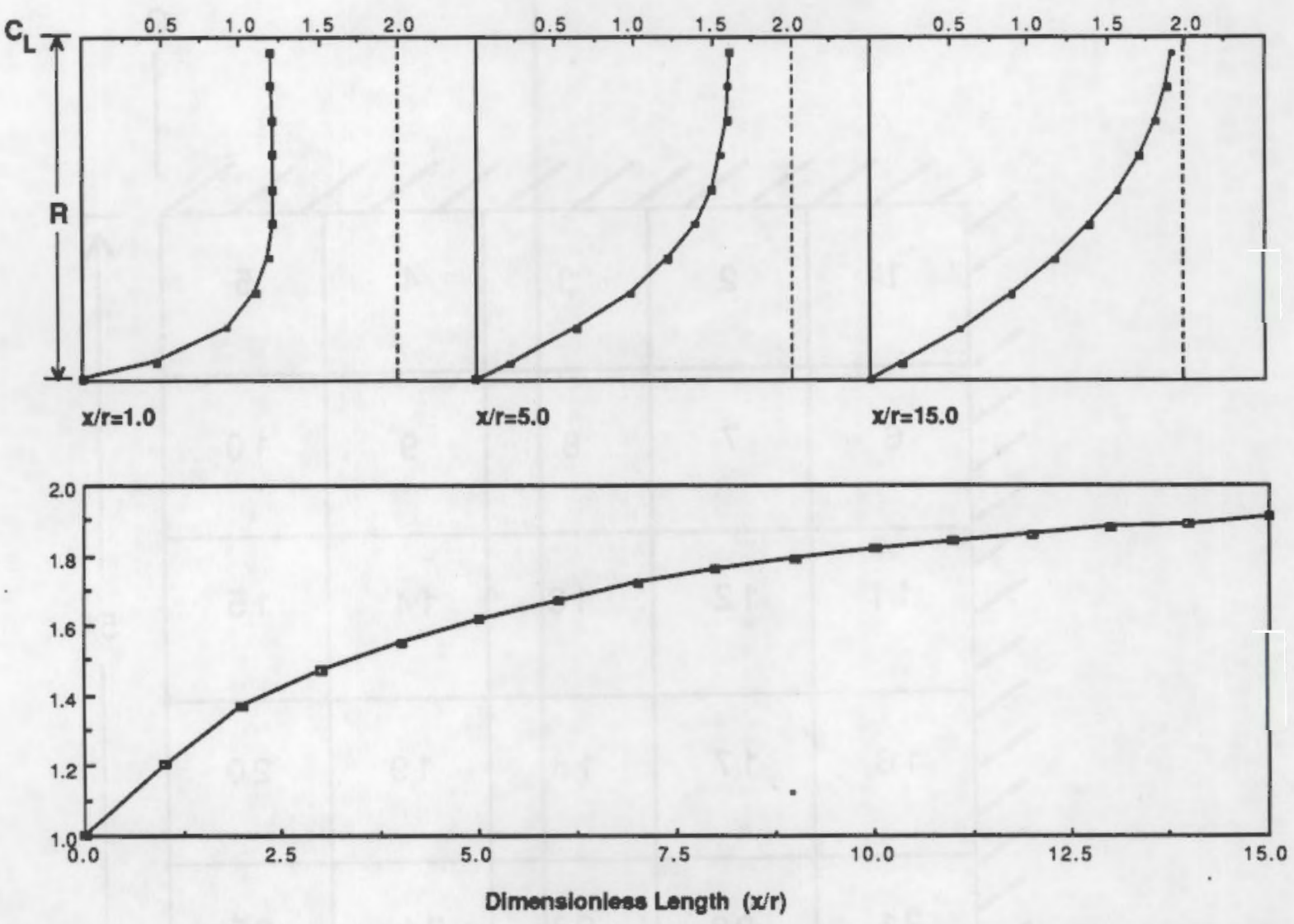

FIGURE 5.12. Velocity Profiles for a Two-Dimensional, Cylindrical-Channel Flow with Uniform Inlet Velocity and Constant Cell Spacing, Re $=100$ Case 


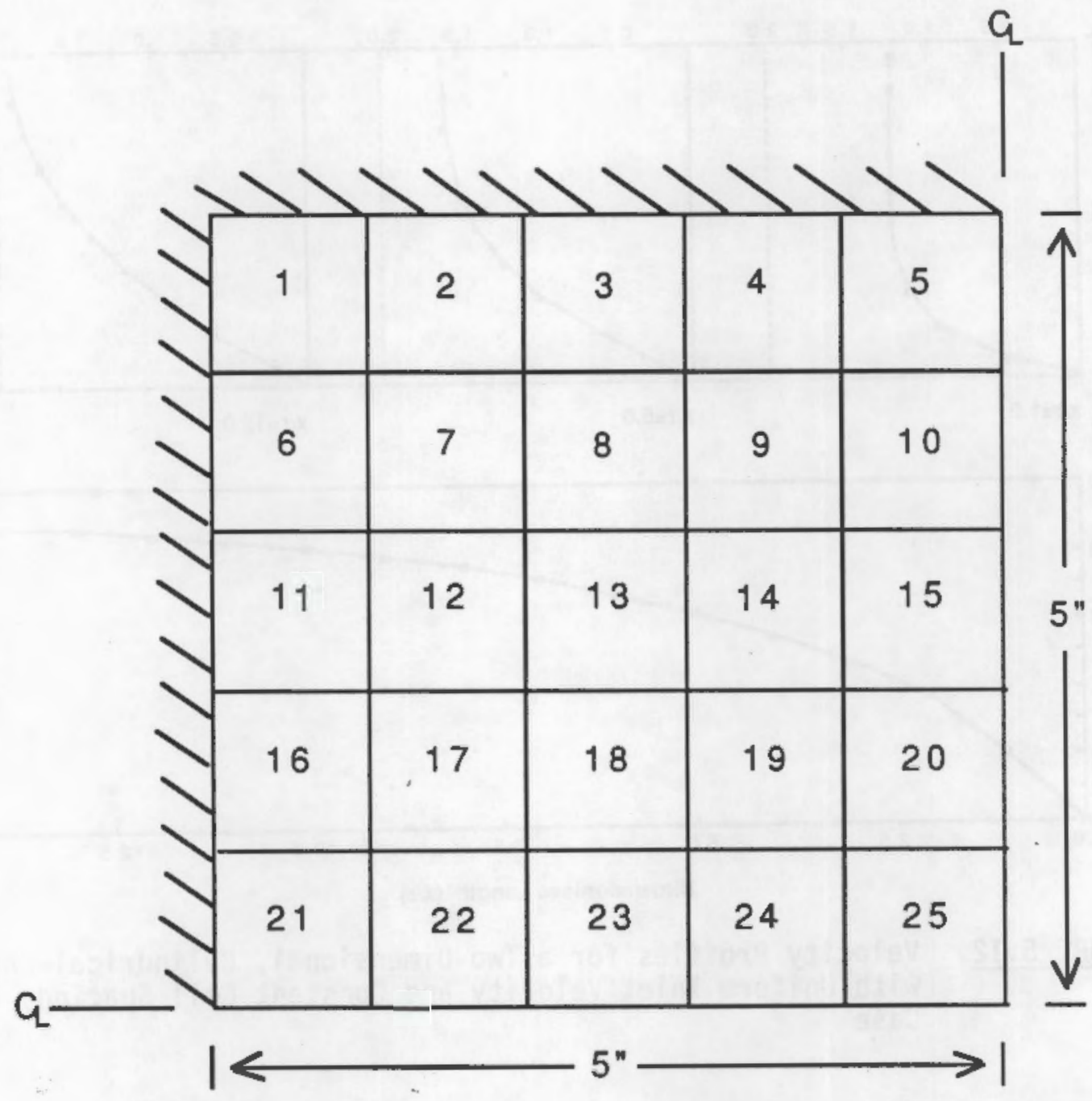

FIGURE 5.13. Square Duct Model Geometry 

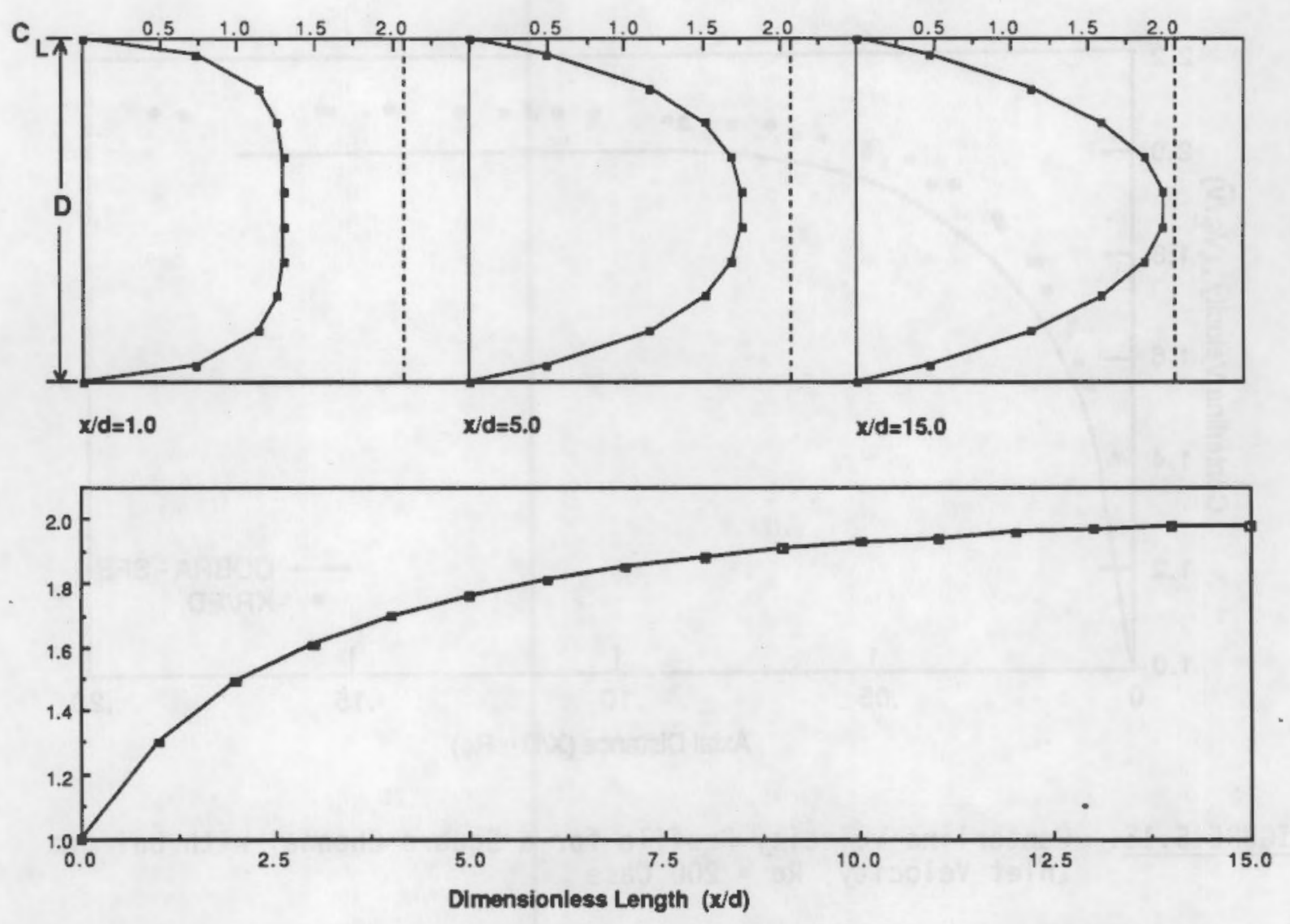

FIGURE 5.14. Velocity Profiles for a Three-Dimensional Cartesian Square Channel with Uniform Inlet Velocity, $\mathrm{Re}=200$ Case 


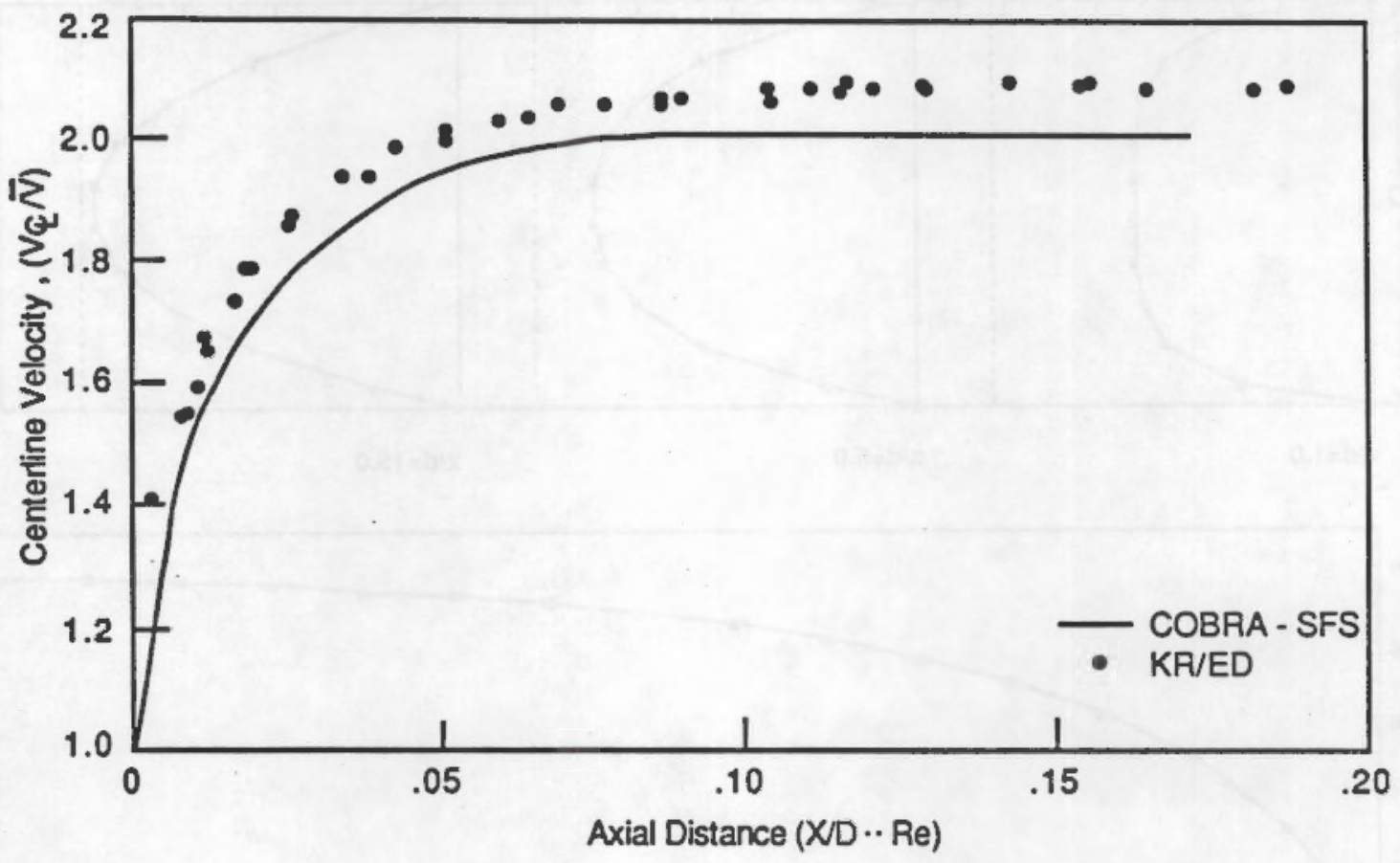

FIGURE 5.15. Centerline Velocity Profile for a Square Channel with Uniform Inlet Velocity, $\mathrm{Re}=200$ Case 
TABLE 5.1. Nusselt Numbers and Mean Temperatures for Constant Surface Temperature Pipe

\begin{tabular}{|c|c|c|c|c|c|c|}
\hline \multirow[b]{2}{*}{$x^{+}$} & \multicolumn{3}{|c|}{$\theta_{m}$} & \multicolumn{3}{|c|}{$\mathrm{Nu}_{\mathrm{m}}$} \\
\hline & Kays (1966) & $\frac{\text { COBR }}{10 \text { Channel }}$ & $\frac{- \text { SFS }}{20 \text { Channet }}$ & Kays (1966) & $\frac{\text { COBRA }}{10 \text { Channel }}$ & $\frac{- \text { SFS }}{20 \text { Channel }}$ \\
\hline 0 & 1.0 & 1.0 & 1.0 & $\infty$ & $\infty$ & $\infty$ \\
\hline 0.01 & 0.836 & 0.851 & 0.850 & 8.99 & 8.07 & 8.13 \\
\hline 0.04 & 0.626 & 0.637 & 0.634 & 5.87 & 5.64 & 5.70 \\
\hline 0.08 & 0.457 & 0.467 & 0.462 & 4.89 & 4.76 & 4.83 \\
\hline 0.10 & 0.394 & 0.404 & 0.398 & 4.66 & 4.53 & 4.61 \\
\hline
\end{tabular}

TABLE 5.2. Nusselt Numbers for Square Duct with Constant Surface Temperature

\begin{tabular}{|c|c|c|c|}
\hline \multirow[b]{2}{*}{$x^{+}$} & \multicolumn{2}{|c|}{$\mathrm{Nu}_{\mathrm{m}}$} & \multirow[b]{2}{*}{ \& Error } \\
\hline & Kays (1966) & COBRA-SFS & \\
\hline 0 & $\infty$ & $\infty$ & $\infty$ \\
\hline 0.05 & 5.18 & 4.87 & -6.0 \\
\hline 0.10 & 4.08 & 4.05 & -0.7 \\
\hline 0.15 & 3.71 & 3.71 & 0.0 \\
\hline
\end{tabular}





\subsection{PLENUM MODEL IMPROVEMENTS}

A simplified sketch of a typical spent fuel dry storage cask is shown in Figure 6.1. Convection heat transfer within the cask removes decay heat by circulating fluid up through the heated spent fuel assemblies and down through the cooler regions of the cask. A COBRA-SFS model of this cask, shown in Figure 6.2 , is divided into three regions: an upper plenum, a channel region, and a lower plenum. The upper and lower plenum models consist of single node regions where the fluid is uniformly mixed. A set of thermal connections is used to describe heat transfer between the plenum regions and a boundary temperature.

Certain assumptions are implied when a single-node plenum is used. One assumption is that there is negligible flow resistance in the plenum regions as compared to the channel region. Another is that the temperature distribution in the plenum is sufficiently uniform to not affect the heat transfer from the plenum or the temperature distribution of the fluid entering the channel region.

For many spent fuel storage applications, a single-node mixed-plenum model adequately describes the heat transfer and fluid flow in the plenum region. However, some applications require a more detailed model to accurately describe the plenum region. Improvements have been made to the COBRA-SFS code to allow detailed modeling of the plenum. The modifications are described in Section 6.1. The input changes resulting from these modifications are described in Section 6.2. In Section 6.3, the results from verification runs are compared with analytical solutions.

\subsection{DESCRIPTION OF MODIFICATIONS}

Detailed plenum model modifications added to COBRA-SFS can be grouped into two categories: changes to the flow solution and changes to the plenum heat transfer model. Descriptions of these changes are presented below. 


\subsubsection{Flow Solution Modifications}

A sketch of a typical COBRA-SFS single node plenum model is shown in Figure 6.3. The plenum is connected to the bottom axial level of the channel region so that flows enter and exit through the bottom of the channel node as shown. A detailed model of the plenum is created by extending the channel region to the bottom of the cask as shown in Figure 6.4. The plenum is divided into as many axial levels as necessary to obtain the proper resolution for the flow and temperature distributions. The plenum in the example has been divided into four axial levels.

To model the plenum in this fashion requires the addition of a new flow boundary condition option. The COBRA-SFS code currently allows three primary types of flow boundary conditions. These are:

- specified inlet flow

- specified pressure drop

- uniform pressure drop for specified total flow.

In all three cases, flow is allowed to pass through one or both ends of the channel region. Even when zero inlet flow is specified for each channel, the flows at the channel region outlet are free to move as long as the net sum is zero. A fourth flow boundary condition option has been added that specifies zero flow for both ends of each channel. The implementation of this boundary condition is described below.

The COBRA-SFS flow field solution routine is divided into two parts: a tentative flow solution and a pressure solution. The tentative flow solution is achieved by sweeping the bundle from inlet to exit. In each sweep, the

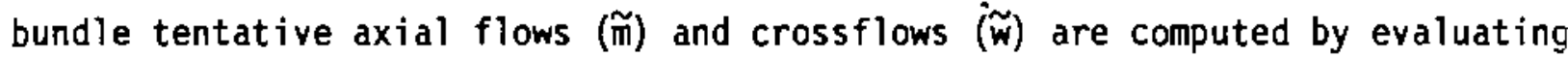
the two linearized momentum equations with current values for pressures and other variables. After all tentative flows and crossflows have been computed at all axial levels, the flows and pressures are adjusted to satisfy continuity by a Newton-Raphson method. The resulting flow field from this pressure solution is then used in the energy equation to obtain an enthalpy and fluid properties distribution for the next axial sweep. 
The tentative axial flows ( $\tilde{\mathrm{m}})$ are calculated by solving a set of linearized momentum equations of the form

$$
[A] \tilde{m}_{j}=-g_{c} A_{j}\left(\tilde{P}_{j}-\tilde{P}_{j-1}\right)+B
$$

where $[A]$ is the coefficient matrix, $\mathbb{P}$ are the previous iterate values for pressure and $B$ is the source term.

When the zero flow option is selected, the inlet flows are set equal to zero. The outlet flows at the top axial level are made to have very smali values by modifying the set of linearized monentum equations. The diagonal elements of matrix [A], designated $A_{i j}$, are added to an extremely large value while the source term remains unchanged. This results in tentative axial flows that are negligibly small while not affecting the calculation of crossflows.

During the pressure solution both the pressure and flow fields are adjusted to satisfy continuity. Estimated pressure changes $\left(\delta P^{\prime}\right)$ are calculated using a Newton-Raphson method. The new axial flows are calculated using the expression

$$
m_{j}^{\prime}=\tilde{m}_{j}+\frac{\partial \tilde{m}_{j}}{\partial P_{j-1}} \delta P_{j-1}^{\prime}
$$

The derivative term is defined as

$$
\frac{\partial m_{j}}{\partial F_{j-1}}=\frac{g_{c} A_{j}}{A_{i j}}
$$

Because the diagonal term, $A_{i}$, has been set to an extremely large number, the changes in the pressure field will have a negligible effect on the tentative axial flows at the top axial level. 
When crossflows along the top or bottom of the channel region are adjacert to a free surface, transverse shear stress from the surface can be neglected. If, however, the crossflows are adjacent to a solid no-slip surface, shear stress terms must be included. For example, the force due to transverse shear stress in the axial direction is expressed as

$$
F_{a x}=\operatorname{se}\left[\frac{2 \mu_{j} v_{j}}{\Delta x_{j}}+\frac{2 \mu_{j+\frac{1}{2}}\left(v_{j}-v_{j+1}\right)}{\Delta x_{j}+\Delta x_{j+1}}\right]
$$

for the bottom axial level. This expression is similar to Equation (5.8) except that the adjacent transverse velocities have a specified value of zero and the axial distance is one-half the width of the current axial level.

\subsubsection{Plenum Heat Transfer Modifications}

The change from a single node to a detailed plenum also affects the models used to represent heat transfer from the plenum. When single node plenums are used, each plenum has an axial and radial one-dimensional thermal connection between the fluid in the plenum and a boundary temperature. Different boundary temperatures may be specified for each direction. The connection, similar to that used in the side boundary specification, may consist of one or a series of regions, with each region having a different expression for heat transfer. These expressions take the form

$$
\begin{aligned}
q_{\text {boundary }}^{\prime \prime}=C_{1}\left[C_{2}\left(T_{i}-T_{i+1}\right)^{C_{3}}\right]\left(T_{i}-T_{i+1}\right) \\
+\sigma\left(\frac{1}{\epsilon_{i}}+\frac{1}{\epsilon_{i+1}}-1\right)^{-1}\left(T_{i}^{4}-T_{i+1}^{4}\right)
\end{aligned}
$$

where $C_{n}=$ user defined constants

$T_{i}=$ temperature for boundary regin $i$

$\sigma=$ Stefan-Boltzmann constant

$\epsilon_{i}=$ surface emissivity for boundary region $i$. 
In addition, each plenum region can have thermal connections to solid structure nodes of the channel region in the axial level adjacent to the plenum. These connections are used to represent axial heat transfer from the cask body or heat transfer from the basket to the bottom or top of the cask.

The fluid enthalpies and flow rates entering the plenum as well as temperatures of the solid structure nodes connected to the plenum are computed in the energy solution for the axial level adjacent to the plenum. These values are then held fixed while the plenum equations are solved. The resulting plenum structure temperatures and plenum fluid enthalpy are held fixed for the next iteration of the rod, fluid, and slab energy solution.

When a detailed plenum model is used, the radial plenum heat transfer path is replaced by solid structure nodes and the side heat transfer model for the channel region, since the channel region now extends to the top and bottom surfaces of the flow region. This offers a great deal more detail because each one-dimensional heat transfer region can be represented by several solid structure nodes. In addition, heat transfer can be modeled in the axial and circumferential directions in addition to the radial direction.

The axial heat transfer from the plenum is still modeled using a series of one-dimensional heat transfer regions. However, instead of connecting to the single node plenum, the innermost surface connects to each individual channel node in the top or bottom axial level by fluid conduction, as shown in Figure 6.5. The heat removed from channel $i$ is given by the expression

$$
Q_{j}=\frac{2 A_{j} k_{i}}{\Delta x}\left(T_{i}-T_{1}\right)=U_{i}\left(T_{i}-T_{1}\right)
$$

where $A_{i}$ is the cross-sectional area of channel $i$

$k_{i}$ is the fluid thermal conductivity

$T_{i}$ is the fluid temperature

$T_{1}$ is the top or bottom surface temperature.

The total heat transfer from an axial level can be expressed as 


$$
\begin{aligned}
Q=\sum Q_{i} & =\sum U_{i}\left(T_{i}-T_{1}\right) \\
& =U_{\text {total }}\left(\tilde{T}-T_{1}\right)
\end{aligned}
$$

$$
\text { where } \begin{aligned}
& U_{\text {total }}=\Sigma U_{i} \\
& \tilde{T}=\Sigma U_{i} T_{i} \\
& U_{\text {total }}
\end{aligned}
$$

The fluid temperatures are held constant while the temperature distribution through each end of the cask is computed. The surface temperatures are then used as boundary conditions for the fluid and slab energy solution.

\subsection{INPUT CHANGES}

As a result of the modifications to the plenum model described in Section 6.1, changes have been made to the COBRA-SFS input structure. These changes are described below on a line-by-line basis. The input description used here is similar to that used in the COBRA-SFS user's manual (Rector et al. 1986b). (Variable description is given only for new data available with this option.)

OPER , 1 AGROUP, IHH, IG, ITDP, NRPF , NP, NH, NG, NGPRFL, NHX, NQ, NQPRFL, NDPA, NRAMPH, NAXP FORMAT $(A 4,1 X, 14 I 5)$

Columns Variable Description

16-20 ITDP

Flag for flow or pressure drop boundary conditions:

$=0$ i specified flow boundary conditions.

$=1$; uniform pressure drop (specified in DPS on OPER .2).

$=2$ i pressure drop resulting in uniform inlet mass flux.

= 3; uniform pressure drop calculated for total mass flow rate (FTOTAL on OPER.2). 
$=4$; zero flow at both top and bottom boundaries.

The boundary condition for the flow field solution is specified by variable ITDP. The options include a specified inlet flow distribution (ITDP=0), a pressure drop across the channel region (ITDP=1), and total flow rate for the problem (ITDP=3). An additional flow boundary condition option (ITDP=4) has been added that specifies zero flow at the top and bottom surfaces of the channel region for each individual channel. When this option is used, the inlet mass flux (GIN), system pressure drop (DPS), and total flow rate (FTOTAL), which are read on OPER.2, are ignored.

When the zero flow boundary condition is used, the entire fluid volume is represented by the channel region and is divided into axial levels. For example, a natural circulation system can be modeled using 20 axial levels in the channel region and an upper and lower plenum region. If the zero flow option is used, each plenum region may be divided into four axial levels, resulting in a total of 28 axial levels and no common plenum regions. This change would affect several other input variables, including the number of axial nodes (NDX[CHAN.1]), the axial length of the channel region (Z[CHAN.2]), and all the tables based on axial position such as channel and gap variations (AXL[VARY.2]) and GAPXL[VARY.5]), side boundary temperatures (ZENDT[BDRY.3]) and axial power distribution (AXIAL[OPER.17]).

BDRY.6 IPLENR(N), AWPS(N), AWPAX $(N), \operatorname{NPSID}(N), N \operatorname{NaAX}(N), \operatorname{TAMBP}(1, N), \operatorname{TAMBP}(2, N)$, $\operatorname{QPSRC}(1, N), \operatorname{QPSRC}(2, N)$

Read only if NPR $>0$ on BDRY.1 FORMAT $(15,2 \mathrm{~F} 5.3,2 \mathrm{I} 5,4 \mathrm{~F} .3)$

Columns Variable Description

1-5 IPLENR(N)

Flag for plenum region under consideration:

$=1$; lower plenum.

$=2$; upper plenum.

6-10 AWPS $(N) \quad$ Nomical plenum radial heat transfer area $\left(i n .{ }^{2}\right)$. 


\begin{tabular}{|c|c|c|}
\hline Columns & Variable & Description \\
\hline $11-15$ & $\operatorname{AWPAX}(\mathrm{N})$ & Nominal plenum axial heat transfer area $\left(\right.$ in. $\left.{ }^{2}\right)$. \\
\hline $16-20$ & $\operatorname{NPSID}(\mathrm{N})$ & Number of radial plenum boundary regions. \\
\hline $21-25$ & $\operatorname{NPAX}(\mathrm{N})$ & Number of axial plenum boundary regions. \\
\hline $26-30$ & $\operatorname{TAMBP}(1, N)$ & Plenum radial boundary temperature, $(F)$. \\
\hline $31-35$ & $\operatorname{TAMBP}(2, N)$ & Plenum axial boundary temperature, $(F)$. \\
\hline $36-40$ & $\operatorname{QPSRC}(1, N)$ & $\begin{array}{l}\text { Optional plenum radial boundary heat flux, (Btu/h-ft2) } \\
\text { (applied to the outermost plenum radial region only). }\end{array}$ \\
\hline $41-45$ & $\operatorname{QPSRC}(2, N)$ & $\begin{array}{l}\text { Optional plenum axial boundary heat flux, (Btu/h-ft2) } \\
\text { (applied to the outermost plenum axial region only). }\end{array}$ \\
\hline
\end{tabular}

Input 1 ines BDRY. 6 through BDRY. 8 describe the heat transfer model from the plenum regions. When the common plenum regions are used, heat is removed through one-dimensional heat transfer paths in the radial and axial directions. When the zero flow option is specified (ITDP[OPER.1]=4), the radial plenum heat transfer path is replaced by the channel region side thermal boundary model. The values for $\operatorname{AWPS}(N), \operatorname{NPSID}(N), \operatorname{TAMBP}(1, N)$, and $\operatorname{QBSRC}(1, N)$ are not used.

The number of connections in the axial heat transfer path (NPAX) is also redefined. When the common plenum regions are used, the first connection describes the heat transferred between the mixed fluid in the plenum and the bottom surface. When the zero flow option is specified, the heat transfer is assumed to be by fluid conduction between the mid-point of each channel node in the bottom axial level and the bottom surface. Therefore, since the fluid.to-surface region does not need to be specified, the value for $\operatorname{NPAX}(N)$ will be one less when the zero flow option is specified. 
BDRY.7 I, SPERP(K, $1, \operatorname{IPL}(N)), \operatorname{NPTYP}(I, 1, I P L(N)), N P W N,(I P I N T P(I, J), \operatorname{MATTYPP}(K, J)$, $\operatorname{AREAXCP}(K, J), D X P L E N(J), J=1, N P W N), i=1, N P S I D(N)$ [BDRY.6])

Read only if NPSID(N) >0 on BDRY. 6

FORMAT $(I 5, F 5.3,2 I 5,3(2 I 5,2 F 5.3))$

Columns Variable $1-5 \quad I$

6-10 SPERP(I, 1, IPL (N))

11-15 $\operatorname{NPTYP}(\mathrm{I}, 1, \mathrm{IPL}(\mathrm{N}))$

$16-20 \quad$ NPWN

21-25, IPINTP $(\mathrm{I}, \mathrm{J})$

$41-45$,

$61-65$

26-30, $\operatorname{MATTYPP}(\mathrm{I}, \mathrm{J})$

46-50,

$66-70$

31-35 AREAXCP $(I, J)$

$51-55$

$71-75$

36-40 DXPLEN(I,J)

$76-80$

Description

Plenum radial region number. (Note: Regions must be numbered sequentially from 1 to $\operatorname{NPSID(N).)}$

Plenum radial region heat transfer area multiplier, (normalized to AWPS(N) on BDRY.6).

Thermal connection type for connections between solid structure nodes and plenum radial region 1. (Note: This must correspond to a boundary connection type defined on BDRY.2.)

Number of solid structure nodes connected to plenum radial region 1 .

Identification number of the Jth solid node connected to plenum radial region $I$.

Identification number of the material type for the connection between node IPINTP(I,J) and plenum axial region I.

Heat transfer area for connection $\mathrm{J}$ from solid node IPINTP(I,J) to plenum region I. (Default is node IPINTP $(I, J)$ cross sectional area for axial conduction; WALLCX, specified on SLAB.3.)

Length (in.) for heat transfer from node $\operatorname{IPINTP}(I, J)$ to the center of plenum radial region I. INote: Up to 3 sets of values for IPINTP, MATTYPP, AREAXCP, and DXPLEN may be read on a line. If NPWN is greater than 3, repeat this line starting at column 21 as many times as necessary to define NPWN sets of values.

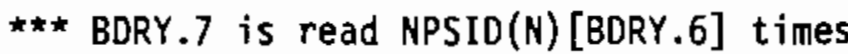

Input line BDRY.7 describes the radial regions for the plenum heat transfer model. When the zero flow boundary option is specified (ITOP[OPER.1]=4), the 
radial heat transfer path is replaced by the channel region side thermal boundary model and input 1 ine BDRY. 7 is not read.

\subsection{VERIFICATION ASSESSMENT}

A detailed plenum model and shear stress terms were added to COBRA-SFS to accurately model buoyant convection flow in an open square cavity. Verification cases, representing simple flow problems, were run to assess the new plenum model.

The COBRA-SFS simulation was performed with the fluid shear stress terms included. The wall shear was modeled using the laminar zero slip wall boundary condition. The heat transfer at the wall was modeled by laminar conduction. The zero flow boundary condition described in Section 6.1 was applied to the flow section.

Both vertical walls of the test simulation geometry were assumed to be constant-temperature boundaries of $155^{\circ} \mathrm{F}$ and $70^{\circ} \mathrm{F}$, respectively. The top and bottom surfaces were assumed adiabatic. The simulation was run with constant cell spacing ( 10 cells in the horizontal direction and 28 cells in the vertical direction). The convecting medium was air. The geometry of the problem is shown in Figure 6.6. The output for this case is presented in Appendix D.

A comparison of COBRA-SFS results and experimental data is shown in Figure 6.7. The experimental results of Eckert and Carlson (1961) in a 10:1aspect-ratio cavity were chosen to verify the new models. The temperature distribution at the three axial levels is displayed. In general, the agreement between the data of Eckert and Carlson and the COBRA-SFS predictions are excellent. 

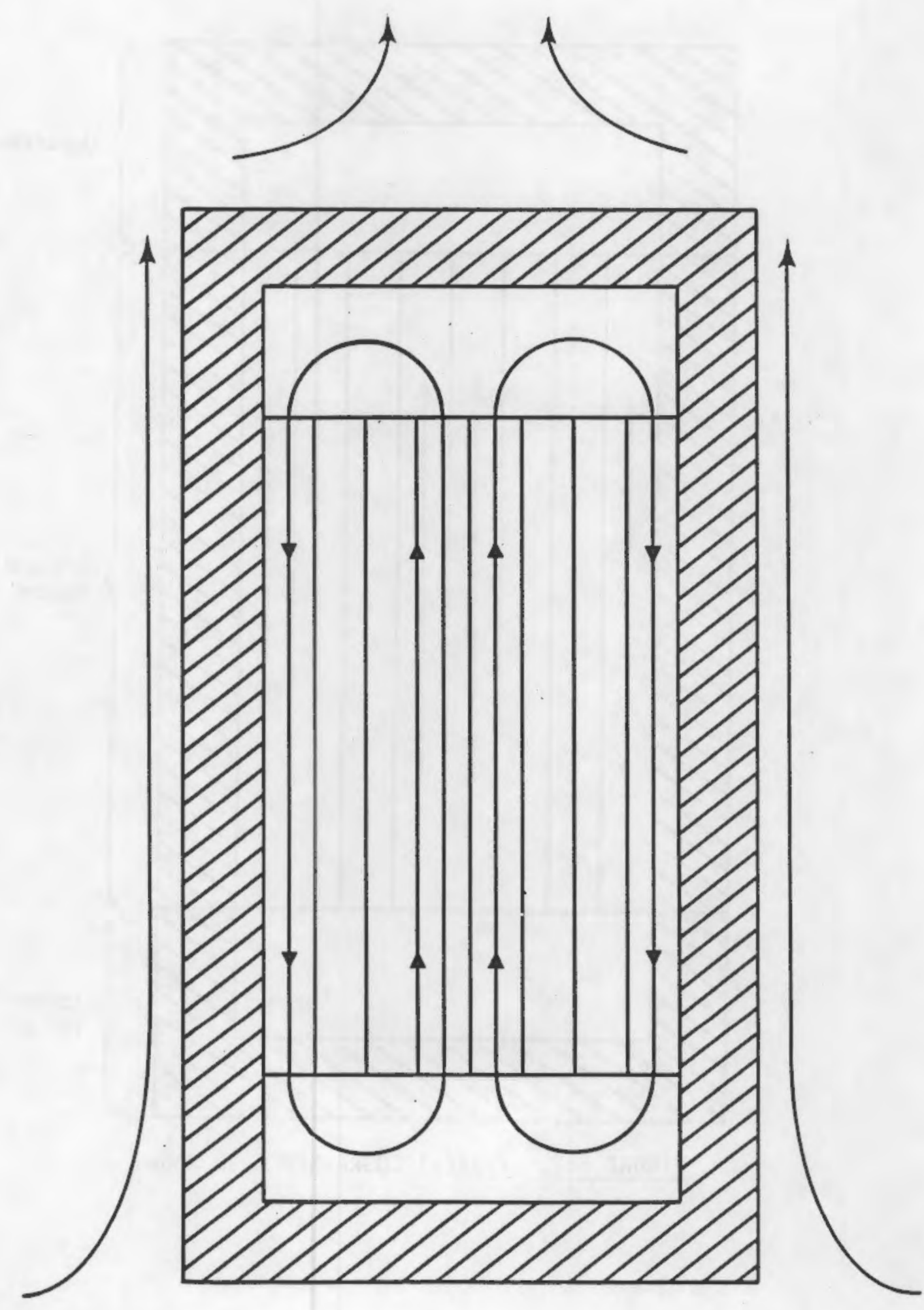

FIGURE 6.1. Cut-Away Sketch of a Typical Spent Fuel Cask 


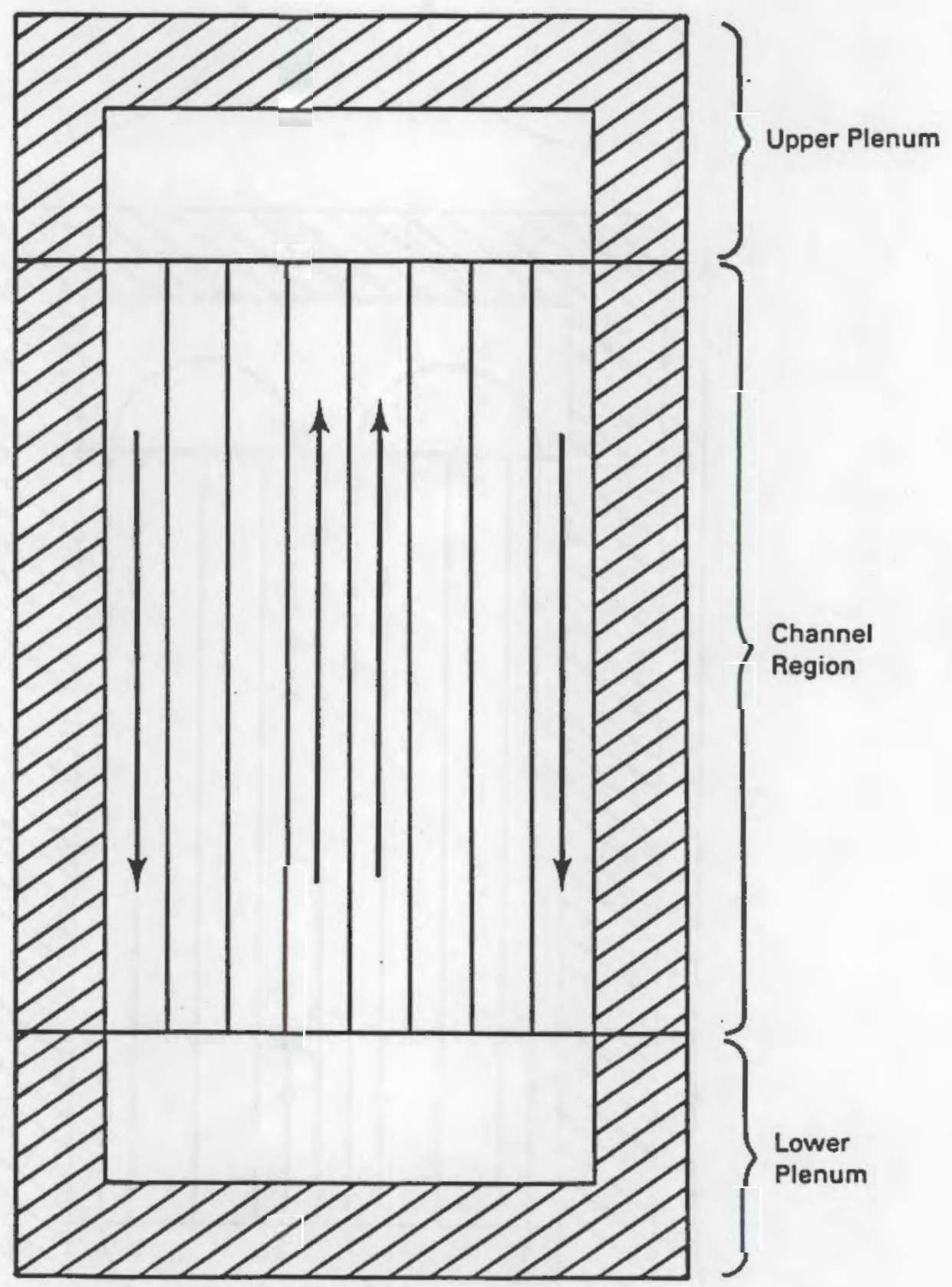

FIGURE 6.2. Typical COBRA-SFS Cask Model 


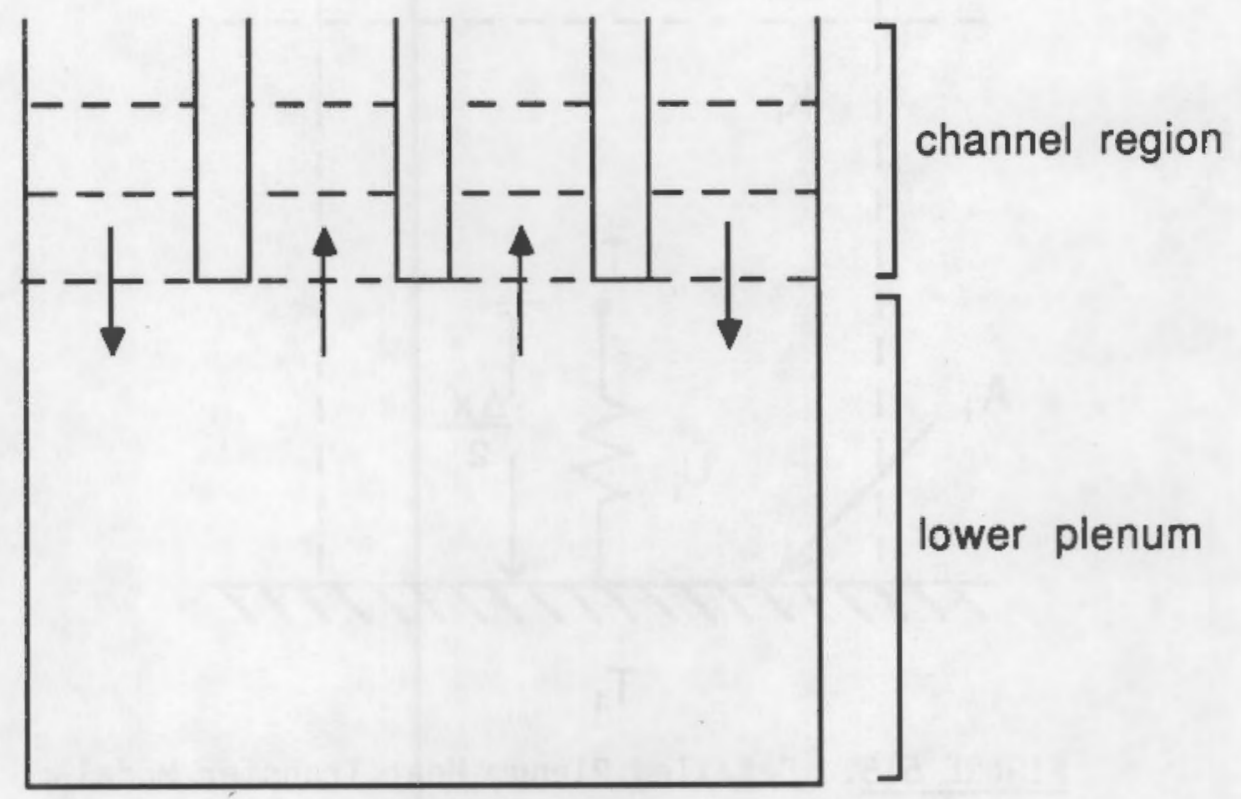

FIGURE 6.3. COBRA-SFS Plenum Model

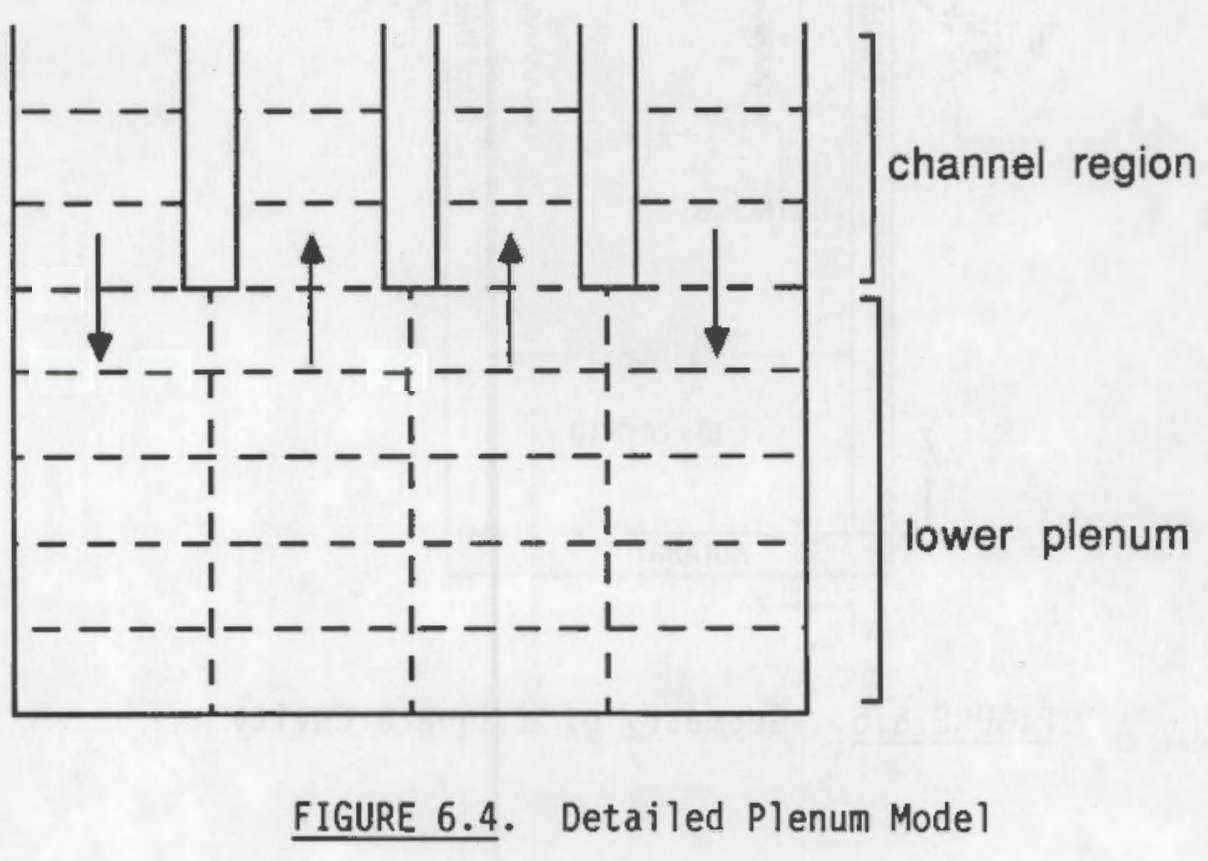




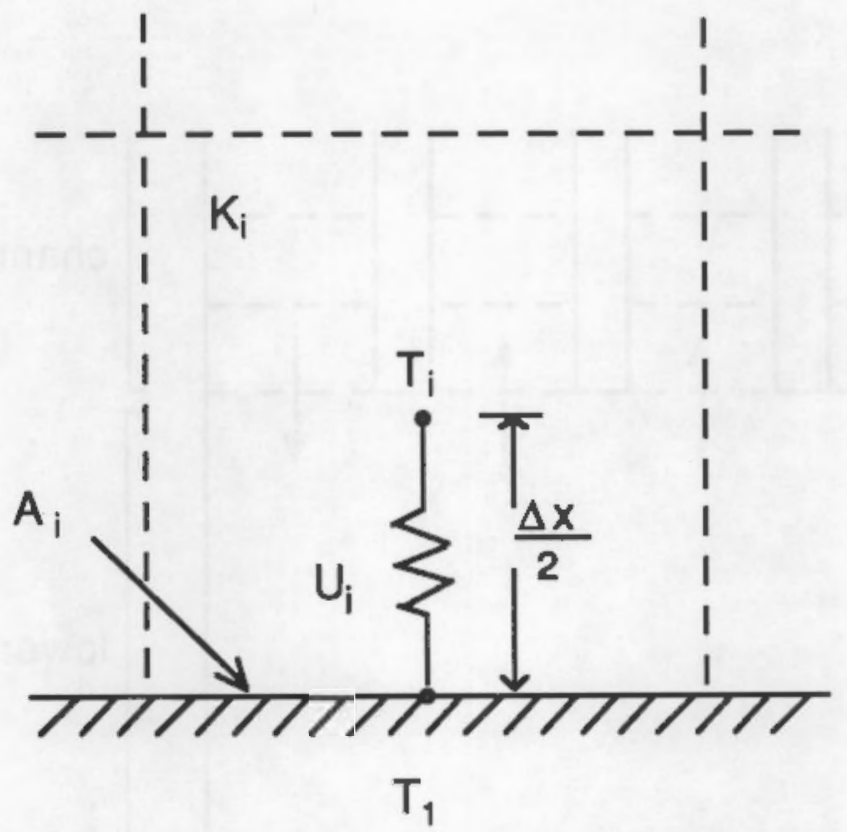

FIGURE 6.5. Detailed Plenum Heat Transfer Model

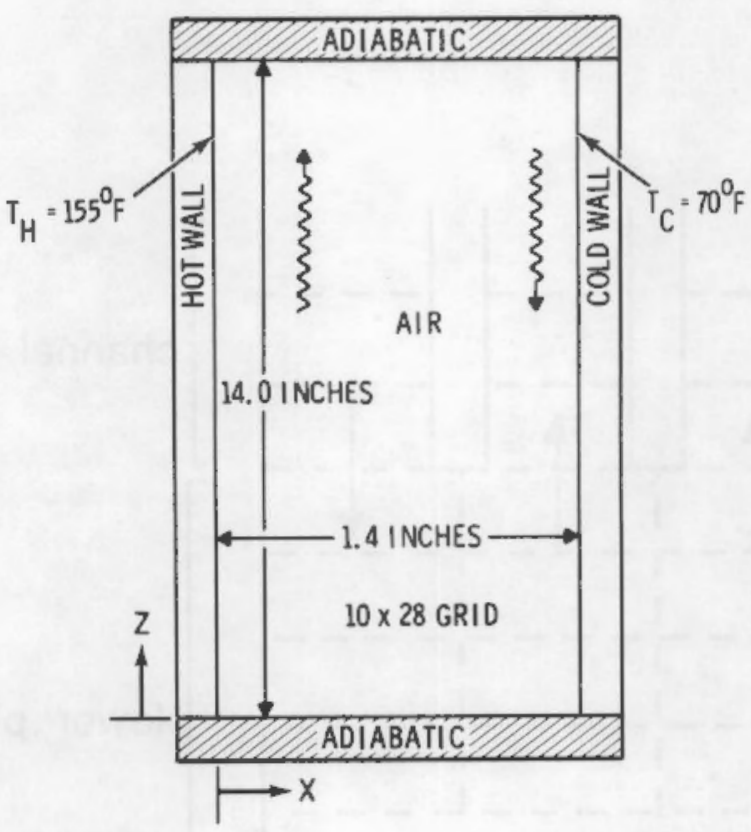

FIGURE 6.6. Geometry of a Square Cavity 


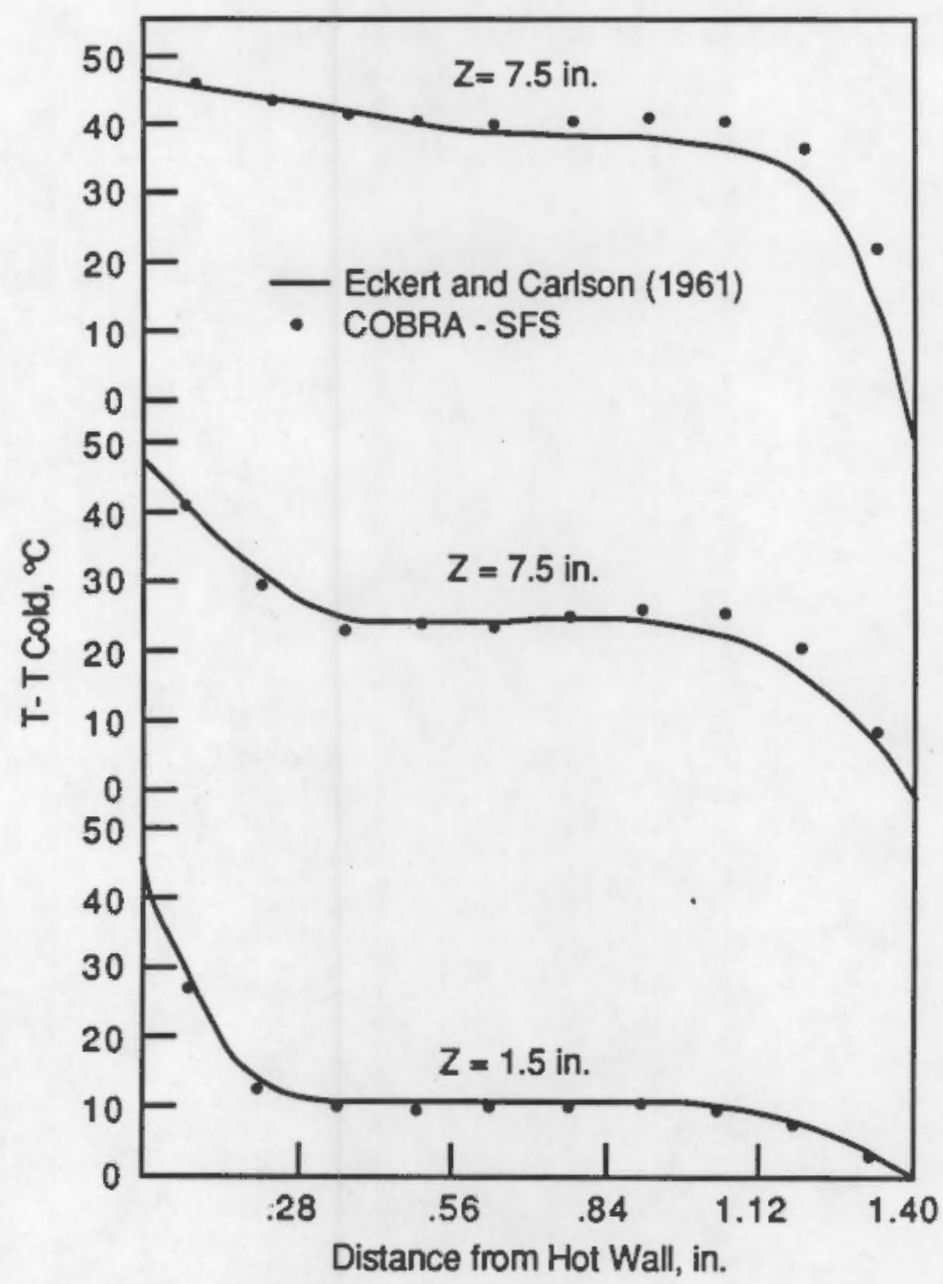

FIGURE 6.7. Natural Convection in a Two-Dimensional Cavity 



\subsection{AOOITIONAL CODE FEATURES}

In addition to the flow solution improvements described in Section 5.0 and plenum model improvements described in Section 6.0, several other features have been added to optimize the usefulness of the COBRA-SFS code. Each feature is described and the associated input modifications are presented. These features include:

- temperature-dependent solid thermal conductivities (Section 7.1)

- solid heat generation transient tables (Section 7.2)

- axially varying solid material types (Section 7.3)

- solid-to-fluid connection (Section 7.4).

\subsection{TEMPERATURE-DEPENDENT SOLID THERMAL CONDUCTIVITIES}

The thermal conductivity of most solid materials varies as a function of temperature. The original version of COBRA-SFS used a single value of thermal conductivity for each material. The code has been modified to allow temperature-dependent thermal conductivity for each solid material type to be expressed as a polynomial:

$$
k=c_{0}+c_{1} \times T+c_{2} \times T^{2}+c_{3} \times T^{3}
$$

where $C_{0}, C_{1}, C_{2}$, and $C_{3}$ are user-specified constants and $T$ is the temperature in ${ }^{\circ}$.

The flow and temperature equations are solved iteratively at each time step. At each iteration, the solid thermal conductivity for each slab node is updated to reflect the current temperature.

The coefficients for the thermal conductivity expression are specified in the solid material property card: 


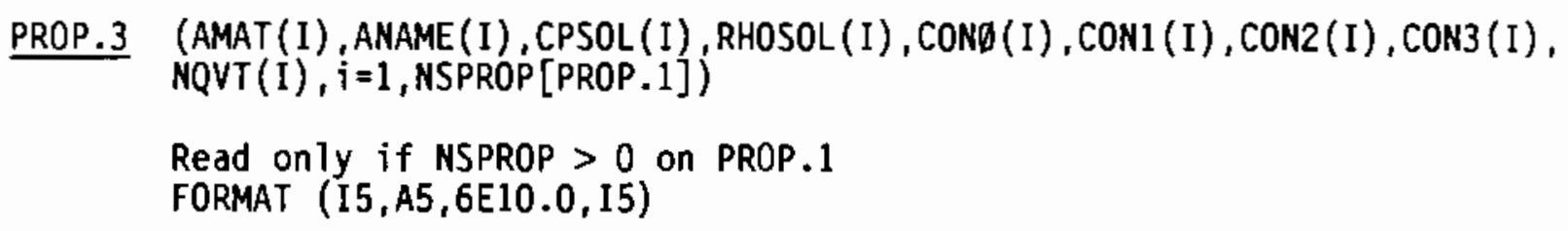

Columns Variable

1-5 AMAT (I)

6-10 ANAME(I)

$11-20 \quad \operatorname{CPSOL}(\mathrm{I})$

21-30 RHOSOL (I)

$31-40 \quad \operatorname{con} \theta(1)$

$41-50$

$51-60$

$61-70$

71-75 NQVT(I)
Description

Solid material type identification number.

Solid material name (for user convenience).

Specific heat (Btu/1bm- ${ }^{\circ} \mathrm{F}$ ) (for transient calculations).

Density $\left(1 \mathrm{bm} / \mathrm{ft}^{3}\right.$ (for transient calculations).

Coefficients of an expression for solid thermal conductivity (Btu/h-ft- ${ }^{\circ} \mathrm{F}$ ) that has the form:

$k=\operatorname{con} \emptyset(I)+\operatorname{con} 1(I) \star T+\operatorname{con} 2(I) \star T^{2}+\operatorname{con} 3(I) * T^{3}$

where $T$ is the temperature in ${ }^{\circ} \mathrm{R}$.

Transient heating rate forcing function. Corresponds to profiles read in OPER.14 and 15 .

Note that this is compatible with the old input format for PROP.3. Constant thermal conductivity is specified with the coefficient $\operatorname{coN} \emptyset(I)$ in columns 31 40, the rest are defaulted to zero.

The temperature-dependent thermal conductivity modifications were verified by comparing COBRA-SFS results with an analytical solution from Arpaci (1966) for a plate with uniform heat generation and a thermal conductivity of the form:

$$
k=k_{\mathrm{R}}(1+\beta T)
$$

where $k_{R}$ is the thermal conductivity at reference temperature, $T_{R}$. A halfsymmetrical section of the plate was modeled using ten equally-spaced slab nodes.

The results of the comparison are presented in Figure 7.1 for four values of $\beta$. In all four cases, the comparison between code results and the analytical 
solution is excellent, indicating that the temperature-dependent themal conductivity has been installed correctly.

\subsection{SOLID HEAT GENERATION TRANSIENT TABLES}

The original version of COBRA-SFS did not provide for variation of slab heat generation as a function of time. In many situations, slab heat generation will vary with time as in the case of decaying gamma heating in cask structures. For this reason, a modification was made to allow specification of the transient heat generation profile as a function of material type. The only input modification is in Card PROP.3 (which is shown in Section 7.1). The variable NQVT [PROP.3] specifies one of the transient profiles read on Cards OPER.14 and 15 .

\subsection{AXIALLY VARYING MATERIAL TYPES}

In the original version of COBRA-SFS, the assumption is made that the problem geometry, including solid material types, is uniform in the axial direction. The solid material type is specified solely as a function of slab node location in the cross-sectional plane. However, there are many situations where a slab node will consist of different solid material types at different axial locations. For this reason, an option was added to specify material types as a function of axial level. The material type for each node is used to determine material properties such as thermal conductivity.

The input modifications for axially varying material types is presented below:

SLAB.1 AGROUP, NKSS, NKSF, NWK, NMAT

FORMAT $(A 4,1 X, 1315)$

Columns variable

Description

1-4 AGROUP Enter SLAB.

6-10 NKSS Number of solid-to-solid themal connection types. 


$\begin{array}{lll}\text { 11-15 } & \text { NKSF } & \text { Number of solid-to-fluid thermal connection types. } \\ 16-20 & \text { NWK } & \text { Number of solid structure nodes. } \\ 21-25 & \text { NMAT } & \text { Number of axial material type profiles. }\end{array}$

The variable NMAT[SLAB.1] is specified only if there are slab locations with axially varying material types. The variable specifies the number of material type profiles to be read in cards SLAB.6 and SLAB.7.

SLAB.3. (KW, MATTYP (KW, 1), WALLXC (KW), QSLAB (KW), NAXK(KW), NSLAB, (KWAL (L, KW), $I \operatorname{CON}(L, K W), L=1, N S L A B)$

Read only if NWK $>0$ on SLAB.1

FORMAT $(2 \mathrm{I} 5,205.3,2 \mathrm{I} 5,5(\mathrm{I} 5, \mathrm{I} 5))$

Columns Variable

Description

1-5 $\mathrm{KW} \quad$ Solid structure node identification number.

6-10 MATIYP(KW,1) Solid node material type identification number (corresponding to a material type specified on PROP.3) or, if greater than NSPROP[PROP.1], an axial material type profile (corresponding to a profile specified on SLAB.6 and 7).

11-15 WALLXC(KW) Solid node cross-sectional area (in. ${ }^{2}$ ) for axial conduction. (Enter zero if axial conduction will not be calculated for this problem.)

16-20 QSLAB (KW) Solid node volumetric heat generation rate $\left(B t u / h-\mathrm{ft}^{3}\right)$.

21-25 $\operatorname{NAXK}(K W) \quad$ Identification number of the axial heat generation profile table [specified on OPER.16] to be applied to $\operatorname{QSLAB}(K W)$. (Default is 1.)

26-30 NSLAB Number of thermal connections to adjacent solid nodes with index numbers greater than $\mathrm{KW}$.

31-35, KWAL $(L, K W) \quad$ Identification number of the $L$ th solid node adjacent 41-45, to node $K W$, where $K W A L(L, K W)>K W$.

etc.

The only change in SLAB.3 is that the variable MATIYP[SLAB.3] specifies not on Ty constant material types (if less than NSPROP[PROP.1]) but also axial 
material profiles (if greater than NSPROP[PROP.1]. The profile number corresponds to variable MAT on SLAB. 6.

SLAB.6. MAT, NSET

Read only if NMAT > 0 on SLAB.1

FORMAT (2I5)

Columns variable Description

1-5 MAT

Axial material type profile identification number. (Used in SLAB.3. Must be greater than NSPROP [PROP.1].)

6-10 NSET Number of sets of material type information.

SLAB.7. (KAX (N) , KMAT (N) , N=1, NSET[SLAB.6])

Read only if MMAT > 0 on SLAB. 1

FORMAT $(4(5 X, 2 I 5))$

Columns Variable

6-10 $\operatorname{KAX}(\mathrm{N})$

$21-25$

$36-40$

$51-55$

$11-15$

26-30

$41-45$

$56-60$

$\operatorname{KMAT}(N)$
Description

Number of axial nodes in axial set $N$, starting from the bottom level. (The total number of nodes must be equal to NDX[CHAN.1].)

$$
\underset{\text { NSET }}{\sum} \operatorname{KAX}(\mathrm{N})=\operatorname{NDX}[\text { CHAN.1] }
$$

Material type for axial set $N$. (Corresponds to material type specified in PROP.3.)

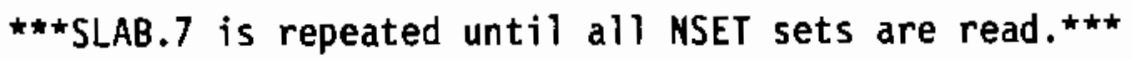
***SLAB.6 and SLAB.7 are read NMAT[SLAB.1] times.***

The axial material type profiles are read in SLAB.6 and SLAB.7. Card SLAB. 6 provides the identification number of the profile (MAT) and the number of material type sets (NSET). Card SLAB.7 provides the material type 
information in terms of consecutive sets, where each set consists of a number of axial levels and a material type.

\subsection{SOLID-TO-FLUID CONNECTIONS}

The thermal connection between a solid node and subchannel consists of two parts, the thermal resistance between the center of the solid node and the wetted surface and the resistance between the surface and center of the subchanne1. In the original version of COBRA-SFS, the thermal resistance in the solid node must be specified directly. Since modifications have been made to allow varying material types and temperature dependent conductivity for solid nodes, this method for specifying resistance will be inadequate for many situations. For this reason, an option was added to specify the resistance in terms of a geometry shape factor, similar to those used in the solid-tosolid thermal connections. The thermal conductivity of the node is determined based on material type and temperature, and is then used to calculate the thermal resistance.

The input modification for this feature is located on Card SLAB.4.

SLAB.4. (IC, RDIMF (IC)RWAL (IC), HID (IC), IC =1, NSKF [SLAB. 1])

Read only if NKSF $>0$ on SLAB. 1

FORMAT (I5, 2E5.0, e105)

Columns Variable

$1-5 \quad I C$

6-10 RDIMF(IC)

11-15 RWAL(IC)

16-25 WID(IC)
Description

Solid-to-fluid thermal connection type identification number.

Geometry factor from the solid structure node to the node surface that faces the channel. (Not used if RWAL is specified for connection IC.)

Thermal resistance (s-ft- ${ }^{\circ} \mathrm{F} / \mathrm{Btu}$ ) from the solid structure node to the node surface that faces the channel. (Not used if RDIMF is specified for connection IC.)

Perimeter of solid node that faces the channel (in.). 
*** SLAB. 4 is read in NKSF[SLAB.1] times. ***

Either a geometry factor (RDIMF[SLAB.4]) or thermal resistance (RWAL[SLAB.4]) may be used to describe the connection between slab node center and the wetted surface. 


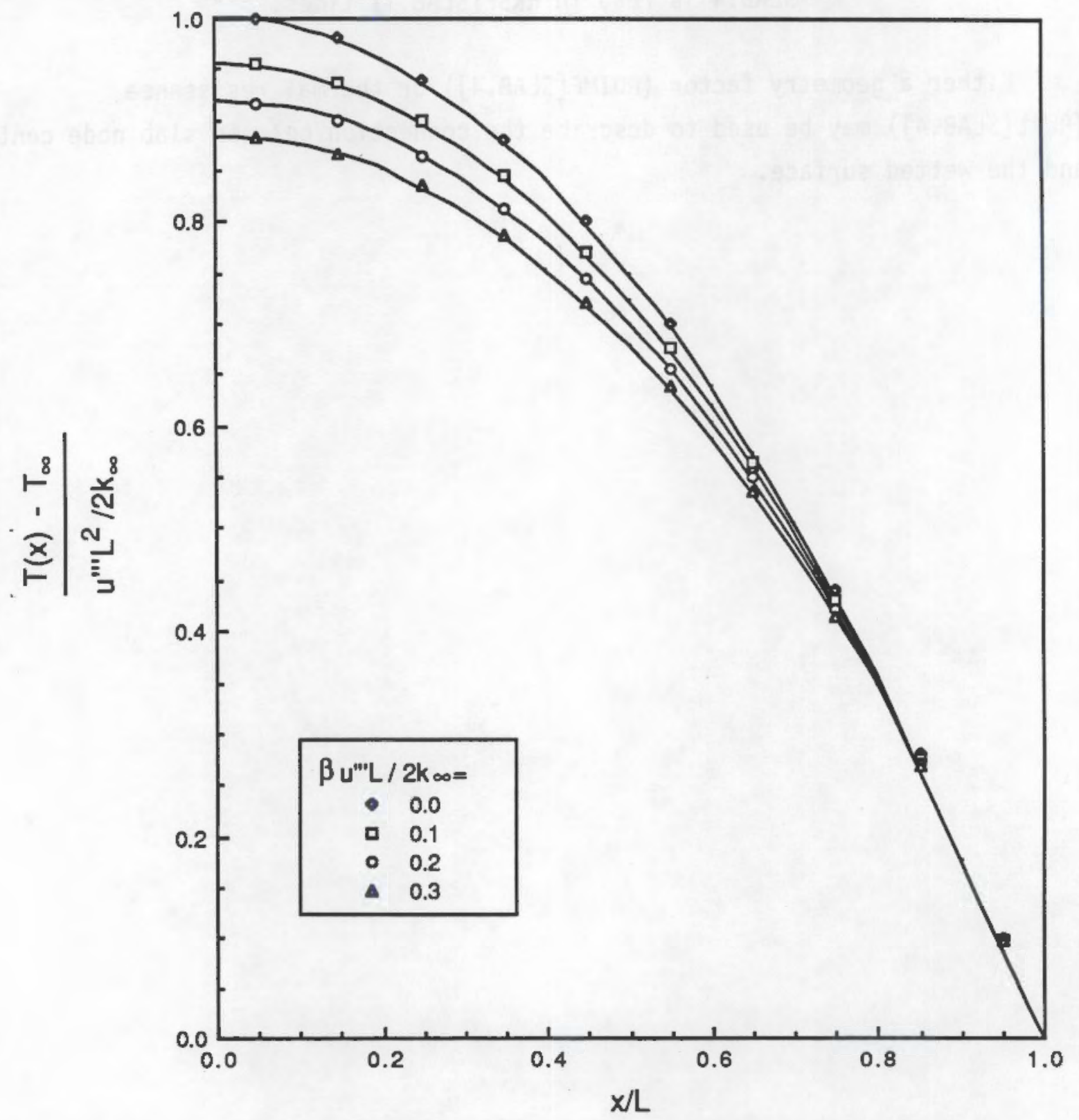

FIGURE 7.1. Temperature Profiles for Heat-Generating Plate with Linearly Varying Thermal Conductivity 


\subsection{REFERENCES}

Arpaci, v. S. 1966. Conduction Heat Transfer. Addison-Wesley, Reading, Massachusetts.

Cox, R. L. 1977. Radiation Heat Transfer in Arrays of Parallel Cylinders. ORNL-5239, 0ak Ridge National Laboratory, 0ak Ridge, Tennessee.

Cuta, J. M., D. R. Rector and J. M. Creer. 1984. Thermal-Hydraulic Analys is of Consolidated Spent PWR Fuel Rods. EPRI-NP-3764, Electric Power Research Institute, Palo Alto, California.

Cuta, J. M., and J. M. Creer. 1986. Comparisons of COBRA-SFS Calculations to Data from Electrically Heated Test Sections Simulating Unconsolidated and Consolidated BWR Spent Fuel. EPRI-NP-4593, Electric Power Research Institute, Palo Alto, California.

Eckert, E. G., and W. 0. Carlson. 1961. "Natural Convection in an Air Layer Enclosed Between Two Vertical Plates with Different Temperatures." Int. J. of Heat and Mass Transfer. 2:106-120.

George, T. L., K. L. Basehore, C. L. Wheeler, W. A. Prather and R. E. Masterson. 1980. COBRA-WC: A Version of COBRA for Single-Phase Multiassembly ThermalHydraulic Transient Analysis. PNL-2359, Pacific Northwest Laboratory, Richland, Washington.

Goldstein, R. J., and D. K. Kreid. 1967. "Measurements of Laminar Flow Development in a Square Duct Using a Laser-Doppler Flow Meter." J. of Applied Mechanics, Trans. ASME. 34(89):813-818.

Kays, E. U., and M. E. Crawford. 1980. Convective Heat and Mass Transfer. McGraw-Hill, Inc., New York, New York.

Khan, E. U., W. A. Prather, T. L. George and J. M. Bates. 1981. A Validation Study of the COBRA-WC Computer Program for LMFBR Thermal-Hydraulic Analysis. PNL-4128, Pacific Northwest Laboratory, Richland, Washington.

Kreid, D. K. 1967. "Measurements of Developing Laminar Flow in a Square Duct Using a Laser-Doppler Flow Meter." J. of Applied Mechanics, Trans. ASME. $34(89): 813-818$.

Lombardo, N. J., J. M. Cuta, T. E. Michener, D. R. Rector and C. L. Wheeler. 1986a. COBRA-SFS: A Thermal-Hydraulic Analys is Computer Code: Volume III: Validation Assessments. PNL-6049, Pacific Northwest Laboratory, Richland, Washington.

Lombardo, N. J., T. E. Michener, C. L. Wheeler, and D. R. Rector. 1986b. COBRA-SFS Predictions of Single-Assembly Spent Fuel Heat Transfer Data. PNL-5781, Pacific Northwest Laboratory, Richland, Washington. 
Mckinnon, M. A., J. M. Creer, T. E. Michener, J. E. Tanner, E. R. Gilbert and R. L. Goodman. 1986. TN-24P PWR Spent Fuel Storage Cask Performance Testing and Analysis. EPRI NP-5128, Palo Alto, California.

Rector, D. R., J. M. Cuta and N. J. Lombardo. 1986. COBRA-SFS ThermalHydraulic Analysis of the CASTOR-1C and REA 2023 BWR Storage Casks Containing Consolidated Spent Fuel. PNL-5802, Pacific Northwest Laboratory, Richland, Washington.

Rector, D. R., R. A. McCann, U. P. Jenquin, C. M. Heeb, J. M. Creer and C. L. Wheeler. 1986a. CASTOR-1C Spent Fuel Storage Cask Decay Heat, Heat Transfer, and Shielding Analysis. PNL-5974, Pacific Northwest Laboratory, Richland, Washington.

Rector, D. R., C. L. Wheeler and N. J. Lombardo. 1986. COBRA-SFS: A ThermalHydraulic Analysis Computer Code Volume I: Mathematical Models and Solution Method. PNL-6049, Vol. 1, Pacific Northwest Laboratory, Richland, Washington.

Rector, D. R., J. M. Cuta, N. J. Lombardo, T. E. Michener and C. L. Wheeler. 1986b. COBRA-SFS: A Thermal-Hydraulic Analys is Code Volume II: User's Manual. PNL-6049, Vol. II, Pacific Northwest Laboratory, Richland, Washington.

Rowe, 0. S. 1973. COBRA-IIIC: A Digital Computer Program for Steady-State and Transient Thermal-Hydraulic Analys is of Rod Bundle Nuclear Fuel Elements. BNWL-1695, Pacific Northwest Laboratory, Richland, Washington.

Sparrow, E. M., and A. L. Loeffler, Jr. 1959. "Longitudinal Laminar Flow Between Cylinders Arranged in Regular Array." AIChE Journal. 5(3):325-330.

Stewart, C. H., C. L. Wheeler, R. J. Cena, C. A. McMonagle, J. M. Cuta and D. S. Trent. 1977. COBRA-IV: The Model and the Method. BNWL-2214, Pacific Northwest Laboratory, Richland, washington.

Wheeler, C. L., R. A. McCann, N. J. Lombardo, D. R. Rector, and T. E. Michener. 1986. "HYDRA and COBRA-SFS Temperature Calculations for CASTOR-1C, REA-2023, CASTOR-V/21, and TN-24P Cask." In Proceedings, Third International Spent Fuel Storage Technology Symposium/Workshop, Vol. 1, 577-S98. CONF-960417, National Technical Information Service, Springfield, Virginia.

WiTes, L. E., N. J. Lombardo, C. M. Heeb, U. P. Jenquin, T. E. Michener, C. L. Wheeler, J. M. Creer and R. A. McCann. 1986. BWR Spent Fuel Storage Cask Performance Test: Volume II - Pre- and Post-Test Decay Heat, Heat Transfer and Shielding Analysis. PNL-5777 Vol. II, Pacific Northwest Laboratory, Richland, Washington. 
APPENDIX A

DEVELOPING FLOW IN A PLANAR CHANNEL OUTPUT 


\section{APPENDIX A}

\section{DEVELOPING FLOW IN A PLANAR CHANNEL OUTPUT}

cobra dimension parameters:

\begin{tabular}{|c|c|c|c|c|c|}
\hline $1 d=$ & 6 & le= & 40 & lif $=$ & 1 \\
\hline $1 \mathrm{~h}=$ & 9 & $11 \mathrm{p}=$ & 8 & $1 \mathrm{q}=$ & \\
\hline $1 \mathrm{r}=$ & 9 & $11 \mathrm{t}=$ & 3 & $1 u=$ & \\
\hline $11 \mathrm{w}=$ & 6 & $1 x=$ & 8 & $11 z=$ & 1 \\
\hline $1 a=$ & 15 & $1 b=$ & 1 & $11 c=$ & \\
\hline $1 d=$ & 1 & $1 e=$ & 1 & $l \mathbf{f}=$ & \\
\hline ma $=$ & 20 & $m c=$ & 40 & $m e=$ & 3 \\
\hline mgr= & 50 & $\mathbf{m} \mathbf{h}=$ & 6 & $\boldsymbol{m i}=$ & 1 \\
\hline$m j=$ & 1 & $\mathbf{m k} \mathbf{k}=$ & 3 & $m l=$ & \\
\hline $1 \mathrm{~mm}=$ & 20 & $\mathrm{~m} n=$ & 6 & $\mathrm{mp}^{\mathrm{x}}$ & 2 \\
\hline $\mathrm{mq}=$ & 1 & $m r=$ & 20 & $\mathrm{~ms}=$ & 3 \\
\hline $\mathbf{m t}=$ & 1 & mand & 40 & $\pi x=$ & 3 \\
\hline$m y=$ & 4 & $n d=$ & 9 & no $=$ & \\
\hline$n v=$ & 2 & $\ln z=$ & 10 & & \\
\hline
\end{tabular}

1***** the following is an 1mage 11st1ng of the cobra-sfs input cards thth*

radx generated input is not ingluded

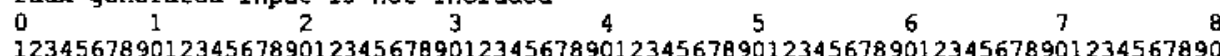

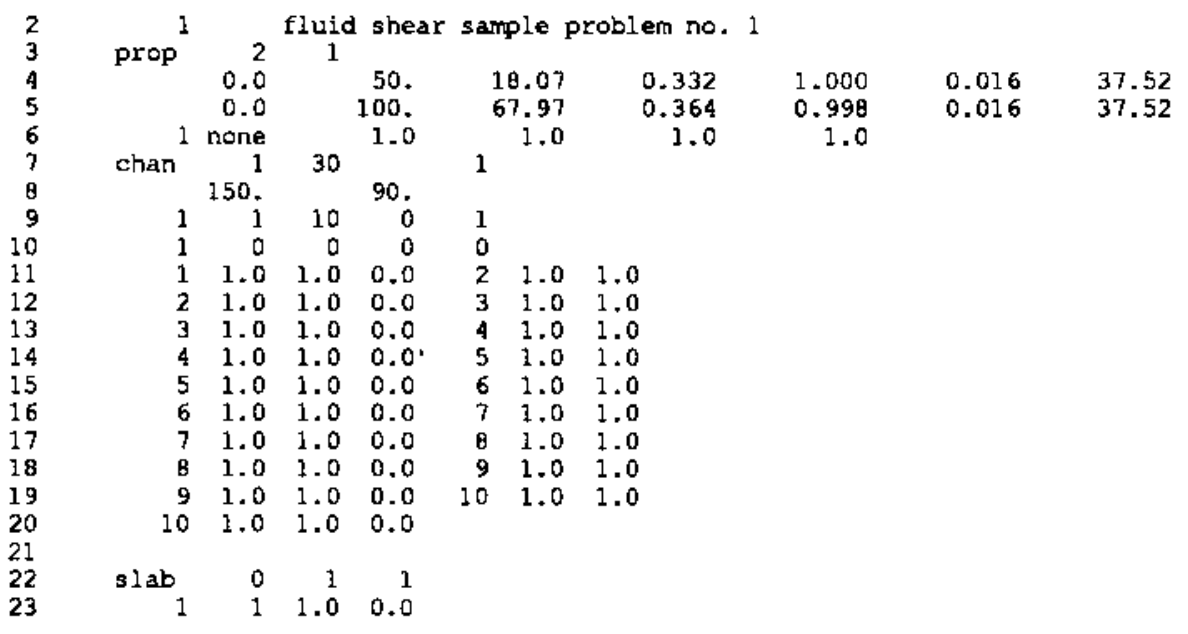




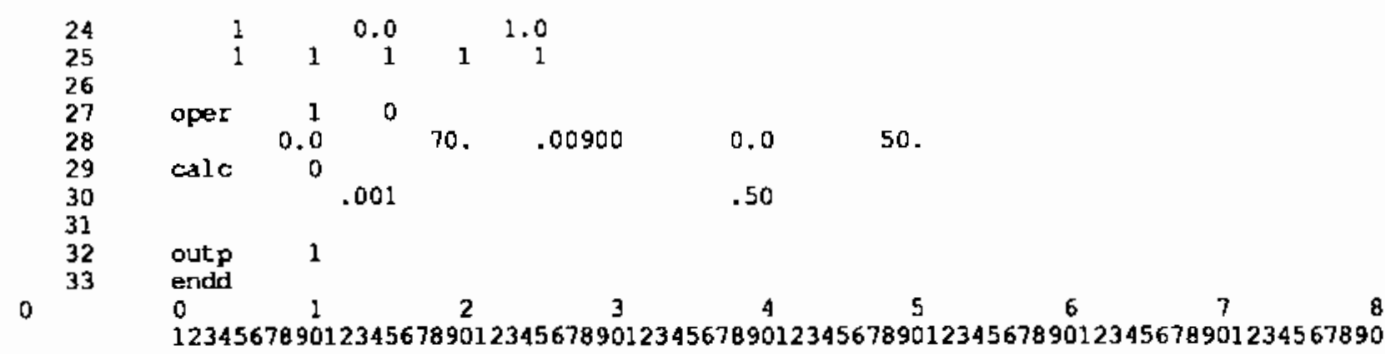

11nput for case 1 fluid shear sample problem no. 1

date 01/05/89 time

\begin{tabular}{|c|c|c|c|c|c|c|c|c|c|c|c|c|c|c|c|}
\hline \multirow{2}{*}{\multicolumn{2}{|c|}{$\begin{array}{l}\text { summary of } \\
\text { group ni }\end{array}$}} & Input & opt & ons & & & & & & & & & & & \\
\hline & & n2 & n 3 & $n 4$ & n5 & n6 & n7 & n' & n9 & ת10 & תll & n12 & ת13 & ก14 & n15 \\
\hline prop & 2 & 1 & 0 & 0 & 0 & 0 & 0 & 0 & 0 & 0 & 0 & 0 & 0 & 0 & 0 \\
\hline chan & 1 & 30 & 0 & 1 & 0 & 0 & 0 & 0 & 0 & 0 & 0 & 0 & 0 & 0 & 0 \\
\hline slab & 0 & 1 & 1 & 0 & 0 & 0 & 0 & 0 & 0 & 0 & 0 & 0 & 0 & 0 & 0 \\
\hline oper & 1 & 0 & 0 & 0 & 0 & 0 & 0 & 0 & 0 & 0 & 0 & 0 & 0 & 0 & 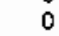 \\
\hline calc & 0 & 0 & 0 & 0 & 0 & 0 & 0 & 0 & 0 & 0 & 0 & 0 & 0 & 0 & \\
\hline outp & 1 & 0 & 0 & 0 & 0 & 0 & 0 & 0 & 0 & 0 & 0 & 0 & 0 & 0 & \\
\hline endd & 0 & 0 & 0 & 0 & 0 & 0 & 0 & 0 & 0 & 0 & 0 & 0 & 0 & 0 & 0 \\
\hline
\end{tabular}

fluid property table

$\begin{array}{cc}\begin{array}{cc}\text { pliq } \\ \text { plia) }\end{array} & \text { terliq } \\ \text { (ps) } & \text { (f) } \\ 0.0000 & 50.0000\end{array}$

$\begin{array}{rr}0.0000 & 50.0000 \\ 0.0000 & 100.0000\end{array}$

hilg
(btulibm)
18.0700

18.0700

conllq
(btu/hz-ft-f)
cpliq
(btu/lbm-f)
(ft $3 / 1 \mathrm{hm}$ )
1.0000
0.9980

solld property table

type material
cpsol
1.
1.0000

0.3640

0.0160

$\mathrm{lbm} / \mathrm{hr}-\mathrm{ft}$
37.5200

37.5200

1

none
rhosol
(1bm/ ft3)

thermal conductivity

$1.000 \mathrm{E}+00+1.000 \mathrm{E}+00 * t+0.000 \mathrm{E}+00 * t * * 2+0.000 \mathrm{E}+00 * t * * 3$

assembly number 1 input description

axial heat flux profile number 1

heat transfer correlation number

niet flow vs, time profile number

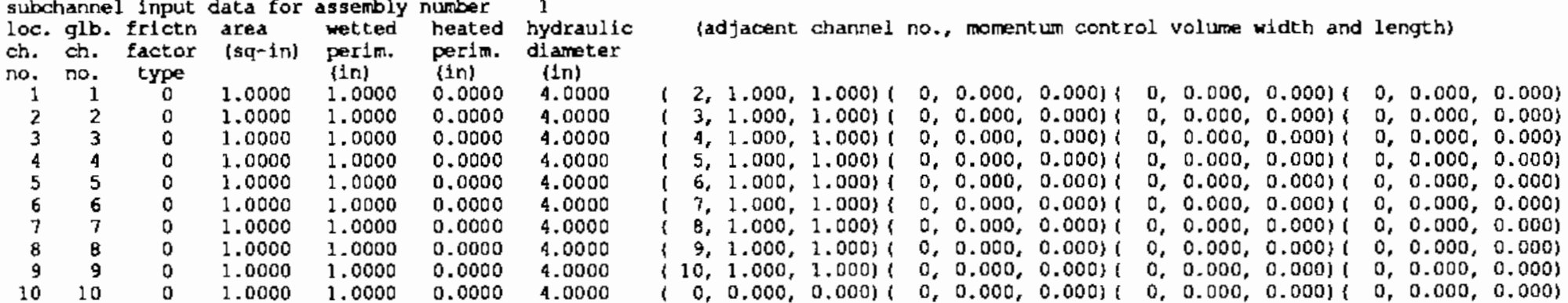


solid-to-fluid themal connection type table

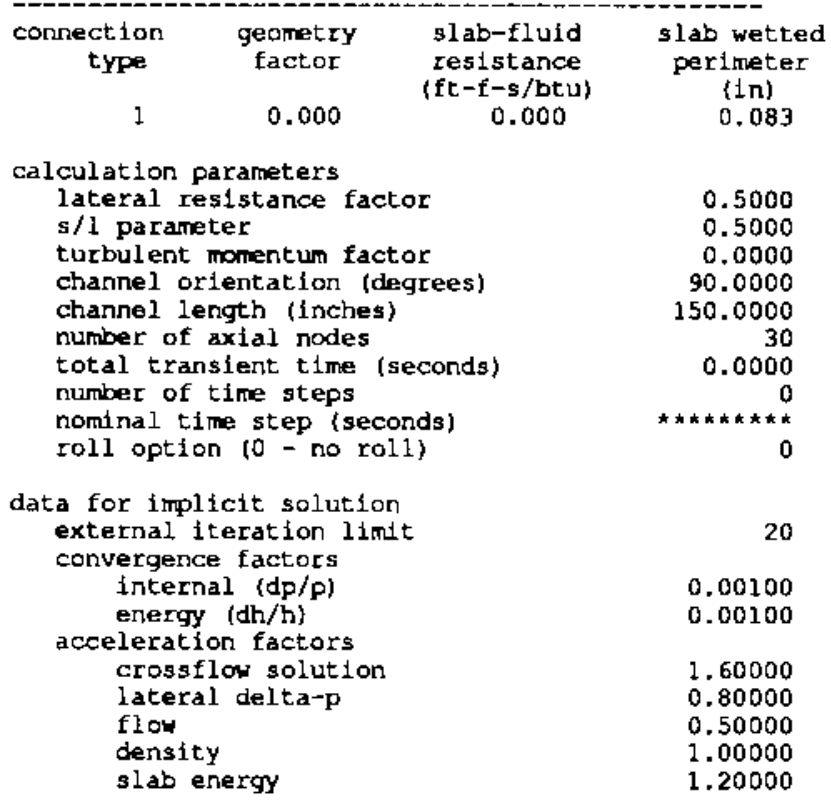

axial noding

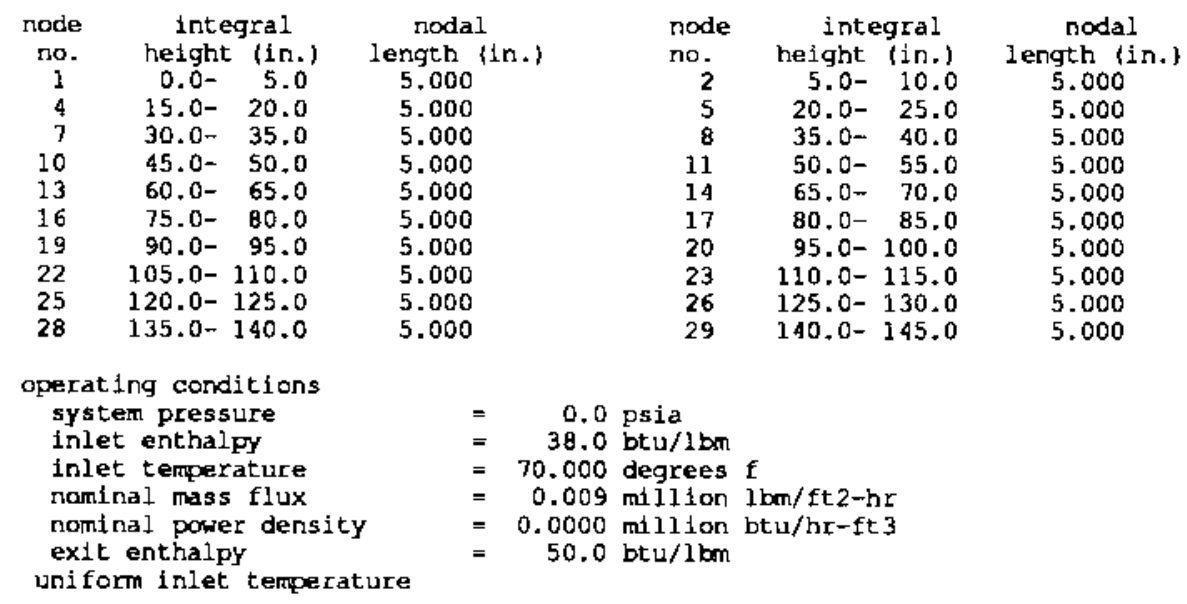

uni form inlet terperature

\begin{tabular}{|c|c|c|c|}
\hline node & int & egral & nodal \\
\hline$n_{3}$ & $\begin{array}{l}\text { height } \\
10.0-\end{array}$ & $\begin{array}{l}(\ln .) \\
15.0\end{array}$ & $\begin{array}{c}\text { length }(\mathrm{in} .) \\
5.000\end{array}$ \\
\hline 6 & $25.0-$ & 30.0 & 5.000 \\
\hline 9 & $40.0-$ & 45.0 & 5.000 \\
\hline 12 & $55.0-$ & 60.0 & 5.000 \\
\hline 15 & $70.0-$ & 75.0 & 5.000 \\
\hline & $85.0-$ & 90.0 & 5.000 \\
\hline 21 & $100.0-$ & 105.0 & 5.000 \\
\hline & $115.0-$ & 120.0 & 5.000 \\
\hline 27 & $130.0-$ & 135.0 & 5.000 \\
\hline & $145.0-$ & 150.0 & .000 \\
\hline
\end{tabular}


0 unf form inlet mass velocity

parameter sumary

parameter description

max. no. of solid material property types

$\max$. no. of boundary thermal connection types

nodes

max. no. of assembly types

max. no. of loss coeff. profiles, friction factor or heat transfer corr.

max. no. of slab-slab and slab-fluld connection types

max. no. of channels wh

max if not using toll option; 3 if roll $1 \mathrm{~s}$ used

max. no. of chabel gap colidections

max. no. of assembly grouplngs in network model

$\max$. no. of loss coefficients

$\max$. no. of axial locatlons for gap and area variations

max. no. of polnts in selected profile tables

max. no. of fuel nodes in a rod

max. no. of entries in property, axial heat flux or translent tables

max. no. of channel groups that have local axial losses

$\max$. no. of fuel rods

max. no. of gaps that can have gap spacing variations

max. no. of tuel types

max. no. of axial heat

$\max$. no. of slab nodes

$\max$. no. of axial nodes plus one

max. no. of axial fuel type divisions

to a wall node

max. no. of boundary temperature types

max. no. of surfaces in a user-defined radiation group

no. of radiation surfaces in enclosure type 1

no. of radiation surfaces in enclosure type 2

no. of radiation surfaces in enclosure type 3

no. of radiation surfaces in enclosure type 4

no. of radiation surfaces in enclosure type 5

no. of radiation surfaces in enclosure type

$\begin{array}{rr}6 & 1 \\ 15 & 0 \\ 8 & 1 \\ 7 & 0 \\ 3 & 1 \\ 6 & 1 \\ 6 & 0 \\ 15 & 1 \\ 20 & 0 \\ 40 & 10 \\ 31 & 31 \\ 50 & 9 \\ 6 & 0 \\ 1 & 0 \\ 3 & 0 \\ 9 & 0 \\ 20 & 0 \\ 6 & 1 \\ 20 & 2 \\ 1 & 0 \\ 20 & 0 \\ 30 & 0 \\ 1 & 0 \\ 1 & 1 \\ 40 & 1 \\ 31 & 31 \\ 4 & 0 \\ 9 & 1 \\ 2 & 0 \\ 2 & 0 \\ 10 & 0 \\ 15 & 0 \\ 1 & 0 \\ 1 & 0 \\ 1 & 0 \\ 1 & 0 \\ 1 & 0\end{array}$

total heat generation in the problem is $0.00000 \mathrm{btu} / \mathrm{sec}$ or $0.00000 \mathrm{kw}$

data from iterative solution using the rectrculation madule

time $=0.0000 \quad \mathrm{dt}=x_{n * k *}$ implicit dt $=0.0000$ explicit dt $=8.9968 \quad$ made $=0$ 


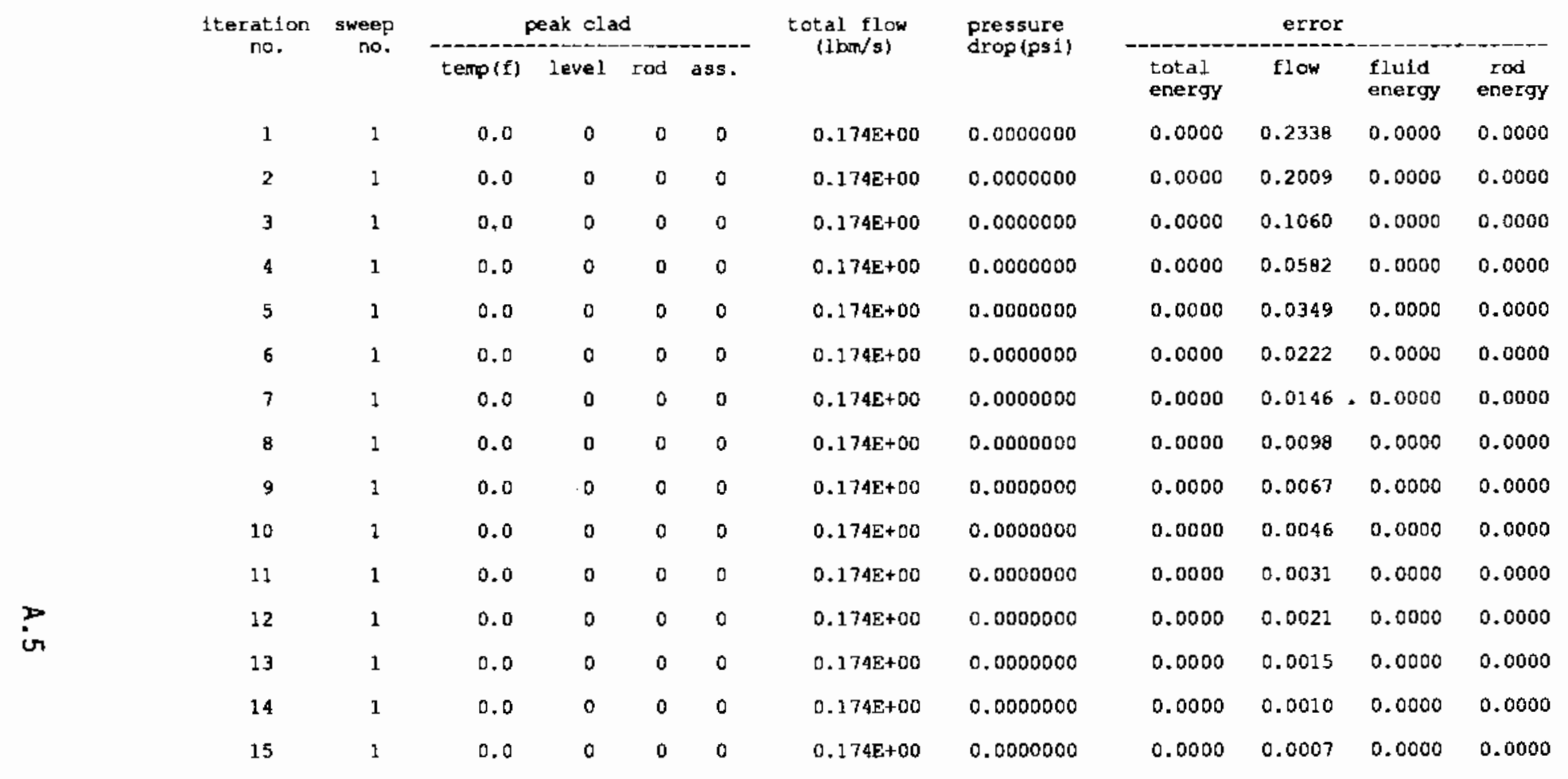

cobra-sfs code results

case 1 fluid shear sample problem no. 1

date $01 / 05 / 89$ tine

calculated fluid conditions at time $=0.0000$ seconds $\begin{array}{ll}\text { channel } & 1 \\ \text { assembly } & 1\end{array}$

$\begin{array}{ccccccccc}\begin{array}{c}\text { distance } \\ \text { (in.) }\end{array} & \begin{array}{c}\text { delta-p } \\ \text { (psi) }\end{array} & \begin{array}{c}\text { enthalpy } \\ \text { (btu/lb) }\end{array} & \begin{array}{c}\text { temperature } \\ \text { (deg-f) }\end{array} & \begin{array}{c}\text { density } \\ (1 b / c u-f t)\end{array} & \begin{array}{c}\text { flow } \\ (\text { bb/sec) }\end{array} & \begin{array}{c}\text { mass flux } \\ \text { (mlb/hr-ft2) }\end{array} & \begin{array}{c}\text { velocity } \\ \text { (ft/sec) }\end{array} & \begin{array}{c}\text { area } \\ (\text { sq-in) }\end{array} \\ 0.0 & 0.0000114 & 38.03 & 70.00 & 62.5000 & 0.0173611 & 0.0090000 & 0.0400000 & 1.00000 \\ 5.0 & 0.0000096 & 38.03 & 70.00 & 62.5000 & 0.0128477 & 0.0066602 & 0.0296011 & 1.00000 \\ 10.0 & 0.0000085 & 38.03 & 70.00 & 62.5000 & 0.0094237 & 0.0048852 & 0.0217121 & 1.00000 \\ 15.0 & 0.0000076 & 38.03 & 70.00 & 62.5000 & 0.0071913 & 0.0037280 & 0.0165688 & 1.00000 \\ 20.0 & 0.0000070 & 38.03 & 70.00 & 62.5000 & 0.0058563 & 0.0030359 & 0.0134930 & 1.00000 \\ 25.0 & 0.0000065 & 38.03 & 70.00 & 62.5000 & 0.0050852 & 0.0026362 & 0.0117163 & 1.00000 \\ 30.0 & 0.0000061 & 38.03 & 70.00 & 62.5000 & 0.0046272 & 0.0023987 & 0.0106611 & 1.00000\end{array}$




$\begin{array}{lllllllll}35.0 & 0.0000057 & 38.03 & 70.00 & 62.5000 & 0.0043323 & 0.0022459 & 0.0099816 & 1.00000 \\ 40.0 & 0.0000053 & 38.03 & 70.00 & 62.5000 & 0.0041229 & 0.0021373 & 0.0094992 & 1.00000 \\ 45.0 & 0.0000050 & 38.03 & 70.00 & 62.5000 & 0.0039618 & 0.0020538 & 0.0091281 & 1.00000 \\ 50.0 & 0.0000047 & 38.03 & 70.00 & 62.5000 & 0.0038312 & 0.0019861 & 0.0088271 & 1.00000 \\ 55.0 & 0.0000043 & 38.03 & 70.00 & 62.5000 & 0.0037219 & 0.0019294 & 0.0085753 & 1.00000 \\ 60.0 & 0.0000041 & 38.03 & 70.00 & 62.5000 & 0.0036286 & 0.0018811 & 0.0093603 & 1.00000 \\ 65.0 & 0.0000038 & 38.03 & 70.00 & 62.5000 & 0.0035479 & 0.0018392 & 0.0091743 & 1.00000 \\ 70.0 & 0.0000035 & 38.03 & 70.00 & 62.5000 & 0.0034772 & 0.0018026 & 0.0080114 & 1.00000 \\ 75.0 & 0.0000032 & 38.03 & 70.00 & 62.5000 & 0.0034147 & 0.00177702 & 0.0078675 & 1.00000 \\ 80.0 & 0.0000030 & 38.03 & 70.00 & 62.5000 & 0.0033590 & 0.0017413 & 0.0077392 & 1.00000 \\ 85.0 & 0.0000027 & 38.03 & 70.00 & 62.5000 & 0.0033091 & 0.0017154 & 0.0076242 & 1.00000 \\ 90.0 & 0.0000025 & 38.03 & 70.00 & 62.5000 & 0.0032640 & 0.0016921 & 0.0075202 & 1.00000 \\ 95.0 & 0.0000023 & 38.03 & 70.00 & 62.5000 & 0.0032230 & 0.0016708 & 0.0074259 & 1.00000 \\ 100.0 & 0.0000020 & 38.03 & 70.00 & 62.5000 & 0.0031857 & 0.0016514 & 0.0073398 & 1.00000 \\ 105.0 & 0.0000018 & 38.03 & 70.00 & 62.5000 & 0.0031514 & 0.0016337 & 0.0072609 & 1.00000 \\ 110.0 & 0.0000016 & 38.03 & 70.00 & 62.5000 & 0.0031199 & 0.0016174 & 0.0071883 & 1.00000 \\ 115.0 & 0.0000014 & 38.03 & 70.00 & 62.5000 & 0.0030908 & 0.0016023 & 0.0071212 & 1.00000 \\ 120.0 & 0.0000012 & 38.03 & 70.00 & 62.5000 & 0.0030639 & 0.0015883 & 0.0070592 & 1.00000 \\ 125.0 & 0.0000010 & 38.03 & 70.00 & 62.5000 & 0.0030389 & 0.0015753 & 0.0070015 & 1.00000 \\ 130.0 & 0.0000008 & 38.03 & 70.00 & 62.5000 & 0.0030156 & 0.0015633 & 0.0069478 & 1.00000 \\ 135.0 & 0.0000006 & 38.03 & 70.00 & 62.5000 & 0.0029938 & 0.0015520 & 0.0068978 & 1.00000 \\ 140.0 & 0.0000004 & 38.03 & 70.00 & 62.5000 & 0.0029735 & 0.0015415 & 0.0068510 & 1.00000 \\ 145.0 & 0.0000002 & 38.03 & 70.00 & 62.5000 & 0.0029544 & 0.0015316 & 0.0068069 & 1.00000 \\ 150.0 & 0.0000000 & 38.03 & 70.00 & 62.5000 & 0.00029289 & 0.0015183 & 0.0067481 & 1.00000\end{array}$

$\begin{array}{cc}\text { distance } & \text { delta-p } \\ \text { (fn.) } & (p s 1) \\ 0.0 & 0.0000112 \\ 5.0 & 0.0000097 \\ 10.0 & 0.0000085 \\ 15.0 & 0.0000076 \\ 20.0 & 0.0000070 \\ 25.0 & 0.0000065 \\ 30.0 & 0.0000061 \\ 35.0 & 0.0000057 \\ 40.0 & 0.0000053 \\ 45.0 & 0.0000050 \\ 50.0 & 0.0000047 \\ 55.0 & 0.0000043 \\ 60.0 & 0.0000041 \\ 65.0 & 0.0000038 \\ 70.0 & 0.0000035 \\ 75.0 & 0.0000032 \\ 80.0 & 0.0000030 \\ 85.0 & 0.0000027 \\ 90.0 & 0.0000025 \\ 95.0 & 0.0000023 \\ 100.0 & 0.0000020 \\ 105.0 & 0.0000018 \\ 110.0 & 0.0000016 \\ 115.0 & 0.0000014\end{array}$

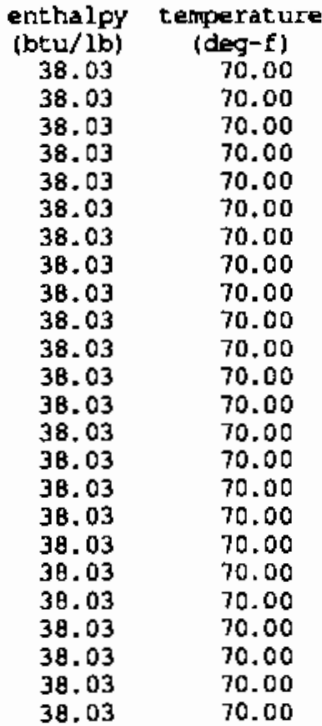

$\begin{array}{cc}\text { density } & \text { flow } \\ (1 b / c u-f t) & (1 b / s e c) \\ 62.5000 & 0.0173611 \\ 62.5000 & 0.0169192 \\ 62.5000 & 0.0157376 \\ 62.5000 & 0.0145039 \\ 62.5000 & 0.0134378 \\ 62.5000 & 0.0125780 \\ 62.5000 & 0.0118992 \\ 62.5000 & 0.0113605 \\ 62.5000 & 0.0109257 \\ 62.5000 & 0.0105676 \\ 62.5000 & 0.0102673 \\ 62.5000 & 0.0100113 \\ 62.5000 & 0.0097904 \\ 62.5000 & 0.0095976 \\ 62.5000 & 0.0094278 \\ 62.5000 & 0.0092769 \\ 62.5000 & 0.0091419 \\ 62.5000 & 0.0090203 \\ 62.5000 & 0.0089101 \\ 62.5000 & 0.0088099 \\ 62.5000 & 0.0087183 \\ 62.5000 & 0.0086341 \\ 62.5000 & 0.0085567 \\ 62.5000 & 0.0084850\end{array}$

mass flux
(mlb/hr-ft2)
0.0090000
0.0087709
0.0081584
0.0075188
0.0069662
0.0065205
0.0061685
0.0058893
0.0056639
0.0054783
0.0053226
0.0051899
0.0050754
0.0049754
0.0048874
0.0048091
0.0047391
0.0046761
0.0046190
0.0045671
0.0045196
0.0044759
0.0044358
0.0043986

$\begin{array}{cc}\begin{array}{c}\text { veloc1ty } \\ \text { (ft/sec) }\end{array} & \begin{array}{c}\text { area } \\ \text { (sq-1n) } \\ 0.0400000\end{array} \\ 1.00000 \\ 0.0389817 & 1.00000 \\ 0.0362595 & 1.00000 \\ 0.0334170 & 1.00000 \\ 0.0309607 & 1.00000 \\ 0.0289798 & 1.00000 \\ 0.0274157 & 1.00000 \\ 0.0261745 & 1.00000 \\ 0.0251728 & 1.00000 \\ 0.0243478 & 1.00000 \\ 0.0236558 & 1.00000 \\ 0.0230661 & 1.00000 \\ 0.0225571 & 1.00000 \\ 0.0221129 & 1.00000 \\ 0.0217216 & 1.00000 \\ 0.0213739 & 1.00000 \\ 0.0210628 & 1.00000 \\ 0.0207827 & 1.00000 \\ 0.0205290 & 1.00000 \\ 0.0202980 & 1.00000 \\ 0.0200869 & 1.00000 \\ 0.0198931 & 1.00000 \\ 0.0197145 & 1.00000 \\ 0.0195495 & 1.00000\end{array}$




$\begin{array}{lllllllll}120.0 & 0.0000012 & 38.03 & 70.00 & 62.5000 & 0.0084186 & 0.0043642 & 0.0193966 & 1.00000 \\ 125.0 & 0.0000010 & 38.03 & 70.00 & 62.5000 & 0.0083570 & 0.0043322 & 0.0192544 & 1.00000 \\ 130.0 & 0.0000008 & 38.03 & 70.00 & 62.5000 & 0.0082995 & 0.0043024 & 0.0191220 & 1.00000 \\ 135.0 & 0.0000006 & 38.03 & 70.00 & 62.5000 & 0.0082458 & 0.0042746 & 0.0189984 & 1.00000 \\ 140.0 & 0.0000004 & 38.03 & 70.00 & 62.5000 & 0.0081956 & 0.0042486 & 0.0188826 & 1.00000 \\ 145.0 & 0.0000002 & 38.03 & 70.00 & 62.5000 & 0.0081474 & 0.0042236 & 0.0187715 & 1.00000 \\ 150.0 & 0.0000000 & 38.03 & 70.00 & 62.5000 & 0.0080972 & 0.0041976 & 0.0186559 & 1.00000\end{array}$

calculated fluid conditions at time $=0.0000$ seconds channel 3

\begin{tabular}{|c|c|c|c|c|c|c|c|c|}
\hline $\begin{array}{c}\text { distance } \\
\text { (in.) }\end{array}$ & $\begin{array}{l}\text { delta-p } \\
\text { (psi) }\end{array}$ & $\begin{array}{l}\text { enthalpy } \\
\text { (btu/lb) }\end{array}$ & $\begin{array}{l}\text { temperature } \\
\text { (deg-f) }\end{array}$ & $\begin{array}{c}\text { density } \\
(1 b / c u-f t)\end{array}$ & $\begin{array}{c}\text { flow } \\
(1 \mathrm{~b} / \mathrm{sec})\end{array}$ & $\begin{array}{c}\operatorname{mass} f l u x \\
(m l b / h r-f t 2)\end{array}$ & $\begin{array}{l}\text { velocity } \\
\text { (ft } / \mathrm{sec})\end{array}$ & $\begin{array}{l}\text { area } \\
(5 q-i n)\end{array}$ \\
\hline 0.0 & 0.0000109 & 38.03 & 70.00 & 62.5000 & 0.0173611 & 0.0090000 & 0.0400000 & 1.00000 \\
\hline 5.0 & 0.0000097 & 38.03 & 70.00 & 62.5000 & 0.0179195 & 0.0092895 & 0.0412866 & 1.00000 \\
\hline 10.0 & 0.0000086 & 38.03 & 70.00 & 62.5000 & 0.0179376 & 0.0092988 & 0.0413282 & 1.00000 \\
\hline 15.0 & 0.0000077 & 38.03 & 70.00 & 62.5000 & 0.0176521 & 0.0091509 & 0.0406705 & 1.00000 \\
\hline 20.0 & 0.0000070 & 38.03 & 70.00 & 62.5000 & 0.0172431 & 0.0089388 & 0.0397280 & 1.00000 \\
\hline 25.0 & 0.0000065 & 38.03 & 70.00 & 62.5000 & 0.0168076 & 0.0087131 & 0.0387247 & 1.00000 \\
\hline 30.0 & 0.0000061 & 38.03 & 70.00 & 62.5000 & 0.0163896 & 0.0084963 & 0.0377615 & 1.00000 \\
\hline 35.0 & 0.0000057 & 38.03 & 70.00 & 62.5000 & 0.0160037 & 0.0082963 & 0.0368726 & 1.00000 \\
\hline 40.0 & 0.0000053 & 38.03 & 70.00 & 62.5000 & 0.0156528 & 0.0081144 & 0.0360640 & 1.00000 \\
\hline 45.0 & 0.0000050 & 38.03 & 70.00 & 62.5000 & 0.0153353 & 0.0079498 & 0.0353325 & 1.00000 \\
\hline 50.0 & 0.0000047 & 38.03 & 70.00 & 62.5000 & 0.0150486 & 0.0078012 & 0.0346720 & 1.00000 \\
\hline 55.0 & 0.0000043 & 38.03 & 70.00 & 62.5000 & 0.0147898 & 0.0076671 & 0.0340758 & 1.00000 \\
\hline 60.0 & 0.0000041 & 38.03 & 70.00 & 62.5000 & 0.0145561 & 0.0075459 & 0.0335373 & 1.00000 \\
\hline 65.0 & 0.0000038 & 38.03 & 70.00 & 62.5000 & 0.0143446 & 0.0074363 & 0.0330500 & 1.00000 \\
\hline 70.0 & 0.0000035 & 38.03 & 70.00 & 62.5000 & 0.0141528 & 0.0073368 & 0.0326081 & 1.00000 \\
\hline 75.0 & 0.0000032 & 38.03 & 70.00 & 62.5000 & 0.0139783 & 0.0072464 & 0.0322061 & 1.00000 \\
\hline 80.0 & 0.0000030 & 38.03 & 70.00 & 62.5000 & 0.0138191 & 0.0071638 & 0.0318393 & 1.00000 \\
\hline 85.0 & 0.0000027 & 38.03 & 70.00 & 62.5000 & 0.0136734 & 0.0070883 & 0.0315036 & 1.00000 \\
\hline 90.0 & 0.0000025 & 38.03 & 70.00 & 62.5000 & 0.0135397 & 0.0070190 & 0.0311954 & 1.00000 \\
\hline 95.0 & 0.0000023 & 38.03 & 70.00 & 62.5000 & 0.0134166 & 0.0069551 & 0.0309117 & 1.00000 \\
\hline 100.0 & 0.0000020 & 38.03 & 70.00 & 62.5000 & 0.0133029 & 0.0068962 & 0.0306498 & 1.00000 \\
\hline 105.0 & 0.0000018 & 38.03 & 70.00 & 62.5000 & 0.0131977 & 0.0068417 & 0.0304074 & 1.00000 \\
\hline 110.0 & 0.0000016 & 38.03 & 70.00 & 62.5000 & 0.0131001 & 0.0067911 & 0.0301825 & 1.00000 \\
\hline 115.0 & 0.0000014 & 38.03 & 70.00 & 62.5000 & 0.0130093 & 0.0067440 & 0.0299734 & 1.00000 \\
\hline 120.0 & 0.0000012 & 38.03 & 70.00 & 62.5000 & 0.0129247 & 0.0067002 & 0.0297785 & 1.00000 \\
\hline 125.0 & 0.0000010 & 38.03 & 70.00 & 62.5000 & 0.0128457 & 0.0066592 & 0.0295965 & 1.00000 \\
\hline 130.0 & 0.0000008 & 38.03 & 70.00 & 62.5000 & 0.0127718 & 0.0066209 & 0.0294263 & 1.00000 \\
\hline 135.0 & 0.0000006 & 38.03 & 70.00 & 62.5000 & 0.0127026 & 0.0065850 & 0.0292667 & 1.00000 \\
\hline 140.0 & 0.0000004 & 38.03 & 70.00 & 62.5000 & 0.0126374 & 0.0065512 & 0.0291165 & 1.00000 \\
\hline 145.0 & 0.0000002 & 38.03 & 70.00 & 62.5000 & 0.0125751 & 0.0065189 & 0.0289730 & 1.00000 \\
\hline 150.0 & 0.0000000 & 38.03 & 70.00 & 62.5000 & 0.0125174 & 0.0064890 & 0.0288401 & 1.00000 \\
\hline
\end{tabular}

calculated fluid conditions at time $=0.0000$ seconds $\begin{array}{ll}\text { channel } & 4 \\ \text { assembly } & 1\end{array}$

\begin{tabular}{|c|c|c|c|c|c|c|c|}
\hline $\begin{array}{l}\text { distance } \\
\text { (1n.) } \\
0.0\end{array}$ & $\begin{array}{c}\text { delta-p } \\
\text { (psi) } \\
0.0000107\end{array}$ & $\begin{array}{c}\text { enthalpy } \\
\text { (btu/lb) } \\
38.03\end{array}$ & $\begin{array}{c}\text { temperature } \\
\text { (deg-f) } \\
70.00\end{array}$ & $\begin{array}{c}\text { density } \\
(1 \mathrm{~b} / \mathrm{cu}-\mathrm{ft}) \\
62.5000\end{array}$ & $\begin{array}{c}\text { flow } \\
\{1 \mathrm{~b} / \mathrm{sec}\} \\
0.0173611\end{array}$ & $\begin{array}{c}\text { mass flux } \\
(\mathrm{mlb} / \mathrm{hr}-\mathrm{ft} 2) \\
0.0090000\end{array}$ & $\begin{array}{r}\text { velocity } \\
\text { (ft/sec) } \\
0.0400000\end{array}$ \\
\hline
\end{tabular}




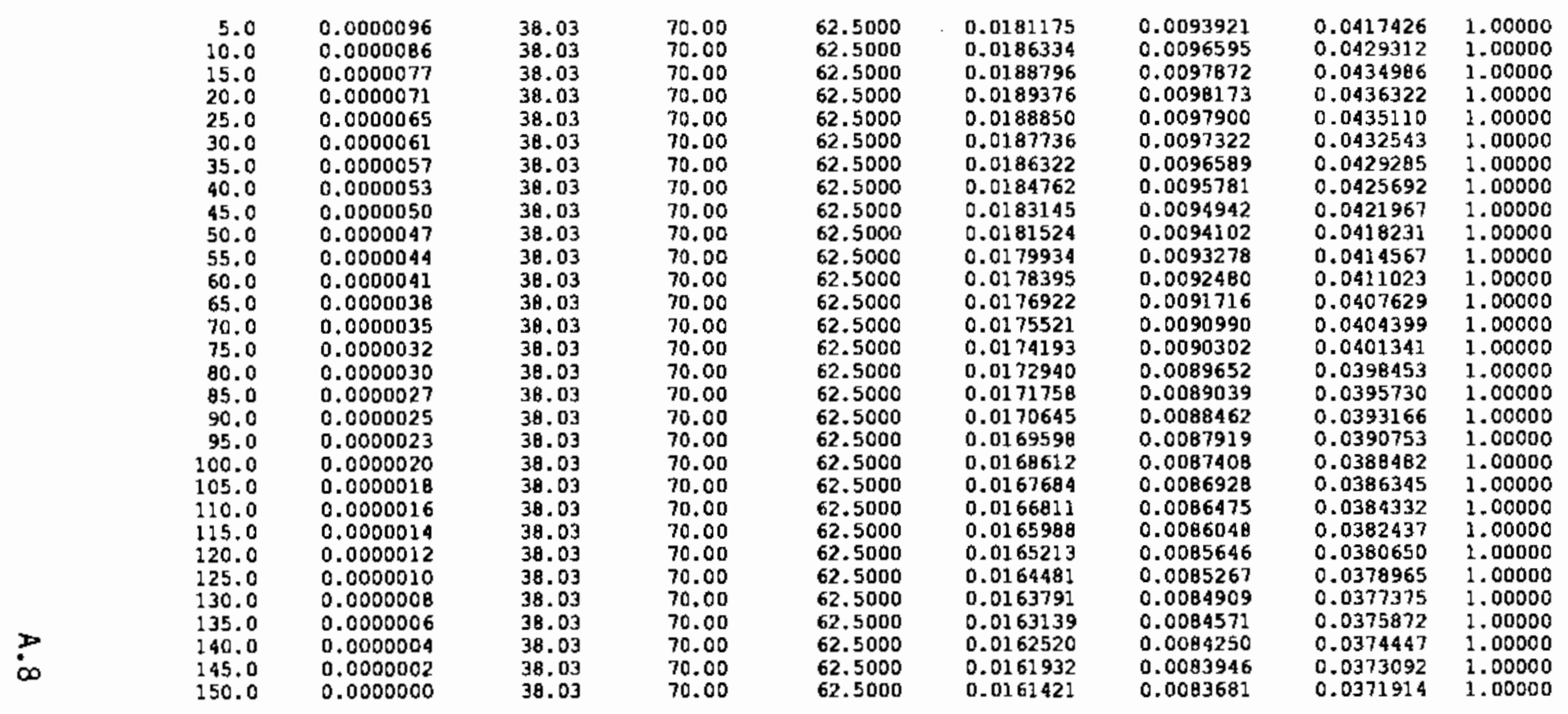

calculated fluid conditions at time $=0.0000$ seconds $\begin{array}{ll}\text { channel } & 5 \\ \text { assembly } & 1\end{array}$

\begin{tabular}{|c|c|c|c|c|c|c|c|c|}
\hline $\begin{array}{l}\text { distance } \\
\text { (In.) }\end{array}$ & $\begin{array}{l}\text { delta-p } \\
\text { (psi) }\end{array}$ & $\begin{array}{l}\text { enthalpy } \\
\text { (btu/lb) }\end{array}$ & $\begin{array}{c}\text { temperature } \\
\text { (deg-f) }\end{array}$ & $\begin{array}{c}\operatorname{dens} 1 t y \\
(1 b / c u-f t)\end{array}$ & $\begin{array}{c}\text { flow } \\
(\mathrm{l} / \mathrm{sec})\end{array}$ & $\operatorname{mass}_{\text {mlux }}$ & $\begin{array}{l}\text { velocity } \\
\text { (ft/sec) }\end{array}$ & $\begin{array}{l}\text { area } \\
(\text { so-in) }\end{array}$ \\
\hline 0.0 & 0.0000105 & 38.03 & 70.00 & 62.5000 & 0.0173611 & 0.0090000 & 0.0400000 & 1.00000 \\
\hline 5.0 & 0.0000096 & 38.03 & 70.00 & 62.5000 & 0.0180977 & 0.0093819 & 0.0416971 & 1.00000 \\
\hline 10.0 & 0.0000086 & 38.03 & 70.00 & 62.5000 & 0.0187782 & 0.0097346 & 0.0432649 & 1.00000 \\
\hline 15.0 & 0.0000078 & 38.03 & 70.00 & 62.5000 & 0.0192694 & 0.0099892 & 0.0443966 & 1.00000 \\
\hline 20.0 & 0.0000071 & 38.03 & 70.00 & 62.5000 & 0.0195860 & 0.0101534 & 0.0451261 & 1.00000 \\
\hline 25.0 & 0.0000066 & 38.03 & 70.00 & 62.5000 & 0.0197773 & 0.0102525 & 0.0455669 & 1.00000 \\
\hline 30.0 & 0.0000061 & 38.03 & 70.00 & 62.5000 & 0.0198868 & 0.0103093 & 0.0458191 & 1.00000 \\
\hline 35.0 & 0.0000057 & 38.03 & 70.00 & 62.5000 & 0.0199434 & 0.0103387 & 0.0459497 & 1.00000 \\
\hline 40.0 & 0.0000053 & 38.03 & 70.00 & 62.5000 & 0.0199647 & 0.0103497 & 0.0459986 & 1.00000 \\
\hline 45.0 & 0.0000050 & 38.03 & 70.00 & 62.5000 & 0.0199611 & 0.0103478 & 0.0459903 & 1.00000 \\
\hline 50.0 & 0.0000047 & 38.03 & 70.00 & 62.5000 & 0.0199397 & 0.0103368 & 0.0459412 & 1.00000 \\
\hline 55.0 & 0.0000044 & 38.03 & 70.00 & 62.5000 & 0.0199056 & 0.0103191 & 0.0458626 & 1.00000 \\
\hline 60.0 & 0.0000041 & 38.03 & 70.00 & 62.5000 & 0.0198625 & 0.0102967 & 0.0457632 & 1.00000 \\
\hline 65.0 & 0.0000038 & 38.03 & 70.00 & 62.5000 & 0.0198132 & 0.0102711 & 0.0456495 & 1.00000 \\
\hline 70.0 & 0.0000035 & 38.03 & 70.00 & 62.5000 & 0.0197597 & 0.0102434 & 0.0455263 & 1.00000 \\
\hline 75.0 & 0.0000032 & 38.03 & 70.00 & 62.5000 & 0.0197037 & 0.0102144 & 0.0453974 & 1.00000 \\
\hline$B 0.0$ & 0.0000030 & 38.03 & 70.00 & 62.5000 & 0.0196465 & 0.0101847 & 0.0452655 & 1.00000 \\
\hline 85.0 & 0.0000028 & 38.03 & 70.00 & 62.5000 & 0.0195889 & 0.0101549 & 0.0451328 & 1.00000 \\
\hline
\end{tabular}




$\begin{array}{rllllllll}90.0 & 0.0000025 & 38.03 & 70.00 & 62.5000 & 0.0195316 & 0.0101252 & 0.0450008 & 1.00000 \\ 95.0 & 0.0000023 & 38.03 & 70.00 & 62.5000 & 0.0194751 & 0.0100959 & 0.0448707 & 1.00000 \\ 100.0 & 0.0000020 & 38.03 & 70.00 & 62.5000 & 0.0194199 & 0.0100673 & 0.0447434 & 1.00000 \\ 105.0 & 0.0000018 & 38.03 & 70.00 & 62.5000 & 0.0193660 & 0.0100393 & 0.0446193 & 1.00000 \\ 110.0 & 0.0000016 & 38.03 & 70.00 & 62.5000 & 0.0193138 & 0.0100123 & 0.0444990 & 1.00000 \\ 115.0 & 0.0000014 & 38.03 & 70.00 & 62.5000 & 0.0192633 & 0.0099861 & 0.0443826 & 1.00000 \\ 120.0 & 0.0000012 & 38.03 & 70.00 & 62.5000 & 0.0192146 & 0.0099609 & 0.0442704 & 1.00000 \\ 125.0 & 0.0000010 & 38.03 & 70.00 & 62.5000 & 0.0191677 & 0.0099366 & 0.0441625 & 1.00000 \\ 130.0 & 0.0000008 & 38.03 & 70.00 & 62.5000 & 0.0191227 & 0.0099132 & 0.0440587 & 1.00000 \\ 135.0 & 0.0000006 & 38.03 & 70.00 & 62.5000 & 0.0190794 & 0.0098908 & 0.0439590 & 1.00000 \\ 140.0 & 0.0000004 & 38.03 & 70.00 & 62.5000 & 0.0190379 & 0.0098692 & 0.0438632 & 1.00000 \\ 145.0 & 0.0000002 & 38.03 & 70.00 & 62.5000 & 0.0189984 & 0.0098488 & 0.0437724 & 1.00000 \\ 150.0 & 0.0000000 & 38.03 & 70.00 & 62.5000 & 0.0189660 & 0.0098320 & 0.0436976 & 1.00000\end{array}$

calculated fluid conditions at time $=0.0000$ seconds $\begin{array}{ll}\text { channel } & 6 \\ \text { assembly } & 1\end{array}$

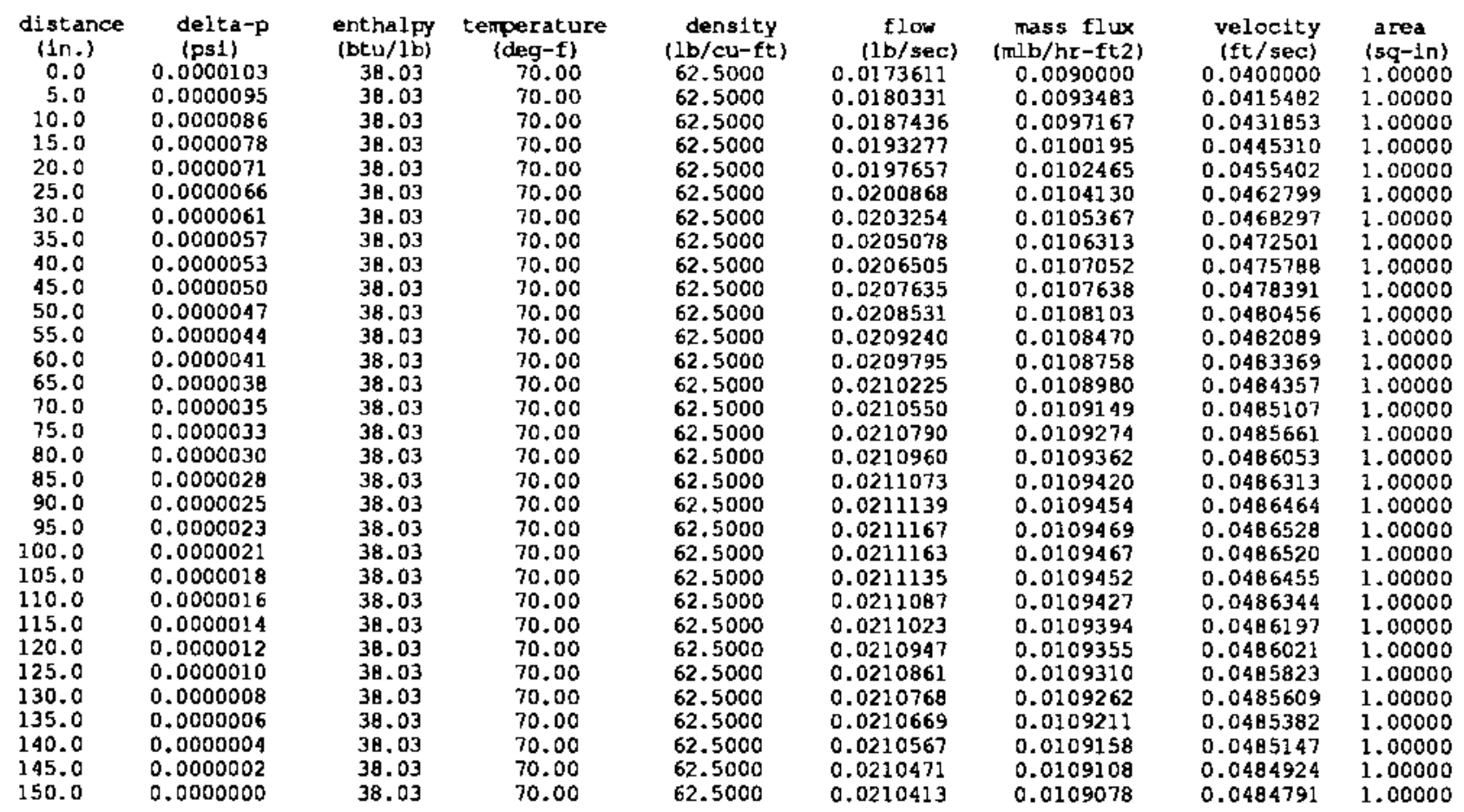




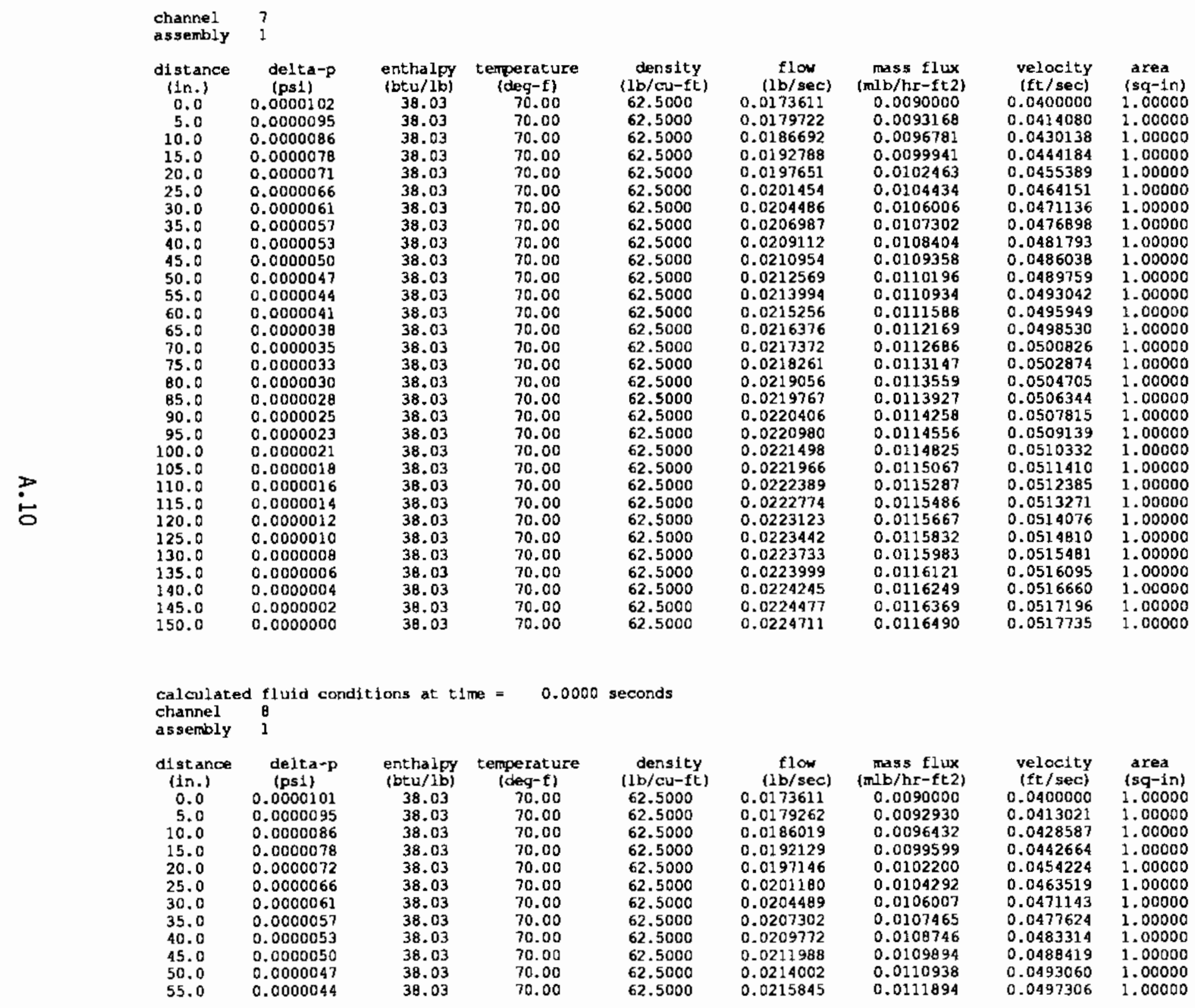




$\begin{array}{lllllllll}60.0 & 0.0000041 & 38.03 & 70.00 & 62.5000 & 0.0217538 & 0.0112772 & 0.0501200 & 1.00000 \\ 65.0 & 0.0000038 & 38.03 & 70.00 & 62.5000 & 0.0219098 & 0.0113580 & 0.0504802 & 1.00000 \\ 70.0 & 0.0000035 & 38.03 & 70.00 & 62.5000 & 0.0220539 & 0.0114327 & 0.0508121 & 1.00000 \\ 75.0 & 0.0000033 & 38.03 & 70.00 & 62.5000 & 0.0221872 & 0.0115018 & 0.051192 & 1.00000 \\ 80.0 & 0.0000030 & 38.03 & 70.00 & 62.5000 & 0.0223107 & 0.0115659 & 0.0514039 & 1.00000 \\ 85.0 & 0.0000028 & 38.03 & 70.00 & 62.5000 & 0.0224254 & 0.0116254 & 0.0516682 & 1.00000 \\ 90.0 & 0.0000025 & 38.03 & 70.00 & 62.5000 & 0.0225321 & 0.0116807 & 0.0519141 & 1.00000 \\ 95.0 & 0.0000023 & 38.03 & 70.00 & 62.5000 & 0.0226315 & 0.0117322 & 0.0521430 & 1.00000 \\ 100.0 & 0.0000021 & 38.03 & 70.00 & 62.5000 & 0.0227242 & 0.0117802 & 0.0523566 & 1.00000 \\ 105.0 & 0.0000018 & 38.03 & 70.00 & 62.5000 & 0.0228108 & 0.0118251 & 0.0525560 & 1.00000 \\ 110.0 & 0.0000016 & 38.03 & 70.00 & 62.5000 & 0.0228918 & 0.0118671 & 0.0527426 & 1.00000 \\ 115.0 & 0.0000014 & 38.03 & 70.00 & 62.5000 & 0.0229676 & 0.0119064 & 0.0529173 & 1.00000 \\ 120.0 & 0.0000012 & 38.03 & 70.00 & 62.5000 & 0.0230387 & 0.0119432 & 0.0530811 & 1.00000 \\ 125.0 & 0.0000010 & 38.03 & 70.00 & 62.5000 & 0.0231054 & 0.0119778 & 0.05332348 & 1.00000 \\ 130.0 & 0.0000008 & 38.03 & 70.00 & 62.5000 & 0.0231661 & 0.0120103 & 0.0533793 & 1.00000 \\ 135.0 & 0.0000006 & 38.03 & 70.00 & 62.5000 & 0.0232271 & 0.0120409 & 0.0535152 & 1.00000 \\ 140.0 & 0.0000004 & 38.03 & 70.00 & 62.5000 & 0.0232828 & 0.0120698 & 0.0536436 & 1.00000 \\ 145.0 & 0.0000002 & 38.03 & 70.00 & 62.5000 & 0.0233358 & 0.0120973 & 0.0537656 & 1.00000 \\ 150.0 & 0.0000000 & 38.03 & 70.00 & 62.5000 & 0.0233856 & 0.0121231 & 0.0538805 & 1.00000\end{array}$

calculated fluid conditions at time $=0.0000$ seconds channel 9

\section{distance}

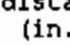

5.0
10.0
15.0
20.0
25.0
30.0
35.0
40.0
45.0
50.0
55.0
60.0
65.0
70.0
75.0
80.0
85.0
90.0
95.0
100.0
105.0
110.0
115.0
120.0
125.0
130.0
135.0
140.0

$5.0 \quad 0.0000095$

$10.0 \quad 0.0000086$

$15.0 \quad 0.0000078$

$20.0 \quad 0.0000072$

0.0000066

0.0000061

0.0000057

0.0000053

$45.0 \quad 0.0000050$

0.0000047

0.0000044

6.00 .0000041

$65.0 \quad 0.0000038$

0.0000035

$75.0 \quad 0.0000033$

$\begin{array}{ll}9.0 & 0.0000028\end{array}$

0.000025

$\begin{array}{ll}105.0 & 0.0000018 \\ 10.0 & 0.0000016\end{array}$

0.0000014

0.0000012

0.0000010

0.0000008

0.0000006

0.0000004 enthalpy temperature

38.03

38.03

38.03

38.0

38.03

38.03

38.03

38.03

38.03

38.03

38.03

38.03

38.03

38.03

38.03

38.03

38.0

38.0

38.0

38.0

38.03

38.03

38.03

38.03

38.03
38.03
70.00

70.00
70.00

30.00 density 62.5000 62.5000 62.5000 62.5000 62.5000 62.5000 62.5000 62.5000 62.5000 62.5000 62.5000 62.5000 62.5000 62.5000 62.5000

62.5000

62.5000

62.5000

62.5000

62.5000

62.5000

62.5000

62.5000

62.5000

62.5000

62.5000

62.5000

62.5000

62.5000
0.0538805 (1b/sec) 0.0178964 0.0185550 0.0191615 0.0196665 0.0200772 0.0204181 0.0207115 0.0209729 0.0212113 0.0214318 0.0216372 0.0218293 .0220094 0.0221787 0.0223379 0.0224880 0.0226297 0.0227634 0.0230095 0.0232300 0.0233317 0.0234281 0.0235196 0.0236890 0.0237676 mass flux

0.0090000 0.0092775 0.0099333 0.0101951 0.0104080 0.0105847 0.0107368 0.0109960 0.0111103 0.0112167 0.0114097 0.0114974 0.0115800 0.0116578 0.011731 0.0118661 0.011928 0.0119868 0.012042 0.012095 0.012145 0.0121926 0.0122376 0.0122804 0.0123211 velocity area
(ft/sec) (sq-in) $0.0400000 \quad 1.00000$ $0.0412333 \quad 1.00000$ $0.0427508 \quad 1.00000$ $0.0441482 \quad 1.00000$ $0.0453115 \quad 1.00000$ 0.04704331 .00000 0.04937891 .00000 $0.0498521 \quad 1.00000$ 0.05070971 .00000 0.05109961 .00000 0.05146661 .00000 0.05181251 .00000 $\begin{array}{ll}0.0521388 & 1.00000 \\ 0.0524469 & 1.00000\end{array}$ $0.0527383 \quad 1.00000$ $0.0530139 \quad 1.00000$ $0.0532748 \quad 1.00000$ $\begin{array}{lll}0.0535219 & 1.00000\end{array}$ $\begin{array}{lll}0.0537562 & 1.00000\end{array}$ $0.0539784 \quad 1.00000$ $0.0541892 \quad 1.00000$ $0.0543893 \quad 1.00000$ $0.0545795 \quad 1.00000$ $0.0547606 \quad 1.00000$ 


$\begin{array}{lllllllll}145.0 & 0.0000002 & 38.03 & 70.00 & 62.5000 & 0.0238425 & 0.0123600 & 0.0549331 & 1.00000 \\ 150.0 & 0.0000000 & 38.03 & 70.00 & 62.5000 & 0.0239121 & 0.0123960 & 0.0550934 & 1.00000\end{array}$

colculated fluld conditions at time $=0.0000$ seconds channel 10
assembly

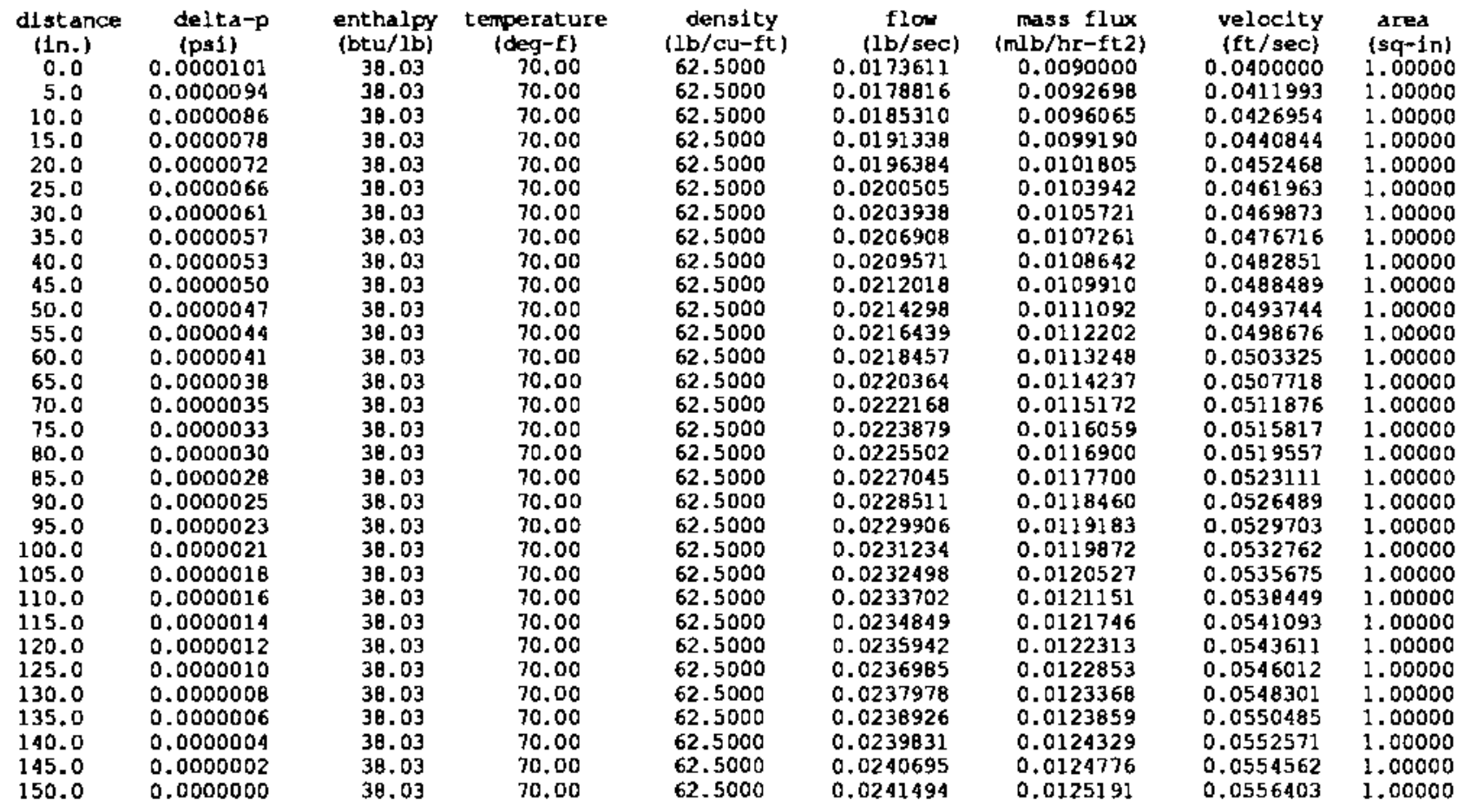

slab temperature sumary $\quad$ time $=0.0000$ seconds

axial zone
(1nches)

11

1

$\begin{array}{ll}0.0-5.0 & 70.00 \\ 5.0-10.0 & 70.00\end{array}$

$0.0-10.0$
$10.0-15.0$

$15.0-20.070 .00$ 


$\begin{array}{rl}20.0-25.0 & 70.00 \\ 25.0-30.0 & 70.00 \\ 30.0-35.0 & 70.00 \\ 35.0=40.0 & 70.00 \\ 40.0=45.0 & 70.00 \\ 45.0=50.0 & 70.00 \\ 50.0=55.0 & 70.00 \\ 55.0-60.0 & 70.00 \\ 60.0-65.0 & 70.00 \\ 65.0-70.0 & 70.00 \\ 70.0-75.0 & 70.00 \\ 75.0=80.0 & 70.00 \\ 80.0-85.0 & 70.00 \\ 85.0-90.0 & 70.00 \\ 90.0-95.0 & 70.00 \\ 95.0-100.0 & 70.00 \\ 100.0-105.0 & 70.00 \\ 105.0-110.0 & 70.00 \\ 110.0-115.0 & 70.00 \\ 115.0-120.0 & 70.00 \\ 120.0-125.0 & 70.00 \\ 125.0-130.0 & 70.00 \\ 130.0-135.0 & 70.00 \\ 135.0-140.0 & 70.00 \\ 140.0-145.0 & 70.00 \\ 145.0-150.0 & 70.00\end{array}$

crossflow between adjacent channels at t1me $=0.0000$ seconds

\begin{tabular}{|c|c|c|c|c|c|c|c|c|c|c|}
\hline \multirow{3}{*}{\multicolumn{2}{|c|}{$\begin{array}{l}\text { assembly number } \\
\text { axial zone } \\
0.0-5.0\end{array}$}} & 1 & 1 & 1 & 1 & 1 & 1 & 1 & 1 & 1 \\
\hline & & 12 & & $\begin{array}{ll}3 & 4\end{array}$ & 45 & 5 & 6 & 78 & $\theta$ & 910 \\
\hline & & 0.01083 & 0.01189 & 0.01055 & 0.00874 & 0.00697 & 0.00536 & 0.00389 & 0.00253 & 0.00125 \\
\hline 5.0 & 10.0 & 0.00822 & 0.01105 & 0.01101 & 0.00977 & 0.00814 & 0.00643 & 0.00476 & 0.00314 & 0.00156 \\
\hline $10.0-$ & 15.0 & 0.00536 & 0.00832 & 0.00900 & 0.00841 & 0.00723 & 0.00583 & 0.00437 & 0.00290 & 0.00145 \\
\hline & 20.0 & 0.00320 & 0.00576 & 0.00675 & 0.00661 & 0.00585 & 0.00479 & 0.00363 & 0.00242 & 0.00121 \\
\hline & 25.0 & 0.00185 & 0.00391 & 0.00496 & 0.00509 & 0.00463 & 0.00386 & 0.00294 & 0.00198 & 0.00099 \\
\hline 25 . & 30.0 & 0.00110 & 0.00273 & 0.00373 & 0.00400 & 0.00374 & 0.00316 & 0.00244 & 0.00164 & 0.00082 \\
\hline 30.0 & 35.0 & 0.00071 & 0.00200 & 0.00293 & 0.00327 & 0.00313 & 0.00269 & 0.00209 & 0.00142 & 0.00071 \\
\hline 35.0 & 40.0 & 0.00050 & 0.00155 & 0.00239 & 0.00276 & 0.00272 & 0.00237 & 0.00186 & 0.00127 & 0.00064 \\
\hline 40.0 & 45.0 & 0.00039 & 0.00125 & 0.00201 & 0.00240 & 0.00240 & 0.00213 & 0.00169 & 0.00116 & 0.00059 \\
\hline 45.0 & 50.0 & 0.00031 & 0.00103 & 0.00172 & 0.00211 & 0.00216 & 0.00195 & 0.00156 & 0.00108 & 0.00055 \\
\hline & 55.0 & 0.00026 & 0.00088 & 0.00150 & 0.00188 & 0.00196 & 0.00179 & 0.00145 & 0.00101 & 0.00051 \\
\hline $55.0-$ & 60.0 & 0.00022 & 0.00075 & 0.00131 & 0.00168 & 0.00179 & 0.00165 & 0.00135 & 0.00095 & 0.00048 \\
\hline 60.0. & 65.0 & 0.00019 & 0.00066 & 0.00116 & 0.00152 & 0.00164 & 0.00153 & 0.00126 & 0.00089 & 0.00046 \\
\hline 65.0 & 70.0 & 0.00017 & 0.00058 & 0.00104 & 0.00137 & 0.00150 & 0.00142 & 0.00118 & 0.00084 & 0.00043 \\
\hline 70.0 & 75.0 & 0.00015 & 0.00051 & 0.00093 & 0.00125 & 0.00138 & 0.00133 & 0.00111 & 0.00079 & 0.00041 \\
\hline 75.0 & 80.0 & 0.00013 & 0.00046 & 0.00084 & 0.00114 & 0.00128 & 0.00124 & 0.00105 & 0.00075 & 0.00039 \\
\hline & 85.0 & 0.00012 & 0.00041 & 0.00076 & 0.00104 & 0.00118 & 0.00116 & 0.00099 & 0.00071 & 0.00037 \\
\hline 85.0 & 90.0 & 0.00011 & 0.00037 & 0.00069 & 0.00096 & 0.00110 & 0.00108 & 0.00093 & 0.00067 & 0.00035 \\
\hline & $-\quad 95.0$ & 0.00010 & 0.00034 & 0.00063 & 0.00089 & 0.00102 & 0.00101 & 0.00088 & 0.00064 & 0.00033 \\
\hline $95.0-$ & -100.0 & 0.00009 & 0.00031 & 0.00058 & 0.00082 & 0.00095 & 0.00095 & 0.00083 & 0.00061 & 0.00032 \\
\hline 100.0 & 105.0 & 0.00008 & 0.00028 & 0.00054 & 0.00076 & 0.00089 & 0.00090 & 0.00078 & 0.00058 & 0.00030 \\
\hline 105.0 & 110.0 & 0.00008 & 0.00026 & 0.00050 & 0.00071 & 0.00083 & 0.00084 & 0.00074 & 0.00055 & 0.00029 \\
\hline 110.0 & 115.0 & 0.00007 & 0.00024 & 0.00046 & 0.00066 & 0.00078 & 0.00079 & 0.00070 & 0.00052 & $0.0002 \mathrm{~B}$ \\
\hline & 20.0 & 0.00006 & 0.00022 & 0.00043 & 0.00061 & 0.00073 & 0.00075 & 0.00066 & 0.00049 & 0.00026 \\
\hline
\end{tabular}




$\begin{array}{llllllllll}120.0-125.0 & 0.00006 & 0.00021 & 0.00040 & 0.00057 & 0.00069 \cdot & 0.00071 & 0.00063 & 0.00047 & 0.00025 \\ 125.0-130.0 & 0.00006 & 0.00019 & 0.00037 & 0.00054 & 0.00064 & 0.00067 & 0.00060 & 0.00045 & 0.00024 \\ 130.0-135.0 & 0.00005 & 0.00018 & 0.00035 & 0.00050 & 0.00061 & 0.00063 & 0.00057 & 0.00043 & 0.00023 \\ 135.0-140.0 & 0.00005 & 0.00017 & 0.00033 & 0.00047 & 0.00057 & 0.00060 & 0.00054 & 0.00041 & 0.00022 \\ 140.0-145.0 & 0.00005 & 0.00016 & 0.00031 & 0.00045 & 0.00055 & 0.00057 & 0.00051 & 0.00039 & 0.00021 \\ 145.0-150.0 & 0.00006 & 0.00018 & 0.00032 & 0.00044 & 0.00052 & 0.00053 & 0.00048 & 0.00036 & 0.00019\end{array}$

iterations = 15

Input transient time completed

common durmed to tape 8

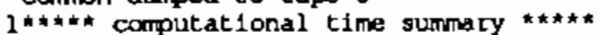

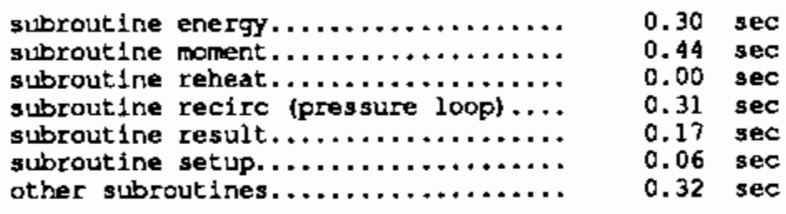

total cpu time...

$1.60 \mathrm{sec}$ 
APPENDIX B

DEVELOPING FLOW IN A CYLINDRICAL PIPE OUTPUT 
APPENDIX B

\section{NATURAL CIRCULATION IN A SQUARE CAVITY OUTPUT}

cobra dimension parameters:

$\begin{array}{rr}1 \mathrm{~d}= & 6 \\ 1 \mathrm{~h}= & 9 \\ 1 \mathrm{r}= & 9 \\ 1 \mathrm{iw}= & 6 \\ \mathrm{la}= & 15 \\ \mathrm{ld}= & 1 \\ \mathrm{ma}= & 20 \\ \mathrm{mg}= & 50 \\ \mathrm{mj}= & 1 \\ \mathrm{lnutr} & 20 \\ \mathrm{mq}= & 1 \\ \mathrm{mt}= & 1 \\ \mathrm{my}= & 4 \\ \mathrm{mv}= & 2\end{array}$

$\begin{array}{rr}\text { le }= & 40 \\ \text { lipe } & 8 \\ \text { lit= } & 3 \\ \text { ix }= & 8 \\ 1 b= & 1 \\ l e= & 1 \\ m c= & 40 \\ m b= & 6 \\ m k= & 3 \\ m n= & 6 \\ m r= & 20 \\ m a= & 40 \\ n d= & 9 \\ l n z= & 10\end{array}$

$\begin{array}{rr}\text { iif }= & 15 \\ \text { iq }= & 7 \\ 1 \mathrm{u}= & 6 \\ 112= & 15 \\ 11 \mathrm{c}= & 1 \\ \mathrm{lf}= & 1 \\ \mathrm{me}= & 31 \\ \mathrm{ml}= & 12 \\ \mathrm{ml}= & 9 \\ \mathrm{mp}= & 20 \\ \mathrm{~ms}= & 30 \\ \mathrm{mx}= & 31 \\ \mathrm{no}= & 2\end{array}$

品

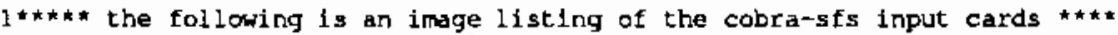

radx generated input is not included

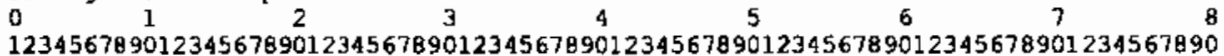

\begin{tabular}{|c|c|c|c|c|c|c|c|c|}
\hline 2 & 1 & fluid & shea & sample & roblem no. & & & \\
\hline $\begin{array}{l}3 \\
4\end{array}$ & prop & & & & & & & \\
\hline $\begin{array}{l}q \\
5\end{array}$ & $\begin{array}{l}0.0 \\
0.0\end{array}$ & & $\begin{array}{r}50 \\
100\end{array}$ & $\begin{array}{l}18.07 \\
67.97\end{array}$ & $\begin{array}{l}0.332 \\
0.364\end{array}$ & $\begin{array}{l}1.000 \\
0.998\end{array}$ & $\begin{array}{l}0.016 \\
0.016\end{array}$ & $\begin{array}{l}37.52 \\
37.52\end{array}$ \\
\hline 6 & 1 none & & 1.0 & 1.0 & 1.0 & 1.0 & & \\
\hline 7 & chan 1 & 30 & & 1 & & & & \\
\hline 8 & 150. & & 90. & & & & & \\
\hline 9 & 11 & 10 & 0 & 1 & & & & \\
\hline 10 & 10 & 0 & 0 & 0 & & & & \\
\hline 11 & 13.14 & 1.0 & 0.0 & 26.28 & 1.0 & & & \\
\hline 12 & 29.42 & 1.0 & 0.0 & 312.57 & 1.0 & & & \\
\hline 13 & 315,71 & 1.0 & 0.0 & 418.85 & 1.0 & & & \\
\hline 14 & 421.99 & 1.0 & 0.0 & 525.13 & 1.0 & & & \\
\hline 15 & 528.27 & 1.0 & 0.0 & 631.42 & 1.0 & & & \\
\hline 16 & 634.59 & 1.0 & 0.0 & 737.70 & 1.0 & & & \\
\hline 17 & 740.84 & 1.0 & 0.0 & 843.98 & 1.0 & & & \\
\hline 18 & 847.12 & 1.0 & 0.0 & 950.27 & 1.0 & & & \\
\hline 19 & 953.41 & 1.0 & 0.0 & 1056.55 & 1.0 & & & \\
\hline 20 & 1059.69 & 1.0 & 0.0 & & & & & \\
\hline $\begin{array}{l}21 \\
22\end{array}$ & slab & & & & & & & \\
\hline 23 & ${ }_{1}$ & 1.0 & 0.0 & & & & & \\
\hline
\end{tabular}




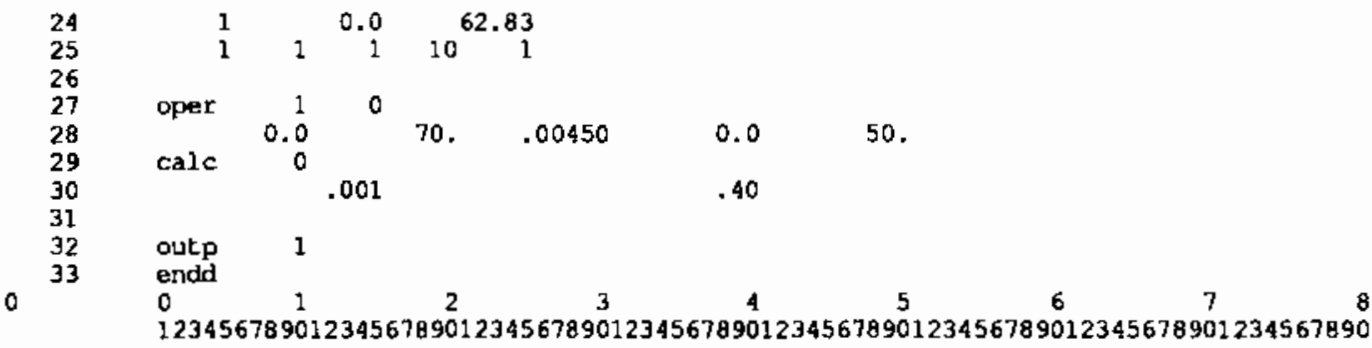

linput for case 1 fluid shear sample problem no.

date $01 / 05 / 89$ time

\begin{tabular}{lrrrrrrrrrrrrrrr}
\multicolumn{2}{c}{ summary of } & input & options & & & & & & \\
group & n1 & n2 & n3 & n4 & $n 5$ & $n 6$ & $n 7$ & $n 8$ & $n 9$ & $n 10$ & $n 11$ & $n 12$ & $n 13$ & $n 14$ & $n 15$ \\
prop & 2 & 1 & 0 & 0 & 0 & 0 & 0 & 0 & 0 & 0 & 0 & 0 & 0 & 0 & 0 \\
chan & 1 & 30 & 0 & 1 & 0 & 0 & 0 & 0 & 0 & 0 & 0 & 0 & 0 & 0 & 0 \\
slab & 0 & 1 & 1 & 0 & 0 & 0 & 0 & 0 & 0 & 0 & 0 & 0 & 0 & 0 & 0 \\
oper & 1 & 0 & 0 & 0 & 0 & 0 & 0 & 0 & 0 & 0 & 0 & 0 & 0 & 0 & 0 \\
calc & 0 & 0 & 0 & 0 & 0 & 0 & 0 & 0 & 0 & 0 & 0 & 0 & 0 & 0 & 0 \\
outp & 1 & 0 & 0 & 0 & 0 & 0 & 0 & 0 & 0 & 0 & 0 & 0 & 0 & 0 & 0 \\
endd & 0 & 0 & 0 & 0 & 0 & 0 & 0 & 0 & 0 & 0 & 0 & 0 & 0 & 0 & 0
\end{tabular}

\section{fluid property table}

$\begin{array}{cc}\text { pliq } & \text { temliq } \\ \text { (psia) } & \text { (f) } \\ 0.0000 & 50.0000 \\ 0.0000 & 100.0000\end{array}$

$$
\begin{array}{r}
\text { hliq } \\
\text { (btu/1 bm) } \\
18.0700
\end{array}
$$

(btu/hr-ft-

(be cpliq$$
00
$$
solid property table
type material

1 none
cpsol
(beu/hr-f)
1.0000
rhosol
1.0000

thermal conductivity

$1.000 \mathrm{E}+00+1.000 \mathrm{E}+00 * t+0.000 \mathrm{E}+00 * t * 2+0.000 \mathrm{E}+00 * \mathrm{E} * * 3$

assembly number 1 Input description

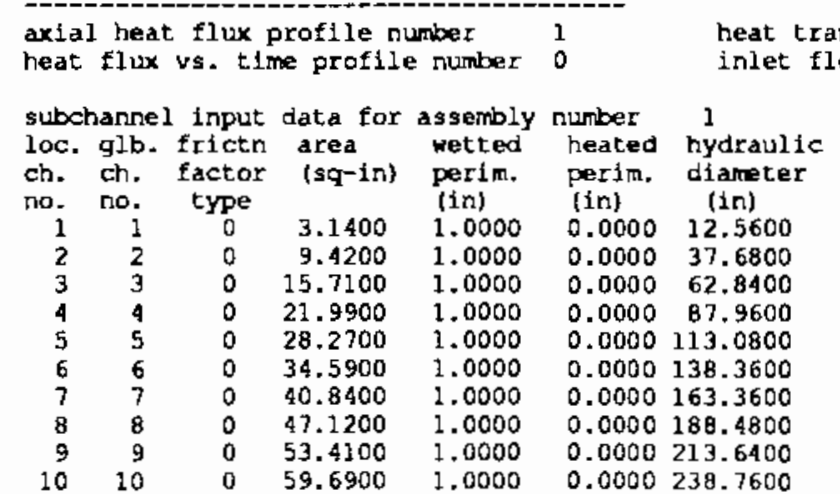

heat transfer correlation number 0

(adjacent channel no., momentum control volume width and length)

$\{2,6.280,1.000)(0,0.000,0.000)(0,0.000,0.000)(0,0.000,0.000)$ $3,12.570,1.000)(0,0.000,0.000)(0,0.000,0.000)(0,0.000,0.000)$ $4,18.850,1.000\})(0,0.000,0.000)(0,0.000,0.000)(0,0.000,0.000)$ $5,25.130,1.000\}\{0,0.000,0.000)\{0,0.000,0.000\}(0,0.000,0.000)$ $6,31.420,1.000\}(0,0.000,0.000\}\{0,0.000,0.000\}(0,0.000,0.000)$ $7,37.700,1.000)(0,0.000,0.000)\{0,0.000,0.000)(0,0.000,0.000)$ $8,43.980,1.000)(0,0.000,0.000)(0,0.000,0.000)(0,0.000,0.000)$ $9,50.270,1.000)(0,0.000,0.000)(0,0.000,0.000)(0,0.000,0.000)$
$10,56.550,1.000)(0,0.000,0.000)(0,0.000,0.000)(0,0.000,0.000)$ $0,0.000,0.000)(0,0.000,0.000\}(0,0.000,0.000)(0,0.000,0.000)$ 
solid-to-fluid themal connection type table

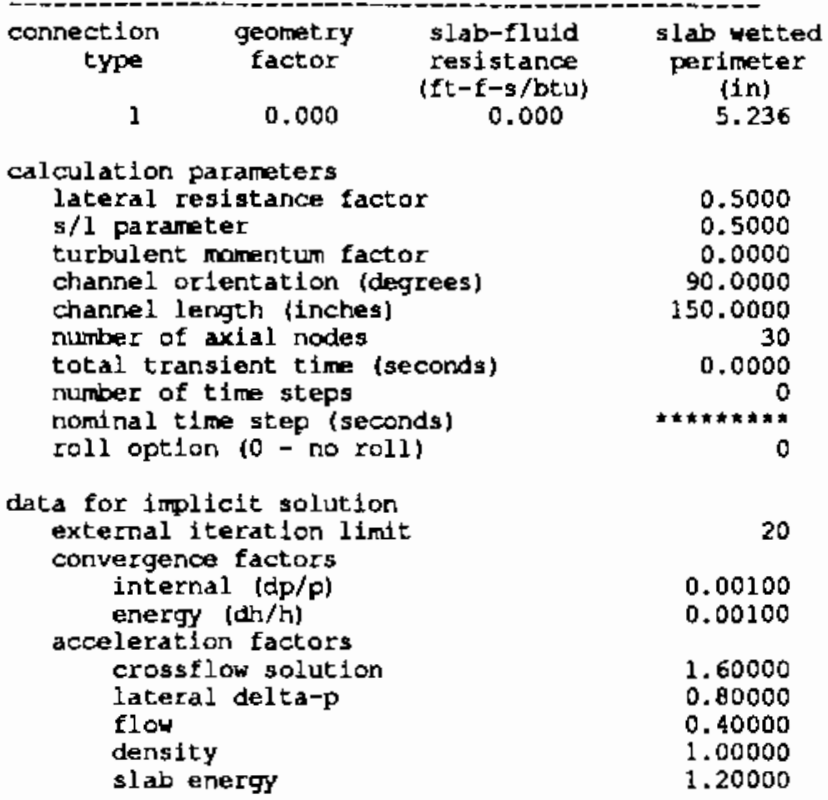

axial nodtng

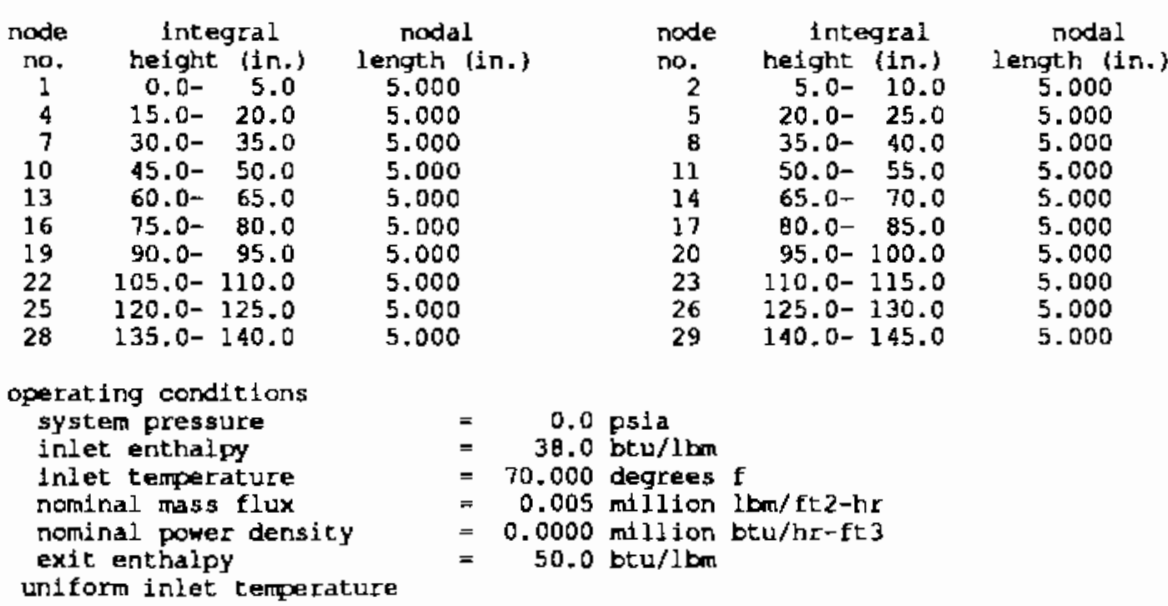

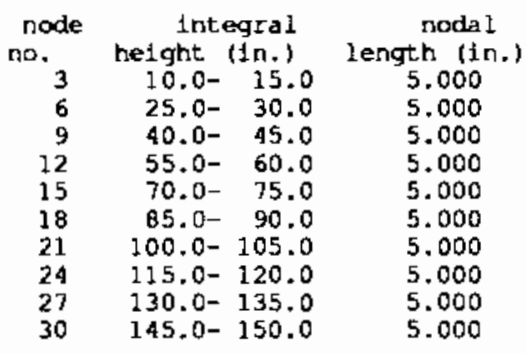


parameter surmary

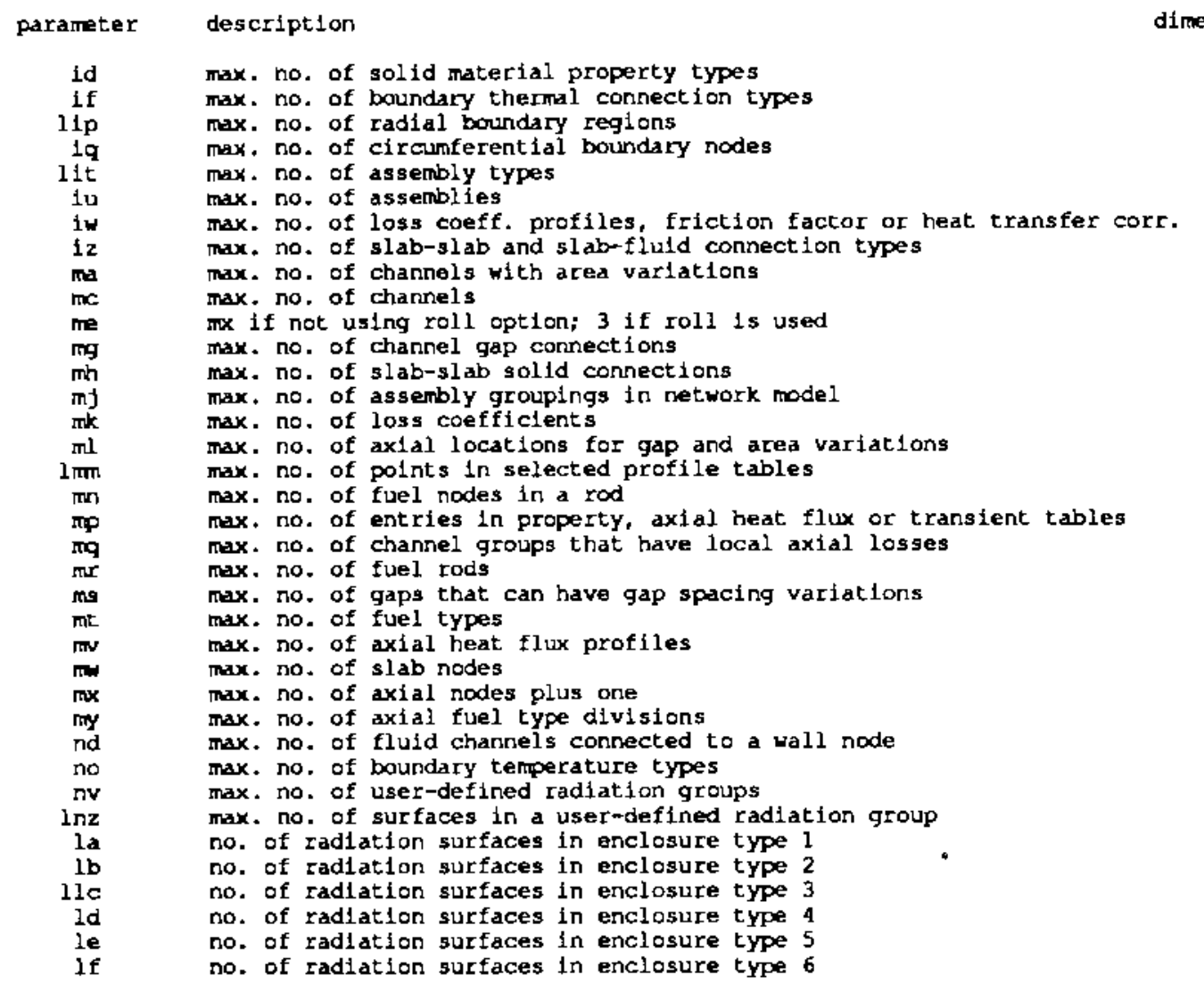




$\begin{array}{lllllllll}45.0 & 0.0000049 & 38.03 & 70.00 & 62.5000 & 0.0433877 & 0.0071631 & 0.0318361 & 3.14000 \\ 50.0 & 0.0000046 & 38.03 & 70.00 & 62.5000 & 0.0442333 & 0.0073027 & 0.0374566 & 3.14000 \\ 55.0 & 0.0000043 & 38.03 & 70.00 & 62.5000 & 0.0450066 & 0.0074304 & 0.0930240 & 3.14000 \\ 60.0 & 0.0000040 & 38.03 & 70.00 & 62.5000 & 0.0457149 & 0.0075473 & 0.0335437 & 3.14000 \\ 65.0 & 0.0000038 & 38.03 & 70.00 & 62.5000 & 0.0463646 & 0.0076546 & 0.0340204 & 3.14000 \\ 70.0 & 0.0000035 & 38.03 & 70.00 & 62.5000 & 0.0469612 & 0.0077531 & 0.0344582 & 3.14000 \\ 75.0 & 0.0000033 & 38.03 & 70.00 & 62.5000 & 0.0475097 & 0.0078436 & 0.0348606 & 3.14000 \\ 80.0 & 0.0000031 & 38.03 & 70.00 & 62.5000 & 0.0480142 & 0.0079269 & 0.0352308 & 3.14000 \\ 85.0 & 0.0000028 & 38.03 & 70.00 & 62.5000 & 0.0484788 & 0.0080036 & 0.0355717 & 3.14000 \\ 90.0 & 0.0000026 & 38.03 & 70.00 & 62.5000 & 0.0489068 & 0.0080743 & 0.0358857 & 3.14000 \\ 95.0 & 0.0000024 & 38.03 & 70.00 & 62.5000 & 0.0493013 & 0.0081394 & 0.0361752 & 3.14000 \\ 100.0 & 0.0000021 & 38.03 & 70.00 & 62.5000 & 0.0496551 & 0.0081995 & 0.0364422 & 3.14000 \\ 105.0 & 0.0000019 & 38.03 & 70.00 & 62.5000 & 0.0500008 & 0.0082549 & 0.0366835 & 3.14000 \\ 110.0 & 0.0000017 & 38.03 & 70.00 & 62.5000 & 0.0503107 & 0.0083061 & 0.0369159 & 3.14000 \\ 115.0 & 0.0000015 & 38.03 & 70.00 & 62.5000 & 0.0505968 & 0.0083533 & 0.0371258 & 3.14000 \\ 120.0 & 0.0000013 & 38.03 & 70.00 & 62.5000 & 0.0508612 & 0.0083970 & 0.0373198 & 3.14000 \\ 125.0 & 0.0000010 & 38.03 & 70.00 & 62.5000 & 0.0511055 & 0.0084373 & 0.0374991 & 3.14000 \\ 130.0 & 0.0000008 & 38.03 & 70.00 & 62.5000 & 0.0513314 & 0.0084746 & 0.0376648 & 3.14000 \\ 135.0 & 0.0000006 & 38.03 & 70.00 & 62.5000 & 0.0515403 & 0.0085091 & 0.0378181 & 3.14000 \\ 140.0 & 0.0000004 & 38.03 & 70.00 & 62.5000 & 0.0517338 & 0.0085410 & 0.0379601 & 3.14000 \\ 145.0 & 0.0000002 & 38.03 & 70.00 & 62.5000 & 0.0519136 & 0.0085707 & 0.0380921 & 3.14000 \\ 150.0 & 0.0000000 & 38.03 & 70.00 & 62.5000 & 0.0520784 & 0.0085979 & 0.0382129 & 3.14000\end{array}$

calculated fluid conditions at time $=0.0000$ seconds $\begin{array}{ll}\text { channel } & 2 \\ \text { assembly } & 1\end{array}$

$\begin{array}{rr}\text { distance } & \begin{array}{c}\text { delta-p } \\ \text { (psi) }\end{array} \\ 0.0 & 0.0000089 \\ 5.0 & 0.0000083 \\ 10.0 & 0.0000076 \\ 15.0 & 0.0000070 \\ 20.0 & 0.0000065 \\ 25.0 & 0.0000061 \\ 30.0 & 0.0000058 \\ 35.0 & 0.0000055 \\ 40.0 & 0.0000051 \\ 45.0 & 0.0000049 \\ 50.0 & 0.0000046 \\ 55.0 & 0.0000043 \\ 60.0 & 0.0000040 \\ 65.0 & 0.0000038 \\ 70.0 & 0.0000035 \\ 75.0 & 0.0000033 \\ 80.0 & 0.0000031 \\ 85.0 & 0.0000028 \\ 90.0 & 0.0000026 \\ 95.0 & 0.0000024 \\ 100.0 & 0.0000021 \\ 105.0 & 0.0000019 \\ 110.0 & 0.0000017 \\ 115.0 & 0.0000015 \\ 120.0 & 0.0000013 \\ 125.0 & 0.0000010\end{array}$

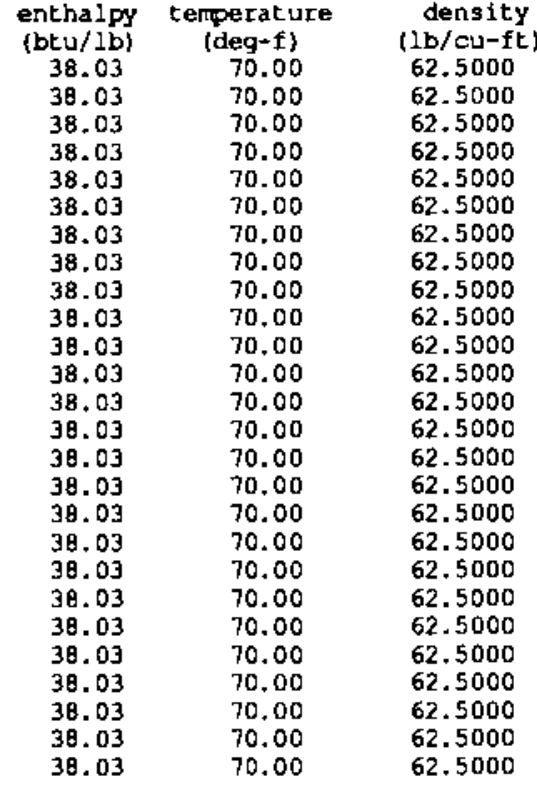

$\begin{array}{cc}\begin{array}{c}f l 0 w \\ (1 b / s e c)\end{array} & \begin{array}{c}\text { mass flux } \\ \left(m l b / h l^{-f t 2)}\right.\end{array} \\ 0.0817708 & 0.0045000 \\ 0.0907857 & 0.0049961 \\ 0.1000016 & 0.0055033 \\ 0.1072392 & 0.0059016 \\ 0.1127397 & 0.0062043 \\ 0.1171394 & 0.0064464 \\ 0.1208701 & 0.0066517 \\ 0.1241522 & 0.0068323 \\ 0.1270910 & 0.0069941 \\ 0.1297430 & 0.0071400 \\ 0.1321459 & 0.0072722 \\ 0.1343291 & 0.0073924 \\ 0.1363171 & 0.0075018 \\ 0.1381307 & 0.0076016 \\ 0.1397879 & 0.0076928 \\ 0.1413044 & 0.0077762 \\ 0.1426937 & 0.0078527 \\ 0.1439679 & 0.0079228 \\ 0.1451378 & 0.0079872 \\ 0.1462127 & 0.0080464 \\ 0.1472013 & 0.0081008 \\ 0.1481112 & 0.0081508 \\ 0.1489491 & 0.0081969 \\ 0.1497214 & 0.0082394 \\ 0.1504394 & 0.0082786 \\ 0.1510904 & 0.0083148\end{array}$

$\begin{array}{ll}\begin{array}{c}\text { velocity } \\ \text { (ft/sec) }\end{array} & \begin{array}{c}\text { area } \\ \text { (sq-in) }\end{array} \\ 0.0200000 & 9.42000 \\ 0.0222049 & 9.42000 \\ 0.0244590 & 9.42000 \\ 0.0262292 & 9.42000 \\ 0.0275745 & 9.42000 \\ 0.0286507 & 9.42000 \\ 0.0295631 & 9.42000 \\ 0.0303659 & 9.42000 \\ 0.0310847 & 9.42000 \\ 0.0317333 & 9.42000 \\ 0.0323210 & 9.42000 \\ 0.0328550 & 9.42000 \\ 0.0333413 & 9.42000 \\ 0.0337848 & 9.42000 \\ 0.0341902 & 9.42000 \\ 0.0345611 & 9.42000 \\ 0.0349009 & 9.42000 \\ 0.0352125 & 9.42000 \\ 0.0354987 & 9.42000 \\ 0.0357616 & 9.42000 \\ 0.0360034 & 9.42000 \\ 0.0362259 & 9.42000 \\ 0.0364309 & 9.42000 \\ 0.0366197 & 9.42000 \\ 0.0367939 & 9.42000 \\ 0.0369546 & 9.42000\end{array}$




\begin{tabular}{|c|c|c|c|c|c|c|c|c|}
\hline $\begin{array}{l}130.0 \\
135.0 \\
140.0 \\
145.0 \\
150.0\end{array}$ & $\begin{array}{l}0.0000008 \\
0.0000006 \\
0.0000004 \\
0.0000002 \\
0.0000000\end{array}$ & $\begin{array}{l}38.03 \\
38.03 \\
38.03 \\
38.03 \\
38.03\end{array}$ & $\begin{array}{l}70.00 \\
70.00 \\
70.00 \\
70.00 \\
70.00\end{array}$ & $\begin{array}{l}62.5000 \\
62.5000 \\
62.5000 \\
62.5000 \\
62.5000\end{array}$ & $\begin{array}{l}0.1516968 \\
0.1522569 \\
0.1527750 \\
0.1532567 \\
0.1537008\end{array}$ & $\begin{array}{l}0.0083482 \\
0.0083790 \\
0.0084075 \\
0.0084340 \\
0.0084584\end{array}$ & $\begin{array}{l}0.0371029 \\
0.0372399 \\
0.0373666 \\
0.0374844 \\
0.0375931\end{array}$ & $\begin{array}{l}9.42000 \\
9.42000 \\
9.42000 \\
9.42000 \\
9.42000\end{array}$ \\
\hline $\begin{array}{l}\text { calculated } \\
\text { channel } \\
\text { assembly }\end{array}$ & $\begin{array}{l}\text { fluld cond } \\
3 \\
1\end{array}$ & ons at time & 0.0000 & seconds & & & & \\
\hline $\begin{array}{l}\text { d1stance } \\
\text { (in.) } \\
0.0 \\
5.0 \\
10.0 \\
15.0 \\
20.0 \\
25.0 \\
30.0 \\
35.0 \\
40.0 \\
45.0 \\
50.0 \\
55.0 \\
60.0 \\
65.0 \\
70.0 \\
75.0 \\
80.0 \\
85.0 \\
90.0 \\
95.0 \\
100.0 \\
105.0 \\
110.0 \\
115.0 \\
120.0 \\
125.0 \\
130.0 \\
135.0 \\
140.0 \\
145.0 \\
150.0\end{array}$ & $\begin{array}{l}\text { delta-p } \\
\text { (psi) } \\
0.0000089 \\
0.0000083 \\
0.0000076 \\
0.0000070 \\
0.0000065 \\
0.0000061 \\
0.0000058 \\
0.0000055 \\
0.0000051 \\
0.0000049 \\
0.0000046 \\
0.0000043 \\
0.0000040 \\
0.0000038 \\
0.0000035 \\
0.0000033 \\
0.0000031 \\
0.0000028 \\
0.0000026 \\
0.0000024 \\
0.0000021 \\
0.0000019 \\
0.0000017 \\
0.0000015 \\
0.0000013 \\
0.0000010 \\
0.0000008 \\
0.0000006 \\
0.0000004 \\
0.0000002 \\
0.0000000\end{array}$ & $\begin{array}{c}\text { enthalpy } \\
\text { (btu/1b) } \\
38.03 \\
38.03 \\
38.03 \\
38.03 \\
38.03 \\
38.03 \\
38.03 \\
38.03 \\
38.03 \\
38.03 \\
38.03 \\
38.03 \\
38.03 \\
38.03 \\
38.03 \\
38.03 \\
38.03 \\
38.03 \\
38.03 \\
38.03 \\
38.03 \\
38.03 \\
38.03 \\
38.03 \\
38.03 \\
38.03 \\
38.03 \\
38.03 \\
38.03 \\
38.03 \\
38.03\end{array}$ & $\begin{array}{c}\text { temperature } \\
\text { (deg-f) } \\
70.00 \\
70.00 \\
70.00 \\
70.00 \\
70.00 \\
70.00 \\
70.00 \\
70.00 \\
70.00 \\
70.00 \\
70.00 \\
70.00 \\
70.00 \\
70.00 \\
70.00 \\
70.00 \\
70.00 \\
70.00 \\
70.00 \\
70.00 \\
70.00 \\
70.00 \\
70.00 \\
70.00 \\
70.00 \\
70.00 \\
70.00 \\
70.00 \\
70.00 \\
70.00 \\
70.00\end{array}$ & $\begin{array}{c}\text { density } \\
(1 \mathrm{~b} / \mathrm{cu}-\mathrm{ft}) \\
62.5000 \\
62.5000 \\
62.5000 \\
62.5000 \\
62.5000 \\
62.5000 \\
62.5000 \\
62.5000 \\
62.5000 \\
62.5000 \\
62.5000 \\
62.5000 \\
62.5000 \\
62.5000 \\
62.5000 \\
62.5000 \\
62.5000 \\
62.5000 \\
62.5000 \\
62.5000 \\
62.5000 \\
62.5000 \\
62.5000 \\
62.5000 \\
62.5000 \\
62.5000 \\
62.5000 \\
62.5000 \\
62.5000 \\
62.5000 \\
62.5000\end{array}$ & $\begin{array}{c}\text { flow } \\
(1 \mathrm{~b} / \mathrm{sec}) \\
0.1363715 \\
0.1519360 \\
0.1674110 \\
0.1793026 \\
0.1881935 \\
0.1952001 \\
0.2010478 \\
0.2061074 \\
0.2105642 \\
0.2145240 \\
0.2180601 \\
0.2212299 \\
0.2240805 \\
0.2266514 \\
0.2289761 \\
0.2310829 \\
0.2329964 \\
0.2347374 \\
0.2363244 \\
0.2377732 \\
0.2390978 \\
0.2403104 \\
0.2414219 \\
0.2424418 \\
0.2433787 \\
0.2442400 \\
0.2450326 \\
0.2457625 \\
0.2464360 \\
0.2470622 \\
0.2476477\end{array}$ & $\begin{array}{c}\text { mass flux } \\
\text { (mlb/hr-ft2\} } \\
0.0045000 \\
0.0050136 \\
0.0055242 \\
0.0059166 \\
0.0062100 \\
0.0064412 \\
0.0066342 \\
0.0068011 \\
0.0069482 \\
0.0070789 \\
0.0071956 \\
0.0073002 \\
0.0073942 \\
0.0074791 \\
0.0075558 \\
0.0076253 \\
0.0076884 \\
0.0077459 \\
0.0077983 \\
0.0078461 \\
0.0078898 \\
0.0079298 \\
0.0079665 \\
0.0080001 \\
0.0080310 \\
0.0080595 \\
0.0080856 \\
0.0081097 \\
0.0081319 \\
0.0081526 \\
0.0081719\end{array}$ & $\begin{array}{c}\text { velocity } \\
\text { (ft/sec) } \\
0.0200000 \\
0.0222827 \\
0.02455222 \\
0.0262962 \\
0.0276001 \\
0.0286277 \\
0.0294853 \\
0.0302273 \\
0.0308810 \\
0.0314617 \\
0.0319803 \\
0.0324452 \\
0.0328632 \\
0.0332403 \\
0.0335812 \\
0.0338902 \\
0.0341708 \\
0.0344262 \\
0.0346589 \\
0.0348714 \\
0.0350657 \\
0.0352435 \\
0.0354065 \\
0.0355561 \\
0.0356935 \\
0.0358198 \\
0.0359360 \\
0.0360431 \\
0.036141 \mathrm{~B} \\
0.0362337 \\
0.0363196\end{array}$ & $\begin{array}{c}\text { area } \\
\text { (sq-in) } \\
15.71000 \\
15.71000 \\
15.71000 \\
15.71000 \\
15.71000 \\
15.71000 \\
15.71000 \\
15.71000 \\
15.71000 \\
15.71000 \\
15.71000 \\
15.71000 \\
15.71000 \\
15.71000 \\
15.71000 \\
15.71000 \\
15.71000 \\
15.71000 \\
15.71000 \\
15.71000 \\
15.71000 \\
15.71000 \\
15.71000 \\
15.71000 \\
15.71000 \\
15.71000 \\
15.71000 \\
15.71000 \\
15.71000 \\
15.71000 \\
15.71000\end{array}$ \\
\hline $\begin{array}{l}\text { calculated } \\
\text { channel } \\
\text { assembly }\end{array}$ & $\begin{array}{l}\text { fluid cond } \\
4 \\
1\end{array}$ & ns at time & 0.0000 & seconds & & & & \\
\hline $\begin{array}{c}\text { dist ance } \\
\text { (1n.) } \\
0.0 \\
5.0 \\
10.0\end{array}$ & $\begin{array}{l}\text { delta-p } \\
\text { (psi) } \\
0.0000089 \\
0.0000083 \\
0.0000076\end{array}$ & $\begin{array}{c}\text { enthalpy } \\
\text { (btu/lb) } \\
38.03 \\
38.03 \\
38.03\end{array}$ & $\begin{array}{c}\text { termperature } \\
\text { (deg-f) } \\
70.00 \\
70.00 \\
70.00\end{array}$ & $\begin{array}{c}\text { density } \\
\text { (1b/cu-ft) } \\
62.5000 \\
62.5000 \\
62.5000\end{array}$ & $\begin{array}{c}\text { flow } \\
(1 \mathrm{~b} / \mathrm{sec}) \\
0.1908854 \\
0.2137364 \\
0.2353856\end{array}$ & $\begin{array}{c}\text { mass flux } \\
(\text { mlb/hr-ft2) } \\
0.0045000 \\
0.0050387 \\
0.0055491\end{array}$ & $\begin{array}{r}\text { velocity } \\
\text { (ft/sec) } \\
0.0200000 \\
0.0223942 \\
0.0246625\end{array}$ & $\begin{array}{c}\text { area } \\
\text { (sq-in) } \\
21.99000 \\
21.99000 \\
21.99000\end{array}$ \\
\hline
\end{tabular}




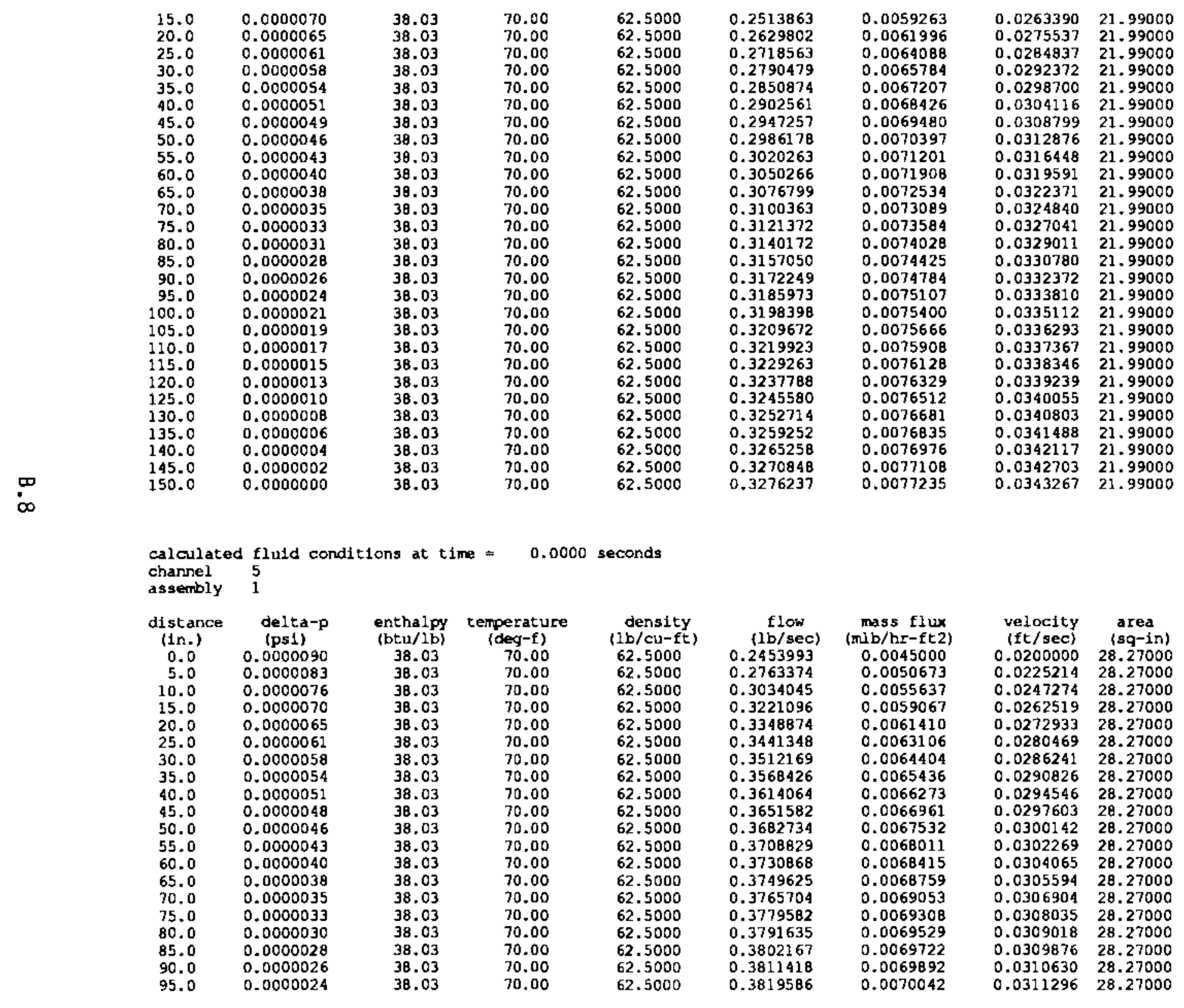




$\begin{array}{lllllllll}100.0 & 0.0000021 & 38.03 & 70.00 & 62.5000 & 0.3826831 & 0.0070174 & 0.0311886 & 28.27000 \\ 105.0 & 0.0000019 & 38.03 & 70.00 & 62.5000 & 0.3833285 & 0.0070293 & 0.0312412 & 28.27000 \\ 110.0 & 0.0000017 & 38.03 & 70.00 & 62.5000 & 0.3839057 & 0.0070399 & 0.0312882 & 28.27000 \\ 115.0 & 0.0000015 & 38.03 & 70.00 & 62.5000 & 0.3844236 & 0.0070494 & 0.0313305 & 288.27000 \\ 120.0 & 0.0000013 & 38.03 & 70.00 & 62.5000 & 0.3848900 & 0.0070579 & 0.0313685 & 28.27000 \\ 125.0 & 0.0000010 & 38.03 & 70.00 & 62.5000 & 0.3853112 & 0.0070656 & 0.0314028 & 28.27000 \\ 130.0 & 0.0000008 & 38.03 & 70.00 & 62.5000 & 0.3856924 & 0.0070726 & 0.0314339 & 28.27000 \\ 135.0 & 0.0000006 & 38.03 & 70.00 & 62.5000 & 0.3860383 & 0.0070790 & 0.0314621 & 28.27000 \\ 140.0 & 0.0000004 & 38.03 & 70.00 & 62.5000 & 0.3863527 & 0.0070847 & 0.0314877 & 28.27000 \\ 145.0 & 0.0000002 & 38.03 & 70.00 & 62.5000 & 0.3866465 & 0.0070901 & 0.0315116 & 28.27000 \\ 150.0 & 0.0000000 & 38.03 & 70.00 & 62.5000 & 0.3869598 & 0.0070959 & 0.0315372 & 28.27000\end{array}$

calculated fluid conditions at time $=0.0000$ seconds $\begin{array}{ll}\text { channel } & 6 \\ \text { assembly } & 1\end{array}$

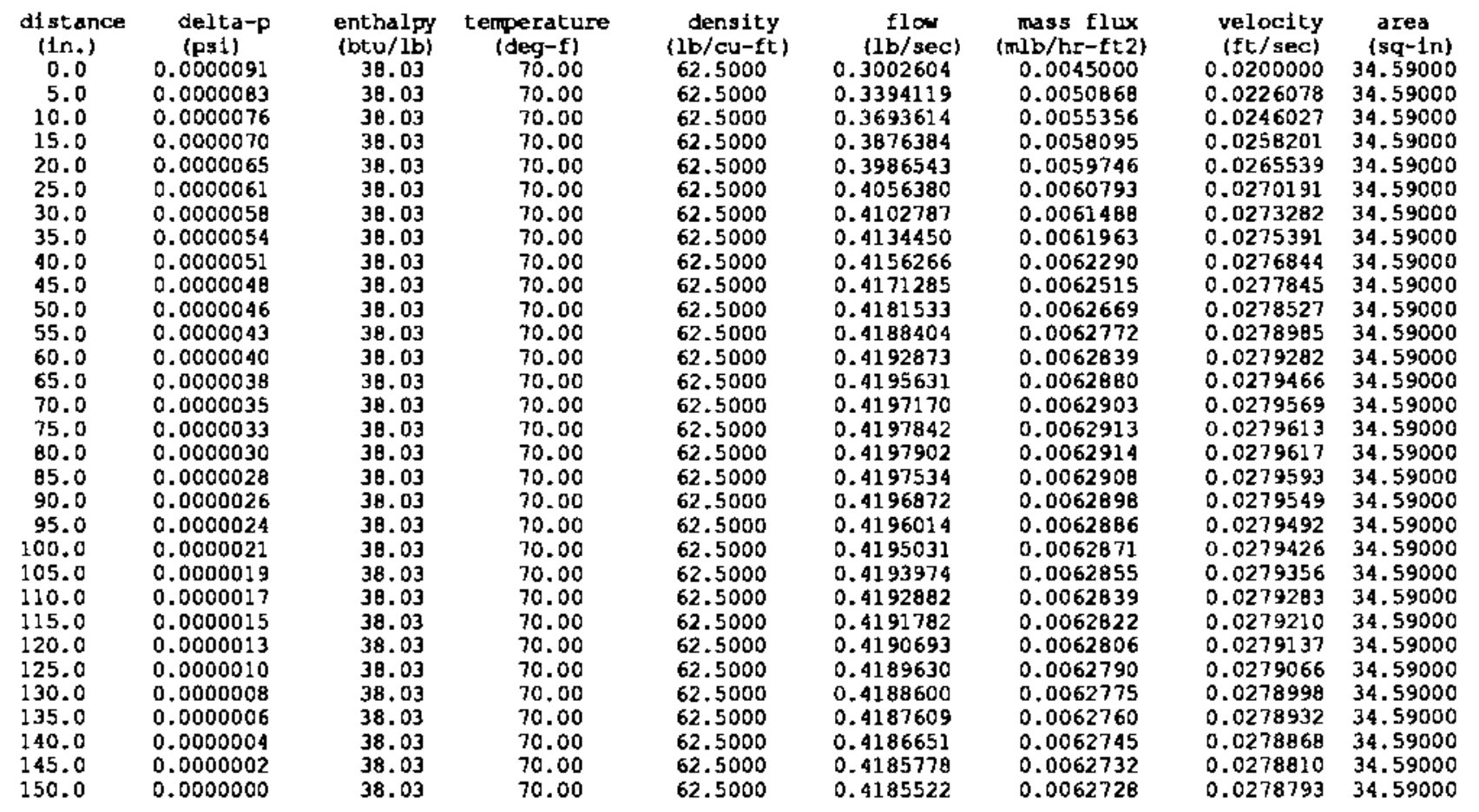




\begin{tabular}{|c|c|c|c|c|c|c|c|c|c|}
\hline 品 & $\begin{array}{l}\text { distance } \\
\{1 n .\} \\
0.0 \\
5.0 \\
10.0 \\
15.0 \\
20.0 \\
25.0 \\
30.0 \\
35.0 \\
40.0 \\
45.0 \\
50.0 \\
55.0 \\
60.0 \\
65.0 \\
70.0 \\
75.0 \\
80.0 \\
85.0 \\
90.0 \\
95.0 \\
100.0 \\
105.0 \\
110.0 \\
115.0 \\
120.0 \\
125.0 \\
130.0 \\
135.0 \\
140.0 \\
145.0 \\
150.0\end{array}$ & $\begin{array}{c}\text { delta-p } \\
\text { (ps1) } \\
0.0000092 \\
0.0000083 \\
0.0000075 \\
0.0000070 \\
0.0000065 \\
0.0000061 \\
0.0000058 \\
0.0000054 \\
0.0000051 \\
0.0000048 \\
0.0000046 \\
0.0000043 \\
0.0000040 \\
0.0000038 \\
0.0000035 \\
0.0000033 \\
0.0000030 \\
0.0000028 \\
0.0000026 \\
0.0000024 \\
0.0000021 \\
0.0000019 \\
0.0000017 \\
0.0000015 \\
0.0000013 \\
0.0000010 \\
0.0000008 \\
0.0000006 \\
0.0000004 \\
0.0000002 \\
0.0000000\end{array}$ & $\begin{array}{r}\text { enthalpy } \\
\text { (btu/1b) } \\
38.03 \\
38.03 \\
38.03 \\
38.03 \\
38.03 \\
38.03 \\
38.03 \\
38.03 \\
38.03 \\
38.03 \\
38.03 \\
38.03 \\
38.03 \\
38.03 \\
38.03 \\
38.03 \\
38.03 \\
38.03 \\
38.03 \\
38.03 \\
38.03 \\
38.03 \\
38.03 \\
38.03 \\
38.03 \\
38.03 \\
38.03 \\
38.03 \\
38.03 \\
38.03 \\
38.03\end{array}$ & $\begin{array}{c}\text { temperature } \\
\text { (deg-f) } \\
70.00 \\
70.00 \\
70.00 \\
70.00 \\
70.00 \\
70.00 \\
70.00 \\
70.00 \\
70.00 \\
70.00 \\
70.00 \\
70.00 \\
70.00 \\
70.00 \\
70.00 \\
70.00 \\
70.00 \\
70.00 \\
70.00 \\
70.00 \\
70.00 \\
70.00 \\
70.00 \\
70.00 \\
70.00 \\
70.00 \\
70.00 \\
70.00 \\
70.00 \\
70.00 \\
70.00\end{array}$ & $\begin{array}{l}\text { density } \\
(1 b / c u-f t) \\
62.5000 \\
62.5000 \\
62.5000 \\
62.5000 \\
62.5000 \\
62.5000 \\
62.5000 \\
62.5000 \\
62.5000 \\
62.5000 \\
62.5000 \\
62.5000 \\
62.5000 \\
62.5000 \\
62.5000 \\
62.5000 \\
62.5000 \\
62.5000 \\
62.5000 \\
62.5000 \\
62.5000 \\
62.5000 \\
62.5000 \\
62.5000 \\
62.5000 \\
62.5000 \\
62.5000 \\
62.5000 \\
62.5000 \\
62.5000 \\
62.5000\end{array}$ & $\begin{array}{c}\text { flow } \\
\text { (1b/sec) } \\
0.3545139 \\
0.3988231 \\
0.4249835 \\
0.4366372 \\
0.4409178 \\
0.4417547 \\
0.4409537 \\
0.4393668 \\
0.4374307 \\
0.4353810 \\
0.4333456 \\
0.4313918 \\
0.4295520 \\
0.4278393 \\
0.4262556 \\
0.4247972 \\
0.4234572 \\
0.4222275 \\
0.4210993 \\
0.4200644 \\
0.4191148 \\
0.4182431 \\
0.4174423 \\
0.4167062 \\
0.4360292 \\
0.4154061 \\
0.4148323 \\
0.4143034 \\
0.4138339 \\
0.4133586 \\
0.4129847\end{array}$ & $\begin{array}{c}\text { mass flux } \\
(\mathrm{mlb} / \mathrm{hr}-\mathrm{ft} 2) \\
0.0045000 \\
0.0050624 \\
0.0053945 \\
0.0055424 \\
0.005596 \mathrm{~B} \\
0.0056074 \\
0.0055972 \\
0.0055771 \\
0.0055525 \\
0.0055265 \\
0.0055006 \\
0.0054758 \\
0.0054525 \\
0.005430 \mathrm{~B} \\
0.0054106 \\
0.0053921 \\
0.0053751 \\
0.0053595 \\
0.0053452 \\
0.0053321 \\
0.0053200 \\
0.0053089 \\
0.005298 \mathrm{~B} \\
0.0052894 \\
0.0052808 \\
0.0052729 \\
0.0052656 \\
0.0052589 \\
0.0052527 \\
0.0052469 \\
0.0052422\end{array}$ & $\begin{array}{l}\text { velocity } \\
\text { (ft/sec) } \\
0.0200000 \\
0.0224997 \\
0.0239756 \\
0.0246330 \\
0.0248745 \\
0.0249217 \\
0.0248765 \\
0.0247870 \\
0.0246778 \\
0.0245621 \\
0.0244473 \\
0.0243371 \\
0.0242333 \\
0.0241367 \\
0.0240473 \\
0.0239651 \\
0.0238895 \\
0.0238201 \\
0.0237564 \\
0.0236981 \\
0.0236445 \\
0.0235953 \\
0.0235501 \\
0.0235086 \\
0.0234704 \\
0.0234353 \\
0.0234029 \\
0.0233730 \\
0.0233454 \\
0.0233197 \\
0.0232986\end{array}$ & $\begin{array}{c}\text { area } \\
\text { (sq-1n) } \\
40.84000 \\
40.84000 \\
40.84000 \\
40.84000 \\
40.84000 \\
40.84000 \\
40.84000 \\
40.84000 \\
40.84000 \\
40.84000 \\
40.84000 \\
40.84000 \\
40.84000 \\
40.84000 \\
40.84000 \\
40.84000 \\
40.84000 \\
40.84000 \\
40.84000 \\
40.84000 \\
40.84000 \\
40.84000 \\
40.84000 \\
40.84000 \\
40.84000 \\
40.84000 \\
40.84000 \\
40.84000 \\
40.84000 \\
40.84000 \\
40.84000\end{array}$ \\
\hline
\end{tabular}

calculated fluid conditions at time $=0.0000$ seconds channel 8

as sembly

$\begin{array}{cc}\begin{array}{c}\text { distance } \\ \text { (1n.) }\end{array} & \begin{array}{c}\text { delta-p } \\ \text { (psi) }\end{array} \\ 0.0 & 0.0000093 \\ 5.0 & 0.0000083 \\ 10.0 & 0.00000075 \\ 15.0 & 0.0000069 \\ 20.0 & 0.0000065 \\ 25.0 & 0.0000061 \\ 30.0 & 0.0000058 \\ 35.0 & 0.0000054 \\ 40.0 & 0.0000051 \\ 45.0 & 0.0000048 \\ 50.0 & 0.0000046 \\ 55.0 & 0.0000043 \\ 60.0 & 0.0000040 \\ 65.0 & 0.0000038\end{array}$

enthalpy cemperature

38.03

38.03

38.03

38.03

38.03

38.03
38.03

38.03

38.03

38.03

38.03

38.03

38.03

38.03 (deg-f)

$(\mathrm{deg}-\mathrm{f})$
70.00

70.00

70.00

70.00
70.00

70.00

70.00

70.00

70.00
70.00

70.00
70.00

70.00

70.00

70.00
70.00

70.00 density (1b/cu-ft) 62.5000
62.5000

62.5000

62.5000

62.5000

62.5000

62.5000
62.5000

62.5000
62.5000

62.5000

62.5000
62.5000

62.5000

62.5000
62.5000

62.5000 (lb/sec) 0.4090278 0.4459872 0.4540267 0.4489695 0.4909900 0.4309900 0.4152718 0.4152718 0.4088746 0.4033328 0.3985247 0.3943369
0.3906714 0.3874463 $(\mathrm{mlb} / \mathrm{hr}=\mathrm{ft} 2)$ 0.0045000 0.0049951 0.0049394 0.0048421 0.0047416 0.0046497 0.0046497 0.0045687 0.0044373 0.0043844 0.0043384 0.0042980

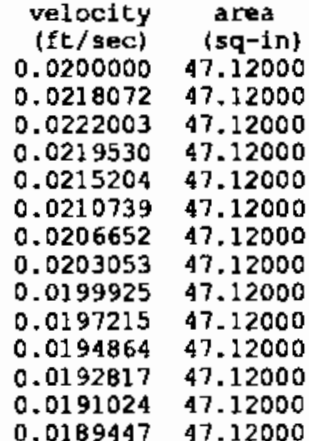




$\begin{array}{rllllllll}70.0 & 0.0000035 & 38.03 & 70.00 & 62.5000 & 0.3845941 & 0.0042312 & 0.0188053 & 47.12000 \\ 75.0 & 0.0000033 & 38.03 & 70.00 & 62.5000 & 0.3820597 & 0.0042033 & 0.0186814 & 47.12000 \\ 80.0 & 0.0000030 & 38.03 & 70.00 & 62.5000 & 0.3797978 & 0.0041784 & 0.0185708 & 47.12000 \\ 85.0 & 0.0000028 & 38.03 & 70.00 & 62.5000 & 0.3777710 & 0.0041561 & 0.0184717 & 47.12000 \\ 90.0 & 0.0000026 & 38.03 & 70.00 & 62.5000 & 0.3759484 & 0.0041361 & 0.0183825 & 47.12000 \\ 95.0 & 0.0000024 & 38.03 & 70.00 & 62.5000 & 0.3743041 & 0.0041180 & 0.0183021 & 47.12000 \\ 100.0 & 0.0000021 & 38.03 & 70.00 & 62.5000 & 0.3728164 & 0.0041016 & 0.0182294 & 47.12000 \\ 105.0 & 0.0000019 & 38.03 & 70.00 & 62.5000 & 0.3714669 & 0.0040868 & 0.0181634 & 47.12000 \\ 110.0 & 0.0000017 & 38.03 & 70.00 & 62.5000 & 0.3702400 & 0.0040733 & 0.0181034 & 47.12000 \\ 115.0 & 0.0000015 & 38.03 & 70.00 & 62.5000 & 0.3691221 & 0.0040610 & 0.0180488 & 47.12000 \\ 120.0 & 0.0000013 & 38.03 & 70.00 & 62.5000 & 0.3681017 & 0.0040497 & 0.0179989 & 47.12000 \\ 125.0 & 0.0000010 & 38.03 & 70.00 & 62.5000 & 0.3671687 & 0.0040395 & 0.0179532 & 47.12000 \\ 130.0 & 0.0000008 & 38.03 & 70.00 & 62.5000 & 0.3663144 & 0.0040301 & 0.0179115 & 47.12000 \\ 135.0 & 0.0000006 & 38.03 & 70.00 & 62.5000 & 0.3655312 & 0.0040215 & 0.0178732 & 47.12000 \\ 140.0 & 0.0000004 & 38.03 & 70.00 & 62.5000 & 0.3648111 & 0.0040135 & 0.0178380 & 47.12000 \\ 145.0 & 0.0000002 & 38.03 & 70.00 & 62.5000 & 0.3641381 & 0.0040061 & 0.0178051 & 47.12000 \\ 150.0 & 0.0000000 & 38.03 & 70.00 & 62.5000 & 0.3635177 & 0.0039993 & 0.01777477 & 47.12000\end{array}$

calculated fluld conditions at time $=0.0000$ seconds channel 9

distance delta-p

$\begin{array}{cc}\begin{array}{c}\text { distance } \\ \text { (1n.) }\end{array} & \begin{array}{c}\text { delta-p } \\ (\mathrm{pg} 1)\end{array} \\ 0.0 & 0.0000094 \\ 5.0 & 0.0000083 \\ 10.0 & 0.0000075 \\ 15.0 & 0.0000069 \\ 20.0 & 0.0000065 \\ 25.0 & 0.0000061 \\ 30.0 & 0.000005 \mathrm{~B} \\ 35.0 & 0.0000054 \\ 40.0 & 0.0000051 \\ 45.0 & 0.0000048 \\ 50.0 & 0.0000046 \\ 55.0 & 0.0000043 \\ 60.0 & 0.0000040 \\ 65.0 & 0.0000038 \\ 70.0 & 0.0000035 \\ 75.0 & 0.0000033 \\ 80.0 & 0.0000030 \\ 85.0 & 0.0000028 \\ 90.0 & 0.0000026 \\ 95.0 & 0.0000024 \\ 100.0 & 0.0000021 \\ 105.0 & 0.0000019 \\ 110.0 & 0.0000017 \\ 115.0 & 0.0000015 \\ 120.0 & 0.0000013 \\ 125.0 & 0.0000010 \\ 130.0 & 0.0000008 \\ 135.0 & 0.0000006 \\ 140.0 & 0.0000004 \\ 145.0 & 0.0000002 \\ 150.0 & 0.0000000\end{array}$

$\begin{array}{cc}\begin{array}{c}\text { enthaipy } \\ \text { (btu/1b) }\end{array} & \begin{array}{c}\text { terperature } \\ \text { (deg-f) }\end{array} \\ 38.03 & 70.00 \\ 38.03 & 70.00 \\ 38.03 & 70.00 \\ 38.03 & 70.00 \\ 38.03 & 70.00 \\ 38.03 & 70.00 \\ 38.03 & 70.00 \\ 38.03 & 70.00 \\ 38.03 & 70.00 \\ 38.03 & 70.00 \\ 38.03 & 70.00 \\ 38.03 & 70.00 \\ 38.03 & 70.00 \\ 38.03 & 70.00 \\ 38.03 & 70.00 \\ 38.03 & 70.00 \\ 38.03 & 70.00 \\ 38.03 & 70.00 \\ 38.03 & 70.00 \\ 38.03 & 70.00 \\ 38.03 & 70.00 \\ 38.03 & 70.00 \\ 38.03 & 70.00 \\ 38.03 & 70.00 \\ 38.03 & 70.00 \\ 38.03 & 70.00 \\ 33.03 & 70.00 \\ 38.03 & 70.00 \\ 38.03 & 70.00 \\ 38.03 & 70.00 \\ 38.03 & 70.00\end{array}$

$\begin{array}{cc}\begin{array}{c}\text { dens1ty } \\ (1 \mathrm{~b} / \mathrm{cu}-\mathrm{ft})\end{array} & \begin{array}{c}\text { flow } \\ (1 \mathrm{~b} / \mathrm{sec})\end{array} \\ 62.5000 & 0.4636285 \\ 62.5000 & 0.4526211 \\ 62.5000 & 0.4164070 \\ 62.5000 & 0.3835238 \\ 62.5000 & 0.3587448 \\ 62.5000 & 0.3407536 \\ 62.5000 & 0.3274589 \\ 62.5000 & 0.3172955 \\ 62.5000 & 0.3092706 \\ 62.5000 & 0.3027668 \\ 62.5000 & 0.2973865 \\ 62.5000 & 0.2928613 \\ 62.5000 & 0.2890036 \\ 62.5000 & 0.2856776 \\ 62.5000 & 0.282782 \mathrm{~B} \\ 62.5000 & 0.2802432 \\ 62.5000 & 0.2780000 \\ 62.5000 & 0.2760070 \\ 62.5000 & 0.2742273 \\ 62.5000 & 0.2726312 \\ 62.5000 & 0.2711942 \\ 62.5000 & 0.2698962 \\ 62.5000 & 0.2687202 \\ 62.5000 & 0.2676520 \\ 62.5000 & 0.2666796 \\ 62.5000 & 0.2657924 \\ 62.5000 & 0.2649817 \\ 62.5000 & 0.2642399 \\ 62.5000 & 0.2635605 \\ 62.5000 & 0.2629261 \\ 62.5000 & 0.2622654\end{array}$

mass flux

0.0045000

0.0045000
0.0043932

0.0040417

0.0040417
0.0037225

0.0034820

0.0033074

0.0031783

0.0030797

0.0030018

0.0029387

0.0028864

0.0028425

0.0028051

0.0027728

0.0027447

0.0027201

0.0026983

0.0026789

0.0026617

0.0026462

0.0026322

0.0026196

0.0026082
0.0025978

0.0025884

0.0025798

0.0025719

0.0025647

0.0025520

0.0025456

$\begin{array}{cc}\begin{array}{c}\text { velocity } \\ \text { (ft/sec) }\end{array} & \begin{array}{c}\text { area } \\ \text { (sq-in) }\end{array} \\ 0.0200000 & 53.41000 \\ 0.0195252 & 53.41000 \\ 0.0179630 & 53.41000 \\ 0.0165444 & 53.41000 \\ 0.0154755 & 53.41000 \\ 0.0146994 & 53.41000 \\ 0.0141259 & 53.41000 \\ 0.0136875 & 53.41000 \\ 0.0133413 & 53.41000 \\ 0.0130608 & 53.41000 \\ 0.0128287 & 53.41000 \\ 0.0126334 & 53.41000 \\ 0.0124670 & 53.41000 \\ 0.0123236 & 53.41000 \\ 0.0121987 & 53.41000 \\ 0.0120891 & 53.41000 \\ 0.0119924 & 53.41000 \\ 0.0119064 & 53.41000 \\ 0.0118296 & 53.41000 \\ 0.0117608 & 53.41000 \\ 0.0116988 & 53.41000 \\ 0.0116428 & 53.41000 \\ 0.0115920 & 53.41000 \\ 0.0115460 & 53.41000 \\ 0.0115040 & 53.41000 \\ 0.0114658 & 53.41000 \\ 0.0114308 & 53.41000 \\ 0.0113988 & 53.41000 \\ 0.0113695 & 53.41000 \\ 0.0113421 & 53.41000 \\ 0.0113136 & 53.41000\end{array}$


calculated fiuid conditions at time $=$ channel 10

$\begin{array}{ccccc}\begin{array}{c}\text { distance } \\ \text { (in.) }\end{array} & \begin{array}{c}\text { delta-p } \\ \text { (p5i) }\end{array} & \begin{array}{c}\text { enthalpy } \\ \text { (btu/1b) } \\ 0.0\end{array} & \begin{array}{c}\text { demperature } \\ \text { (deg-f) }\end{array} & \begin{array}{c}\text { density } \\ (\text { bb/cu-ft }\end{array} \\ 5.0 & 0.0000095 & \begin{array}{c}38.03 \\ 70.00\end{array} & 62.5000 \\ 10.0 & 0.0000075 & 38.03 & 70.00 & 62.5000 \\ 15.0 & 0.0000069 & 38.03 & 70.00 & 62.5000 \\ 20.0 & 0.0000065 & 38.03 & 70.00 & 62.5000 \\ 25.0 & 0.0000061 & 38.03 & 70.00 & 62.5000 \\ 30.0 & 0.0000058 & 38.03 & 70.00 & 62.5000 \\ 35.0 & 0.0000054 & 38.03 & 70.00 & 62.5000 \\ 40.0 & 0.0000051 & 38.03 & 70.00 & 62.5000 \\ 45.0 & 0.0000048 & 38.03 & 70.00 & 62.5000 \\ 50.0 & 0.0000046 & 38.03 & 70.00 & 62.5000 \\ 55.0 & 0.0000043 & 38.03 & 70.00 & 62.5000 \\ 60.0 & 0.0000040 & 38.03 & 70.00 & 62.5000 \\ 65.0 & 0.0000038 & 38.03 & 70.00 & 62.5000 \\ 70.0 & 0.0000035 & 38.03 & 70.00 & 62.5000 \\ 75.0 & 0.0000033 & 38.03 & 70.00 & 62.5000 \\ 80.0 & 0.0000030 & 38.03 & 70.00 & 62.5000 \\ 85.0 & 0.0000028 & 38.03 & 70.00 & 62.5000 \\ 90.0 & 0.0000026 & 38.03 & 70.00 & 62.5000 \\ 95.0 & 0.0000024 & 38.03 & 70.00 & 62.5000 \\ 100.0 & 0.0000021 & 38.03 & 70.00 & 62.5000 \\ 105.0 & 0.0000019 & 38.03 & 70.00 & 62.5000 \\ 110.0 & 0.0000017 & 38.03 & 70.00 & 62.5000 \\ 115.0 & 0.0000015 & 38.03 & 70.00 & 62.5000 \\ 120.0 & 0.0000013 & 38.03 & 70.00 & 62.5000 \\ 125.0 & 0.0000010 & 38.03 & 70.00 & 62.5000 \\ 130.0 & 0.0000008 & 38.03 & 70.00 & 62.5000 \\ 135.0 & 0.0000006 & 38.03 & 70.00 & 62.5000 \\ 140.0 & 0.0000004 & 38.03 & 70.00 & 62.5000 \\ 145.0 & 0.0000002 & 38.03 & 70.00 & 62.5000 \\ 150.0 & 0.0000000 & 38.03 & 70.00 & 62.5000\end{array}$

0.0000 seconds$$
70.00
$$

$\begin{array}{cccc}\begin{array}{c}\text { flow } \\ \text { (lb/sec) }\end{array} & \begin{array}{c}\text { mass flux } \\ \text { (mlb/hr-ft2) } \\ 0.5181424\end{array} & \begin{array}{r}\text { velocity } \\ \text { (ft/sec) }\end{array} & \begin{array}{c}\text { area } \\ \text { (sq-tn) }\end{array} \\ 0.3274091 & 0.0045000 & 0.0200000 & 59.69000 \\ 0.2230108 & 0.0019335 & 0.0126378 & 59.69000 \\ 0.1747620 & 0.0015178 & 0.0086081 & 59.69000 \\ 0.1524747 & 0.0013242 & 0.0067457 & 59.69000 \\ 0.1407541 & 0.0012224 & 0.0054354 & 59.69000 \\ 0.1334400 & 0.0011589 & 0.0051507 & 59.69000 \\ 0.1282474 & 0.0011338 & 0.0049503 & 59.69000 \\ 0.1242760 & 0.0010793 & 0.0047970 & 59.69000 \\ 0.1211092 & 0.0010518 & 0.0046747 & 59.69000 \\ 0.1185163 & 0.0010293 & 0.0045747 & 59.69000 \\ 0.1163517 & 0.0010105 & 0.0044911 & 59.69000 \\ 0.1145167 & 0.0009946 & 0.0044203 & 59.69000 \\ 0.1129416 & 0.0009809 & 0.0043595 & 59.69000 \\ 0.1115754 & 0.0009690 & 0.0043067 & 59.69000 \\ 0.1103801 & 0.0009586 & 0.0042606 & 59.69000 \\ 0.1093266 & 0.0009495 & 0.0042199 & 59.69000 \\ 0.1083922 & 0.0009414 & 0.0041839 & 59.69000 \\ 0.1075590 & 0.0009341 & 0.0041517 & 59.69000 \\ 0.1068125 & 0.0009277 & 0.0041229 & 59.69000 \\ 0.1061412 & 0.0009218 & 0.0040970 & 59.69000 \\ 0.1055351 & 0.0009166 & 0.0040736 & 59.69000 \\ 0.1049865 & 0.0009118 & 0.0040524 & 59.69000 \\ 0.1044883 & 0.0009075 & 0.0040332 & 59.69000 \\ 0.1040350 & 0.0009035 & 0.0040157 & 59.69000 \\ 0.1036215 & 0.0008999 & 0.0039997 & 59.69000 \\ 0.1032438 & 0.0008967 & 0.0039852 & 59.69000 \\ 0.1028983 & 0.0008937 & 0.0039719 & 59.69000 \\ 0.1025830 & 0.0008909 & 0.0039596 & 59.69000 \\ 0.1022925 & 0.0008884 & 0.0039484 & 59.69000 \\ 0.1019264 & 0.0008852 & 0.0039343 & 59.69000\end{array}$

$0.0039343 \quad 59.69000$ slab temperature summary

(assembiy no. - channel no.)

$\begin{array}{rr}0.0-5.0 & 70.00 \\ 5.0-10.0 & 70.00 \\ 10.0-15.0 & 70.00 \\ 15.0-20.0 & 70.00 \\ 20.0-25.0 & 70.00 \\ 25.0-30.0 & 70.00\end{array}$

time $=0.0000$ seconds 


$\begin{array}{rl}30.0-35.0 & 70.00 \\ 35.0=40.0 & 70.00 \\ 40.0-45.0 & 70.00 \\ 45.0=50.0 & 70.00 \\ 50.0-55.0 & 70.00 \\ 55.0-60.0 & 70.00 \\ 60.0=65.0 & 70.00 \\ 65.0-70.0 & 70.00 \\ 70.0-75.0 & 70.00 \\ 75.0-80.0 & 70.00 \\ 80.0-85.0 & 70.00 \\ 85.0=90.0 & 70.00 \\ 90.0-95.0 & 70.00 \\ 95.0-100.0 & 70.00 \\ 100.0-105.0 & 70.00 \\ 105.0-110.0 & 70.00 \\ 110.0-115.0 & 70.00 \\ 115.0-120.0 & 70.00 \\ 120.0-125.0 & 70.00 \\ 125.0-130.0 & 70.00 \\ 130.0-135.0 & 70.00 \\ 135.0-140.0 & 70.00 \\ 140.0-145.0 & 70.00 \\ 145.0-150.0 & 70.00\end{array}$

0.0000 seconds

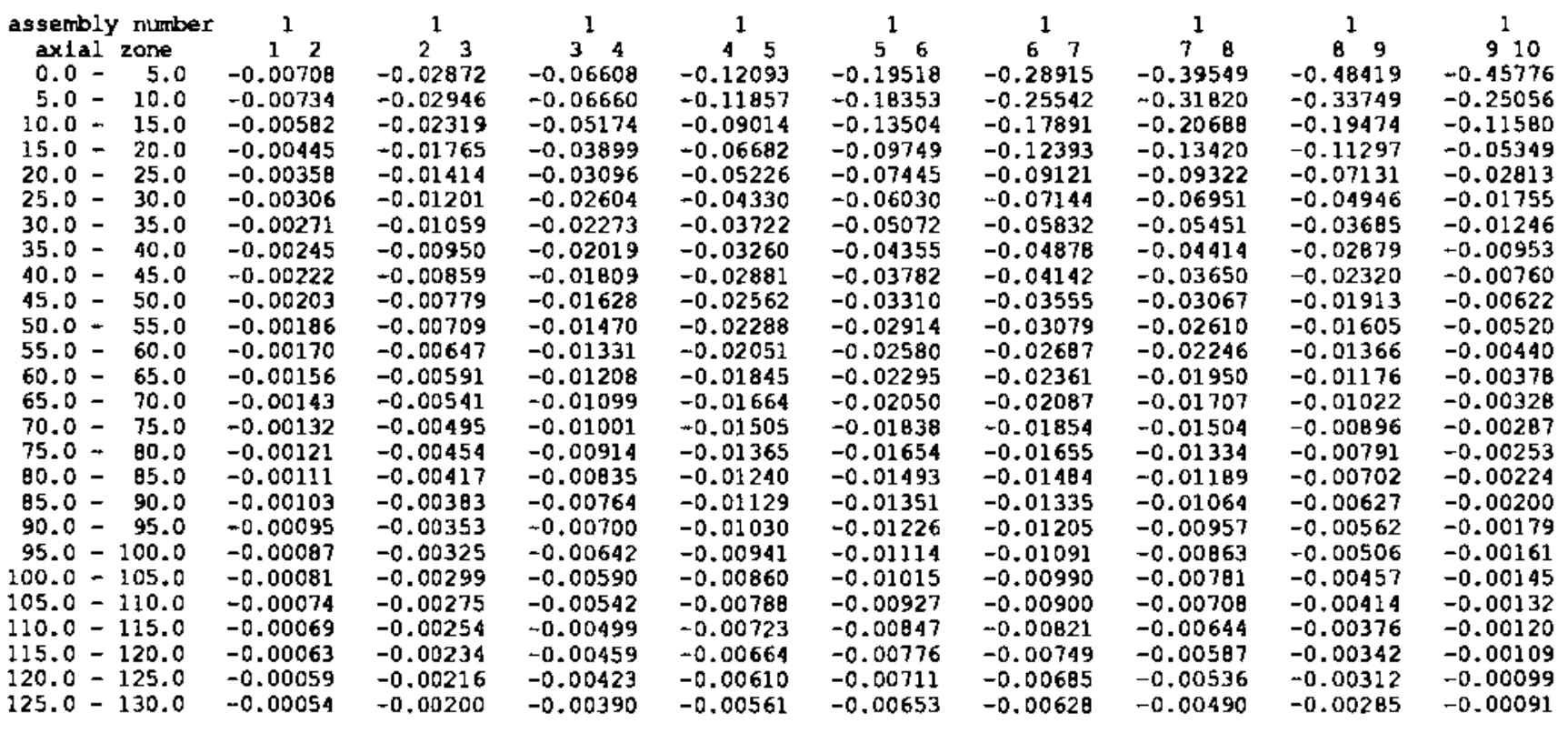




$\begin{array}{llllllllll}130.0-135.0 & -0.00050 & -0.00185 & -0.00360 & -0.00517 & -0.00600 & -0.00576 & -0.00449 & -0.00261 & -0.00083 \\ 135.0-140.0 & -0.00046 & -0.00171 & -0.00332 & -0.00477 & -0.00552 & -0.00529 & -0.00411 & -0.00239 & -0.00076 \\ 140.0-145.0 & -0.00043 & -0.00159 & -0.00309 & -0.00443 & -0.00514 & -0.00493 & -0.00384 & -0.00222 & -0.00070 \\ 145.0-150.0 & -0.00040 & -0.00146 & -0.00287 & -0.00416 & -0.00491 & -0.00485 & -0.00395 & -0.00246 & -0.00088\end{array}$

1terations $=14$

Input transient time completed

carmon dumped to tape 8
$1 * k * *$ computational time summary $* * * * *$
subroutine energy. $\ldots \ldots \ldots \ldots \ldots \ldots \ldots$

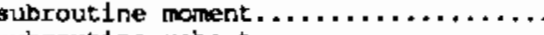
$0.28 \mathrm{sec}$
$0.00 \mathrm{sec}$
subroutine recirc (pressure loop).... 0.28 sec

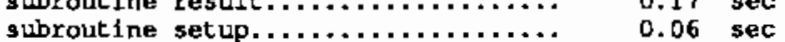

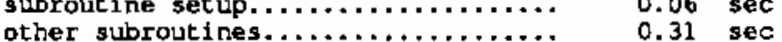
total cpu time............................
total cps time................. $1.52 \mathrm{sec}$ 
APPENDIX C

DEVELOPING FLOW IN A SQUARE DUCT OUTPUT 


\section{APPENDIX C}

\section{DEVELOPING FLOW IN A SQUARE DUCT OUTPUT}

cobra dimension parameters:

$\begin{array}{rr}i d= & 6 \\ 1 \mathrm{~h}= & 9 \\ 1 \mathrm{r}= & 9 \\ 1 \mathrm{lw}= & 6 \\ 1 \mathrm{~d}= & 15 \\ 1 \mathrm{~d}= & 1 \\ \mathrm{ma}= & 20 \\ \mathrm{mg}= & 50 \\ \mathrm{mj}= & 1 \\ 1 \mathrm{~mm}= & 20 \\ \mathrm{mq}= & 1 \\ \mathrm{mt}= & 1 \\ \mathrm{my}= & 4 \\ \mathrm{nv}= & 2\end{array}$

\begin{tabular}{|c|c|}
\hline \multirow{2}{*}{\multicolumn{2}{|c|}{$\begin{aligned} \mathbf{i e}= \\
\text { ifom }\end{aligned}$}} \\
\hline & lipm \\
\hline \multirow{2}{*}{\multicolumn{2}{|c|}{$1 x=$}} \\
\hline & \\
\hline $\begin{array}{l}1 b= \\
1 e=\end{array}$ & \\
\hline \multicolumn{2}{|c|}{$1 \mathbf{e}=$} \\
\hline$m c=$ & \\
\hline \multirow{3}{*}{\multicolumn{2}{|c|}{$\begin{array}{l}m h= \\
m k= \\
m n=\end{array}$}} \\
\hline & \\
\hline & \\
\hline \multirow{2}{*}{\multicolumn{2}{|c|}{$\begin{array}{l}m \mathbf{r}= \\
m w=\end{array}$}} \\
\hline & \\
\hline $\operatorname{lnz}=$ & \\
\hline
\end{tabular}

$\begin{array}{rr}1 i f= & 15 \\ 1 q= & 7 \\ 1 u= & 6 \\ 1 \text { iz= } & 15 \\ 11 c= & 1 \\ 1 \mathrm{f}= & 1 \\ \mathrm{me}= & 31 \\ \mathrm{~m}= & 12 \\ \mathrm{~m}= & 9 \\ \mathrm{mq}= & 20 \\ \mathrm{~ms}= & 30 \\ \mathrm{mx}= & 31 \\ \mathrm{no}= & 2\end{array}$

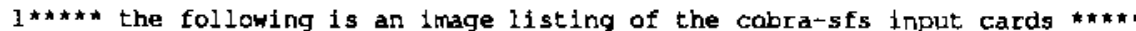

1**** the following is an mage listing of the
radx generated input is not included

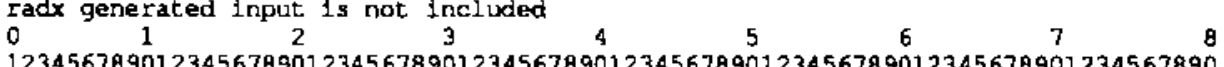

\begin{tabular}{|c|c|c|c|c|c|c|c|c|c|c|c|c|}
\hline 2 & 1 & & fluts & shea & sam & ple & roble & mo. & 3 & & & \\
\hline 3 & prop & 2 & 1 & 50 & & & & & & & & \\
\hline $\begin{array}{l}4 \\
5\end{array}$ & & $\begin{array}{l}0.0 \\
0.0\end{array}$ & & 100. & & $\begin{array}{l}8.077 \\
7.97\end{array}$ & & $\begin{array}{r}.332 \\
.364\end{array}$ & & $\begin{array}{l}1.000 \\
0.998\end{array}$ & $\begin{array}{l}0.016 \\
0.016\end{array}$ & $\begin{array}{l}37.52 \\
37.52\end{array}$ \\
\hline 6 & 1 & none & & 1.0 & & 1.0 & & 1.0 & & 1.0 & & \\
\hline 7 & chan & & 30 & 0 & 1 & & & & & & & \\
\hline 8 & & 150. & & 90. & & & & & & & & \\
\hline 9 & 1 & 1 & 25 & 0 & 1 & & & & & & & \\
\hline 10 & $i$ & 0 & 0 & 0 & 0 & & & & & & & \\
\hline 11 & 1 & 1.0 & 1.0 & 0.0 & 2 & 1.0 & 1.0 & 6 & 1.0 & 1.0 & & \\
\hline 12 & 2 & 1.0 & 1.0 & 0.0 & 3 & 1.0 & 1.0 & 7 & 1.0 & 1.0 & & \\
\hline 13 & 3 & 1.0 & 1.0 & 0.0 & 4 & 1.0 & 1.0 & 8 & 1.0 & 1.0 & & \\
\hline 14 & 4 & 1.0 & 1.0 & 0.0 & 5 & 1.0 & 1.0 & 9 & 1.0 & 2.0 & & \\
\hline 15 & 5 & 1.0 & 1.0 & 0.0 & 10 & 1.0 & 1.0 & & & & & \\
\hline 16 & 6 & 1.0 & 1.0 & 0.0 & 7 & 3.0 & 1.0 & 11 & 1.0 & 1.0 & & \\
\hline 17 & 7 & 1.0 & 1.0 & 0.0 & 8 & 1.0 & 1.0 & 12 & 1.0 & 1.0 & & \\
\hline 18 & 8 & 1.0 & 1.0 & 0.0 & 9 & 1.0 & 1.0 & 13 & 1.0 & 1.0 & & \\
\hline 19 & 9 & 1.0 & 1.0 & 0.0 & 10 & 1.0 & 1.0 & 14 & 1.0 & 1.0 & & \\
\hline 20 & 10 & 1.0 & 1.0 & 0.0 & 15 & 1.0 & 1.0 & & & & & \\
\hline 21 & 11 & 1.0 & 1.0 & 0.0 & 12 & 1.0 & 1.0 & 16 & 1.0 & 1.0 & & \\
\hline 22 & 12 & 1.0 & 1.0 & 0.0 & 13 & 1.0 & 1.0 & 17 & 1.0 & 1.0 & & \\
\hline 23 & 13 & 10 & 1.0 & 0.0 & 14 & & 30 & 18 & 10 & 10 & & \\
\hline
\end{tabular}




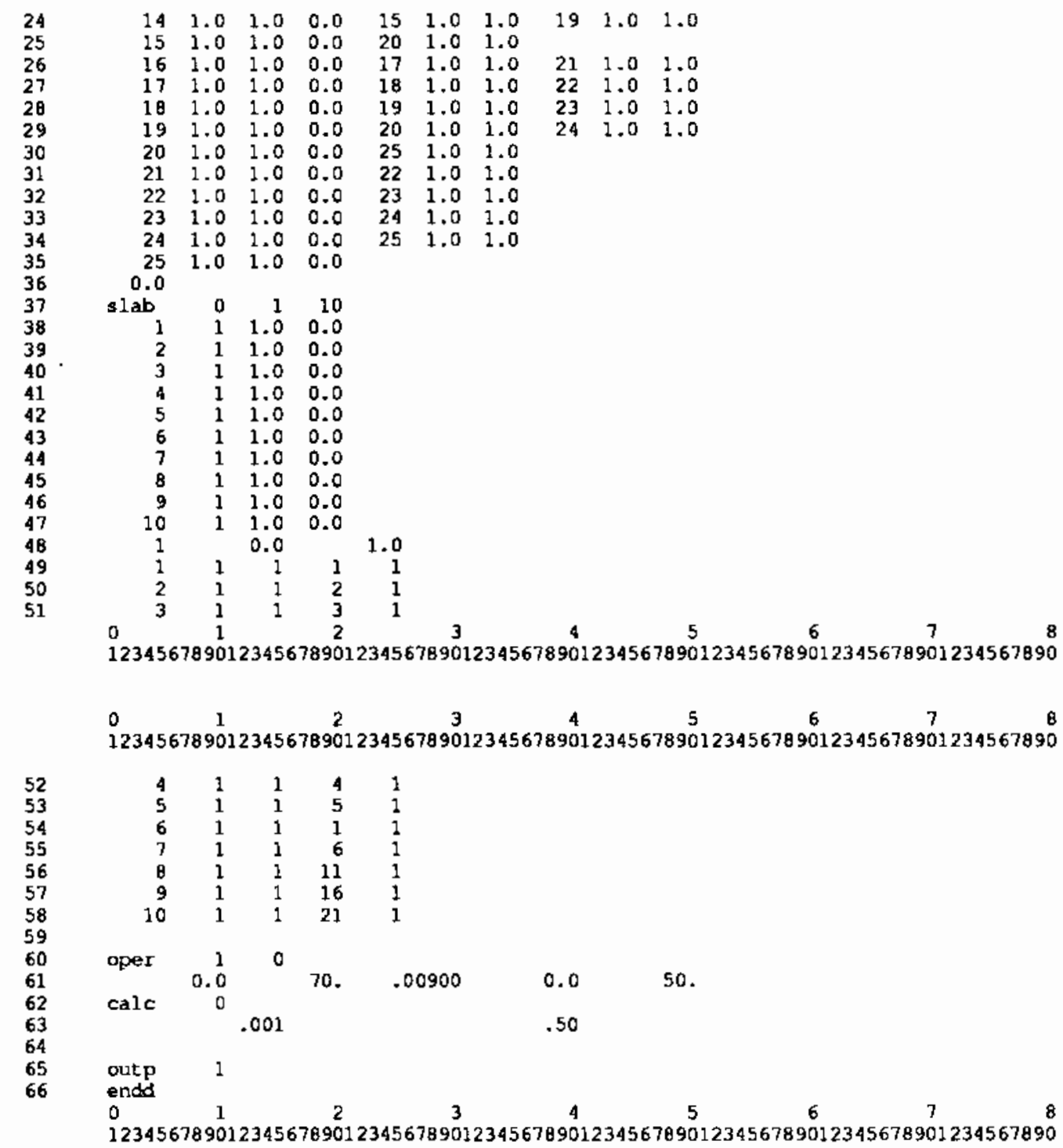

11 nput for case 1 fluld shear sample problem no. 1 


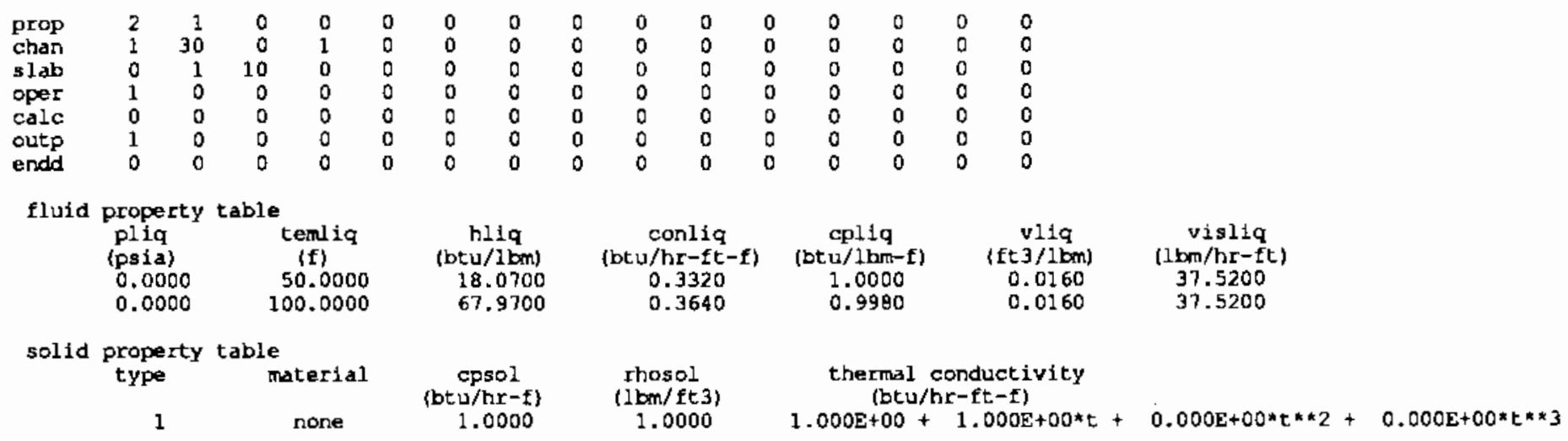

\section{assembly number 1 input description}

\section{axtal heat flux proflle number}

heat flux vs. time proftle number heat transfer correlation number 0

yodraulic dianeter

(in)

4.0000

4.0000

4.0000
4.0000

4.0000

4.0000

4.0000
4.0000

4.0000

4.0000

4.0000

4.0000

4.0000

4.0000

4.0000

4.0000

4.0000

4.0000

4.0000

4.0000

4.0000

4.0000

4.0000

4.0000

4.0000 (adjacent channel no., momentum control volume width and length)

$(2,1.000,1.000)(6,1.000,1.000)(0,0.000,0.000)(0,0.000,0.000)$ $3,1.000,1.000)(7,1.000,1.000)\} 0,0.000,0.000)(0,0.000,0.000\}$ $5,1.000,1.000)(8,1.000,1.000)(0,0.000,0.000)(0,0.000,0.000\}$ $10,1.000,1.000\}(0,0.000,0.000)(0,0.000,0.000)(0,0.000,0.000)$ $7,1.000,1.000\}(11,1.000,1.000)(0,0.000,0.000)(0,0.000,0.000)$ $8,1.000,1.000)(12,1.000,1.000)(0,0.000,0.000)(0,0.000,0.000)$ $9,1.000,1.000)(13,1.000,1.000)(0,0.000,0.000)(0,0.000,0.000)$ $10,1.000,1.000)(14,1.000,1.000)(0,0.000,0.000)(0,0.000,0.000)$ $15,1.000,1.000)(0,0.000,0.000)(0,0.000,0.000\}(0,0.000,0.000)$ $12,1.000,1.000)(16,1.000,1.000)(0,0.000,0.000)(0,0.000,0.000)$ $13,1.000,1.000)(17,1.000,1.000)(0,0.000,0.000)(0,0.000,0.000)$ $(14,1.000,1.000)(18,1.000,1.000)(0,0.000,0.000)(0,0.000,0.000)$ $15,1.000,1.000)(19,1.000,1.000)(0,0.000,0.000)(0,0.000,0.000)$ $20,1.000,1.000)(0,0.000,0.000)(0,0.000,0.000)(0,0.000,0.000)$ $17,1.000,1.000)(21,1.000,1.000)(0,0.000,0.000)(0,0.000,0.000)$ $18,1.000,1.000)(22,1.000,1.000)(0,0.000,0.000)(0,0.000,0.000)$ $19,1.000,1.000)(23,1.000,1.000)(0,0.000,0.000)(0,0.000,0.000)$ $20,1.000,1.000)(24,1.000,1.000)(0,0.000,0.000)(0,0.000,0.000)$ $25,1.000,1.000)(0,0.000,0.000)(0,0.000,0.000)\{0,0.000,0.000\}$ $22,1.000,1.000)(0,0.000,0.000)\{0,0.000,0.000\}(0,0.000,0.000\}$ $23,1.000,1.000)(0,0.000,0.000)(0,0.000,0.000)(0,0.000,0.000)$ $(24,1.000,1.000\}\{0,0.000,0.000\}\{0,0.000,0.000\}(0,0.000,0.000)$ $0,0.000,0.000\}\{0,0.000,0.000)(0,0.000,0.000)(0,0.000,0.000)$ 
solld-to-fiuld thermal connection type table

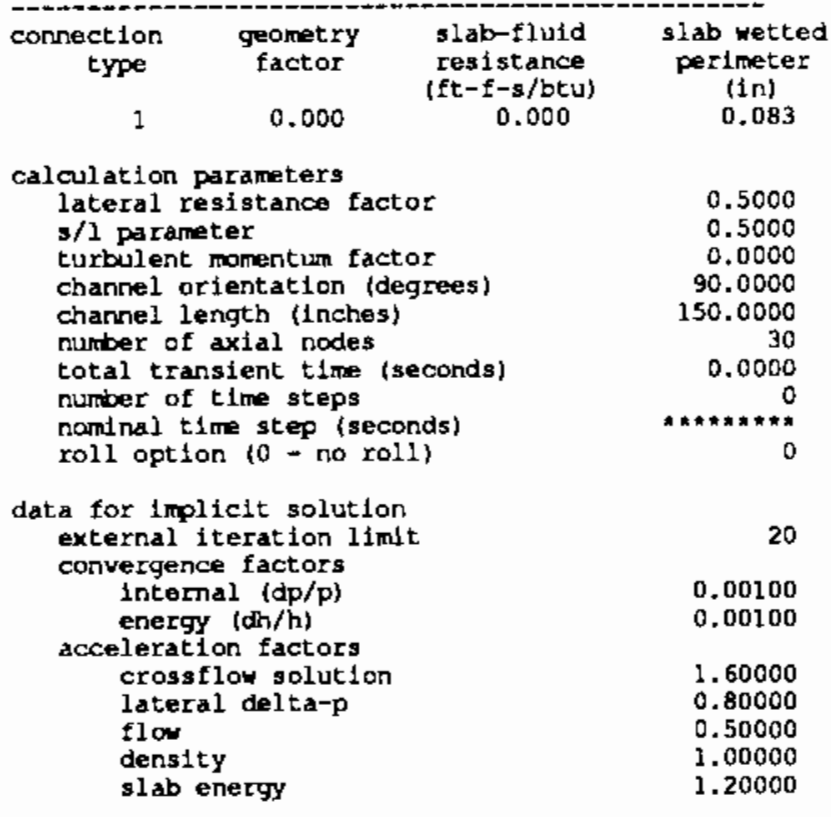

axial noding

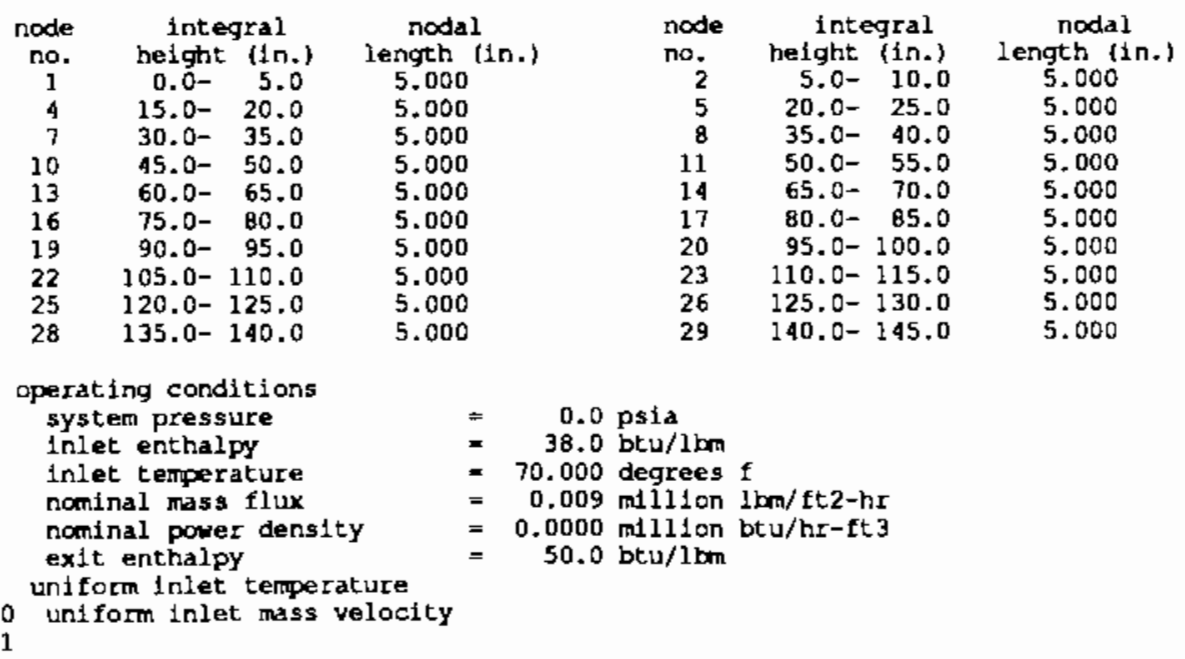

\begin{tabular}{|c|c|c|c|}
\hline $\begin{array}{l}\text { node } \\
\text { no. }\end{array}$ & $\begin{array}{l}\text { int } \\
\text { he } \mathrm{ght}\end{array}$ & egral & $\begin{array}{l}\text { nodal } \\
\text { length }\end{array}$ \\
\hline & $10,0-$ & 15.0 & 5.000 \\
\hline 6 & $25.0 \cdots$ & 30.0 & 5.000 \\
\hline 9 & $40.0-$ & 45.0 & 5.000 \\
\hline 12 & $55.0-$ & 60.0 & 5.000 \\
\hline 15 & $70.0-$ & 75.0 & 5.000 \\
\hline 18 & $85.0-$ & 90.0 & 5.000 \\
\hline 21 & $100.0-$ & 105.0 & 5.000 \\
\hline 24 & $115.0-$ & 120.0 & 5.000 \\
\hline 27 & $130.0-$ & 135.0 & 5.000 \\
\hline 30 & $145.0-$ & 350.0 & 5.000 \\
\hline
\end{tabular}




\section{parameter summary}

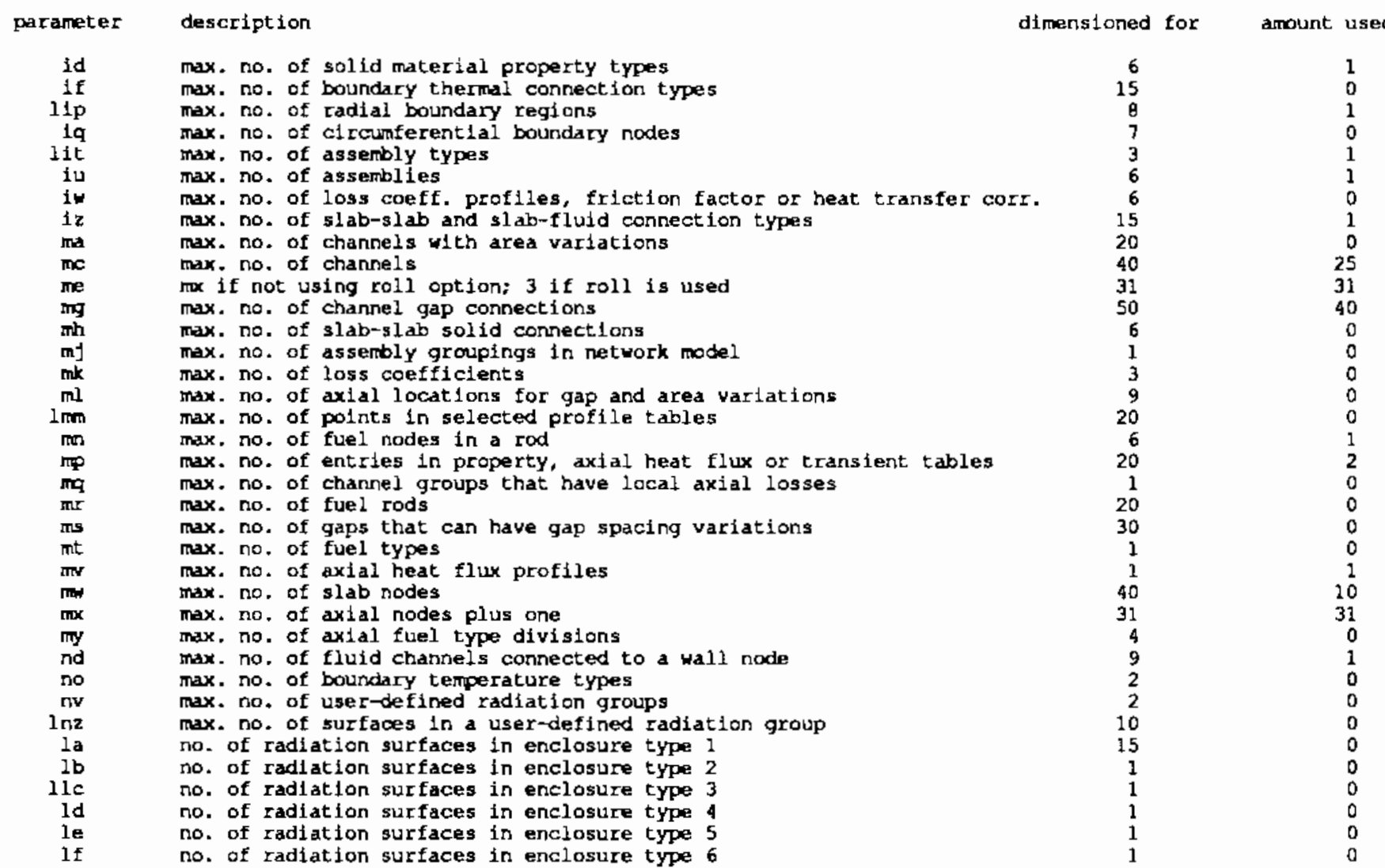

total heat generation in the problem is $0.00000 \mathrm{btu} / \mathrm{sec}$ or $0.00000 \mathrm{kw}$

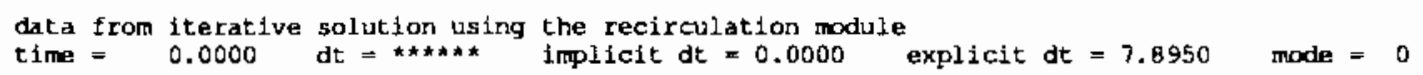

pressure

error

no.

no.

$(1 \mathrm{bm} / \mathrm{s})$

drop(psi)

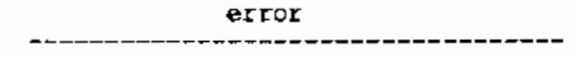


cenp (f) level rod ass.

$\begin{array}{llllll}1 & 1 & 0.0 & 0 & 0 & 0 \\ 2 & 1 & 0.0 & 0 & 0 & 0 \\ 3 & 1 & 0.0 & 0 & 0 & 0 \\ 4 & 1 & 0.0 & 0 & 0 & 0 \\ 5 & 1 & 0.0 & 0 & 0 & 0 \\ 6 & 1 & 0.0 & 0 & 0 & 0 \\ 7 & 1 & 0.0 & 0 & 0 & 0 \\ 8 & 1 & 0.0 & 0 & 0 & 0 \\ 9 & 1 & 0.0 & 0 & 0 & 0 \\ 10 & 1 & 0.0 & 0 & 0 & 0\end{array}$

cobra-sfs code results

or

$\begin{array}{llllll}0.434 E+00 & 0.0000000 & 0.0000 & 0.4952 & 0.0000 & 0.0000 \\ 0.434 E+00 & 0.0000000 & 0.0000 & 0.2666 & 0.0000 & 0.0000 \\ 0.434 E+00 & 0.0000000 & 0.0000 & 0.1346 & 0.0000 & 0.0000 \\ 0.434 E+00 & 0.0000000 & 0.0000 & 0.0676 & 0.0000 & 0.0000 \\ 0.434 E+00 & 0.0000000 & 0.0000 & 0.0333 & 0.0000 & 0.0000 \\ 0.434 E+00 & 0.0000000 & 0.0000 & 0.0163 & 0.0000 & 0.0000 \\ 0.434 E+00 & 0.0000000 & 0.0000 & 0.0080 & 0.0000 & 0.0000 \\ 0.434 E+00 & 0.0000000 & 0.0000 & 0.0039 & 0.0000 & 0.0000 \\ 0.434 E+00 & 0.0000000 & 0.0000 & 0.0019 & 0.0000 & 0.0000 \\ 0.434 E+00 & 0.0000000 & 0.0000 & 0.0010 & 0.0000 & 0.0000\end{array}$

date 01/05/89 t1me

\begin{tabular}{|c|c|c|c|c|c|c|c|c|}
\hline $\begin{array}{l}\text { calculated } \\
\text { channel } \\
\text { assembly }\end{array}$ & $\begin{array}{l}\text { f fluid cor } \\
1 \\
1\end{array}$ & ons at $t$ & 0.000 & seconds & & & & \\
\hline $\begin{array}{c}\text { dístance } \\
\text { (1n.) }\end{array}$ & $\begin{array}{l}\text { delta-p } \\
\{p s i\}\end{array}$ & $\begin{array}{l}\text { enthalpy } \\
\text { (btu/lb) }\end{array}$ & $\begin{array}{c}\text { temperature } \\
\text { (deg-f) }\end{array}$ & $\begin{array}{c}\text { density } \\
(1 \mathrm{~b} / \mathrm{cu}-\mathrm{ft})\end{array}$ & $\begin{array}{c}\text { flow } \\
\text { (1b/sec) }\end{array}$ & $\begin{array}{c}\text { mass flux } \\
(m l b / h r-f t 2)\end{array}$ & $\begin{array}{l}\text { velocity } \\
\text { (ft/sec) }\end{array}$ & $\begin{array}{l}\text { area } \\
(s q-1 n)\end{array}$ \\
\hline 0.0 & 0.0000599 & 38.03 & 70.00 & 62.5000 & 0.0173611 & 0.0090000 & 0.0400000 & 1.00000 \\
\hline 5.0 & 0.0000543 & 38.03 & 70.00 & 62.5000 & 0.0073186 & 0.0037940 & 0.0168621 & 1.00000 \\
\hline 10.0 & 0.0000506 & 38.03 & 70.00 & 62.5000 & 0.0037433 & 0.0019405 & 0.0086245 & 1.00000 \\
\hline 15.0 & 0.0000475 & 38.03 & 70.00 & 62.5000 & 0.0028313 & 0.0014677 & 0.0065232 & 1.00000 \\
\hline 20.0 & 0.0000447 & 38.03 & 70.00 & 62.5000 & 0.0024726 & 0.0012818 & 0.0056968 & 1.00000 \\
\hline 25.0 & 0.0000422 & 38.03 & 70.00 & 62.5000 & 0.0022479 & 0.0011653 & 0.0051792 & 1.00000 \\
\hline 30.0 & 0.0000399 & 38.03 & 70.00 & 62.5000 & 0.0020898 & 0.0010834 & 0.0048150 & 1.00000 \\
\hline 35.0 & 0.0000378 & 38.03 & 70.00 & 62.5000 & 0.0019749 & 0.0010238 & 0.0045502 & 1.00000 \\
\hline 40.0 & 0.0000358 & 38.03 & 70.00 & 62.5000 & 0.0018891 & 0.0009793 & 0.0043525 & 1.00000 \\
\hline 45.0 & 0.0000339 & 38.03 & 70.00 & 62.5000 & 0.0018232 & 0.0009452 & 0.0042007 & 1.00000 \\
\hline 50.0 & 0.0000320 & 38.03 & 30.00 & 62.5000 & 0.0017713 & 0.0009182 & 0.0040811 & 1.00000 \\
\hline 55.0 & 0.0000302 & 38.03 & 70.00 & 62.5000 & 0.0017295 & 0.0008966 & 0.0039847 & 1.00000 \\
\hline 60.0 & 0.0000284 & 38.03 & 70.00 & 62.5000 & 0.0016951 & 0.0008787 & 0.0039055 & 1.00000 \\
\hline 65.0 & 0.0000267 & 38.03 & 70.00 & 62.5000 & 0.0016665 & 0.0008639 & 0.0038395 & 1.00000 \\
\hline 70.0 & 0.0000250 & 38.03 & 70.00 & 62.5000 & 0.0016423 & 0.0008514 & 0.0037838 & 1.00000 \\
\hline 75.0 & 0.0000233 & 38.03 & 70.00 & 62.5000 & 0.0016216 & 0.0008407 & 0.0037363 & 1.00000 \\
\hline 80.0 & 0.0000217 & 38.03 & 70.00 & 62.5000 & 0.0016039 & 0.0008315 & 0.0036953 & 1.00000 \\
\hline 85.0 & 0.0000201 & 38.03 & 70.00 & 62.5000 & 0.0015885 & 0.0008235 & 0.0036599 & 1.00000 \\
\hline 90.0 & 0.0000185 & 38.03 & 70.00 & 62.5000 & 0.0015751 & 0.0008165 & 0.0036290 & 1.00000 \\
\hline
\end{tabular}




$\begin{array}{rllllllll}95.0 & 0.0000169 & 38.03 & 70.00 & 62.5000 & 0.0015634 & 0.0008105 & 0.0036020 & 1.00000 \\ 100.0 & 0.0000153 & 38.03 & 70.00 & 62.5000 & 0.0015531 & 0.0008051 & 0.0035783 & 1.00000 \\ 105.0 & 0.0000137 & 38.03 & 70.00 & 62.5000 & 0.0015440 & 0.0008004 & 0.0035574 & 1.00000 \\ 110.0 & 0.0000122 & 38.03 & 70.00 & 62.5000 & 0.0015360 & 0.0007962 & 0.0035389 & 1.00000 \\ 115.0 & 0.0000106 & 38.03 & 70.00 & 62.5000 & 0.0015288 & 0.0007926 & 0.003525 & 1.00000 \\ 120.0 & 0.0000091 & 38.03 & 70.00 & 62.5000 & 0.0015225 & 0.0007893 & 0.0035079 & 1.00000 \\ 125.0 & 0.0000076 & 38.03 & 70.00 & 62.5000 & 0.0015169 & 0.0007864 & 0.0034949 & 1.00000 \\ 130.0 & 0.0000060 & 38.03 & 70.00 & 62.5000 & 0.0015119 & 0.0007838 & 0.0034834 & 1.00000 \\ 135.0 & 0.0000045 & 38.03 & 70.00 & 62.5000 & 0.0015074 & 0.0007814 & 0.0034731 & 1.00000 \\ 140.0 & 0.0000030 & 38.03 & 70.00 & 62.5000 & 0.0015034 & 0.0007794 & 0.0034639 & 1.00000 \\ 145.0 & 0.0000015 & 38.03 & 70.00 & 62.5000 & 0.0014999 & 0.0007776 & 0.0034559 & 1.00000 \\ 150.0 & 0.0000000 & 38.03 & 70.00 & 62.5000 & 0.0014953 & 0.0007751 & 0.0034451 & 1.00000\end{array}$

calculated fluid conditions at time $=0.0000$ seconds $\begin{array}{ll}\text { channel } & \mathbf{2} \\ \text { assembly } & 1\end{array}$

\begin{tabular}{|c|c|c|c|c|c|c|c|c|}
\hline $\begin{array}{l}\text { distance } \\
\text { (in.) }\end{array}$ & $\begin{array}{l}\text { delta-p } \\
\text { (psi) }\end{array}$ & $\begin{array}{l}\text { enthalpy } \\
\text { (btu/lb) }\end{array}$ & $\begin{array}{c}\text { temperature } \\
\text { (deg- } f \text { ) }\end{array}$ & $\begin{array}{c}\text { density } \\
(\mathrm{lb} / \mathrm{cu}-\mathrm{ft})\end{array}$ & $\begin{array}{c}\text { flow } \\
(1 \mathrm{~b} / \mathrm{sec})\end{array}$ & $\begin{array}{c}\text { mass flux } \\
(m i b / h r-f(c)\end{array}$ & $\begin{array}{c}\text { velocity } \\
\text { (ft/sec) }\end{array}$ & $\begin{array}{l}\text { area } \\
\text { (sq-in) }\end{array}$ \\
\hline 0.0 & 0.0000597 & 38.03 & 70.00 & 62.5000 & 0.0173611 & 0.0090000 & 0.0400000 & 1.00000 \\
\hline 5.0 & 0.0000544 & 38.03 & 70.00 & 62.5000 & 0.0132895 & 0.0068893 & 0.0306191 & 1.00000 \\
\hline 10.0 & 0.0000506 & 38.03 & 70.00 & 62.5000 & 0.0103714 & 0.0053765 & 0.0238957 & 1.00000 \\
\hline 15.0 & 0.0000475 & 38.03 & 70.00 & 62.5000 & 0.0087059 & 0.0045131 & 0.0200584 & 1.00000 \\
\hline 20.0 & 0.0000447 & 38.03 & 70.00 & 62.5000 & 0.0077288 & 0.0040066 & 0.0178072 & 1.00000 \\
\hline 25.0 & 0.0000422 & 38.03 & 70.00 & 62.5000 & 0.0070988 & 0.0036800 & 0.0163557 & 1.00000 \\
\hline 30.0 & 0.0000399 & 38.03 & 70.00 & 62.5000 & 0.0066616 & 0.0034534 & 0.0153482 & 1.00000 \\
\hline 35.0 & 0.0000378 & 38.03 & 70.00 & 62.5000 & 0.0063434 & 0.0032884 & 0.0146151 & 1.00000 \\
\hline 40.0 & 0.0000358 & 38.03 & 70.00 & 62.5000 & 0.0061037 & 0.0031641 & 0.0140629 & 1.00000 \\
\hline 45.0 & 0.0000339 & 38.03 & 70.00 & 62.5000 & 0.0059179 & 0.0030679 & 0.0136349 & 1.00000 \\
\hline 50.0 & 0.0000320 & 38.03 & 70.00 & 62.5000 & 0.0057705 & 0.0029914 & 0.0132952 & 1.00000 \\
\hline 55.0 & 0.0000302 & 38.03 & 70.00 & 62.5000 & 0.0056510 & 0.0029295 & 0.0130200 & 1.00000 \\
\hline 60.0 & 0.0000284 & 38.03 & 70.00 & 62.5000 & 0.0055527 & 0.0028785 & 0.0127933 & 1.00000 \\
\hline 65.0 & 0.0000267 & 38.03 & 70.00 & 62.5000 & 0.0054705 & 0.0028359 & 0.0126040 & 1.00000 \\
\hline 70.0 & 0.0000250 & 38.03 & 70.00 & 62.5000 & 0.0054010 & 0.0027999 & 0.0124440 & 1.00000 \\
\hline 75.0 & 0.0000233 & 38.03 & 70.00 & 62.5000 & 0.0053418 & 0.0027692 & 0.0123075 & 1.00000 \\
\hline 80.0 & 0.0000217 & 38.03 & 70.00 & 62.5000 & 0.0052908 & 0.0027428 & 0.0121901 & 1.00000 \\
\hline 85.0 & 0.0000201 & 38.03 & 70.00 & 62.5000 & 0.0052467 & 0.0027199 & 0.0120885 & 1.00000 \\
\hline 90.0 & 0.0000185 & 38.03 & 70.00 & 62.5000 & 0.0052083 & 0.0027000 & 0.0120000 & 1.00000 \\
\hline 95.0 & 0.0000169 & 38.03 & 70.00 & 62.5000 & 0.0051748 & 0.0026826 & 0.0119226 & 1.00000 \\
\hline 100.0 & 0.0000153 & 38.03 & 70.00 & 62.5000 & 0.0051453 & 0.0026673 & 0.0118547 & 1.00000 \\
\hline 105.0 & 0.0000137 & 38.03 & 70.00 & 62.5000 & 0.0051193 & 0.0026538 & 0.0117948 & 1.00000 \\
\hline 110.0 & 0.0000122 & 38.03 & 70.00 & 62.5000 & 0.0050963 & 0.0026419 & 0.0117419 & 1.00000 \\
\hline 115.0 & 0.0000106 & 38.03 & 70.00 & 62.5000 & 0.0050760 & 0.0026314 & 0.0116951 & 1.00000 \\
\hline 120.0 & 0.0000091 & 38.03 & 70.00 & 62.5000 & 0.0050579 & 0.0026220 & 0.0116535 & 1.00000 \\
\hline 125.0 & 0.0000076 & 38.03 & 70.00 & 62.5000 & 0.0050419 & 0.0026137 & 0.0116165 & 1.00000 \\
\hline 130.0 & 0.0000060 & 38.03 & 70.00 & 62.5000 & $0.00 \$ 0276$ & 0.0026063 & 0.0115835 & 1.00000 \\
\hline 135.0 & 0.0000045 & 38.03 & 70.00 & 62.5000 & 0.0050148 & 0.0025997 & 0.0115541 & 1.00000 \\
\hline 140.0 & 0.0000030 & 38.03 & 70.00 & 62.5000 & 0.0050034 & 0.0025938 & 0.0115279 & 1.00000 \\
\hline 145.0 & 0.0000015 & 38.03 & 70.00 & 62.5000 & 0.0049933 & 0.0025885 & 0.0115047 & 1.00000 \\
\hline 150.0 & 0.0000000 & 38.03 & 70.00 & 62.5000 & 0.0049818 & 0.0025825 & 0.0114780 & 1.00000 \\
\hline
\end{tabular}


assenbly 1

$\begin{array}{rrrr}\begin{array}{c}\text { distance } \\ \text { (in.) }\end{array} & \begin{array}{c}\text { delta-p } \\ \text { (psi) }\end{array} & \begin{array}{c}\text { enthalpy } \\ \text { (btu/lb) } \\ 0.0\end{array} & \begin{array}{r}\text { temperatu) } \\ \text { (deg-f) }\end{array} \\ 5.0 & 0.0000595 & 38.03 & 70.00 \\ 10.0 & 0.0000546 & 38.03 & 70.00 \\ 15.0 & 0.0000475 & 38.03 & 70.00 \\ 20.0 & 0.0000447 & 38.03 & 70.00 \\ 25.0 & 0.0000422 & 38.03 & 70.00 \\ 30.0 & 0.0000399 & 38.03 & 70.00 \\ 35.0 & 0.0000378 & 38.03 & 70.00 \\ 40.0 & 0.0000358 & 38.03 & 70.00 \\ 45.0 & 0.0000339 & 38.09 & 70.00 \\ 50.0 & 0.0000320 & 38.09 & 70.00 \\ 55.0 & 0.0000302 & 38.03 & 70.00 \\ 60.0 & 0.0000284 & 38.03 & 70.00 \\ 65.0 & 0.0000267 & 38.03 & 70.00 \\ 70.0 & 0.0000250 & 38.03 & 70.00 \\ 75.0 & 0.0000233 & 38.03 & 70.00 \\ 80.0 & 0.0000217 & 38.03 & 70.00 \\ 85.0 & 0.0000201 & 38.03 & 70.00 \\ 90.0 & 0.0000185 & 38.03 & 70.00 \\ 95.0 & 0.0000169 & 38.03 & 70.00 \\ 100.0 & 0.0000153 & 38.09 & 70.00 \\ 105.0 & 0.0000137 & 38.03 & 70.00 \\ 110.0 & 0.0000122 & 38.03 & 70.00 \\ 115.0 & 0.0000106 & 38.03 & 70.00 \\ 120.0 & 0.0000091 & 38.03 & 70.00 \\ 125.0 & 0.0000076 & 38.03 & 70.00 \\ 130.0 & 0.0000060 & 38.03 & 70.00 \\ 135.0 & 0.0000045 & 38.03 & 70.00 \\ 140.0 & 0.0000030 & 38.03 & 70.00 \\ 145.0 & 0.0000015 & 38.03 & 70.00 \\ 150.0 & 0.0000000 & 38.03 & 70.00\end{array}$

$\begin{array}{ccccc}\begin{array}{c}\text { density } \\ \text { (lb/cu-ft) }\end{array} & \begin{array}{c}\text { flow } \\ \text { (Ib/sec) }\end{array} & \begin{array}{c}\text { mass flux } \\ \text { (mlb/hr-ft2) } \\ 62.5000\end{array} & \begin{array}{c}\text { velocity } \\ \text { (ft/sec) }\end{array} & \begin{array}{c}\text { area } \\ \text { (sq-in) }\end{array} \\ 62.5000 & 0.0173611 & 0.0090000 & 0.0400000 & 1.00000 \\ 62.5000 & 0.0122103 & 0.0075060 & 0.0333602 & 1.00000 \\ 62.5000 & 0.0106589 & 0.0063298 & 0.0281325 & 1.00000 \\ 62.5000 & 0.0096497 & 0.0055256 & 0.0245581 & 1.00000 \\ 62.5000 & 0.0089791 & 0.0046548 & 0.0222329 & 1.00000 \\ 62.5000 & 0.0085140 & 0.0044136 & 0.0206879 & 1.00000 \\ 62.5000 & 0.0081773 & 0.0042391 & 0.0196162 & 1.00000 \\ 62.5000 & 0.0079245 & 0.0041081 & 0.0182582 & 1.00000 \\ 62.5000 & 0.0077287 & 0.0040065 & 0.0178069 & 1.00000 \\ 62.5000 & 0.0075727 & 0.0039257 & 0.0174476 & 1.00000 \\ 62.5000 & 0.0074459 & 0.0038599 & 0.0171553 & 1.00000 \\ 62.5000 & 0.0073408 & 0.0038055 & 0.0169133 & 1.00000 \\ 62.5000 & 0.0072526 & 0.0037598 & 0.0167101 & 1.00000 \\ 62.5000 & 0.0071778 & 0.0037210 & 0.0165376 & 1.00000 \\ 62.5000 & 0.0071136 & 0.0036877 & 0.0163898 & 1.00000 \\ 62.5000 & 0.0070583 & 0.0036590 & 0.0162623 & 1.00000 \\ 62.5000 & 0.0070102 & 0.0036341 & 0.0161516 & 1.00000 \\ 62.5000 & 0.0069683 & 0.0036124 & 0.0160550 & 1.00000 \\ 62.5000 & 0.0069315 & 0.0035933 & 0.0159703 & 1.00000 \\ 62.5000 & 0.0068992 & 0.0035766 & 0.0158958 & 1.00000 \\ 62.5000 & 0.0068707 & 0.0035618 & 0.0158301 & 1.00000 \\ 62.5000 & 0.0068455 & 0.0035487 & 0.0157719 & 1.00000 \\ 62.5000 & 0.0068231 & 0.0035371 & 0.0157204 & 1.00000 \\ 62.5000 & 0.0068032 & 0.0035268 & 0.0156746 & 1.00000 \\ 62.5000 & 0.0067755 & 0.0035176 & 0.0156338 & 1.00000 \\ 62.5000 & 0.0067697 & 0.0035094 & 0.0155994 & 1.00000 \\ 62.5000 & 0.0067556 & 0.0035021 & 0.0155650 & 1.00000 \\ 62.5000 & 0.0067430 & 0.0034956 & 0.0155360 & 1.00000 \\ 62.5000 & 0.0067319 & 0.0034898 & 0.0155103 & 1.00000 \\ 62.5000 & 0.0067197 & 0.0034835 & 0.0154822 & 1.00000\end{array}$

calculated fluld conditions at time $=0.0000$ seconds channel assembly

$\begin{array}{cccc}\begin{array}{c}\text { distance } \\ \text { (1n.) }\end{array} & \begin{array}{c}\text { delta-p } \\ \text { (psi) }\end{array} & \begin{array}{c}\text { enthalpy } \\ \text { (btu/lb) } \\ 0.0\end{array} & \begin{array}{c}\text { temperature } \\ \text { (deg-t) }\end{array} \\ 5.0000593 & 0.0000546 & 38.03 & 70.00 \\ 10.0 & 0.0000507 & 38.03 & 70.00 \\ 15.0 & 0.0000475 & 38.03 & 70.00 \\ 20.0 & 0.0000447 & 38.03 & 70.00 \\ 25.0 & 0.0000422 & 38.03 & 70.00 \\ 30.0 & 0.0000399 & 38.03 & 70.00 \\ 35.0 & 0.0000378 & 38.03 & 70.00 \\ 40.0 & 0.0000358 & 38.03 & 70.00 \\ 45.0 & 0.0000339 & 38.03 & 70.00 \\ 50.0 & 0.0000320 & 38.03 & 70.00 \\ 55.0 & 0.0000302 & 38.03 & 70.00 \\ 60.0 & 0.0000284 & 38.03 & 70.00\end{array}$

$\begin{array}{ccccc}\begin{array}{c}\text { density } \\ (1 \mathrm{~b} / \mathrm{cu}-\mathrm{ft})\end{array} & \begin{array}{c}\text { flow } \\ (\mathrm{b} / \mathrm{sec})\end{array} & \begin{array}{c}\text { mass flux } \\ \text { (mlb/hr-ft2) } \\ 02.5000\end{array} & \begin{array}{c}\text { velocity } \\ \text { (ft/sec) }\end{array} & \begin{array}{c}\text { area } \\ \text { (sq-in) }\end{array} \\ 62.50000000000 & 0.0173611 & 0.009000000 & 1.00000 \\ 62.5000 & 0.0126596 & 0.0075995 & 0.0337757 & 1.00000 \\ 62.5000 & 0.0112559 & 0.0065683 & 0.0291925 & 1.00000 \\ 62.5000 & 0.0103038 & 0.0058351 & 0.0259336 & 1.00000 \\ 62.5000 & 0.0096687 & 0.005315 & 0.0237399 & 1.00000 \\ 62.5000 & 0.0092352 & 0.004722 & 0.0222766 & 1.00000 \\ 62.5000 & 0.0089284 & 0.0046285 & 0.0212779 & 1.00000 \\ 62.5000 & 0.0087027 & 0.0045115 & 0.0205710 & 1.00000 \\ 62.5000 & 0.0085304 & 0.0044221 & 0.0196539 & 1.00000 \\ 62.5000 & 0.0083945 & 0.0043517 & 0.0193410 & 1.00000 \\ 62.5000 & 0.0082846 & 0.0042947 & 0.0190877 & 1.00000 \\ 62.5000 & 0.0081937 & 0.0042476 & 0.0188784 & 1.00000\end{array}$




$\begin{array}{rllllllll}65.0 & 0.0000267 & 38.03 & 70.00 & 62.5000 & 0.0081174 & 0.0042080 & 0.0187024 & 1.00000 \\ 70.0 & 0.0000250 & 38.03 & 70.00 & 62.5000 & 0.0080524 & 0.0041744 & 0.0185527 & 1.00000 \\ 75.0 & 0.0000233 & 38.03 & 70.00 & 62.5000 & 0.0079966 & 0.0041454 & 0.0184241 & 1.00000 \\ 80.0 & 0.0000217 & 38.03 & 70.00 & 62.5000 & 0.0079483 & 0.0041204 & 0.018328 & 1.00000 \\ 85.0 & 0.0000201 & 38.03 & 70.00 & 62.5000 & 0.0079062 & 0.0040986 & 0.0182159 & 1.00000 \\ 90.0 & 0.0000185 & 38.03 & 70.00 & 62.5000 & 0.0078694 & 0.0040795 & 0.0181310 & 1.00000 \\ 95.0 & 0.0000169 & 38.03 & 70.00 & 62.5000 & 0.0078370 & 0.0040627 & 0.0180564 & 1.00000 \\ 100.0 & 0.0000153 & 38.03 & 70.00 & 62.5000 & 0.0078085 & 0.0040479 & 0.0179907 & 1.00000 \\ 105.0 & 0.0000137 & 38.03 & 70.00 & 62.5000 & 0.0077832 & 0.0040348 & 0.0179326 & 1.00000 \\ 110.0 & 0.0000122 & 38.03 & 70.00 & 62.5000 & 0.0077609 & 0.0040232 & 0.0178810 & 1.00000 \\ 115.0 & 0.0000106 & 38.03 & 70.00 & 62.5000 & 0.0077410 & 0.0040129 & 0.0178353 & 1.00000 \\ 120.0 & 0.0000091 & 38.03 & 70.00 & 62.5000 & 0.00777233 & 0.0040038 & 0.0177946 & 1.00000 \\ 125.0 & 0.0000076 & 38.03 & 70.00 & 62.5000 & 0.0077076 & 0.0039956 & 0.0177583 & 1.00000 \\ 130.0 & 0.0000060 & 38.03 & 70.00 & 62.5000 & 0.0076935 & 0.0039883 & 0.0177259 & 1.00000 \\ 135.0 & 0.0000045 & 38.03 & 70.00 & 62.5000 & 0.0076810 & 0.0039818 & 0.0176970 & 1.00000 \\ 140.0 & 0.0000030 & 38.03 & 70.00 & 62.5000 & 0.0076697 & 0.0039760 & 0.0176711 & 1.00000 \\ 145.0 & 0.0000015 & 38.03 & 70.00 & 62.5000 & 0.0076599 & 0.0039709 & 0.0176483 & 1.00000 \\ 150.0 & 0.0000000 & 38.03 & 70.00 & 62.5000 & 0.0076489 & 0.0039652 & 0.0176231 & 1.00000\end{array}$

calculated fluid conditions at t1me $=0.0000$ seconds $\begin{array}{ll}\text { channel } & 5 \\ \text { assembly } & 1\end{array}$

distance delta-p

$\begin{array}{cccc}\begin{array}{c}\text { distance } \\ \text { (1n.) }\end{array} & \begin{array}{c}\text { delta-p } \\ \text { (psi) }\end{array} & \begin{array}{c}\text { enthalpy } \\ \text { (btu/lb) } \\ 0.0\end{array} & \begin{array}{c}0.0000593 \\ \text { temperature } \\ \text { (deg-f) }\end{array} \\ 5.0 & 0.0000546 & 38.03 & 70.00 \\ 10.0 & 0.0000508 & 38.03 & 70.00 \\ 15.0 & 0.0000475 & 38.03 & 70.00 \\ 20.0 & 0.0000447 & 38.03 & 70.00 \\ 25.0 & 0.0000422 & 38.03 & 70.00 \\ 30.0 & 0.0000400 & 38.03 & 70.00 \\ 35.0 & 0.0000378 & 38.03 & 70.00 \\ 40.0 & 0.0000358 & 38.03 & 70.00 \\ 45.0 & 0.0000339 & 38.03 & 70.00 \\ 50.0 & 0.0000320 & 38.03 & 70.00 \\ 55.0 & 0.0000302 & 38.03 & 70.00 \\ 60.0 & 0.0000284 & 38.03 & 70.00 \\ 65.0 & 0.0000267 & 38.03 & 70.00 \\ 70.0 & 0.0000250 & 38.03 & 70.00 \\ 75.0 & 0.0000233 & 38.03 & 70.00 \\ 80.0 & 0.0000217 & 38.03 & 70.00 \\ 85.0 & 0.0000201 & 38.03 & 70.00 \\ 90.0 & 0.0000185 & 38.03 & 70.00 \\ 95.0 & 0.0000169 & 38.03 & 70.00 \\ 100.0 & 0.0000153 & 38.03 & 70.00 \\ 105.0 & 0.0000137 & 38.03 & 70.00 \\ 110.0 & 0.0000122 & 38.03 & 70.00 \\ 115.0 & 0.0000106 & 38.03 & 70.00 \\ 120.0 & 0.0000091 & 38.03 & 70.00 \\ 125.0 & 0.0000076 & 38.03 & 70.00 \\ 130.0 & 0.0000060 & 38.03 & 70.00 \\ 135.0 & 0.0000045 & 38.03 & 70.00 \\ 140.0 & 0.0000030 & 38.03 & 70.00 \\ 145.0 & 0.0000015 & 38.03 & 70.00\end{array}$

density
$(1 b / c 0-f t)$
62.5000
62.5000
62.5000
62.5000
62.5000
62.5000
62.5000
62.5000
62.5000
62.5000
62.5000
62.5000
62.5000
62.5000
62.5000
62.5000
62.5000
62.5000
62.5000
62.5000
62.5000
62.5000
62.5000
62.5000
62.5000
62.5000
62.5000
62.5000
62.5000
62.5000
flow
$(1 \mathrm{~b} / \mathrm{sec})$ 0.0173611 0.0146534 0.0127544 0.0114053
0.0104899 0.0104899 0.0098811 0.0091869 0.0091869 0.0089819 0.0087087 0.0086130 0.0085343 0.0084685 0.0084126 0.0083645 $0.008322 \mathrm{~B}$ 0.0082865 0.0082546 0.0082266 0.0082018 0.0081799 0.0081604 0.0081431 0.0081276 0.0081139 0.0081016 0.0080906 0.0080807
0.0080722 mass flux (mlb/hr-ft2) 0.0075963 0.0075963
0.0066119

0.0059125

0.0054380

0.0051224

0.0049099

0.0046562

0.0045765

0.0045146

0.0044650

0.0044242

0.0043901

0.0043611

.0043146

0.0043146
0.0042957

0.0042792

0.0042647

0.0042518

0.0042404

0.0042214

0.0042134

0.0042062

0.0041999

0.0041891

0.0041846

$\begin{array}{cc}\begin{array}{c}\text { velocity } \\ \text { (ft/sec) }\end{array} & \begin{array}{c}\text { area } \\ \text { (sq-in) }\end{array} \\ 0.0400000 & 1.00000 \\ 0.0337614 & 1.00000 \\ 0.0293861 & 1.00000 \\ 0.0262778 & 1.00000 \\ 0.0241687 & 1.00000 \\ 0.0227661 & 1.00000 \\ 0.0218219 & 1.00000 \\ 0.0211667 & 1.00000 \\ 0.0206942 & 1.00000 \\ 0.0203400 & 1.00000 \\ 0.0200648 & 1.00000 \\ 0.0198442 & 1.00000 \\ 0.0196631 & 1.00000 \\ 0.0195114 & 1.00000 \\ 0.0193826 & 1.00000 \\ 0.0192718 & 1.00000 \\ 0.0191758 & 1.00000 \\ 0.0190921 & 1.00000 \\ 0.0190187 & 1.00000 \\ 0.0189540 & 1.00000 \\ 0.0188969 & 1.00000 \\ 0.0188464 & 1.00000 \\ 0.0188015 & 1.00000 \\ 0.0187616 & 1.00000 \\ 0.0187260 & 1.00000 \\ 0.0186943 & 1.00000 \\ 0.0186660 & 1.00000 \\ 0.0186407 & 1.00000 \\ 0.0186180 & 1.00000 \\ 0.0185982 & 1.00000\end{array}$


calculated fluid conditions at t1me $=0.0000$ seconds channel 6

\begin{tabular}{|c|c|c|c|c|c|c|c|c|}
\hline $\begin{array}{c}\text { distance } \\
\text { (In.) }\end{array}$ & $\begin{array}{l}\text { delta-p } \\
\text { (psi) }\end{array}$ & $\begin{array}{l}\text { enthalpy } \\
\text { (btu/lb) }\end{array}$ & $\begin{array}{c}\text { temperature } \\
\text { (deg-f) }\end{array}$ & $\begin{array}{c}\text { density } \\
(1 \mathrm{~b} / \mathrm{cu}-\mathrm{ft} t)\end{array}$ & $\begin{array}{c}\text { flow } \\
(1 \mathrm{~b} / \mathrm{sec})\end{array}$ & $\begin{array}{c}\operatorname{mass} f l u x \\
(m \mathrm{~L} / \mathrm{hr}-\mathrm{ft} 2)\end{array}$ & $\begin{array}{l}\text { velocity } \\
\text { (ft/sec) }\end{array}$ & $\begin{array}{l}\text { area } \\
\text { (sq-in) }\end{array}$ \\
\hline 0.0 & 0.0000597 & 38.03 & 70.00 & 62.5000 & 0.0173611 & 0.0090000 & 0.0400000 & 1.00000 \\
\hline 5.0 & 0.0000544 & 38.03 & 70.00 & 62.5000 & 0.0132895 & 0.0068893 & 0.0306191 & 1.00000 \\
\hline 10.0 & 0.0000506 & 38.03 & 70.00 & 62.5000 & 0.0103714 & 0.0053765 & 0.0238957 & 1.00000 \\
\hline 15.0 & 0.0000475 & 38.03 & 70.00 & 62.5000 & 0.0087059 & 0.0045131 & 0.0200584 & 1.00000 \\
\hline 20.0 & 0.0000447 & 38.03 & 70.00 & 62.5000 & 0.0077288 & 0.0040066 & 0.0178072 & 1.00000 \\
\hline 25.0 & 0.0000422 & 38.03 & 70.00 & 62.5000 & 0.0070988 & 0.0036800 & 0.0163557 & 1.00000 \\
\hline 30.0 & 0.0000399 & 38.03 & 70.00 & 62.5000 & 0.0066616 & 0.0034534 & 0.0153482 & 1.00000 \\
\hline 35.0 & 0.0000378 & 38.03 & 70.00 & 62.5000 & 0.0063434 & 0.0032884 & 0.0146151 & 1.00000 \\
\hline 40.0 & 0.0000358 & 38.03 & 70.00 & 62.5000 & 0.0061037 & 0.0031641 & 0.0140629 & 1.00000 \\
\hline 45.0 & 0.0000339 & 38.03 & 70.00 & 62.5000 & 0.0059179 & 0.0030679 & 0.0136349 & 1.00000 \\
\hline 50.0 & 0.0000320 & 38.03 & 70.00 & 62.5000 & 0.0057705 & 0.0029914 & 0.0132952 & 1.00000 \\
\hline 55.0 & 0.0000302 & 38.03 & 70.00 & 62.5000 & 0.0056510 & 0.0029295 & 0.0130200 & 1.00000 \\
\hline 60.0 & 0.0000284 & 38.03 & 70.00 & 62.5000 & 0.0055527 & 0.0028785 & 0.0127933 & 1.00000 \\
\hline 65.0 & 0.0000267 & 38.03 & 70.00 & 62.5000 & 0.0054705 & 0.0028359 & 0.0126040 & 1.00000 \\
\hline 70.0 & 0.0000250 & 38.03 & 70.00 & 62.5000 & 0.0054010 & 0.0027999 & 0.0124440 & 1.00000 \\
\hline 75.0 & 0.0000233 & 38.03 & 70.00 & 62.5000 & 0.0053418 & 0.0027692 & 0.0123075 & 1.00000 \\
\hline 80.0 & 0.0000217 & 38.03 & 70.00 & 62.5000 & 0.0052908 & 0.0027428 & 0.0121901 & 1.00000 \\
\hline 85.0 & 0.0000201 & 38.03 & 70.00 & 62.5000 & 0.0052467 & 0.0027199 & 0.0120885 & 1.00000 \\
\hline 90.0 & 0.0000185 & 38.03 & 70.00 & 62.5000 & 0.0052083 & 0.0027000 & 0.0120000 & 1.00000 \\
\hline 95.0 & 0.0000169 & 38.03 & 70.00 & 62.5000 & 0.0051748 & 0.0026826 & 0.0119226 & 1.00000 \\
\hline 100.0 & 0.0000153 & 38.03 & 70.00 & 62.5000 & 0.0051453 & 0.0026673 & 0.0118547 & 1.00000 \\
\hline 105.0 & 0.0000137 & 38.03 & 70.00 & 62.5000 & 0.0051193 & 0.0026538 & 0.0117948 & 1.00000 \\
\hline 110.0 & 0.0000122 & 38.03 & 70.00 & 62.5000 & 0.0050963 & 0.0026419 & 0.0117419 & 1.00000 \\
\hline 115.0 & 0.0000106 & 38.03 & 70.00 & 62.5000 & 0.0050760 & 0.0026314 & 0.0116951 & 1.00000 \\
\hline 120.0 & 0.0000091 & 38.03 & 70.00 & 62.5000 & 0.0050579 & 0.0026220 & 0.0116535 & 1.00000 \\
\hline 125.0 & 0.0000076 & 38.03 & 70.00 & 62.5000 & 0.0050419 & 0.0026137 & 0.0116165 & 1.00000 \\
\hline 130.0 & 0.0000060 & 38.03 & 70.00 & 62.5000 & 0.0050276 & 0.0026063 & 0.0115835 & 1.00000 \\
\hline 135.0 & 0.0000045 & 38.03 & 70.00 & 62.5000 & 0.0050148 & 0.0025997 & 0.0115541 & 1.00000 \\
\hline 140.0 & 0.0000030 & 38.03 & 70.00 & 62.5000 & 0.0050034 & 0.0025938 & 0.0115279 & 1.00000 \\
\hline 145.0 & 0.0000015 & 38.03 & 70.00 & 62.5000 & 0.0049933 & 0.0025885 & 0.0115047 & 1.00000 \\
\hline 150.0 & 0.0000000 & & 70.00 & 62.5000 & 0.0049818 & 0.0025825 & 0.0114780 & 1.00000 \\
\hline
\end{tabular}

calculated fluld conditions at time $=0.0000$ seconds channel 7

$\begin{array}{cccc}\begin{array}{c}\text { distance } \\ \text { (1n.) }\end{array} & \begin{array}{c}\text { delta-p } \\ \text { (psi) }\end{array} & \begin{array}{c}\text { enthalpy } \\ \text { (btu/1b) }\end{array} & \begin{array}{c}\text { temperature } \\ \text { (deg-f) }\end{array} \\ 0.0 & 0.0000595 & 38.03 & 70.00 \\ 5.0 & 0.0000546 & 38.03 & 70.00 \\ 10.0 & 0.0000507 & 38.03 & 70.00 \\ 15.0 & 0.0000475 & 38.03 & 70.00 \\ 20.0 & 0.0000447 & 38.03 & 70.00 \\ 25.0 & 0.0000422 & 38.03 & 70.00 \\ 30.0 & 0.0000399 & 38.03 & 70.00\end{array}$

density (1b/cu-ft) 62.5000 62.5000

62.5000
62.5000

62.5000

62.5000

62.5000 flow 0.017361 0.0178752 0.0172836 0.0165312 0.0158083 0.0151653
0.0146191

(ma,$$
\begin{array}{r}
\text { mass } f l u x \\
(\mathrm{mlb} / \mathrm{hr}-\mathrm{ft} 2) \\
0.0090000 \\
0.0092665 \\
0.0089598 \\
0.0085698 \\
0.0081950 \\
0.0078617 \\
0.0075786
\end{array}
$$

$\begin{array}{cc}\begin{array}{c}\text { velocity } \\ \text { (ft/sec) }\end{array} & \begin{array}{c}\text { area } \\ \text { (sq-1n) }\end{array} \\ 0.0400000 & 1.00000 \\ 0.0411844 & 1.00000 \\ 0.0398213 & 1.00000 \\ 0.0380879 & 1.00000 \\ 0.0364222 & 1.00000 \\ 0.0349409 & 1.00000 \\ 0.0336825 & 1.00000\end{array}$




$\begin{array}{rllllllll}35.0 & 0.0000378 & 38.03 & 70.00 & 62.5000 & 0.0141652 & 0.0073432 & 0.0326366 & 1.00000 \\ 40.0 & 0.0000358 & 38.03 & 70.00 & 62.5000 & 0.0137898 & 0.0071486 & 0.0317718 & 1.00000 \\ 45.0 & 0.0000339 & 38.03 & 70.00 & 62.5000 & 0.0134790 & 0.0069875 & 0.0310555 & 1.00000 \\ 50.0 & 0.0000320 & 38.03 & 70.00 & 62.5000 & 0.0132205 & 0.0068535 & 0.0304601 & 1.00000 \\ 55.0 & 0.0000302 & 38.03 & 70.00 & 62.5000 & 0.0130045 & 0.0067415 & 0.0299624 & 1.00000 \\ 60.0 & 0.0000284 & 38.03 & 70.00 & 62.5000 & 0.0128228 & 0.0066474 & 0.0295438 & 1.00000 \\ 65.0 & 0.0000267 & 38.03 & 70.00 & 62.5000 & 0.0126690 & 0.0065676 & 0.0291893 & 1.00000 \\ 70.0 & 0.0000250 & 38.03 & 70.00 & 62.5000 & 0.0125377 & 0.0064996 & 0.0288869 & 1.00000 \\ 75.0 & 0.0000233 & 38.03 & 70.00 & 62.5000 & 0.0124251 & 0.0064411 & 0.0286273 & 1.00000 \\ 80.0 & 0.0000217 & 38.03 & 70.00 & 62.5000 & 0.0123278 & 0.0063907 & 0.0284032 & 1.00000 \\ 85.0 & 0.0000201 & 38.03 & 70.00 & 62.5000 & 0.0122433 & 0.0063469 & 0.0282086 & 1.00000 \\ 90.0 & 0.0000185 & 38.03 & 70.00 & 62.5000 & 0.0121697 & 0.0063087 & 0.0280389 & 1.00000 \\ 95.0 & 0.0000169 & 38.03 & 70.00 & 62.5000 & 0.0121051 & 0.0062753 & 0.0278903 & 1.00000 \\ 100.0 & 0.0000153 & 38.03 & 70.00 & 62.5000 & 0.0120484 & 0.0062459 & 0.0277596 & 1.00000 \\ 105.0 & 0.0000137 & 38.03 & 70.00 & 62.5000 & 0.0119985 & 0.0062200 & 0.0276444 & 1.00000 \\ 110.0 & 0.0000122 & 38.03 & 70.00 & 62.5000 & 0.0119543 & 0.0061971 & 0.0275426 & 1.00000 \\ 115.0 & 0.0000106 & 38.03 & 70.00 & 62.5000 & 0.0119151 & 0.0061768 & 0.0274524 & 1.00000 \\ 120.0 & 0.0000091 & 38.03 & 70.00 & 62.5000 & 0.0118803 & 0.0061587 & 0.0273722 & 1.00000 \\ 125.0 & 0.0000076 & 38.03 & 70.00 & 62.5000 & 0.0118494 & 0.0061427 & 0.0273009 & 1.00000 \\ 130.0 & 0.0000060 & 38.03 & 70.00 & 62.5000 & 0.0118218 & 0.0061284 & 0.0272374 & 1.00000 \\ 135.0 & 0.0000045 & 38.03 & 70.00 & 62.5000 & 0.0117972 & 0.0061156 & 0.0271806 & 1.00000 \\ 140.0 & 0.0000030 & 38.03 & 70.00 & 62.5000 & 0.0117752 & 0.0061043 & 0.0271301 & 1.00000 \\ 145.0 & 0.0000015 & 38.03 & 70.00 & 62.5000 & 0.0117554 & 0.0060940 & 0.0270845 & 1.00000 \\ 150.0 & 0.0000000 & 38.03 & 70.00 & 62.5000 & 0.0117360 & 0.0060839 & 0.0270397 & 1.00000\end{array}$

calculated fluid conditions at time $=0.0000$ seconds $\begin{array}{ll}\text { charnel } & 8 \\ \text { assembly } & 1\end{array}$

$\begin{array}{rc}\text { distance } & \text { delta-p } \\ \text { (in.) } & \text { (psi) } \\ 0.0 & 0.0000593 \\ 5.0 & 0.0000546 \\ 10.0 & 0.0000507 \\ 15.0 & 0.0000475 \\ 20.0 & 0.0000447 \\ 25.0 & 0.0000422 \\ 30.0 & 0.0000400 \\ 35.0 & 0.0000378 \\ 40.0 & 0.0000358 \\ 45.0 & 0.0000339 \\ 50.0 & 0.0000320 \\ 55.0 & 0.0000302 \\ 60.0 & 0.0000284 \\ 65.0 & 0.0000267 \\ 70.0 & 0.0000250 \\ 75.0 & 0.0000233 \\ 80.0 & 0.0000217 \\ 85.0 & 0.0000201 \\ 90.0 & 0.0000185 \\ 95.0 & 0.0000169 \\ 100.0 & 0.0000153 \\ 105.0 & 0.0000137 \\ 110.0 & 0.0000122 \\ 115.0 & 0.0000106\end{array}$

$\begin{array}{cc}\begin{array}{c}\text { enthalpy } \\ \text { (btu/1b) } \\ 38.03\end{array} & \begin{array}{c}\text { temperature } \\ \text { (deg-f) }\end{array} \\ 38.03 & 70.00 \\ 38.03 & 70.00 \\ 38.03 & 70.00 \\ 38.03 & 70.00 \\ 38.03 & 70.00 \\ 38.03 & 70.00 \\ 38.03 & 70.00 \\ 38.03 & 70.00 \\ 38.03 & 70.00 \\ 38.03 & 70.00 \\ 38.03 & 70.00 \\ 38.03 & 70.00 \\ 38.03 & 70.00 \\ 38.03 & 70.00 \\ 38.03 & 70.00 \\ 38.03 & 70.00 \\ 38.03 & 70.00 \\ 38.03 & 70.00 \\ 38.03 & 70.00 \\ 38.03 & 70.00 \\ 38.03 & 70.00 \\ 38.03 & 70.00 \\ 38.03 & 70.00\end{array}$

$\begin{array}{cc}\begin{array}{c}\text { density } \\ (1 \mathrm{~b} / \mathrm{cu}-\mathrm{ft})\end{array} & \begin{array}{c}\mathrm{flow} \\ (1 \mathrm{~b} / \mathrm{sec})\end{array} \\ 62.5000 & 0.0173611 \\ 62.5000 & 0.0188941 \\ 62.5000 & 0.0192909 \\ 62.5000 & 0.0192268 \\ 62.5000 & 0.0189848 \\ 62.5000 & 0.0186782 \\ 62.5000 & 0.0183631 \\ 62.5000 & 0.0180662 \\ 62.5000 & 0.0177979 \\ 62.5000 & 0.0175606 \\ 62.5000 & 0.0173533 \\ 62.5000 & 0.0171732 \\ 62.5000 & 0.0170170 \\ 62.5000 & 0.0169814 \\ 62.5000 & 0.0167637 \\ 62.5000 & 0.0166610 \\ 62.5000 & 0.0165713 \\ 62.5000 & 0.0164927 \\ 62.5000 & 0.0164236 \\ 62.5000 & 0.0163627 \\ 62.5000 & 0.0163089 \\ 62.5000 & 0.0162612 \\ 62.5000 & 0.0162190 \\ 62.5000 & 0.0161814\end{array}$

mass flux
$(\mathrm{mlb} / \mathrm{hr}-\mathrm{ft}$ t)
0.0090000
0.0097947
0.0100004
0.0099672
0.0098417
0.0096828
0.0095194
0.0093655
0.0092264
0.0091034
0.0089960
0.0089026
0.0088216
0.0087513
0.0086903
0.0086371
0.0085906
0.0085498
0.0085140
0.0084824
0.0084545
0.0084298
0.0084079
0.0083884

$\begin{array}{cc}\begin{array}{c}\text { velocity } \\ \text { (ft/sec) }\end{array} & \begin{array}{c}\text { area } \\ \text { (sq-1n) } \\ 0.0400000\end{array} \\ 1.00000 \\ 0.0435320 & 1.00000 \\ 0.0444462 & 1.00000 \\ 0.0442985 & 1.00000 \\ 0.0437409 & 1.00000 \\ 0.0430346 & 1.00000 \\ 0.0423086 & 1.00000 \\ 0.0416245 & 1.00000 \\ 0.0410063 & 1.00000 \\ 0.0404597 & 1.00000 \\ 0.0399821 & 1.00000 \\ 0.0395670 & 1.00000 \\ 0.0392071 & 1.00000 \\ 0.0388949 & 1.00000 \\ 0.0386235 & 1.00000 \\ 0.0383870 & 1.00000 \\ 0.0381803 & 1.00000 \\ 0.0379992 & 1.00000 \\ 0.0378400 & 1.00000 \\ 0.0376997 & 1.00000 \\ 0.0375757 & 1.00000 \\ 0.0374659 & 1.00000 \\ 0.0373685 & 1.00000 \\ 0.0372819 & 1.00000\end{array}$




$\begin{array}{lllllllll}120.0 & 0.0000091 & 38.03 & 70.00 & 62.5000 & 0.0161479 & 0.0083711 & 0.0372047 & 1.00000 \\ 125.0 & 0.0000076 & 38.03 & 70.00 & 62.5000 & 0.0161180 & 0.0083556 & 0.0371359 & 1.00000 \\ 130.0 & 0.0000060 & 38.03 & 70.00 & 62.5000 & 0.0160914 & 0.0083418 & 0.0370745 & 1.00000 \\ 135.0 & 0.0000045 & 38.03 & 70.00 & 62.5000 & 0.0160675 & 0.0083294 & 0.0370196 & 1.00000 \\ 140.0 & 0.0000030 & 38.03 & 70.00 & 62.5000 & 0.0160462 & 0.0083384 & 0.0369705 & 1.00000 \\ 145.0 & 0.0000015 & 38.03 & 70.00 & 62.5000 & 0.0160268 & 0.0083083 & 0.0369259 & 1.00000 \\ 150.0 & 0.0000000 & 38.03 & 70.00 & 62.5000 & 0.0160095 & 0.0082993 & 0.0368858 & 1.00000\end{array}$

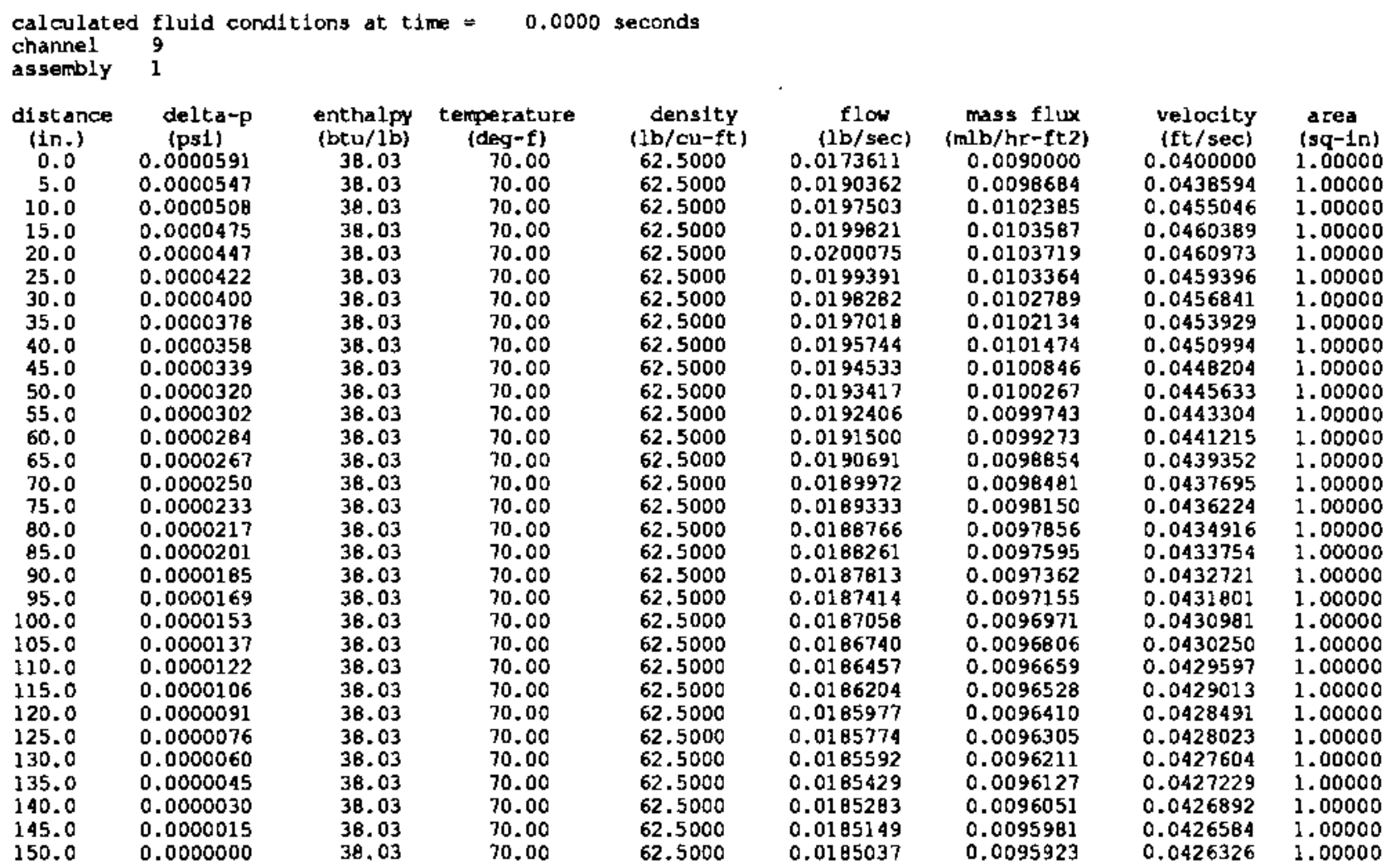

calculated fluid conditions at time $=0.0000$ seconds channel 10

\begin{tabular}{|c|c|c|c|c|c|c|c|c|}
\hline $\begin{array}{l}\text { dist ance } \\
\text { (in.) } \\
0.0\end{array}$ & $\begin{array}{c}\text { delta-p } \\
\text { (psi) } \\
0.0000590\end{array}$ & $\begin{array}{c}\text { enthalpy } \\
\{\text { btu/1b\} } \\
38.03\end{array}$ & $\begin{array}{c}\text { temperature } \\
\text { (deg-f) } \\
70.00\end{array}$ & $\begin{array}{c}\text { density } \\
\{1 b / c u-f t\} \\
62.5000\end{array}$ & $\begin{array}{c}\text { flow } \\
(1 \mathrm{~b} / \mathrm{sec}) \\
0.0173611\end{array}$ & $\begin{array}{c}\text { mass f1ux } \\
(\mathrm{mlb} / \mathrm{hr}-\mathrm{ft} 2) \\
0.0090000\end{array}$ & $\begin{array}{r}\text { veloc1ty } \\
\text { (ft/sec) } \\
0.0400000\end{array}$ & $\begin{array}{l}\text { ared } \\
(s q-1 n) \\
1.00000\end{array}$ \\
\hline
\end{tabular}




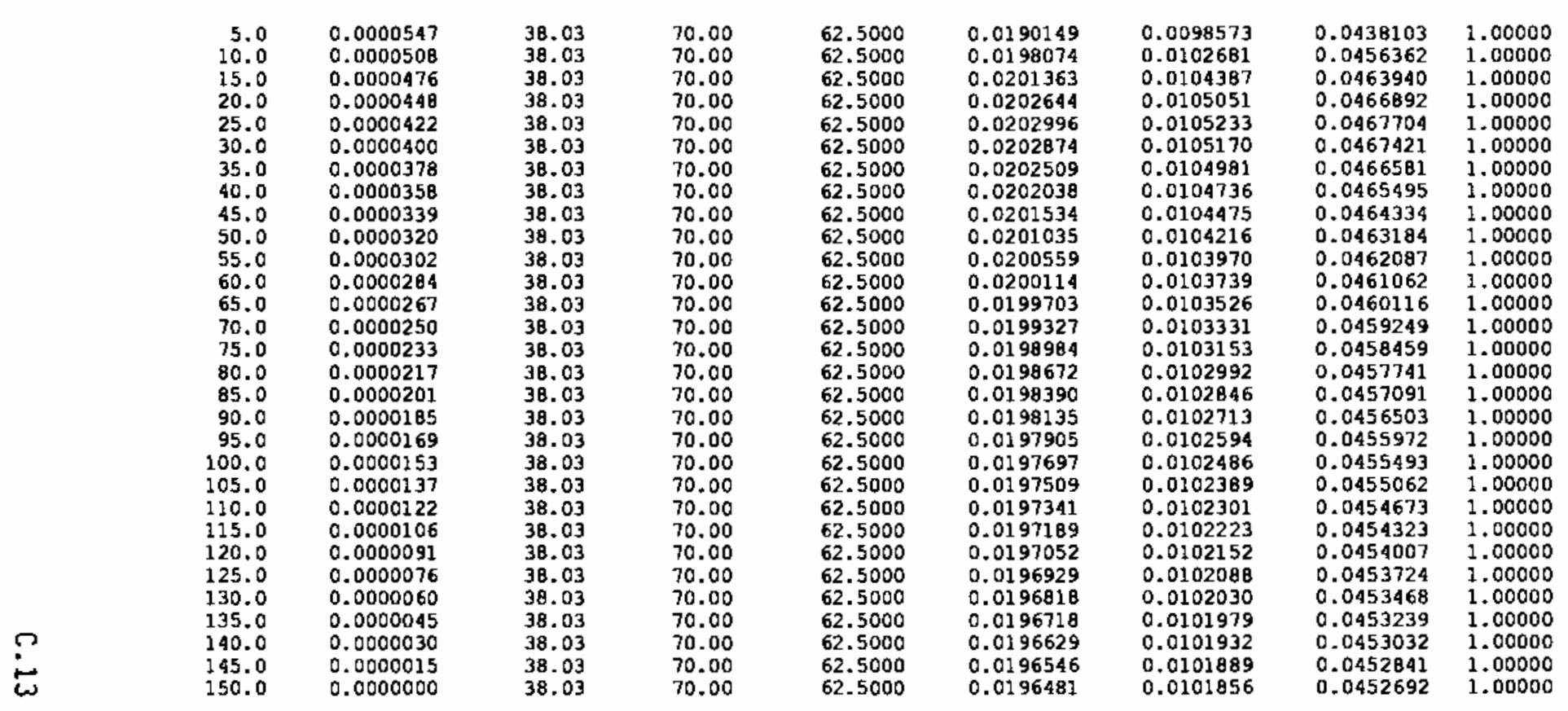

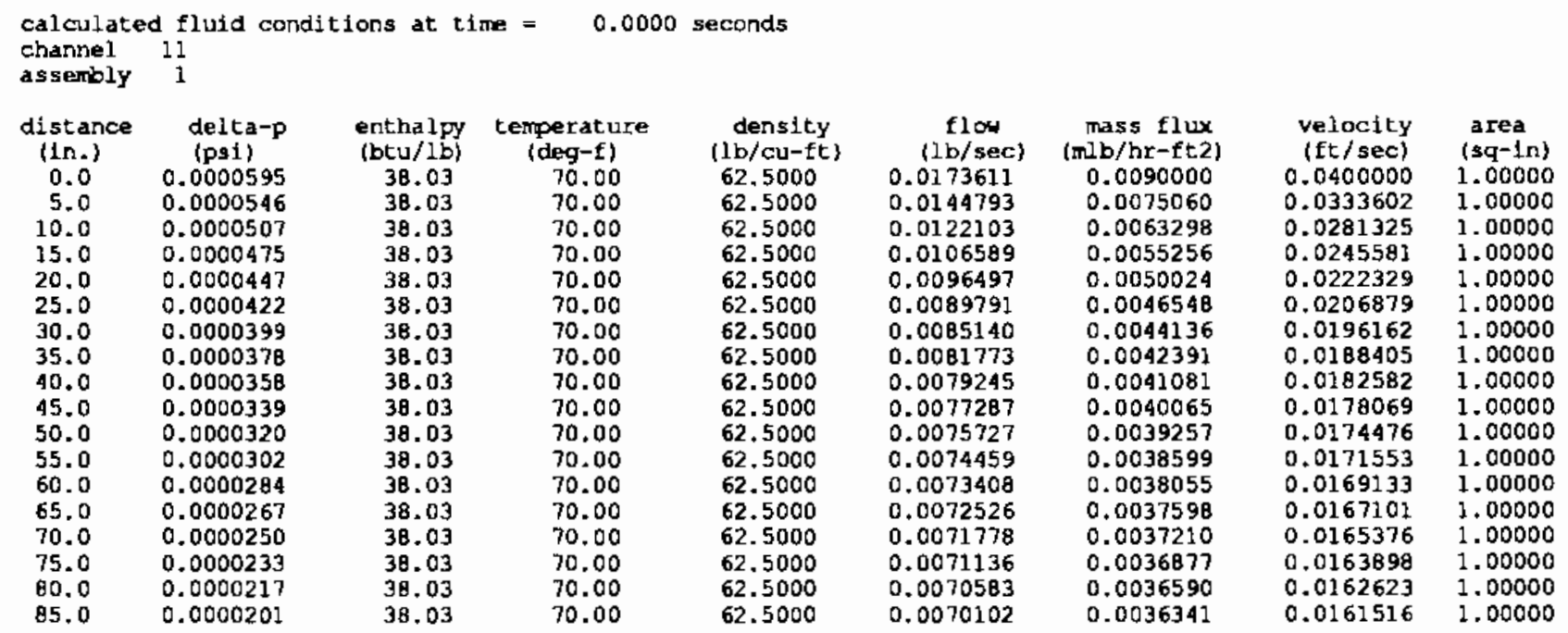




$\begin{array}{rllllllll}90.0 & 0.0000185 & 38.03 & 70.00 & 62.5000 & 0.0069683 & 0.0036124 & 0.0160550 & 1.00000 \\ 95.0 & 0.0000169 & 38.03 & 70.00 & 62.5000 & 0.0069315 & 0.0035933 & 0.0159703 & 1.00000 \\ 100.0 & 0.0000153 & 38.03 & 70.00 & 62.5000 & 0.0068992 & 0.0035766 & 0.0158958 & 1.00000 \\ 105.0 & 0.0000137 & 38.03 & 70.00 & 62.5000 & 0.0069707 & 0.0035618 & 0.0158301 & 1.00000 \\ 110.0 & 0.0000122 & 38.03 & 70.00 & 62.5000 & 0.0068455 & 0.0035487 & 0.0157719 & 1.00000 \\ 115.0 & 0.0000106 & 38.03 & 70.00 & 62.5000 & 0.0068231 & 0.0035371 & 0.0157204 & 1.00000 \\ 120.0 & 0.0000091 & 38.03 & 70.00 & 62.5000 & 0.0068032 & 0.0035268 & 0.0156746 & 1.00000 \\ 125.0 & 0.0000076 & 38.03 & 70.00 & 62.5000 & 0.0067855 & 0.0035176 & 0.0156338 & 1.00000 \\ 130.0 & 0.0000060 & 38.03 & 70.00 & 62.5000 & 0.0067697 & 0.0035094 & 0.0155974 & 1.00000 \\ 135.0 & 0.0000045 & 38.03 & 70.00 & 62.5000 & 0.0067556 & 0.0035021 & 0.0155650 & 1.00000 \\ 140.0 & 0.0000030 & 38.03 & 70.00 & 62.5000 & 0.0067430 & 0.0034956 & 0.0155360 & 1.00000 \\ 145.0 & 0.0000015 & 38.03 & 70.00 & 62.5000 & 0.0067319 & 0.0034898 & 0.0155103 & 1.00000 \\ 150.0 & 0.0000000 & 38.03 & 70.00 & 62.5000 & 0.0067197 & 0.0034835 & 0.0154822 & 1.00000\end{array}$

calculated fluid conditions at time $=0.0000$ seconds channel 12

$\begin{array}{cc}\text { distance } & \begin{array}{c}\text { delta-p } \\ \text { (in.) }\end{array} \\ 0.0 & 0.00005593 \\ 5.0 & 0.0000546 \\ 10.0 & 0.0000507 \\ 15.0 & 0.0000475 \\ 20.0 & 0.0000447 \\ 25.0 & 0.0000422 \\ 30.0 & 0.0000400 \\ 35.0 & 0.0000378 \\ 40.0 & 0.0000358 \\ 45.0 & 0.0000339 \\ 50.0 & 0.0000320 \\ 55.0 & 0.0000302 \\ 60.0 & 0.0000284 \\ 65.0 & 0.0000267 \\ 70.0 & 0.0000250 \\ 75.0 & 0.0000233 \\ 80.0 & 0.0000217 \\ 85.0 & 0.0000201 \\ 90.0 & 0.0000185 \\ 95.0 & 0.0000169 \\ 100.0 & 0.0000153 \\ 105.0 & 0.0000137 \\ 110.0 & 0.0000122 \\ 115.0 & 0.0000106 \\ 120.0 & 0.0000091 \\ 125.0 & 0.0000076 \\ 130.0 & 0.0000060 \\ 135.0 & 0.0000045 \\ 140.0 & 0.0000030 \\ 145.0 & 0.0000015 \\ 150.0 & 0.0000000\end{array}$

$\begin{array}{cc}\begin{array}{c}\text { enthalpy } \\ \text { (btu/lb) }\end{array} & \begin{array}{c}\text { temperature } \\ \text { (deg-f) }\end{array} \\ 38.03 & 70.00 \\ 38.03 & 70.00 \\ 38.03 & 70.00 \\ 38.03 & 70.00 \\ 38.03 & 70.00 \\ 38.03 & 70.00 \\ 38.03 & 70.00 \\ 38.03 & 70.00 \\ 38.03 & 70.00 \\ 38.03 & 70.00 \\ 38.03 & 70.00 \\ 38.03 & 70.00 \\ 38.03 & 70.00 \\ 38.03 & 70.00 \\ 38.03 & 70.00 \\ 38.03 & 70.00 \\ 38.03 & 70.00 \\ 38.03 & 70.00 \\ 38.03 & 70.00 \\ 38.03 & 70.00 \\ 38.03 & 70.00 \\ 38.03 & 70.00 \\ 38.03 & 70.00 \\ 38.03 & 70.00 \\ 38.03 & 70.00 \\ 38.03 & 70.00 \\ 38.03 & 70.00 \\ 38.03 & 70.00 \\ 38.03 & 70.00 \\ 38.03 & 70.00 \\ 38.03 & 70.00\end{array}$

$\begin{array}{lcc}\begin{array}{c}\text { density } \\ (\text { b/cu-ft })\end{array} & \begin{array}{c}\text { flow } \\ (1 \mathrm{~b} / \mathrm{sec})\end{array} & \begin{array}{c}\text { mass flux } \\ \text { (mlb/hr-ft2) }\end{array} \\ 62.5000 & 0.0173611 & 0.0090000 \\ 62.5000 & 0.0188941 & 0.0097947 \\ 62.5000 & 0.0192909 & 0.0100004 \\ 62.5000 & 0.0192268 & 0.0099672 \\ 62.5000 & 0.0189848 & 0.0098417 \\ 62.5000 & 0.0186782 & 0.0096828 \\ 62.5000 & 0.0183631 & 0.0095194 \\ 62.5000 & 0.0180662 & 0.0093655 \\ 62.5000 & 0.0177979 & 0.0092264 \\ 62.5000 & 0.0175606 & 0.0091034 \\ 62.5000 & 0.0173533 & 0.0089960 \\ 62.5000 & 0.0171732 & 0.0089026 \\ 62.5000 & 0.0170170 & 0.0088216 \\ 62.5000 & 0.0168814 & 0.0087513 \\ 62.5000 & 0.0167637 & 0.0086903 \\ 62.5000 & 0.0166610 & 0.0086371 \\ 62.5000 & 0.0165713 & 0.0085906 \\ 62.5000 & 0.0164977 & 0.0085498 \\ 62.5000 & 0.0164236 & 0.0085140 \\ 62.5000 & 0.0163627 & 0.0084824 \\ 62.5000 & 0.0163089 & 0.0084545 \\ 62.5000 & 0.0162612 & 0.0084298 \\ 62.5000 & 0.0162190 & 0.0084079 \\ 62.5000 & 0.0161814 & 0.0083884 \\ 62.5000 & 0.0161479 & 0.0083711 \\ 62.5000 & 0.0161180 & 0.0083556 \\ 62.5000 & 0.0160914 & 0.0083418 \\ 62.5000 & 0.0160675 & 0.0083294 \\ 62.5000 & 0.0160462 & 0.0083184 \\ 62.5000 & 0.0160268 & 0.0083083 \\ 62.5000 & 0.0160095 & 0.0082993\end{array}$

$\begin{array}{cc}\begin{array}{c}\text { velocity } \\ \text { (ft } / \text { sec) }\end{array} & \begin{array}{c}\text { area } \\ \text { (sq-1n) }\end{array} \\ 0.0400000 & 1.00000 \\ 0.0435320 & 1.00000 \\ 0.0444462 & 1.00000 \\ 0.0442985 & 1.00000 \\ 0.0437409 & 1.00000 \\ 0.0430346 & 1.00000 \\ 0.0423086 & 1.00000 \\ 0.0416245 & 1.00000 \\ 0.0410063 & 1.00000 \\ 0.0404597 & 1.00000 \\ 0.0399821 & 1.00000 \\ 0.0395670 & 1.00000 \\ 0.0392071 & 1.00000 \\ 0.0388949 & 1.00000 \\ 0.0386235 & 1.00000 \\ 0.0383870 & 1.00000 \\ 0.0381803 & 1.00000 \\ 0.0379992 & 1.00000 \\ 0.0378400 & 1.00000 \\ 0.0376997 & 1.000000 \\ 0.0375757 & 1.00000 \\ 0.0374659 & 1.00000 \\ 0.0373685 & 1.00000 \\ 0.0372819 & 1.00000 \\ 0.0372047 & 1.00000 \\ 0.0371359 & 1.00000 \\ 0.0370745 & 1.00000 \\ 0.0370196 & 1.00000 \\ 0.0369705 & 1.00000 \\ 0.0369259 & 1.00000 \\ 0.0368858 & 1.00000 \\ 0 & \end{array}$

calculated fluld conditions at time $=0.0000$ seconds 


\begin{tabular}{|c|c|c|c|c|c|c|c|c|c|}
\hline & $\begin{array}{l}\text { channel } \\
\text { assembly }\end{array}$ & $\begin{array}{r}13 \\
3\end{array}$ & & & & & & & \\
\hline & $\begin{array}{l}\text { calculate } \\
\text { channel } \\
\text { assembly }\end{array}$ & $\begin{array}{l}d \text { flute con } \\
14 \\
1\end{array}$ & $s$ at $t$ & 0.000 & seconds & & & & \\
\hline & $\begin{array}{c}\text { distance } \\
\text { (in.) } \\
0.0 \\
5.0 \\
10.0 \\
15.0 \\
20.0 \\
25.0 \\
30.0 \\
35.0 \\
40.0 \\
45.0 \\
50.0 \\
55.0\end{array}$ & $\begin{array}{l}\text { delta-p } \\
\text { (psi) } \\
0.0000589 \\
0.0000547 \\
0.0000508 \\
0.0000476 \\
0.0000448 \\
0.0000423 \\
0.0000400 \\
0.0000378 \\
0.0000358 \\
0.0000339 \\
0.0000320 \\
0.0000302\end{array}$ & $\begin{array}{c}\text { enthalpy } \\
\text { (btu/lb) } \\
38.03 \\
38.03 \\
38.03 \\
38.03 \\
38.03 \\
38.03 \\
38.03 \\
38.03 \\
38.03 \\
38.03 \\
38.03 \\
38.03\end{array}$ & 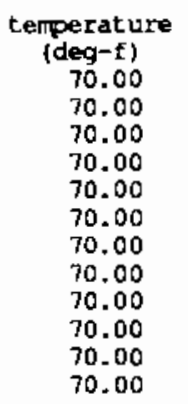 & $\begin{array}{c}\text { density } \\
(1 \mathrm{~b} / \mathrm{cu}+\mathrm{ft}) \\
62.5000 \\
62.5000 \\
62.5000 \\
62.5000 \\
62.5000 \\
62.5000 \\
62.5000 \\
62.5000 \\
62.5000 \\
62.5000 \\
62.5000 \\
62.5000\end{array}$ & $\begin{array}{l}\begin{array}{c}f l o w \\
(1 \mathrm{~b} / \mathrm{sec})\end{array} \\
0.0173611 \\
0.0200330 \\
0.0218934 \\
0.0230785 \\
0.0238604 \\
0.0243923 \\
0.0247618 \\
0.0250229 \\
0.0252100 \\
0.0253461 \\
0.0254461 \\
0.0255205\end{array}$ & $\begin{array}{c}\text { mass flux } \\
(\mathrm{mlb} / \mathrm{hr}-\mathrm{ft} 2) \\
0.0090000 \\
0.0103851 \\
0.0113495 \\
0.0119639 \\
0.0123692 \\
0.0126450 \\
0.0128365 \\
0.0129719 \\
0.0130689 \\
0.0131394 \\
0.0131913 \\
0.0132298\end{array}$ & $\begin{array}{l}\text { velocity } \\
\text { (ft/sec) } \\
0.0400000 \\
0.0461561 \\
0.0504424 \\
0.0531729 \\
0.0549744 \\
0.0561999 \\
0.0570512 \\
0.0576527 \\
0.0580840 \\
0.0583973 \\
0.0586278 \\
0.0587992\end{array}$ & $\begin{array}{l}\text { area } \\
\text { (sq-in) } \\
1.00000 \\
1.00000 \\
1.00000 \\
1.00000 \\
1.00000 \\
1.00000 \\
1.00000 \\
1.00000 \\
1.00000 \\
1.00000 \\
1.00000 \\
1.00000\end{array}$ \\
\hline
\end{tabular}




$\begin{array}{lllllllll}60.0 & 0.0000284 & 38.03 & 70.00 & 62.5000 & 0.0255764 & 0.0132588 & 0.0589281 & 1.00000 \\ 65.0 & 0.0000267 & 38.03 & 70.00 & 62.5000 & 0.0256189 & 0.0132809 & 0.0590260 & 1.00000 \\ 70.0 & 0.0000250 & 38.03 & 70.00 & 62.5000 & 0.0256515 & 0.0132978 & 0.0591011 & 1.00000 \\ 75.0 & 0.0000233 & 38.03 & 70.00 & 62.5000 & 0.0256768 & 0.0133108 & 0.0591593 & 1.00000 \\ 80.0 & 0.0000217 & 38.03 & 70.00 & 62.5000 & 0.0256965 & 0.0133211 & 0.0592047 & 1.00000 \\ 85.0 & 0.0000201 & 38.03 & 70.00 & 62.5000 & 0.0257120 & 0.0133291 & 0.0592405 & 1.00000 \\ 90.0 & 0.0000185 & 38.03 & 70.00 & 62.5000 & 0.0257244 & 0.0133355 & 0.0592690 & 1.00000 \\ 95.0 & 0.0000169 & 38.03 & 70.00 & 62.5000 & 0.0257343 & 0.0133406 & 0.0592918 & 1.00000 \\ 100.0 & 0.0000153 & 38.03 & 70.00 & 62.5000 & 0.0257423 & 0.0133448 & 0.0593102 & 1.00000 \\ 105.0 & 0.0000137 & 38.03 & 70.00 & 62.5000 & 0.0257487 & 0.0133481 & 0.0593251 & 1.00000 \\ 110.0 & 0.0000122 & 38.03 & 70.00 & 62.5000 & 0.0257541 & 0.0133509 & 0.0593373 & 1.00000 \\ 115.0 & 0.0000106 & 38.03 & 70.00 & 62.5000 & 0.0257584 & 0.0133532 & 0.0593474 & 1.00000 \\ 120.0 & 0.0000091 & 38.03 & 70.00 & 62.5000 & 0.0257621 & 0.0133550 & 0.0593558 & 1.00000 \\ 125.0 & 0.0000076 & 38.03 & 70.00 & 62.5000 & 0.0257651 & 0.0133566 & 0.0593627 & 1.00000 \\ 130.0 & 0.0000060 & 38.03 & 70.00 & 62.5000 & 0.0257676 & 0.0133579 & 0.0593685 & 1.00000 \\ 135.0 & 0.0000045 & 38.03 & 70.00 & 62.5000 & 0.0257697 & 0.0133590 & 0.0593734 & 1.00000 \\ 140.0 & 0.0000030 & 38.03 & 70.00 & 62.5000 & 0.0257715 & 0.0133599 & 0.0593775 & 1.00000 \\ 145.0 & 0.0000015 & 38.03 & 70.00 & 62.5000 & 0.0257729 & 0.0133607 & 0.0593808 & 1.00000 \\ 150.0 & 0.0000000 & 38.03 & 70.00 & 62.5000 & 0.0257767 & 0.0133626 & 0.0593894 & 1.00000\end{array}$

calculated fluld conditions at time $\# 0.0000$ seconds channel 15

家

$\begin{array}{cccc}\begin{array}{c}\text { distance } \\ \text { (1n.) }\end{array} & \begin{array}{c}\text { delta-p } \\ \text { (ps1) }\end{array} & \begin{array}{c}\text { enthalpy } \\ \text { (btu } 1 \text { lb) }\end{array} & \begin{array}{r}\text { temperature } \\ \text { (deg-f) }\end{array} \\ 5.0 & 0.000058 B & 38.03 & 70.00 \\ 10.0 & 0.0000547 & 38.03 & 70.00 \\ 15.0 & 0.0000509 & 38.03 & 70.00 \\ 20.0 & 0.0000476 & 38.03 & 70.00 \\ 25.0 & 0.0000448 & 38.03 & 70.00 \\ 30.0 & 0.0000423 & 38.03 & 70.00 \\ 35.0 & 0.0000400 & 38.03 & 70.00 \\ 40.0 & 0.0000378 & 38.03 & 70.00 \\ 45.0 & 0.0000358 & 38.03 & 70.00 \\ 50.0 & 0.0000339 & 38.03 & 70.00 \\ 55.0 & 0.0000302 & 38.03 & 70.00 \\ 60.0 & 0.0000284 & 38.03 & 70.00 \\ 65.0 & 0.0000267 & 38.03 & 70.00 \\ 70.0 & 0.0000250 & 38.03 & 70.00 \\ 75.0 & 0.0000233 & 38.03 & 70.00 \\ 80.0 & 0.0000217 & 38.03 & 70.00 \\ 85.0 & 0.0000201 & 38.03 & 70.00 \\ 90.0 & 0.0000185 & 38.03 & 70.00 \\ 95.0 & 0.0000169 & 38.03 & 70.00 \\ 100.0 & 0.0000153 & 38.03 & 70.00 \\ 105.0 & 0.0000137 & 38.03 & 70.00 \\ 110.0 & 0.0000122 & 38.03 & 70.00 \\ 115.0 & 0.0000106 & 38.03 & 70.00 \\ 120.0 & 0.0000091 & 38.03 & 70.00 \\ 125.0 & 0.0000076 & 38.03 & 70.00 \\ 130.0 & 0.0000060 & 38.03 & 70.00 \\ 135.0 & 0.0000045 & 38.03 & 70.00 \\ 140.0 & 0.0000030 & 38.03 & 70.00\end{array}$

density

$(\mathrm{lb} / \mathrm{cu}-\mathrm{ft})$

62.5000
62.5000

62.5000

62.5000

62.5000

62.5000

62.5000

62.5000

62.5000

62.5000

62.5000

62.5000

62.5000

62.5000

62.5000

62.5000

62.5000

62.5000

62.5000

62.5000

62.5000

62.5000

62.5000

62.5000

62.5000

62.5000

62.5000

62.5000

62.5000 (1b/sec) 0.0200206 0.0219705 0.0232701 0.0241759 0.0248357 0.0253314 .0260126 0.0262520 0.0264460 0.0266051 0.0267368 0.0268469 .0269395 0.0270180 0.0270850 0.0271424 0.0271920 0.0272349 ..0272722 0.0273048 0.0273333 0.0273585 0.0273806 0.0274002 0.0274175 0.0274329 mass flux 0.0090000 0.0103787 0.0113895 0.0120632 0.0128748 0.0131318 0.0133296 0.0134849 0.0136090 0.0137096 0.0137921 0.0138604 0.0139174 0.0139654 0.0140409 0.0140706 0.0140963 0.0141186 0.0141379 0.0141548 0.0141696 0.0141941 0.0142043 0.0142133 0.0142212 (ft/sec) (sq-in 0.04000001 .00000 1.00000 1.00000 1.00000 $0.0572214 \quad 1.00000$ $0.0583635 \quad 1.00000$ $0.0592426 \quad 1.00000$ $0.0599330 \quad 1.00000$ $0.0604846 \quad 1.00000$ $0.0632981 \quad 1.00000$ $0.0616016 \quad 1.00000$ 0.06185521 .00000 0.06206861 .00000 0.06224951 .00000 $0.0624038 \quad 1.00000$ $0.0625362 \quad 1.00000$ $0.0626503 \quad 1.00000$ $0.0627491 \quad 1.00000$ 0.06283511 .00000 1.00000 $0.0629760 \quad 1.00000$ 0.06303391 .00000 $0.0630849 \quad 1.00000$ 0.06313001 .00000 $0.0631700 \quad 1.00000$ $0.0632370 \quad 1.0000$ 


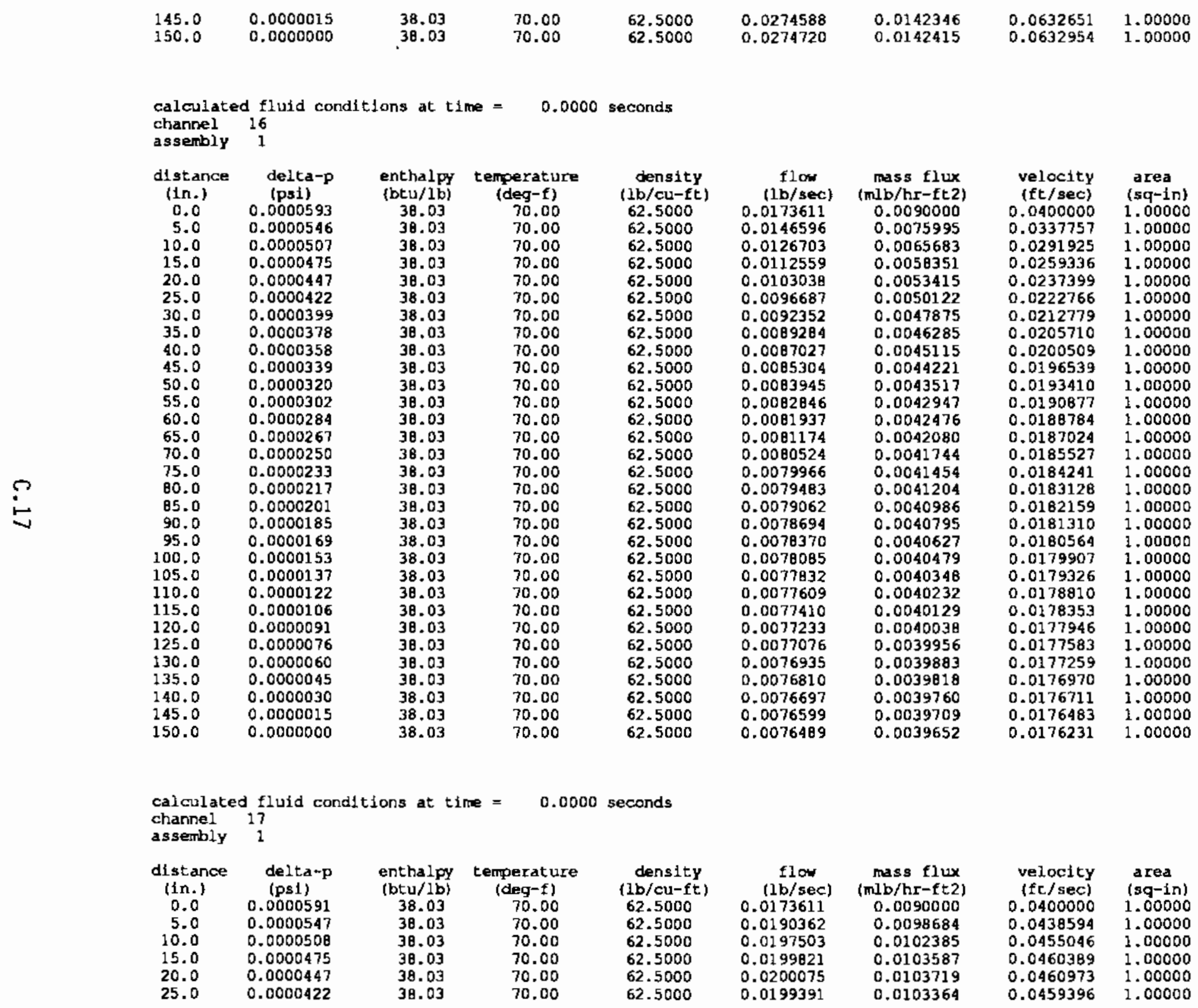




$\begin{array}{rllllllll}30.0 & 0.0000400 & 38.03 & 70.00 & 62.5000 & 0.0198282 & 0.0102789 & 0.0456841 & 1.00000 \\ 35.0 & 0.0000378 & 38.03 & 70.00 & 62.5000 & 0.0197018 & 0.0102134 & 0.0453929 & 1.000000 \\ 40.0 & 0.0000358 & 38.03 & 70.00 & 62.5000 & 0.0195744 & 0.0101474 & 0.0450994 & 1.000000 \\ 45.0 & 0.0000339 & 38.03 & 70.00 & 62.5000 & 0.0194533 & 0.0100846 & 0.0448204 & 1.00000 \\ 50.0 & 0.0000320 & 38.03 & 70.00 & 62.5000 & 0.0193417 & 0.0100267 & 0.0445633 & 1.00000 \\ 55.0 & 0.0000302 & 38.03 & 70.00 & 62.5000 & 0.0192406 & 0.0099743 & 0.0443304 & 1.00000 \\ 60.0 & 0.0000284 & 38.03 & 70.00 & 62.5000 & 0.0191500 & 0.0099273 & 0.0441215 & 1.000000 \\ 65.0 & 0.0000267 & 38.03 & 70.00 & 62.5000 & 0.0190691 & 0.0098854 & 0.0439352 & 1.000000 \\ 70.0 & 0.0000250 & 38.03 & 70.00 & 62.5000 & 0.0189972 & 0.0098481 & 0.0437695 & 1.00000 \\ 75.0 & 0.0000233 & 38.03 & 70.00 & 62.5000 & 0.0189333 & 0.0096150 & 0.0436224 & 1.000000 \\ 80.0 & 0.0000217 & 38.03 & 70.00 & 62.5000 & 0.0188766 & 0.0097856 & 0.0434916 & 1.000000 \\ 85.0 & 0.0000201 & 38.03 & 70.00 & 62.5000 & 0.0188261 & 0.0097595 & 0.0433754 & 1.000000 \\ 90.0 & 0.0000185 & 38.03 & 70.00 & 62.5000 & 0.0187813 & 0.0097362 & 0.0432721 & 1.000000 \\ 95.0 & 0.0000169 & 38.03 & 70.00 & 62.5000 & 0.0187414 & 0.0097155 & 0.0431801 & 1.000000 \\ 100.0 & 0.0000153 & 38.03 & 70.00 & 62.5000 & 0.0187058 & 0.0096971 & 0.0430981 & 1.00000 \\ 105.0 & 0.0000137 & 38.03 & 70.00 & 62.5000 & 0.0186740 & 0.0096806 & 0.0430250 & 1.00000 \\ 110.0 & 0.0000122 & 38.03 & 70.00 & 62.5000 & 0.0186457 & 0.0096659 & 0.0429597 & 1.00000 \\ 115.0 & 0.0000106 & 38.03 & 70.00 & 62.5000 & 0.0186204 & 0.0096528 & 0.0429013 & 1.00000 \\ 120.0 & 0.0000091 & 38.03 & 70.00 & 62.5000 & 0.0185977 & 0.0096410 & 0.0428491 & 1.00000 \\ 125.0 & 0.0000076 & 38.03 & 70.00 & 62.5000 & 0.0185774 & 0.0096305 & 0.0428023 & 1.00000 \\ 130.0 & 0.0000060 & 38.03 & 70.00 & 62.5000 & 0.0185592 & 0.0096211 & 0.0427604 & 1.00000 \\ 135.0 & 0.0000045 & 38.03 & 70.00 & 62.5000 & 0.0185429 & 0.0096127 & 0.0427229 & 1.00000 \\ 140.0 & 0.00000030 & 38.03 & 70.00 & 62.5000 & 0.0185283 & 0.0096051 & 0.0426892 & 1.00000 \\ 145.0 & 0.0000015 & 38.03 & 70.00 & 62.5000 & 0.0185149 & 0.0095981 & 0.0426584 & 1.00000 \\ 150.0 & 0.0000000 & 38.03 & 70.00 & 62.5000 & 0.0185037 & 0.0095923 & 0.0426326 & 1.00000\end{array}$
as sembly 1

$\begin{array}{cc}\text { distance } & \text { delta-p } \\ \text { (1n.) } & \text { (psi) } \\ 0.0 & 0.0000589 \\ 5.0 & 0.0000547 \\ 10.0 & 0.0000508 \\ 15.0 & 0.0000476 \\ 20.0 & 0.0000448 \\ 25.0 & 0.0000423 \\ 30.0 & 0.0000400 \\ 35.0 & 0.0000378 \\ 40.0 & 0.0000358 \\ 45.0 & 0.0000339 \\ 50.0 & 0.0000320 \\ 55.0 & 0.0000302 \\ 60.0 & 0.0000284 \\ 65.0 & 0.0000267 \\ 70.0 & 0.0000250 \\ 75.0 & 0.0000233 \\ 80.0 & 0.0000217 \\ 85.0 & 0.0000201 \\ 90.0 & 0.0000185 \\ 95.0 & 0.0000169 \\ 100.0 & 0.0000153 \\ 105.0 & 0.0000137 \\ 110.0 & 0.0000122\end{array}$

$\begin{array}{cc}\begin{array}{c}\text { enthalpy } \\ \text { (btu/lb) } \\ 38.03\end{array} & \begin{array}{c}\text { tenperature } \\ \text { (deg-f) }\end{array} \\ 38.03 & 70.00 \\ 38.03 & 70.00 \\ 38.03 & 70.00 \\ 38.03 & 70.00 \\ 38.03 & 70.00 \\ 38.03 & 70.00 \\ 38.03 & 70.00 \\ 38.03 & 70.00 \\ 38.03 & 70.00 \\ 38.03 & 70.00 \\ 38.03 & 70.00 \\ 38.03 & 70.00 \\ 38.03 & 70.00 \\ 38.03 & 70.00 \\ 38.03 & 70.00 \\ 38.03 & 70.00 \\ 38.03 & 70.00 \\ 38.03 & 70.00 \\ 38.03 & 70.00 \\ 38.03 & 70.00 \\ 38.03 & 70.00 \\ 38.03 & 70.00\end{array}$

density \{1b/cu-ft 62.5000 62.5000 62.5000 62.5000 62.5000 62.5000 62.5000 62.5000 62.5000 62.5000 62.5000 62.5000 62.5000 62.5000 62.5000 62.5000 62.5000 62.5000 62.5000 62.5000 62.5000 62.5000 flow $(1 \mathrm{~b} / \mathrm{sec})$
0.0173611 0.0200330 0.0218934 0.0230785 0.0238604 0.0243923 0.0247618 0.0250229 0.0252100 0.0253461 0.0254461 0.0255205 0.0255764 0.0256189 0.0256515 0.0256768 0.0256965 0.0257120 0.0257244 0.0257423 0.025748 ? 0.0257541

$\begin{array}{ccc}\begin{array}{c}\text { mass flux } \\ \text { (mlb/hr-ft2) } \\ 0.0090000\end{array} & \begin{array}{c}\text { velocity } \\ \text { (ft/sec) }\end{array} & \begin{array}{c}\text { area } \\ (s q-1 \mathrm{~s})\end{array} \\ 0.0103851 & 0.0460000 & 1.00000 \\ 0.0113495 & 0.0504424 & 1.00000 \\ 0.0119639 & 0.0531729 & 1.00000 \\ 0.0123692 & 0.0549744 & 1.00000 \\ 0.0126450 & 0.0561999 & 1.00000 \\ 0.0128365 & 0.0570512 & 1.00000 \\ 0.0129719 & 0.0576527 & 1.00000 \\ 0.0130689 & 0.0580840 & 1.00000 \\ 0.0131394 & 0.0583973 & 1.00000 \\ 0.0131913 & 0.0586278 & 1.00000 \\ 0.0132298 & 0.0587992 & 1.00000 \\ 0.0132588 & 0.0589281 & 1.00000 \\ 0.0132809 & 0.0590260 & 1.00000 \\ 0.0132978 & 0.0591011 & 1.00000 \\ 0.0133108 & 0.0591593 & 1.00000 \\ 0.0133211 & 0.0592047 & 1.00000 \\ 0.0133291 & 0.0592405 & 1.00000 \\ 0.0133355 & 0.0592690 & 1.00000 \\ 0.0133406 & 0.0592918 & 1.00000 \\ 0.0133448 & 0.0593102 & 1.00000 \\ 0.0133481 & 0.0593251 & 1.00000 \\ 0.0133509 & 0.0593373 & 1.00000\end{array}$




$\begin{array}{lllllllll}115.0 & 0.0000106 & 38.03 & 70.00 & 62.5000 & 0.0257584 & 0.0133532 & 0.0593474 & 1.00000 \\ 120.0 & 0.0000091 & 38.03 & 70.00 & 62.5000 & 0.0257611 & 0.0133550 & 0.0593558 & 1.00000 \\ 125.0 & 0.0000076 & 38.03 & 70.00 & 62.5000 & 0.0257651 & 0.0133566 & 0.0593627 & 1.00000 \\ 130.0 & 0.0000060 & 38.03 & 70.00 & 62.5000 & 0.0257676 & 0.0133579 & 0.0593685 & 1.00000 \\ 135.0 & 0.0000045 & 38.03 & 70.00 & 62.5000 & 0.0257697 & 0.0133590 & 0.0593734 & 1.00000 \\ 140.0 & 0.0000030 & 38.03 & 70.00 & 62.5000 & 0.0257715 & 0.0133599 & 0.0593775 & 1.00000 \\ 345.0 & 0.0000015 & 38.03 & 70.00 & 62.5000 & 0.0257729 & 0.0133607 & 0.0593808 & 1.00000 \\ 150.0 & 0.0000000 & 38.03 & 70.00 & 62.5000 & 0.0257767 & 0.0133626 & 0.0593894 & 1.00000\end{array}$

calculated fluid conditions at time $=0.0000$ seconds $\begin{array}{lr}\text { channel } & 19 \\ \text { assembly } & 1\end{array}$

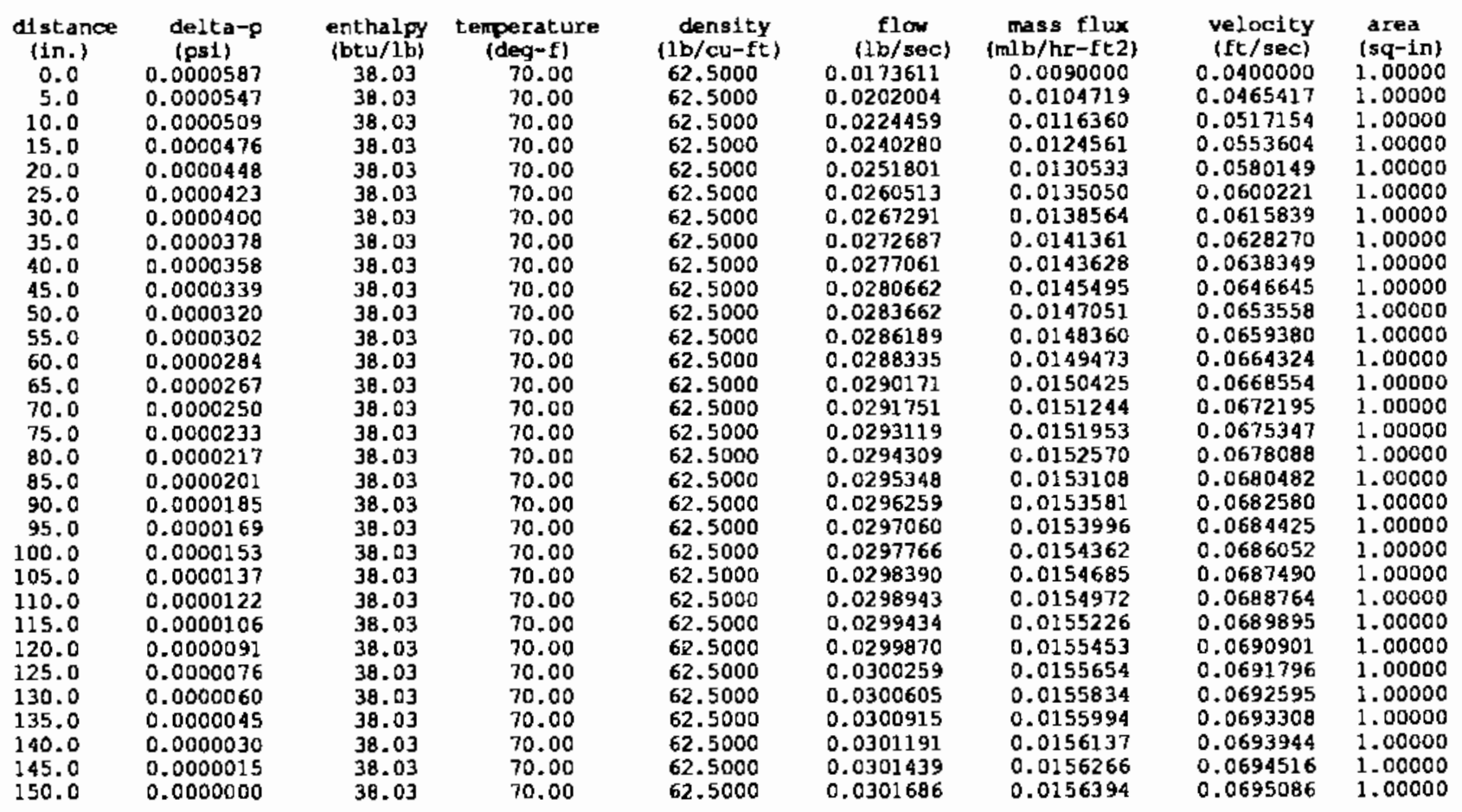

calculated fluid conditions at time $=0.0000$ seconds channel 20

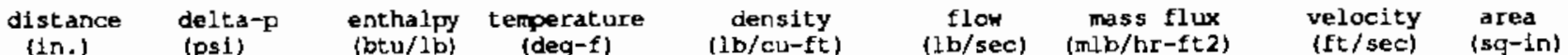




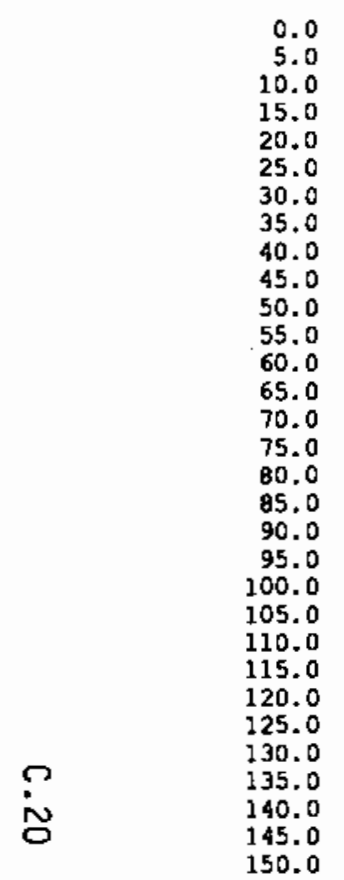

$\begin{array}{llll}0.0000586 & 38.03 & 70.00 & 62.5000 \\ 0.0000547 & 38.03 & 70.00 & 62.5000 \\ 0.0000509 & 38.03 & 70.00 & 62.5000 \\ 0.0000476 & 38.03 & 70.00 & 62.5000 \\ 0.00000448 & 38.03 & 70.00 & 62.5000 \\ 0.0000423 & 38.03 & 70.00 & 62.5000 \\ 0.0000400 & 38.03 & 70.00 & 62.5000 \\ 0.0000378 & 38.03 & 70.00 & 62.5000 \\ 0.0000358 & 38.03 & 70.00 & 62.5000 \\ 0.0000339 & 38.03 & 70.00 & 62.5000 \\ 0.0000320 & 38.03 & 70.00 & 62.5000 \\ 0.0000302 & 38.03 & 70.00 & 62.5000 \\ 0.0000284 & 38.03 & 70.00 & 62.5000 \\ 0.0000267 & 38.03 & 70.00 & 62.5000 \\ 0.0000250 & 38.03 & 70.00 & 62.5000 \\ 0.0000233 & 38.03 & 70.00 & 62.5000 \\ 0.0000217 & 38.03 & 70.00 & 62.5000 \\ 0.0000201 & 38.03 & 70.00 & 62.5000 \\ 0.0000185 & 38.03 & 70.00 & 62.5000 \\ 0.0000169 & 38.03 & 70.00 & 62.5000 \\ 0.0000153 & 38.03 & 70.00 & 62.5000 \\ 0.0000137 & 38.03 & 70.00 & 62.5000 \\ 0.0000122 & 38.03 & 70.00 & 62.5000 \\ 0.0000106 & 38.03 & 70.00 & 62.5000 \\ 0.0000091 & 38.03 & 70.00 & 62.5000 \\ 0.0000076 & 38.03 & 70.00 & 62.5000 \\ 0.0000060 & 38.03 & 70.00 & 62.5000 \\ 0.0000045 & 38.03 & 70.00 & 62.5000 \\ 0.0000030 & 38.03 & 70.00 & 62.5000 \\ 0.0000015 & 38.03 & 70.00 & 62.5000 \\ 0.0000000 & 38.03 & 70.00 & 62.5000\end{array}$
0.0201967 0.0225426 0.0242515

0.0255377

0.0265453

0.0273579

0.0280279

0.0285894

0.0294752

0.0298285

0.0301356

0.0304038

0.0306390

0.0308460

0.0310286

0.0311900

0.0313332

0.0314603

0.0315733

0.0316740

0.0317638

0.0318440

0.0319157

0.0319798

0.0320373

0.0320888

0.0321349

0.0321765
0.0090000 0.0104700 0.0116861 .0132388 0.0137611 0.0141824 0.0145296 0.0148208 0.0150680 0.0152799 0.0154631 0.0156223 0157613 0.0158833 0.0159906 0.0160852 0.0161689 0.0162431 0.0163090 0.0163676 0.0164198 0.0164664 0.0165079 0.0165451 0.0165783 0.0166081 0.0166348 0.0166587 0.0166803 0.0167005

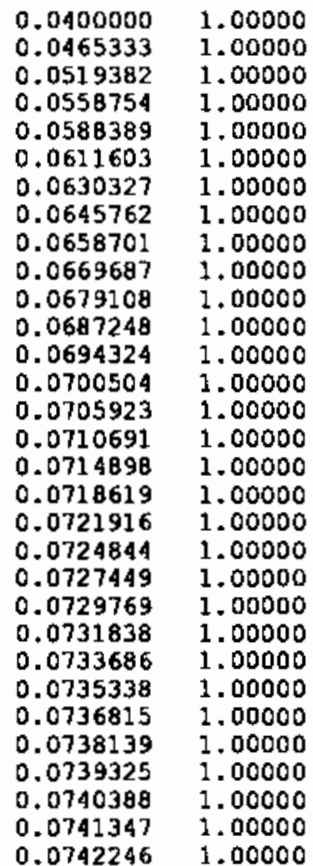

$0.0742246 \quad 1.00000$

calculated fluid conditions at t1me $=0.0000$ seconds channel 2l

$\begin{array}{cccr}\begin{array}{c}\text { distance } \\ \text { (1n.) }\end{array} & \begin{array}{c}\text { delta-p } \\ \text { (psi) }\end{array} & \begin{array}{r}\text { enthalpy } \\ \text { (btu/lb) } \\ 0.0\end{array} & \begin{array}{r}\text { temperatur } \\ \text { (deg-f) } \\ \text { (0000593 }\end{array} \\ 5.0 & 0.0000546 & 38.03 & 70.00 \\ 10.0 & 0.0000508 & 38.03 & 70.00 \\ 15.0 & 0.0000475 & 38.03 & 70.00 \\ 20.0 & 0.0000447 & 38.03 & 70.00 \\ 25.0 & 0.0000422 & 38.03 & 70.00 \\ 30.0 & 0.0000400 & 38.03 & 70.00 \\ 35.0 & 0.0000378 & 38.03 & 70.00 \\ 40.0 & 0.0000358 & 38.03 & 70.00 \\ 45.0 & 0.0000339 & 38.03 & 70.00 \\ 50.0 & 0.0000320 & 38.03 & 70.00 \\ 55.0 & 0.0000302 & 38.03 & 70.00 \\ 60.0 & 0.0000284 & 38.03 & 70.00 \\ 65.0 & 0.0000267 & 38.03 & 70.00 \\ 70.0 & 0.0000250 & 38.03 & 70.00 \\ 75.0 & 0.0000233 & 38.03 & 70.00 \\ 80.0 & 0.0000217 & 38.03 & 70.00\end{array}$

dens1ty
$(1 b / \mathrm{cu}-\mathrm{ft}$
62.5000
62.5000
62.5000
62.5000
62.5000
62.5000
62.5000
62.5000
62.5000
62.5000
62.5000
62.5000
62.5000
62.5000
62.5000
62.5000
62.5000

flow

mass flux velocity area $(1 \mathrm{~b} / \mathrm{sec})$ (mb/hr-fc2) (ft/sec) 0.0173611 0.0090000
0.0075963 $0.0127544 \quad 0.0066119$ 0.0114053 0.0104899 0.0054380 0.0098811 0.0051224 0.0049099 0.0091869 .0089819 0.0097687 0.0086130 0.0085343 0.0084685 0.0084126 0.0083645 0.0047625 0.0046562 0.0045765 0.0045146 0.0044650 0.0044242 0.0043901 0.0043611 0.0043362 $0.0337614 \quad 1.00000$ $0.0293861 \quad 1.00000$ $0.0262778 \quad 1.00000$ 0.02416871 .00000 $0.0227661 \quad 1.00000$ $0.0218219 \quad 1.00000$ $0.0211667 \quad 1.00000$ 0.02069421 .00000 $0.0203400 \quad 1.00000$ $0.0200648 \quad 1.00000$ $0.0198442 \quad 1.00000$ $0.0196631 \quad 1.00000$ $\begin{array}{lll}0.0195114 & 1.00000\end{array}$ $0.0193826 \quad 1.00000$ $\begin{array}{llll}0.0083228 & 0.0043146 & 0.0191758 & 1.00000\end{array}$ 


$\begin{array}{rllllllll}85.0 & 0.0000201 & 38.03 & 70.00 & 62.5000 & 0.0082865 & 0.0042957 & 0.0190921 & 1.00000 \\ 90.0 & 0.0000185 & 38.03 & 70.00 & 62.5000 & 0.0082546 & 0.0042792 & 0.0190187 & 1.00000 \\ 95.0 & 0.0000169 & 38.03 & 70.00 & 62.5000 & 0.0082266 & 0.0042647 & 0.0189540 & 1.00000 \\ 100.0 & 0.0000153 & 38.03 & 70.00 & 62.5000 & 0.0082018 & 0.0042518 & 0.0188969 & 1.00000 \\ 105.0 & 0.0000137 & 38.03 & 70.00 & 62.5000 & 0.0081799 & 0.0042404 & 0.0188464 & 1.00000 \\ 110.0 & 0.0000122 & 38.03 & 70.00 & 62.5000 & 0.0081604 & 0.0042303 & 0.0188015 & 1.00000 \\ 115.0 & 0.0000106 & 38.03 & 70.00 & 62.5000 & 0.0081431 & 0.0042214 & 0.0187616 & 1.00000 \\ 120.0 & 0.0000091 & 38.03 & 70.00 & 62.5000 & 0.0081276 & 0.0042134 & 0.0187260 & 1.00000 \\ 125.0 & 0.0000076 & 38.03 & 70.00 & 62.5000 & 0.0081139 & 0.0042062 & 0.0186943 & 1.00000 \\ 130.0 & 0.0000060 & 38.03 & 70.00 & 62.5000 & 0.0081016 & 0.0041999 & 0.0186660 & 1.00000 \\ 135.0 & 0.0000045 & 38.03 & 70.00 & 62.5000 & 0.0080906 & 0.0041942 & 0.0186407 & 1.00000 \\ 140.0 & 0.0000030 & 38.03 & 70.00 & 62.5000 & 0.0080807 & 0.0041891 & 0.0186180 & 1.00000 \\ 145.0 & 0.0000015 & 38.03 & 70.00 & 62.5000 & 0.0080722 & 0.0041846 & 0.0185982 & 1.00000 \\ 150.0 & 0.0000000 & 38.03 & 70.00 & 62.5000 & 0.0080623 & 0.0041795 & 0.0185755 & 1.00000\end{array}$

calculated fluid conditions at time $=0.0000$ seconds channel 22

$\begin{array}{ccccc}\begin{array}{c}\text { distance } \\ \text { (1n.) }\end{array} & \begin{array}{c}\text { delta-p } \\ \text { (ps1) }\end{array} & \begin{array}{c}\text { enthalpy } \\ \text { (btul1b) } \\ 0.0\end{array} & \begin{array}{c}\text { temperature } \\ \text { (deg-f) }\end{array} & \begin{array}{c}\text { density } \\ (1 \mathrm{~b} / \mathrm{cu}-\mathrm{ft})\end{array} \\ 5.0 & 0.0000590 & 38.03 & 70.00 & 62.5000 \\ 10.0 & 0.0000508 & 38.03 & 70.00 & 62.5000 \\ 15.0 & 0.0000476 & 38.03 & 70.00 & 62.5000 \\ 20.0 & 0.0000448 & 38.03 & 70.00 & 62.5000 \\ 25.0 & 0.0000422 & 38.03 & 70.00 & 62.5000 \\ 30.0 & 0.0000400 & 38.03 & 70.00 & 62.5000 \\ 35.0 & 0.0000378 & 38.03 & 70.00 & 62.5000 \\ 40.0 & 0.0000358 & 38.03 & 70.00 & 62.5000 \\ 45.0 & 0.0000339 & 38.03 & 70.00 & 62.5000 \\ 50.0 & 0.0000320 & 38.03 & 70.00 & 62.5000 \\ 55.0 & 0.0000302 & 38.03 & 70.00 & 62.5000 \\ 60.0 & 0.0000284 & 38.03 & 70.00 & 62.5000 \\ 65.0 & 0.0000267 & 38.03 & 70.00 & 62.5000 \\ 70.0 & 0.0000250 & 38.03 & 70.00 & 62.5000 \\ 75.0 & 0.0000233 & 38.03 & 70.00 & 62.5000 \\ 80.0 & 0.0000217 & 38.03 & 70.00 & 62.5000 \\ 85.0 & 0.0000201 & 38.03 & 70.00 & 62.5000 \\ 90.0 & 0.0000185 & 38.03 & 70.00 & 62.5000 \\ 95.0 & 0.0000169 & 38.03 & 70.00 & 62.5000 \\ 100.0 & 0.0000153 & 38.03 & 70.00 & 62.5000 \\ 105.0 & 0.0000137 & 38.03 & 70.00 & 62.5000 \\ 110.0 & 0.0000122 & 38.03 & 70.00 & 62.5000 \\ 115.0 & 0.0000106 & 38.03 & 70.00 & 62.5000 \\ 120.0 & 0.0000091 & 38.03 & 70.00 & 62.5000 \\ 125.0 & 0.0000076 & 38.03 & 70.00 & 62.5000 \\ 130.0 & 0.0000060 & 38.03 & 70.00 & 62.5000 \\ 135.0 & 0.0000045 & 38.03 & 70.00 & 62.5000 \\ 140.0 & 0.0000030 & 38.03 & 70.00 & 62.5000 \\ 145.0 & 0.0000015 & 38.03 & 70.00 & 62.5000 \\ 150.0 & 0.0000000 & 38.03 & 70.00 & 62.5000\end{array}$

$\begin{array}{cc}\begin{array}{c}\text { flow } \\ (1 b / s e c)\end{array} & \begin{array}{c}\text { mass flux } \\ \text { (mlb/hrftet) } \\ 0.0173611\end{array} \\ 0.0090000 \\ 0.0190149 & 0.0098573 \\ 0.0198074 & 0.0102681 \\ 0.0201363 & 0.0104387 \\ 0.0202644 & 0.0105051 \\ 0.0202996 & 0.0105233 \\ 0.0202874 & 0.0105170 \\ 0.0202509 & 0.0104981 \\ 0.0202038 & 0.0104736 \\ 0.0201534 & 0.0104475 \\ 0.0201035 & 0.0104216 \\ 0.0200559 & 0.0103970 \\ 0.0200114 & 0.0103739 \\ 0.0199703 & 0.0103526 \\ 0.0199327 & 0.0103331 \\ 0.0198984 & 0.0103153 \\ 0.0198672 & 0.0102992 \\ 0.0198390 & 0.0102846 \\ 0.0198135 & 0.0102713 \\ 0.0197905 & 0.0102594 \\ 0.0197697 & 0.0102486 \\ 0.0197509 & 0.0102389 \\ 0.0197341 & 0.0102301 \\ 0.0197189 & 0.0102223 \\ 0.0197052 & 0.0102152 \\ 0.0196929 & 0.0102089 \\ 0.0196818 & 0.0102030 \\ 0.0196718 & 0.0101979 \\ 0.0196629 & 0.0101932 \\ 0.0196546 & 0.0101889 \\ 0.0196481 & 0.0101856\end{array}$

velocity area 0.0400000 (sq-1n) $0.0438103 \quad 1.00000$ $0.0456362 \quad 1.00000$ $0.0463940 \quad 1.00000$ $0.0466892 \quad 1.00000$ $0.0467704 \quad 1.00000$ $0.0467421 \quad 1.00000$ $\begin{array}{ll}0.0466581 & 1.00000\end{array}$ $0.0465495 \quad 1.00000$ 0.04643341 .00000 $0.0463184 \quad 1.00000$ $0.0462087 \quad 1.00000$ $\begin{array}{ll}0.0461062 & 1.00000 \\ 0.0460116 & 1.00000\end{array}$ $0.0460116 \quad 1.00000$ $0.0459249 \quad 1.00000$ $\begin{array}{ll}0.0458459 & 1.00000 \\ 0.0457741 & 1.00000\end{array}$ $\begin{array}{ll}0.0457741 & 1.00000 \\ 0.0457091 & 1.00000\end{array}$ $0.0457091 \quad 1.00000$ $\begin{array}{ll}0.0456503 & 1.00000 \\ 0.0455972 & 1.00000\end{array}$ $\begin{array}{ll}0.0455972 & 1.00000 \\ 0.0455493 & 1.00000\end{array}$ $\begin{array}{ll}0.0455493 & 1.00000 \\ 0.0455062 & 1.00000\end{array}$ $0.0454673 \quad 1.00000$ $0.0454323 \quad 1.00000$ $0.0454007 \quad 1.00000$ $0.0453724 \quad 1.00000$ $0.0453468 \quad 1.00000$ 0.04532391 .00000 0.04530321 .00000 $\begin{array}{ll}0.0452841 & 1.00000 \\ 0.0452692 & 1.00000\end{array}$ 


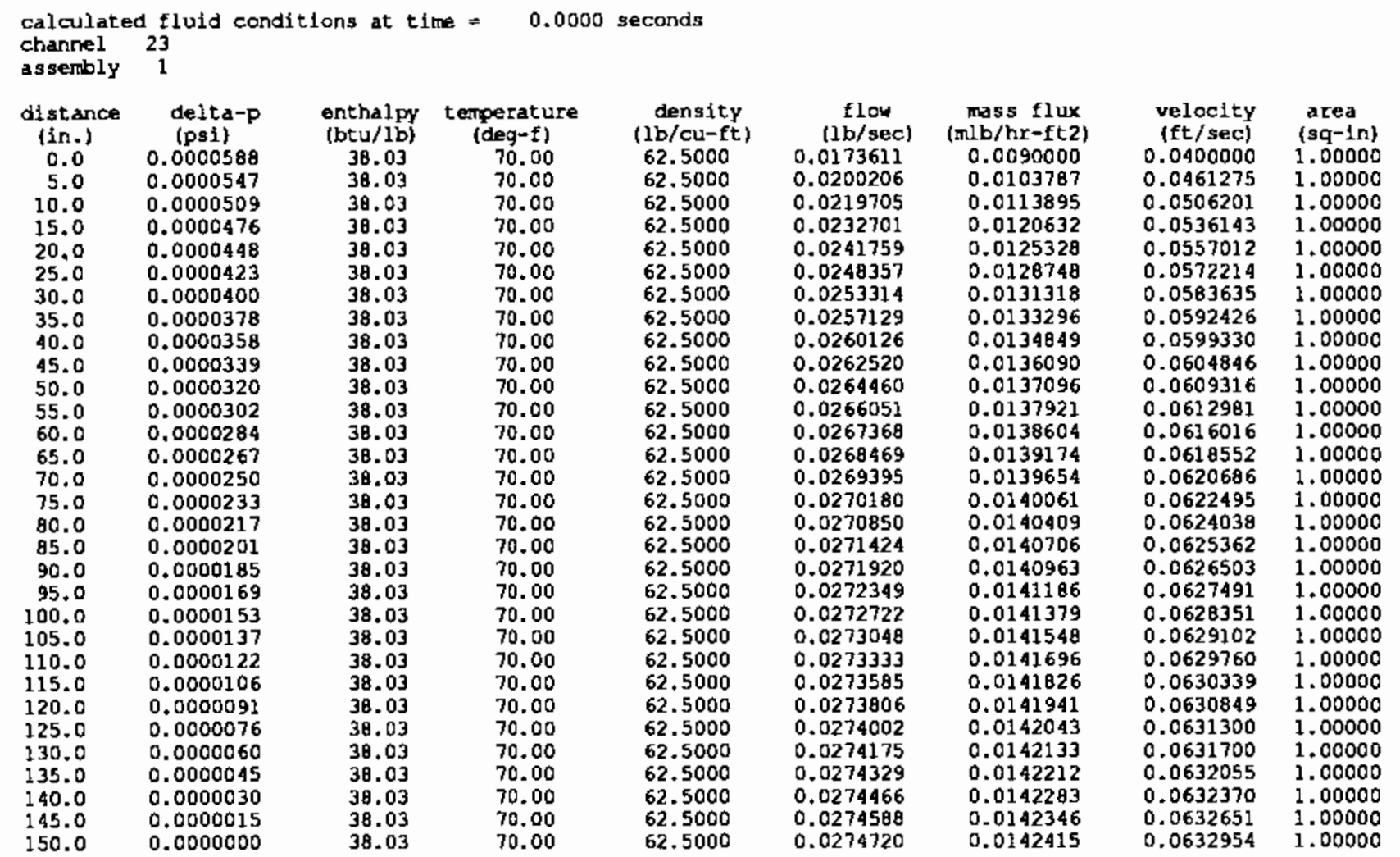

calculated fluid conditions at time $=0.0000$ seconds channel 24

$\begin{array}{cccc}\begin{array}{c}\text { distance } \\ \text { (in.) }\end{array} & \begin{array}{c}\text { delta-p } \\ \text { (psi) }\end{array} & \begin{array}{c}\text { enthalpy } \\ \text { (btu/lb) }\end{array} & \begin{array}{c}\text { temperature } \\ \text { (deg-f) }\end{array} \\ 0.0 & 0.0000586 & 38.03 & 70.00 \\ 5.0 & 0.0000547 & 38.03 & 70.00 \\ 10.0 & 0.0000509 & 38.03 & 70.00 \\ 15.0 & 0.0000476 & 38.03 & 70.00 \\ 20.0 & 0.0000448 & 38.03 & 70.00 \\ 25.0 & 0.0000423 & 38.03 & 70.00 \\ 30.0 & 0.0000400 & 38.03 & 70.00 \\ 35.0 & 0.0000378 & 38.03 & 70.00 \\ 40.0 & 0.0000358 & 38.03 & 70.00 \\ 45.0 & 0.0000339 & 38.03 & 70.00 \\ 50.0 & 0.0000320 & 38.03 & 70.00\end{array}$

density
$(1 \mathrm{~b} / \mathrm{cu}-\mathrm{ft})$
62.5000
62.5000
62.5000
62.5000
62.5000
62.5000
62.5000
62.5000
62.5000
62.5000
62.5000

flow
$(1 \mathrm{~b} / \mathrm{sec})$
0.0173611
0.0201967
0.0225426
0.0242515
0.0255377
0.0265453
0.0273579
0.0280279
0.0285894
0.0290663
0.0294752

$\begin{array}{ll}\text { velocity } & \text { area } \\ \text { (ft } / \text { sec) } & \text { (sq-1n) } \\ 0.0400000 & 1.00000 \\ 0.0465333 & 1.00000 \\ 0.0519382 & 1.00000 \\ 0.0558754 & 1.00000 \\ 0.0588389 & 1.00000 \\ 0.0611603 & 1.00000 \\ 0.0630327 & 1.00000 \\ 0.0645762 & 1.00000 \\ 0.0658701 & 1.00000 \\ 0.0669687 & 1.00000 \\ 0.0679108 & 1.00000\end{array}$
0.0090000 0.0104700 0.0116861 0.0125720 0.01373811 0.0141824 0.0145296 0.0148208 0.0152799

$0.0679108 \quad 1.00000$ 


$\begin{array}{rllllllll}55.0 & 0.0000302 & 38.03 & 70.00 & 62.5000 & 0.0298285 & 0.0154631 & 0.0687248 & 1.00000 \\ 60.0 & 0.0000284 & 38.03 & 70.00 & 62.5000 & 0.0301356 & 0.0156223 & 0.0694324 & 1.00000 \\ 65.0 & 0.0000267 & 38.03 & 70.00 & 62.5000 & 0.0304038 & 0.0157613 & 0.0700504 & 1.00000 \\ 70.0 & 0.0000250 & 38.03 & 70.00 & 62.5000 & 0.0306390 & 0.0158833 & 0.0705923 & 1.00000 \\ 75.0 & 0.0000233 & 38.03 & 70.00 & 62.5000 & 0.0308460 & 0.0159906 & 0.0710691 & 1.00000 \\ 80.0 & 0.0000217 & 38.03 & 70.00 & 62.5000 & 0.0310286 & 0.0160852 & 0.0714898 & 1.00000 \\ 85.0 & 0.0000201 & 38.03 & 70.00 & 62.5000 & 0.0311900 & 0.0161689 & 0.0718619 & 1.00000 \\ 90.0 & 0.0000185 & 38.03 & 70.00 & 62.5000 & 0.0313332 & 0.0162431 & 0.0721916 & 1.00000 \\ 95.0 & 0.0000169 & 38.03 & 70.00 & 62.5000 & 0.0314603 & 0.0163090 & 0.0724844 & 1.00000 \\ 100.0 & 0.0000153 & 38.03 & 70.00 & 62.5000 & 0.0315733 & 0.0163676 & 0.0727449 & 1.00000 \\ 105.0 & 0.0000137 & 38.03 & 70.00 & 62.5000 & 0.0316740 & 0.0164198 & 0.0729769 & 1.00000 \\ 110.0 & 0.0000122 & 38.03 & 70.00 & 62.5000 & 0.0317638 & 0.0164664 & 0.0731838 & 1.00000 \\ 115.0 & 0.0000106 & 38.03 & 70.00 & 62.5000 & 0.0318440 & 0.0165079 & 0.0733686 & 1.00000 \\ 120.0 & 0.0000091 & 38.03 & 70.00 & 62.5000 & 0.0319157 & 0.0165451 & 0.0735338 & 1.00000 \\ 125.0 & 0.0000076 & 38.03 & 70.00 & 62.5000 & 0.0319798 & 0.0165783 & 0.0736815 & 1.00000 \\ 130.0 & 0.0000060 & 38.03 & 70.00 & 62.5000 & 0.0320373 & 0.0166081 & 0.0738139 & 1.000000 \\ 135.0 & 0.0000045 & 38.03 & 70.00 & 62.5000 & 0.0320888 & 0.0166348 & 0.0739325 & 1.00000 \\ 140.0 & 0.0000030 & 38.03 & 70.00 & 62.5000 & 0.0321349 & 0.0166587 & 0.0740388 & 1.00000 \\ 145.0 & 0.0000015 & 38.03 & 70.00 & 62.5000 & 0.0321765 & 0.0166803 & 0.0741347 & 1.00000 \\ 150.0 & 0.0000000 & 38.03 & 70.00 & 62.5000 & 0.0322155 & 0.0167005 & 0.0742246 & 1.00000\end{array}$

calculated fluid conditions at time $=$

0.0000 seconds channel 25

$\begin{array}{rrrr}\begin{array}{c}\text { distance } \\ \text { (1n.) }\end{array} & \begin{array}{c}\text { delta-p } \\ \text { (psi) }\end{array} & \begin{array}{r}\text { enthalpy } \\ \text { (btu/lb) }\end{array} & \begin{array}{r}\text { temperatur } \\ \text { (deg-f) }\end{array} \\ 0.0 & 0.0000585 & 38.03 & 70.00 \\ 5.0 & 0.0000547 & 38.03 & 70.00 \\ 10.0 & 0.0000509 & 38.03 & 70.00 \\ 15.0 & 0.0000476 & 38.03 & 70.00 \\ 20.0 & 0.0000448 & 38.03 & 70.00 \\ 25.0 & 0.0000423 & 38.03 & 70.00 \\ 30.0 & 0.0000400 & 38.03 & 70.00 \\ 35.0 & 0.0000378 & 38.03 & 70.00 \\ 40.0 & 0.0000358 & 38.03 & 70.00 \\ 45.0 & 0.0000339 & 38.03 & 70.00 \\ 50.0 & 0.0000320 & 38.03 & 70.00 \\ 55.0 & 0.0000302 & 38.03 & 70.00 \\ 60.0 & 0.0000284 & 38.03 & 70.00 \\ 65.0 & 0.0000267 & 38.03 & 70.00 \\ 70.0 & 0.0000250 & 38.03 & 70.00 \\ 75.0 & 0.0000233 & 38.03 & 70.00 \\ 80.0 & 0.0000217 & 38.03 & 70.00 \\ 85.0 & 0.0000201 & 38.03 & 70.00 \\ 90.0 & 0.0000185 & 38.03 & 70.00 \\ 95.0 & 0.0000169 & 38.03 & 70.00 \\ 100.0 & 0.0000153 & 38.03 & 70.00 \\ 105.0 & 0.0000137 & 38.03 & 70.00 \\ 110.0 & 0.0000122 & 38.03 & 70.00 \\ 115.0 & 0.0000106 & 38.03 & 70.00 \\ 120.0 & 0.0000091 & 38.03 & 70.00 \\ 125.0 & 0.0000076 & 38.03 & 70.00 \\ 130.0 & 0.0000060 & 38.03 & 70.00 \\ 135.0 & 0.0000045 & 38.03 & 70.00\end{array}$

density
$\{1 \mathrm{~b} / \mathrm{cu}-\mathrm{ft}$
62.5000
62.5000
62.5000
62.5000
62.5000
62.5000
62.5000
62.5000
62.5000
62.5000
62.5000
62.5000
62.5000
62.5000
62.5000
62.5000
62.5000
62.5000
62.5000
62.5000
62.5000
62.5000
62.5000
62.5000
62.5000
62.5000
62.5000
62.5000
(lb/sec) 0.017361 0.0201975
0.0226489 0.0244903 0.0259151 0.0270619 0.0280117 0.0288144 0.0295032 0.0301008 0.0306234 0.0310832 0.0314894 0.0318496 0.0321698 0.0324549 0.0327093 0.0329365 0.0331397 0.0333216 0.0334845 0.0336306 0.0337616 0.0338792 0.0339848 0.034079 ? 0.0341649 0.0342416 mass flux (mlb/hr-ft2) 0.0090000 0.0117412 0.0126958 0.0134344 0.0140289 0.0145212 0.0149374 0.0152945 0.0156042 0.0158752 0.0161135 0.0163241 0.0165108 0.0166768 0.0168246 0.0169565 0.0170743 .0172739 0.0173584 0.0174341 0.0175020 0.0175630 0.0176177 0.0176669 0.0177111 0.0177508

$\begin{array}{cc}\begin{array}{c}\text { velocity } \\ \text { (ft/sec) }\end{array} & \begin{array}{c}\text { area } \\ \text { (sq-1n) }\end{array} \\ 0.0400000 & 1.00000 \\ 0.0465352 & 1.00000 \\ 0.0521831 & 1.00000 \\ 0.0564256 & 1.00000 \\ 0.0597083 & 1.00000 \\ 0.0623506 & 1.00000 \\ 0.0645389 & 1.00000 \\ 0.0663885 & 1.00000 \\ 0.0679755 & 1.00000 \\ 0.0693522 & 1.00000 \\ 0.0705563 & 1.00000 \\ 0.0716156 & 1.00000 \\ 0.0725516 & 1.00000 \\ 0.0733815 & 1.00000 \\ 0.0741191 & 1.00000 \\ 0.0747761 & 1.00000 \\ 0.0753622 & 1.00000 \\ 0.0758857 & 1.00000 \\ 0.0763539 & 1.00000 \\ 0.0767729 & 1.00000 \\ 0.0771484 & 1.00000 \\ 0.0774849 & 1.00000 \\ 0.0777868 & 1.00000 \\ 0.0780578 & 1.00000 \\ 0.0783011 & 1.00000 \\ 0.0785196 & 1.00000 \\ 0.0787160 & 1.00000 \\ 0.0788926 & 1.00000\end{array}$




$\begin{array}{lllllllll}140.0 & 0.0000030 & 38.03 & 70.00 & 62.5000 & 0.0343105 & 0.0177865 & 0.0790513 & 1.00000 \\ 145.0 & 0.0000015 & 38.03 & 70.00 & 62.5000 & 0.0343728 & 0.0178188 & 0.0791949 & 1.00000 \\ 150.0 & 0.0000000 & 38.03 & 70.00 & 62.5000 & 0.0344292 & 0.0178481 & 0.0793249 & 1.00000\end{array}$

slab temperature summary

time $=0.0000$ seconds

$\begin{array}{rlll}\begin{array}{c}\text { axial zone } \\ \text { (1nches) }\end{array} & (1) & (21 & (3) \\ 0.0-5.0 & 70.00 & 70.00 & 70.00 \\ 5.0-10.0 & 70.00 & 70.00 & 70.00 \\ 10.0-15.0 & 70.00 & 70.00 & 70.00 \\ 15.0-20.0 & 70.00 & 70.00 & 70.00 \\ 20.0=25.0 & 70.00 & 70.00 & 70.00 \\ 25.0-30.0 & 70.00 & 70.00 & 70.00 \\ 30.0-35.0 & 70.00 & 70.00 & 70.00 \\ 35.0-40.0 & 70.00 & 70.00 & 70.00 \\ 40.0-45.0 & 70.00 & 70.00 & 70.00 \\ 45.0-50.0 & 70.00 & 70.00 & 70.00 \\ 50.0-55.0 & 70.00 & 70.00 & 70.00 \\ 55.0-60.0 & 70.00 & 70.00 & 70.00 \\ 60.0-65.0 & 70.00 & 70.00 & 70.00 \\ 65.0-70.0 & 70.00 & 70.00 & 70.00 \\ 70.0-75.0 & 70.00 & 70.00 & 70.00 \\ 75.0-80.0 & 70.00 & 70.00 & 70.00 \\ 80.0-85.0 & 70.00 & 70.00 & 70.00 \\ 95.0-90.0 & 70.00 & 70.00 & 70.00 \\ 90.0-95.0 & 70.00 & 70.00 & 70.00 \\ 95.0-100.0 & 70.00 & 70.00 & 70.00 \\ 100.0-105.0 & 70.00 & 70.00 & 70.00 \\ 105.0-110.0 & 70.00 & 70.00 & 70.00 \\ 110.0-115.0 & 70.00 & 70.00 & 70.00 \\ 115.0-120.0 & 70.00 & 70.00 & 70.00 \\ 120.0-125.0 & 70.00 & 70.00 & 70.00 \\ 125.0-130.0 & 70.00 & 70.00 & 70.00 \\ 130.0-135.0 & 70.00 & 70.00 & 70.00 \\ 135.0-140.0 & 70.00 & 70.00 & 70.00 \\ 140.0-145.0 & 70.00 & 70.00 & 70.00 \\ 145.0-150.0 & 70.00 & 70.00 & 70.00\end{array}$

$\begin{array}{ll}(4) & (5) \\ & \\ 70.00 & 70.00 \\ 70.00 & 70.00 \\ 70.00 & 70.00 \\ 70.00 & 70.00 \\ 70.00 & 70.00 \\ 70.00 & 70.00 \\ 70.00 & 70.00 \\ 70.00 & 70.00 \\ 70.00 & 70.00 \\ 70.00 & 70.00 \\ 70.00 & 70.00 \\ 70.00 & 70.00 \\ 70.00 & 70.00 \\ 70.00 & 70.00 \\ 70.00 & 70.00 \\ 70.00 & 70.00 \\ 70.00 & 70.00 \\ 70.00 & 70.00 \\ 70.00 & 70.00 \\ 70.00 & 70.00 \\ 70.00 & 70.00 \\ 70.00 & 70.00 \\ 70.00 & 70.00 \\ 70.00 & 70.00 \\ 70.00 & 70.00 \\ 70.00 & 70.00 \\ 70.00 & 70.00 \\ 70.00 & 70.00 \\ 70.00 & 70.00 \\ 70.00 & 70.00\end{array}$

1
70
70
70
70
70
70
70
70
70
70
70
70
70
70
70
70
70.
70
70.
70
70
70
70
70
70
70
70
70
70
70

$6)$

70.00
70.00
70.00
70.00
70.00
70.00
70.00
70.00
70.00
70.00
70.00
70.00
70.00
70.00
70.00
70.00
70.00
70.00
70.00
70.00
70.00
70.00
70.00
70.00
70.00
70.00
70.00
70.00
70.00
70.00
7

17
70.00
70.00
70.00
70.00
70.00
70.00
70.00
70.00
70.00
70.00
70.00
70.00
70.00
70.00
70.00
70.00
70.00
70.00
70.00
70.00
70.00
70.00
70.00
70.00
70.00
70.00
70.00
70.00
70.00
70.00

$(9)$
70.00
70.00
70.00
70.00
70.00
70.00
70.00
70.00
70.00
70.00
70.00
70.00
70.00
70.00
70.00
70.00
70.00
70.00
70.00
70.00
70.00
70.00
70.00
70.00
70.00
70.00
70.00
70.00
70.00
70.00

(9)

70.00

70.00

70.00

70.00

70.00

70.00

70.00

70.00

70.00

70.00

70.00

70.00

70.00

70.00

70.00

70.00

70.00

70.00

70.00

70.00

70.00

70.00

70.00

70.00

70.00

70.00

70.00

70.00

70.00

crossflow between adjacent channels at t1me $=0.0000$ seconds

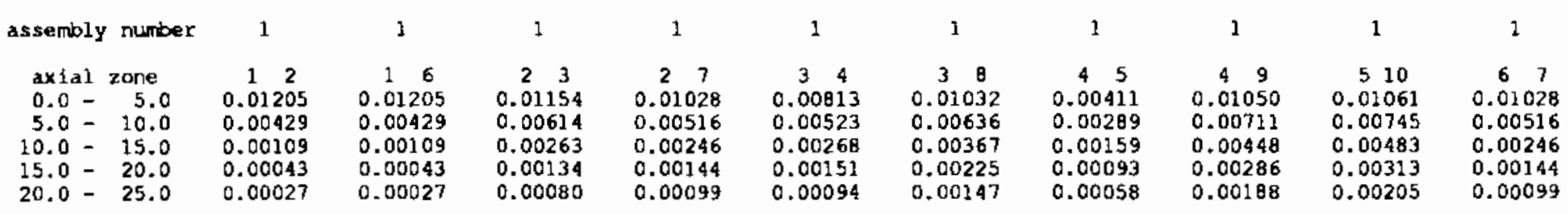

$20.0-25.0$

$\begin{array}{lll}0.00027 & 0.00027 & 0.00080\end{array}$
70.00

70.00

70.00

70.00

70.00

70.00

70.00

70.00

70.00

70.00

70.00

70.00

70.00

70.00

70.00

70.00

70.00

70.00

70.00

70.00

70.00

70.00

70.00

70.00

70.00

70.00 


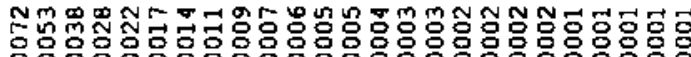

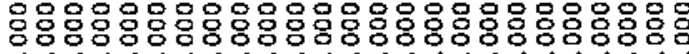

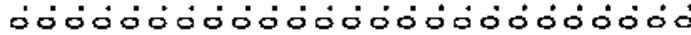

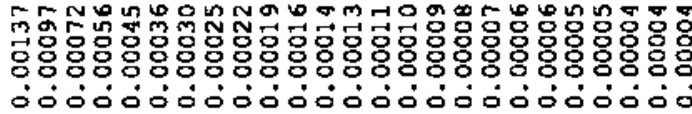

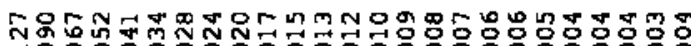

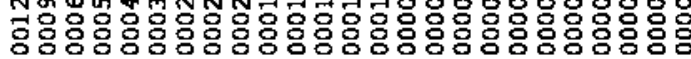

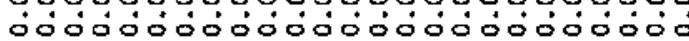

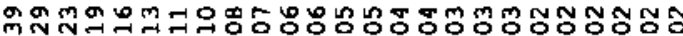

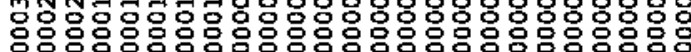

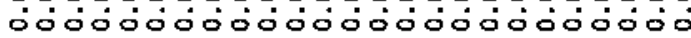

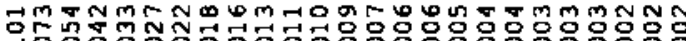

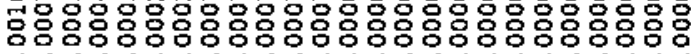

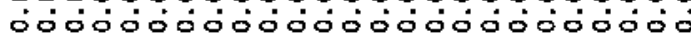

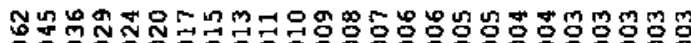

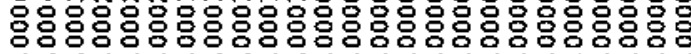

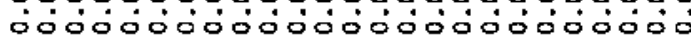

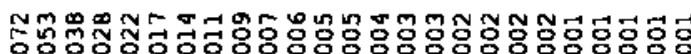

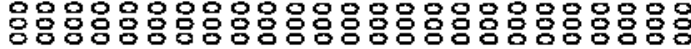

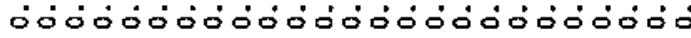

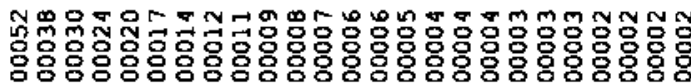

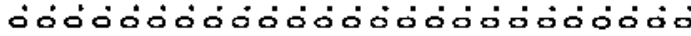

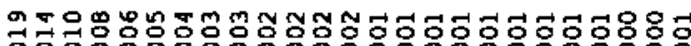

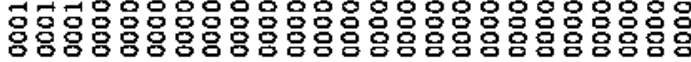

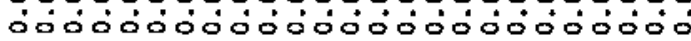

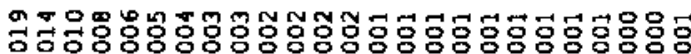

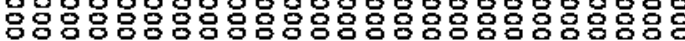

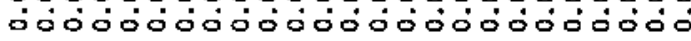

0000000000000000000000000

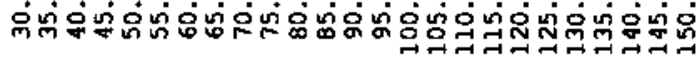

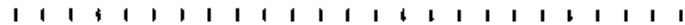
0000000000000000000000000 ฝं

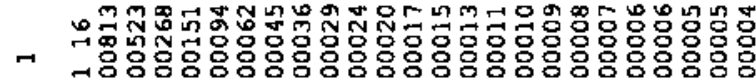

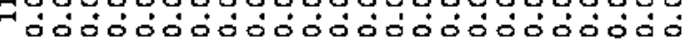

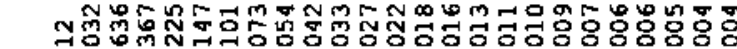

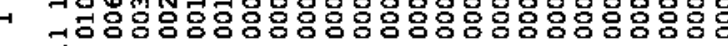

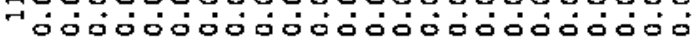

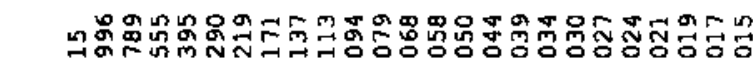

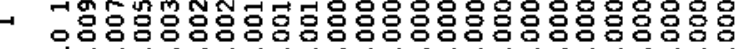

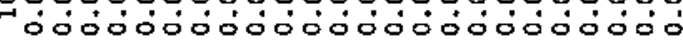

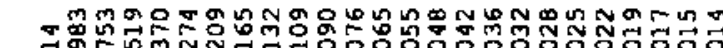

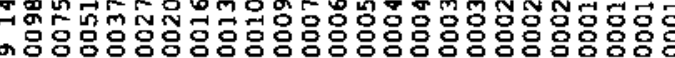

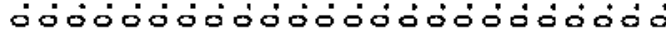

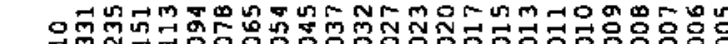

-

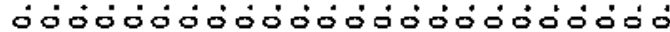

-

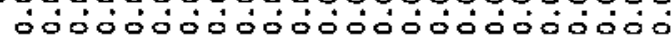

ต

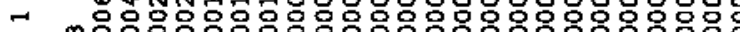

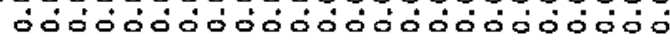

ㄷํㅇำ

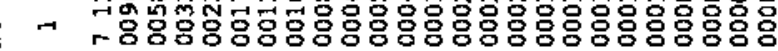

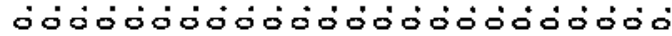

$$
\rightarrow
$$

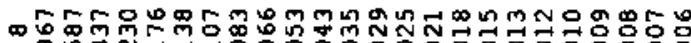

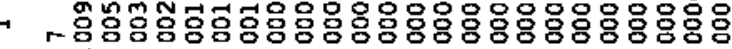

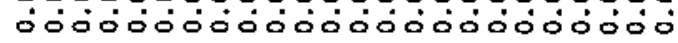

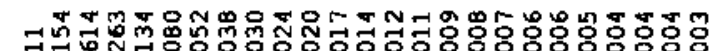

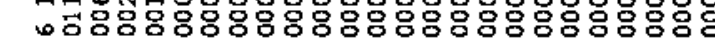

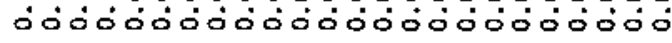

000000000000000000000000

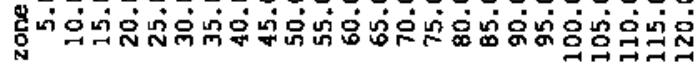

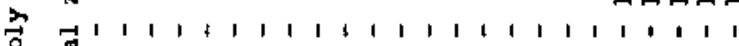

है

\% ส 


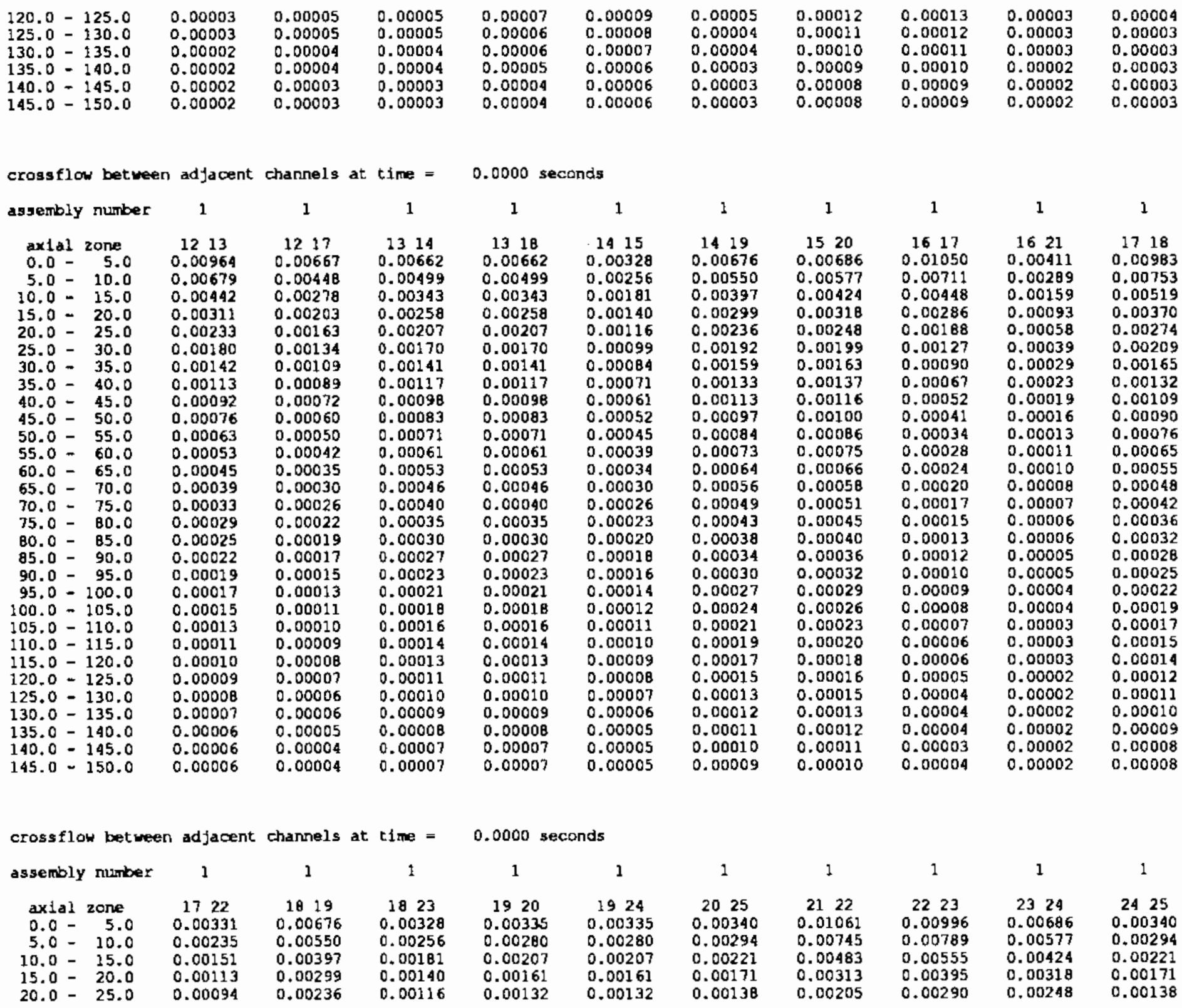




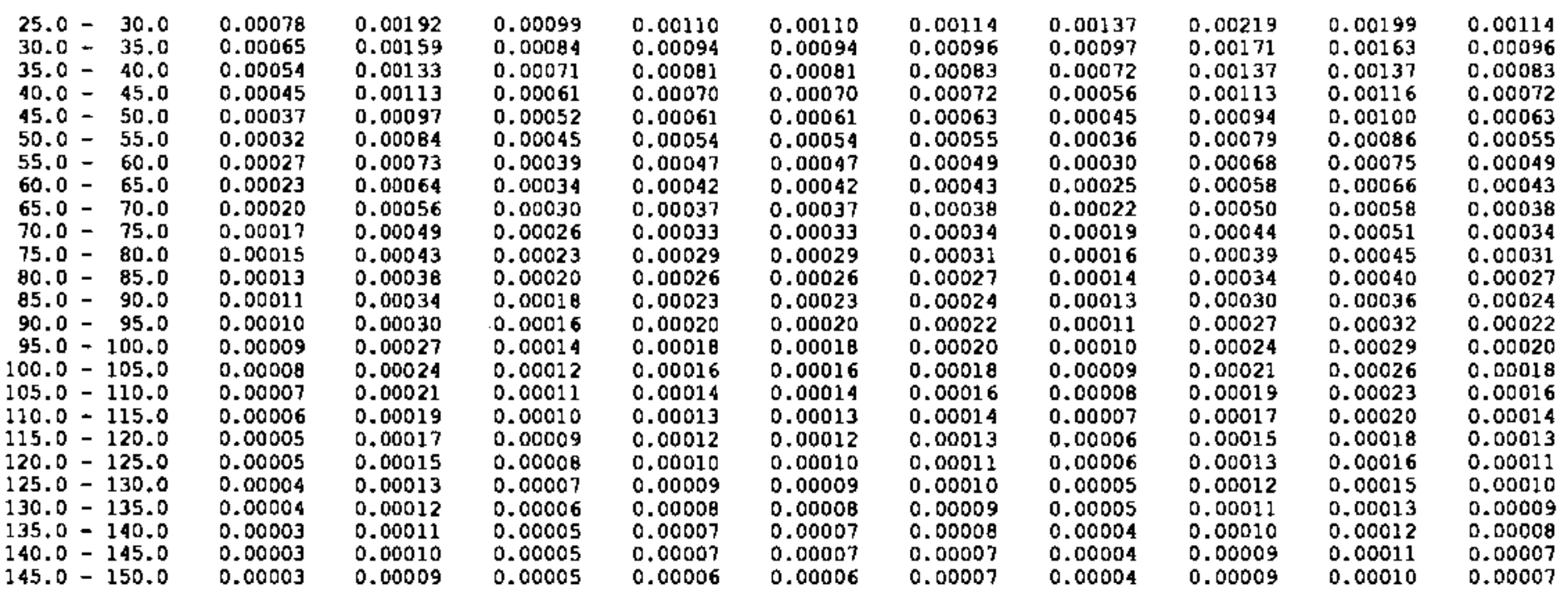

1terations $=10$

1nput transient t1me completed

common dumped to tape 8

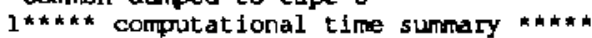

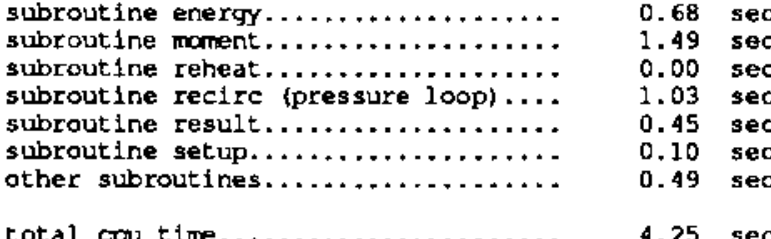

$0.68 \mathrm{sec}$

.

$.03 \mathrm{sec}$

.10 sec

$4.25 \mathrm{sec}$ 
- 


\section{APPENDIX D}

NATURAL CIRCULATION IN A SQUARE CAVITY OUTPUT 
APPENDIX D

\section{DEVELOPING FLOW IN A CYLINDRICAL PIPE OUTPUT}

cobra dimension parameters:

\begin{tabular}{|c|c|c|c|c|}
\hline $1 d=$ & 6 & $1 e=$ & 40 & lif $=$ \\
\hline Ih $=$ & 9 & $11 p=$ & 8 & $i q=$ \\
\hline $1 \mathrm{r}=$ & 9 & $11 \mathrm{t}=$ & 3 & $1 \mathrm{u}=$ \\
\hline $21=$ & 6 & $1 x=$ & 8 & $11 z=$ \\
\hline $1 a=$ & 15 & $1 \mathrm{~b}=$ & 1 & $11 \mathrm{c}=$ \\
\hline $1 d=$ & 1 & $1 e=$ & 1 & lf $=$ \\
\hline $\operatorname{ma}=$ & 20 & $m c=$ & 40 & me= \\
\hline $\mathrm{mg}=$ & 50 & mh= & 6 & $m i=$ \\
\hline mj= & 1 & $m \mathrm{k}=$ & 3 & $\mathrm{ml}=$ \\
\hline $1 \mathrm{~min}$ & 20 & mก= & 6 & $\mathrm{mp}^{2}=$ \\
\hline $\mathbf{m q}=$ & 1 & $2 \pi r=$ & 20 & max \\
\hline$m=$ & 1 & 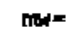 & 40 & $m \mathrm{x}=$ \\
\hline$m y=$ & 4 & nd $=$ & 9 & no $=$ \\
\hline nv $=$ & 2 & $\ln 2=$ & 10 & \\
\hline
\end{tabular}

1kk*** the following $1 \mathrm{~s}$ an image listing of the cobra-sfs input cards ankk*

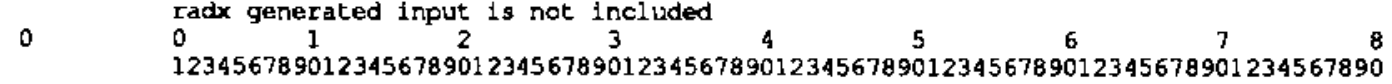

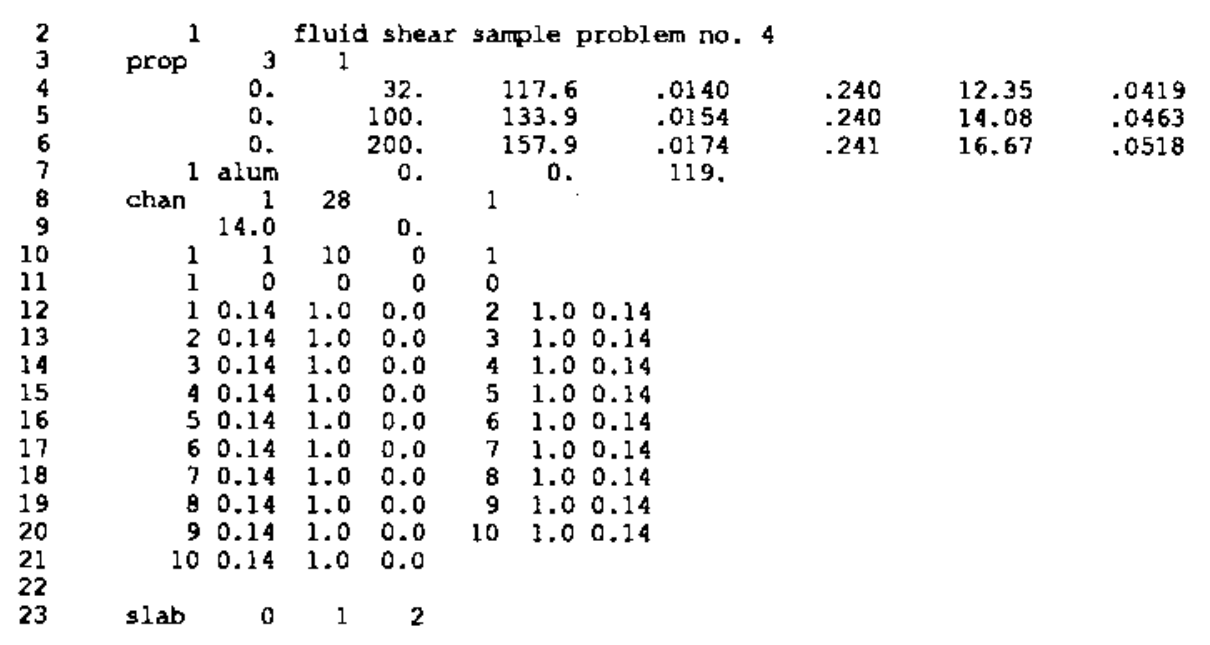




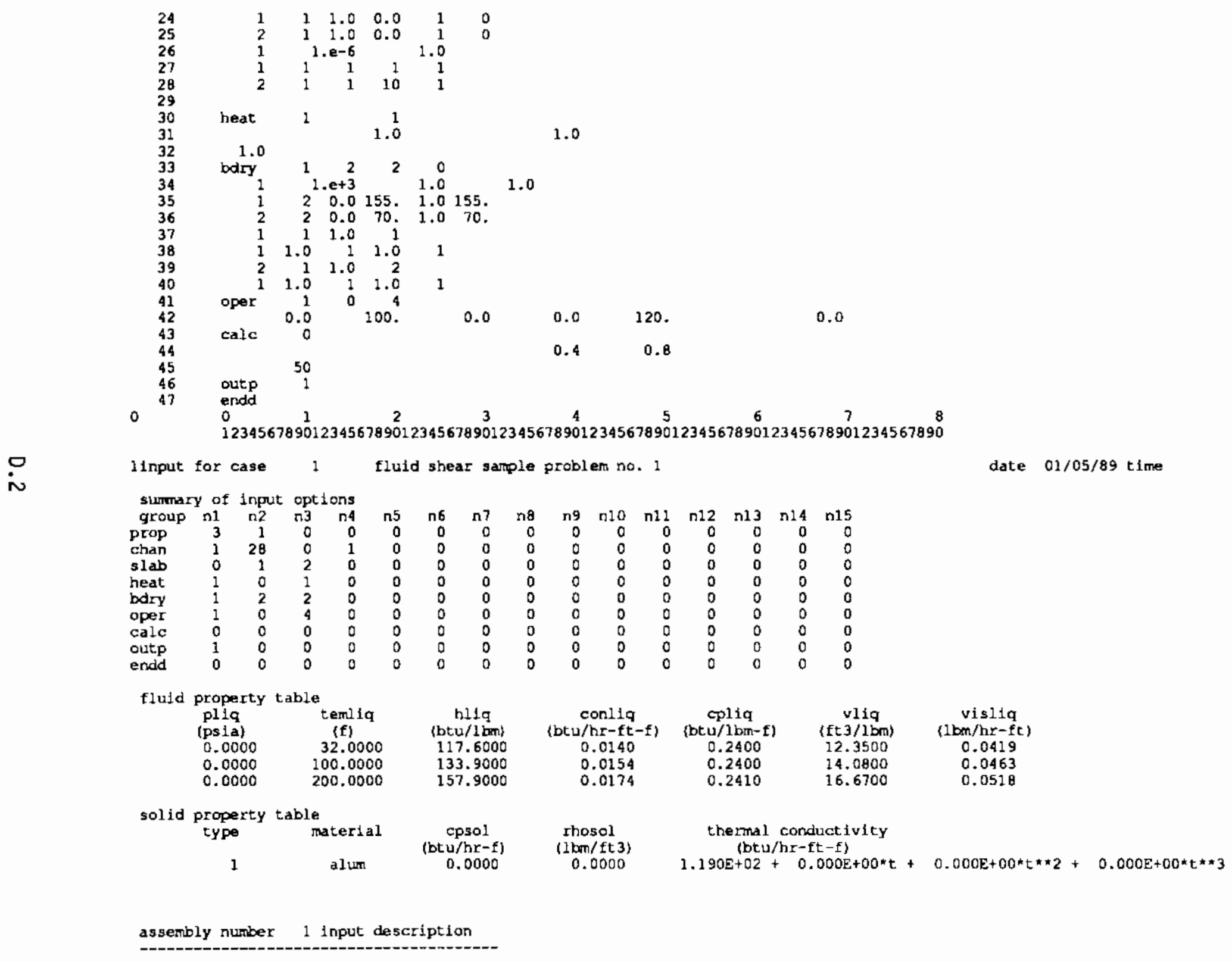



$\begin{array}{ll}\text { axial heat flux profile number } & 1 \\ \text { heat flux vs. time profile number } & 0\end{array}$

subchannel input data for assembly number loc. glb. frictn area wetted heated hydraulic
ch. ch. factor (sq-in) perlm. perim. diameter (1n) (in) no; no; type 1 (in) (In) (in) $\begin{array}{lllllll}2 & 2 & 0 & 0.1400 & 1.0000 & 0.0000 & 0.5600\end{array}$

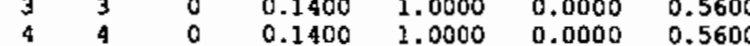
$\begin{array}{lllllll}5 & 5 & 0 & 0.1400 & 1.0000 & 0.0000 & 0.5600 \\ 6 & 6 & 0 & 0.1400 & 1.0000 & 0.0000 & 0.5600\end{array}$ $\begin{array}{lllll}0 & 0.1400 & 1.0000 & 0.0000 & 0.5600\end{array}$ $\begin{array}{lllllll}8 & 8 & 0 & 0.3400 & 1.0000 & 0.0000 & 0.5600\end{array}$

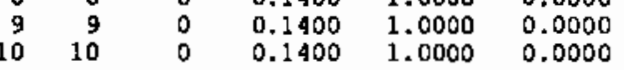

solid-to-fluld thermal connection type table

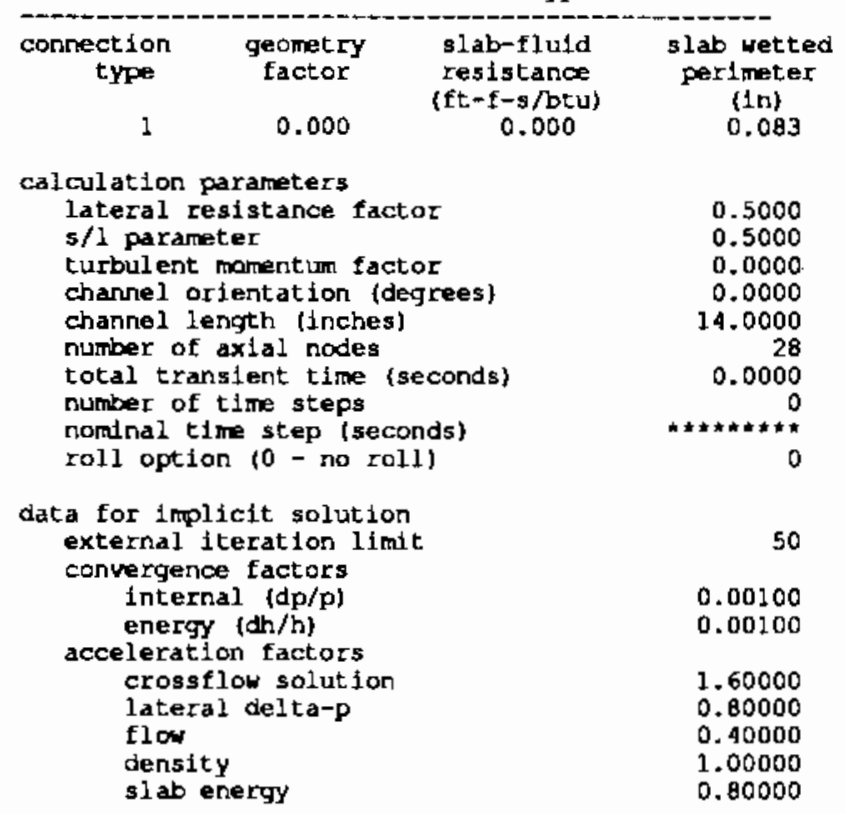

axial noding

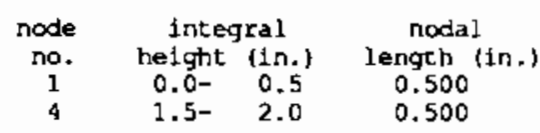

(adjacent channel no.., momentum control volume width and length)

$(2,1.000,0.140)(0,0.000,0.000)(0,0.000,0.000)(0,0.000,0.000)$ $3,1.000,0.140)(0,0.000,0.000)(0,0.000,0.000)(0,0.000,0.000)$ $5,1.000,0.140)(0,0.000,0.000)(0,0.000,0.000)(0,0.000,0.000)$ $6,1.000,0.140)(0,0.000,0.000)(0,0.000,0.000)(0,0.000,0.000)$ $7,1.000,0.140)(0,0.000,0.000)(0,0.000,0.000)(0,0.000,0.000)$ $8,1.000,0.140)(0,0.000,0.000)(0,0.000,0.000)(0,0.000,0.000)$ $9,1.000,0.140)(0,0.000,0.000)(0,0.000,0.000)(0.0 .000,0.000)$ $10,1.000,0.140)(0.0 .000,0.000)(0,0.000,0.000)(0.0 .000,0.000)$ $0,0.000,0.000)(0,0.000,0.000)<0,0.000,0.000\}(0,0.000,0.000)$

.




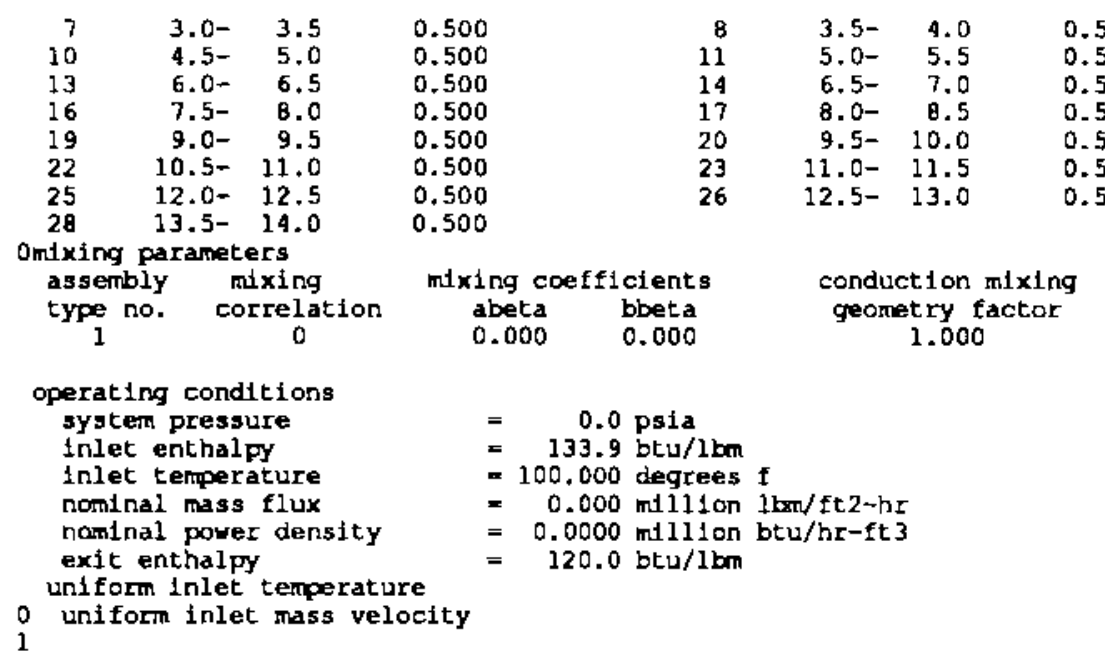

\section{parameter surmaxy}

dimensioned for

max. no. of solid material property types

$\max$. no. of boundary thermal connection types

$\max$. no. of radial boundary regions

max. no. of clrcumferentlal boundary nodes

max. no. of assembly types

max. no. of assemblies

max. no. of loss coeff. profiles, friction factor or heat transfer corr.

max. no. of slab-5lab and slab-fluid connect ion types

max. no. of channels with area variations

$\max$. no. of channels

now if not using roll option; 3 if roll is used

max. no. of channel gap connections

max. no. of slab-slab solid connections

max. no. of assembly groupings in network model

max. no. of loss coefficients

max. no. of axial locations for gap and area variations

max. no. of points in selected proflle tables

max. no. of fuel nodes in a rod

max. no. of entries in property, axlal heat flux or transient tables

max. no. of channel groups that have local axial losses

max. no. of fuel rods

$\max$. no. of gaps that can have gap spacing variations

max. no. of fuel types

$\max$. no. of axial heat

$\max$. no. of axíal nodes plus one

max. no. of axial fuel type divisions

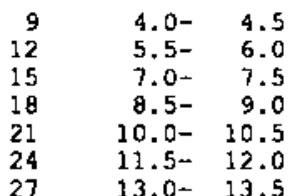

0.500

0.500

0.500

0.500

0.500

0.500

$\begin{array}{rr}6 & 1 \\ 15 & 1 \\ 8 & 2 \\ 7 & 2 \\ 3 & 1 \\ 6 & 1 \\ 6 & 1 \\ 15 & 1 \\ 20 & 0 \\ 40 & 10 \\ 31 & 29 \\ 50 & 9 \\ 6 & 0 \\ 1 & 0 \\ 3 & 0 \\ 9 & 0 \\ 20 & 0 \\ 6 & 1 \\ 20 & 3 \\ 1 & 0 \\ 20 & 0 \\ 30 & 0 \\ 1 & 0 \\ 1 & 1 \\ 40 & 2 \\ 31 & 29 \\ 4 & 0\end{array}$


max. no. of fluid channels connected to a wall node

$\max$. no. of boundary temperature types

max. no. of surfaces in a user-defined radiation group

no. of radiation surfaces in enclosure type 1

no. Of radlation surfaces in enclosure type 2

no. of radiation surfaces in enclosure type 3

no. of radiation surfaces ln enclosure type 4

no. of radiation surfaces in enclosure type 6

total heat generation in the problem is $0.00000 \mathrm{btu} / \mathrm{sec}$ or $0.00000 \mathrm{kw}$

\begin{tabular}{|c|c|c|c|c|c|c|c|c|c|c|c|}
\hline \multirow{3}{*}{$\begin{array}{l}\text { data from } \\
\text { time }= \\
\begin{array}{c}\text { iteration } \\
\text { no. }\end{array}\end{array}$} & \multirow{3}{*}{$\begin{array}{l}\text { 1terative } \\
0.0000 \\
\text { sweep } \\
\text { no. }\end{array}$} & \multirow{2}{*}{\multicolumn{4}{|c|}{$\begin{array}{l}\text { solution using the } \\
\text { dt }={ }_{1 \pi * m \star \star} \\
\text { peak clad }\end{array}$}} & \multirow{3}{*}{$\begin{array}{l}\text { tion module } \\
0.0000 \\
\text { total flow } \\
(1 \mathrm{bm} / \mathrm{s})\end{array}$} & \multicolumn{2}{|c|}{ plicit dt $=0.0586$} & \multirow{2}{*}{$\begin{aligned}= & 0 \\
& \text { error }\end{aligned}$} & \multirow{2}{*}{\multicolumn{2}{|c|}{ 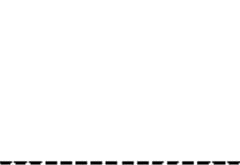 }} \\
\hline & & & & & & & pressure & & & & \\
\hline & & $\operatorname{temp}(f)$ & level & rod & ass. & & drop $\left(p_{5} 1\right)$ & $\begin{array}{l}\text { total } \\
\text { energy }\end{array}$ & fla & $\begin{array}{l}\text { fluid } \\
\text { energy }\end{array}$ & $\begin{array}{l}\text { rod } \\
\text { energy }\end{array}$ \\
\hline 1 & $\frac{1}{2}$ & $\begin{array}{l}0.0 \\
0.0\end{array}$ & $\begin{array}{l}0 \\
0\end{array}$ & $\begin{array}{l}0 \\
0\end{array}$ & 0 & $0.121 \mathrm{E}-09$ & 0.0000000 & $\begin{array}{l}0.0000 \\
0.0000\end{array}$ & $\begin{array}{l}1.0000 \\
1.0000\end{array}$ & $\begin{array}{l}0.0643 \\
0.7063\end{array}$ & $\begin{array}{l}0.0000 \\
0.0000\end{array}$ \\
\hline 2 & $\begin{array}{l}1 \\
2\end{array}$ & $\begin{array}{l}0.0 \\
0.0\end{array}$ & $\begin{array}{l}0 \\
0\end{array}$ & $\begin{array}{l}0 \\
0\end{array}$ & $\begin{array}{l}0 \\
0\end{array}$ & $0.377 \mathrm{E}-09$ & 0.0000000 & $\begin{array}{l}0.0000 \\
0.0000\end{array}$ & $\begin{array}{l}3.8083 \\
3.8083\end{array}$ & $\begin{array}{l}0.0484 \\
0.0149\end{array}$ & $\begin{array}{l}0.0000 \\
0.0000\end{array}$ \\
\hline 3 & $\begin{array}{l}1 \\
2\end{array}$ & $\begin{array}{l}0.0 \\
0.0\end{array}$ & $\begin{array}{l}0 \\
0\end{array}$ & $\begin{array}{l}0 \\
0\end{array}$ & $\begin{array}{l}0 \\
0\end{array}$ & $0.435 \mathrm{E}-09$ & 0.0000000 & $\begin{array}{l}0.0000 \\
0.0000\end{array}$ & $\begin{array}{l}3.4334 \\
1.4334\end{array}$ & $\begin{array}{l}0.0110 \\
0.0048\end{array}$ & $\begin{array}{l}0.0000 \\
0.0000\end{array}$ \\
\hline 4 & $\frac{1}{2}$ & $\begin{array}{l}0.0 \\
0.0\end{array}$ & $\begin{array}{l}0 \\
0\end{array}$ & $\begin{array}{l}0 \\
0\end{array}$ & $\begin{array}{l}0 \\
0\end{array}$ & $0.242 \mathrm{E}-0.9$ & 0.0000000 & $\begin{array}{l}0.0000 \\
0.0000\end{array}$ & $\begin{array}{l}0.9217 \\
0.9217\end{array}$ & $\begin{array}{l}0.0046 \\
0.0025\end{array}$ & $\begin{array}{l}0.0000 \\
0.0000\end{array}$ \\
\hline 5 & $\begin{array}{l}1 \\
2\end{array}$ & $\begin{array}{l}0.0 \\
0.0\end{array}$ & $\begin{array}{l}0 \\
0\end{array}$ & $\begin{array}{l}0 \\
0\end{array}$ & $\begin{array}{l}0 \\
0\end{array}$ & $0.525 \mathrm{E}-09$ & 0.0000000 & $\begin{array}{l}0.0000 \\
0.0000\end{array}$ & $\begin{array}{l}0.7818 \\
0.7818\end{array}$ & $\begin{array}{l}0.0017 \\
0.0017\end{array}$ & $\begin{array}{l}0.0000 \\
0.0000\end{array}$ \\
\hline 6 & $\frac{1}{2}$ & $\begin{array}{l}0.0 \\
0.0\end{array}$ & $\begin{array}{l}0 \\
0\end{array}$ & $\begin{array}{l}0 \\
0\end{array}$ & $\begin{array}{l}0 \\
0\end{array}$ & $0.505 E-09$ & 0.0000000 & $\begin{array}{l}0.0000 \\
0.0000\end{array}$ & $\begin{array}{l}0.5354 \\
0.5354\end{array}$ & $\begin{array}{l}0.0010 \\
0.0011\end{array}$ & $\begin{array}{l}0.0000 \\
0.0000\end{array}$ \\
\hline 7 & $\begin{array}{l}1 \\
2\end{array}$ & $\begin{array}{l}0.0 \\
0.0\end{array}$ & $\begin{array}{l}0 \\
0\end{array}$ & $\begin{array}{l}0 \\
0\end{array}$ & $\begin{array}{l}0 \\
0\end{array}$ & $0.497 \mathrm{E}-09$ & 0.0000000 & $\begin{array}{l}0.0000 \\
0.0000\end{array}$ & $\begin{array}{l}0.3841 \\
0.3841\end{array}$ & $\begin{array}{l}0.0007 \\
0.0007\end{array}$ & $\begin{array}{l}0.0000 \\
0.0000\end{array}$ \\
\hline 8 & $\frac{1}{2}$ & $\begin{array}{l}0.0 \\
0.0\end{array}$ & $\begin{array}{l}0 \\
0\end{array}$ & $\begin{array}{l}0 \\
0\end{array}$ & $\begin{array}{l}0 \\
0\end{array}$ & $0.442 E-09$ & 0.0000000 & $\begin{array}{l}0.0000 \\
0.0000\end{array}$ & $\begin{array}{l}0.2573 \\
0.2573\end{array}$ & $\begin{array}{l}0.0006 \\
0.0009\end{array}$ & $\begin{array}{l}0.0000 \\
0.0000\end{array}$ \\
\hline 9 & $\frac{1}{2}$ & $\begin{array}{l}0.0 \\
0.0\end{array}$ & 0 & $\begin{array}{l}0 \\
0\end{array}$ & $\begin{array}{l}0 \\
0\end{array}$ & $0.228 \mathrm{E}-09$ & 0.0000000 & $\begin{array}{l}0.0000 \\
0.0000\end{array}$ & $\begin{array}{l}0.2283 \\
0.2283\end{array}$ & $\begin{array}{l}0.0007 \\
0.0005\end{array}$ & $\begin{array}{l}0.0000 \\
0.0000\end{array}$ \\
\hline 10 & $\frac{1}{2}$ & $\begin{array}{l}0.0 \\
0.0\end{array}$ & $\begin{array}{l}0 \\
0\end{array}$ & $\begin{array}{l}0 \\
0\end{array}$ & $\begin{array}{l}0 \\
0\end{array}$ & $0.210 \mathrm{E}-0.9$ & 0.0000000 & $\begin{array}{l}0.0000 \\
0.0000\end{array}$ & $\begin{array}{l}0.1868 \\
0.1868\end{array}$ & $\begin{array}{l}0.0004 \\
0.0004\end{array}$ & $\begin{array}{l}0.0000 \\
0.0000\end{array}$ \\
\hline 11 & 1 & 0.0 & 0 & 0 & 0 & $0.792 \mathrm{E}-09$ & 0.0000000 & 0.0000 & 0.1524 & 0.0003 & 0.0000 \\
\hline
\end{tabular}




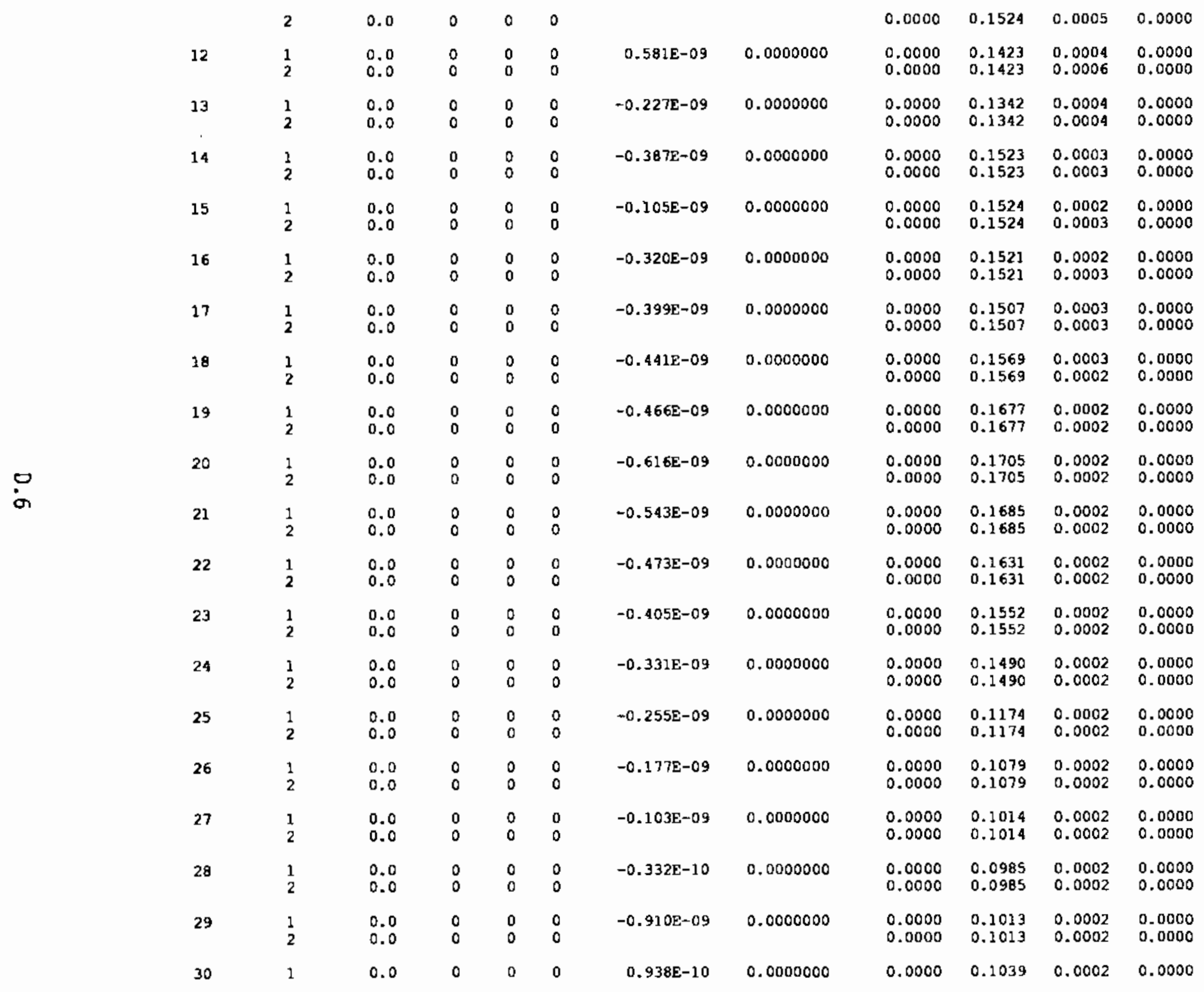




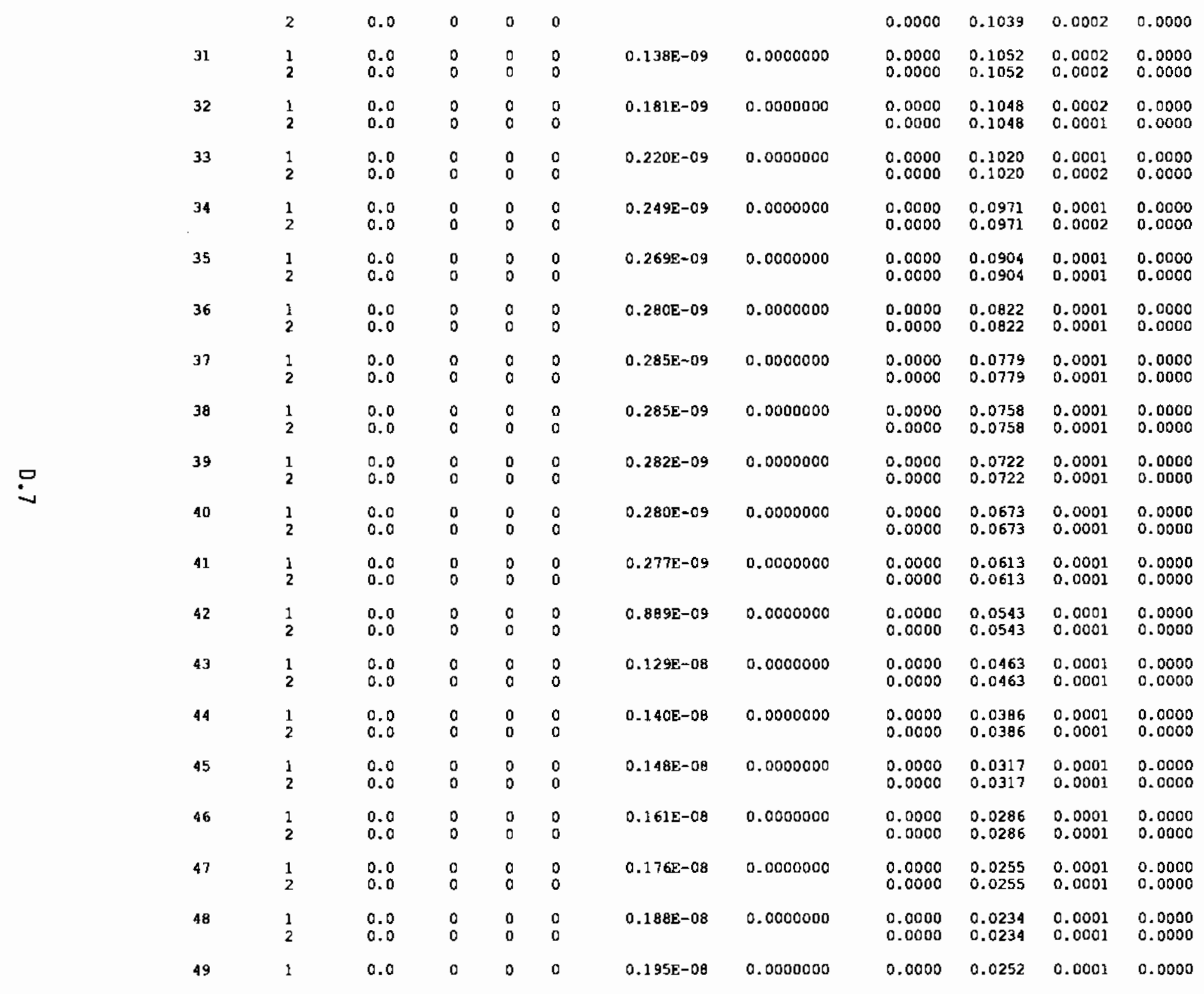




\begin{tabular}{|c|c|c|c|c|c|c|c|c|c|c|c|}
\hline & 2 & 0.0 & 0 & 0 & 0 & & & 0.0000 & 0.0252 & 0.0001 & 0.0000 \\
\hline 50 & $\begin{array}{l}1 \\
2\end{array}$ & $\begin{array}{l}0.0 \\
0.0\end{array}$ & $\begin{array}{l}0 \\
0\end{array}$ & $\begin{array}{l}0 \\
0\end{array}$ & $\begin{array}{l}0 \\
0\end{array}$ & $0.2078-08$ & 0.0000000 & $\begin{array}{l}0.0000 \\
0.0000\end{array}$ & $\begin{array}{l}0.0257 \\
0.0257\end{array}$ & $\begin{array}{l}0.0001 \\
0.0001\end{array}$ & $\begin{array}{l}0.0000 \\
0.0000\end{array}$ \\
\hline
\end{tabular}

cobra-sfs code results

case 1 fluid shear sample problem no. 1

date $01 / 05 / 89$ time

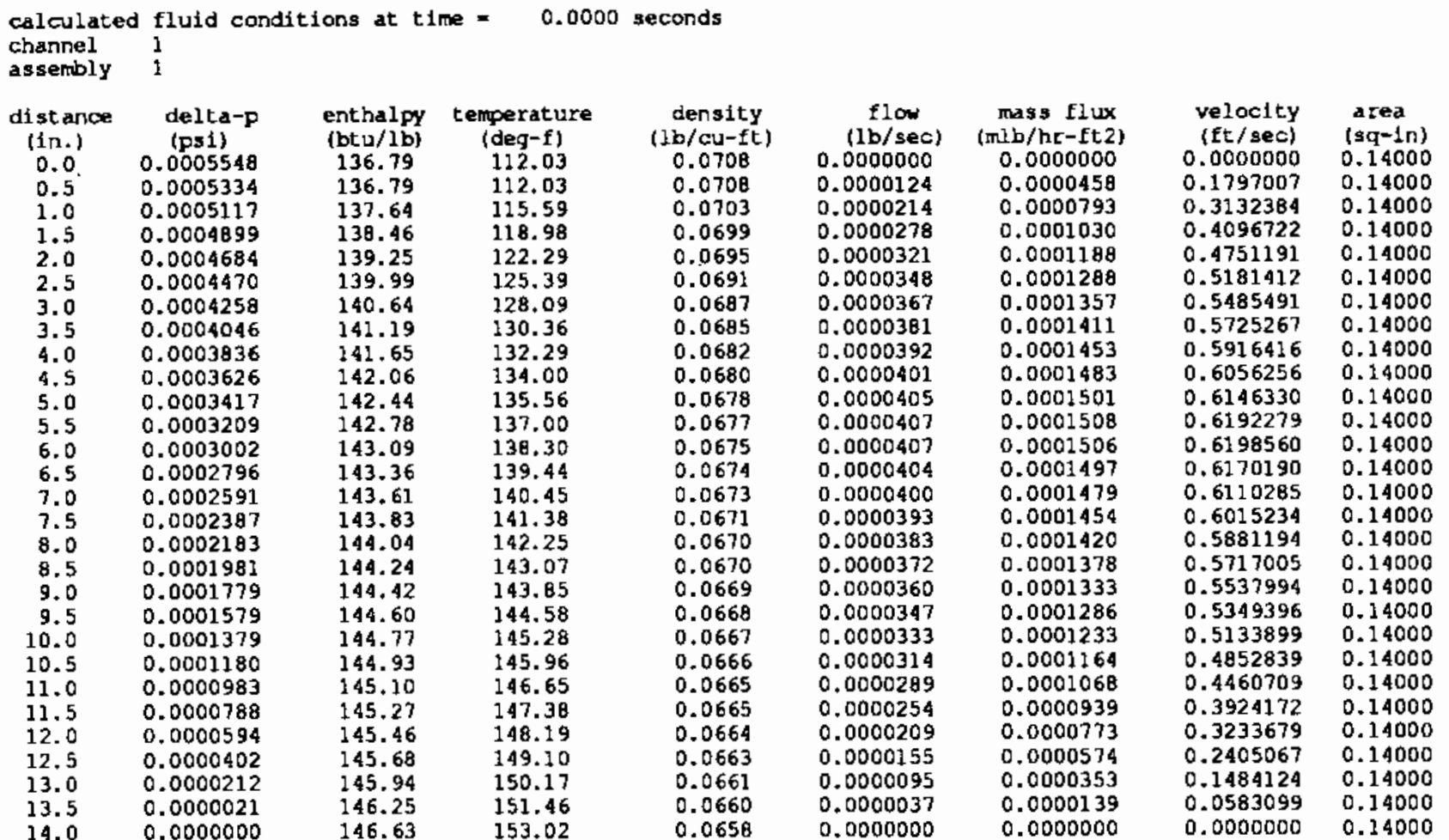

calculated fluid condftions at time $=0.0000$ seconds channel 2

flow mass flux velocity area 


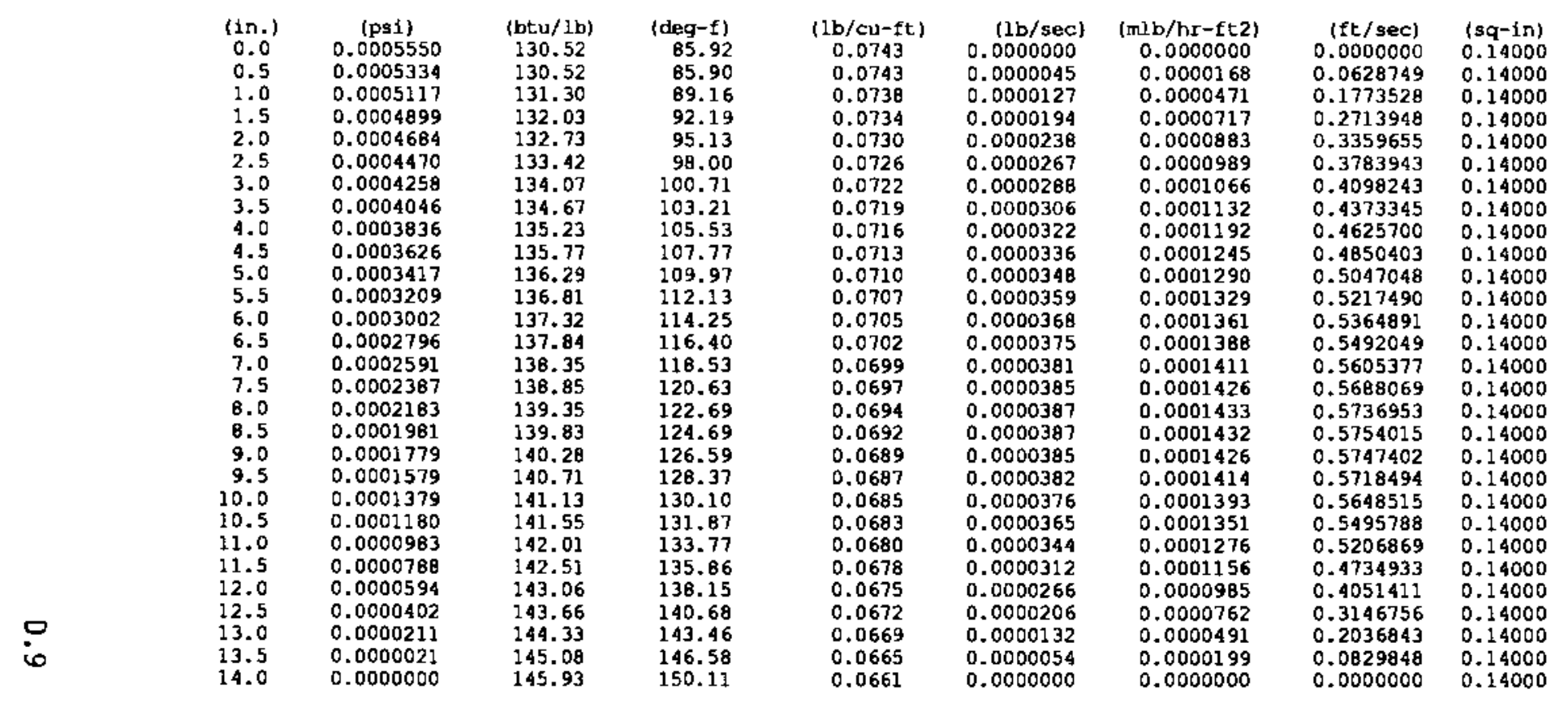

calculated fluid conditions at time $=0.0000$ seconds $\begin{array}{ll}\text { channel } & 3 \\ \text { assembly } & 1\end{array}$

$\begin{array}{ccccccccc}\begin{array}{c}\text { distance } \\ \text { (in.) }\end{array} & \begin{array}{c}\text { delta-p } \\ \text { (psi) }\end{array} & \begin{array}{c}\text { enthalpy } \\ \text { (btu/lb) }\end{array} & \begin{array}{c}\text { temperature } \\ \text { (deg-f) }\end{array} & \begin{array}{c}\text { density } \\ \text { (lb/cu-ft) }\end{array} & \begin{array}{c}\text { flow } \\ \text { (lb/sec) }\end{array} & \begin{array}{c}\text { mass flux } \\ \text { (mlb/hr-ft2) }\end{array} & \begin{array}{c}\text { velocity } \\ \text { (ft/sec) }\end{array} & \begin{array}{c}\text { area } \\ \text { (sq-1n) }\end{array} \\ 0.0 & 0.0005552 & 129.04 & 79.72 & 0.075] & 0.0000000 & 0.0000000 & 0.000000 & 0.14000 \\ 1.0 & 0.0005335 & 129.03 & 79.70 & 0.0751 & 0.0000018 & 0.0000066 & 0.0245797 & 0.14000 \\ 1.5 & 0.0005117 & 129.97 & 83.61 & 0.0746 & 0.0000081 & 0.0000299 & 0.1113447 & 0.14000 \\ 1.5 & 0.0004899 & 130.68 & 86.56 & 0.0742 & 0.0000133 & 0.0000494 & 0.1849905 & 0.14000 \\ 2.0 & 0.0004683 & 131.24 & 88.89 & 0.0738 & 0.0000163 & 0.00000602 & 0.2266495 & 0.14000 \\ 2.5 & 0.0004470 & 131.71 & 90.86 & 0.0736 & 0.0000173 & 0.0000639 & 0.2411863 & 0.14000 \\ 3.0 & 0.0004258 & 132.15 & 92.71 & 0.0733 & 0.0000173 & 0.0000642 & 0.2432473 & 0.14000 \\ 3.5 & 0.0004046 & 132.59 & 94.55 & 0.0731 & 0.0000173 & 0.0000641 & 0.2438017 & 0.14000 \\ 4.0 & 0.0003836 & 133.06 & 96.49 & 0.0728 & 0.0000174 & 0.0000644 & 0.2457225 & 0.14000 \\ 4.5 & 0.0003626 & 133.57 & 98.60 & 0.0725 & 0.0000175 & 0.0000649 & 0.2487678 & 0.14000 \\ 5.0 & 0.0003417 & 134.09 & 100.81 & 0.0722 & 0.0000178 & 0.0000658 & 0.2530861 & 0.14000 \\ 5.5 & 0.0003209 & 134.63 & 103.02 & 0.0719 & 0.0000181 & 0.0000669 & 0.2584351 & 0.14000 \\ 6.0 & 0.0003002 & 135.15 & 105.21 & 0.0716 & 0.0000184 & 0.0000681 & 0.2640992 & 0.14000 \\ 6.5 & 0.0002796 & 135.67 & 107.38 & 0.0714 & 0.0000187 & 0.0000692 & 0.2694250 & 0.14000 \\ 7.0 & 0.0002591 & 136.20 & 109.57 & 0.0711 & 0.0000190 & 0.0000703 & 0.2748576 & 0.14000 \\ 7.5 & 0.0002387 & 136.74 & 111.84 & 0.0708 & 0.0000196 & 0.0000726 & 0.2848678 & 0.14000 \\ 8.0 & 0.0002183 & 137.31 & 114.20 & 0.0705 & 0.0000205 & 0.0000758 & 0.2986466 & 0.14000 \\ 8.5 & 0.0001981 & 137.87 & 116.54 & 0.0702 & 0.0000213 & 0.0000788 & 0.3118440 & 0.14000\end{array}$




$\begin{array}{rllllllll}9.0 & 0.0001779 & 138.41 & 118.77 & 0.0699 & 0.0000220 & 0.0000815 & 0.3238708 & 0.14000 \\ 9.5 & 0.0001579 & 138.91 & 120.89 & 0.0696 & 0.0000227 & 0.0000841 & 0.3356255 & 0.14000 \\ 10.0 & 0.0001379 & 139.41 & 122.95 & 0.0694 & 0.0000234 & 0.0000867 & 0.3472686 & 0.14000 \\ 10.5 & 0.0001180 & 139.92 & 125.07 & 0.0691 & 0.0000239 & 0.0000885 & 0.3558935 & 0.14000 \\ 11.0 & 0.0000983 & 140.47 & 127.37 & 0.0688 & 0.0000238 & 0.0000881 & 0.3555128 & 0.14000 \\ 11.5 & 0.0000788 & 141.09 & 129.96 & 0.0685 & 0.0000226 & 0.0000837 & 0.3395524 & 0.14000 \\ 12.0 & 0.0000594 & 141.79 & 132.88 & 0.0682 & 0.0000201 & 0.0000743 & 0.3029715 & 0.14000 \\ 12.5 & 0.0000402 & 142.58 & 136.17 & 0.0678 & 0.0000160 & 0.0000592 & 0.2425690 & 0.14000 \\ 13.0 & 0.0000211 & 143.47 & 139.86 & 0.0673 & 0.0000103 & 0.0000383 & 0.1579730 & 0.14000 \\ 13.5 & 0.0000020 & 144.47 & 144.02 & 0.0668 & 0.0000040 & 0.0000146 & 0.0607905 & 0.14000 \\ 14.0 & 0.0000000 & 145.57 & 148.64 & 0.0663 & 0.0000000 & 0.0000000 & 0.0000000 & 0.14000\end{array}$

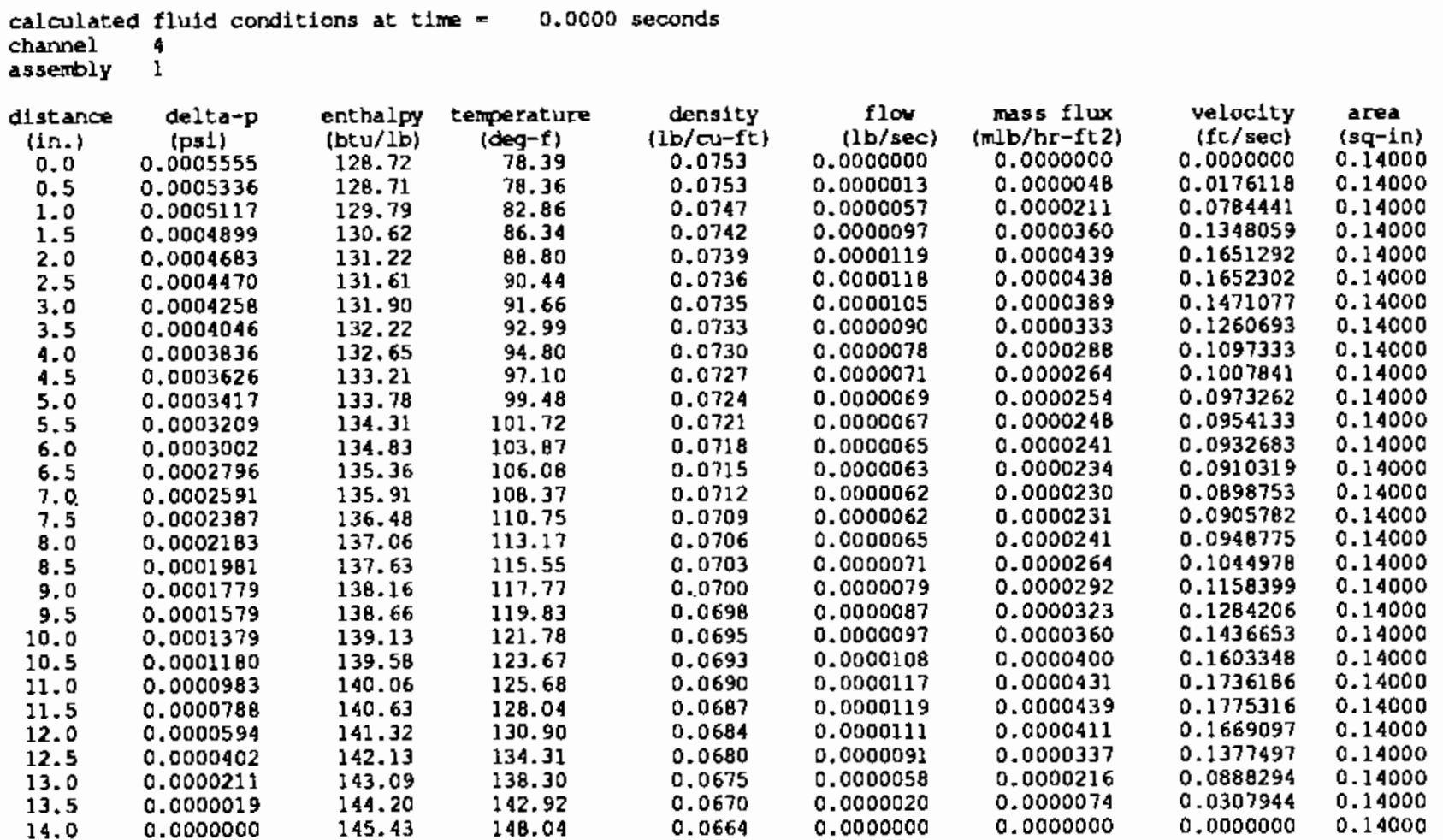

calculated fluid conditions at time $=0.0000$ seconds channel 5

distance delta-p enthajpy temperature density flow mass flux velocity area 


\begin{tabular}{|c|c|c|c|c|}
\hline 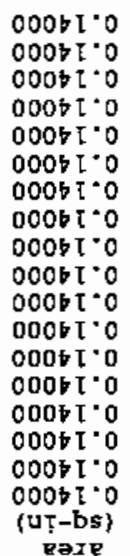 & 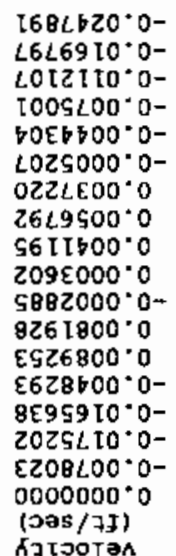 & 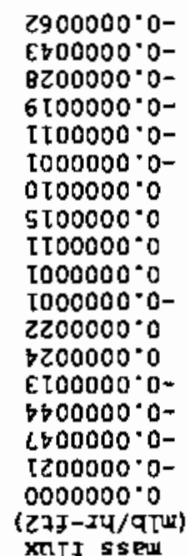 & 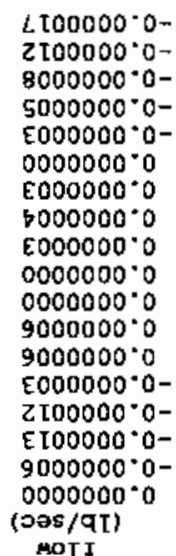 & 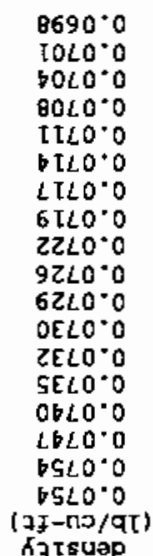 \\
\hline
\end{tabular}

\begin{tabular}{|c|c|}
\hline 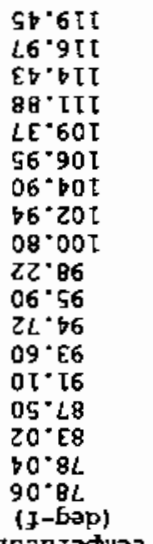 & 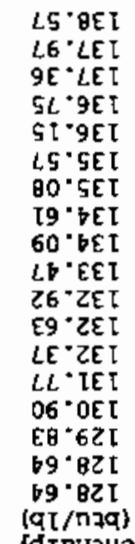 \\
\hline
\end{tabular}

\begin{tabular}{|c|c|}
\hline 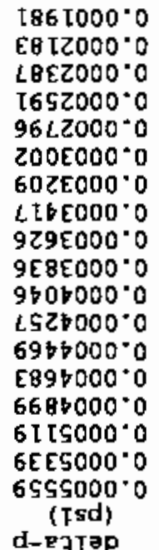 & 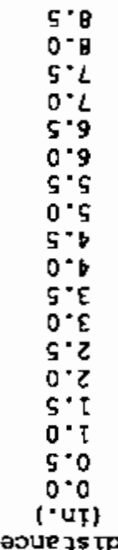 \\
\hline
\end{tabular}

\section{Ktquasse}

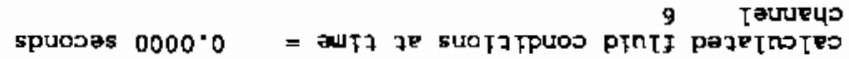

\begin{tabular}{|c|c|c|c|c|c|c|c|c|}
\hline 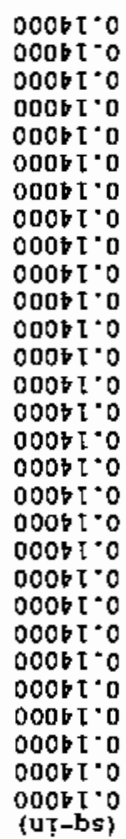 & 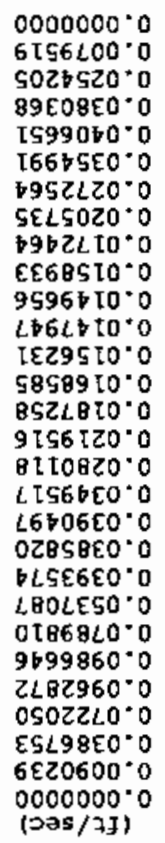 & 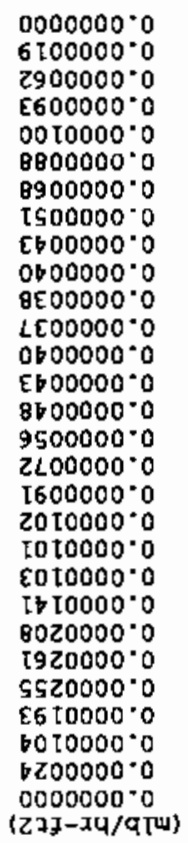 & 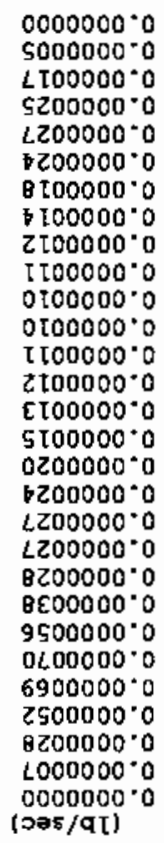 & 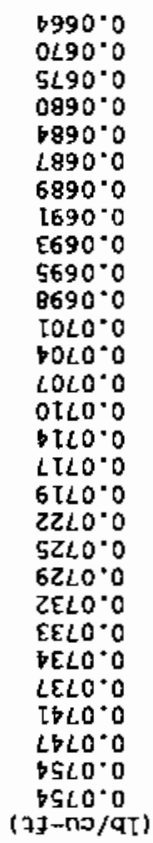 & 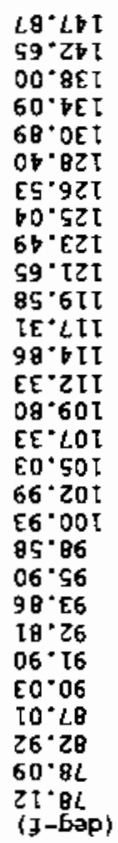 & 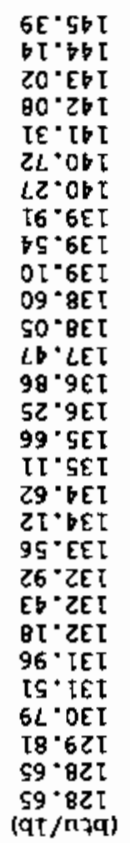 & 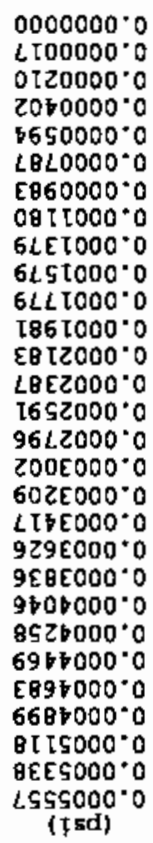 & 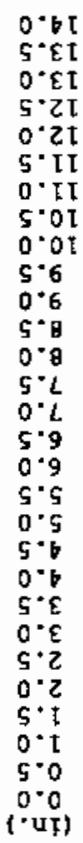 \\
\hline
\end{tabular}




$\begin{array}{rrrrrrrrr}9.0 & 0.0001779 & 139.12 & 121.77 & 0.0695 & -0.0000023 & -0.0000086 & -0.0343622 & 0.14000 \\ 9.5 & 0.0001579 & 139.63 & 123.87 & 0.0693 & -0.0000031 & -0.0000116 & -0.0469266 & 0.14000 \\ 10.0 & 0.0001379 & 140.06 & 125.66 & 0.0690 & -0.0000041 & -0.0000153 & -0.0618063 & 0.14000 \\ 10.5 & 0.0001180 & 140.40 & 127.08 & 0.0689 & -0.00000050 & -0.0000186 & -0.0753596 & 0.14000 \\ 11.0 & 0.0000983 & 140.71 & 128.37 & 0.0687 & -0.0000054 & -0.0000201 & -0.0816061 & 0.14000 \\ 11.5 & 0.0000787 & 141.07 & 129.89 & 0.0685 & -0.00000051 & -0.0000190 & -0.0773020 & 0.14000 \\ 12.0 & 0.0000594 & 141.57 & 131.96 & 0.0683 & -0.0000042 & -0.0000156 & -0.0636203 & 0.144000 \\ 12.5 & 0.0000401 & 142.24 & 134.74 & 0.0679 & -0.0000029 & -0.0000107 & -0.0440633 & 0.14000 \\ 13.0 & 0.0000208 & 143.09 & 138.30 & 0.0675 & -0.0000014 & -0.0000054 & -0.0222003 & 0.14000 \\ 13.5 & 0.0000015 & 144.14 & 142.67 & 0.0670 & -0.0000003 & -0.0000010 & -0.0041305 & 0.14000 \\ 14.0 & 0.0000000 & 145.36 & 147.73 & 0.0664 & 0.0000000 & 0.0000000 & 0.0000000 & 0.14000\end{array}$

calculated fluld conditions at time $=0.0000$ seconds $\begin{array}{ll}\text { channel } & 7 \\ \text { assembly } & 1\end{array}$

$\begin{array}{ccc}\text { distance } & \text { delta-p } \\ \text { (1n.) } & 0.0 \\ 0.0 & 0.0005561 \\ 0.5 & 0.0005340 \\ 1.0 & 0.0005119 \\ 1.5 & 0.0004899 \\ 2.0 & 0.0004683 \\ 2.5 & 0.0004469 \\ 3.0 & 0.0004257 \\ 0 & 0.0004046 \\ & 0.5 & 0.0003836 \\ N & 4.0 & 0.00 \\ 4.5 & 0.0003626 \\ 5.0 & 0.0003417 \\ 5.5 & 0.0003209 \\ 6.0 & 0.0003002 \\ 6.5 & 0.0002796 \\ 7.0 & 0.0002591 \\ 7.5 & 0.0002387 \\ 8.0 & 0.0002183 \\ 8.5 & 0.0001981 \\ 9.0 & 0.0001779 \\ 9.5 & 0.0001579 \\ 10.0 & 0.0001379 \\ 10.5 & 0.0001180 \\ 11.0 & 0.0000983 \\ 11.5 & 0.0000787 \\ 12.0 & 0.0000593 \\ 12.5 & 0.0000400 \\ 13.0 & 0.0000207 \\ 13.5 & 0.0000013 \\ 14.0 & 0.0000000\end{array}$

$\begin{array}{cc}\begin{array}{c}\text { enthalpy } \\ \text { (btu/1b) } \\ 128.61\end{array} & \begin{array}{c}\text { temperature } \\ \text { (deg-f) }\end{array} \\ 128.61 & 77.94 \\ 129.79 & 82.81 \\ 130.89 & 87.45 \\ 131.82 & 91.31 \\ 132.53 & 94.29 \\ 133.03 & 96.36 \\ 133.44 & 98.09 \\ 133.97 & 100.28 \\ 134.48 & 102.43 \\ 134.99 & 104.52 \\ 135.50 & 106.65 \\ 136.03 & 108.88 \\ 136.60 & 111.26 \\ 137.19 & 113.72 \\ 137.78 & 116.15 \\ 138.35 & 118.55 \\ 138.91 & 120.87 \\ 139.43 & 123.05 \\ 139.91 & 125.05 \\ 140.34 & 126.82 \\ 140.71 & 128.38 \\ 141.06 & 129.84 \\ 141.43 & 131.39 \\ 141.88 & 133.26 \\ 142.45 & 135.64 \\ 143.18 & 138.69 \\ 144.11 & 142.52 \\ 145.23 & 147.20\end{array}$

$\begin{array}{cc}\begin{array}{c}\text { density } \\ \text { (1b/cu-ft) }\end{array} & \text { flow } \\ 0.0754 & 0.0000000 \\ 0.0754 & -0.0000026 \\ 0.0747 & -0.0000065 \\ 0.0740 & -0.0000091 \\ 0.0735 & -0.0000098 \\ 0.0731 & -0.0000089 \\ 0.0728 & -0.0000073 \\ 0.0726 & -0.0000061 \\ 0.0723 & -0.0000059 \\ 0.0720 & -0.0000060 \\ 0.0717 & -0.0000059 \\ 0.0715 & -0.0000056 \\ 0.0712 & -0.0000052 \\ 0.0709 & -0.0000051 \\ 0.0705 & -0.0000053 \\ 0.0702 & -0.0000057 \\ 0.0699 & -0.0000062 \\ 0.0696 & -0.0000069 \\ 0.0694 & -0.0000077 \\ 0.0691 & -0.0000087 \\ 0.0689 & -0.0000097 \\ 0.0687 & -0.0000107 \\ 0.0685 & -0.0000112 \\ 0.0683 & -0.0000108 \\ 0.0681 & -0.0000094 \\ 0.0678 & -0.0000069 \\ 0.0675 & -0.0000036 \\ 0.0670 & -0.0000005 \\ 0.0665 & 0.0000000\end{array}$

mass flux
$(\mathrm{mlb} / \mathrm{hr}-\mathrm{ft} 2)$
0.0000000
-0.0000096
-0.0000240
-0.0000336
-0.0000363
-0.0000331
-0.0000271
-0.0000226
-0.0000217
-0.0000220
-0.0000218
-0.0000206
-0.0000193
-0.0000188
-0.0000195
-0.0000210
-0.0000230
-0.0000255
-0.0000285
-0.0000321
-0.0000360
-0.0000395
-0.0000413
-0.0000400
-0.0000349
-0.0000257
-0.0000133
-0.0000019
0.0000000

$\begin{array}{cc}\text { velocity } & \begin{array}{c}\text { area } \\ \text { (ft/sec) }\end{array} \\ 0.0000000 & 0.14000 \\ -0.0356018 & 0.14000 \\ -0.0901197 & 0.14000 \\ -0.1269612 & 0.14000 \\ -0.1378120 & 0.14000 \\ -0.1263481 & 0.14000 \\ -0.1035733 & 0.14000 \\ -0.0868828 & 0.14000 \\ -0.0835723 & 0.14000 \\ -0.0853735 & 0.14000 \\ -0.0847222 & 0.14000 \\ -0.0805422 & 0.14000 \\ -0.0756692 & 0.14000 \\ -0.0740033 & 0.14000 \\ -0.0772421 & 0.14000 \\ -0.0832772 & 0.14000 \\ -0.0916334 & 0.14000 \\ -0.1020945 & 0.14000 \\ -0.1146675 & 0.14000 \\ -0.1295211 & 0.14000 \\ -0.1457303 & 0.14000 \\ -0.1602343 & 0.14000 \\ -0.1679451 & 0.14000 \\ -0.1633380 & 0.14000 \\ -0.1428409 & 0.14000 \\ -0.1057781 & 0.14000 \\ -0.0552737 & 0.14000 \\ -0.0079100 & 0.14000 \\ 0.0000000 & 0.14000\end{array}$

calculated fluid conditions at time $=0.0000$ seconds channel 18

distance delta-p enthalpy temperature density flow mass flux velocity area 


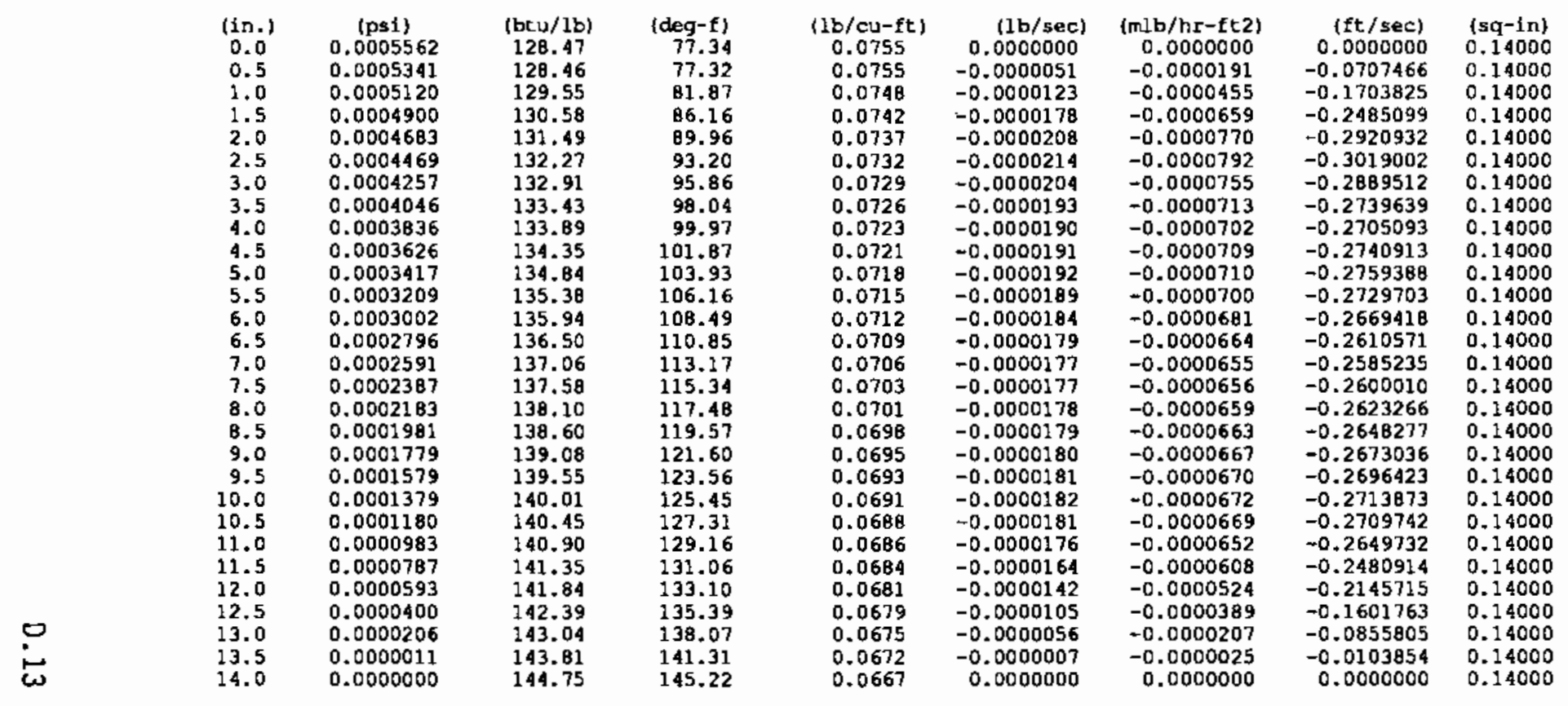

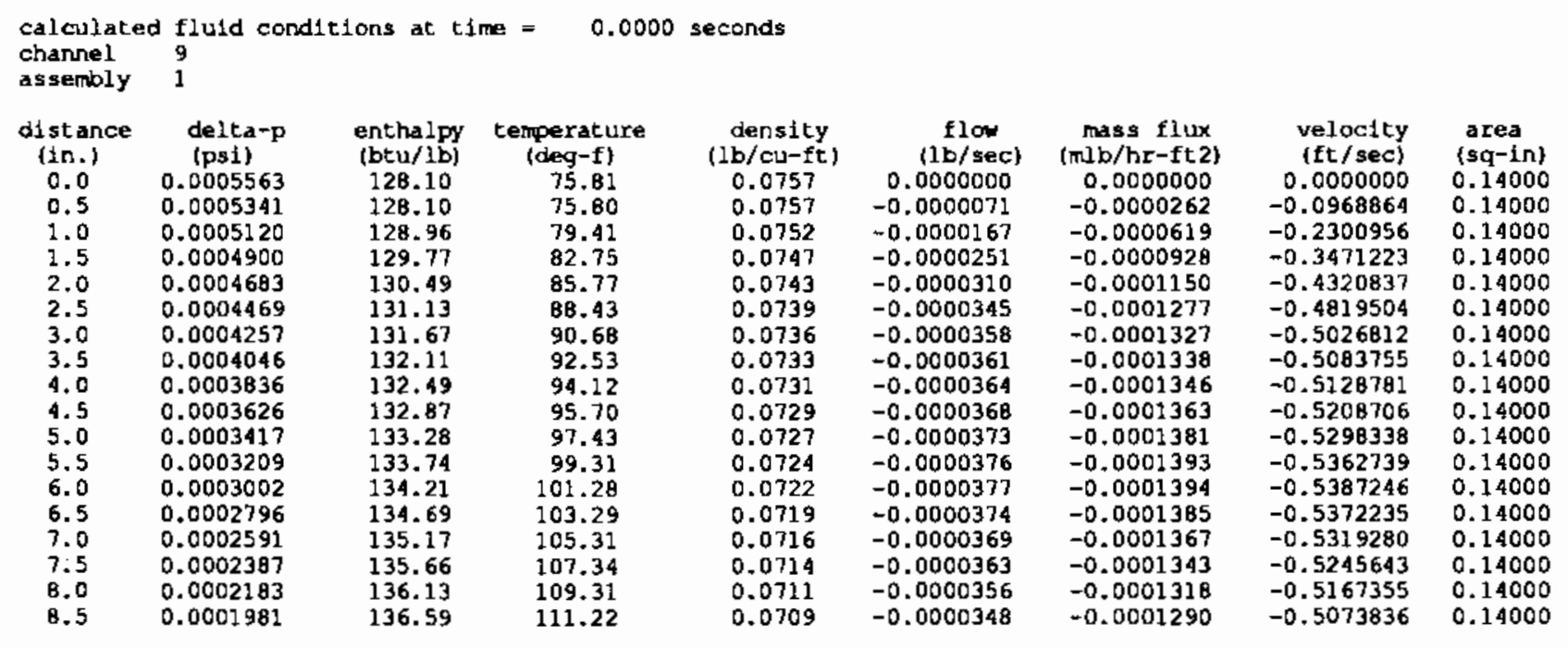




$\begin{array}{rrrrrrrrr}9.0 & 0.0001779 & 137.06 & 113.18 & 0.0706 & -0.0000339 & -0.0001255 & -0.4957063 & 0.144000 \\ 9.5 & 0.0001579 & 137.54 & 115.18 & 0.0704 & -0.0000328 & -0.0001215 & -0.4815531 & 0.14000 \\ 10.0 & 0.0001379 & 138.04 & 117.25 & 0.0701 & -0.0000315 & -0.0001168 & -0.4646355 & 0.14000 \\ 10.5 & 0.0001181 & 138.56 & 119.43 & 0.0698 & -0.0000300 & -0.0001111 & -0.4438790 & 0.14000 \\ 11.0 & 0.0000983 & 139.11 & 121.73 & 0.0695 & -0.0000280 & -0.0001038 & -0.4167442 & 0.14000 \\ 11.5 & 0.0000788 & 139.70 & 124.16 & 0.0692 & -0.0000254 & -0.0000940 & -0.3789363 & 0.14000 \\ 12.0 & 0.0000593 & 140.31 & 126.70 & 0.0689 & -0.0000217 & -0.0000803 & -0.3250592 & 0.14000 \\ 12.5 & 0.0000400 & 140.94 & 129.34 & 0.0686 & -0.0000166 & -0.0000615 & -0.2501925 & 0.14000 \\ 13.0 & 0.0000205 & 141.60 & 132.09 & 0.0682 & -0.0000101 & -0.0000374 & -0.1529868 & 0.14000 \\ 13.5 & 0.0000009 & 142.30 & 135.01 & 0.0679 & -0.0000030 & -0.0000110 & -0.0452266 & 0.14000 \\ 14.0 & 0.0000000 & 143.00 & 137.92 & 0.0676 & 0.0000000 & 0.0000000 & 0.0000000 & 0.14000\end{array}$

calculated fluld conditions at time $=0.0000$ seconds chanel 10

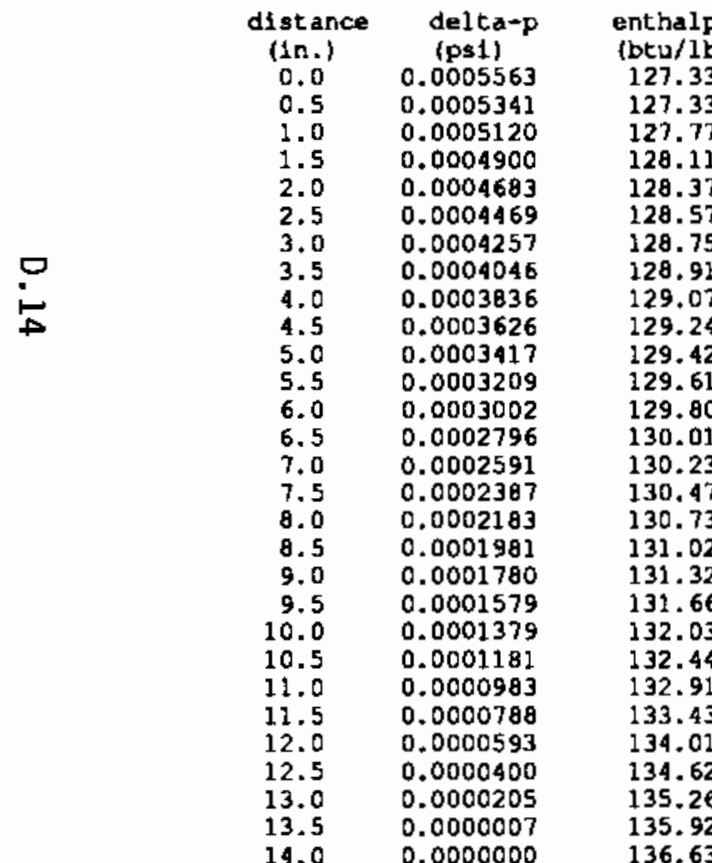

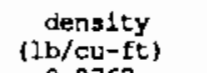

flow

mass flux

velocity

area

0.0000000 (mlb/hr-ft2)

0.0000000

(sq-in)

$-0.0000053$

$-0.0000195$

0.0712890

0.14000

72.5

$0.0759-0.0000140$

00517

$0.0755-0.0000290$

$-0.0000827$

6100

75.83

76.91

78.50

0.0754

$-0.0000290$

01072

0.14000

$\begin{array}{ll}-0.3949577 & 0.14000\end{array}$

$0.0753-0.0000359-0.0001331-0.4916016-0.14000$

$0.0752-0.0000373-0.0001380-0.5102461-0.14000$

79.17

79.84
80.55

0.0751

001380

0.14000

$0.0750 \quad-0.0000395$

$-0.0001417$

$-0.52484390 .1400$

81.30

0.0749

$-0.0001509$

$-0.56059110 .14000$

$0.0747-0.0000430$

$-0.0001555$

$-0.5783446 \quad 0.14000$

83.77

84.69

0.0746

$-0.0000437$

$-0.0001592$

$-0.5930987 \quad 0.14000$

$0.0744-0.0000442-0.0001637-0.6119860 \quad 0.14000$

$\begin{array}{llllll}0.0743 & -0.0000444 & -0.0001644 & -0.6160202 & 0.14000\end{array}$

$0.0740-0.0000440$

$0.0736-0.0000427$

$0.0731-0.0000402$

$0.0729-0.0000383$

0.0726

$-0.000035$

$-0.0001642$

$-0.0001630$

$-0.0001581$

$-0.0001541$

$-0.0001489$

$-0.0001419$

$\begin{array}{lll}-0.0001320 & -0.5073838 & 0.14000\end{array}$

$-0.6160202 \quad 0.14000$

$-0.61377120 .14000$

$-0.6077854 \quad 0.14000$

$-0.5983897 \quad 0.14000$

$-0.5853037 \quad 0.14000$

$-0.56758170 .34000$

$-0.5429186 \quad 0.14000$

100.44

102.99

108.42

0.0719

$-0.0000112$

$-0.45597140 .14000$

$\begin{array}{llll}-0.0000989 & -0.3838127 & 0.14000\end{array}$

$\begin{array}{lll}-0.0000737 & -0.2873481 & 0.14000\end{array}$

$\begin{array}{rrr}-0.0000413 & -0.1620542 & 0.14000 \\ 0.0000000 & 0.0000000 & 0.14000\end{array}$

slab temperature sumuary

time $=0.0000$ seconds

0.0000000

(assembly no. - channel no.) 


\begin{tabular}{|c|c|c|c|}
\hline & $\begin{array}{c}\text { axial zone } \\
\text { (Inches) }\end{array}$ & (1) & $\left(\begin{array}{l}12\end{array}\right)$ \\
\hline in & $\begin{array}{r}0.0-0.5 \\
0.5=1.0 \\
1.0=1.5 \\
1.5=2.0 \\
2.0=2.5 \\
2.5=3.0 \\
3.0=3.5 \\
3.5=4.0 \\
4.0=4.5 \\
4.5=5.0 \\
5.0=5.5 \\
5.5=6.0 \\
6.0=6.5 \\
6.5=7.0 \\
7.0=7.5 \\
7.5=8.0 \\
8.0=8.5 \\
8.5=9.0 \\
9.0=9.5 \\
9.5=10.0 \\
10.0=10.5 \\
10.5=11.0 \\
11.0=11.5 \\
11.5=12.0 \\
12.0=12.5 \\
12.5=13.0 \\
13.0=13.5 \\
13.5-14.0\end{array}$ & $\begin{array}{l}155.00 \\
155.00 \\
155.00 \\
155.00 \\
155.00 \\
155.00 \\
155.00 \\
155.00 \\
155.00 \\
155.00 \\
155.00 \\
155.00 \\
155.00 \\
155.00 \\
155.00 \\
155.00 \\
155.00 \\
155.00 \\
155.00 \\
155.00 \\
155.00 \\
155.00 \\
155.00 \\
155.00 \\
155.00 \\
155.00 \\
155.00 \\
155.00\end{array}$ & $\begin{array}{l}70.00 \\
70.00 \\
70.00 \\
70.00 \\
70.00 \\
70.00 \\
70.00 \\
70.00 \\
70.00 \\
70.00 \\
70.00 \\
70.00 \\
70.00 \\
70.00 \\
70.00 \\
70.00 \\
70.00 \\
70.00 \\
70.00 \\
70.00 \\
70.00 \\
70.00 \\
70.00 \\
70.00 \\
70.00 \\
70.00 \\
70.00 \\
70.00\end{array}$ \\
\hline
\end{tabular}

crossflow between adjacent channels at time =

0.0000 seconds

\begin{tabular}{|c|c|c|c|c|c|c|c|c|c|c|}
\hline & & 1 & 1 & 1 & 1 & 1 & 1 & 1 & 1 & 1 \\
\hline$a+a 1$ & & 12 & 2 & 3 & 4 & 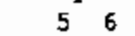 & 67 & $\because$ & 8 & 910 \\
\hline $0.0-$ & 0.5 & -0.00030 & -0.00041 & -0.00045 & -0.00048 & -0.00050 & -0.00048 & -0.00042 & -0.00030 & -0.00013 \\
\hline & 1.0 & -0.00022 & -0.00041 & 0.00056 & -0.00067 & -0.00072 & -0.00070 & -0.00 & -0.00044 & -0.00021 \\
\hline & 1.5 & -0.0001 & 0.00031 & & $n$ & & 100 & & -0. & 00020 \\
\hline 5 & 2.0 & -0.0 & -0. & & 003 & -0. & 2003 & -0 & -0 . & -0.00016 \\
\hline & 2.5 & & & & & & & & & \\
\hline & 3.0 & -0.00004 & -0.0 & 0.0001 & -0 . & -0 & -0 . & & & 006 \\
\hline 30 & 3.5 & -0.00003 & -0.0 & 0.00008 & & & 0. & & & \\
\hline & 4.0 & -0.00003 & -0 & -0. & -0. & & -0 . & & & 002 \\
\hline & 4.5 & -0.00002 & 0005 & -0.0 & -0 & & & & & \\
\hline & 5.0 & -0.00001 & -0 . & -0.0 & -0 . & & -0 . & & & \\
\hline & 5.5 & 0.00 & -0. & -0 . & & & & & & -0 \\
\hline & 6.0 & 0.00000 & & & & & & & & \\
\hline & 6.5 & 0.00001 & -0. & -0.0 & -0. & & 0.0000 & & & -0. \\
\hline & 7.0 & 0.00001 & & -0.000 & & & & & & \\
\hline & 7.5 & 0.0 & 0.0 & -0.000 & -0. & -0.0 & & & & 0.00000 \\
\hline & & & & & & & & & & 0.00000 \\
\hline 8 & $\begin{array}{l}8.5 \\
9.0\end{array}$ & 0.8 & $\begin{array}{l}0.00003 \\
0.00003\end{array}$ & $\begin{array}{l}0.0000 \\
0.0000\end{array}$ & $\begin{array}{r}-0 . \\
0 .\end{array}$ & & & & & $\begin{array}{l}0.00001 \\
0.00001\end{array}$ \\
\hline & 9.5 & 0.00003 & 0.00004 & 0.00002 & 0.00000 & 0.00000 & 0.00002 & 0.00004 & 0.00005 & 0.00002 \\
\hline
\end{tabular}




$\begin{array}{rlllllllll}9.5-10.0 & 0.00003 & 0.00005 & 0.00003 & 0.00001 & 0.00001 & 0.00003 & 0.00005 & 0.00006 & 0.00003 \\ 10.0-10.5 & 0.00004 & 0.00007 & 0.00006 & 0.00003 & 0.00003 & 0.00005 & 0.00007 & 0.00007 & 0.00003 \\ 10.5-11.0 & 0.00006 & 0.00011 & 0.00011 & 0.00009 & 0.00008 & 0.00009 & 0.00010 & 0.00009 & 0.00005 \\ 11.0-11.5 & 0.00009 & 0.00016 & 0.00019 & 0.00018 & 0.00017 & 0.00016 & 0.00016 & 0.00013 & 0.00006 \\ 11.5-12.0 & 0.00011 & 0.00022 & 0.00028 & 0.00030 & 0.00029 & 0.00027 & 0.00023 & 0.00018 & 0.00009 \\ 12.0-12.5 & 0.00013 & 0.00027 & 0.00037 & 0.00042 & 0.00042 & 0.00039 & 0.00033 & 0.00025 & 0.00012 \\ 12.5-13.0 & 0.00014 & 0.00032 & 0.00045 & 0.00053 & 0.00055 & 0.00052 & 0.00044 & 0.00032 & 0.00016 \\ 13.0-13.5 & 0.00014 & 0.00033 & 0.00048 & 0.00057 & 0.00060 & 0.00057 & 0.00050 & 0.00038 & 0.00021 \\ 13.5-14.0 & 0.00009 & 0.00022 & 0.00031 & 0.00036 & 0.00037 & 0.00037 & 0.00036 & 0.00034 & 0.00027\end{array}$

side boundary temperature summary time $=0.0000$ seconds boundary slab node no.

axial zone (inches)

$\begin{array}{rll}0.0-0.5 & 155.00 & 155.00 \\ 0.5=1.0 & 155.00 & 155.00 \\ 1.0=1.5 & 155.00 & 155.00 \\ 1.5=2.0 & 155.00 & 155.00 \\ 2.0=2.5 & 155.00 & 155.00 \\ 2.5=3.0 & 155.00 & 155.00 \\ 3.0=3.5 & 155.00 & 155.00 \\ 3.5=4.0 & 155.00 & 155.00 \\ 4.0=4.5 & 155.00 & 155.00 \\ 4.5=5.0 & 155.00 & 155.00 \\ 5.0=5.5 & 155.00 & 155.00 \\ 5.5=6.0 & 155.00 & 155.00 \\ 6.0-6.5 & 155.00 & 155.00 \\ 6.5-7.0 & 155.00 & 155.00 \\ 7.0=7.5 & 155.00 & 155.00 \\ 7.5=8.0 & 155.00 & 155.00 \\ 8.0-8.5 & 155.00 & 155.00 \\ 8.5=9.0 & 155.00 & 155.00 \\ 9.0-9.5 & 155.00 & 155.00 \\ 9.5=10.0 & 155.00 & 155.00 \\ 10.0=10.5 & 155.00 & 155.00 \\ 10.5=11.0 & 155.00 & 155.00 \\ 11.0=11.5 & 155.00 & 155.00 \\ 11.5=12.0 & 155.00 & 155.00 \\ 12.0=12.5 & 155.00 & 155.00 \\ 12.5=13.0 & 155.00 & 155.00 \\ 13.0=13.5 & 155.00 & 155.00 \\ 13.5-14.0 & 155.00 & 155.00\end{array}$

side boundary temperature summary boundary slab node no.

\section{sum}

(1)

(2)

1 


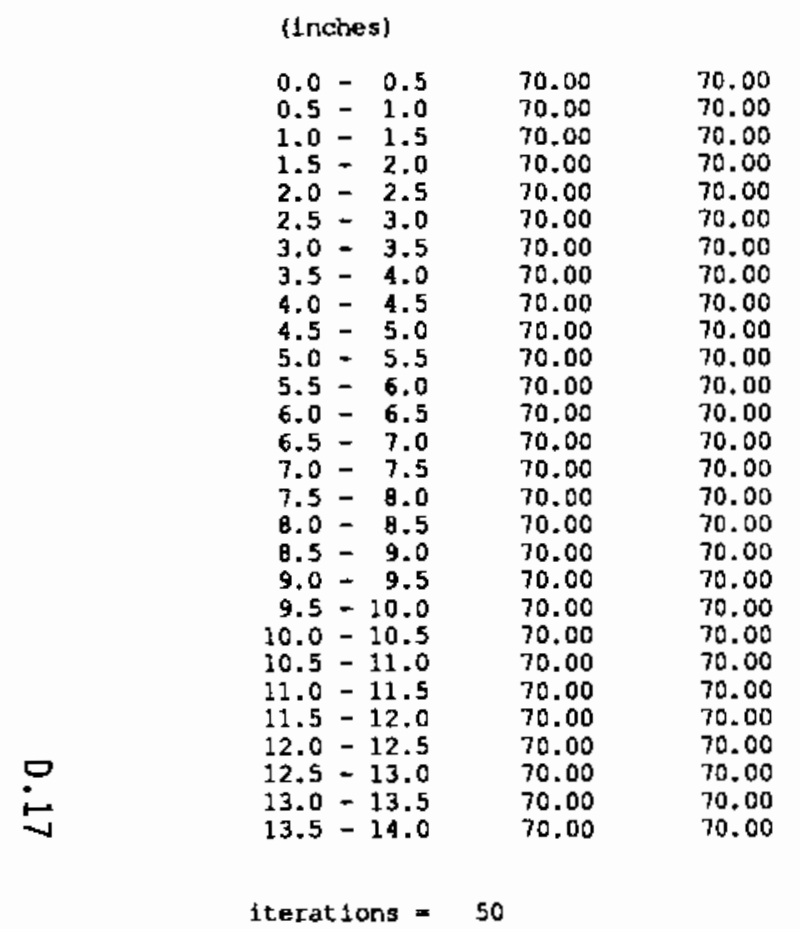

input transient time completed

cormon dumped to tape 8

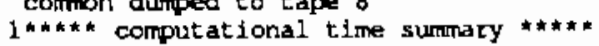

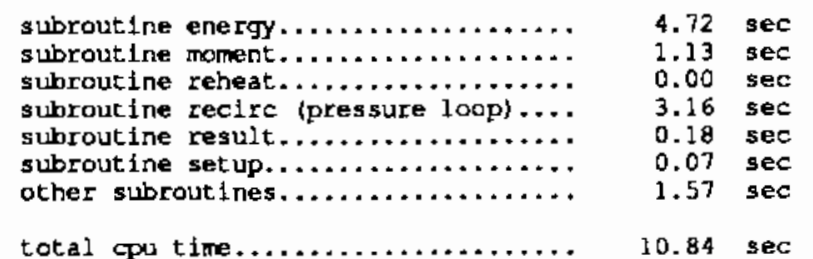




\section{DISTRIBUTION}

No. of

Copies

82 DOE/Office of Scientific and Technical Information

R. Stein

U.S. Department of Energy

Office of Civilian Radioactive Waste Management

RW-33

Washington, DC 20585

T. Nguyen

U.S. Department of Energy

Office of Civilian Radioactive Waste Management

RW-32

Washington, DC 20585

K. A. Klein

U.S. Department of Energy

Office of Civilian Radioactive Waste Management

RW-32

Washington, DC 20585

C. Head

U.S. Department of Energy

office of Civilian Radioactive Waste Management

RW-32

Washington, DC 20585

W. J. Danker

U.S. Department of Energy

Office of Civilian Radioactive Waste Management

RH-33

Washington, DC 20585

J. S. Finucane

U.S. Department of Energy

Energy Information

Administration

EI-53

Washington, DC 20585
No. of

Copies

M. Fisher

U.S. Department of Energy

Idaho Operations office

785 DOE Place

Idaho Falls, ID 83402

S. T. Hinschberger

U.S. Department of Energy

Idaho Operations Office

785 DOE Place

Idaho Falls, ID 83402

K. G. Golliher

U.S. Department of Energy

Albuquerque Operations Office

P.0. Box 5400

Albuquerque, NM 87115

C. J. Daukowskj

U.S. Department of Energy

Attention: Defense Programs

San Francisco Operations Office

1333 Broadway

Oakland, CA 94612

C. Matthews

U.S. Department of Energy

Oak Ridge Nationa] Laboratory

P.0. Box E

Oak Ridge, TN 37830

F. C. Sturtz

U.S. Nuclear Regulatory Commission

Office of Nuclear Materials Safety and Safeguards

Washington, DC 20555

C. Feldman

U.S. Nuclear Regulatory Commission

Office of Nuclear Regulatory Research

MS 1130-SS

Washington, DC 20555 
No. of

Copies

C. H. Peterson

U.S. Nuclear Regulatory Comission

Office of Nuclear Material Safety and Safeguards

MS 623-SS

Washington, DC 20555

J. Roberts

U.S. Nuclear Regulatory Comission

Office of Nuclear Material Safety and Safeguards

MS 396-SS

Washington, DC 20555

\section{B. A. Rowtes}

Battelle Memorial Institute

Office of Spent Fuel

Storage Installation

Division of Fuet Cycle and Material Safety

Washington, DC 20555

\section{J. A. Carr}

Battelle Memorial Institute

Office of Nuclear Waste Isolation

505 King Avenue

Columbus, $\mathrm{OH} 43201$

Technical Library

Battelle Memorial Institute

Office of Nuclear Waste Isolation

505 King Avenue

Columbus, $\mathrm{OH} 43201$

J. H. Jones

Babcock and Wilcox

3315 01d Forest Road

P.0. Box 10935

Lynchburg, VA 24506-0935

R. Kunita

Carolina Power \& Light Co.

P.0. Box 1551

Raleigh, NC 27602
No. of

Copies

C. K. Anderson

Combustion Engineering, Inc.

1000 Prospect Hill Road

windsor, CT 06095

J. Jedroch

Ebasco Services Incorporated

Two World Trade Center

New York, NY 10048

P. E. Eggers

Eggers Ridihalgh Partners, Inc.

1445 Sumnit Street

Columbus, $\mathrm{OH} 43201$

FLUOR Engineers, Inc.

Advanced Technology Division

3333 Michelson Drive

Irvine, CA 92730

R. Anderson

General Nuclear Services, Inc.

135 Darling Drive

Avon, CT 06001

L. B. Ballou

Lawrence Livermore Nationa] Laboratory

P.0. Box 808

Livermore, CA 94550

M. W. Schwartz

Lawrence Livermore National Laboratory

P.0. Box 808

Livermore, Ca 94550

C. E. Walter

Lawrence Livermore Nationa] Laboratory

P.0. Box 808

Livermore, Ca 94550

H. Lowenberg

Lowenberg Associates 10901 Rosemont Drive Rockville, MD 20852 
No. of

Copies

J. Houston

Nuclear Assurance Corporation 6251 Crooked Creek Road \#200

Norcross, GA 30092-3107

C. L. Wheeter

Numerical Applications, Inc.

825 Goethals Drive

Richland, WA 99352

B. Lehnert

NUTECH Engineers

145 Martinvale Lane

San Jose, CA 95116

C. V. Parks

Oak Ridge National Laboratory

P.0. Box $X$

Oak Ridge, TN 37831

D. Woods

Ralph M. Parsons Co.

100 West Walnut Street

Pasadena, CA 91124

J. V. Massey

PSNA

15951 Los Gatos Blvd, Suite 1 Los Gatos, CA 95032

T. L. Sanders

Sandia National Laboratory

P.0. Box 5800

Albuquerque, NM 87185

M. E. Mason

Transnuclear, Inc.

Two Skyline Drive

Hawthorne, NY 10532-2120
No. of

Copies

M. L. Smith

Virginia Power $\mathrm{C}_{0}$.

5000 Dominion B1vd.

Glen Allen, VA 23060

K. L. Basehore

Virginia Electric and Power Co.

5000 Dominion Blvd.

Glen Allen, VA 23060

D. L. Larkin

Washington Public Power Supply System

P.0. Box 968

Richland, WA 99352

R. 0. Anderson

Northern States Power Company

15 S. 15th Street

Minneapolis, NM 55401

G. Swindlehurst

Duke Power Company

P.0. Box 33189

422 S. Church Street

Charlotte, NC 28242

D. Hamilton

Middle South Services, Inc.

Box 61000

New Orleans, LA 70161

G. R. Bond

Manager, Nuclear Fuels

General Public Utilities, NUC

100 Interpace Parkway

Parsippany, NJ 07054

J. R. Ratliff

Tennessee Valley Authority

409 Krystal Building

Chattanooga, TN 37401 
No. of

Copies

B. Rice

Texas Utilities Generating Co.

Skyway Tower

400 North 01 ive Street, LD81

Dallas, TX 75201

H. E. Bliss

Nuclear Fuel Services

Commonwealth Edison

72 West Adams Street

P.0. Box 767

Chicago, IL 60690

R. T. Harris

Northeast Utilities Service Co.

P.0. Box 270

Hartford, CT 0610]

A. Ladieu

Yankee Atomic Electric Company

1671 Worcester Road

Framingham, MA 01701

D. S. Rowe

Rowe and Associates

Suite 200, 2050 112th Avenue NE

Bellevue, WA 98007

Y. Hsij

Division of Systems Integration

Office of Nuclear Regulation

U.S. Nuclear Regulatory Commission

Washington, OC 20555

L. Phillips

Division of Systems Integration

Office of Nuclear Regulation

U.S. Nuclear Regulatory Commission

Washington, DC 20555

L. Agee

Electric Power Research

Institute

P.0. Box 10412

Palo Alto, CA 94303
No. of

Copies

R. Lambert

Electric Power Research Institute

P.0. Box 10412

Palo Alto, CA 94303

G. S. Srikantiah

Electric Power Research Institute

P.0. Box 10412

Palo Alto, CA 94303

R. Rice

EG\&G Idaho, Inc.

P.0. Box 1625

Idaho Falls, ID 83415

W. J. Severson

Westinghouse Electric Corp.

Nuclear Waste Department

P.0. Box 3912

Pittsburgh, PA 15230

D. Klein

Mechanical Engineering Department

University of Texas

Austin, TX 78712

A. C. Klein

Oregon State University

Radiation Center

35 th and Jefferson

Corvallis, OR 97331

D. G. Hoover

Genera] Electric SNE\&T

6835 Via Del Oro

San Jose, CA 95153-5354 
No. of

Coptes

ONSITE

DOE Richland Qperations office

E. C. Norman/D. E. Kenyon

4 West inghouse Hanford Company

C. L. Brown

G. T. Harper

T. B. McCarl

L. M. McWethy

48 Pacific Northwest Laboratory

D. J. Bradley

J. M. Cuta

L. A. Strope

E. R. Gilbert

C. M. Heeb
No. of

Copies
J. M. Creer (5)
L. R. Dodd
R. E. Einziger
M. D. Freshiey
T. L. Gilbride
A. B. Johnson, Jr.
B. M. Johnson
N. J. Lombardo
P. S. Lowery
M. A. Mckinnon
T. E. Michener
E. W. Pearson
D. R. Rector (20)
C. W. Stewart
Technical Report Files (5)
Publishing Coordination 
